Intellectual Property Rights in an Age of Electronics and Information

\section{April 1986}

NTIS order \#PB87-100301

\section{Intellectual Property Rights}

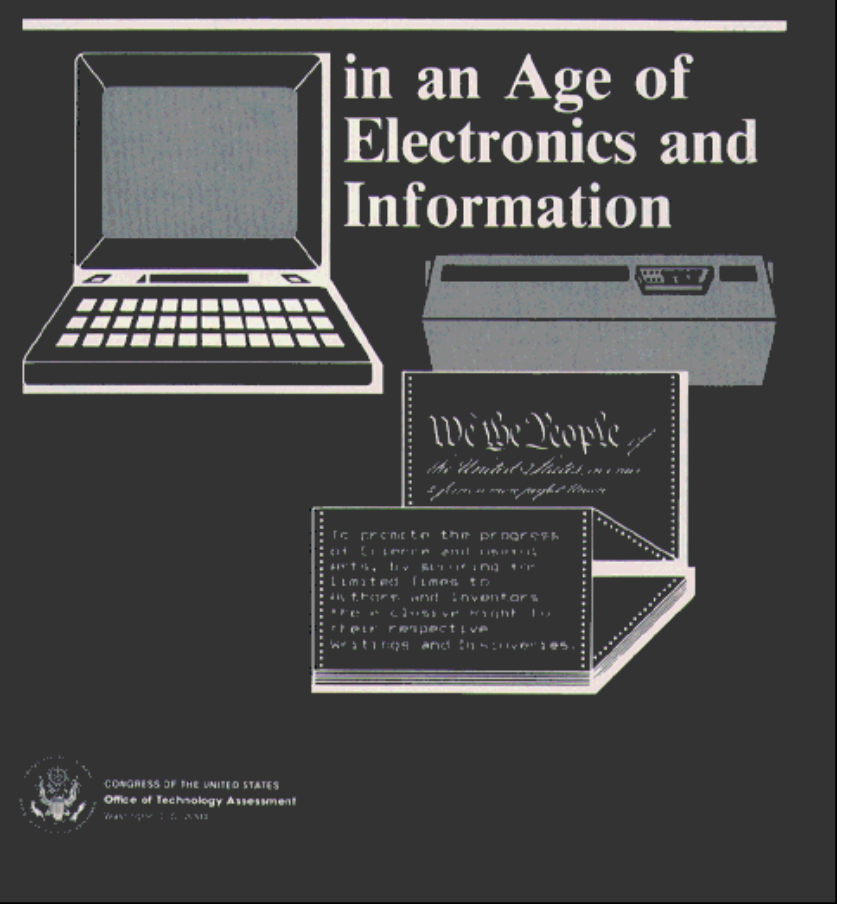


Recommended Citation:

U.S. Congress, Office of Technology Assessment, Intellectual Property Rights in an Age of Electronics and Information, OTA-CIT-302 (Washington, DC: U.S. Government Printing office, April 1986).

Library of Congress Catalog Card Number 86-600522

For sale by the Superintendent of Documents

U.S. Government Printing Office, Washington, DC 20402 


\section{Foreword}

This report examines the impact of recent and anticipated advances in communication and information technologies on the intellectual property system. It focuses primarily on the Federal copyright system, and on the continuing effectiveness of copyright law as a policy tool in the light of technologies such as audioand videorecorders, computer programs, electronic databases, and telecommunications networks. To obtain a comprehensive view, the study examined the intellectual property system from a number of perspectives: the constitutional basis of intellectual property policy; the system's goals, laws, and economics; the creative environment; problems of enforcement; the international context; and the Federal role in administering intellectual property rights.

OTA found that technological developments are affecting all aspects of the intellectual property system. Moreover, because we are only beginning to move into the era of electronic information, the full impact of new technologies will not become fully apparent for some time. Fundamental changes are occurring in information technologies that will antiquate many of the policy mechanisms now in force, and bring new intellectual property problems requiring new solutions. Thus, even if Congress acts now in response to current problems, it will need to be prepared to act again within the next decade.

The report was requested by Senator Charles McC Mathias, J r., Chairman of the Senate J udiciary Committee, Subcommittee on Patents, Copyrights and Trademarks; and by Congressman Peter W. Rodino, J r., Chairman of the House J udiciary Committee, Congressman Robert W. Kastenmeier, Chairman of the Subcommittee on Courts, Civil Liberties, and the Administration of J ustice, Congressman Hamilton Fish, and Congressman Carlos Moorhead.

In preparing this report, OTA has drawn on working papers developed by OTA staff and contractors, the comments of participants at seven OTA workshops held to discuss issues, the results of two public opinion surveys conducted by Yankelovich, Skelly \& White, and conversations between OTA staff and over 130 interested individuals. Drafts of the report were reviewed by the OTA advisory panel, officials from the Copyright Office, the Patent and Trademark Office, the Library of Congress, the Department of Commerce, the Department of State, the Office of the U.S. Trade Representative, and a broad range of individuals from law firms, public interest groups, trade associations, private industry, and academia.

OTA appreciates the participation of the advisory panelists, workshop participants, Federal agency officials, and interested citizens, without whose help this report would not have been possible. The report itself, however, is the sole responsibility of OTA, not of those who ably advised and assisted us in its preparation.

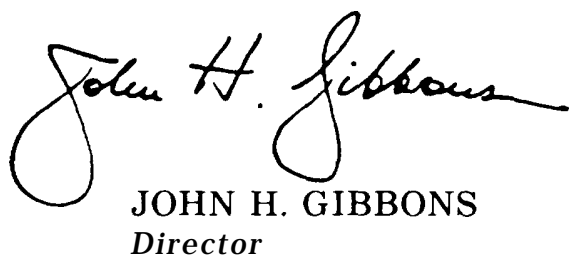




\title{
Intellectual Property Rights in an Age of Electronics and Information Advisory Panel
}

\author{
Paul Goldstein, Chairman \\ Professor of Law, Stanford Law School, Stanford University \\ J on Baumgarten \\ Dorothy Nelkin \\ Partner \\ Paskus, Gordon \& Hyman \\ Professor of Sociology \\ Charles Benton \\ President of the Board \\ Benton Foundation \\ Stanley Besen \\ Economist \\ Rand Corp. \\ Honorable Stephen Breyer \\ J udge of the U.S. Court of Appeals \\ Stan Cornyn \\ Senior Vice President \\ Warner Records \\ Oswald Ganley \\ Professor and Executive Director \\ Program on Information Resources Policy \\ Harvard University \\ Gustave Hauser \\ Chairman and Chief Executive Officer \\ Hauser Communications, Inc. \\ Mitchell Kapor \\ President \\ Lotus Corp. \\ Cornell University \\ J ames Nelson \\ State Librarian and Commissioner \\ Kentucky Department for Libraries and \\ Archives \\ J ohn Shattuck \\ Vice President for Government Community \\ and Public Affairs \\ Harvard University \\ Oliver Smoot \\ Executive Vice President \\ Computer and Business Equipment \\ Manufacturers Association \\ Patricia Sturdivant \\ Associate Superintendent \\ Houston Independent School District \\ Sherry Turkle \\ Associate Professor of Sociology \\ Massachusetts Institute of Technology \\ J ack Valenti \\ President \\ Motion Picture Association of America, \\ Inc. \\ Robert Lekachman \\ Professor of Economics \\ Vivian Weil \\ Lehman College \\ Senior Research Associate \\ Illinois Institute of Technology \\ William Lilley, III \\ Vice President for Corporate Affairs \\ Martha Williams \\ Professor of Information Science \\ CBS, Inc. \\ University of Illinois \\ George Minot \\ Senior Vice President \\ CompuServ, Inc.
}

The Advisory Panel provided advice and constructive criticism throughout this project. The panel does not, however, necessarily approve, disapprove, or endorse this report. OTA assumes full responsibility for the report and the accuracy of its contents.

iv 


\author{
J ohn Andelin, Assistant Director, OTA \\ Science, Information, and Natural Resources Division \\ F red W. Weingarten, Program Manager \\ Communication and Information Technologies Program \\ Project Staff \\ D. Linda Garcia, Project Director \\ Conceptual Framework and Societal Analysis \\ Lauren Ackerman \\ International and Institutional Analysis \\ Earl Dowdy \\ Technology and Economic Analysis \\ Paul Goldwhite \\ Summer Intern \\ Robert Kost \\ Legal Analysis \\ Arati Prabhakar \\ Congressional Fellow \\ Linda G. Roberts \\ Analysis of Creative Environment and Public Outreach Activities \\ Susan Walton \\ Contractor, Editorial Assistance
}

\author{
Administrative Staff \\ Liz Emanuel Audrey Newman Shirley Gayheart* \\ Renee Lloyd Patricia Keville
}




\section{Contractors and Consultants}

J ames Beniger

Department of Sociology

Princeton University

Cliff Berg

National Academy of Public Administration

Stanley Besen

Rand Corp.

Anne Wells Branscomb

Attorney

Deborah Buckner

Yankelovich, Skelly \& White, Inc.

Christopher Burns

Christopher Burns, Inc.

Herbert Dordick

Department of Communications

Temple University

J ose-Marie Griffiths

King Research, Inc.

Roland Hornet

Communications Law and Policy Consultants

Donald King

King Research, Inc.

Kenneth L. Kraemer

Irvine Research Corp.

Leslie King

Irvine Research Corp.
Patricia Martin

Christopher Burns, Inc.

L. Ray Patterson

School of Law

Emory University

W. Curtiss Priest

Center for Policy Alternatives

Massachusetts Institute of Technology

Carroll Pursell

Professor of History

University of California, Santa Barbara

David Richardson

Yankelovich, Skelly \& White, Inc.

David Schetter

Irvine Research Corp.

A. Allan Schmid

Department of Agricultural Economics

Michigan State University

Harold Seidman

National Academy of Public Administration

Petra Shattuck

Department of Political Science

City University of New York

Richard Solomon

Massachusetts Institute of Technology

$J$ ane Yurow

J ane Yurow Associates 


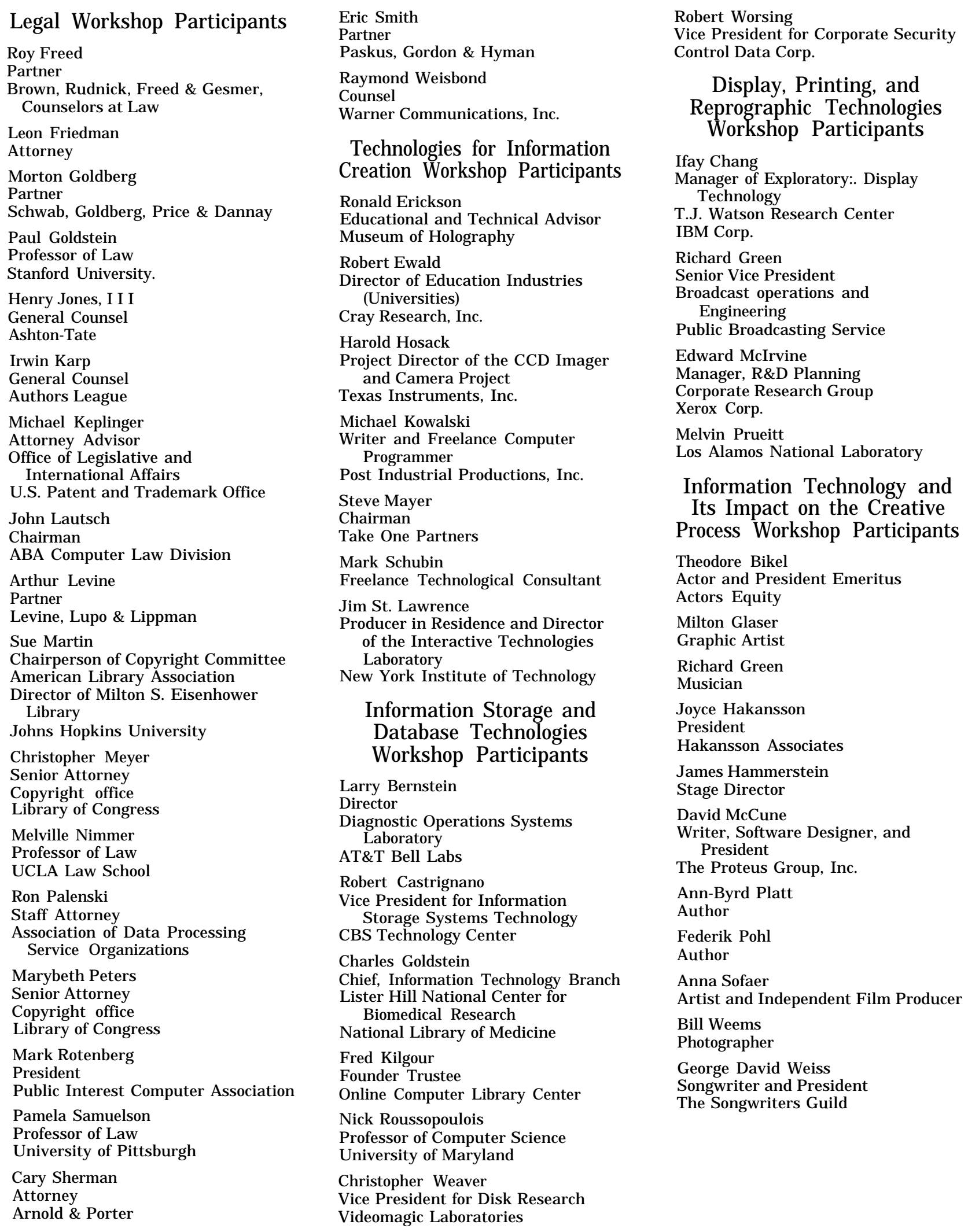




\section{Mini-Economic Workshop Participants}

\author{
Stanley Besen \\ Economist \\ Rand Corp. \\ Christopher Burns \\ Consultant \\ Christopher Burns. Inc. \\ Robert Lekachman \\ Professor of Economics \\ Lehman College \\ Patricia Martin \\ Consultant \\ Christopher Burns. Inc. \\ W. Curtiss Priest \\ Center for Policy Alternatives \\ Massachusetts I nstitute of Technol ogy \\ A. Allan Schmid \\ Professor of Economics \\ Michigan State University
}

Students' Perceptions of the Intellectual Property Rights

Issue Workshop Participants

Lisa Feldman

10th Grader

Magruder High School

Carl Fletcher

12th Grader

Ballou High School

Eugene Gholz

9th Grader

Georgetown Day High School

Nick Landau

11th Grader

Georgetown Day High School

Eric Martinusen

11th Grader

Georgetown Day High School

Michael Meredith

12th Grader

George Mason High School

Robert Salsbury

9th Grader

George Mason High School

Elinor Scully

11th Grader

George Mason High School

Clare Shannon

10th Grader

George Mason High School

Ron Smith

10th Grader

Richard Montgomery HHigh School

Wyvonella Spratt

11th Grader

Ballou High School

Deborah Van Lenten

11th Grader

Wooten High School
Marty White

12th Grader

Ballou High School

\section{External Reviewers}

Chapter 1: Conceptual Framework for Analyzing Intellectual Property Issues Rights

Bernard Barber

Professor of Sociology

Columbia University

J ack Copeland

President

National Educational Media, Inc.

Elizabeth Eisenstein

Professor of Social History

University of Michigan

J ack Golodner

Director

Department for Professional Employees

AFL-ClO

Stanley Gortikov

President

Recording Industry Association of America, Inc.

J ohn Hersey

Author

L. Ray Patterson

Professor of Law

Emory University

David Peyton

Director of Government Relations

Information Industry Association

Mike Remington

Chief Counse

House Subcommittee on Courts, Civil Liberties, and the Administration of J ustice

Daniel Toohey

Attorney

Dow, Lohnes \& Albertson

Chapter 2: Intellectual Property Goals in a Changing Information Environment

Bernard Barber

Professor of Sociology

Columbia University

J ack Copeland

President

National Educational Media, Inc

Elizabeth Eisenstein

Professor of Social History

University of Michigan

Stanley Gortikov

President

Recording Industry Association of America, Inc.

J ohn Hersey

Author
David Liebowitz

Attorney

Wiley \& Rein

L. Ray Patterson

Professor of Law

Emory University

David Peyton

Director of Government Relations

Information Industry Association

Petra Shattuck

Professor of Political Science and

Public Law

City University of New York

Cary Sherman

Attorney

Arnold \& Porter

Daniel Toohey

Attorney

Dow, Lohnes \& Albertson

Bruce H. Turnbull

Attorney

Weil, Gotshaf \& Manges

Chapter 3: The Accommodation of Intellectual Property Law to Technological Change

Charles Boiler

Executive Director

American Copyright Council

Duncan Davidson

Attorney

Cambridge Venture Partners

Edward Frankel

Computer Law Specialist

Hugh Gibbons

Professor of Law

Franklin Pierce Law Center

J ohn Hersey

Author

J ohn Lautsch

President

Computer Law Division of the American Bar Association

Melville Nimmer

Professor of Law

University of California-Los Angeles

L. Ray Patterson

Professor of Law

Emory University

Marybeth Peters

Senior Attorney and Policy Planning Advisor

U.S. Copyright Office

David Peyton

Director of Government Relations

Information Industry Association

Manny Pokotilow

Attorney

Caesar, Riuse, Berstein \& Cohen, Ltd. 
Mike Remington

Chief Counsel

House Subcommittee on Courts, Civil

Liberties, and the Administration

of J ustice

Robert Rines

Attorney

Rines \& Rines

Pamela Samuelson

Professor of Law

University of Pittsburgh

Bob Shaw

Attorney and President of the

Patent, Trademark, and Copyright

Research Foundation

Robert Stern

Attorney

Daniel Toohey

Attorney

Dow, Lohnes \& Albertson

Allen Wagner

University Counsel

University of California, Berkeley

Chapter 4: Impact of Technology on Enforcement of Intellectual Property Rights

Fritz Attaway

Vice President and Counsel

Motion Picture Association of America, Inc

Ivan Bender

Attorney

Larry Bernstein

Director

Diagnostics operations Systems Laboratory

AT\&T Bell Laboratories

Robert Castrignano

Vice President Information Storage Systems Technology

CBS Inc.

Edward Conklin

Vice President

FORTH, Inc.

Stanley Gortikov

President

Recording Industry of America, Inc.

Frederick Kilgour

Founder Trustee

Or-dine Computer Library Center

Michael Kowalski

Writer/Freelance Computer Programmer

Postindustrial Productions, Inc.

J im St. Lawrence

Director of the Interactive Technologies Laboratory

New York Institute of Technology

Bernard Lechner

Staff Vice President for Advanced Video Systems Research

RCA laboratories
David Leibowitz

Attorney

Wiley \& Rein

Edward Mcl rvine

Manager of $R \& D$ Planning

Xerox Corp.

L. Ray Patterson

Professor of Law

Emory University

David Peyton

Director of Government Relations

Information Industry Association

Barbara Polansky

Copyright Administrator

American Chemical Society

Mike Remington

Chief Counse

House Subcommittee on Courts, Civil Liberties, and the Administration

of J ustice

\section{Chapter 5: I mpact of Technology} on the Creative Environment

Bernard Barber

Professor of Sociology

Columbia University

Theodore Bikel

Actor and President Emeritus

Actors Equity

Ann Byrd-Platt

Author

J ack Copeland

President

National Educational Media, Inc.

Susan Dooha

Executive Director

Graphics Artists Guild

Elizabeth Eisenstein

Professor of Social History

University of Michigan

Richard Green

Senior Vice President

Broadcasting Operations and Engineering

Public Broadcasting Service

J ohn Hersey

Author

Nancy Marshal

Associate Director of University Libraries

University of Wisconsin-Berkeley

Edward Mcl rvine

Manager for R\&D Planning

Xerox Corp.

Barbara Nessin

Professor of Law

Emory University

Barbara Nessim

Graphic Artist

David Peyton

Director of Government Relations Information Industry Association
David Richtman

Cambridge Technology Systems

J im St. Lawrence

Director of the Interactive

Technologies Laboratory

New York Institute of Technology

George David Weiss

Songwriter and President

The Songwriters Guild

Chapter 6: Technology, Intellectual Property, and the Operation of Information Markets

Marjorie Blumenthal

Economist

General Electric Information Services Co.

Duncan Davidson

Partner

Cambridge Venture Partners

Henry Geller

Director

Washington Center for Public Policy Research

Duncan MacRae

Professor of Political Science

University of North Carolina

Bruce M. Owen

Economist

E conomists Inc.

Curtiss Priest

Research Associate

MIT Center for Policy Alternatives

Mike Remington

Chief Counse

House Subcommittee on Courts, Civil Liberties, and the Administration of J ustice

Michael Rubin

Office of the Assistant Secretary for Productivity, Technology, and Innovation

U.S. Department of Commerce

Fred Smith

President

Competitive Enterprise Institute

A. Allan Schmid

Professor of Economics

Michigan State University

Lester $\mathrm{C}$. Thurow

Professor of Management and

Economics

Massachusetts Institute of Technology

Anita Walgren

National Telecommunications and Information Administration

U.S. Department of Commerce

David Waterman

Professor of Communications

University of Southern California

Lawrence White

Professor of Economics

New York University 
Chapter 7: New Technologies and the Intellectual Property Bargain

Charles Boiler

Executive Director

American Copyright Council

Nancy Buc

Weil, Gotshall \& Manges

J ack Copeland

President

National Educational Media, Inc.

Roy Freed

Attorney

Brown, Rudnick, Freed \& Gesner

Leon Friedman

Professor of Law

Hofstra University

Henry Geller

Director

Washington Center for Public

Policy Research

J ohn Hersey

Author

Nancy Marshall

Counsel

National Library Association

Maurice Mitchell

Director

Annenberg Schools Washington Program

L. Ray Patterson

Professor of Law

Emory University

David Peyton

Director of Government Relations

Information Industry Association

Michael Remington

Chief Counsel

House Committee on the J udiciary

Mark Rotenburg

Public Interest Computer Association

Cary Sherman

Attorney

Arnold \& Porter

Daniel Toohey

Attorney

Dow, Lohnes \& Albertson

Ray Weisbond

Attorney

Warner Communications, Inc

Chapter 8: Impact of Technology on the International Intellectual Property System

Norman Alterman

Vice President and Deputy General Counsel

Motion Picture Association of America, Inc.

Fritz Attaway

Vice President and Counsel

Motion Picture Association of

America, Inc.
Charles Boiler

Executive Director

American Copyright Council

Robert Bruce

Attorney

Debevoise \& Plimpton

Marsha Carow

Vice President

Harcourt Brace J ovanovich, Inc.

J ohn Clements

Director of Governmental Affairs

American Federation of I nformation Processing Societies

Stanley Gorkikov

Recording Industry Association of America, Inc.

J acques Gorlin

Consultant

Eileen Hill

International Trade Administration

U.S. Department of Commerce

David Leibowitz

Attorney

Wiley \& Rein

Marybeth Peters

Senior Attorney and Policy Planning Advisor

U.S. Copyright Office

David Peyton

Director of Government Relations Information Industry Association

Barbara Pohansky

Copyright Administrator

American Chemical Society

Carol Risher

Director of Copyright and New

Technology

Association of American

Publishers, Inc.

Cary Sherman

Attorney

Arnold \& Porter

Gary Slaiman

Attorney

Weil, Gotshal \& Manges

Daniel Toohey

Attorney

Dow, Lohnes \& Albertson

Harvey Winter

Director

Office of Business Practices

U.S. Department of State

Alice Zalick

Assistant General Counsel

Office of the United States

Trade Representative

Chapter 9: Federal Role in the Administration of Intellectual Property Rights

Robert Cassler

Chief Counsel

Copyright Royalty Tribunal
J ohn Clements

Director of Governmental Affairs

American Federation of Information

Processing Societies

Roger Garcia

Government Division

Congressional Research Service

Library of Congress

J udy Goans

Office of Legislation and

International Affairs

U.S. Patent and Trademark Office

U.S. Department of Commerce

Ronald Moe

Government Division

Congressional Research Service

Library of Congress

Harold Relyea

Government Division

Congressional Research Service

Library of Congress

Mike Remington

Chief Counsel

House Subcommittee on Courts, Civil Liberties, and the Administration of J ustice

Petra Shattuck

Professor of Political Science and Public Law

City University of New York

Cary Sherman

Attorney

Arnold \& Porter

Daniel Toohey

Attorney

Dow, Lohnes \& Albertson

Anita Walgren

National Telecommunications and Information Agency

U.S. Department of Commerce

Harvey Winter

Director

Office of Business Practices

U.S. Department of State

\section{List of Other Contributors}

Raymond Ahlberg

Industry Specialist

U.S. Department of Commerce

David Altschul

Vice President

Warner Records

Stella Alvo

Co-owner

The Video Bus

Nicholas Arcomano

Vice President and Counsel

SESAC, Inc

Moses Asch

Founder and President

Folkways Records 
Russ Bach

Vice President, WEA

Warner Records

Donald Barr

President

Barr Films

Barbara Bayah

Classroom Teacher

Cupertino Union Public Schools

Paul Bender

Dean

Arizona State Law School

Paul Bortz

Managing Director

Browne, Bortz \& Coddington, Inc.

Gene Boucher

Executive Director

American Guild of Musical Artists

Robert Bramson

Attorney

Schnader, Harrison, Segal \& Lewis

Barry Bronson

Member of the Technical Staff

Hewlett Packard

Toni Carbo-Bearman

Executive Director

National Commission on Libraries and Information Science

Charles Butts

Vice President

Houghton Mifflin Co.

Doug Carothers

Patent Attorney

Xerox Palo Alto Research Center

Felix Chamberlain

Artists and Repetoire

Warner Records

Robert Churchill

President

Churchill Films

Sandy Cohen

Attorney

Weil, Gotshal \& Manges

Roger Cole

Assistant Director for

Administration

Eastman-Kodak Co.

Howard Colson

Assistant Vice President

Public Relations

Broadcast Music, Inc.

Edward Conklin

Vice President

FORTH, Inc.

Edward Cramer

President

Broadcast Music, Inc.

Bill Crowell

Vice President for Research

MicroPro International

Cally Curtis

President

Curtis Films
Len Cutler

Director of the Instruments and

Photronics Lab

Hewlett Packard

J oan Desens

Lexica Corp.

J ean Dexheimer

Director, Inter-U niversity Consortium for Educational Computing

Carnegie Mellon University

Thomas DiRenzo

Vice President, Direct Marketing and Communications

Institute for Scientific Information

Hugh Donaghue

Vice President

Government Programs and

International Trade Relations

Control Data Corp.

George Dummer

Director

Office of Sponsored Programs

Massachusetts Institute of Technol ogy

Moria Egan

Assistant to the President for Government Relations

New York Public Library

Alan Eisenberg

Executive Secretary,

Actors Equity Association

William Eldridge

Director of Research

Federal J udical Center

Robert Enenstein

President

Educational Microcomputer Associates, Inc.

Paul Fagan

Chief Economist

ASCAP

Laurie Failes

Teacher

Lexington, MA, Public Schools

Leonard Feist

Harry Fox Agency

National Music Publishers

Association, Inc.

Lee Felsenstein

President

Golemics, Inc.

Eamon Fennessy

President

Copyright Clearance Center, Inc.

LeRoy Finkel

Computer Coordinator

San Mateo County Office of Education

Frank Fischer

Urban Institute

Andrew Flugelman

President

Freeware
Steve Fluty

Editor

Viewtext Magazine

Steve Fox

Associate Director of Patents and Licenses

Hewlett Packard

Sarah Frank

BBC-TV Co-Productions

Michael Franklin

Executive Secretary

Director's Guild of America

C.E. Gallivan

Director of Marketing

Hewlett Packard

Kit Galloway

President

Mobile Image

Eugene Garfield

President

Institute for Scientific Information

Clifton H. Garrett

Deputy District Attorney

County of Los Angeles

Major Frauds Division

Electronic Crime Section

Andrew Gerber

Student

Massachusetts I nstitute of Technology

Ric Giardina

General Counsel

MicroPro International

Steven Gilbert

Director, Computer Literacy Project EDUCOM

Terry Gilbreth

Director

Electronic and Media Publishing Holt, Rinehart \& Winston

Michael Glen

Attorney

Intel Corp.

Mel Goldberg

Former Vice President

$A B C$

Mary Goldscmidt

Vice President

Lotus Corp.

J ack Golodner

Director

Department for Professional Employees

AFL-ClO

Ed Goode

Chairman

Computer Science Department

Lexington, MA, High School

Bobby Goodson

President

International Council on Computers in Education

Karla Graue

National Cable Association 
Peter A. Gross

President

Lexica Corp.

Lyn Gubser

Executive Director

Association for Educational

Communications \& Technology

Marianne Hall

Commissioner

Copyright Royalty Tribunal

Mel Harris

President

Paramount Corp.

W.B. "Trip" Hawkins

President

Electronic Arts

Richard H. Hersh

Vice President for Research

University of Oregon

Alexander Hoffman

Vice President

Doubleday \& Co., Inc.

Vivian Homer

Electronic Media Consultant

Former Vice President for Program Development

Warner Communications

Lucy Hammer

Ambassador Dougan's Office

U.S. Department of State

Dov J acobs

Free-lance Software Developer

Nick J ohnson

University of I owa Law School

(formerly FCC Commissioner)

Alan Kent

Assistant Dean

School of Library and Information Science

University of Pittsburgh

Daniel Klassen

President

Information Technology Design

Associates

Walter Koetke

Director of Technology

Scholastic Publishing Co.

Bernard Korman

Chief Counsel

ASCAP

Dan Lacy

Vice President

McGraw Hill, Inc.

J im Lardner

Reporter

The New Yorker

Edith Leonian

Philip Leonian

Advertising Photographers of America

Society of Photographer and Artist's

Representatives, Inc.
David Levine

Executive Director

Dramatists Guild

Del Lipert

Vice President

Digital Equipment Corp.

Beth Lewd

Computers in Education Specialist

Lexington, MA, Public Schools

William H. McAllister

Director, Patents and Licenses

Hewlett Packard

Scott Mace

Reporter

InfoWorld

J ohn Mallinson

Director

Center for Magnetic Recording

University of California, La J olla

Rick Manning

Executive

Data Courier

Andrew Manshell

Counsel

Birch Tree Group

Ernest R. (Bodie) Marx

Vice President

Mindscape, Inc.

Gene Mater

Vice President

CBS

International Group

Donald McCoy

Vice President and General Manager

CBS Technology Center

Al McPherson

Engineer

Warner Records

Gloria Messinger

Managing Director

ASCAP

Steve Metalitz

Staff Director and Chief Counsel

Senate Subcommittee on Patents, Copyrights, and Trademarks

Mark Meyers

Vice President for Research and Director Webster Research Center Xerox Corp.

Timothy Miles

Industry Specialist

Department of Commerce

Maurice Mitchell

Director

The Washington Program in

Communications Policy Studies

Annenburg Schools

Gerald Mossinghof

President

Pharmaceutical Manufacturers Association
Robert Nahory

Manager Optical Properties of semiconductors Research

Bell Communications Research

William Nix

Vice President and Deputy General Attorney

Motion Picture Association of America, Inc.

Dan Oelhsen

Editor-in-Chief

Electronic Publishing

Simon \& Schuster

Greg Olsen

Founder and CEO

EPITAXX, Inc.

Ralph Oman

Chief Counsel

Senate Subcommittee on Patents, Copyrights, and Trademarks

Ken Orsati

Executive Director

Screen Actor's Guild

Don Parker

Vice President for Research

QMS, Inc.

J anice Patterson

Director, Computer Operations

Wisconsin Center for Education Research

University of Wisconsin

Kenton Pattie

Vice President

NAVA/ICIA

Russell Pipe

Transnational Data Reporting Service

Abe Polonsky

Screenwriter

Dave Poltrack

Vice President for Research

Broadcast Group

CBS, Inc.

Linda Prowse

Engineering Management Training Manager

Hewlett Packard

Sherrie Rabinowitz

Mobile I mage

J ames Ratcliffe

Director of Public Affairs

R.R. Donnelley and Sons, Inc.

Retta Richardson

Executive Director

Southern Educational

Communications Association

Susan Rifkin

U.S. Patent \& Trademark Office

Office of Technology Assessment and F orecasting 
Humberto Rivera

President

GeoVision, Inc.

Seymour Rubenstein

President Emeritis

MicroPro International

Marie Salah

Teacher

Watertown, MA, Public Schools

Carol Schele

Smithsonian Institution

Karen Sheingold

Director

Center for Children and Computers

Bank Street College of Education

William Skok

Office of Business Practices

U.S. Department of State

Alan Smith

Vice President, Administration

Broadcast Music, Inc.

Bob Spielvogel

Lexica Corp.

Richard Stern

Attorney

Stern \& Roberts

Erwin C. Surrency

Law Library

University of Georgia
Rene Tegtmeyer

Assistant Commissioner

U.S. Patent and Trademark Office

Gail Thackery

Assistant District Attorney

Philadel phia, PA

Victor Vyssotsky

Executive Director for Research

Information Sciences

AT\&T Bell Laboratories

Eric Walter

Vice President of Operations

Electronic Arts

Robert Wesslund

Vice President for Technology Exchange

Control Data Corp.

Savan Wilson

Director of Education

Mississippi Authority for

Educational TV

Ethel Winant

Producer

Metromedia Producers, Inc.

Sanford I. Wolff

National Executive Secretary

American Federation of Television and Radio Artists
Charles Wood

Consultant

Information Integrity Investments

Delbert Yocam

Executive Vice President

Apple Computer, Inc.

J ohn van Raalte

Senior Scientist

Advanced Display Technologies

RCA Laboratories

Isa Zimmerman

Assistant Superintendent

Lexington, MA, Public Schools

\section{OTA Reviewers}

Ben Amick, Analyst

Clyde Behney, Program Manager

Audrey Buyrn, Program Manager

Richard Dalbello, Analyst

J im Dray, Research Analyst

Gretchen Kolsrud, Program Manager

Nancy Naismith, Program Manager

Robert Niblock, Program Manager

Lisa Raines, Analyst 


\section{Contents}

Chapter Page

Summary . . . . . . . . . . . . . . . . . . . . . . 3

I. Conceptual Framework for Analyzing Intellectual Property Rights Issues . . . . . . . . . . . . . . . . . . . . . . . . . . . . . 19

2. Intellectual Property Goals in a Changing Information Environment . . . . . 31

3. The Accommodation of Intellectual Property Law to Technological

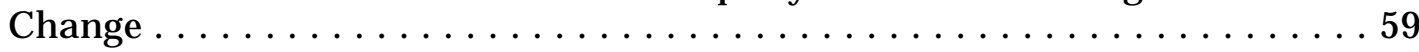

4. Impact of Technology on Enforcement of Intellectual Property Rights. . . . 97

5. I mpact of Technology on the Creative Environment . . . . . . . . . . . . 127

6. Technology, Intellectual Property, and the Operation of Information Markets . . . . . . . . . . . . . . . . . . . . . . . . . . . . . . . . . . . . . 157

7. New Technologies and the Intellectual Property Bargain . . . . . . . . . 187

8. I mpact of New Technologies on the International Intellectual Property System . . . . . . . . . . . . . . . . . . . . . . . . . . . . . . . .., ..., . 213

9. Federal Role in the Administration of Intellectual Property Rights. . . . . . 257

10. Strategic Choices for Congress . . . . . . . . . . . . . . . . . . . 285

Appendix A: List of Contractor Reports. . . . . . . . . . . . . . . . . . . . . . . , 299 
Summary 


\section{Contents}

Capabilities and Problems Posed by the New Technologies . . . . . . . . . . . 6.6

What Are The Stakes? . . . . . . . . . . . . . . . . . . . . . . . . . . . . . 9

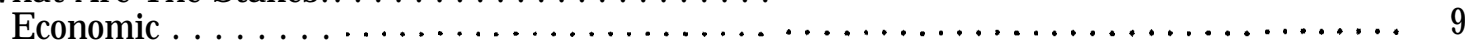

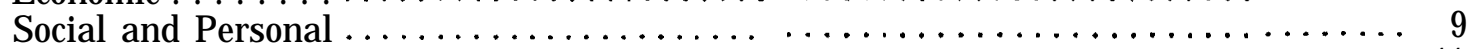

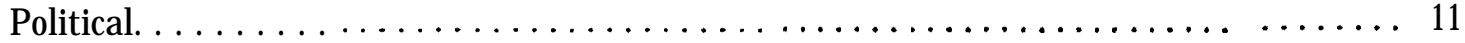

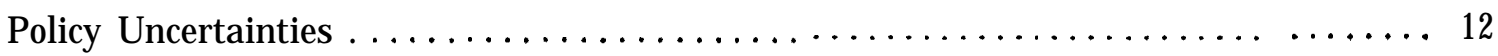

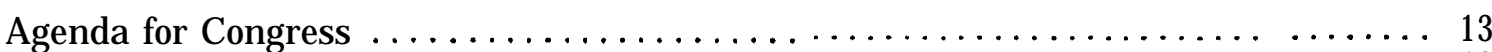

What Policy Goals To Pursue . . . . . . . . . . . . . . . . . . . . . . . . . 13

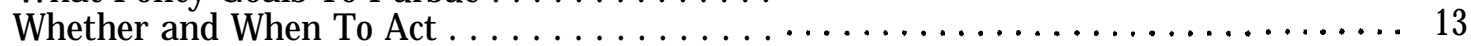

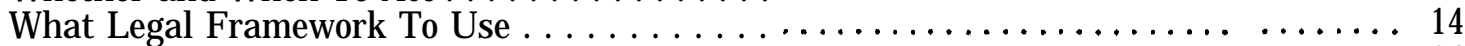

How Broadly To Define the Problem . . . . . . . . . . . . . . . . . . . . . . . 14

Within What Institutional Framework Should Intellectual Property Issues

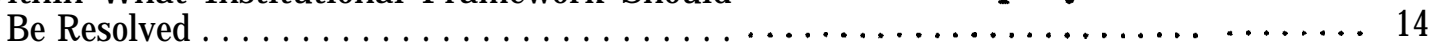

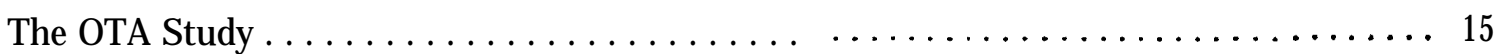

Figures

Figure No. $\quad$ Page

S-1. Simplified Chart of Developments, Uses, and Impacts of

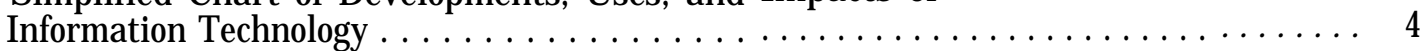

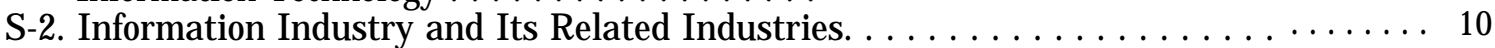

S-3. Trends From 1960 to 1980 Volume and Costs of Communication

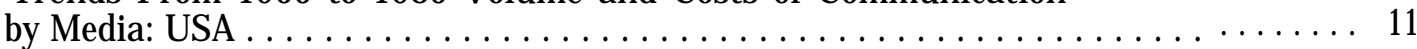


Domestic intellectual property law-principally the law covering patents, copyrights, and trademarks-is rooted in the United States Constitution. Under the law, the government is authorized to grant intellectual property rights not as rewards but as inducements to authors and inventors to create and disseminate intellectual works. The statutory nature and purpose of the constitutional authorization is stated explicitly in the 1909 Copyright Act:

The enactment of copyright legislation by Congress under the terms of the Constitution is not based on any natural right that the author has in his writings, for the Supreme Court has held that such rights as he has are purely statutory rights, but on the ground that the welfare of the public will be served and progress of science and useful arts will be promoted ... Not primarily for the benefit of the author, but primarily for the benefit of the public such rights are given. Not that any particular class of citizens, however worthy, may benefit, but because the policy is believed to be for the benefit of the great body of people, in that it will stimulate writing and invention to give some bonus to authors and inventors.

The mechanisms by which the intellectual property system worked in the past were straightforward. The government granted rights to an author or inventor. From this point on, the government's role was relatively minor. Rewards were determined in the marketplace. In order to benefit from copyright, an author had to publish his works, thus making them available to the public. In order to obtain a patent, the inventor had to reduce his ideas to useful applications. The holders of copyrights and patents holders were responsible for detecting infringements and preventing unauthorized use of a work. Enforcing one's right was not unduly burdensome. This was particularly true in the case of copyright. Given the expense and the organizational requirements needed to reproduce works there were only a limited number of printers, and thus it was relatively easy to keep track of their activities.

Today, however, technology is complicating this process and undermining many of the mechanisms that governed the system in the past. This trend is likely to continue; as shown on figure S-1, today's technologies are the beginning, not the end, of the information revolution. Computers, two-way interactive cable, fiber optics, optical disks, communications satellites, and other devices are becoming steadily more sophisticated and powerful, and their uses are expanding almost daily. The greatest impact, however, will come not from single technologies, but rather from their use in combination.

Although Congress has always had to reckon with technological change, the new information and communications technologies available today are challenging the intellectual property system in ways that may only be resolvable with substantial changes in the system or with new mechanisms to allocate both rights and rewards. Once a relatively slow and ponderous process, technological change is now outpacing the legal structure that governs the system, and is creating pressures on Congress to adjust the law to accommodate these changes. The pressures are coming from a number of different parties, and they are motivated by a wide range of concerns:

-Authors, publishers, film makers, and producers; representatives of the recording industry; and other copyright holders whose works can be delivered electronically: This group is concerned that technologies such as tape recorders and videocassette recorders are so widely used that they undermine their ability to enforce their copyrights. They are calling on Congress to adopt stronger enforcement measures. Alternatively, some group members would like Congress to provide new ways to protect their incomes, such as imposing taxes or royalties on blank tapes. 
Figure S-1.-Information Industry and Its Related Industries

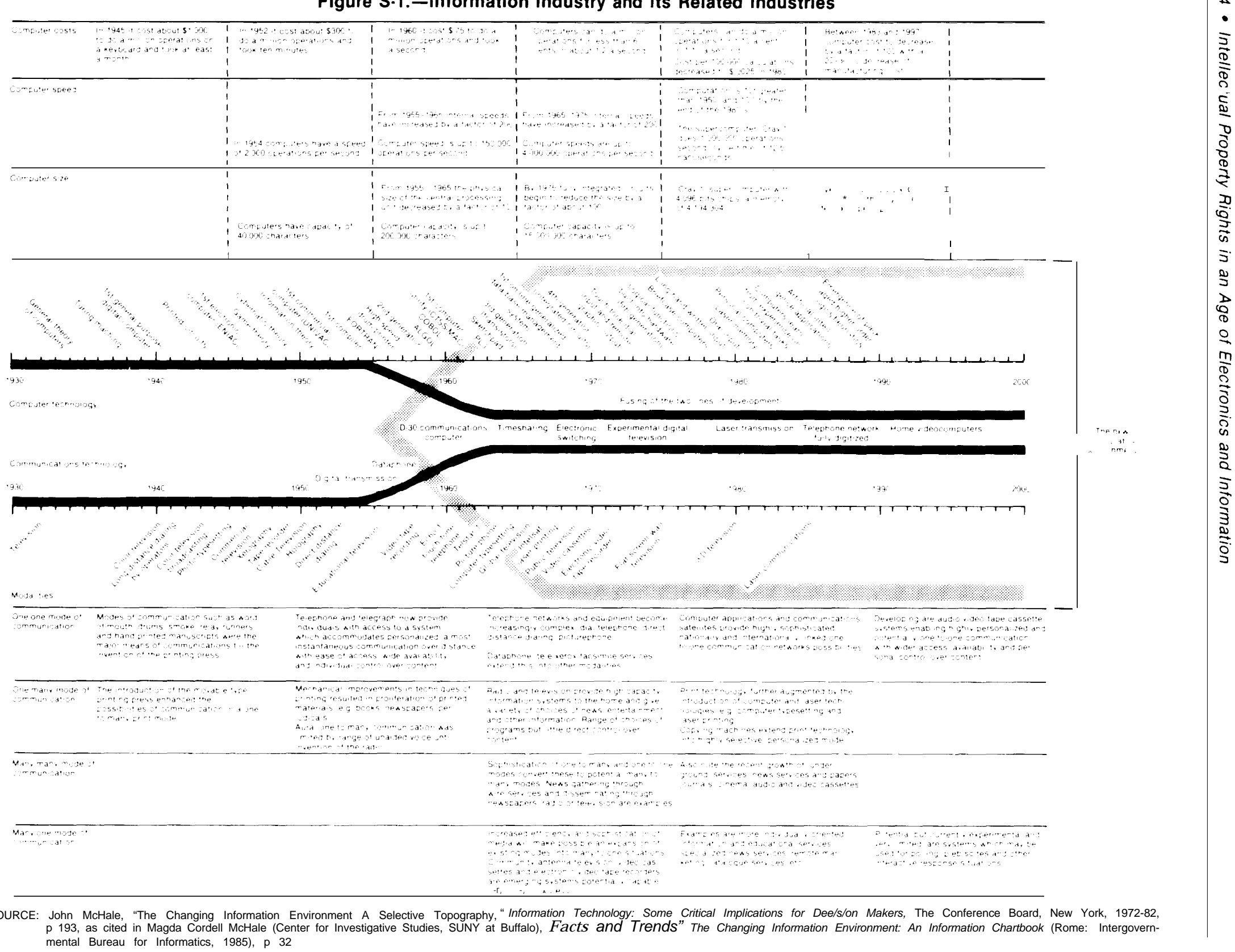


- Designers and producers of computer software and other functional works that do not fit comfortably into existing categories of intellectual property law: This group is concerned that, given the uncertainties in the law, their works will be inadequately protected. They are calling for more explicit and extensive protection under existing or under new laws.

- Database producers, information analysts, and others who package existing information for specific uses: This group opposes restrictions on the use and reuse of copyrighted materials. They also want incentives to be reallocated so that they receive a greater financial return for the value that they add to information by analyzing, reorganizing, and packaging it.

- Manufacturers of equipment capable of copying, reproducing, or recording (paper copiers, satellite antennas, videocassette recorders, and audio tapes): Members of this group oppose the imposition of taxes or royalties on tapes and any other actions that might increase the cost of their products to the consumer, or that make them less convenient to use. They claim that they aid copyright holders by creating new markets for products and so should not be penalized by having taxes imposed.

- Educators and scientists: Members of this group generally oppose extensions of the law, arguing that such extensions would make the resources and materials they need to do their work prohibitively expensive. Some members of this group seek to exempt educational uses from the law. Others are calling for licensing agreements that would allow them to use copyrighted materials at reduced rates.

- The general public: Many people are becoming increasingly accustomed to having new technology available at low cost to use as they please in their homes and offices. They want assurance that they can continue to copy films, records, and other information for their private use.

- Developing countries: Many developing countries want to use American intellec- tual property products to further their social, economic, and political development. These nations believe that the United States and other industrialized nations should relax intellectual property protection so that they can afford to make use of these new products and services.

These competing interests give rise to policy questions that resist quick, simple answers. Part of the problem is that new technologies are bringing new parties into the intellectual property debate, many of whom hold values and attitudes that differ from those of more traditional players - the authors, printers, and publishers, for example. The extreme case of this is the so-called computer "hacker" who believes that software and other forms of information should be shared freely. Holding less extreme but more common views are those members of the public who believe that they should be able to continue to use the new technologies to copy materials, at home, for their own personal use. In addition, there are those secondary information providers-information brokers and database producers, for examplewho, in contrast to the original creators of information, want fewer restrictions on the use and reuse of information.

Complicating intellectual property issues even further is the fact that technology is also changing the roles that people involved in the copyright system play. In fact, taking advantage of the new technologies, many people now play multiple roles, and their attitudes about intellectual property protection may vary accordingly.

The relationship among traditional players are also changing, breaking down old alliances, and generating some new ones. Working on an electronic network, for example, the author of a book can now edit, print, publish, and distribute his works; tasks that were traditionally within the purview of the publisher. Under these circumstances, the author may be less inclined to assign his rights to the publisher. Similarly, because it provides new outlets for distribution such as pay-per-view cable tele- 
vision and videocassettes, technology is also changing the relationships among film makers, film producers, and film distributors. Transmitting his works directly to the user on video- cassettes, for example, an independent film maker can circumvent the major film companies and, in the same fashion, a major film company can avoid dealing with theater chains.

\section{CAPABILITIES AND PROBLEMS POSED BY THE NEW TECHNOLOGIES}

To understand the legal and political pressures that new technologies place on the intellectual property system, one needs to understand their unique capabilities. A few examples convey the scope and pace of technological progress and the problems that it poses:

- A problem of identifying authorship: A group of authors using personal computers connected by a telephone network can collaborate in writing an article, a piece of software, or a database. This work can exist in various forms, in different places, and can be modified by anyone having access to the network. This networking technology provides new opportunities to combine talents, resources, and knowledge. Also, using satellite technology, authors, scholars, or other creators from all over the world can work together simultaneously on the same project.

However, this same networking capability might create problems for the intellectual property system. Copyright, for example, is granted to "original" works of "authorship. In a world where there are many authors of one work, worldwide collaboration, and ever-changing materials, a law based on the concepts of originality and authorship may become too unwieldly to administer.

- A problem of identifying infringements and enforcing rights: The increased communications capacity (in terms of speed, bandwidth, and distance) made possible by fiber optic technology will allow computer users to rapidly transmit incredible amounts of information at a rate of 100 average length pages in a second. Such a capabil- ity could permit the creation of centralized libraries with universal access.

On the other hand, these high-speed communications media, combined with large capacity optical disk storage technologies, will also pose enforcement problems for the intellectual property system. They allow individuals to trade vast quantities of copyrighted materials without the knowledge or permission of copyright holders. With these technologies, the situation is no longer simply one of an individual trading or giving away a book to someone else; rather, it is one in which individuals can inexpensively and privately share the contents of an entire library.

- A problem of private use: At the end of World War II, copyrighted information flowed into American homes through three channels-print publications, radios, and phonograph records. And although people could enjoy these works freely, they could not copy them conveniently and at low cost. Today, the situation has changed radically. Americans can now receive a much greater amount and variety of copyrighted materials via a whole host of new media-satellite, cable and broadcast television, computers, videocassette recorders, and telephone lines, to name a few. Moreover, using computer networking technology, they can now easily and inexpensively reproduce and transmit copyrighted works.

This remarkable state of affairs raises several problems for the copyright system. First, if a private citizen copies information-a film or record, for exampleshould this be considered an infringement 
of copyright? At present, the law gives little guidance in this area; nor, until recently, did it need to. Such private use was so limited it posed no threat to industry profits. Second, if it were decided that home copying infringed copyright, how could a ban against it be enforced? Since many people could be engaged in this kind of behavior in the privacy of their own homes, their activities would be impossible to track.

- A problem of functional works: At one time a writer wrote solely to communicate meaning to his readers. He did so in novels, biographies, news stories, scientific treatises, and even in recipes. Today, however, a writer can write for a machine rather than a human audience. He does so when he writes computer software-instructions that tell the machine what to do. A computer program can also create new programs, and even control industrial processes. In the future, information itself will play a similar functional role. A piece of information entered into a database, for example, may automatically retool one of several manufacturing facilities.

Writings of this kind are becoming central to the economy because they can efficiently substitute for labor and mechanical processes. It is, however, precisely the capability of substituting for machine processes that causes problems for the traditional intellectual property system.

Intellectual property law provides two basic forms of protection-patent and copyright. These schemes reflect a basic distinction between invention and authorship. Inventions are essentially useful devices or processes, whereas works of authorship convey information and ideas. And although both schemes encourage the production and dissemination of ideas, they do so in two different ways. Patent requires disclosure, and copyright assumes that in order to profit from a work, an author must publish it. Moreover, the types of protection granted reflect the differences between writings and inventions. Copyright prevents commercial copying; patent prevents commercial use.

With the development of computer software and other functional works, the clear distinction between inventions and writings is beginning to break down. These developments raise questions about whether new information-based products can be accommodated within the old legal framework, and whether efforts to do so will undermine the original intent of the law.

-A problem of derivative use: A major newspaper maintains its index on computer. A user of this index takes the information in it and analyzes it for another client, giving him up-to-date, timely information that is precisely tailored to his needs. Using electronic technology, a research chemist can search all bibliographic data on a particular chemical in a matter of hours, instead of the weeks it once would have taken. An investor who must make a snap decision about whether to buy or sell can call up a constantly updated database, and use the information to pursue his profits.

The new information technologies, which allow for this kind of customized information on demand, are creating a wide range of new opportunities to expand the variety, scope, and sophistication of information-based products and services. In fact, a whole new industry has developed to provide these services; and it is now one of the fastest growing sectors in the economy.

As the opportunities to create derivative works increase and as this sector comes to play a larger role in the economy, questions arise about what kinds of information can legally be used to create secondary information products. Under existing intellectual property law, copyright holders have the right to benefit from all subsequent works based on their original works. If interpreted broadly, it is possi- 
ble, however, that this approach will inhibit the production and use of secondary materials.

- A problem of intangible works: In their homes, people can now receive electronically a broad range of information-based products and services-e.g., shopping, stock market and banking information, educational software, videogames, films, and musical works, to name a few. In the long run, however, individual access to information may be more costly and thus more limited as intellectual work become transmitted in intangible forms.

Publication and dissemination of intellectual works were fostered under the traditional copyright scheme because authors had to publish copies of their work in order to profit. Although the author retained the right to print and publish a work, he no longer controlled the copies after the first sale. Since public dissemination went hand in hand with profit-making, this system promoted the interests of both the public and the author.

As more and more works are transmitted electronically, however, public access to information, originally built into the copyright system, may in fact become more limited. Not only may the individual price of information be higher; now people may have to pay for it every time they wish to use it.

When printing was the dominant technology, this was not the case. Once a person bought a copy of a book or magazine, he owned it. It became his personal property. He could consult it repeatedly, without additional cost. He could share it, rent it, or resell it, without the proprietor's permission. Copyright holders, therefore, did not control the market for their works. Their monopoly was limited. Booksellers competed for sales, not only with the proprietor, but also with one another. Information, therefore, was available from many sources at a competitive price.

With the electronic distribution of works, however, proprietors have more control. Because their works need not be sold in hard copies, and because it is questionable whether individuals can legally copy them, they do not have to compete with resellers, wholesalers, or others who might drive down the price of their products. As the only source of distribution, people must come to the copyright holder on his own terms. Now controlling access to their works, copyright holders can restrict it in order to enhance their profits. If they were to do this, copyright law would no longer perform the function it was designed for under the Constitution. Moreover, once copyright serves to limit access, it raises issues for communications policy as well as for copyright.

- A problem of meeting educational goals: The intellectual property system was originally designed to enhance learning and the useful arts. This goal is more difficult to meet today because of the increasing market value of intellectual properties. The technologies provide numerous opportunities for educational use. However, because software development is often expensive, it is in the interest of the developer to concentrate on products for customers who can pay the most-businesses, not schools. The schools then have the choice of doing without software, diverting money from other equally needed educational materials, or developing their own software, since they cannot legally copy copyrighted works. The copyright problem in this situation is simple: Copyright, designed as a policy tool to enhance learning, fails to meet its goal.

- A problem of integrity: Assisted by the computer, a film maker can create scenes that were never actually filmed, or take existing images and place them in entirely new contexts. These capabilities open new avenues for creativity. But at the same time, they may be used to misrepresent a work or undermine its integrity. An unscrupulous artist, for example, might use technology to distort a well-known piece of art for his own purposes or profit without the knowledge of the original artist. In this electronic environment, creators 
may become as concerned about the integrity of their works as they are about their profits. To be effective, intellectual property law may need to take into account the problem of artistic integrity, as well as that of financial rewards.

- An international problem: All of the capabilities and problems that characterize domestic use of the new technologies are equally prominent-sometimes more sowhen they are used internationally. Satellite technology permits global communication, but it also beams in programming that nations may not want. Satellites collect valuable agricultural and environ- mental information about the developing world. But once it has been analyzed by a commercial company and copyrighted, it may be priced too high for developing countries to afford. A nation near the United States is able to pick up and unscramble satellite programming that viewers want-and do so without paying the fee charged by the company. Domestic companies have no way to monitor use or enforce their copyright claims. These problems are exacerbated by considerable disagreement among nations about intellectual property issues.

\section{WHAT ARE THE STAKES?}

The new technologies are extremely powerful tools. For the United States, therefore, the stakes of identifying the best laws and policies for their use are very high. These stakes fall into three general categories: 1) economic, 2) social and personal, and 3) political.

\section{E conomic}

Information technologies and informationbased products and services are becoming central to the economy as a whole. The new technologies and the information they embody can be used to improve efficiency, increase productivity, and thus engender economic growth. Information is reusable, and unlike capital resources, such as steel or iron, it can be produced and distributed using few physical resources. Not only is information an efficient substitute for labor, it can also be used to improve the overall efficiency of the production process. Businesses, for example, are now applying computer technology to almost all of their activities: from recruiting to laying off workers, from ordering raw materials to manufacturing products, from analyzing markets to performing strategic planning, and from inventing new technologies to designing applications for their use. To serve these needs, a whole new industry has been spawned. (See figure S-2. ) One of the fastest growing sectors of the economy, this industry is spearheading the Nation's economic growth and enhancing its competitive position in the international marketplace.

The economic stakes raised by the new technologies are particularly high for the copyright industries-publishing and other industries that rely on the legal protections provided by copyright law. It is estimated that in 1982, the combined sales of these industries constituted approximately 5 percent of the gross national product. Estimates suggest that more than 2.2 percent of the labor force is affected by trade in intellectual property. The amount of financial damage that these industries suffer due to infringements of intellectual property rights is extremely hard to estimate. Very few independent, quantitative data are available, and existing analyses often contradict each other.

\section{Social and Personal}

Information is a dominant force in our lives. In the United States, an enormous amount of information is communicated in the form of words through electronic media. In the 1970s, for example, it was estimated that the American population was exposed to about 8.7 trillion words each day through electronic media such as radio; television; and print media such 


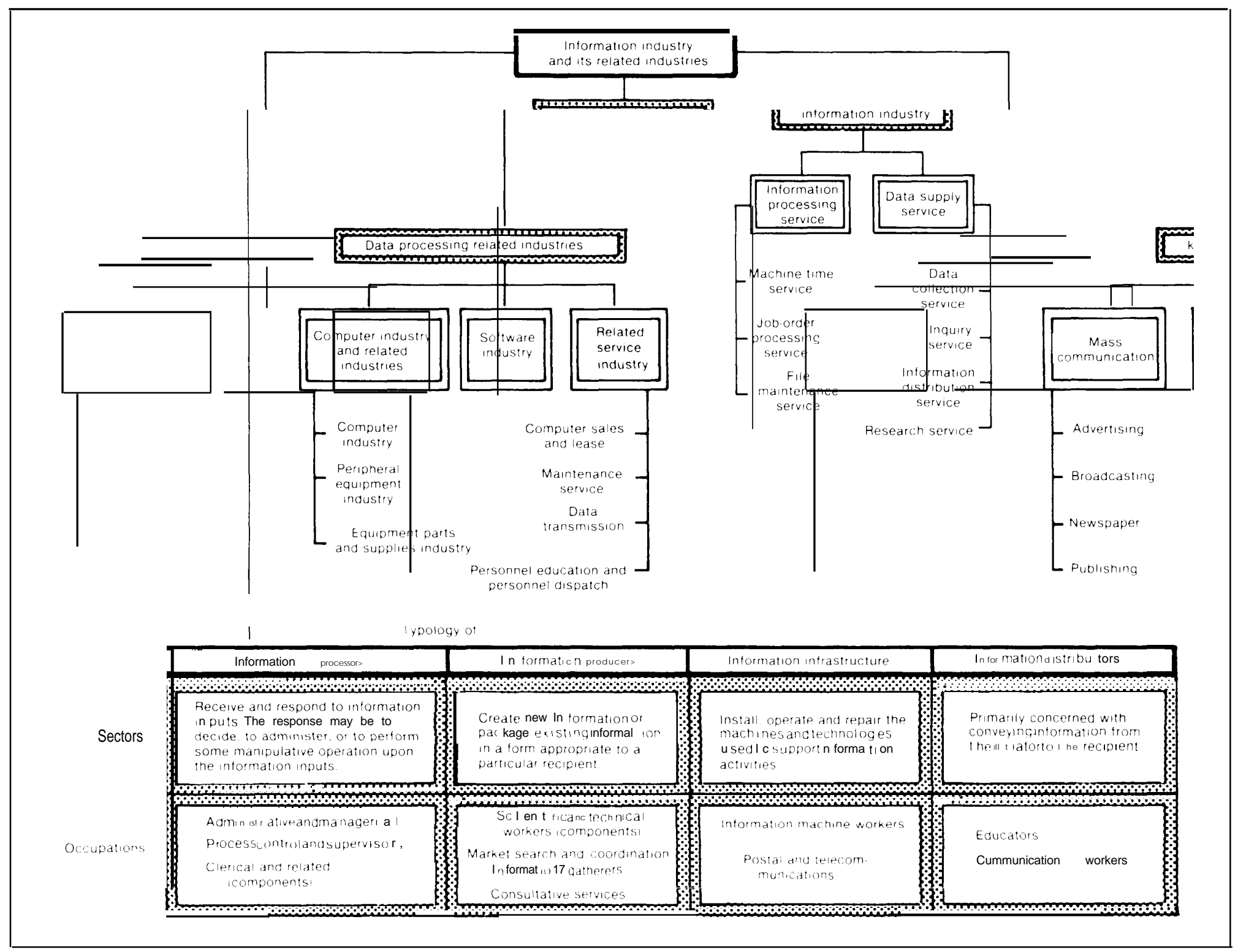

SOURCE: H.P. Gassman, "Is There a Fourth Economic Sector?" OECD Observer, No. 113, November 1981, pp. 18-20, as cited in Magda Cordell McHale (Center for Investi and Trends: The Changing Information Environment: An Information Chartbook (Rome: Intergovernmental Bureau for Informatics, 1985). p. 32 . 
as newspapers, books, and magazines. This figure is rising; each year, the number of words communicated increases at an average rate of 1.2 percent per year. And, as is illustrated in figure S-3, the fastest growing media for transmitting and receiving information are electronic.

Information, in all forms, is essential to all facets of our lives. It is the principal resource we use to meet our personal needs: coping with day-to-day problems; dealing with life's traumas and crises; supporting religion, family life, and cultural heritage; and accommodating our recreation, entertainment, and leisure time needs. Never in history have we had the opportunity to be so fully and currently informed about world, national, and local affairs.

Given the central importance of information, the public has high stakes in decisions about intellectual property rights. Moreover, the public has high expectations about how technology can serve its information needs. A survey conducted for OTA confirmed that many people believe they have the right to use these technologies as they please, although they draw the line at using them for commercial gain. The generation now in the schools has grown increasingly accustomed to the benefits of technology. Many youth view their tel-

Figure S-3.-Trends From 1960 to 1980 Volume and Costs of Communication by Media: USA (plotted on log by log scales)

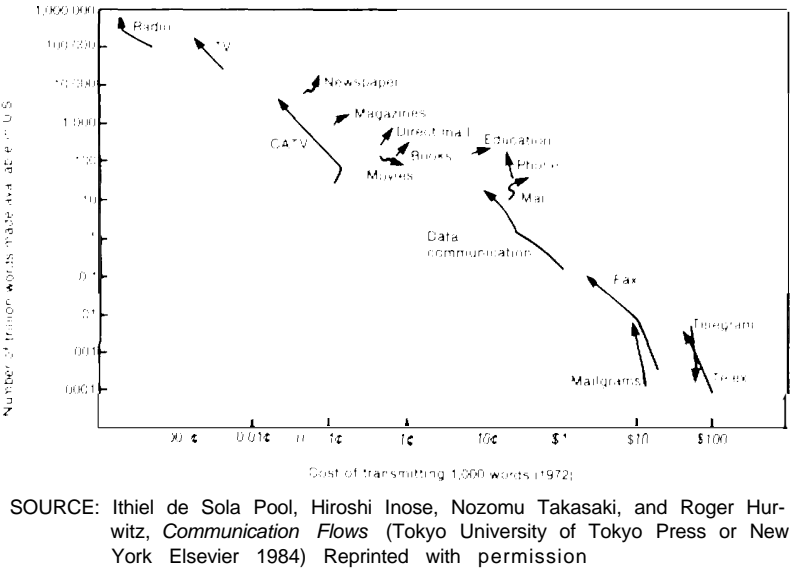

ephones and tape recorders, videocassette recorders, and other electronic devices as an integral part of their lives.

\section{Political}

In democratic societies, citizens must be well informed about issues, candidates for office, and local affairs. Similarly, a democratic polity requires a well-informed citizenry. Increasingly, information and communications technologies serve these information needs.

The government regularly needs huge amounts of information to make complex legal and policy decisions. Many government agencies would find it hard to conduct their daily business without resorting to customized information on demand. The Internal Revenue Service and the Social Security Administration, for example, require large automated information systems to handle the accounts of hundreds of millions of clients. And the operation of national defense depends on the use of complex communication systems both for day-to-day management of the military establishment and for the command and control of sophisticated weaponry. The government's budget for information technology has risen from $\$ 9.2$ billion in fiscal year 1982 to an estimated $\$ 15.2$ billion in fiscal year 1986 .

Citizens' groups and political parties are also relying more heavily on the new technologies to achieve their aims. Technology, for example, is being used to target voters and potential supporters, communicate with voters, manage information, and even to design campaign strategies. Computers are also being used as lobbying tools. To illustrate the longterm effects of population growth, one lobbying group, for example, uses a portable computer and interactive software to inform Members of Congress about its point of view.

In each of these realms-economic, social, and political-the stakes in the intellectual property debate are rising as fast as the technologies are becoming more technically sophisticated and widely used. 

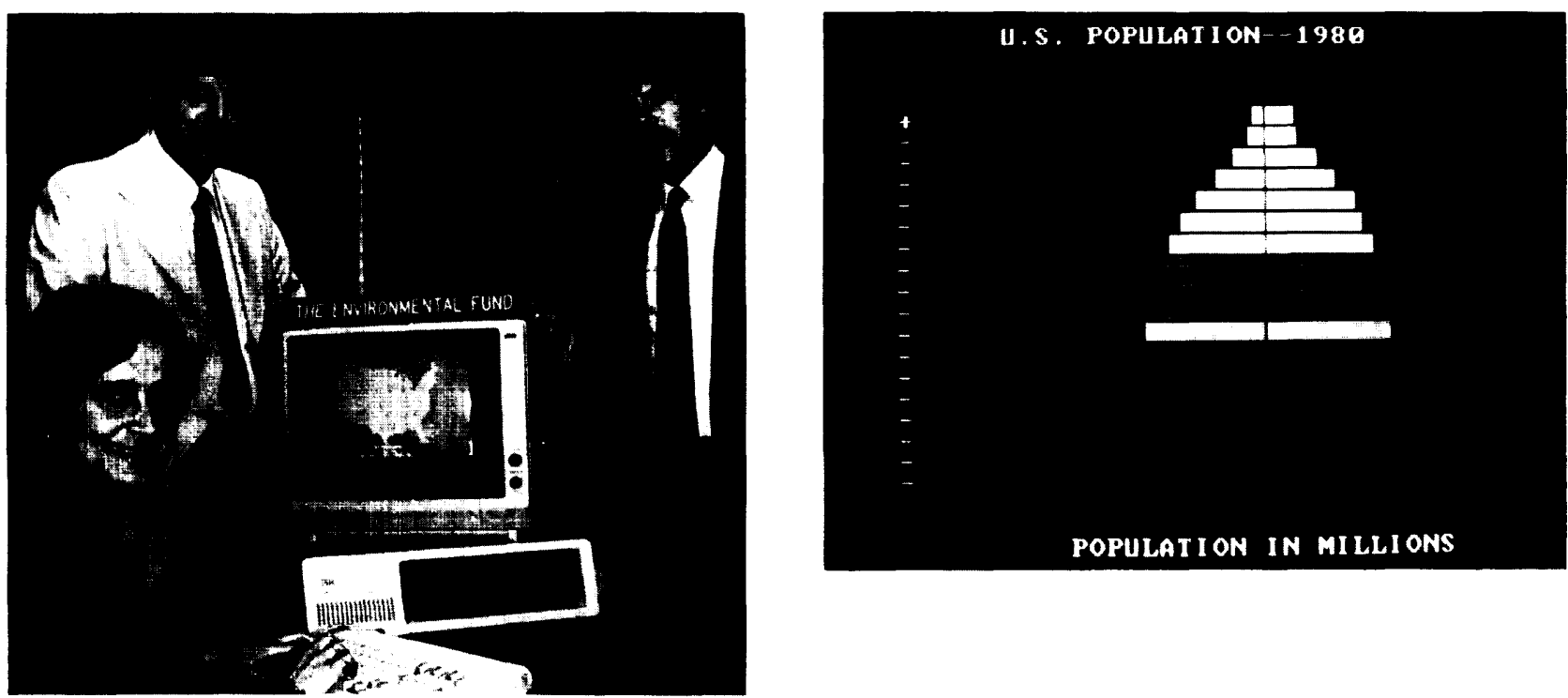

\section{POLICY UNCERTAINTIES}

In designing new laws or policies on intellectual property, the government will have to contend with a number of uncertainties. These include:

- The peculiar characteristics of information as a commodity: Information has special characteristics that distinguish it from other economic commodities and confound our understanding of how information markets work. Information is, for example, simultaneously an economic commodity and a societal resource. Since it is inherently leaky; it is hard to own or control. And although costly to produce, information is inexpensive to copy. Given these unique properties, economists are only beginning to understand the role of information in the market place. They have yet to determine, for example, how to measure value or identify when value is added to an information-based product or service-both needed to resolve issues of derivative use. Moreover, the few available data are fragmentary, nonquantitative, and often subjective.
- The increased complexity of the intellectual property system: The new technologies are increasing the complexity of the intellectual property system, and so creating new uncertainties for policy makers. The number and variety of information providers, kinds of information-based products and services, ways of using information, and types of information users are proliferating, giving rise to new relationships among the parties involved. These changes are occurring in very unpredictable ways. Thus, in the future, Congress will need to have more information about the intellectual property system.

- The changing nature of the technology: The electronic age has just begun. Today, new technologies are multiplying the kinds of media that can be used to package, store, deliver, and use intellectual works. Over the long run, however, the increased convergence of information and communication technologies may reverse this trend. Packaged, stored, and delivered electronically, text, sound, and images will all be 
interchangeable. Our understanding of how and when such changes will take place, and of how they might affect the intellec- tual property system, is replete with uncertainty.

\section{AGENDA FOR CONGRESS}

Faced with a growing number of requests for action, in addition to a ubiquitous and rapidly changing technology, Congress confronts the problem of trying to take into account the magnitude and the scope of technological change, while also balancing interests and responding to present concerns. In considering how Congress might proceed, OTA identified five major strategic choices:

1. what policy goals to pursue,

2. whether and when to act,

3. what legal framework to use,

4. how broadly to define the problem, and

5. within what institutional framework issues should be resolved.

\section{What Policy Goals To Pursue}

OTA found that the intellectual property system may no longer serve social, economic, and political goals with the same ease in an information age, given the enhanced value of information in all realms of life. It is likely, therefore, that Congress, when designing new intellectual property laws and policies, will have to choose more explicitly among policy goals. Alternatively, Congress could use policy mechanisms other than the granting of intellectual property rights to foster some goals not supported by the present system. In the pursuit of economic goals, for example, other economic incentives-such as subsidies or tax exemptions-might be granted. Unlike the extension of intellectual property rights, such mechanisms would have few negative consequences for learning and the creative environment.

\section{Whether and When To Act}

Decisions about when to act are clearly related to decisions about whether to act, and to decisions about whether to deal with problems separately or in a comprehensive fashion. In considering these choices, OTA found that technological developments are, indeed, affecting all aspects of the intellectual property system. Moreover, because we are only beginning to move into an electronic era, the full impact of the new technologies will not become completely apparent for some time. Fundamental changes in technology are occurring that will antiquate many of today's solutions and bring new kinds of problems requiring new kinds of solutions. Thus, even if Congress decides to act now in some areas, it will need to be prepared to reconsider these actions within the next decade.

Some problems are particularly pressing because stakeholders are seeking immediate legislative action, societal stakes are particularly high, or technological change is occurring so rapidly that Congress must act sooner rather than later if it wants to deliberately channel its impact. OTA identified four such problems: enforcement, private use, functional works, and the international intellectual property system.

Other problems, although equally important, are less ripe for immediate action. Engendered by technologies still in their infancy, these problems are only now just emerging, and our understanding of them is severely limited. Examples of such problems include assigning value and distributing rewards in cases of derivative use, protecting the integrity of works in an electronic environment, and attributing and assigning authorship when works are generated by interactive or electronic processes.

Although it may be too early to determine long-term solutions to these problems, OTA concluded that some steps will need to be taken 
now if they are to be adequately dealt with in the long run. One approach might be to begin now to systematically collect data about, and enhance our understanding of, information needs, information users and producers, and information-based products and services. This approach might require institutional changes, since, at present, no agency within the Government is set up to carry out such a task.

\section{What Legal Framework To Use}

The intellectual property system was carefully designed to balance the public and the private interest. OTA found, however, that because the new information and communication technologies do not fit neatly within the existing framework of the law, the balance may be harder to achieve in the future.

OTA identified functional works as a particularly serious problem in this regard. The analysis found that the distinction between writings and inventions is indeed breaking down with respect to functional works such as computer software and semiconductor chip masks. Because there are many works of this type, they may require their own framework for protection. If it were based on the distinctive characteristics of these works, the law might be more accurately targeted to achieve specific policy outcomes, thus serving as a more robust policy tool. With a new category of law, both producers and users would face less uncertainty each time a new type of work were introduced. OTA's analysis suggests, too, that a fruitful basis for a revision along these lines might be found in the distinctions between works of art, works of fact, and works of function.

\section{How Broadly To Define the Problem}

OTA found that intellectual property policy can no longer be separated from other policy concerns. Because information is, in fact, central to most activities, decisions about intellectual property law may be decisions about the distribution of wealth and social status. Furthermore, given the unlimited scope of the new technologies and the growing trade in in- formation-based products and services, U.S. intellectual property policy is now inextricably tied to international affairs. Communications policy, too, is becoming more linked to intellectual property policy, as more and more intellectual works are being transmitted by media such as cable television, telephone lines, and communication satellites. Today, intellectual property issues also give rise to privacy concerns as copyright holders seek technical means to monitor use. In making decisions about intellectual property policy, therefore, Congress must consider a whole new range of issues, and decisionmakers in all these areas will need to strive for greater coordination.

\section{Within What Institutional Framework Should Intellectual Property Issues Be Resolved}

OTA found that intellectual property issues cannot be resolved without dealing with the question of institutional capabilities and change. In the absence of institutional change, the courts will increasingly be called on to resolve highly complex and technical issues and to make policy in this area. The judiciary, however, may not be suited for this role.

The pace of technological change will continue to put pressure on existing institutional arrangements. To the extent that Congress, in responding to these changes, adopts legislation requiring a more active Government role, new institutional arrangements will probably be required. If this were to be the case, Congress might want to expand the responsibilities of existing agencies, or it might establish a new central agency to address intellectual property issues. Such an agency's mission might include monitoring technological change and assessing how the law might deal with it, providing the necessary expertise to deal with complex technological issues, and collecting and analyzing data about information markets and use. Such an agency might also assume additional regulatory functions, such as distributing rewards or adjudicating disputes. Finally, it might coordinate intellectual property policy with policy in related areas. 


\section{THE OTA STUDY}

The request for this assessment, Intellectual Property Rights in an Age of Electronics and Information, was made by Senator Charles McC. Mathias, J r., Senate Committee on the J udiciary, and by Congressmen Peter W. Rodino, J r., Robert W. Kastenmeier, Hamilton Fish, and Carlos Moorhead, House Committee on the J udiciary.

In thinking about how the new communication and information technologies might affect intellectual property rights, OTA has adopted a broad approach, looking at the kinds of stresses that technology might be placing on the intellectual property system as a whole, and on each of its parts. Such an approach was required because the new technologies do not necessarily have a direct effect on intellectual property rights. Rather, more often than not, their influence on the law is felt indirectly, as a result of such things as technologically induced changes in norms, values, and expectations, as well as in the ways in which intellectual works are created, produced, marketed, and distributed.

Such an approach is also useful because, given the political intensity and high economic stakes of the intellectual property debate today, it is extremely important to view the entire situation as all one piece. Those involved in the policy debate often define issues solely in terms of their own interests and world views. 
Chapter 1

Conceptual Framework for Analyzing Intellectual Property

Rights Issues 


\section{Contents}

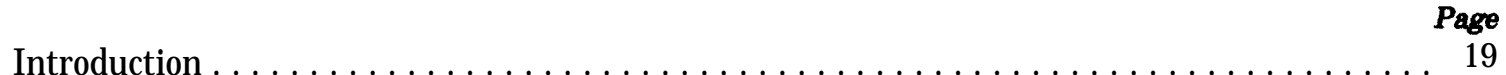

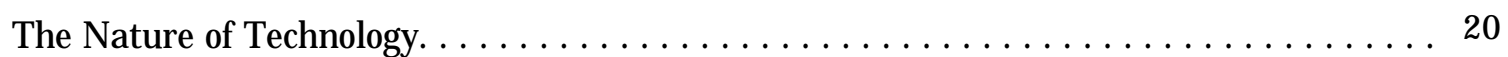

The Intellectual Property System and Its Relationship to Social and Technological

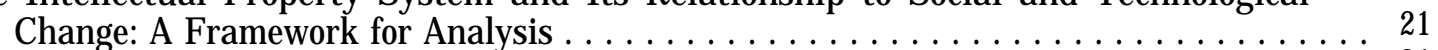

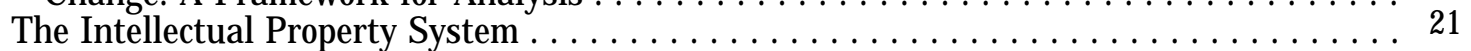

The Intellectual Property System as a Dynamic System:

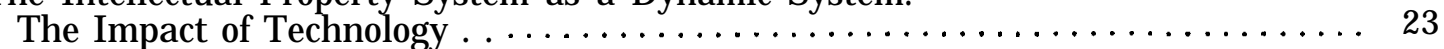

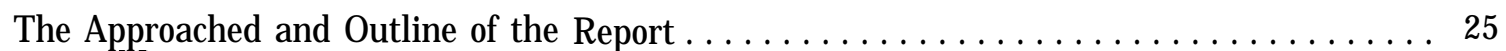

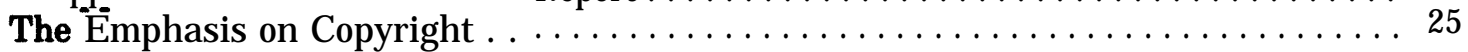

\section{Tables}

\section{Table No.}

Page

1-1. Characteristics of Information Technologies and the Uses of Intellectual Property...

I-2. Framework of Analysis..

Figure No..

Figure

1-1. The Intellectual Property System 
Chapter 1

\section{Conceptual Framework for Analyzing Intellectual Property Rights Issues}

\section{INTRODUCTION}

An intellectual property system is made up of laws and practices and the relationships they generate among individuals and institutions. A system of this kind reflects the larger society of which it is a part. For, although intellectual property rights have been recognized in natural law, historically, governments have granted such rights to achieve a variety of policy goals. This is equally true today. Which policy goals a particular intellectual property system is designed to serve depends, in large measure, on history, circumstances, and the overriding needs of society.

Technological change has been one factor that has had an especially significant influence on both social systems and the intellectual property systems that arise from them. Today, it is posing a formidable challenge to the intellectual property system. Developments in information and communication technology are threatening to outpace previous technological advances in both speed and scope. They are stressing the intellectual property system to the point of raising fundamental questions about the system itself. This chapter presents a theoretical overview of the intellectual property system, and identifies how technology may influence it. It is deliberately abstract, intending to lend perspective to questions whose political and economic significance may make objectivity difficult to achieve.

The U.S. system of intellectual property rights and practices evolved in a way that balances social, political, and economic interests. The system has been modified, both formally and informally, in response to events and circumstances. Its basic framework was set in Section 8, Article 1 of the Constitution, which authorized Congress to grant exclusive ownership rights of writings and inventions for a limited period of time. The purpose was two- fold: 1) to foster the progress of science and the useful arts, and 2) to encourage the creation and dissemination of information and knowledge to the public.

Although this framework was originally designed to deal with the problems and opportunities afforded by the invention of printingthe information technology that dominated the 18th century-it has proven flexible enough to accommodate a variety of new technologies. Today, however, advances in technologies such as microelectronics, fiber optics, and satellites are testing the limits of this flexibility. Developments in areas such as biotechnology'are also influencing the system, but they are beyond the scope of this study.

Bringing swift changes in computers, communications, and other information technologies, these technological advances are likely to have a major social impact, carrying us further into a new "information age." The new technologies transmit information dramatically faster, and they can collect, store, manipulate, and transmit larger amounts of it. With these new technologies, more people can gain access to information, which they can more readily use to trace past actions and predict or influence future events. In the next few decades, as these technologies continue to be developed, they will be used for an ever-expanding number of activities and tasks. This

\footnotetext{
'Although biotechnology has many similarities to information technologies in terms of its having a direct impact on the intellectual property system, this report does not discuss these impacts in detail. (iiven the magnitude of the impact that the development of biotechnology might have on societ $y$, any discussion in this report, which focuses on information technologies cannot do justice to this topic. For a discussion of some of these issues, see U. S. Congress, Office of Technology Assessment, Commercial Biotechnology: .4n International.4 nalysis. OTA-BA-218 (Washington. 1)(': U.S. (iovernment Printing office, January 1984).
} 
advance of technological frontiers will change, in equally significant ways, the structure of the social, economic, and political orders.

J ust as the technologies of the 18th century shaped the intellectual property system as we know it today, so too are the new information and communication technologies likely to alter significantly how society views intellectual property, the mechanisms employed to protect it, and the value that society places on intellectual properties, both as market goods and as public resources. Although information and communication technologies will touch all areas of intellectual property law, they are likely to have the most immediate and pronounced impact on copyright, the area of intellectual property law that has been most concerned with the flow and use of information in society. Moreover, to the extent that traditional legal categories cannot accommodate these technologies, new kinds of intellectual property law may be required.

This report examines how technological developments might affect the intellectual property system. Each chapter focuses on one part of the system.

\section{THE NATURE OF TECHNOLOGY}

Technology can be defined in many ways, both broad and narrow. Some older definitions limit technology to mean specific tools or machines. Other theorists define technology more broadly as know-how: "a system of knowledge intended to have a practical bearing." ${ }^{12}$ Beyond this, one can also include in a definition of technology the human processes and relationships required to bring a scientific idea to lifes

People chose their definition of technology to suit the question they are asking and the problem they must solve. Scientists and engineers, for example, may have less need to consider human factors, and so their definitions concentrate more on machines and physical structures-roads, airports, and nuclear reactors. ${ }^{4}$ But a purely mechanical definition of technology would be inadequate for a study analyzing how technology affects the intellectual property system. Technology touches this system directly and indirectly, affecting its

\footnotetext{
"Jay Weinstein, Sociology Technology: Foundations of Post. ,4 cademic Science ( New Brunswick, London: Transaction Books, $1982)$. p. X 1. For this view, see also J.K. Fiebleman, "Pure Science, Applied Science, Technology Engineering: An Attempt at Definitions, "Technology and Culture, fall, 1961, pp. 3053 17; andC. Susskind. [Understanding Technology (Baltimore, MD: J ohns Hopkins University Press, 19731.

"For a discussion of technology understood as " a form of social organization, see Todd R. La Porte, Technology' as Social Organization, Institute of Governmental Studies, Working Paper \#84-1, University of California, Berkeley. I bid.
}

laws and rules and influencing the social and economic conditions in which relationships take place. To illustrate the potential effect of technology in both these spheres, we must broaden the focus of the analysis and include in it the areas where physical objects and people meet. As Todd La Porte has said, one must look at "who is technology," as well as "what is technology."

This report defines technology broadly, incorporating relationships and transactions be tween creators, publishers, distributors, and users of intellectual property as well as the hardware they use. To maintain this view, while also allowing for independent analysis of machines, tools, and techniques, we will consider technology a "package' that, to borrow from Langdon Winner's categories, comprises: ${ }^{6}$

apparatus: the physical devices of technical performance such as tools, instruments, machines, etc; techniques: the technical activities, such as skills, methods, procedures, and routines that people engage in to accomplish tasks; and

\footnotetext{
I bid., p. 8.

"For a study that conceives of technology as a package, see J ames N. Danziger, William H. Dutton, Rob Kling, and Kenneth I. Kramer, Computers and Politics: High Technol ogy' in American Local Governments (New York: Columbia University Press, 1982).
} 
social arrangements: the relationships that are established and the transactions that take place allowing people to carry out technical processes and to give physical form to their ideas.'

Using this definition, this and subsequent chapters are based on a broad model of the relationship between technological and social change. ${ }^{8}$ In this model, technology is consid-

IJangdon Winner. Autonomous Technology: Technics-()utof-(' ntrol as a The'me' of Political Thought (('an] bridge, MA and L.ondon. England: the M IT Press),pp. 11-12,

"The study of technology and society has a long history going back two centuries to the works of Adam Smith, Henri Saint- ered to be one of many factors influencing society, while society is viewed as affecting technological development through its structures, laws, and practices.

Simon, and Karl Marx. In fact, it was the growing interest in technological developments that gave birth to the field of soci. ology. Interest has intensified in recent years, as both scholars and policy makers have sought to anticipate and ameliorate the unintended consequences of the deployment of technology. Once again, these interests have given rise to a new field of study, that of technology assessment. For two accounts of the history of ideas about technology, see Weinstein, op. cit., and Winner, op. cit.

\section{THE INTELLECTUAL PROPERTY SYSTEM AND ITS RELATIONSHIP TO SOCIAL AND TECHNOLOGICAL CHANGE: A FRAMEWORK FOR ANALYSIS}

\section{The Intellectual Property System}

Theoretical models and actual systems often differ significantly. In the real world, the form and structures of intellectual property systems are worked out in the political arena. Seldom is a system a well-conceived and well-designed construct; it is more likely to take shape haphazardly, reflecting the political compromises and historical events that went into its making. The American intellectual property system is a product of such compromises, and strong forces are still shaping it today. Those involved in the debate often define issues narrowly, in terms limited to their own interests and world views. But, given the magnitude of the technological changes occurring, and their potential impact on the intellectual property system, it is extremely important to view the entire situation as a whole, in terms of the interrelationships of its parts.

In looking at how technology might affect the intellectual property system, it is useful to conceive of the system as a set of incentives and rewards designed to affect the behavior of individuals or organized groups engaged in creative or inventive activities. This system is divided into five interrelated parts:

1. policy goals that it seeks to accomplish,
2. property rights that provide incentives and rewards,

3. operating rules,

4. mechanisms by which policy goals are achieved, and

5. the realm of people and activities that the system is designed to influence.

The intellectual property system can be visualized as shown in figure 1-1. As this diagram illustrates, the outputs of the system provide feedback about how effectively the system is working.

Policy goals are the ends towards which the intellectual property system is directed; they mirror the goals of the society. Thus, as illustrated in chapter 2, time and social change may alter intellectual property goals. As the goals change, other parts of the system are likely to change in response.

Property rights are granted as incentives and rewards. A property right might include, for example, one or any number of the following rights: ${ }^{9}$

\footnotetext{
These terms were borrowed from Lawrence Becker, "The Moral Basis of Property Rights,. "Property J . Roland Penvork and John W. Chapman (eds. I New Y ork: New York University Press, 19801, pp. 189-190.
} 
Figure 1-1.-The Intellectual Property System

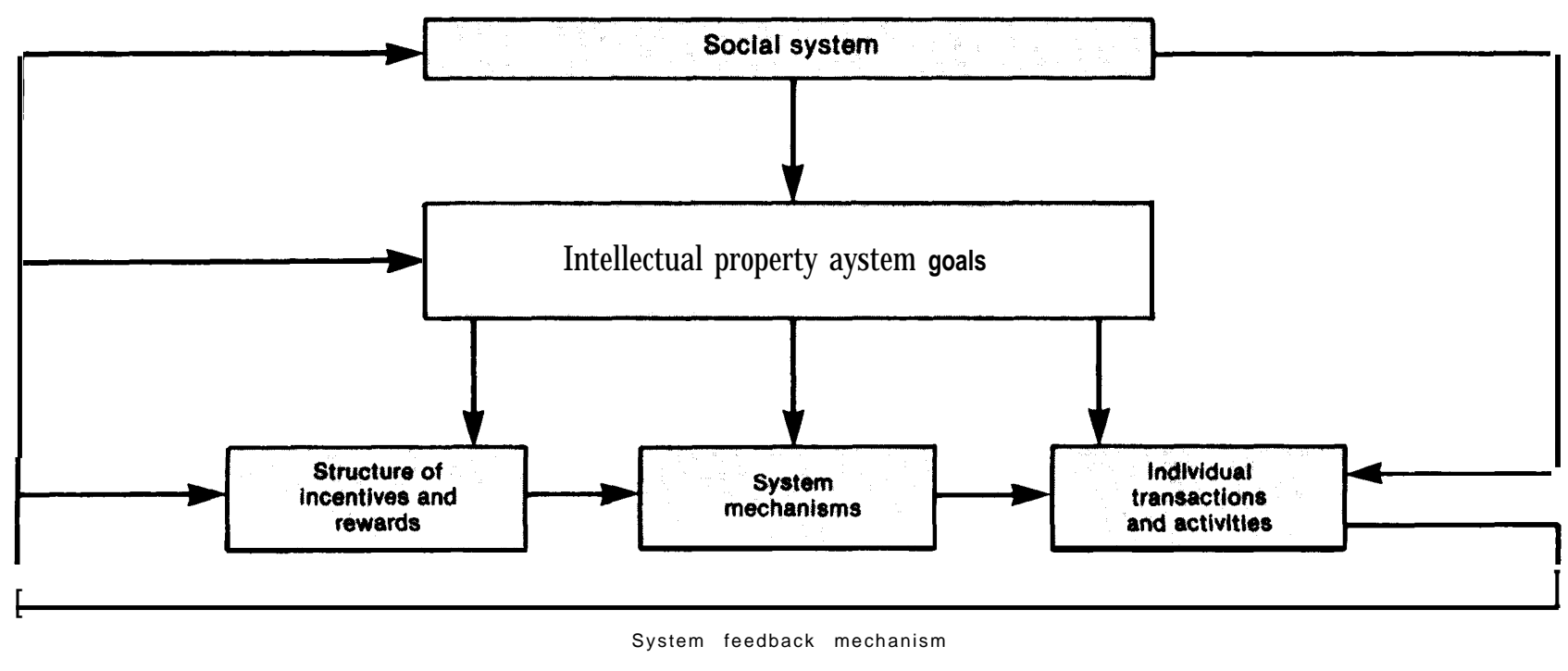

SOURCE Office of Technology Assessment

1. the right to possessor physically control something,

2. the right to use or enjoy its benefits,

3. the right to manage or decide how it is to be used,

4. the right to receive income from it,

5. the right to consume or destroy it,

6. the right to modify it,

7. the right to transfer it,

8. the right to distribute it, and

9. the right to exclude others from using it.

Rights may be granted only under certain conditions, or they maybe limited in their application. For example, to claim a patent in the United States, an inventor must demonstrate that his invention is useful, nonobvious, and novel. To receive a copyright, an author's work must be original. ${ }^{10} \mathrm{Neither}$ right offers permanent protection. Patent rights generally last for 17 years, and copyrights are granted to individuals for life plus 50 years and to corporations for 75 years.

Together, these rights, incentives, and the conditions under which they are granted constitute the operating rules of the intellectual

_ ${ }^{10}$ The word "work' is a general term referring to any intellectual creation. It is used in the legal sense to distinguish particular copies from what is protected by copyright. property system. The rules make demands on everyone involved in the system. The granting of a right to one party, for example, may in effect create a corresponding obligation or liability on the part of another. Structuring the way the parties relate to and depend on one another, these rights and incentives serve as the rules governing the behavior of individuals involved in the creation, production, distribution and use of works, products, and services designated as intellectual properties.

Different intellectual property systems may define intellectual properties differently, and each may attach different rights, responsibilities, and benefits to them. The structure of rights will be determined, in part, by the policy goals of the system, and by the mechanisms chosen to achieve them. Thus, a system designed primarily to encourage learning and invention, as is American patent law, may re quire inventors to disclose information. In contrast, a system designed principally to regulate economic relationships, such as trade secret law may, in fact, prohibit disclosure. Similarly, a copyright system with the chief goal of fostering the dissemination of information might grant rights only in published works; whereas one aiming to reward author- 
ship might protect works before they are made publicly available.

Similarly, the mechanisms used to achieve policy goals-the way in which the system operates-can vary among and within systems, depending on the kind of work to be protected, the nature of the activities to be influenced, the kinds of rights to be granted, and the policy goals to be achieved. F or example, a system that grants rights on the condition of an act such as publication, or on the condition of qualities such as usefulness or novelty, might require a very different administrative apparatus than a system with no such conditions. We see, for example, that because patents are granted under more stringent conditions than copyrights, the Patent and Trademark Office historically has had more resources and administrative responsibilities than the Copyright Office has had.

The people, institutions, and activities that the intellectual property laws aim to influence are also crucial elements in the system. What activities these people do, as well as the socioeconomic constraints under which they operate, determine whether a particular incentive or reward might achieve its intended policy goal. To be most effective, rewards and incentives must match the motivations, needs, and perceptions of the people they are designed to influence, and they must accurately reflect the kinds of activities that they pursue. If an incentive miscalculates the economics of creating, producing, and distributing an intellectual property, it will not motivate people to keep creating. In addition, because people creating different forms of intellectual property operate in different environments and have varying concerns, they may respond best to different kinds of inducements.

The outputs of the intellectual property system-such as the amount, quality, and diversity of works-reveal, in part, how well it is working. But a number of difficulties arise in any effort to evaluate a system's performance. First, there are problems in selecting criteria that best measure effectiveness-that is, which results to note and which to ignore. Second, one cannot easily determine whether these criteria are being met. Finally, evaluating and assessing the accuracy and independence of the information needed to analyze the system is fraught with difficulty. At present, most of the information about such things as the extent of infringement, the potential economic damages of infringement, or the uses made of information-based products and services is available only from the stakeholders themselves.

The Intellectual Property System

as a Dynamic System: The Impact of Technology

The dynamic nature of the intellectual property system further complicates its analysis. It exists within society, and shifts in response to social, political, and economic circumstances. Thus, when society values change, so may the motives and attitudes of creators, inventors, and users of intellectual properties. Similarly, changes in economic conditions can alter relationships and positions between and among individuals and groups in the system, redistributing their shares of financial obligations and rewards.

Of the many factors that might affect the intellectual property system, technological change is likely to have the greatest impact. We can see this clearly in examining the effects of new technologies on the intellectual property system.

Electronic information technologies are fundamentally different from print technology in a number of ways. For example, broadcasting technologies (radio, television) make a work simultaneously available in the homes of so many users that arrangements for payments for the transfer of works to them is often prohibitively expensive. Other technological advances, such as photocopiers and audio and video tape machines, have so reduced the cost and decentralized the process of copying works that rights holders are no longer assured that they have control over the production and integrity of their intellectual property. As infor- 
Table 1-1.-Characteristics of Information Technologies and the Uses of Intellectual Property

\begin{tabular}{|c|c|c|c|}
\hline $\begin{array}{l}\text { Technical characteristics } \\
\text { of works }\end{array}$ & Uses of works & $\begin{array}{l}\text { Technical characteristics } \\
\text { of works }\end{array}$ & Uses of works \\
\hline \multirow{3}{*}{$\begin{array}{l}\text { Mechanical print } \\
\text { Produced in tangible "units" } \\
\text { (but requires expensive } \\
\text { machines and special skills } \\
\text { to copy in large quantities) }\end{array}$} & \multirow{3}{*}{$\begin{array}{l}\text { Publishers, printers, and } \\
\text { booksellers cooperate to publish } \\
\text { work and sell units to individuals } \\
\text { or libraries, authors received per- } \\
\text { copy royalty on first sale of a } \\
\text { copy; copyright holder retains } \\
\text { rights to print and publish "the } \\
\text { work" }\end{array}$} & Digital electronic & \\
\hline & & Simultaneously available & $\begin{array}{l}\text { Many Individuals may access a } \\
\text { central store of works, a "data } \\
\text { base" }\end{array}$ \\
\hline & & $\begin{array}{l}\text { Reproducible at very low } \\
\text { cost }\end{array}$ & \multirow[t]{2}{*}{$\begin{array}{l}\text { Prices for magnetic and optical } \\
\text { storage media will continue to } \\
\text { fall; media are very high in } \\
\text { capacity, and very fast in making } \\
\text { reproductions: perfect copies can } \\
\text { be made from copies }\end{array}$} \\
\hline \multirow{3}{*}{$\begin{array}{l}\text { Fixed in tangible copies } \\
\text { (one "canonical" form of } \\
\text { "the work" exists) }\end{array}$} & \multirow{3}{*}{$\begin{array}{l}\text { Individuals read, scholars quote or } \\
\text { cite; owner of a copy may copy } \\
\text { parts of it by hand, or sell, rent, or } \\
\text { destroy his copy }\end{array}$} & & \\
\hline & & Versatile & $\begin{array}{l}\text { Many types of works (e, } \mathrm{g} \text {, text, } \\
\text { music, video-taped or filmed } \\
\text { pictures) may be stored and }\end{array}$ \\
\hline & & & communicated digitally \\
\hline \multirow[t]{2}{*}{$\begin{array}{l}\text { "Originals" sold in tangible } \\
\text { copies }\end{array}$} & \multirow{2}{*}{$\begin{array}{l}\mathrm{E} g \text {, audio recordings and } \\
\text { videocassettes are initially } \\
\text { manufactured and sold somewhat } \\
\text { like traditional, mechanically } \\
\text { printed books }\end{array}$} & Decentralized and pervasive & $\begin{array}{l}\text { Highly capable machines are } \\
\text { becoming ubiquitous in homes } \\
\text { and offices }\end{array}$ \\
\hline & & Interconnected & Machines may be privately linked \\
\hline \multirow[t]{2}{*}{$\begin{array}{l}\text { Reproducible at moderate } \\
\text { cost (e. g., xerograhic copies, } \\
\text { audio and video tapes) }\end{array}$} & \multirow{2}{*}{$\begin{array}{l}\text { Small works, or parts of large } \\
\text { works, are often copied privately } \\
\text { by users with machines, rather } \\
\text { than by hand, copies of copies are } \\
\text { poorer in quality than copies of } \\
\text { originals }\end{array}$} & & $\begin{array}{l}\text { by switched telephone clrcults: } \\
\text { Impunity; and joint authorship is } \\
\text { not restricted by the physical } \\
\text { separation of the authors }\end{array}$ \\
\hline & & Dynamic & Work may be Interactive or \\
\hline Decentralized & $\begin{array}{l}\text { Many Individuals have equipment } \\
\text { and skills to make copies }\end{array}$ & & "canonical" copy may not exist \\
\hline Technology-bounded & $\begin{array}{l}\text { Different media and equipment } \\
\text { usually needed to use and copy } \\
\text { different types of works }\end{array}$ & Processible & $\begin{array}{l}\text { Machines may be programmed to } \\
\text { transform and manipulate works, } \\
\text { perhaps masking evidence of } \\
\text { original authorship }\end{array}$ \\
\hline $\begin{array}{l}\text { Analog electronic broadcast } \\
\text { Simultaneously available } \\
\text { (one "intangible copy") }\end{array}$ & $\begin{array}{l}\text { Advertisers may pay for work to } \\
\text { attract potential customers to } \\
\text { their product, alternatively, users } \\
\text { may pay (e g, public broadcasting, } \\
\text { subscription television) }\end{array}$ & Autonomous & $\begin{array}{l}\text { Works may be functional, rather } \\
\text { than only meaningful, as are } \\
\text { traditional copyrightable works }\end{array}$ \\
\hline
\end{tabular}

mation technologies become computerized, the copy, transfer, and manipulation of works are becoming even more decentralized, speedy, and inexpensive.

At a basic level, the very definitions on which intellectual property rights are based take on new meanings, or become strained and even irrelevant, when applied to the context created by new technologies. They raise questions, for example, about what constitutes a' 'derivative work' when works are made available through intangible electronic waves or digital bits; about what constitutes a "work"; and about who owns the right to it when it is interactive, and when creators have combined their efforts to produce it.
The characteristics that differentiate the new technologies from the old, and that create potential problems for the system, are summarized above in table 1-1.

Changing technology may influence each part of the system directly, or it may affect it indirectly by modifying the larger social environment in which the intellectual property system operates. New technologies, for example, may affect the boundaries of the system and the nature of the rights that it provides. In doing so, they may change the "rules of the game" by which it operates. As discussed in chapter 3, each new technology has brought questions about whether and where it should fit into the existing system. Most recently, for 
example, Congress, borrowing from both copyright and patent law, adopted a new suigeneris law, i that established a separate niche for computer chip technology in the intellectual property system.

Technological developments may also change the mechanisms used to achieve intellectual property goals. Chapter 4 points out that demonstrating "authorship' or "originality as a condition for receiving property rights, while relatively straightforward in a print culture, is much more complicated in an age of electronic technology. Similarly, as illustrated in chapter 7, a system that assumes copyright holders can enforce their own rights against infringement may operate unsuccessfully if de-

Suigeneris is a latin phrase used to describe any law that is "of its own kind or class." Sui generis intellectual property law, then. is legislation that stands apart from existing patent copyright. trademark, or unfair competition law centralized reproduction and electronic transmission prevents identifying where and when infringements take place.

Because technology brings about new kinds of interactions between people, as well as new technological apparatus and new processes and techniques, it is also likely to affect the people, institutions, and activities that are part of the realm of the intellectual property system. As noted in many of the following chapters, new technologies not only affect what people do and how and why they do it, they also may restructure the socioeconomic opportunities available to them and the constraints under which they operate. And, in creating a multitude of new opportunities for application, use, and profit-making, issues may arise among the parties in the system the resolution of which, over the long run, may prompt changes in the goals, the boundaries, and the structure of the system itself.

\section{THE APPROACH AND OUTLINE OF THE REPORT}

Using the above model, this assessment analyzes the impact of the new information and communications technologies on the U.S. intellectual property system. Table 1-2 outlines the problems to be analyzed.

In this table, six major criteria are suggested to evaluate how well the system is functioning. Corresponding to these criteria are a number of research questions that might be asked to determine how well the criteria are being met, and some possible indicators of the system's effectiveness. The broad scope of the table illustrates the magnitude and complexity of the problem. It also suggests some useful questions around which to build an analysis, many of which serve as starting points in the following chapters.

\section{The Emphasis on Copyright}

In general terms, intellectual property law includes any law that grants rights in the products of the intellect. As such, it is a generic term that covers patent, copyright, trademark law, and the Semiconductor Chip Act, as well as trade secrets and tort misappropriation law. There are two major reasons for this emphasis. First, since copyright is concerned primarily with the use and flow of information and information-based products and services, it is the area of intellectual property law that will be most affected by advances $m$ communication and information technologies. Second, it is to copyright rather than to other provisions that the creators, developers, producers, and distributors of new information technologies are looking in their efforts to gain legislative protection for their works.

This emphasis notwithstanding, we have tried to look broadly at the impact of technology on the entire intellectual property system. This broad perspective allows us to address not only the problem and opportunities that the new technologies present for the copyright system itself, but also to consider alternative ways, including some entirely new ones, of addressing them. 
Table 1-2.-Framework of Analysis

Questions for research

indicators/types of Information that might be collected
Evaluative criteria

7. Effectiveness in meeting

overall systems goals

A. Creation and dissemination Degree of creativity of creative, informational, and scientific works

\section{B. Enhancement of the learning} environment

C. Economic growth and development
Availability

\section{Congruence of incentives}

Degree of scientific and technological development

State of the arts and entertainment

Overall condition of education

Growth of information-based industries
- Evaluations of creators, critics, users

- Output of works

- Number of prizes offered in these fields

- Number of people engaged in these fields

- Interactions of members of the creative environment

- Number and variety of informational resources

- Evaluations of creators, publishers, producers, users

- Diversity of works

- Price of works

- Opportunities for access

- Evaluations of creators, publishers, and producers

- Level of output

- Emergence of new fields

- Number of scientists/technologists

- Number and quality of scientific publications

- Interactions between members of the scientific/ technical community

- Patents issued

ž Awards granted

- Evaluations by members of the scientific/technical community

- Emergence of new fields

- Number of creators

- Condition of production/distribution industries

- Availability of resources for creation/production/ distribution

- Awards granted

- Market for creative works

- Evaluations by national educators/businessmen/ parents/National Science Foundation/etc.

- Literacy rates

- Test scores

- Availability and qualifications of faculty/teachers

- Quantity and quality of educational materials/ information-based resources

- Interactions among members of the educational community

- Development of new industries and profit-making opportunities

- Percentage of employment

- Number of firms

- Contribution to gross national product

- Use of information-based products and services in non-information industries

International competitiveness - Balance of trade

2. Efficiency in achieving goals $\begin{gathered}\text { Costs and benefits of granting } \\ \text { rights }\end{gathered}$

- Institutional costs

- Transactional costs

- Social costs in terms of achieving systems goals

- Benefits measured in terms of achieving system goals

- Estimates of harm due to infringement/lack of intellectual property protection

- Profit margins

- Industry competition

- Estimates of economic value of intellectual property rights to proprietors 
Evaluative criteria

3. Enforceability

4. System durability

5. Precision as policy tool

6. Congruence with international Ability to resolve conflicts and other national systems

\section{Costs and benefits of alternative measures for achieving system goals}

Extent of Infringement

Ease of detection

Legitimacy of the system

Flexibility in the face of change

Legitimacy of the system

Ability to resolve conflicts/ harmonize interests

Reliability/predictability as a guide to action

Robustness of principles

Predictability of outcome

independence/compatibility with respect to other policy areas

Sensitivity to differences among different kinds of information-based products and services
Table 1-2.-Framework of Analysis-Continued

\author{
Indicators/types of information \\ Questions for research
}

Harmony with other intellect al property systems

Compatibility with other international regimes-i.e. GATT, UNESCO
- Institutional costs

- Transactional costs

- Social/economic costs/benefit in terms of achieving system goals

- Public/institutional behaviors

- Technologial capabilities to access/reproduce/ reformat information-based products and services

- Privacy of use and decentralized access to reproductive/access/and communication technologies

- Technological capabilities to preclude authorized access/use

- Transaction costs

- Technological capabilities to monitor access/use

- Public attitudes/support for the system

- Frequency of legislative revision/amendment

Ž Resort to alternative forms of protection

- Consensus in cases of first impression

- Consistent/coherent application of law

- Public attitudes/support for the system

- Extent of infringement

- Acceptance of decisions by parties in dispute-i.e., number of appeals

- Extent of unresolved issues - ı.e., fair use, copyrightability of computer software

Ž Internal coherence/consistency of law . Resort to other forms of protection - Overlap with other law

- Quality, quantity, independence of available informat ion

- Number of agencies involved

- Cross-cutting issues

- Interested congressional committees

- Convergence of stake holder Interests

- Intensification of issues

- Roles of different kinds of Information-based products and services

- Economics of different kinds of information markets

- Public attitudes toward different types of information-based products and services

- Technological characteristics of different information-based products and services

- Enforcement mechanisms

- Level of infringement

- International court cases

- Resort to other policies mechanisms to deter infringement- i.e., trade sanctions

- Level and participation in international regimes

- Scope of international treaties

- Incompatibilities with international law - i.e., informalities

-Policy conflicts and inconsistencies 
Chapter 2

\section{Intellectual Property Goals in a Changing Information Environment}




\section{Contents}

Findings

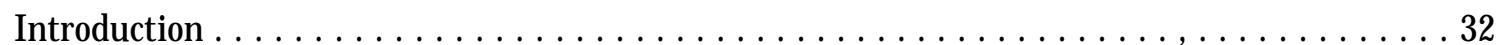

Evolution of the Concept and Practice of Granting Intellectual Property Rights. . . . 33

Emergence of the Concept of Intellectual Property Rights . . . . . . . . . . . . . 33

Copyright as a Mechanism for Censorship and the Regulation of Trade . . . . . . . . . 34

Copyrights To Prevent Monopoly Practices: The I dea of Author Rights . . . . . . . . . 35

Traditional Goals of the U.S. Intellectual Property System . . . . . . . . . . . . . . . . . 37

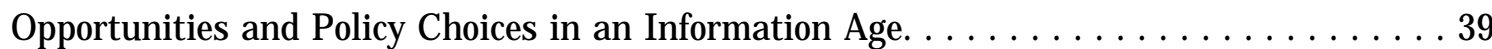

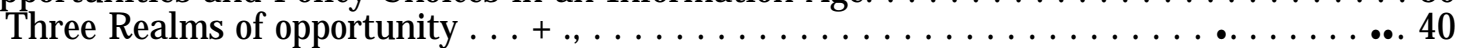

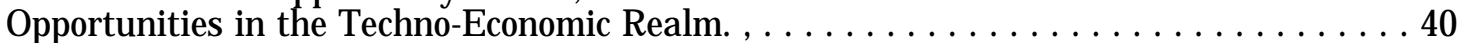

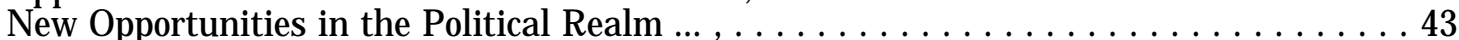

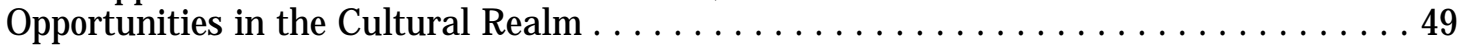

The Potential for Conflict in the Use of New Technologies $\ldots \ldots \ldots \ldots \ldots \ldots \ldots \ldots$

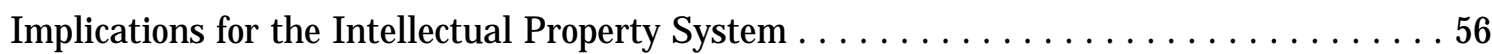

Figures

Figure No.

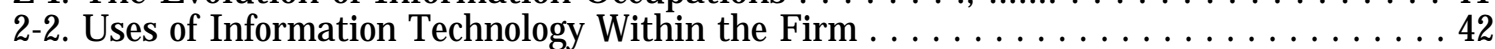

2-3. Information Industry and Its Related Industries $\ldots \ldots \ldots \ldots \ldots \ldots \ldots \ldots \ldots$

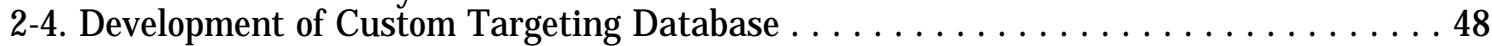

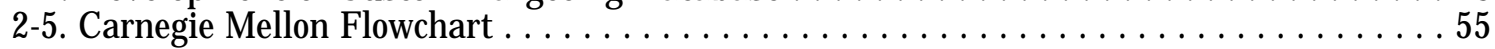




\section{Intellectual Property Goals in a Changing Information Environment}

\section{FINDINGS}

In an information age, decisions about the granting of intellectual property rights are Linked to other information policy decisions, and in making them, we are making decisions about the nature of society itself. Given the convergence of these issues, it may be necessary to establish clearer priorities about the goals towards which intellectual property policy is directed.

The new information and communication technologies create, for both individuals and society as a whole, new cultural, economic, and political opportunities, as well as new information requirements and needs. These technologies are capable not only of generating, storing, and processing vast amounts of information; they can also provide greater access to information, enhance the environment for learning and creativity, generate new opportunities for profitmaking and economic growth, and facilitate participation in political and social affairs.

Insofar as they afford new socioeconomic opportunities, the new information and communication technologies will assume a greater role in society, and in the economy, giving rise to public policy issues about their use. I ssues will emerge, for example, with respect to which information needs will be met; which opportunities will be developed; and which parties will benefit from them.

Concerned primarily with the use and flow of information in society, intellectual property law has historically served in the United States to decide many of these issues. In resolving them, an effort has been made to strike a suitable balance between the needs of creators, producers, and distributors of intellectual properties and the social, economic, and political needs of the nation as a whole. In such a fashion, intellectual property law has been able to simul- taneously serve a wide variety of social and economic public policy goals.

The ability of intellectual property law to strike such a balance was not particularly difficult in the past, when the social and economic stakes in information were lower than today and when relatively few and well-defined players were involved in the intellectual property process. Information-based products and services were peripheral to the performance of many social and economic activities, and people had lower expectations about their use and the level of profit that might be derived from them. As a result, issues involving the granting of intellectual property rights could be worked out among the major players without much public involvement or concern.

The resolution of these issues in an information age, however, will be more problematic, re quiring that more stakeholders be taken into account and that decisions be made about the distribution of incentives and rewards. Given the variety of opportunities that the new technologies afford, the increased value of information, changing relationships among the traditional participants in the intellectual property system, and rising expectations about the benefits of these technologies, the number of stakeholders with disparate interests and competing claims on the system will be greater than ever before. In such a context, the granting of intellectual property rights, instead of mutually serving a variety of different stakeholders, and equally fostering a broad set of diverse policy goals, may pit some stakeholders and goals against one other. Moreover, given the ease of access to the new technologies, members of the public are now major stakeholders in the system, and as such their attitudes and behavior are likely to have a greater impact on policy choices and outcomes. 


\section{INTRODUCTION}

Although intellectual property rights have been recognized in natural law, historically, governments have granted such rights to achieve a variety of policy goals. This is equally true today. In the West, the granting of copyright, for instance, is viewed primarily as a mechanism for encouraging the dissemination of information. But in Eastern bloc countries, the policy goals differ and it is regarded chiefly as 'an instrument for the management of cultural processes."1

Which policy goal a particular intellectual property system is designed to serve depends, in large measure, on the history, circumstances, and overriding needs of a society at the time the system is first set up. Developing countries, for example, which must import most cultural and scientific materials, have often been unwilling to extend protection to foreign works. This was true of the United States during its first 100 years, and is the case in many Third World countries today.

Despite their varying goals, however, all intellectual property systems basically concern policies involving the use and flow of information. This is especially true of the copyright system, which was established specifically to deal with the social and economic changes brought about by what, historically, has proved one of the most "world shaking" information technologies-the printing press. Characterizing copyright role in structuring information flow, Edward Plowman and L. Clark Hamilton wrote:

In a wider perspective, a number of basic dimensions of the nature and function of copyright may be distinguished. In an overall, cultural perspective, the stated purpose of copyright is to encourage intellectual creation by serving as the main means of recompensing the intellectual worker and to protect his moral rights. In an economic sense, copy-

\footnotetext{
'Puscher, "Copyright in the German Democratic Republic," Copyright Bulletin of the USA, vol. 10, No. 3, 1976, as cited in Stephen Stewart, The Law of International Copyright and Neighboring Rights (London: Butterworth \& Co. (Publishers) Ltd., 1983), p. 10.
}

right can be seen as a method for the regulation of trade and commerce.

Copyright thus serves as a mechanism by which the law brings the world of science, art, and culture into relationship with the world of commerce. In a social sense, copyright is an instrument for the cultural, scientific and technological organization of society. Copyright is thus used as a means to channel and control flows of information in society. [emphasis added]. ${ }^{2}$

The patent and trade secrets systems also involve the flow of information. The patent system is designed primarily to foster scientific and technical information. Although patent law permits only the inventor or patent holder to make, use, or sell his invention, it also re quires that the inventor disclose to the world the information necessary to enable others to reconstruct the invention after a 17-year period of protection has elapsed. Patent law, there fore, seeks to encourage the distribution of information by making disclosure a condition of protection. The trade secrets system, in contrast to the patent system, is designed to discourage the widespread flow of certain types of information. Secrecy is maintained in order to give the holder of the trade secret a competitive advantage in the marketplace.

Like the printing press, the new information technologies also affect society. They are changing the way people work and conduct their business; how they interact and relate to one another; the way they learn, create, and process information, and their needs and expectations. In fact, these new technologies are altering the way man views himself and his place in the world. ${ }^{3}$

Together, the development and widespread use of these new technologies have helped to usher in what some social observers characterize as a "post-industrial," or "information"

\footnotetext{
'Edward W. Plowman and L. Clark Hamilton, Copyright: Intellectual Property in the Information Age (London: Routledge and Kegan Paul, 1980), p. 25.

'Sherri Turkel, The Second Self: Computers and the Human Spirit (New York: Simon \& Schuster, 1984),
} 
society. ${ }^{4}$ In this society, the creation, use, and communication of information plays a central role. Not only will the amount of information continue to increase, but people will also rely on it in more and in different circumstances. The changes brought on by the new technologies will generate new social, economic, and cultural opportunities and choices, which will bring with them the need for major policy decisions.

Because intellectual property policy, and especially copyright policy, serve as a policy tool that structures the use and flow of information, it is likely to play a major role in an information age. How the intellectual property system is structured will determine not only which individuals and groups benefit from the new opportunities afforded by the new technologies, but also in what ways and the extent to which, as a society, we might take advantage of them. Furthermore, if the enhanced value of information creates conflicts between economic, political, and cultural goals, the structure of the system will establish some of the rules that determine whether information will be treated as an economic commodity or a societal resource.

Given the relationship between intellectual property goals and social change, and the probable influence of the copyright system in an information age, the question arises of whether the policy goals of the United States intellectual property system, established in an agrarian society and when print technology dominated, are still appropriate for today.

\section{Evolution of the Concept and Practice of Granting Intellectual Property Rights}

Social, economic, political, and technological factors all influence the nature of intellec-

\footnotetext{
${ }^{4} \mathrm{~F}$ or discussions and characterizations of the "I nformation Society. "See, for example, U.S. Congress, Office of Technology Assessment, Computer-Based National I nformation Systems, OTA-CIT-146 (Washington, DC: U.S. Government Printing Office, September 198 1); Susan Artandi, “Man, Information, and Society: New Patterns of Interaction, J ournal for the American Society for Information Science, J anuary 1979; and Daniel Bell, The Coming of Post Industrial Society (New York: Basic Books, 1973).
}

tual property systems and the goals that governments have sought to promote by granting those rights. The connection between these factors and intellectual property systems is clearly visible if one examines the concept of intellectual property as it evolved over time. Intellectual property rights began in a autocratic period, as a tool of monarchs to stimulate invention, regulate trade, reward favorites, establish patronage, and control and censor the dissemination of ideas and information. Two hundred years later, in a democratic context, this tool evolved into a system designed to foster freedom of expression and the creation and dissemination of new ideas.

\section{Emergence of the Concept of Intellectual Property Rights}

The birth of the idea of intellectual property itself demanded certain social conditions. It required a centralized political authority and a government that intervened in economic affairs; the development of trade and commerce; a market for literature, art, and invention; and the growth of the idea of, and respect for, the individual as creator. Only in the late Middle Ages did such conditions develop, and only then did the concept of intellectual property rights, as we know it today, emerge. ${ }^{5}$

In addition to these societal changes, technological change-and in particular, the development and widespread deployment of the printing press-also created the need for intellectual property protection. Before the development of printing, inventors, embodying their ideas within their own persons, did not need to concern themselves with the prospect

"Bruce W. Bugbee, Genesis of American Patent and Copyright Law (Washington, DC: Public Affairs Press, 1967). This latter condition existed in Roman times where the social climate was supportive of individual attribution and payment for intellectual activities. In a number of texts from the period, for example, there are references to individuals as authors and to the terms of payment for intellectual contributions. Moreover, plagiarism was clearly considered to be unethical. There is no evidence, however, that such attitudes and procedures were in $a_{y} w_{y}$ sanctioned by law. Conditions radicall changed during the Middle Ages, however, when monasteries and other religious institutions began to assume primary responsibility for intellectual and creative pursuits. As in pre-Roman times, the idea of individual, as author, lost support. Plowman and Hamilton, Copyright, pp. 9-11. 
of others reaping the financial rewards of their work. They simply went from town to town selling their intellectual wares. However, once their ideas were recorded and widely distributed in print, the inventors lost this control and, hence, their economic bargaining power. The problem created by the printing press was even greater for authors whose profits were derived not from their ideas but from what subsequently was even more easily duplicated, the written word itself.

The first intellectual property rights were granted as patents. Characterized by one author as being "the idea of progress appearing in the law, patents were associated with technological development from the start. ${ }^{6}$ Offered by sovereigns and local governments as part of their overall economic policies to stimulate commerce and technological advance, they were, essentially, monopolies designed to entice artisans and inventors into their States or localities.

Copyrights-or the granting of rights in literary property-did not develop in either concept or practice until the 15th century. Even more than patent rights, copyright can be identified with one specific technology, the printing press.

The printing press brought about major social, economic, and political changes. ${ }^{8}$ By great-

'Significant inventions of the late Middle Ages included various processes that would increase the efficiency of artisans, such as textile-making equipment, textile dye processes, glass manufacturing, stained glass processes, mining and metallurgy, windmills, and ship-building designs. Bruce W. Bugbee, Gene sis of American Patent and Copyright Law (Washington, DC: Public Affairs Press, 1967), pp. 12, 167.

The city-state of Venice, with its important role in world commerce and its strong central government, became the first government to grant patents. The importance that the Venetians attached to the goal of economic development is reflected by the fact that a patent right granted in a work had to be relinquished if it did not prove to be commercially successful. As towns and commerce revived, technological development accelerated, and political centralization increased, this practice of granting patent rights spread throughout Europe.

'F or a detailed and in-depth discussion of the social changes brought about by the advent of printing, see Elizabeth L. Eisenstin, The Printing Press as an Agent of Change: Communications and cultural transformations in early modem Europe, vol. I and 11 (Cambridge, England: Cambridge University Press, 1982); For a discussion of the more general impact of communication technology on society, see Harold Innis, The Bias of Communication (Toronto: University of Toronto Press, 1951). ly increasing the speed and reducing the costs of reproduction, printing made it much easier to disseminate ideas. By increasing the general level of literacy, it also made more people susceptible to, and eager to partake of, such ideas. As a result, the market for information products and literary works grew, and their economic value was greatly enhanced. In fact, one might say that printing was the growth industry of the time. Later, as books and manuscripts ceased to be isolated on monestary shelves, and became available to many people simultaneously, they began to serve as an important forum for public discussion.

Occurring at the time of religious and political turmoil, printing presented the monarchs of Europe with both a political threat and an economic opportunity. The law of copyright was developed to deal with this threat, as well as to take advantage of this opportunity. The shape the law took reflects its dual purpose: censorship of the press and regulation of trade. Although copyright systems were established across Europe, England provides the most useful illustration of how the system worked, since the American system was derived from English experience.

\section{Copyright as a Mechanism for} Censorship and the Regulation of Trade

As in most European countries, England's need for copyright protection arose with the invention of the printing press, and it had its origins in the English censorship laws. These acts included the Star Chamber Decrees of 1566,1586 , and 1637, as well as three acts passed in the 1640s during the Interregnum, and the Licensing Act of 1692. Together, they provided for such things as the granting of patents for specified works, the confinement of printing to authorized presses, the licensing of books before publication, and the use of trade organizations and special government agencies for enforcement. $^{9}$

While direct censorship was the most effective means of confronting the political threat

\footnotetext{
'Benjamin Kaplan, An Unhurried View of Copyright (New York and London: Columbia University Press, 1967).
} 
brought about by the new technology, it also stifled the printing industry, and thus limited the government economic benefits from printing. Seeking to both end the dissemination of heretical and seditious literature, but still profit from the burgeoning printing trade, the English Government aligned itself with publishers. In exchange for an agreement to enforce the censorship laws, the government granted the publishers' guild, known as the Stationers, a monopoly right to print, publish, and sell works-a copyright.

The effectiveness of this arrangement came about, as Ithiel de Sola Pool has noted, because "the printing press was a bottleneck where copies could be easily examined and controlled."111 The arrangement was also beneficial to publishers. It not only provided them with a monopoly; but also, as partners with government, they were free to manage their own affairs, ${ }^{12}$ Thus, through their bylaws, they regulated the book trade. ' 3

\section{Copyrights To Prevent Monopoly}

Practices: The Idea of Author Rights

In the period following the Restoration, the Government's major concern was no longer press censorship. Instead, there was a growing wariness about the publishers' monopoly

\footnotetext{
“The copyright was limited to members of the Stationers' guild so that only registered members could print books. Once a publisher entered the title of a work, his name, and the date of publication into the company register, he obtained a perpetual copyright in it. With what was essentially an economic right designed to protect his investment from competition, the publisher could also trade in rights. He could buy copyrights, sell them, or assign them to any other member of the company. When cases of copyright infringement and disputes among publishers arose, they were decided by the company courts. The Stationers' copyright remained in force for over 150 years, when the conditions underlying the system changed significantly. Stephen Stewart, Law of International Copyright, and Neighboring Rights (London: Butterworths \& Co. (Publishers), Ltd., 1983).

"I thiel de Sola Pool, Technol ogies of F reedom (Cambridge, MA: Belknap Press, 1983), pp. 16-17.

"Originating as a craft guild in the early 15th century, the Stationers were established as a company by Henry VIII in 1557. They consisted of members of the book trade-printers, book binders and booksellers. For a discussion of the history of the Stationers' Company and its role in the development of copyright, see Lyman Ray Patterson, Copyright in Historical Perspective (Nashville, TN: Vanderbilt University Press, 1968). Chapter IV.

"Stewart, The Law of International Copyright, p. 18.
}

of the book trade. By buying up all of the rights to copy books, the publishers had effectively limited their competition, restricted the supply of books, and artificially raised prices. No longer in favor of blatant censorship, ${ }^{14}$ or sympathetic to monopoly, the Parliament found this situation unacceptable. In 1695, it failed to renew the Licensing Act of 1692, thus allowing the Stationers copyright to lapse.

The result was confusion in the book trade. Piracy became commonplace. The Stationers aggressively appealed to Parliament to reestablish order with a new copyright law. As Lord Camden later described it:

They-the stationers (whose property by that time) consisted of all the literature of the Kingdom, for they had contrived to get all the copies into their own hands-came up to Parliament in the form of petitioners, with tears in their eyes, hopeless and forlorn, they brought with them their wives and children to excite compassion, and induce Parliament to grant them a statutory security. '5

Responsive to the Stationers' petitions to reestablish order in the book trade, but opposed to excessive monopolies, the Parliament passed legislation in 1709 that was supposed to meet both concerns. This was the Statute of Anne. Characterized as the first modern copyright law, it served as the model for copyright law in the United States, and all other English-speaking countries.

Although the Statute of Anne resembled the Stationers' copyright in some ways, it was designed to end their monopoly of the book trade and included several provisions to assure this end. Copyright would no longer be exclusive; the statute made it available to everyone. Moreover, it was limited to a period of 14

\footnotetext{
"It should be noted that the repression of the press did not end in 1693. Instead of using copyright as a mechanism to control the press, the British Government used a tax policy. The government imposed taxes, for example, on newsprint, ads, and on newspapers. one newspaper The Spectator, folded in 1712, as a result of increased publication costs due to heavy taxation. de Sola Pool, Technologies of Freedom, p. 15.

"'"Donaldson v. Becket" (H.L. 1774), as reported in $17 \mathrm{Han}$ sard, Parliamentary History of England, 953, 995 (1813), as quoted in Kaplan, Unhurried View, p. 7.
} 
years. 'G As a concession to the Stationers, the act allowed them to maintain their existing copyrights for a period of 21 years, after which the works attached to them would be returned to the public domain.

Entitled "A Bill for the Encouragement of Learning and for Securing the Property of Copies of Books to the Rightful Owners Thereof," the new statute stated clearly that copyright should benefit authors. The law advanced the idea of authors' rights, absent from the Stationers' copyright, although authors had previously been paid for their works. ${ }^{17}$ In the new political and economic context, however, parliamentary leaders viewed the granting of copyright to authors as a good device to break the publishers' monopoly, although not necessarily inherently virtuous. ${ }^{18}$

The legitimacy of the claim of authors' rights also found support within the larger society. In 1690, J ohn Locke argued in his Two Treatises on Civil Government that the author has a natural right in his work since he had expended his own labor in creating it. " At the same time, European thinkers and jurists put forth similar views. ${ }^{20}$ The public and the courts, -. . . - -

'The statute allowed a second' term of 14 years if the author was alive. Even if he had sold his copyright, the author could claim it back after 14 years.

"Manuscripts were generally bought from authors for some lump sum. Once the authors sold his material to the publishers, it was the publishers who had the right to make multiple copies, Kaplan, Unhurried View, 1967.

"I ronically, in the end, the publishers were the most effective and outspoken constituency in generating acceptance for the idea of authors' natural rights in their work, and it was they who benefited most from it. The previous statutes, it should be remembered, provided publishers with an economic right, which protected only the economic benefits derived from the publication and sale of copies. The issue of who owned the work was not involved. However, with the growing acceptance of the idea that the author had a natural right in his work, the notion of what the right protected was considerably expanded. Since authors routinely assigned their copyrights to publishers, having no other recourse to distribute their works, it was the publishers, and not the authors, who benefited over the long run from this expanded right. Patterson, Historical Perspective, p. 18.

"John Locke, Two Treatises on Civil Government (Cambridge, England: Cambridge University Press, 1967).

"'European jurists conceived of authors rights as being natural to the way things are. In France this attitude was incorporated into two basic decrees granting authors: 1) the right to public performance (1791), and 2) the right to copy and reproduction (1793). These two decrees served as the mainstay of French copyright law for over 160 years. Plowman and Hamilton, Copyright, p. 16. too, were generally more willing to reward the author for his special contribution to society. As Kaplan has pointed out, there was a gradual moving away from the Elizabethan perspective that imitation was admirable and innovation dangerous, and a growing appreciation of the role of the creator. ${ }^{21}$

These developments, notwithstanding, copyright in England remained a statutory right, reflecting its origins as a privilege granted by government to achieve a particular public policy purpose. The issue of authors' common law rights was tested in two major court decisions. In the first, Millar v. Taylor (1769), the publishers' and authors' point of view prevailed: the court ruled that the author had a common law copyright in perpetuity. Five years later, however, this position was reversed with the decision in the case of Donaldson v. Becket delivered by the House of Lords in 1774 . While recognizing the author's common law right to print, publish, and sell his work, and his right to assign his copyright to another, the House of Lords held that this right was supplanted by the Statute of Ame. Thus, while the author had a right to decide whether to publish or not, once he had chosen to do so, his copyright was a statutory one and it was limited by the terms of the statute. ${ }^{22}$

As this brief account suggests, the concept of intellectual property rights emerged at a particular time when socioeconomic conditions were ripe for it. It emerged as a public policy device to deal with the problems and enhance the benefits of the rash of technological innovations that occurred in the late Middle Ages and early Renaissance. The law of copyright, in particular, was related to the advent of one technology, the printing press.

"As Kaplan notes, "From the classical writers as expounded by critics of the Italian and French Renaissance, the Elizabethans had received the notion that artists' excellence lay in imitating the best works of the past, not in attempting free imitations. All they needed, indeed, all the possible subjects and materials for literary production were al ready disclosed in existing writings, the "publica materia " to which Horace referred. What was required of an author was to give an expression compatible with his own time. "Kaplan, Unhurried View, p. 23 ,

"I bid., p. 14; see also discussion by Patterson, which suggests that if the common law courts had had a role in the early development of copyright, the English might have adopted a stronger position in favor of the author. Ibid., p. 16. 
While the structure of the laws and the goals to which they were put have changed with time and historical circumstance, intellectual property law has essentially remained a mechanism government can use to structure and channel the societal impacts of technological change. In the Elizabethan era, intellectual property law was used to control the flow of information. But when transplanted to the United States, it was conceived of not only as an instrument to foster the creation of new inventions and ideas but also to encourage their dissemination among the public.

\section{Traditional Goals of the \\ U.S. Intellectual Property System}

Although the ruling monarchs of Europe had regarded the widespread dissemination of information with considerable alarm, the opposite view prevailed in the United States. Building a nation required the establishment of communication links, the development of a unified market, the forging of a common culture, and the building of a democratic polity. The widespread flow of information was essential to accomplish these tasks, and the establishment of an intellectual property system, they believed, would aid the creation and spread of information. Appreciative of the potential that information held for fostering national development, the Founding Fathers saw the granting of intellectual property rights, not as a natural right, but as a statutory, or positive right, in this case granted to promote learning.

To understand the import attached to the idea of learning, one must consider the historical context of the times. The writers of the Constitution were products of the enlightenment. Their views and attitudes reflected the increasingly pervasive awareness of the power of knowledge to affect social change. As the historian Peter Gay has described it:

In the century of the enlightenment, educated Europeans awoke to a new sense of life. They experienced an expansive sense of power over nature and themselves; the pitiless cycles of epidemics, famines, risky life and early death, devastating war and uneasy peace- the treadmill of human existence-seemed to be yielding at last to the application of critical intelligence. Fear of change, up to then nearly universal, was giving way to fear of stagnation; the word innovation, traditionally an effective term of abuse, became a word of praise. $^{23}$

Looking at the concept of learning in this context it is clear that, to the Founding Fathers, learning was more than an end in and of itself. It was the hope of an age, the means to achieve a whole range of goals. With knowledge and learning, virtually anything was considered to be possible.

That knowledge should be fostered and disseminated was also a paramount belief of the times. The age of enlightenment was, according to Gay:

... an age of academics-academics of medicine, of agriculture, of literature, each with its prizes, its journals, and its well attended meetings. In the academies and outside them, in factories and workshops and coffeehouses, intelligence, liberated from the bonds of tradition, often heedless of aesthetic scruples or religious restraints, devoted itself to practical results; it kept in touch with scientists and contributed to technological refinements. ${ }^{24}$

Given this general mood of the age, it is easy to understand why the idea of granting intellectual property rights was so popular. Correctly anticipating acceptance of such a right, $\mathrm{J}$ ames Madison, wrote in The Federalist, for example, "The utility of this power will scarcely be questioned." ${ }^{\prime 25} \mathrm{He}$ was right. There was practically no discussion of intellectual property rights at the Constitutional Convention, even though provisions for granting such rights merited a prominent place in the Constitution. The convention was convened in early May 1787, and was adjourned in mid-September. The issue of intellectual property rights, however, did not arise until August 18th, when $\mathrm{J}$ ames Madison and Charles Pinckney each put

\footnotetext{
'Peter Gay, The Age of Enlightenment: An Interpretation. The Science of Freedom (New York: W. W. Norton \& Co., 1977), p. 3.

"Gay, Age of Enlightenment, p. 9

“'As quoted in Bugbee, Genesis, p. 130.
} 
forth proposals to include among Congress' powers the right to grant intellectual property rights. And the idea was not considered again until September 5th, when the Convention unanimously approved without discussion a committee proposal to adopt a constitutional clause empowering the Congress "To Promote the Progress of Sciences and Useful Arts, by securing for limited Times to Authors and Inventors the Exclusive Right to their respective Writings and Discoveries." ${ }^{26}$

That the enhancement of learning was the purpose of this clause-Article 1, Section 8 of the Constitution-can be reasonably discerned despite the lack of debate at the convention. Two intellectual property rights proposals were submitted, one by Madison and one by Pinckney. Although introduced independently of each other, they both were couched among other proposals aimed at advancing the state of science and learning. Both proposals also authorized Congress, for example, to:

- grant charters of incorporation in cases where the public good may require them;

- establish a university;

- encourage by premiums and provisions, the advancement of knowledge and discoveries; and

- establish public institutions, rewards, and immunities for the promotion of agriculture, commerce, trade and manufacture. ${ }^{27}$

Because all of these proposals were submitted jointly, one can assume that they shared a common intent.

J ust as it was clear from the time of the Constitutional Convention that intellectual property law was intended to serve the goals of education and learning, so it was also plainly understood that intellectual property rights were to be considered statutory rights, granted to fulfill a public policy purpose. This idea is apparent in the first Federal copyright act of 1790 insofar as it excluded nonresidents from the benefits of copyright. It was reaffirmed, moreover, by the Supreme Court in the famous

“l bid., 128-130.

"Patterson, Historical Perspective, ch. 12. case of Wheaton v. Peters which, drawing heavily on the British case of Donaldson v. Becket, concluded that copyright was a statutory construct to the point of requiring compliance with the formalities of the law as a condition of protection. ${ }^{28}$ It is clearly laid out again in the legislative committee report on the 1909 Copyright Act, which describes the purpose of copyright as follows:

\footnotetext{
The enactment of copyright legislation by Congress under the terms of the constitution is not based on any natural right that the author has in his writings, for the Supreme Court has held that such rights as he has are purely statutory rights, but on the ground that the welfare of the public will be served and progress of science and useful arts will be promoted . . . Not primarily for the benefit of the author, but primarily for the benefit of the public such rights are given. Not that any particular class of citizens, however worthy, may benefit, but because the policy is believed to be for the benefit of the great body of people, in that it will stimulate writing and invention to give some bonus to authors and inventors.
}

The Founding Fathers' hopes for the intellectual property system were well founded. In the century and a half after its establishment, there was not only a great flourishing of creative, technological, and scientific works; but also, many of these works were designed with the needs of society and the common man in mind. Edward Riddle noted how much American technology reflected a concern for the public welfare in his report to the commissioner of patents about the 1851 technology exhibit at the Crystal Palace in London. Comparing the U.S. contribution to those of other E uropean states, he said:

The Russian exhibition was a proof of the wealth, power, enterprise, and intelligence of Nicholas; that of the United States an evidence of the ingenuity, industry, and capacity of a free and educated people. The one was the ukase of an emperor to the notabilities of Europe; the other the epistle of a people to the workingmen of the world. . . . We

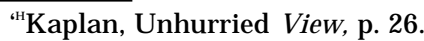


showed the results of pure democracy upon the industry of men.

This close association of technology with democracy was widespread throughout America in the first 100 years of its development. ${ }^{30}$ A democratic polity was thought to be a prerequisite to advancement in applied science, while technological achievements were expected to provide the physical means of achieving the democratic objectives of political, social, and economic equality. Visiting America in 1831, Alexis de Tocqueville, the well-known commentator on American society, observed this linkage. Describing the relationship between technology and democracy, he wrote:

... the extreme social mobility in America was fertile soil for progress in technology, because democratic peoples were ambitious, never satisfied with their status, and-above all-were al ways free to change it. . . . You may be sure that the more a nation is democratic, enlightened, and free, the greater will be the number of these interested promoters

${ }^{29} \mathrm{Edw}$ ard Riddle, "Report on the World's Exposition, " Report of the Commissioner of Patents for the Year 1851, House Exec. Docs., 32 Cong., 1 sess., No. 102, Part 1, pp. 484-85, as cited in Hugo A. Maier, "Technology and Democracy, 18001869, "J ournal of American History, vol. 43, p. 625.

“ Meier, Technology \& Democracy, p. 618. of scientific genious, and the more will discoveries immediately applicable to productive industry confer gain, fame, and even power on their authors. ${ }^{31}$

This enthusiasm for learning and the belief that it is linked to technological development and socioeconomic progress is less apparent today. One can particularly see this in the area of intellectual property law. Unlike the founders of the intellectual property system, who saw the law as mutually serving both educational and economic goals, many people now see these goals as competing with one another. A number of people fear, for example, that widespread public access to the new technologies will limit industry's ability to exploit fully the economic potential of these technologies. Emphasizing that economic growth and development is to the benefit of all individuals, they urge that the law be restructured to favor business needs over individual ones, and economic goals over social ones. As the following discussion points out, conflicts such as these are likely to become more prevalent in an information age.

\footnotetext{
"Alexis de Tocqueville, J ourney to America, translated by George Lawrence, J .P. Mayer (cd. ) (New York: Anchor Books, 1971).
}

\section{OPPORTUNITIES AND POLICY CHOICES IN AN INFORMATION AGE}

The development of new technologies creates opportunities for society as a whole, as well as for individuals and groups. The new information and communication technologies will also create such opportunities. These technologies are capable not only of generating, storing, and processing vasts amounts of information; they can also provide greater access to information, enhance the environment for learning and creativity, generate new opportunities for profit-making and economic growth, and enhance the decisionmaking process as well as facilitate participation in political and social affairs.

Whether and how people develop technological opportunities offered by recent advances, and who will benefit from them, depends on an array of societal variables. The direction technology takes, for example, might be affected by such factors as the role of government and policy makers, cultural mores, the extent of existing technological infrastructure, or the structure of the economic system.

As we have seen, one way that governments have historically sought to structure and channel the direction of technological change has been through the intellectual property system. To understand how intellectual property policy might affect the development of the new information and communication technologies and the distribution of the opportunities that these technologies afford, it is necessary, first, 
to briefly identify these opportunities and point out where the realization of one may complement or preclude the development of another.

\section{Three Realms of Opportunity}

Examining how society has evolved in the face of technological development, the sociologist, Daniel Bell, characterizes modern society as being divided into three distinct realms: the techno-economic, the political, and the cultural. ${ }^{32}$ In preindustrial societies, these realms were relatively indistinct from one another. However, with the advance of technology and the specialization that it imposes, they have become increasingly differentiated. Today, each has its own rhythm of change, its own set of values, and its own corresponding mode of behavior. Moreover, because the forces that drive each of these realms are no longer complementary, they are generating a growing number of conflicts between them. ${ }^{33}$

Bell's framework for anaylzing advanced industrial societies is a useful tool for identifying the kinds of economic, political, and cultural opportunities that the new information technologies provide. Because it describes how each realm operates and the values that it supports, it can help to pinpoint the particular needs that the new technologies might serve. Moreover, insofar as it identifies the areas where there may be conflict between realms, it may suggest circumstances under which there might be competition for information resources, and hence conflicts about intellectual property goals.

\section{Opportunities in the Techno-Economic Realm}

The techno-economic realm is organized primarily to produce and distribute goods and services. The principle value underlying this realm is that of 'functional rationality' '-that is to say, according to the rule that each indi-

"Daniel Bell, The Cultural Contradictions of Capitalism (New York: Basic Books, 1976).

"I bid,, p. 10. vidual and each group in the system carry out rationally conceived, specified roles which, when taken together, are designed to maximize production. The principle means of achieving this value is by economizing; decisions are made on the basis of cost/benefit analyses, and technology is applied to substitute less efficient processes with more efficient ones. Designed to further this kind of rationality and efficiency, the techno-economic realm is structured in a bureaucratic, and hierarchical fashion. 34

Today, the new information and communication technologies provide numerous ways of enhancing the values of the techno-econom.ic realm: they can improve efficiency, increase productivity, and thus they can engender economic growth. Information is, for example, re usable and, unlike capital resources such as steel or iron, it requires very few physical resources for its production and distribution. ${ }^{35}$ Moreover, information can now be used not only to substitute more efficiently for labor; it can also be used to improve the overall efficiency of the productive process itself. And, as productive processes become increasingly complex in advanced industrial societies, the largest reserve of economic opportunities will be in organizing and coordinating productive activity through the process of information handling." Given these characteristics and capabilities, information is likely to become more important as a resource in the techno-economic realm.

This growing importance of information to the economy is evident from the continued growth of the information sector of the economy, a trend that, as can be seen from figure $z-1$, has been paralleled in other advanced industrial societies. In fact, it was to highlight such changes that terms such as the "information society" and the "information age"

\footnotetext{
“l bid., p. 11.

"Harlan Cleveland, "The Twilight of Hierarchy: Speculations on the Global Information Society, "Bruce R. Guile (cd. ) Information Technol ogies and Social Transformation (Washington, DC: National Academy Press, 1985), p. 56.

"Charles J ohnshur, "Information Resources and Economic Productivity, Information Economics and Policy I (North Holland: Elsevier Science Publishers, 1983), pp. 13-35.
} 
Figure 2-1.-The Evolution of Information Occupations

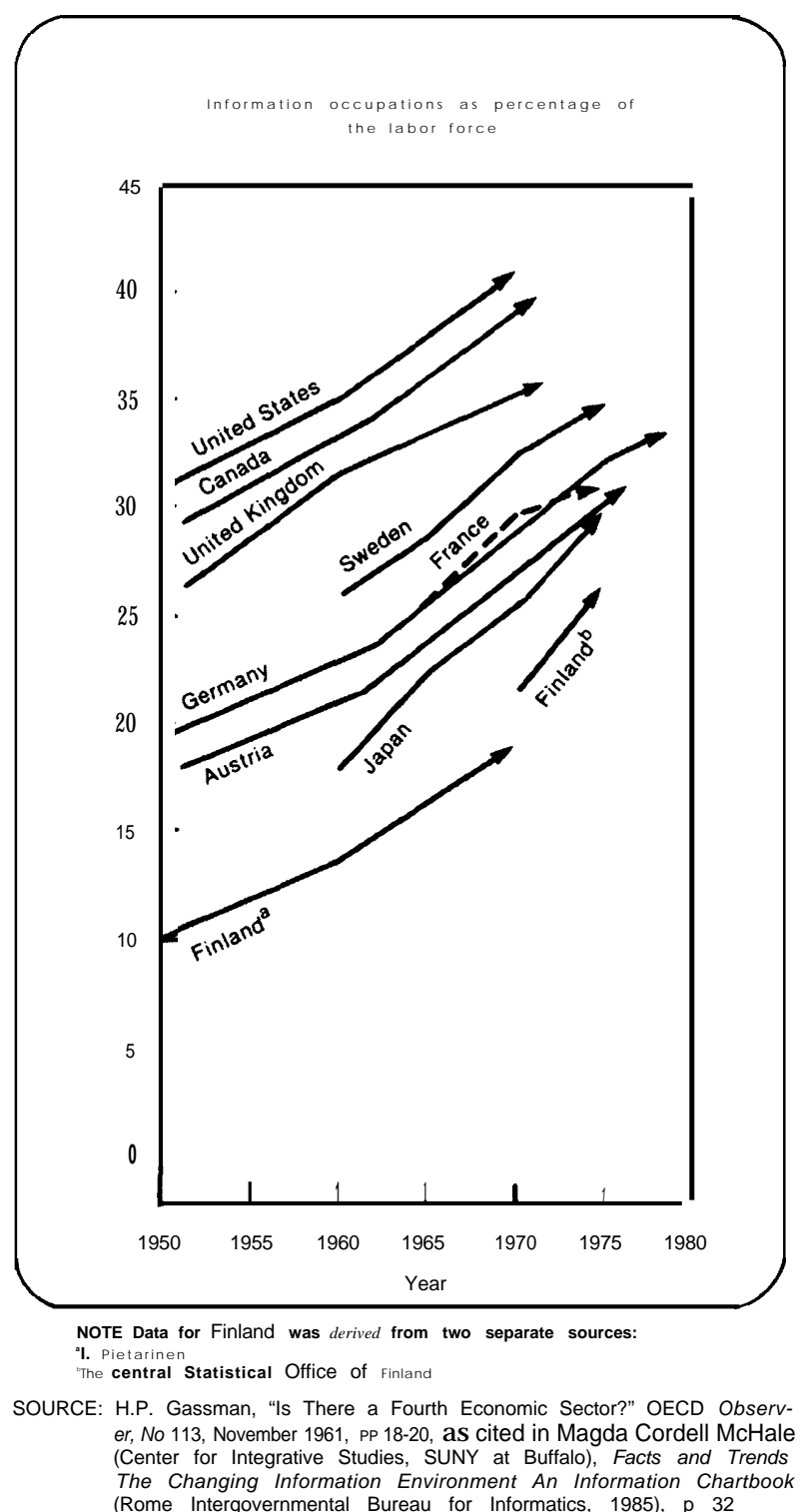

were first employed. ${ }^{37} \mathrm{~A}$ recent analysis estimates that the information sector constitutes

\footnotetext{
"Fritz Machlup was one of the first to note these changes and to measure the information sector in his pioneering work, now a classic, entitled The Production and Distribution of Knowledge in the United States. Others have followed this tradition. By far, one of the most ambitious efforts to date has been the innovative work of Marc Uri Porat for the Office of Telecommunications in the U.S. Department of Commerce. In 1967, according to Porat, information activities accounted for 45.2 percent of the GNP-25. 1 percent in the "primary information" sector (which produces information goods and services as final output) and 21.1 percent in a "secondary information" sector (the bureaucracies of non-information enterprises).
}

34 percent of the gross national product (GNP), and accounts for 41.23 percent of the national labor force. ${ }^{38}$

The changing economic role of information can also be seen by examining how information technologies are being used by business and industry. Businesses are now applying computer technology to almost all of their activities: from recruiting to laying off workers, from ordering raw materials to manufacturing products, from analyzing markets to performing strategic planning, and from inventing new technologies to designing applications for their use. ${ }^{39}$ These technologies, moreover, are being applied not just to traditional tasks; the diffusion of the new technologies is also being used to reconfigure the nature of the business process itself. ${ }^{40} \mathrm{Figure} 2-2$, for example, identifies how new technologies might be used to rationalize all of a firms activities. As a result, some economists are suggesting that in the future, whether or not a businss will be competitive, will depend on the extent to which it can find creative applications for these technologies." Representatives of industrv agree. As Airlliam H. Gruber, President of Research and Planning, Inc., described it:

The difference between now and five years ago is that then technology had a limited function. You weren't betting your company on it. Now you are. ${ }^{43}$

\footnotetext{
${ }^{38}$ Michael Roger Ruben and Mary Taylor Huber, The Knowledge Industry in the United States: 1960-1980. This volume updates work done by Fritz Machlup. In their breakdown of the information sector of the economy, Rubin and Huber note that, leaving education aside, the contribution of knowledge production to the GNP increased from 17.9 percent in 1967 to 24.5 percent in 1980. The contribution of education, on the other hand, fell from 16.6 percent to 12.0 percent during the same period, a decline that accounts for the fact that knowledge production's overall contribution remained relatively stable at about onethird of the GNP.

Theodore J. Gordon, "Computers in Business, " Guile, In formation Technologies and Social Transformation, p. 154.

"40"Information Power: How Companies Are Using New Technologies To Gain a Competitive Edge, Business Week, Oct. 14, 1985, p. 108

"Michael E. Porter, Competitive Advantage: Creating and Sustaining Superior Performance (London: Free Press, 1985). ${ }^{43} 1 \mathrm{bid}$.
} 
Figure 2.2.-Uses of Information Technology Within the Firm

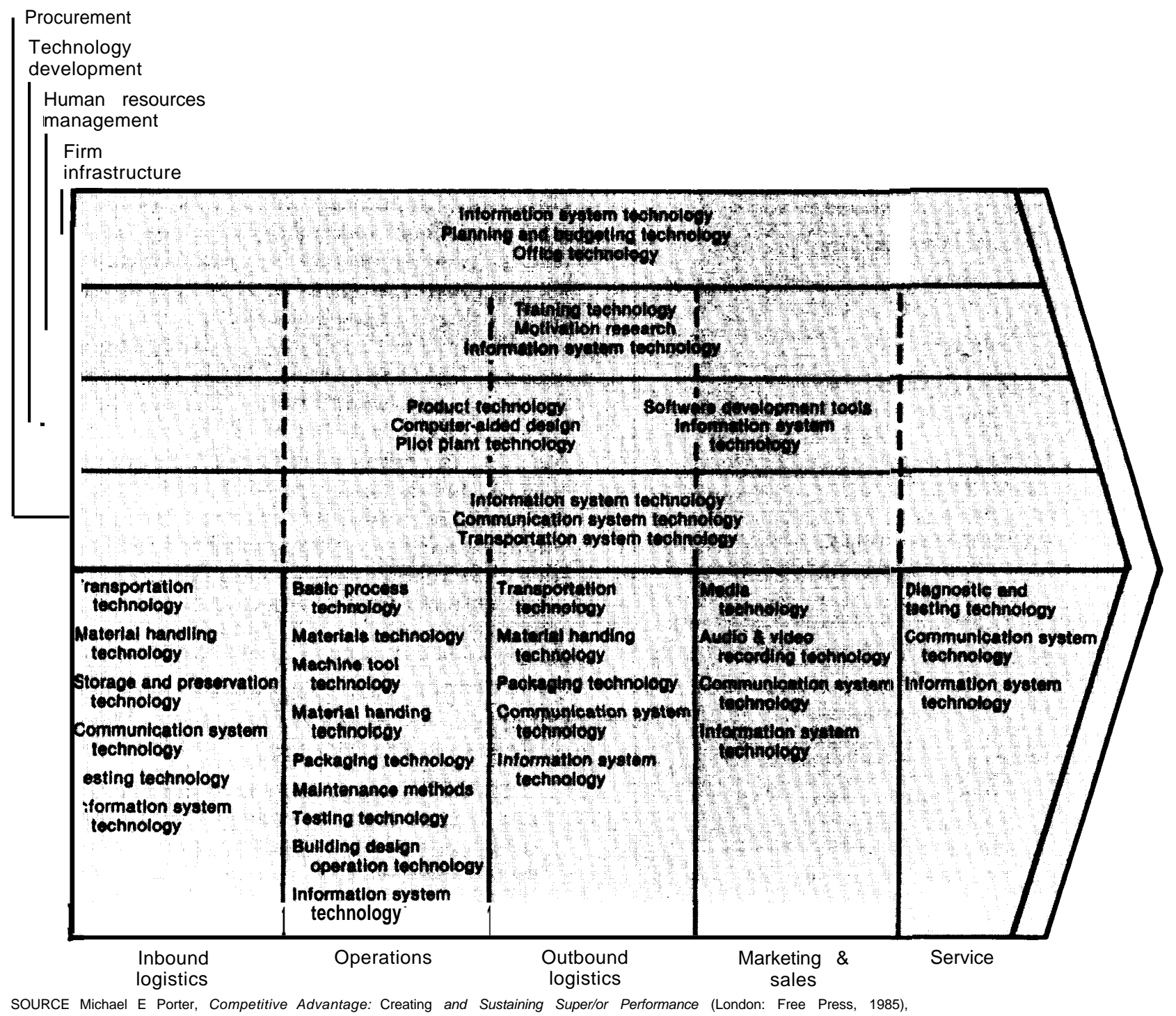

Many businesses are already successfully employing technology to their competive advantage. Merrill Lynch \& Co., for example, used computers to identify and automatically invest funds that were idle in checking, savings, credit card, and security accounts: In so doing, it was able to attract billions of dollars in assets from other places. Even though competitors were soon to-follow suit with their own service offerings, Merrill Lynch, with its head start, was able to maintain almost 70 percent of the market. ${ }^{44}$ Similarly, the America Hos"ibid., p. 109. pital Supply Corp. gained a competitive advantage by being the first to communicate directly with its customers via computer terminals. As a result, it was not only able to provide services at less cost than its rivals, it could also use the data collected in the process to more accurately analyze trends and customers needs. ${ }^{45}$

Because of its new economic and managerial importance, information is becoming much more commercially valuable. Businesses have always been willing to pay for information such

\footnotetext{
"I bid.
} 
as market research and economic forecasts. Today, however, they are not only buying more; they are willing to pay much higher prices for it. Consider, for example, the high price that a consortium of J apanese engineering companies was willing to pay to understand what went wrong on Three Mile Island. They offered to contribute $\$ 18$ million to assist in the clean up in exchange for access to all of the pertinent documents and records related to the accident. ${ }^{46}$ On a more routine basis, American business firms might pay $\$ 800$ per year for a monthly professional information service, or perhaps $\$ 15,000$ for a market research report shared by others in the industry. ${ }^{47}$

Today even private information can have commercial value. The direct mail business is a good example. Packaging data about individual credit ratings, security clearances, and background checks together with demographic data, this $\$ 13$ billion industry sells individual names to magazine publishers and local service companies for prices as high as $\$ 1$ per name. $^{48}$

The new technologies provide new ways and new opportunities to meet these burgeoning information needs. They allow information to be processed in a whole variety of new ways, adding value to it from the point at which it is created or composed to the point at which it is assimilated or used. For example, a book may be produced with paper and ink, on audio cassette, or on optical disk; its content may be adapted into a television "mini-series" or an interactive game that can be distributed in a variety of forms.

As the opportunities for creating new information products and services have increased, so too has the number of commercial providers. Taking advantage of the increased demand for information, the new technologies have spawned a rapidly growing information industry, the

\footnotetext{
"Christopher Bums, "Three Mile Island: I nformation Meltdown, "Information Management Review, May 1985.

"Christopher Burns, Inc., The Economics of Information, contract report prepared for the Office of Technology Assessment, U. S. Congress, 1985.

“'l bid.
}

scope of which can be seen in figure 2-3. Devel oping hand in hand with the new technologies, this industry is relatively young. More than half of the companies that comprise it were formed since 1970. Nevertheless, it is one of the fastest growing industries in the economy. In 1984, there were nearly 2,500 online databases. Based on an Information Industry Association survey of 1982, it is estimated that these services accounted for revenue of \$3.6 billion. ${ }^{49}$ By 1985, the number of data bases had grown by about 12 percent.

In addition to service providers, new industries have also been established whose sole purpose is to provide information-on-demand. With estimated revenues of $\$ 660$ million, this industry consists of small research companies and a few major libraries that have made a business out of finding documents and copying them for users. In the private sector, these are called "fee-based libraries, ' "on-demand companies, or sometimes 'information brokers." They also include 5,000 special research libraries in the United States supported by a few inter-library loan networks such as the Online Computer Library Center and the British Lending Library. ${ }^{50}$

Given its increased value, information will most likely be exchanged less freely. Instead, it will be treated more and more like a commodity, to be bought and sold in the marketplace. In fact, the rush for profits in information products and services is so pronounced that it might reasonably be compared to the California Gold Rush, a metaphor used most effectively by the information industry as the theme for its 1985 annual conference.

\section{New Opportunities in the Political Realm}

The polity is the realm of power. It is the area of social activity where disputes are resolved and social justice is defined, and where resources and values are allocated in accordance with the general idea of justice. The basic

\footnotetext{
“I bid.

“'I bid., p. II-8.
} 

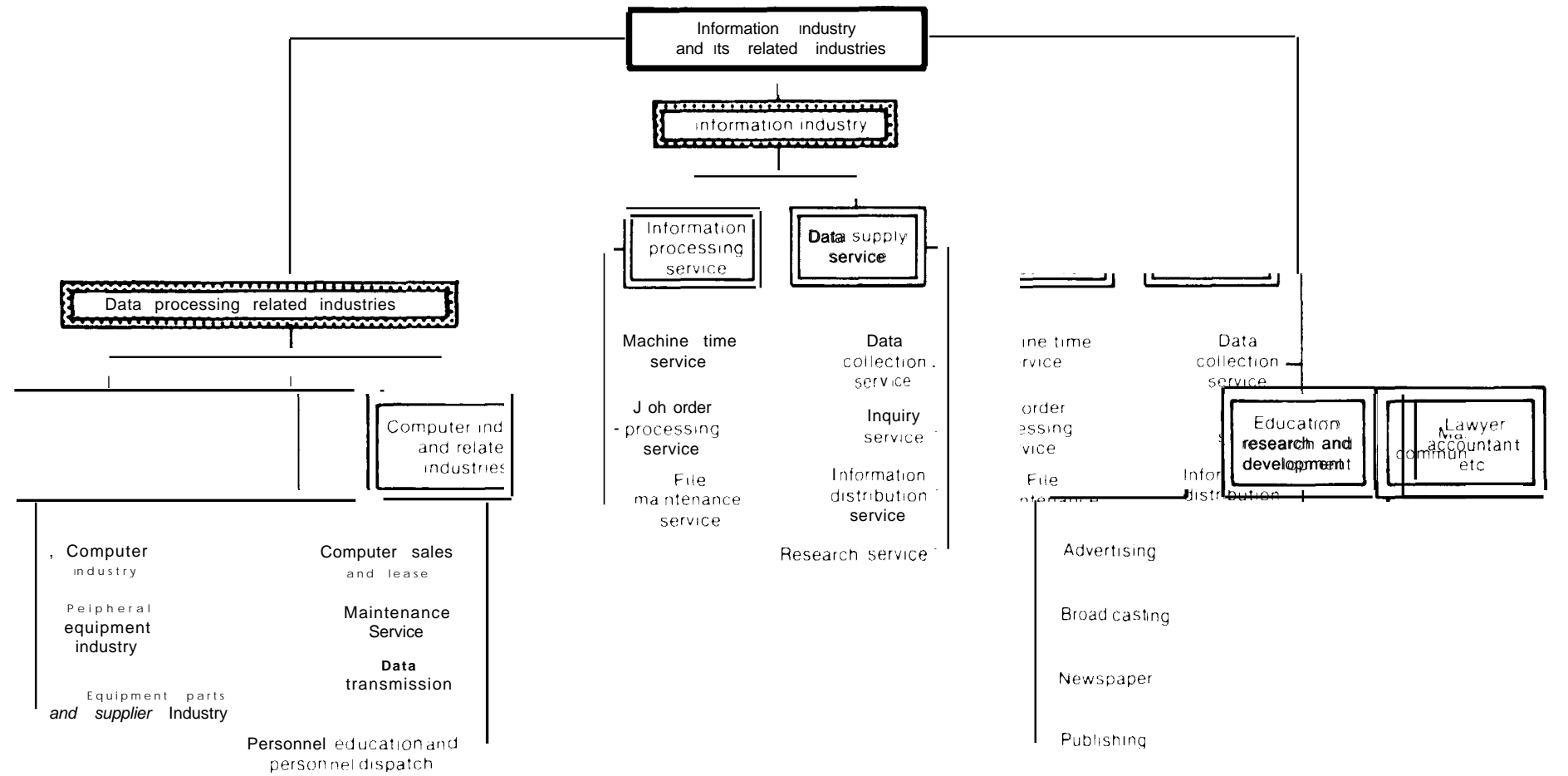

person nel dispatch

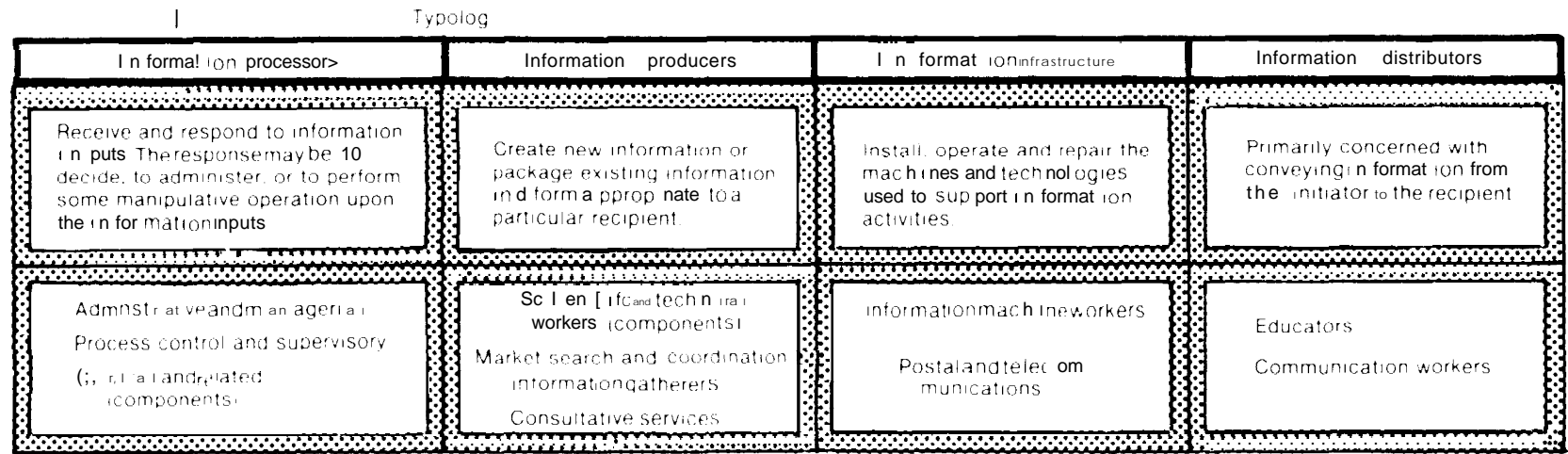

¿OURCE:HPGassman, "IS There a Fourth Economic Sector?" OECD Observer, No 113, November 1981, pp 18-20, as citedın Magda Cordell McHale (Center for Integrative Studies, SUNY at Buffalo), Facts and Trends The Changing In formation Environment An Information Chartbook (Rome Intergovernmental Bureau for Informatics, 1985), p 32 


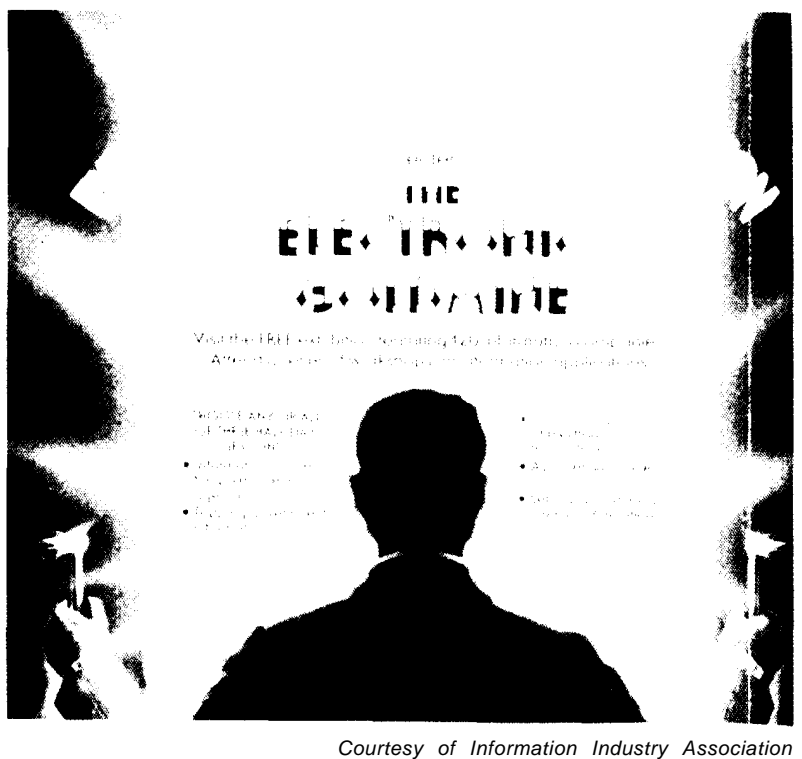

value that maintains the polity is "legitimacy" - the general adherence of the people to the conception of justice embodied in the society's traditions or constitution, and acknowledgement of the authority that governs on its behalf. ${ }^{51}$ Whereas in the economic realm change takes place in a linear fashion through increased specialization and economization, in the political realm change comes about more haphazardly, through the competition for power and influence. In a democratic polity, the means of bringing about change is participation and persuasion; individuals and groups seek to gain access to resources and values by shaping attitudes and beliefs about what constitutes justice. To be effective, they must have access to both the means to influence as well as the means to be influenced. They must have the right to obtain information as well as the right to distribute it. In contrast to the bureaucratic structure of the economic realm, the political realm in a democratic society is decentralized and open."

Communication and information pervade political life." Without them there can be no na-

\footnotetext{
"Bell, Cultural Contradictions, p. 1.

"I bid.

"'In the discussion that follows, the term communications refers to both the information and the process by which information is shared and exchanged.
}

tion. F or it is through the process of communications that people first develop a sense of community and a shared set of values that legitimize political authority. ${ }^{54}$ By magnifying and amplifying some actions, the communications process, moreover, distinguishes between what is a private act and what is a public affair. It organizes what may seemingly be random activities to show how individuals and groups are related to one another in the pursuit of power, providing individuals who want to influence the course of political events a road map to guide them. ${ }^{55}$ Citizens rely on the communications process to gather information, to identify like-minded people, to organize their forces, and to articulate their political preferences. Furthermore, because it generates a common fund of knowledge and information, the communication system facilitates productive and rational debate. Without some knowledge and understanding of how others are informed, and of what they believe, individuals could not make reasoned and sensible arguments and decisions. ${ }^{56}$ The communications process also provides guidance to political leaders. Because communication channels flow in two directions, communications serve not only to inform citizens about political events, they also provide feedback to political leaders about the values and attitudes of their constituents. ${ }^{57}$

Given this intimate relationship between the communications and political processes, it is not surprising that, just as the new technologies afford opportunities in the economic realm, so they create new political opportunities. Capable of sending a vast amount and a

\footnotetext{
${ }^{54}$ Karl Deutsch, Nationalism and Social Communication (New York: Free Press, 1963).

${ }^{55}$ Lucien W. Pye (cd.), Communications and Political Development, Studies in Political Development [Princeton, N] : Princeton University Press, 1965), p. 6.

${ }^{56}$ Ibid.

${ }^{57}$ Mass media communicators, for example, interpret public attitudes, They adjust their materials to take into account how the public reacts to their descriptions of news and events. Those in position of political power, in turn, adapt their behaviors to conform to the media's portrayal of the public's mood at any one time. For a discussion of this theory see, Elihu Katz, "The Two Step Flow of Communications: An Up-To-Date Report on the Hypothesis, " Public Opinions Quarterly, vol. 21, spring 1957.
} 
wide variety of information long distances at unprecedented speeds, these technologies allow entire populations to experience major pub lic and political events in common, thereby fostering a sense of national community. Because they are also interactive, these technologies can play a greater role in helping political leaders to communicate to the public and to assess its mood, thus helping to reinforce the legitimacy of the political system. Moreover, given the decentralized distribution of many of the new technologies, and their capacity to store, copy, manipulate, retrieve, and send information, they can be used to foster participation, hel ping individuals to gain access to information and other political resources, to locate parties holding similar positions, to articulate and widely disseminate their views, and to more effectively and efficiently organize their political involvement. Already we see evidence of the new technologies being used in several of these ways.

In the past few years, for example, a growing number of political leaders are beginning to use the new technologies to communicate more effectively with their constituents. A number of senators and representatives now produce their own news clips and interviews, which they transmit via satellite to their local television stations. This technique allows them to speak directly to the public, without others commenting on, or interpreting, their remarks. ${ }^{58}$

Computer technology also provides new ways to enhance the efficiency of political communications. Using the mass media, for example, politicians have to spend considerable money and effort to send a message' that will have enough overall appeal to pay for the effort. Using the new electronic media, on the

\footnotetext{
${ }^{58}$ Paul West, "The Video Connection: Beaming It Straight to the Constitutents, "Washington Journalism Review, J une 1985, pp. 48-50. Congressmen have always appealed to the public directly through newsletters, questionnaires, and other franked materials. However, some observers consider the use of satellite technology as a different kind of development, which may give cause for alarm. Unlike the previous kinds of appeals, which were sent to individuals and which were clearly identified as being politically oriented, the new video materials are often distributed as part of local news broadcasts, and thus their origin and intent might be misconstrued.
}

other hand, whether it be cable, teletext, or the computer, politicians can "custom target" their messages to those who are the most likely to be responsive to it. In this manner, they can more efficiently allocate their time and resources, focusing them on those voters who are the most likely to give them support. ${ }^{59}$

The new technologies, moreover, have potential to aid citizens in acquiring the information about government that they need in order to participate effectively in political life. A growing number of communities and government agencies, for example, now allow individuals to access their computerized records using public terminals. ${ }^{60}$ Moreover, some people hope that, in the future, individuals will not only be permitted to access an agency's data but also the computer software used to analyze this data. With such information, citizens would be able to rerun agency decisionmaking models, using their own assumptions or data. ${ }^{61}$ In addition, cablecasting ${ }^{62}$ and teletextap provide

${ }^{59}$ Kevin L. Kramer and Edward J. Schneider "Innovations in Campaign Research: Finding the Voters in the 1980s, "Robert G. Meadow (cd.), New Communication Technologies in Politics: The Papers for a Conference, The Washington Program, Annenberg School of Communications, 1985. See also William C. Paley and Shelly M offett, "The New Electronic Media-Instant Action and Reaction, " Campaigns and Elections, C. 4, 1984, pp. 4-12.

${ }^{60}$ The idea of government databases, accessible to the public, has existed since the 1960s and early 1970s. At that time, many people hoped that the automation of government operations would produce vast stores of information about the government and community which could be made available to interested citizens through remote computer terminals. Although the ideal of remote access never materialized, today use of public terminals for access to these databases within government agencies is common, and becoming more so. Kenneth $L$. Kraemer, J ohn Leslie King, and David G. Schetter, innovative Use of Information Technology in Facilitating Public Access to Agency Decisionmaking: An Assessment of the Experience in State and Local Governments, final report prepared for the Office of Technology Assessment, March 1985, pp. 35-36.

${ }^{61}$ Ibid.

"Utilization of these channels by local government is generally low. Most cities have only about two cable applications for governmental affairs progr amming. These have mainly been limited to a variety of one-way services that require a minimal production effort, such as for broadcasting city council meetings, for community bulletin boards, and for calendars and short local news items. Ibid., p. 35.

${ }^{63}$ There is considerable potential to provide public access to information related to government decisionmaking via teletext and videotex services. At present, the kinds of information provided generally are limited to such things as notification about schedules for hearings, meetings, etc., or to the posting of the results of such activities. Ibid. 
new channels for public access to governmental decisionmaking by increasing the levels of public awareness, interest, and knowledge about governmental affairs.

To effectively champion one's views, individuals, however, do not just act alone; they act in concert. The new technologies, with their capabilities to store, manipulate, retrieve, and network are optimally suited to help them in this regard. With a personal computer and a modem, individuals can collect and store information related to their concerns; they can maintain lists of potential supporters and contributors and target specific messages to them; they can match organizational resources with organizational needs; and they can gain constant feedback about the progress being made. Figure 2-4 below illustrates, for example, how the new technologies can manipulate and structure information in a way that will improve both the efficiency and effectiveness of a political campaign.

Clearly one need not be a seasoned political activist to take advantage of these new capabilities. Acting on his own, one man in Colorado Springs, for example, led a successful campaign to block a local ordinance placing restrictions on home-based entrepreneurial activities. Surprised that he was the only citizen to attend the first hearing on the ordinance, he brought the issue to the community's attention by publishing it together with a list of his concerns on his computer bulletin board. A small notice in the local newspaper helped to advertise his plan. A number of people contributed their comments via the computer network. When, several weeks later, a second hearing was held, 175 people appeared to defeat the ordinance. ${ }^{64}$

Information technologies can even be used to lobby. Lobbyists for the Environmental Fund, for example, carry a personal computer when visiting congressional offices. Their specially designed interactive software allows congressmen to look at population projections

\footnotetext{
"Dave Hughes, "The Neighborhood ROM, Computer-Aided Local Politics, " 45, Whole Earth Review, March 1985, p. 89.
}

using a range of different assumptions. According to lobbyist Casy Dinges, this kind of interaction is not only effective in informing congressmen of an organization's point of view; it also provides them with a memorable experience, thereby engaging their interest in the issues over the long term. ${ }^{65}$

Because of their effectiveness as political tools, the new technologies are becoming essential to all those who aspire to influence the political process. For, just as these tools are often the critical competitive factor in the economic realm, so too are they in the political realm. Thus, politicians and politically active citizens, like their businessmen counterparts, are hurrying to establish their own information bases. This move towards technology is very apparent, for example, at the level of national politics. Trying to catch up with the Republican Party, which began very early to incorporate technology into its campaign operations, the Democratic National Committee is now endeavoring to equip itself with an information infrastructure that will include a national bulletin board, that is capable of trading political information between the national office and key House candidates. ${ }^{66}$

With the numerous possibilities that the new technologies afford, attention is becoming, focused on the politics of information. In the international arena, for example, Third World countries now assert that the control over information within their national boundaries is vital to their economic, political, and social well-being. To achieve their ends, they are calling for a new World I nformation Order, that would allow them to select the information that enters their nations and that would assure them access to the information they require for development. ${ }^{67}$

\footnotetext{
"Interview with Casy Dinges, Lobbyist, Environmental Fund, April 1985.

"David Burnham, "Democrats Chase Dollars With Computer Aid," The New York Times, Feb. 5, 1986, p. B6.

${ }^{67} J$ oge Becker, Information Technology and A New Information Order, Information and Society Series (Amsterdam: Chartwell-Bratt Ltd., 1984).
} 
Figure 2-4.-Development of Custom Targeting Database

Work flow
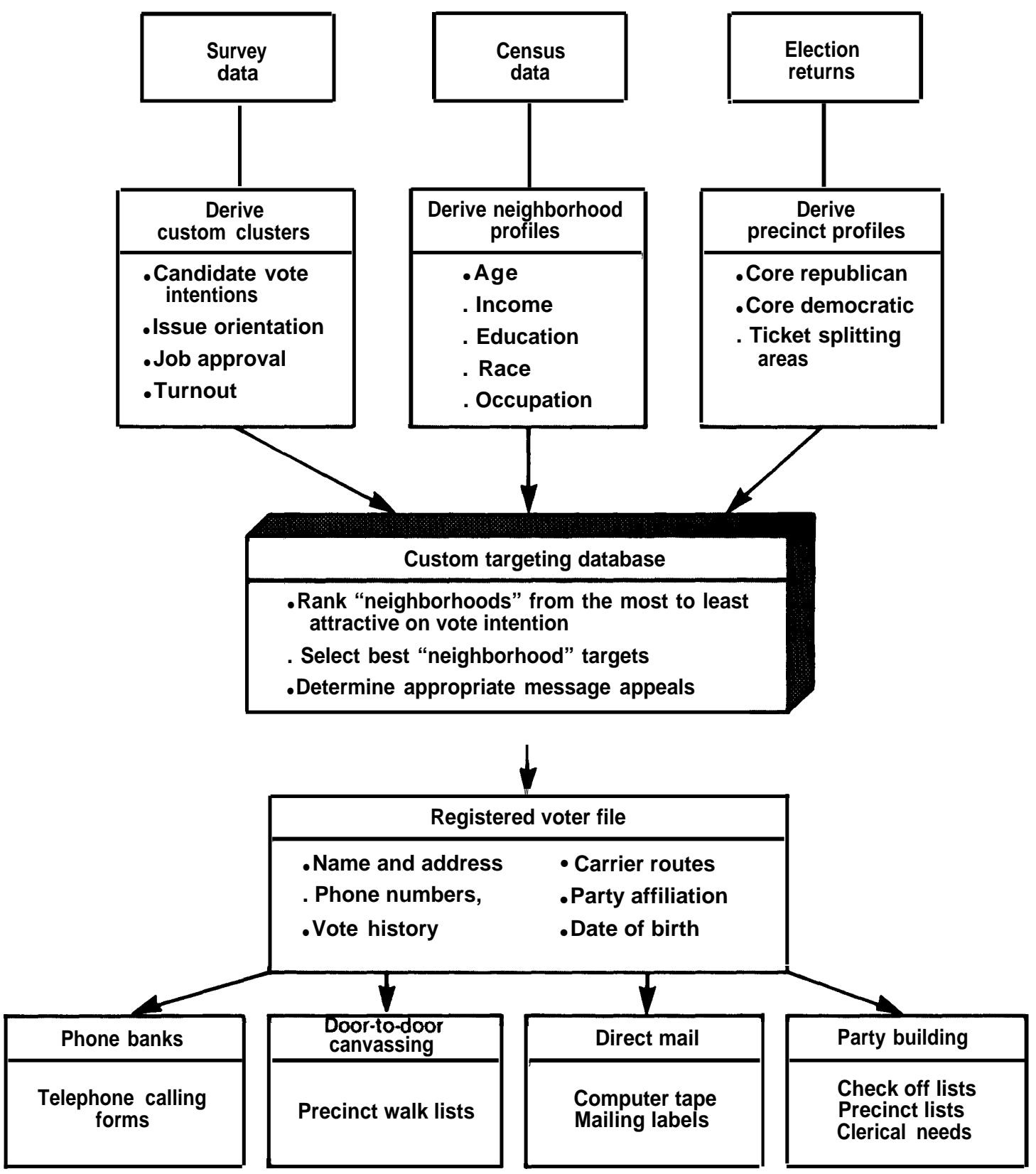

SOURCE Kevin L Kramer, Edward J. Scheneider, "Innovations in Campaign Research, Finding the Voters in the 1980s, " Neabmmunications Technologies in Politics. The Washington Program, Annenberg School of Communications, Robert G. Meodans (cd.), Washington, DC, 1985, p 24 Used with permission 
Political observers in advanced industrialized societies are also considering how the new technologies might affect political life. Among them, they have developed two quite distinct and contradictory scenarios. One of these posits "the rise of the computer state."168 According to this scenario, government and large corporations will use the centralized storage and processing capabilities of computer technology to consolidate their control and to monitor and manipulate behavior. The second scenario, in contrast, envisions the opposite state of political affairs. Characterizing the new technologies as "technologies of freedom, " this view of the future postulates that, given their decentralized use and increased availability, these technologies will lead to a dispersal of political power and permit enhanced participatory democracy."

Evidence can be found to support both of these contentions. As has already been pointed out, some local communities are taking steps to increase the public's access to information. On the other hand, taking advantage of the monitoring and processing capabilities of the new technologies, government is looking more favorably at the prospects of employing such devices as electronic surveillance, computer matching, and polygraph testing..$^{70}$ In the long run, the political outcome will depend less on the technology itself and more on the legal and social structure that determines how the new technologies will be used.

\section{Opportunities in the Cultural Realm}

Culture is the realm of "sensibility of emotion, moral temper, and of the intelligence [that] seeks to order these feelings."'" Providing a consistent moral and aesthetic frame of reference, it serves to develop and sustain the

\footnotetext{
"'See, for example, David Burnham, The Rise of the Computer State: The Threat to Our Freedoms, Our Ethics, and Our Democratic Process (New York: Random House, 1984).

"Ilarlan Cleveland, "The Twilight of Hierarchy: Speculations on the Global Information Society, Bruce R. Guile (cd.), Information Technologies, p. 61.

U.S. Congress, Office of Technology Assessment, Federal Government Information Technology: Electronic Surveillance and Civil Liberties, OTA-C IT-293 (Washington, DC: U.S. Government Printing ()ffice, October 19851.

Bell, Cultural Contradictions, p. 12.
}

identities of both individuals and societies. ${ }^{72}$ This realm comprises all of those imaginative and spiritual activities-such as painting, poetry, or music, as well as litany, liturgy, and ritual-whereby men and women seek to understand their natures-who they are, their relationships to others and to God. ${ }^{73}$ Although the ways that people have dealt with these existential concerns have changed considerably over time and in different eras, the themes that have preoccupied mankind-death, tragedy, love, sacrifice, heroism, obligation, and redemption-have remained constant. Thus new art forms and new ideas do not replace old ones; they become apart of an ever expanding source on which individuals can draw to recreate and reinterpret aesthetic and religious experience. The cultural realm, then, is governed by the principle of communal sharing and exchange. ${ }^{74}$

Communication is the process by which culture is developed and maintained. For it is only when people develop language, and thus a way of communicating, that a culture can, in fact, emerge and be imparted..$^{75}$ Information, the content of communications, is the basic source of all human intercourse." Over the course of human history, it has been embodied and communicated in an ever expanding variety of media, including among them spoken words, graphics, artifacts, music, dance, written text, film, recordings, and computer hardware and software. Together, these media and the channels through which they are distributed, constitute the web of society, which determine the direction and pace of social development. Seen from this perspective, the communication of information permeates the cultural environment and is essential to all aspects of social life. ${ }^{77}$

Linked as they are to all social activity, the new information and communication technologies provide endless opportunities to enhance the cultural realm. Given their networking ca-

\footnotetext{
"Without a cultural tradition, individuals interactions would be meaningless. For, in order to define themselves and to take purposeful action in different situations and in relationships to others, individuals need reference to a relatively stable construct of shared symbols. Tal cott Parsons, The Social System (Glencoe. IL: Free Press, 1964), pp. 11-12.

"Bell, Cultural Contradictions, p. 12.

“'Ibid. p. 15.

"I bid.

"Pye, Political Development. p. 4

Ibid.
} 
pabilities, they provide an expanded infrastructure for information sharing and exchange. They can be used, moreover, not only to generate greater amounts of information and new kinds of cultural forms, but also to make this knowledge more accessible and to provide it in more convenient and suitable ways. In addition, because they are decentralized and widely available, they open the way for many new people to become actively involved in creative activities. Finally, given their ability to store and retrieve vast quantities of information, they can serve as a storehouse of cultural resources, making them accessible and available for generations and civilizations to come.

Many of these opportunities are already being developed. Most prominent is the opportunity to provide more and more information. Between 1960 and 1977, for example, the words supplied in all media grew at a rate of 8.7 per year, which is 5 percent faster than the rate of growth of the the GNP (measured in constant dollars). The total number of words produced has increased from $1.07 \times 10^{9}$ in 1960 to $3.36 \times 10^{9}$ in $1977 .{ }^{78}$ And individuals are consuming, on the average, 1.2 percent more words each year. As already noted in figure $\mathrm{S}-3$, the largest proportion of this growth is attributable to electronic media.

Moreover, this information can now be provided in a much greater number of forms, giving people the opportunity to have more control over, and choice about, the kinds of information and cultural works that they enjoy. One new technology that will increase information channels, for example, is videotex. By taking advantage of television's full channel capacity, this technology can augment the number of information outlets 100 -fold. ${ }^{79}$ Other new technologies that increase the available sources of information are videocassette recorders, optical disks, direct broadcast satel-

\footnotetext{
${ }^{78}$ Ithiel de Sola Pool and Roger Hurwitz, "Methodological Issues in the Measurement of Information Flows, "Workshop on Measurement of Information, Sponsored by the National Science Foundation, Research Program on Communications Policy, Massachusetts Institute of Technology, J uly 1982, p. 8.

"'I rving Louis Horowitz, "N ew Technology, Scientific I nformation and Democratic Choices, "I nformation Age, vol. 5, No. 2, April 1983, p. 69.
}

lites, and computer bulletin boards, to name but a few.

The new technologies also allow people to receive information specifically tailored to their needs. Today many newspapers, for example, use computer technology to create and distribute special editions for different geographical audiences .80 Similarly, community, religious, and citizen-based organizations use technology to select the audience for whom their messages would be most relevant. Using home technologies, people can also select the information they desire. They might, for example, choose bibliographic data or financial information from on-line databases such as the Source or CompuServ. Or, they might just place a query on their electronic bulletin boards.

With the new technology, people can, moreover, use information at times and under conditions that are most convenient for them. With an audio or video recorder, they can listen to or watch programs at a time other than when they were originally aired. Moreover, they can rent or buy an ever growing number of tapes and programs to enjoy at their leisure in their homes. Such flexibility not only allows viewers the choice of when and what to watch; because it permits them to record programming for later viewing, it also allows them to expand their repertoire of home entertainment.

The power of the new technologies to enhance the cultural realm are evident not only with respect to the quantity, variety, and accessibility of the information that individuals can receive in their homes. Of equal, if not more, significance is the fact that these technologies are interactive. As such, they encourage active, not passive, behavior. ${ }^{81} \mathrm{M}$ ore over, given their ability to copy, store, and reprocess information, and to transmit it to large audiences, they make it possible for ordinary individuals to carry out activities that once required the skills of a specialized elite. ${ }^{82}$ Now conceivably, everyone can be a creator

\footnotetext{
"'Anthony Smith, Goodbye Gutenberg: The Newspaper Revolution in the 1980s (Oxford: Oxford University Press, 1980), pp. 51-61.

"Horowitz, Information Age, p. 69.

“'l bid.
} 
and a publisher. Each person can actively contribute to his culture, and not just partake of it.

The ability of technologies to help individuals reach out to the community is no where better illustrated than in the case of videotex. Although this technology has not yet taken hold in the United States, the French experience with it provides a clue about what a national system such as this might entail. Established by the French Government in 1981, the French system, Teletel, now consists of 1.4 million terminals-called Minitels -operating in households and businesses throughout the country. ${ }^{84}$ Using le Kiosque, Teletel's most popular feature, the French people can select from over 200 different kinds of information services. Many use the system simply to "chat" with Minitel friends. Farmers rely on it for in formation about the weather and commodity prices. In addition, the government is now beginning to expand the system to provide human services. Already, pilot programs are underway to develop networks for such groups as diabetics, victims of AIDS, parents of epileptic children, and battered wives. ${ }^{85}$

Although the use of videotext has been much less popular in the United States than in France, Americans are also reaching out to others on electronic bulletin boards. Becoming increasingly popular among the public, bulletin boards not only allow individuals to access information from their homes; they also hel $p$ them to contact others in similar situations or with similar needs, to discuss and share information, or even to collaborate with them on-line. Groups, such as the disabled, who have traditionally been isolated from society, have found in networking a new way of socializing."

The new technologies also serve as catalysts for social action. Still eager to learn, many elderly people have found computing to be a very engaging past time. In fact, because computing is an activity that does not require phys-

\footnotetext{
"Nadine Epstein, “Et Voila! Le Minitel," The New York Times Magine, Mar. 9, 1986, pp. 48-49.

'I bid.

"Sherry SonLag, "For Disabled, Computers Are Creating New Lives," The New York Times, vol. 134, p. I(n) and 1(l).
}

ical prowess, and which can be done at home, a number of senior citizens are thinking about using their newly acquired skills to begin a second career. Recognizing this potential interest, some communities have begun programs to get the elderly more involved." The Little House Senior Adults Center in San Mateo, California, for example, has been so successful with its computer programs that its directors are now thinking about building a computer network for the elderly.

In the same way that individuals benefit from the new technologies, so too will cultural institutions such as libraries, schools, and museums. Using technology, these institutions will be able not only to reach out into the community to provide information and cultural works to those who would otherwise not have access to them, but also to help people to participate in cultural activities. Thus they serve to replenish the cultural store.

As documented in a previous OTA study, Informational Technology and Its Impact on American E ducation, the computer and other information-related technologies can help educational institutions play a major role in providing people with the knowledge and skills they need to participate in and enjoy the benfits of an information age. ${ }^{88}$ The interactive nature of computer technologies allows students to become actively involved, and thus, more engaged, in their own learning process. Using a videodisk to simulate laboratory experiments, for example, students can view on a monitor the explosion that would take place if they were to mix incompatible chemicals .89 Videocassettes are also being successfully used for educational purposes. The film company, Education and Learning, for example, has re-

\footnotetext{
"'Kathy Chin, "The Elderly Learn To Compute, " I nfoworki, May 7, 1984, pp. 24-29.

"U.S. Congress, Office of Technology Assessment, Informational Technol ogy and Its I mpact on American Education, OTACIT-187 (Washington. DC: U.S. Government Printing Office, November 1982). This study found that information technology is already beginning to play an important role in providing education and training in some sectors, and that it is likely to become a major vehicle for doing so in the next few decades.

"J im Bartimo, "Classrooms To Utilize Videodisc Technology, " Infoworld, Mar. 12, 1984, p. 40.
} 
cently compiled a Video Encyclopedia of the 20th century, comprising 75 one hour videocassettes that cover major events from 1893 to 1985. Students can randomly access these tapes to witness famous historical events, such as the Scopes trial, or to view periodic pieces describing such things as the costumes of a particular era. ${ }^{90}$

Universities, too, are also taking advantage of new technologies. Over the past few years, for example, many universities and colleges have been experimenting with ways of integrating computers into their course curricula. At Stevens Institute of Technology, for example, interactive calculus programs are used to assist students in learning to do mathematical analysis. In chemistry, computers are used for graphic simulations and for drill and practice. In introductory computer graphics courses, computers serve as electronic drawing boards, and in the labs they are being used to assemble data, provide interface with equipment, and stimulate experiments that might otherwise be unfeasible, too expensive, or too dangerous. ${ }^{91}$

Of particular benefit to universities will be the development of computer networks, which can connect students and faculty members to a wealth of information, both on and off campuses. These networks, still in their infancy, are modeled after ARPANET, the research network developed by the Department of Defense. Carnegie Mellon University in Pittsburg, Pennsylvania, has al ready taken major steps to devel op such a network. By the end of this year, they plan to link all of their students' personal computers into a time-sharing file system. This system will not only provide for point-to-point communication and electronic mail; it will also allow the user to browse through all of the databases on campus. ${ }^{92}$ Other universities such as MIT and Rensselear Polytechnic Institute are following suit. ${ }^{93} \mathrm{M}$ ost im-

\footnotetext{
“'Fred M. Hechinger, "Video Cassettes Bring History to Life," The New York Times, J an. 14, 1986.

"Donna Osgood, "A Computer on Every Desk, "Byte. J une 1984.

"Ibid.

MIT network system is being developed through Project Athena, a $\$ 70$ million effort to create a single operating system
}

portant of all, universities are now thinking about expanding their networking efforts to link their own systems to those that connect researchers and research throughout the United States. ${ }^{94}$

As institutions that acquire, store, manage, and disseminate information, libraries are also well suited to take advantage of the opportunities that new technologies afford. And, in fact, these technologies have affected all aspects of library services. Software is now commercially available for practically all library operations: circulation, inventory, acquisitions, periodicals, cataloging, and reserves. Moreover, using these technologies, libraries have developed networks that can access national databases, allowing users faster and more efficient access to information.

Considering all of these opportunities together, the new technologies would appear to have been designed especially for a modern age such as ours, which seeks self-fulfillment and self-realization. They offer convenience and personal choice. They can promote self-discovery. And with them, people can enter new realms, mental as well as physical.

Whether or not these opportunities are fully exploited is, of course, uncertain. For just as there are two opposing scenarios about political life in an information age, so too are there two visions of the impact of technology on the individual, one more favorable than the other. While acknowledging their potential, some peopie, for example, are concerned lest these technologies serve to further divide the world between the information rich and the information poor, reinforcing or even exacerbating existing social and economic differences. In fact, the more powerful the technology, the wider the gap might be.

\footnotetext{
that will allow programs available on one part of the system to be available on all others. Similarly, Rensselaer Polytechnic Institute is planning a system that will not only be geared to problem-solving and calculations, but that will also serve to provide electronic mail, word processing, on-line libraries, and communication among faculty and students. Ibid.

"Dennis M. J ennings, Lawrench $\mathrm{H}$. Landweber, Ira $\mathrm{H}$. Fuchs, David J. Farber, and W. Richards Adrion, "Computer Networking for Scientists" Science, vol. 231, Feb. 28, 1986, p. 950.
} 
Those who are concerned fear that the poor will be unable to afford the products of the information age if they are distributed primarily in the market. ${ }^{95}$ They worry, moreover, about the possibility that only those who are already skilled will be able to take advantage of the highly differentiated and individualized services offered by the new technologies. ${ }^{96}$

\footnotetext{
"See, for example, Carol A. Tauer, "Social Justice and Access to Information," Minnesota Libraries, vol. 27, No. 2, summer 1982, pp. 39-42; see also, Stephanie Siegal, "The HighCost of I nformation, " Freedom of I nformation Center Report, No. 489, School of J ournalism, University of Missouri at Columbia, March 1984, pp. 1-7.

"Edward Plowman, "The Communications Revolution," ASLIB Proceedings, vol. 33, No. 10, October 1981, p. 377.
}

They fear too that, given the growing market value of information, information providers may increasily focus on producing high cost and highly profitable information products and services and cut back on their efforts to meet the information needs of the poor. ${ }^{97}$ Where, they ask, in the midst of the information revoIution, is the information that ordinary people need to solve their everyday problems. ${ }^{98}$

\footnotetext{
Ibid

"Fugene Garfield, "Society's Unmet I nformation Needs, " 4S1S Bulletin. October November 1985, p. 6.
}

\section{THE POTENTIAL FOR CONFLICT IN THE USE OF NEW TECHNOLOGIES}

The new communication and information technologies will play a greatly enhanced role in all aspects of life. In fact, as we have seen, their availability and use may, in many cases, be the critical factor for success. The enhanced value of these technologies is reflected, first of all, in the growing number of people who, from whatever realm of life, are striving to integrate these technologies into their daily activities and operations. It is reflected, moreover, in the greatly increased market for information-based products and services, and the flourishing of new industries to provide for these burgeoning information needs.

Not all of these technological opportunities, however, will be exploited. In fact, taking advantage of some opportunities may preclude the development of others. The potential for conflict in the use of new technologies can be seen most clearly by contrasting how information is valued in the realms of economics, politics, and culture. Conflicts are likely to be most pronounced when the economic value of information is very high. For it is under such circumstances that the discrepancy between the need for exclusion, and the need for distribution, sharing, and use is the most starkly drawn.
From the perspective of the economic realm, the value of information is in its exclusivity -that is to say, in the ability of its owner to be able to exploit the difference between what he knows and what other people do not know. ${ }^{99}$ In a horse race, for example, the value of an accurate assessment of the horse's chance increases directly with the exclusivity of that wisdom, and the value is obviously decreased by sharing. Similarly, an important factor in encouraging investment is the presumption that the investor is better informed than others about the outcome of the enterprise. To the degree that all investors have equal access to information this potential for difference is reduced, along with the incentive for investment. ${ }^{100}$

To be supportive of democratic values, information, on the other hand, cannot be exclusive. It must be plentiful, varied, and the channels of access to it must be open. Politicians and political advocates, for example, seek to influence through persuasion. To be successful, they must disseminate their views as widely as possible. In contrast to the business-

\footnotetext{
"Burns, The Economics of Information, p. III-3,

:"x| Ibid.
} 
man who seeks to maintain his trade secrets, the politician benefits when his cause becomes the subject of widespread discussion. And if they are to be politically responsible and to hold legislators politically accountable, citizens also need to become acquainted with and discuss a wide range of political points of view.

In the cultural realm too, information is made more valuable not by its exclusion, but rather by its perpetual use and reuse. To understand a thought or an idea, people must process it together with the information that they already have. In making use of information, therefore, they do not diminish it. They enhance its value. ${ }^{101}$ Moreover, even the individuals who are involved in cultural activities can benefit from the repetitive use of their works. For a scholar's reputation and prestige will be more rapidly enhanced the more often his works are cited, and will dwindle if his works are ignored. Similarly, a recording artist may seek to have his records broadcast as widely as possible, just to establish a widespread reputation and a loyal following. 102

Concerned primarily with the use and flow of information in society, intellectual property law has historically served in the United States to decide which technological opportunities would be developed, and thus which values would be served. For example, the granting of an exclusive right to the creator or provider of an intellectual work changes the basis on which it is made available to society. The criteria to use the work becomes the ability to pay. The granting of such a right, therefore, can favor the values of the economic realm over those of the political and cultural realms. On the other hand, the fair use doctrine, which provides exceptions to what would otherwise be considered a copyright infringement, has the

'(")Harlan Cleveland, "I nformation as a Resource, " The Futurist, December 1982, p. 37.

"'Harlan Cleveland, "The Twilight of Hierarchy, " pp. 186187. Gossip, for example, spreads rapidly among family members, friends, and neighbors. Books and magazines, and now records, tapes, software programs, and films are commonly passed along from one person to the next. Ideas are discussed and debated at social gatherings, among scholars, and in the press. And by making information more available, and more easily accessible, the new technologies will foster these practices even more. express purpose of fostering the values of the cultural and political realms. In like fashion, the first sale doctrine, which limits the proprietor's control of a work once he has sold it, is designed to ensure public access to works. However, neither of these doctrines are supportive of the value of exclusivity.

In resolving these issues, policy makers have sought to strike a suitable balance between the needs of creators, producers, and distributors of intellectual property and the social, economic, and political needs of the nation as a whole. In such a fashion, intellectual property law has been able to simultaneously serve a wide variety of social and economic public policy goals.

The ability of intellectual property law to strike such a balance was not particularly difficult in the past, when the social and economic stakes in information were lower than today and when relatively few and well-defined players were involved in the intellectual property process. Information-based products and services were peripheral to the performance of many social and economic activities, and people had lower expectations about their use and the level of profit that might be derived from them. As a result, issues involving the granting of intellectual property rights could be worked out among the major players without much public involvement or concern.

The resolution of these issues in an information age, however, will be more problematic, requiring that more stakeholders be taken into account and that decisions be made about the distribution of incentives and rewards. Given the variety of opportunities that the new technologies afford, the increased value of information, changing relationships among the traditional participants in the intellectual property system, and rising expectations about the benefits of these technologies, the number of stake holders with disparate interests and competing claims on the system will be greater than ever before. In such a context, the granting of intellectual property rights, instead of mutually serving a variety of different stakeholders may actually pit one against another. 
The problem is exacerbated by the fact that, as the market value of information increases, so does the pressure to treat information activities in economic terms alone. Today, for example, there are a growing number of people engaged in information activities, which were once clearly considered to be outside of the realm of economics, who are now aggressively competing to economically exploit their works. And, to assure that they can do so, they are avidly seeking intellectual property rights.

Not surprisingly, such rivalry for ownership is becoming common in institutions of higher education and research, where the potential for profits is high. Here the claims and counterclaims of ownership are continually multiplying: claims of students against students, students against faculty members, faculty against faculty, and the university against students and faculty. '03 A particularly contentious issue in this regard is "work-f or-hire." Some university administrators now argue, for example, that, just as companies automatically own the copyright on works done on company time and with company resources, so too universities should have the rights to everything created in conjunction with their facilities ${ }^{104}$ These issues of ownership will not be easily resolved. For, as the Carnegie Mellon University flowchart illustrates, there are a wide variety of ways in which rewards can be distributed. (See figure 2-5.)

As the rush to make a profit in information becomes increasingly prevalent, many people are less willing to share their ideas and exchange their views. Some teachers report, for example, that they are unwilling to use computer software that they have developed in

"" Dorothy Nelkin, Science as Intellectual Property: Who Controls Scientific Research (New York: Macmillian Publishing Co., 1984), pp. 1-8.

'“'!J ust beginning to grapple with these issues, universities vary considerably in their work for hire policies. Brown University, for example, follows a relatively liberal policy, allowing faculty, students, and staff to share rewards. In contrast, at Virginia Polytechnic Institute lawyers for the university have recently concluded that students' assignments are the property of their professors. I vars Peterson, "Bits of Ownership: Growing Computer Software Sales Are Forcing Universities To Rethink Their Copyright and Patent Policies, "Science News, Sept. 21, 1985, pp. 189-190.
Figure 2-5. - Carnegie Mellon Flowchart

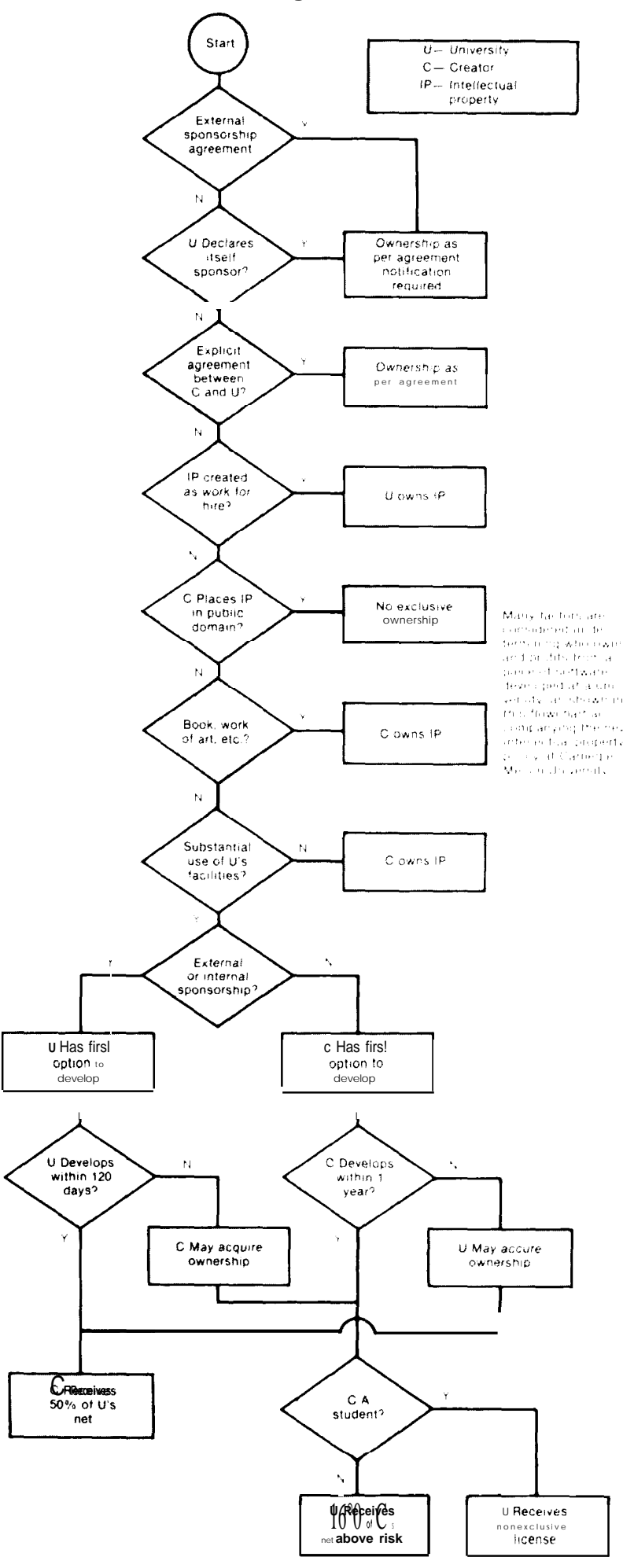

SOURCE Richard Stern, Carnegie-Mellon University 
their classrooms. Because of its high market value, they fear that their local school district will try to copyright it. ${ }^{105}$ Similarly, many people who participate in joint projects, such as electronic conferences, are becoming more hesitant about what they say. Because their ideas bring a high price, they want to reserve for themselves the right to profit from them. ${ }^{106}$

The growing focus on protection and securing ownership rights is also evident in the fields of art and entertainment. One extreme, but perhaps highly illustrious, example is the recent case in Seattle, Washington, where the estate of a well-known songwriter sued a church for singing the benediction to the tune of a copy-

\footnotetext{
“''Discussion with participants, Workshop on Educational Policy, National Educational Computing Conference, summer 1984

'“'Ma rguerite Zientara, "Watch Your Words: Who Owns Information in an Electronic Conference?" Infoworld, Aug. 6,1984, pp. 333-334.
}

righted melody. Protesting the profit-oriented climate of the times, one outraged churchgoer protested saying:

Well, we do understand that the copyright law becomes involved. However, to us simple folk, it would seem that both creator and owners of [the tune] could very easily waive their rights and by doing so enjoy a sense of great honor and deep gratification that their song is now a beloved hymn sung in chorus by many thousands of good people during church services, rather than tothreaten and crush their own beautiful song into near oblivion.

In these times, these fearful, unruly, egotistical and utterly selfish times, this action to stop the singing of a hymn in our churches is surely the ultimate low.

\footnotetext{
")"Harry A. MacLaren, "Letter to the Editor, " Seattle
} Times, J uly 26, 1985, p. A-20.

\section{IMPLICATIONS FOR THE INTELLECTUAL PROPERTY SYSTEM}

To the Founding Fathers, the design of an intellectual property system appeared a relatively simple matter. Building on a long tradition, and on years of European experience, they simply followed the British model, which was equally well suited to meet both countries' needs. This model assumed that, by granting economic rights to the creator of intellectual works, information would be created and disseminated, and thus a number of other social and economic objectives would be achieved. In this model, not only were other societal goals understood to be furthered by fostering the learning environment, these goals were also seen to be mutually compatible and self-enforcing.

In an information age, the situation is more complex. Information is central to all aspects of society. Moreover, the new information technologies provide new opportunities to move ahead in almost all areas of activity. With these opportunities, however, will also come new conflicts. For, given the pivotal role that informa- tion will play in the future, its enhanced value will give rise to a greater number of competing daims on its use.

Given this potential for conflict, a key assumption on which the Founding Fathers established the intellectual property system may no longer be valid in an information age. Instead of equally fostering a number of diverse political, economic, and cultural goals, the granting of economic incentives may, under some circumstances, pit one kind of goal, or one societal purpose, against another. In an environment such as this, it is more essential than ever to remember that in making decisions about the intellectual property system, we are making decisions about the nature of society itself. Therefore, in addressing the question of what are the most appropriate goals for the intellectual property system in an age of information, we must ask ourselves first, given all of the opportunities that the new technologies afford, what kind of a society would we like to live in. 
Chapter 3

The Accommodation of Intellectual Property Law to Technological Change 


\section{Contents}

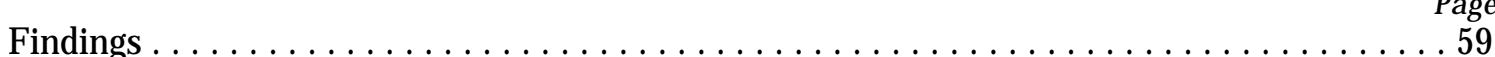

Introduction: The Law's Race With Technology . . . . . . . . . . . . . . . . . . . . . . 59

Part I: Some Basic Intellectual Property Concepts . . . . . . . . . . . . . . . 60

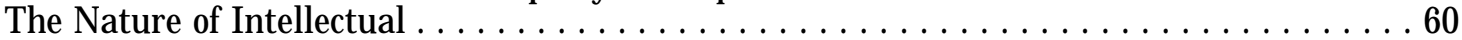

Intellectual Property Boundaries and Policy Objectives . . . . . . . . . . . . . 61

I dea and Expression-The Boundary Between Mine and Yours . . . . . . . . . . . . 62

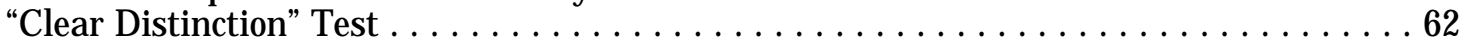

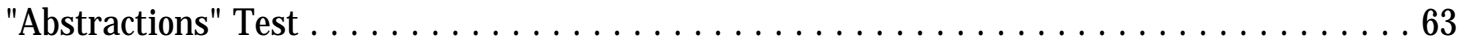

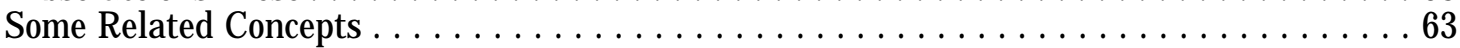

Part II: The Impact of Technology on Three Varieties of Information-

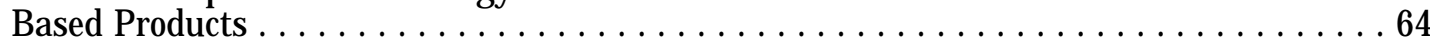

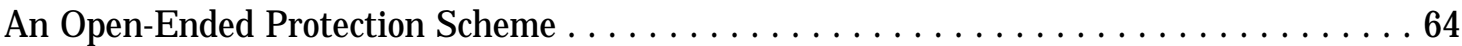

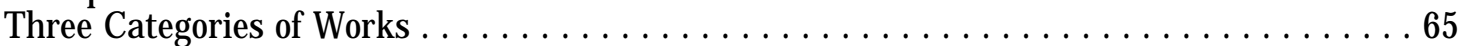

Computer Programs and Trade Secrets . . . . . . . . . . . . . . . . . . . . . . . . . . . 87

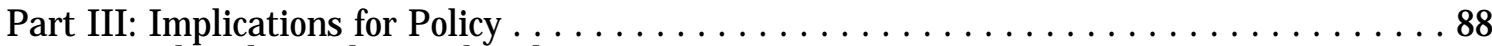

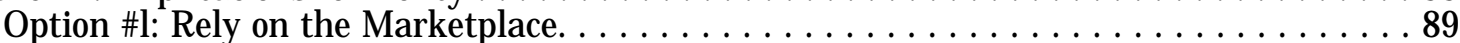

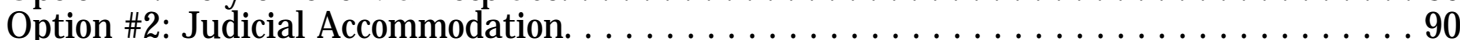

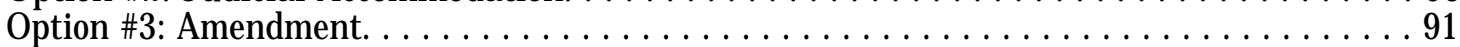

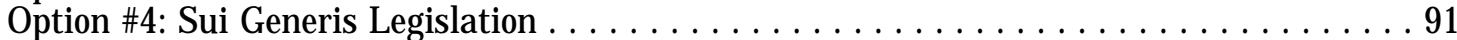

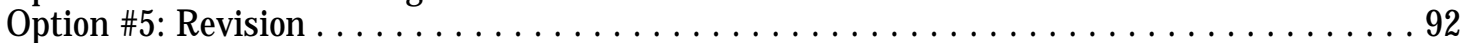

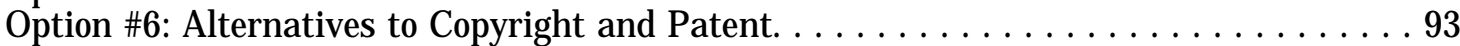

Table

Table No.

3-1. Who Should be Responsible for Solving Intellectual Property Problems?. . . . . . . . 89

Figures

Figure No.

Page

3-1. Property Rights in Information. . . . . . . . . . . . . . . . . . . . . . 64

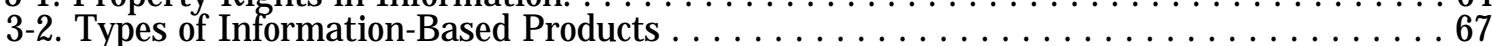

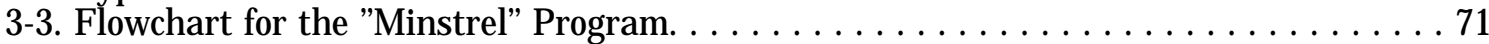

3-4. Computer Programs- "What Is Protected?".. . . . . . . . . . . . . . . . . 82 
Chapter 3

\section{The Accommodation of Intellectual Property Law to Technological Change}

\section{FINDINGS}

- The application of a uniform system of intellectual property principles, such as that embodied in copyright and patent law, to divergent types of information-based products may no longer be possible. Modern technologies are exaggerating dissimilarities between information products that were once protectable under a single system of law, and are, in some cases, giving rise to new products that strain the applicability of old principles of law. Under these new circumstances, information-based products can be grouped into three large categories-works of art, fact, and function, which are subject to different principles of intellectual property protection.

- The assumption of intellectual property law that intellectual property rights-can be determined and remain stable over time is less and less valid. Copyright law, in particular, assumes that the works it protects have a fixed form, and that ownership can be determined by protecting particular expressions of information. Today, however, computer and communication technologies are changing the nature of information-based products in a fundamental way, making them dynamic, interactive, and functional components of processes. The present system of copyright law, which evolved under the model of print publication, may no longer serve to determine the boundaries of ownership in computer-based methods of creation and dissemination.
- Some of these technological impacts may only appear in the long term, when technologies for creating and disseminating information be come more widely used. Many of the technologies, such as computer networks and digital editing, are still in the developmental stage, and the intellectual property issues they raise are only just emerging.

- Some of the effects of technology on the adequacy of intellectual property law, however, have already begun to undermine its usefulness as a policy tool, In particular, neither copyright nor patent law has successfully accommodated works of function, such as computer programs. Copyright law may provide either too much or too little protection for them, and patent law, while available for some novel processes that utilize computer programs, may be unavailable or too cumbersome to protect many types of computer programs.

- Alternatives to Federal intellectual property protection are available, but these too have their drawbacks. State trade secrets law, although widely used for specially designed products, is ineffective in protecting massmarketed products. Moreover, it may entail foregoing uniform Federal and international protections, and, in some cases, it may be preempted by Federal law.

\section{INTRODUCTION: THE LAW'S RACE WITH TECHNOLOGY}

Ten years after the general revision of the United States copyright law, new technologies for creating and disseminating information have raised a new set of questions about the law's ability to accommodate technological change. This uncertainty comes from many 
quarters: the judiciary, the legal community, academia, and the creators whose work the law is designed to protect. Such doubts are not limited to copyright law; they extend to other areas of intellectual property law where information technologies have also left their mark. *

Although most observers agree that technology is changing the way in which intellectual property law operates, many disagree over just how sweeping these technological changes are, and what ought to be done in response to them. Some suggest that the changes are occurring primarily at the margins of intellectual property law, and can be dealt with incrementally by the courts or through specific amendments to the law. ${ }^{2}$ Proponents of this view argue that new technological developments are in many ways like "old wine in new wineskins. Some observers believe that, where problems are specific, they can be dealt with in a specific fashion, without the need to completely rethink or revise intellectual property law. ${ }^{3}$ The Semiconductor Chip Protection Act is an example of a measured, specific congressional response to such a problem.

Others, however, believe that recent technological changes are revolutionary, and have

'See e.g.: Gottschalkv. Benson. 409 U.S. 63,73 (1972): programs are to be patentable, considerable problems

are raised which only commit tees of Congress can manage

" [I]n the main, it seems to me, the Copyright Act is working pretty well. There are some gaps, some parts of it that don't address current needs, but I don't think it is working all that badly right now. "Testimony of David Lange before the Subcommittee on Courts, Civil Liberties, and the Administration of J ustice of the Committee on the J udiciary, House of Representatives, 98th Cong., 1st sess. on Copyright and Technological Change, J uly 20-21, 1983, p. 73.

"'Some specifics of copyright law may change-some may have to change-but the basic principles of copyright ... . will, I think, bear retention. "J on Baumgarten, "Copyright at the Crossroads, "Billboard, Nov. 12, 1983, p. 1. fundamental implications for intellectual property law. Typical of this perspective is a statement in a recent report by The President's Commission on Industrial Competitiveness:

Although the application of our intellectual property rules has been adjusted over time in response to changing commercial practice and evolving technologies, the continuing stream of the new scientific advances calls for rethinking the very concepts derived from earlier centuries on which those rules are based. New concepts of what intellectual property is and how it should be protectedbeyond patents, trademarks, trade secrets, and copyrights-may well be needed, as well as sweeping changes in intellectual property laws and the ways they are administered and enforced. ${ }^{4}$

Advocates of this position argue that the concepts employed in intellectual property law-" authorship, " "invention," "writing"and related notions, are increasingly the obsolete products of a bygone age of print.

Participants in this ongoing debate often confuse the issue of whether intellectual property, as presently conceived, should survive with the issue of whether it can survive. This chapter does not attempt to evaluate the first of these questions, but considers the viability of the present system in the light of vast technological change. The question of viability can be separated into two distinct issues: enforcement, which is dealt within chapter 4 , and the law, which is the subject of this chapter.

'Global Competition: The New Reality, The President's Commission on Industrial Competitiveness, J anuary 1985; Appendix D, "A Special Report on the Protection of Intellectual Property Rights, " p. 305.

\section{PART I: SOME BASIC INTELLECTUAL PROPERTY CONCEPTS}

\section{The Nature of Intellectual Property}

Intellectual property can be distinguished from other forms of property in that it is a bundle of rights attached to the intangible form of an intellectual, scientific, or artistic creation.
While personal property law determines ownership over things, intellectual property law secures ownership in the particular form or expression embodied in things. A comparison of two types of property rights in the same item illustrates this distinction: 


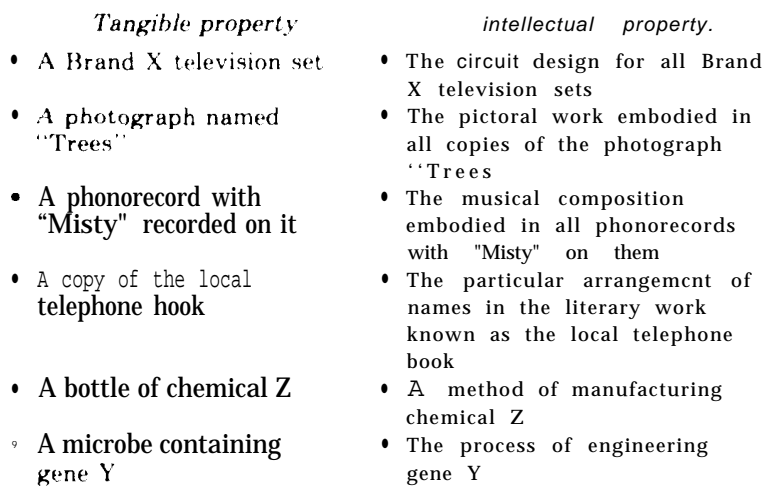

- A method of manufacturing chemical $\mathrm{Z}$

- The process of engineering gene $\mathrm{Y}$

An intellectual property right is the exclusive prerogative to make tangible objects in particular forms. At its simplest, a copyright is the exclusive right to make copies of particular tangible expressions of information, and a patent is the exclusive right to make, use, or sell a particular application of an idea.

\section{Intellectual Property Boundaries and Policy Objectives}

Any property right, whether tangible or intangible, must have boundaries. Property is by definition exclusive; what one owns must be distinguished from what is owned by others. Boundaries of tangible property are relatively easy to establish. A property right in a parcel of real estate, for example, refers to a specific, measurable terrain.

However, because ownership in intellectual property attaches to the intangible characteristics of tangible objects, the boundaries of ownership must be established in terms of those intangible characteristics. For example, to extend a property right to the author of a book on auto mechanics, one must specify which features of the book are subject to the property right: the precise wording of the book; the structure of paragraphs; the style of writing; the organization of topics; the information conveyed to a reader; or the practice of auto mechanics as described by the book. The boundaries of intellectual property are ultimately agreed on by convention, and require that policy makers choose where and why they are established. In theory, copyright in a book on the Civil War could extend to all books on the
Civil War, just as patent rights in a particular thermostat design could extend to all devices that performed similar functions.

In the United States, however, policy makers have set far more limited boundaries for copyrights and patents. As stated in the U.S. Constitution, ownership in writings and inventions is bounded by policies that will "promote the progress of science and useful arts." ${ }^{15}$ Marking off boundaries in intellectual property is essentially a policy choice which has major implications for innovation. Boundaries that are 'marked too broadly may impair the ability of individuals to create, innovate, or improve upon the works of others. Boundaries that are set too narrowly, or that fail to protect the most socially valuable aspects of writings or inventions, may diminish the incentive to create or innovate. To promote science and useful arts, policy makers must strike an optimal balance between what belongs to a creator and what belongs to the public domain.

For patents, the boundaries of ownership in an invention encompass only the novel features of that invention. Patent ownership is established by the "claims' made in the patent application and accepted by the Patent and Trademark Office, and patent law requires that the claimed invention be distinct from previous inventions, which are known as the "prior art.

In contrast, copyright protection attaches to a work at the moment of its creation, and the law requires only that the work be original-that is, not a copy of another author's work. Copyright law does not require that an author claim some aspect of a writing as his own, or that a writing be distinguished from the prior art. Because copyright does not have a threshold determination of ownership, the boundaries of ownership in a work are, of ne-

"Article 1, Section 8, clause 8 of the Constitution, authorizing the Congress to establish intellectual property, law, reads: Congress shall have Power To promote the Progress of Science and useful Art s,bysecuring for limited Timesto a urhors and I nventors the exclusive Right to their respect we Writings and I)isco $\backslash$.cries

The term "Science, as it was usedby the authors of the Constitution, was derived from the Latin "scientia, meaning knowledge, or to know. 
cessity, established by limiting ownership rights to the particular manifestation or expression of information. Copyright does not protect abstract ideas, concepts, systems, and themes.

This assessment is concerned exclusively with the effects of technology on proprietary rights in information-based products and services. Since copyright law has been the traditional system of protecting these works, the boundaries most germane to this chapter are those established by copyright. For this reason, copyright law's method of defining boundaries-the "idea/expression dichotomy" -merits a detailed discussion.

\section{Idea and Expression-The Boundary Between Mine and Yours}

The distinction between idea and expression is one of the most fundamental yet elusive concepts in intellectual property law. Ideas, as such, are neither patentable nor copyrightable. To obtain a patent, the inventor must reduce the principles on which an invention is based to a concrete application. The photoelectric effect is not patentable, although the design for a particular photovoltaic cell may be. Similarly, copyright does not protect "[i]deas, abstract conceptions and similar matters, but rather the "manner of treatment, expresșion, incidents and details... " The distinction" is crucial, since a monopoly on ideas might impair the very goals that intellectual property law seeks to promote. If, for example, the idea of combining music and drama were protected by copyright, Gilbert and Sullivan's plays might well have been the last musicals pro-

\footnotetext{
' Loew's, Inc. v. Columbia Broadcasting System, 131 F. Supp.165(D.C. Cal. 1955); aff'd 239 F.2d 532; aff'd 356 U.S. 43, reh. den. 356 U.S. 934, The idea/expression dichotomy was codified in the 1976 Copyright Act as follows:

In no case does copyright protection for an original work of

au thorship extend to any idea, procedure, process, system, method of opera tion, concept, principle, or discovery, regardless

of the form in which it is described, explained, illustrated. or em-

bodied in such work.

17 [] . S.C. $\$ 102$ (b) (emphasis addedı. None of these terms are defined, and the legislative commentary on the subject says only that section 102(b) "in no way enlarges or contracts the scope of copyright protection. S.Rep. No, 94-473, supra at 54; H.R. Rep. No. 94-1476, supra at 57.
}

duced. Instead, we have available a vast and varied range of musical drama.

Despite its importance, the distinction between an idea and an expression is difficult to draw with certainty. Through the years, courts have developed at least two different theories of what the idea/expression dichotomy means. We will refer to these theories as the "clear distinction" test and the "abstractions" test.

\section{"Clear Distinction" Test}

Copyright scholars generally regard the case of Baker v. Selden ${ }^{7}$ as the wellspring of modern thought on the doctrine of idea and expression. This case concerned an alleged infringement of Selden's Condensed Ledger, or Bookkeeping Simplified, a book that consisted of a series of blank ledger sheets and an introductory essay explaining their use. The unique feature of Selden's ledger was that, "by a peculiar arrangement of columns and headings, [it] presents the entire operation, of a day, a week or a month, on a single page, or on two pages facing each other in an account book. "In his own account book, the defendant in this case accomplished a result very similar to Selden's, using a different arrangement of columns and headings.

The Supreme Court, although agreeing that the plaintiff book might be copyrighted, nevertheless drew "a clear distinction between the book, as such, and the art that it is intended to illustrate." "[N]o one, " said the court, "would contend that the copyright of the treatise would give the exclusive right to the art or manufacture described therein. " A copyright in books on medicine, art, or mathematics gives the author an exclusive right to print and publish those books, but the systems, ideas, or methods described in them "are the common property of the whole world" and any author has the right to express or explain them in his own way. Moreover, since copyright, unlike patent, requires no novelty, the grant of an exclusive right in the art described in a book, "when no examination of its novelty has ever been officially made, would be a surprise and

101 US. 841 (1880). 
a fraud upon the public. . That is the province of letters patent, not of copyright." ${ }^{\prime \prime}$

\section{“Abstractions" Test}

Courts have interpreted "idea and expression in other ways. The "clear distinction' test distinguished copyright from patent protection, but did not define the scope of copyright protection. If copyright protects only the literal expression adopted by an author, it allows others to escape claims of infringement by changing the original in only trivial or insignificant ways. The courts have avoided this result by treating idea and expression as a continuum of similarity. Thus, in Nichols $v$. Universal Pictures Corp.,' J udge Learned Hand articulated what is now known as the "abstractions test":

\footnotetext{
Upon any work . . . a great number of patterns of increasing generality will fit equally well, as more and more of the incident is left out. . . . [T] ]here is a point in this series of abstractions where they are no longer protected, since otherwise the playwright could prevent the use of his "ideas, " to which, apart from their expression, his property is never extended. Nobody has ever been able to fix that boundary, and nobody ever can . . . As respects plays, the controversy chiefly centers upon the characters and sequence of incident, these being the substance.
}

The abstractions test differs subtly from the holding of Baker v. Selden, and points to a confusion in the meaning of idea/expression. The abstractions test relies on general similarities between works that are largely a matter of degree If, for example, it was alleged that My Fair Lady infringed Pygmalion, one would look to the degree of similarity of expression in the two stories-the plot, the characters and their

Id. pp 842-44, The ruling in Baker is more subtle than it appears at first glance. The work in question was of an explanatory, functional sort /see discussion below under works of function), Unlike purely artistic or factual works (see discussion below under works of art and works of fact). the accounting book explained a method or procedure, which thus raised the specter of patent-like protection not present in the case of art or fact. For artistic works in particular, "expression " is not limited to the literal expression of a work. "Ise a plagiarist would escape by immaterial variations. "Nichols v. Universal Pictures Corp., 45 F.2d 119 (2d Cir. 1930).

45 F.2d 119, 12112 d Cir. 1930), cert. denied, 282 U. S. 902 (1931). roles, and the dialog. The principle articulated in Baker v. Selden, however, concerns the kind of protection afforded a writing, drawing a line at the the manner of expression, and extending to neither the underlying concepts or information expressed, nor to the activities or techniques described. These two analysesthe "abstractions' test and the 'clear distinction" test-are often combined into the term "idea/expression, but they are essentially different, Although both limit the boundaries of copyright, each sets that limit in a different way. As we shall see in Part Two of this chapter, neither of these two fundamental copyright principles is particularly applicable to computer processable information.

\section{Some Related Concepts}

A number of closely related, but distinct copyright principles can be derived from the idea/expression dichotomy (see figure 3-I). For example, in order to be copyrighted, a work must be original, which simply means that it cannot have the same expression as another work. The boundaries of a given original expression also include the right to build upon it by creating a derivative work. ${ }^{11} \mathrm{~A}$ given copyright is infringed when there is substantial similarity of expression between the original and another work. The notion of a copyrighted work emphasizes that the boundary of a given expression is intangible, and is distinct from the actual physical object-the copy-in which it is embodied. ${ }^{12}$ The work is the subject of intellectual property ownership; the copy is ordinarily the private property of the purchaser.

However, an identical, but independently created work, is not an infringement, The "originality necessary to support a copyright merely calls for independent creation, not novelty, $1 \mathrm{~N}$ immer on Copyright, Y2,01 [A] (1982). originality\}, is, however. subject to a de minimus standard, and works entirely lacking in creativity or substance cannot be copyrighted. Simple phrases, such as "apply hook to wall, ' for example, may not meet this standard.

'derivative work is defined in section 101 of the act as:

. a work based upon one or more preexist ing works, such as

a translation, musical arrangement, drama tizat 1on. fict 1onaliza-

tion, mot ion picture version, sound recording. art reproduction,

abridgment, condensation. or anyother form in which a work

may be recast, transformed, or adapted.

'Section 202 of the act says that "[ownership of a copy right, or of any of the exclusive rights under a copyright, is distinct from ownership of any material object in which the work is embodied, The material object, or copy, is usually the pri vate property of its purchaser. 17 U.S.C, §109. 
Figure 3-I.-Property Rights in Information

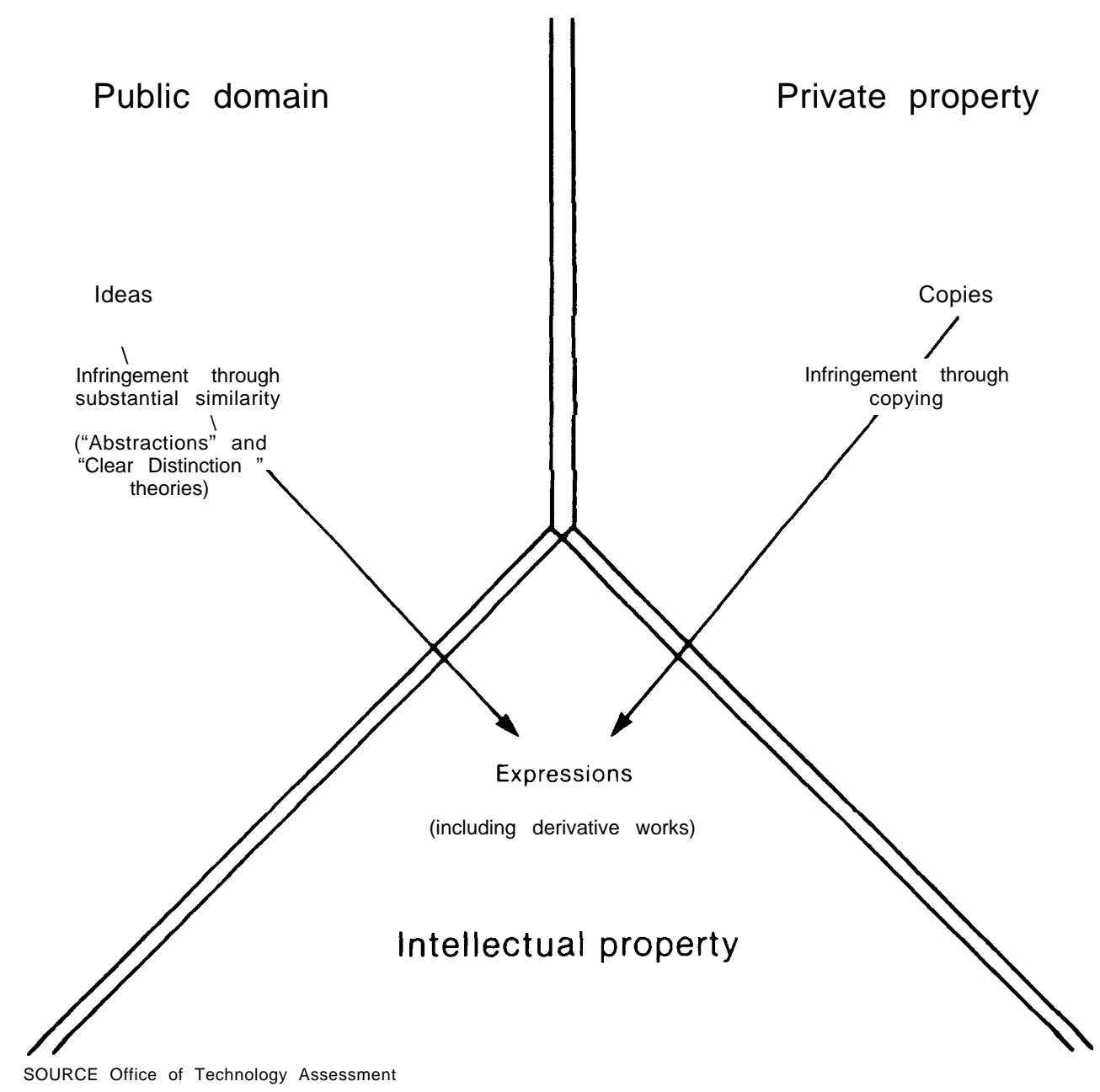

\section{PART II: THE IMPACT OF TECHNOLOGY ON THREE VARIETIES OF INFORMATION-BASED PRODUCTS}

The variety of intellectual and artistic works protected by copyright law in the United States has grown steadily since Congress enacted the first copyright statute in $1790 .{ }^{13}$ As technology introduced new and unprecedented forms of expression into the commercial, artistic, and scholarly worlds, copyright law has taken each into its protective system of rights. Although the forms of expression, media, and economics of creation, distribution, and use varied widely among new types of works, copyright law ab-

${ }^{13} \cdot \overline{C h . ~ 15, ~} \S 1,1$ Stat. 12 sorbed each new type of creation with very little change to its underlying concepts, distinguishing only slightly between the types of works that it protects.

\section{An Open-Ended Protection Scheme}

Copyright protects a vast range of works, many of which bear little similarity to each other. Through the years, copyright has come to protect virtually all artifacts of communication: piggy banks and doctoral theses, tele- 
vision programs and restaurant menus, ash trays and news documentaries, bread wrappers and sound effects recordings, artistic photographs and tablecloth designs, road maps and stock market reports, toilet paper designs and movies, computer programs and greeting cards. Prior to the Copyright Act of 1976, a work had to fall under a category of work defined by statute to be copyrightable. Thus, each time technology created a new form of expression-photography, for example-Congress had to amend the copyright law.

The drafters of the Copyright Act of 1976 sought to avoid the need for constant amendment by making the subject matter of copyright open ended and "technology neutral."14 Instead of listing types of works, the act defines the attributes a work must possess to be protected:

Copyright protection subsists . . . in original works of authorship fixed in any tangible medium of expression, now known or later devel oped, from which they can be perceived, reproduced, or otherwise communicated, either directly or with the aid of a machine or device.

The act, therefore, treats all informationbased products and services the same for purposes of copyrightability. By making the criteria of copyrightability nonspecific and purely formal, the act gives the necessary and sufficient conditions of statutory protection applicable to any conceivable work, regardless of the technologies involved in its creation, distribution, or use.

Since a work can be fixed in any tangible medium "now known or later developed," all works fixed after 1978 are automatically copyrighted, without the earlier requirement that they be published or disseminated; ${ }^{16}$ and, with

\footnotetext{
"'Authors are continually finding new ways of expressing themselves, but it is impossible to foresee the forms that these new expressive methods will take. The bill does not intend eit her to freeze the scope of copyrightable subject matter at the present stage of communication technology or to allow unlimited expansion into areas completely outside the present congressional intent. Section 102 implies neither that that subject matter is unlimited nor that new forms of expression within that general area of subject matter would necessarily be unprotected. H. R. Rep. No. 94-1476.

17 U.S.C. $\S 102(a)$,

' 17 U.S.C. $\S 302(a)$.
}

some exceptions, all works are protected under the same basic bundle of rights. "

Given the broad and pliable language of the act, with its emphasis on technological accommodation, the question is how technology can affect its continuing viability. The answer to this lies in the very broadness of the concept of "works of authorship, " and in the legacy of copyright principles carried forward in the 1976 Act. The 1976 Copyright Act assumes that, by making "works of authorship' a comprehensive category, the copyright system could successfully assimilate unforeseeable technologically based works. However, as illustrated below, because it continues to use concepts fashioned over the previous 200 years, the new copyright law is, like its predecessors, encountering some familiar problems now placed in relief by modern technology.

The central problem of copyright law's continued accommodation to new technologies lies in the indiscriminate application of the doctrine of idea and expression to three fundamentally different categories of works: works of art, works of fact, and works of function. Unless the law recognizes the inherent differences among these types of works, technology may make the boundaries of intellectual property ownership difficult or impossible to establish, and less relevant to the policy goals the law seeks to further.

\section{Three Categories of Works}

Although the copyright law adopts a uniform approach to protected works, not all types of information-based products are the same, nor can they be treated as if they were. A list of stock and bond prices, for example, differs from the musical score of a motion picture, and both of these are distinct from a computer program. In the case of stock prices, the value is in the information itself-the number of shares traded and the daily fluctuation in prices. The value of a musical score, in contrast, lies in the

'-17 U.S.C. §106. All works are subject to reproduction. derivation, and dissemination rights; some are subject to performance eights: others to display rights. 
way it sounds to an audience - the appeal of its melody, rhythm, and harmony. And computer programs are valued for what they dotheir effectiveness at performing a given task in a computer.

This analysis has identified three types of copyrightable works: works of art, works of fact, and works of function. Figure 3-2 shows one way of conceptualizing this trichotomy, and gives examples of the types of informationbased products and services that might fall into each category. Although dividing lines between each categories are not absolutely distinct, major differences between the categories do exist. It is these differences that pose problems for the uniform application of copyright principles to all three categories.

\section{Works of Art and Interactive Technologies}

The phrase works of art, as used in this discussion, denotes works that are created for their own intrinsic value-whether that value is primarily aesthetic, entertaining, or educational in nature. This definition implies no appraisal of qualitative or artistic merit; labels for soup cans and recordings of symphonies are both works of art. Although it is impossible to fix firm boundaries on what constitutes a work of art, this category includes such traditionally copyrightable items as fiction, paintings and other graphic works, sculpture, music, drama, film, and choreography. Other works, such as sculpture used as bases for lamps ${ }^{19}$ or film documentaries ${ }^{20}$ also fall within this category, but contain factual or functional elements as well.

Traditionally, works of art have been amenable to an analysis of idea and expression under the "abstractions test, " since very often the intrinsic value of the work depends heav-

\footnotetext{
'“'Copyright does not concern itself with the qualitative aspects of a work. See: Bleistein v. Donaldson Lithographic Co., 188 U.S. 239 (1903)

${ }^{19}$ As in the case of Mazer v. Stein, 347 U.S. 201 (1954), where a statuette used as the base of a lamp, was found copyrightable insofar as its utilitarian aspects could be separated from its aesthetic aspects.

"Such as the documentary of the Hindenberg disaster in Heding v. Universal City Studios, Inc., 618 F .2d 972 (2nd Cir.), cert. denied, 449 U.S. 841 (1980),
}

ily on the particular expression adopted. The intrinsic value of Duchamp's 'Nude Descending a Staircase, for example, lies in the overall style and manner of execution, the use of lines and solids, and the colors chosen. It is these values that copyright protects when protection is limited to the painting's expression.

Furthermore, works of art have always had a fixity and completeness to them. Although their creation involved preliminary steps such as drafting, sketching, and revision, they did not change in appearance or structure, and re tained a distinct and perpetual identity. Particular works were distinguishable from one another because the expression was complete and final once the work was fixed. Moreover, the fixation of a work in a tangible copy allowed its preservation over time.

It is this static, individuated, and localizable quality of works of art that allows copyright law to speak in terms of the work ${ }^{21} \mathrm{cre}$ ated by an author or authors ${ }^{22}$ belonging to him from the moment of creation, ${ }^{23}$ subject to the laws of the country in which the work was cre ated. ${ }^{24}$ As we have seen in chapter 2 , printing made copyright both possible and necessary, since it permitted the existence of many identical copies of a work and so shifted the primary economic value in writings from the ownership of a particular manuscript to the ownership of a right to make copies of that manuscript, while it simultaneously created markets for unauthorized copies. The very notion of a particular "expression" as the product of a particular author was to a large degree enabled by the invention of the printing press. Evidence for the proprietary boundaries of a work relied on the existence of a single, unchanging artifact-the book, the painting, the sculpture.

This model of the static work of art may no longer apply to works involving certain new technologies. In particular, digital computing and communication technologies pose both

\footnotetext{
17 U.S.C. \$20.

"17 U.S.C. $\$ 20$.

"17 U.S.C. $\$ 30$.

${ }^{24} 17$ U. S. C., ch. 6, infra.
} 
Figure 3-2.- Types of Information-Based Products

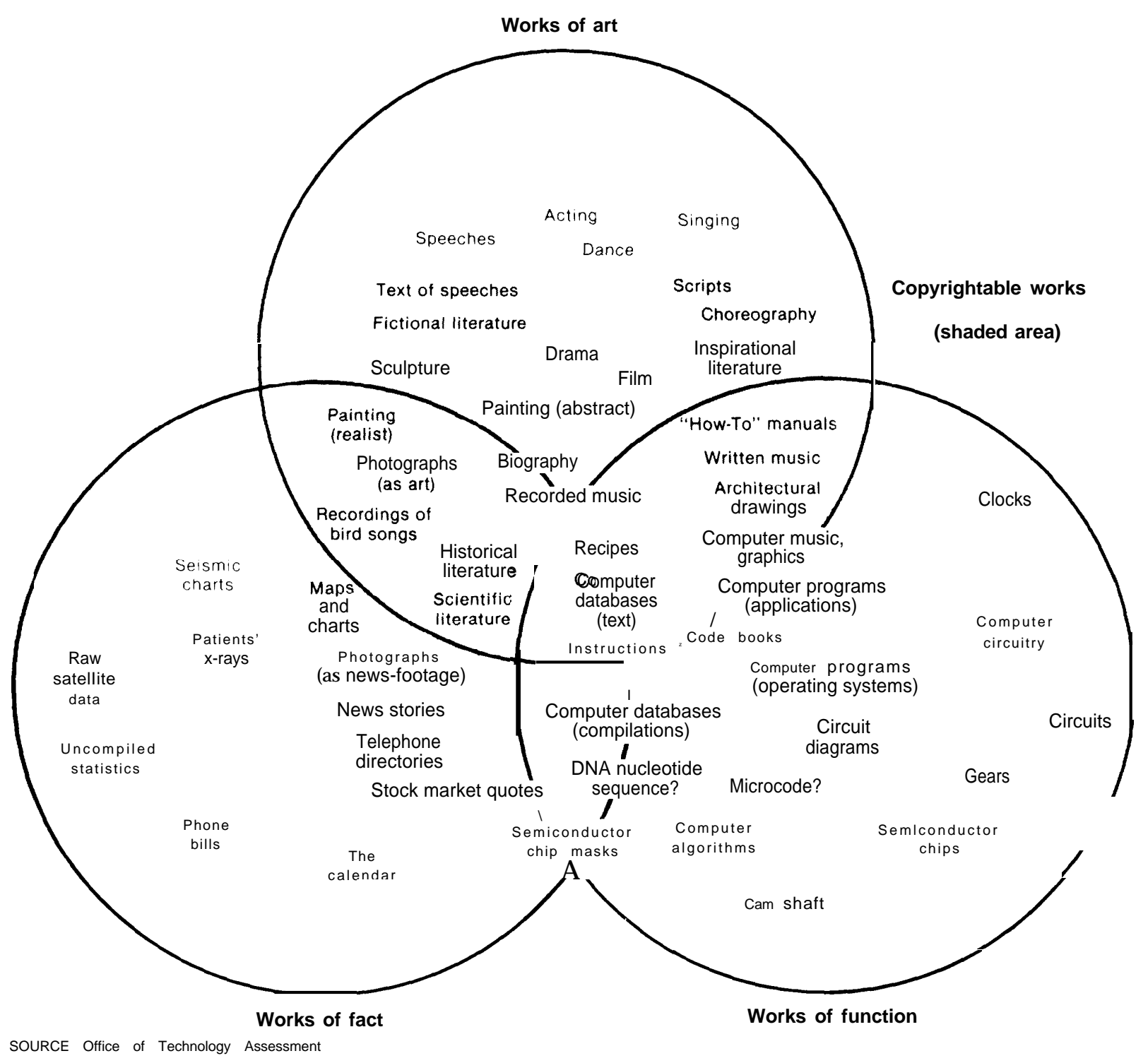

conceptual and legal problems for copyright law in this regard. If print technologies" permitted stasis, electronic technologies permit a new dynamism that makes proprietary boundaries for many works of art indistinct, elusive, and subject to constant change. Although opinions vary widely on the viability and commercial deployment of such things as electronic

"' Print technologies"' is used here in a very broad sense, and would include not only the methods of printing books and magazines, but photographs, records, and motion pictures as well. publishing, on-line conferencing and editing, and interactive computing, these technologies have reasonably clear implications for the principles of ownership:

In short, the process of computer communication produces multitudinous versions of texts, which are partially authored by people and partly automatic. The receivers may be individuals, or they maybe other machines that never print the words in visible form but use the information to produce something else again. So some of the text that is used exists 
electronically but is never apparent; some is flashed briefly on a screen; and some is printed out in hard copy, What starts out as one text varies and changes by degrees to a new one. Totally new concepts will have to be invented to compensate creative work in this environment. The print-based notion of copyright simply will not work. ${ }^{26}$

Some have suggested that, for art and scholarship, the new technology has created an environment more like that of the Middle Ages than of the post-Gutenberg era, resembling the oral tradition rather than the print culture. The ramifications of such a change can be explored by considering two particular embodiments of information technology as they apply to works of art: computer networks and interactive computing.

Computer Networks. The advent of computer networks may mean the loss of the identifiable boundaries of works on which copyright has relied to distinguish yours' from "mine. In this fluid environment, works of art may lose the singular thing-like quality that made copyright protection possible. The extent of the problem is hard to estimate given our limited understanding of the full impact of electronic networks on the creative environment.

A computer network is a collection of computers, called hosts, that communicate with each other. The host computers may be microcomputers, commonly used in homes and businesses, or they may be larger mini-, mainframe, or supercomputers. With connections between hosts ranging from local area networks to satellite-mediated long-haul networks, data in the form of text, voice, and, in principle, video, can be stored, modified, and exchanged by anyone anywhere on the planet. $^{27}$

Computer networks offer a variety of advantages over centralized computing. They permit remote processing, which allows any host in the network to use computer programs stored on another host in the network. Users

\footnotetext{
${ }^{2 n}$ Ithiel de Sola Pool, Technol ogies of F reedom (Cambridge, MA: Belknap Press, 1983), p. 215.

"F or a detailed description of computer networks, see: Andrew S. Tannenbaum, Computer Networks (Englewood Cliffs, NJ : Prentice-Hall, 1981).
}

in such a network can gain remote access to supercomputers to do advanced graphics, chip design (and remote fabrication), or scientific or economic computer simulation. Networks also allow users to access remote databases. Finally, communications, such as computer conferencing, allow collaboration among users of the network. ${ }^{\text {"n }}$

The capacities of computer networks for online creation and worldwide collaboration will demand rethinking several key aspects of copyright law. ${ }^{29}$ First, concepts dealing with the creation of a work will have to take into account several novel features of networks. A network, for example, allows an author to collaborate with others in ways that are different from the past. Collaboration may occur in a very haphazard and informal fashion, and each contributor may be anonymous and his contributions unrecorded. Some may be independent authors, while others may be creating works for hire ${ }^{30}$ Imagine, for example, a network "magazine" in which the readers are also contributors, receiving and perhaps modifying a different version of the text or graphics in the magazine. Under these circumstances, who has a right to claim ownership of a work if it becomes commercially valuable? To which of the multitude of different versions of the work did this person contribute? What share of the contribution was his? What rights does this person possess to insure the integrity of his work?

\footnotetext{
"' "The experience of the ARPANET, which is being reconfirmed in CSNET and other networks, is that collaboration, often envisioned as the least of the three (applications), is in fact the most important. " Peter Denning. "The Science of Computing: Computer Networks, " American Scientist, vol. 73, 1985, pp. 127-129.

${ }^{27}$ Many of the difficulties alluded to here apply with equal force to works of fact and works of function, discussed below. This analysis of the impact of networks and interactive programs on works of art is therefore cumulative. It is confined to works of art for the sake of clarity.

"Some textbooks have al ready been written (although not published) "on-line." See, for example, C. Mead and L. Conway, Introduction to VLSI Systems (Reading, MA: Addison-Wesley, 1980), which was written over the ARPANET.
} 
Although copyright law allows for the possibility of collaborative and anonymous works, ${ }^{31}$ the application of copyright law to on-line creation may become forced and arcane. Questions will arise, in this regard, over what "the' copyrightable work is. If, for example, a picture, a musical composition, or a story is being constantly embellished, and separate versions are being culled from an original and reworked over time, issues of ownership and identification of the work become exceedingly intricate. As with on-line computer databases (described below), the perpetual creation and modification of works of art raises questions about when copyright protection begins and ends. ${ }^{32}$ The deposit and registration of frequently changing works is likewise complicated. ${ }^{33}$

Networks also pose immense practical difficulties for administering the copyright system. Once in a host computer, a work can be easily and quickly transferred to any other host in the network. Even if the work is confined to one "closed network, ${ }^{34}$ it can be entered into other networks by a given host, at which point control over the work is lost. ${ }^{35}$ Copyrighted works, such as photographs, that exist in a closed database library, which is itself part of a network, may be downloaded onto one host in the network and transferred to another network, where they may be excerpted or modified by others with access to the network." If

"17 U.S.C. $\S \S \S 101,201$, and 101, J oint works require that the authors intend that their contributions be merged inseparably into one work, but collective works are separate and independent elements of the whole (like the individual stories which comprise an anthology). In the case of joint works, the intention of the authors may have to be inferred or constructed by a court.

17 (J , S.C. $\$ 10102,302$.

See page 77 of this chapter for a discussion of the application administrative formalities for works of fact,

'Closed networks usually have proprietary access equipment, which permit only those with the right equipment to access the information in the network. LEX IS, the legal database network, and airline reservation systems are examples of closed networks. Solomon, "I ntellectual Property and New Computerbased Media," OTA contract report, Aug. 1, 1984.

(Of course, these activities may be illegal under copyright law, but lacking an "audit trail, " and an awareness of the "leak" on the part of the copyright holder, the possibility of enforcement is practically nonexistent, See ch. 4 on enforcement.

"Questions concerning modification and derivation are perhaps the most perplexing of all. How, for example, can prop- such "sharing" occurred in simple exponential fashion at 15 minute intervals, it would take approximately 8 hours to blanket the entire world's population with copies. "

The problems of administering copyright for on-line works also occur internationally, but with an added twist. Under U.S. law, copyright protection of published works hinges upon the nationality of the author or the location of first publication. ${ }^{38}$ But satellite data transmissions and submarine optical fiber links may muddle the concept of a work's "national origin, " and international collaborative efforts and the simultaneous existence of numerous versions of a work worldwide will preclude its easy identification with a particular nation. Thus, publication and location many no longer be workable criteria when numerous versions of a work are simultaneously appearing throughout the world .39

Interactive Computing. Interactive computing refers to any creative process in which a preliminary or final version of a work is the result of interactions between a person and a programmed machine. The proportion of the work that is the product of the machine, and the proportion that is the product of a human may vary. In many cases, as with word processing programs, the machine contributes little to the creation of a work; it is " transparent' to the writer's creativity. But with some programs, such as those that summarize (abstract) written articles, the processing done by the computer could constitute "an original work of authorship' if it were done by a human being. ${ }^{40}$ Indeed, the machine itself is at once a series of processes, concepts and syn-

erty rights attach to works which are intended to be modifiable components of an interactive process? This question will be dealt with presently under "Interactive Technologies. "

$2^{32}$ is approximately 4.29 billion.

"In general, a work is protected under (J . S. law if: 1 ) one or more of its authors is a national or domiciliary of the United States or any nation which is a member of a copyright treaty to which the United States is a party, or if 2) the work is first published in the United States or in a country which is party to the Universal Copyright Convention. 17 U.S.C. § 104.

"'Publication is the distribution of copies to the public, 17 U.S.C. $\$ 101$; is transmission of digitized information to thousands of host computers a "distribution of copies?'

4. Originality is the sina qua non of copyrightability, but refers only to the fact that a work is not a copy of another. 
theses of human intelligence-so mixed that it is difficult, if not impossible, to separate its parts from the whole." Interactive computing takes many forms, and cuts across many disciplines. Some examples of interactive computing are:

- Interactive fiction is a computer-mediated form of storytelling/writing that permits the user of a program to "co-author" a story by making choices about details of the plot as the story unfolds on the computer.

- Computer-aided design (CAD) is a technology that is widely used in science and engineering. Using CAD systems, engineers may design new products, invent new processes, or even create other software programs that are based on interactions between their own experience and expertise with a CAD system. A program called SYNGEN, for example, suggests potentially useful chemical reactions based on chemical reaction-mechanism theory. Using SYNGEN, some completely new reactions are "invented" that may prove important enough to be further developed in the laboratory. 'z

- Interactive computer graphics permits a creator to use another's images as the "grist" for computer-assisted manipulation in the production of further works. Creators using this technology cannot only generate images of nature that have never existed in reality; they can also take images from existing photographs or films, "map" them into a computer memory, and bring them back to life in totally new settings, with new movement and dialog.

- Computer-processed music permits the processing, editing, and resynthesis of

"Richard Solomon, "Intellectual Property and the New Computer-Based Media, OTA contractor report, Aug. 1, 1985. p. 2.

"James Hendrickson, "Synthesizing Chemicals by Computer, "Technology Review, April 1984, pp. 24-27: see also R.K. Lindsay, et al., Applications of Artificial Intelligence for Organic Chemistry: The DENDRAL Project (New York: McGrawHill, 1980). In this example, similar questions might be raised of patent law: who is the "inventor? "-the programmer, the operator, or the machine'? sometimes costly preexisting works in the production of new works. Music can be sampled and manipulated in a process known as digital editing, and the notes and even the work itself can be rearranged and manipulated to create entirely new works.

The interactive capability of computers poses unique problems for the category of works of art. The problem is in determining where the programmer's expression ends and where the user's contribution to the final form of the expression begins. This problem stems from the fact that computers often mediate between programmer and user, and intermingle the creative efforts of both. Indeed, the program itself may contribute substantially to a creator's final artwork, and in ways that could be considered an autonomous or creative activity if done by a human being. ${ }^{43}$ Because the programmer's, the user's, and even the computer's expressions are intermingled in the process of creation, separating rights in the products of interaction with a program from those in the program itself will become increasingly difficult. Consequently, many interactive computer-based applications may generate entirely new questions of ownership and originality. ${ }^{44}$ Figure $3-3$, which describes a hypothetical interactive program called "MINSTREL," illustrates the difficulties that can arise in sorting out the contributions of the various parties to interactively produced works.

The problems of interactive computing and machine-generated works were considered by the National Commission on New Technological Uses (hereafter CONTU) in its 1976 Re-

"Computer programs may modify themselves based on an interaction with the environment, and then alter the environment itself. Programs now exist, for example, that permit a computer to "learn," in some sense, from its environment. A number of rules for producing a given result are compared with an environment; generalizations are formed as a result of the comparison; and these generalizations are then incorporated into the rules of production. See "Learning" in Proceedings of the National Conference on Artificial Intelligence (Los Altos, CA: American Association for Artificial Intelligence, 1983), and Sleeman \& Brown (cd.), intelligent Tutoring Systems (London: Academic Press, 1982), Part IV "Self-I mproving Teaching Systems."

"There are disputes today, for example, over ownership in the output of programs that automatically route signals through gate-arrays, and in code that is compiled by a proprietary compiler program. Conversation with Richard Stern, Nov. 11, 1985. 
Figure 3-3.-Flowchart for the "Minstrel" Program

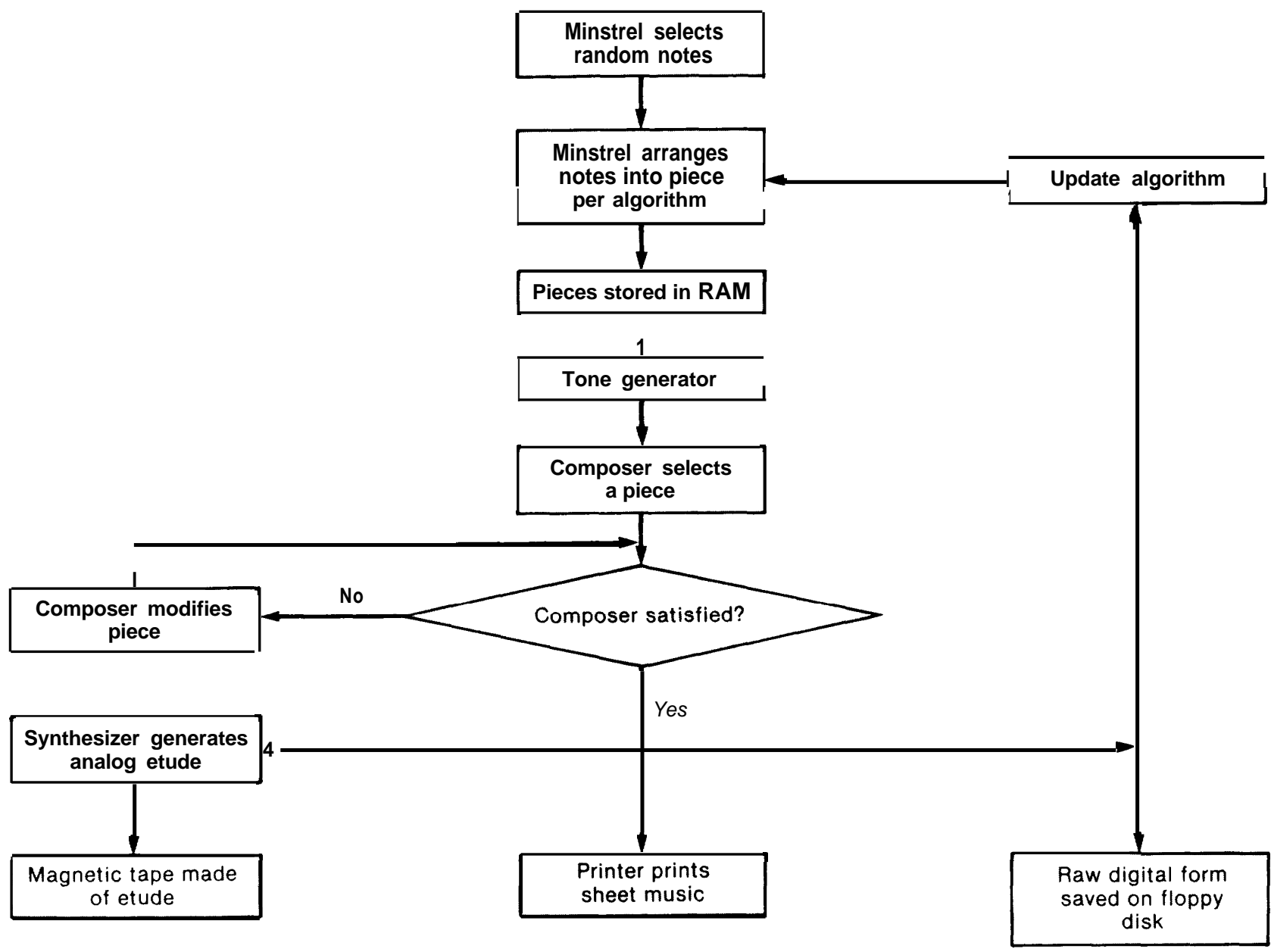

SOURCE Oftice of Technology Assessment.

\section{Interactive Works: The Case of the "Minstrel" Program}

A Composer uses a software program. named "Minstrel" which was written and developed by a Programmer One of the results of this program, Etudes for Unaccompanied Computer, a collection of thematic musical pieces, is the subject of a lawsuit between Programmer and Corn poser

The Programmer had made no license or sale agreements with the Composer for either the use or the purchase of "Minstrel. " $\mathrm{He}$ expected to receive no remuneration fort he Composer's use of the program or for the computer time Indeed. the Programmer had given permission to the Composer to use " Minstrel " and the computer simply "to see what It could do "

The software program "Minstrel" randomly selects "notes" from the standard twelve tone scale These notes are represented as variables in the program on the basis of rules embodied in a music composing algorithm developed by the Programmer, these notes are combined into melodies and chords, and processed into pleasing harmonic, rhythmic, and thematic structures $A$ number of pieces are thus created and stored in Random Access Memory (RAM) The Composer then selects one of the pieces on the basis of his own aesthetic tastes and modifies the selected piece to make improvements These modifications are then incorporated into the original "Minstrel" algo-

port." The commission found that "there is no reasonable basis for considering that a com-

"CONTU was created by the act of Dec. 31, 1974; Public rithm. This process is reiterated so that the program in effect "learns"” from the composer's judgment

Etudes for Unaccompanied Computer was recorded in the following media: 1 ) the final object code (digital) version was downloaded from RAM onto a floppy disk; 2) a final audio (anal'ogue) version was prepared using a commercially available music synthesizer and recorded on magnetic tape; 3) a sheet music version was printed using a special printer designed by the Programmer

When the Composer left the Programmer's laboratory, he took with him the floppy disk, the magnetic tape. and the paper upon which the sheet music to Etudes was printed-all of which were his personal property. The Composer licensed the audio recording to the Record Company, and the sheet music to a Publishing House. This raises some questions:

1 , Who is the author of the "Minstrel" Program after it has been modified by Composer?

2. Who is the author of "<Etudes?" The Composer? The Programmer? The "Minstrel" program?

3. Does the Composer's use of "Minstrel" infringe the Programmer's right to make derivative works from "Minstrel?"

4 Is "Etudes" a work derivative of "Minstrel?"

- - - . -

Law No. 93-53, tit. II ; 88 Stat. 1973. See, generally, The Final Report of the National Commission on New Technological Uses of Copyrighted Works (Washington, DC: Library of Congress, 1979), The Final Report was issued J uly 31, 1978. 
puter in any way contributes authorship to a work produced through its use. The commission said:

The computer, like a camera or a typewrit$e r$, is an inert instrument, capable of functioning only when activated either directly or indirectly by a human. When so activated it is capable of doing only what it is directed to do in a way that it is directed to perform .... The obvious answer is that the author is one who employs the computer. ${ }^{46}$

It is misleading, however, to think of programs as inert tools of creation, in the sense that cameras, typewriters, or any other tools of creation are inert. Moreover, CONTU's comparison of a computer to other instruments of creation begs the question of whether interactive computing employs the computer as cocreator, rather than as an instrument of creation. It is still an open question whether the programmed computer is unlike other tools of creation. Authorities in the field of artificial intelligence $(\mathrm{Al})$, although disagreeing on $\mathrm{Al}$ nature and purpose, do agree that its aim is to produce a pattern of output that would be considered intelligent if it were displayed by a human being. ${ }^{47}$ One must ask, therefore, whether machines or interactions with machines might produce a pattern of output that would be considered creative or original if done by a human being. If machines are in any sense co-creators, the rights of programmers and users of programs may not be easily determined within the present copyright system.

If the questions raised by interactive computing are not settled in the legislature, the judicial system will be called on to resolve them. Thus far, there have been few court decisions on the matter of interactive computer programs, and those that exist have been resolved on extremely narrow grounds. Most of the relevant cases have concerned video games, which employ computer programs (usually recorded in Read Only Memory, or ROM) to generate video images and sounds that respond in a limited way to the game player. The case

"CONTU Final Report, p. 44.

${ }^{4} \mathrm{H}$ oward Gardner, The Mind New Science-A History of the Cognitive Revolution (New York: Basic Books, 1985), ch. 6 . Depending on whom one talks to, Al may have in part already achieved its objectives. law has, for the most part, been built on litigation involving traditional audiovisual works. ${ }^{48}$ In the only case dealing with interactivity, the defendant asserted that, because the player interacted with the game, he was a coauthor of the video work. ${ }^{49}$ The court rejected this argument, saying that a substantial proportion of the work was repetitive and not subject to player control. However, as computer programs increasingly permit the user wider choice in structuring input and output, the analogies between interactive computer programs and traditional works will begin to break down. Courts will then be left with little guidance, and even less expertise, to solve these highly complex conceptual and technological issues. But the decisions they render will, in effect, be policy decisions affecting many aspects of the creative environment.

The courts may not have to react immediately to the difficulties of interactive computing. Creation through interactive computing is new, and is still the domain of pioneering artists with access to the necessary computing power and memory .50 However, as interactive techniques become cheaper and more widely available, either the legislature or the courts will have to confront some questions that will be very difficult to resolve under the present system. These include:

- Does copyright in a program (for example, an interactive graphics program) entitle the copyright owner to the output of these programs? If so, under what circumstances? If that output was unforeseen by the programmer? When the user inputs the data? When the work is "predominately" the result of the machine program, presuming that authorship in outputs might be measured?

\footnotetext{
"See,e.g. Midway Manufacturing Co. v. Arctic International, Inc., CCH Copyright Law Reporter $\uparrow 25,526$ (7th Cir 1983); Stern Electronics, Inc. v. Kaufman, 669 F.2d 852 (2d Cir. 1982); Midway Manufacturing Co. v. Omni Video Games, Inc. 668 F .2d 70 (1 st Cir. 1981). Courts have held video game programs embedded in ROM copyrightable, and video game manufacturers have often copyrighted the audiovisual portion of the game separately. Atari, Inc. v. North American Philips Consumer Electronics Corp., 672 F.2d 607 (7th Cir. 1982).

${ }^{44}$ Williams Electronics, Inc. v. Arctic International, Inc., 685 F.2d 870 \{3rd Cir. 1982).

"''See ch. 5 for a discussion of the impact of interactive computing on the works of artists.
} 
- Ought protection of the program to extend to its output? Where, for public policy purposes, ought expression in a program leave off? What are the appropriate boundaries necessary to insure that both programs and their creative interactions are given incentive?

- How are legal distinctions to be applied to this new-creative environment? Does expression include all of the ways in which a program may literally express itself? Does the user's interaction result in the production of a derivative work, and to whom does the derivative work belong? ${ }^{51}$ What of originality in works that are predominately automated? Who is the author?

Providing answers to these questions will become more urgent as creative activities continue to fuse with machine intelligence. One effect of computer-mediated works of art on copyright may be the blurring of the distinction between the copyrighted work and its product. It may no longer be possible to ascertain the ownership of a particular expression. Both the creators and users of a program may have some claim to its output. Similarly, the line between the creator and the user of a work of art may be less clear, and distinctions may have to be made between the creation, use, and appropriation of an expression.

\section{Works of Fact and Computer Databases}

The category works of fact, as used here, encompasses any work whose value lies in the accurate representation of reality. As with works of art, works of fact is an amorphous category, and may include biographies and dramatized or fictionalized accounts of events, which are also works of art. Maps, nautical charts, news programs, documentaries, and scientific and scholarly literature are examples of works of fact. Compilations, such as telephone directories, stock market quotations, statistical tables, and bibliographies, may also fall into this category.

\footnotetext{
"A derivative work is a work "based upon one or more preexisting works. " 17 U.S.C. $\$ \$ 102,106$
}

Works of fact have long been copyrightable, but copyright protection in works of fact is limited to the way in which facts are expressed. It does not extend to the underlying information or facts expressed. In a map, for example, protection is limited to the details, colors, and symbols chosen by the author, and does not extend to the terrain that is represented by the map. In a statistical table, copyright protects the arrangement and labeling of columns and variables, but not the numbers or statistical values represented. In a news story, copyright protects the wording and the way in which the information is expressed and presented, but does not protect the information about events that are the subject of the news story.

Works of fact have always caused problems for copyright law because, unlike works of art, their economic value is often in the underlying information, rather than in the manner in which that information is expressed. Copyright, therefore, does not necessarily protect the value of a work of fact. This discrepancy will likely be exaggerated by information technologies, because computers can easily manipulate the expression of a work of fact, and communication systems can quickly transfer the work.

The problems with copyright protection for works of fact stem from two otherwise complementary concerns of copyright: the provision of incentives to stimulate the production and dissemination of original works, and the policy goal of sharing information and ideas and making them widely available.

Works of fact often take much time and effort to produce, and some economic incentive is necessary to encourage their production. Tabulating price data, covering news stories, and drafting maps, for example, require independent research and investigation. If an author knows that a competitor may reproduce his work with impunity at little or no cost, he may have less incentive to create the work in the first place. Recognizing that the ostensibly copyrightable component of such works of fact-the wording, selection, arrangement, and presentation of information-is of little bene- 
fit to a proprietor whose competitors can easily change the appearance of facts and information, some courts have sought to expand copyright protection well beyond the particular form that the work takes:

... the test is whether the one charged with infringement has made an independent production, or made a substantial and unfair use of the complainant's work. ${ }^{52}$

Despite the judiciary's tendency to expand copyright protection in works of fact to "unfair" appropriation by competitors, copyright in these works is still severely limited: the information or data within the work is not copyrightable. ${ }^{53}$ Given the imperative that copyright should "promote broad public availability" ${ }^{154}$ of the ideas and information latent in any expression, the protection of information is anathema to copyright philosophy. Early in this century, the Supreme Court recognized the inadequacies of copyright protection for works of fact, and sought to get around them by constructing a "quasi-property right" in news stories to address an underlying wrongdoing. $^{55}$

“Toskvig v. Bruce Pub. Co., 181 F.2d 664 (7th Cir. 1950) a case that concerned a compilation, which is a work formed by the collection and assembling of preexisting materials, or data that is selected, coordinated, or arranged in an original way, 17 U.S.C. $\S 101$, and are particularly vulnerable to this problem. See also: Leon v. Pacific Telephone \& Telegraph Co., 91 F.2d 484 (9th Cir. 1937), Triangle Publications v. New England Newspaper Publishing Co., 46 F, Supp. 198 (I). Mass. 1942), and Quinto v. Legal Times of Washington, Inc., 506 F.Supp 554 (D. D.C. 198 1). As one court has said, if "protection (for compilations) is limited solely to the form of expression, the economic incentives underlying the copyright law are largely swept away. National Business Lists, Inc. v. Dun \& Bradstreet, Inc., 552 F. Supp. 99 (N. D, 111. 1982). Parenthesis added.

"This statement is truer of compilations of data, such as airline schedules or telephone numbers, but also extends to compilations in which the compiled material is itself copyrightable, as in the case of NEXIS, a computerized database of news stories. In the latter, both the format of the compilation and the compiled material is protectable by copyright. However, in no case does copyright extend to the information conveyed by either the compilation or the material compiled.

"Fox Film Corp. v. Doyal, 286 U.S. 123 (1967).

"I nternational New Service v. The Associated Press, 248 U.S. 215 (1918), in which the Court said that "the news element- the information respecting current events contained in the literary production-is not the creation of the writer, but is a report of matters that ordinarily are publici juris; it is the history of the day. "Id. at 234. This case was based on the Copyright Act of 1909, and was implicitly overruled by the Copyright Act of 1976. The difficulties that the court faced, how-
There is a tension, therefore, in copyright protection for works of fact. The tension is between incentives and the public access to information," and this tension is likely to be heightened by modern information and communication technology. A good example is computer database technology.

Computer Database Technology.-A computer database is a compilation of stored computer-readable information. A database vendor frequently sells both the data and the means of accessing, searching, and assembling that data through use of a computer program. Computerized database technology has a number of characteristics that set it apart from traditional methods of compiling information. These characteristics have to do with the way that information is stored, input, searched, and distributed:

- Storage: The storage medium may take many forms: punch card, magnetic tape, hard or floppy disk, microelectronic components within the computer, and the laser-read optical disk. Electronic storage media greatly concentrate the amount of information that can be stored in one location. One 5-inch optical disk, for example, is capable of storing over 10,000 pages of printed information. ${ }^{57}$ The information may be stored in any fashion: serially, chronologically, or as a hierarchy of information types. The type of information stored may be print, audio, or still or motion audiovideo. Anything that can be represented digitally can be stored and ac-

ever, remain. A recent Supreme Court decision, Harper \& Row v. Nation Enterprises, No. 83-1632, May 20, 1985, also dealt with the appropriation of a work of fact, but since the defendant copied some of the plaintiff's work verbatim, the court did not have to reach the issue of idea and expression.

"'The tension is most acute in the case of factual compilations which document information compiled by the government, or information that is already in the public domain, since proprietary rights in the information would have the public pay twice for the same data. see, e.g., Dow J ones \& Co., Inc. v. Board of Trade, 546 F. Supp. 113 (S. D. N. Y 1982).

' The optical disk, which is presently in use in some computer systems and in home stereo systems, is also capable of storing, in digital form, roughly two hours of music or audiovisual material, or thousands of ställ pictures, The Library of Congress' current project utilizes all of these capabilities. At present, commercially available optical disks are strictly for playback, but “write/erase' versions will be available shortly. 
cessed by computer. ${ }^{58}$ The types of works stored on present-day databases include full text literary and legal works, bibliographic information, scientific, financial, legal, criminal, demographic, and defense information. However, since a computer is indifferent to the nature of the information stored, computer programs are also accessible as "data' on a database. ${ }^{59}$

- Input: Information may be input into a database in a number of ways: it may be typed in by a person at a computer terminal; it may be fed in automatically from a sensing device, such as a heat sensor or a pressure gauge; it may be read in from a typed or written document by an optical character reader; systems are coming into use that accept input from the human voice.

- Search: Information is accessed in a database by the use of a computer program, through which users can instruct the computer to search for keywords or categories (fields) of information such as article titles or authors' names. Artificial-intelligence-based programs are becoming available that allow searches in natural languages, such as English, based on the syntax or semantics of a query. Telecommunications links allow users to search for information stored in computers in many different locations throughout the world.

- Distribution: Once accessed, the information is typically fed to a user's terminal and may be copied on a local storage device, such as a magnetic disk. This information may be processed in the user's computer such that it may no longer resemble the "original' information. And

Information theory implies that anything seen, heard, smelled, or felt can be represented, encoded, and replicated by a series of $\mathrm{Os}$ and $1 \mathrm{~s}$, although putting theory into practice has required over 40 years and billions of dollars. Solomon, op. cit.. p. 14. Even smells maybe represented digitally. "Robot Noses, " Business Week, May 13.1985, p. 57.

'Indeed, the de finition of "database' can get quite confusing. For example, a current trend in the design of computer chip manufacturing for very large scale integration (VLSSI) is through the use of a 'design' database that, when guided by various algorithms, can integrate database components in the design of a chip. Thus, to say that databases store information is to simplify the dynamic uses to which this information may automatically be applied. it may, in turn, be searched by, distributed to, and processed in other computers.

These unique characteristics of computer database technology may severely curtail the usefulness of copyright protection for works of fact that are distributed on-line, since copyright protection extends to only the work's expression. This expression may be easily and systematically changed by a person with access to the database and the ability to 'download' and copy information from it with all evidence of copying erased."' Once the information is modified, the user may no longer be liable for infringement, since the information, as such, is not protected. The downloading and the subsequent rearrangement of the information may be entirely legal, especially if the downloading onto disk is permitted under contract. Since information that is rearranged and copied by hand may be legally appropriated, ${ }^{61}$ the same rearrangement might easily be done by the computer in real time as it is being received. ${ }^{62}$

Even if copying onto disk were illegal and did infringe the owner's reproduction, publication, or display rights, the copyright owner could not possibly monitor and enforce all such uses. ${ }^{63}$ Given the relatively low cost of down-

\footnotetext{
${ }^{60} \mathrm{~A}$ computer must, in some fashion, download the information in order to use it. The downloading may not be into permanent disk storage, but memories within the computer all possess some degree of permanence. Indeed, the information must be stored in some way in order for a user to access it. Information that is accessible for only transient durations is very often of little use, since the information must in some way be surveyed, compared, and selected. At least one industry representative cautions that: "(copyright is) a rock-bottom starting point. .. If nothing else, the copyright enables the negotiation of contracts providing for anticipated, and remunerated downloading. " Letter from David Peyton to OTA, Information Industry Association, Aug. 8, 1985. Copyright, in this view, may be necessary, but not sufficient for the protection of databases.

"The status of hand copying under copyright law is uncertain. See Chapter 7: New Technologies and the Intellectual Property Bargain. For works of fact, such as demographic tables or phone listings, the rearrangement of the information is not an infringement-otherwise, copyright would step beyond expression and protect information.

'It might be argued that, in order to transform the information, the computer must first copy into RAM before proceeding with the transformation. This is a strained application of law, since the copy in RAM may be too ephemeral to constitute a' 'fixation, or it may be an "essential step' under section 117 to an otherwise legal procedure.

' 'See ch. 4 on enforcement.
} 
loading, and the continuing expansion of computer storage capabilities, a user might easily compete with his provider, and secure copyright in his "new"' database. Although many database services prohibit such activities by contract, these contracts, as a practical matter, may be unenforceable. The copyright holder may find it extremely cumbersome, if not impossible, to detect and prove infringement, unless the contract itself provides for monitoring.

Beyond these questions about the scope of copyright in works of fact, computer databases also raise a number of separate, but related policy questions. The first is whether databases generated by computers, such as Landsat Earth resources data, can and should receive copyright protection. A second is whether copyright should extend to all contributors to a database. Finally, there is the question of how to best administer copyright in works on a computer database.

The question of computer authorship has to do with a legal requirement that the item to be copyrighted be an 'original work of authorship. "164 Although "originality' requires only that the work not be a copy of another work, questions still exist over whether information that is automatically written or compiled by a computer is a "work of authorship' within the meaning of the law." As discussed at the beginning of this section, in the absence of the creative activity normally associated with writing a novel or composing a song, copyright in works of fact often serves to protect the labor or diligence of a researcher or compiler of facts. However, machines are increasingly replacing human labor involving the recognition, organization, and compilation of facts and information. Electronic compilers and assemblers, for example, have taken over the process of compiling computer code from high-level languages to machinereadable form. Work is also

\footnotetext{
${ }^{64} 17$ U.S.C. $§ 102(a)$.

"'"F or example, oil production, electricity usage, or credit information may be automatically measured and compiled as transactions occur. Even in cases of full text databases, the element of authorship may consist of little more than entering information at a keyboard, or using an optical character reader to scan the material and enter it into the computer.
}

under way on natural language processing systems, which may enable computer systems to "understand' documents within a database, and then produce written abstracts of the document in response to queries from a database user. Similar research is being conducted on machine-generated translations of documents from one language to another." When the element of human labor involved in the processing of information is replaced by automation, the incentive of copyright protection may become entirely disconnected from the authorship that it seeks to inspire. Information that is automatically generated by a computer is "authored, if at all, by a program that is indifferent to legal incentives."

If copyright is to be granted to machineproduced works, it would signal a new role for copyright, and a departure from its traditional role as an incentive for authors. This raises the issue of whether copyright, in addition to providing incentives for authorship, skill, or diligence, should also serve as a method of protecting a return on capital investment in an information-conversion business. In the information age, copyright may increasingly be called upon to serve as an economic regulatory device that establishes proprietary rights in the products of automated processes. Accompanying such sweeping policy changes would be changes in the law. Congress would have to consider whether computer input, processing, and output are legally sufficient to constitute an original work of authorship.

Works of fact stored in computer databases also pose the question of who should receive copyright protection for the individual contributions to the database. Many databases consist of thousands of short records or entries on a particular subject, which are typically produced by many contributors. Very often, none of these contributors can copyright their

\footnotetext{
"U.S. Congress, Office of Technology Assessment, Information Technology $R \& D$ : Critical Trends and Issues, OTA-CIT268 (Washington, DC: U.S. Government Printing Office, February 1985).

"The issue of whether the author of a program can claim copyright in the output of the program is discussed in the previous section on works of art.
} 
contributions, because the individual contributions are often "de minimus" -that is, so lacking in quantity or originality as to make them uncopyrightable, or containing expression that admits of so little variation as to merge with the idea. An individual bibliographic citation, for example, typically contains the name of an author, the name of a book or article, the time and place of publication, and other facts. This citation is probably not copyrightable, since the author of the citation contributed insufficient original expression to constitute authorship or originality. The database itself, however, is a copyrightable compilation or collective work, ${ }^{68}$ and the proprietor or the database owner would own the copyright. Yet, the database owner might not be the one who exercised the skill, industry, and diligence that copyright in works of fact is meant to protect. Instead, countless field agents or government employees perform the labor of researching and assembling the information, and they do not receive copyright. As with machine-produced works, the incentive of copyright in databases is disconnected from the authorship it seeks to promote." Copyright in many computer databases may increasingly play a role as security for investments, rather than simply providing an incentive for authorship.

Finally, there is a question of how copyright in computer databases that are continuously modified should be administered. Copyright law requires that the copyright owner comply with a number of administrative formalities. In general, the copyright owner must deposit two copies of any published work bearing notice of copyright protection in the Copyright Office within 3 months of publication. ${ }^{70}$ The

\footnotetext{
"17 U.S.C.\$\$ 103, 101.

"This issue was central to a controversy surrounding the or-dine Computer Library Center's (OCLC's) bi bliographic database. The contributors to the OCLC database are member libraries, some of whom objected to what they saw as an undeserved windfall for the OCLC database proprietor. In a letter from one of the member libraries to the Copyright Office, a question was asked "whether it is legally or morally legitimate to copyright a database comprising records where both the intellectual content, the physical record creation, and the input of a great bulk of the records are funded with taxpayer's dollars. Copyright Notices, vol. 32, May 1984.

17 U.S.C. $\$ 407$. Failure to deposit these copies may result in a fine of the copyright owner. The Register of Copyrights may exempt categories of materials from deposit requirements,
}

copyright deposit is required in order to acquire copies "for the use and disposition of the Library of Congress. ${ }^{171}$ Indeed, much of the Library of Congress' collection is a product of many years of copyright deposits.

Databases, like any other work, may be deposited for the Library's use and disposition. "Many databases, however, are "dynamic"they-are constantly updated, expanded, and modified, so that the "work' is never in a fixed or final form. Dynamic databases, therefore, raise a question of whether and how copies are to be deposited with the Copyright Office, and whether the objectives of the deposit requirements can be met.

To get around the difficulties of depositing dynamic databases, industry representatives from the American Association of Publishers and the Information Industry Association have proposed "group registration" and the deposit of "identifying materials' of dynamic databases, which would represent portions or samples of the copyrighted database. ${ }^{72} \mathrm{Al}$ though the industry proposal may prove workable for administrative purposes, questions remain over whether the objectives of the deposit requirement will be met. If, in the future, more and more information is stored in computer databases, and is subject to perpetual modification, policy makers may need to reexamine the rationale for deposit in light of the needs of the Library of Congress and the burdens on copyright owners.

or modify deposit requirements. Only the first and last 25 pages of 'identifying material' of computer programs, for example, need be deposited. 37 CFR $\$ 202.20$

17 U.S.C. $\$ 407$. Notes of the Committee on the Judiciary. H.R. N o. 94-1476. The fundamental criteria governing exceptions to the deposit requirements are the needs and wants of the Library, balanced against the hardship of deposit on the copyright owner.

50 Federal Register, 24240 (J une 10, 1985I. While such a solution is perhaps plausible for databases which rely on a more or less constant and overarching "selection and arrangement' of information (see discussion below), it is less plausible for works of art. The protectable expression in many works of fact is often the format or arrangement of data-the formal "receptacle" into which new content can be added. In works of art, however, the protectable expression is the content itself-the way the picture looks or the way that the story reads. When the protectable expression is itself in flux and exists in many different versions in many different places, it may not do to register the creation in the categorical way envisioned the proposals of the AAP and the $11 \mathrm{~A}$, 


\section{Works of Function and Computer Programs}

The category "works of function, " as used in this discussion, denotes those works that use information to describe or implement a process, procedure or algorithm. ${ }^{73}$ They may be physical objects which embody procedural information, such as cams or cogs in a machine, thermostatic controls, or punch cards for a loom. In general, physically embodied works of function implement a procedure, process, or algorithm directly by being incorporated into the intrinsic design of the mechanism. ${ }^{74} \mathrm{How}$ ever, not all works of function are physical embodiments of information. They maybe written works, such as recipes or instruction manuals, which merely describe a procedure or algorithm that must be implemented by a human being.

Modern technology has created a new class of functional works. They are hybrids of those works of function that physically implement processes and those that describe processes. Computer programs are hybrid functional works insofar as they employ words and symbols to implement and control a process. Although understandable by humans, computer programs also initiate and control processes or procedures by operating electronic switches in a computer. These switches may, in turn, control other machines or devices. ${ }^{75}$

Important differences exist between works of function and works of art and fact. Unlike works of art, works of function are seldom valued for their intrinsic or aesthetic qualities.

\footnotetext{
${ }^{73}$ The Dictionary of New Information Technology (New York: Vintage Books, 1982) defines an algorithm as "a procedure, or rule, for the solution of a problem in a finite number of steps.

"For example, a cam in a machine is a physical embodiment of the logical operation: "if there is a 3600 turn, push rod X. It implements this procedure directly when the camshaft is turned 360 . Similarly, a thermostat physically embodies the logical operation "if the temperature rises above $70^{\circ}$, turn off switch Z." [n each case, the design of the object embodies information to a surrounding physical system.

${ }^{75}$ Recombinant DNA may also be thought of as a hybrid functional work; encoded genetic information can be used to control the production of proteins in a living, physical organism. This section focuses principally on computer programs as functional works, and considers recombinant DNA only briefly, and by way of contrast with computer software. One reason for this is that, while both are arguably works of function, they raise separate social, economic, and ethical issues which are be yond the scope of this report.
}

A recipe, for example, is useless without the necessary ingredients and utensils. Similarly, a step-by-step instruction manual for a nonexistent machine, or a computer program without a computer has no value. Works of function also differ from works of fact. The value of a work of fact lies in its accurate representation of reality-maps and news stories, for example, are reports about what is. Works of function, in contrast, are descriptions of what can be if a given procedure is followed.

Although copyright protection is available for works of function, it is subject to a very important limitation: Copyright does not protect the functional aspect of functional works. ${ }^{76}$ Copyright in a recipe, for example, does not grant the copyright holder rights in the procedure described in the recipe. Others are free to bake the cake, and infringe no copyright in doing so. The functional aspects of a recipe are separated from its descriptive aspects, which al one are protectable.

For computer programs, the difficulty is protecting their descriptive aspect-the symbols used in the program-without at the same time protecting their functional aspect-what the symbols do in a computer. Because programs possess both a symbolic and functional nature, copyright may either protect too little if the copyrightable expression is limited to the literal program code, or too much if the copyrightable expression extends beyond the program code.

Computer Programs. ${ }^{77}$ On the basis of the recommendations of the CONTU Commission, and without legislative debate, Congress determined that computer programs could be copyrighted as "literary works" under Section

\footnotetext{
"This is the law under Baker v. Seldon, which was discussed above.

"The words "program" and "software" are often used interchangeably, but software has, in recent years, broadened to include the supporting materials which accompany the sale of computer programs, and even the the content of technologically based communications (e.g., prerecorded videocassettes are often referred to as software). This chapter adopts the terminology of the Copyright Act, and speaks in terms of computer programs, which are sets of "statements or instructions to be used directly or indirectly in a computer in order to bring about a certain result. " 17 U.S.C. § 101.
} 
102 of the 1976 Copyright Act. ${ }^{78}$ Although the issue of whether computer programs could or should be either copyrighted or patented was the subject of considerable legal controversy, it is now dormant.

In the nearly 10 years since CONTU's recommendations, the types of litigation over computer software have evolved through what one lawyer has called two generations. ${ }^{179}$ The first generation concerned the issue of whether computer soft ware is or should be protectable by copyright. Except for certain details, the courts have resolved these questions in favor of copyright protection for programs.

The second generation of computer program litigation, still in progress, concerns what kind and how much protection will be afforded. The questions emerging during this generation point to strains within the conceptual fabric of copyright, which have existed ever since its inception. This chapter will focus on the issues likely to arise in this second generation litigation.

The 1980 amendment to Section 101 of the Copyright Act defines a computer program as "a set of statements or instructions to be used directly or indirectly in a computer in order to bring about a certain result."180 The courts have interpreted this definition in a very comprehensive fashion:

Any Medium: The set of statements or instructions can be embedded in any medium, from paper to magnetic tape to disks to ReadOnly Memory (ROM) silicon chips. ${ }^{81}$

"1980 Computer Software Copyright Act; Dec. 12, 1980; Public I,aw No, 96-517, \$10; 94 Stat. 3028. The amendment affected only $\$ 101$ and 117 of the code, which, respectively, concerned the definition of "computer program and "Limitations on Exclusive Rights.

'Jon Baumgarten. “('copyright and Computer Software: Databases and Chip Technology, " an unpublished bibliography, 1985.

“'Title $17 \$ 101$, as amended Public Law 96-517, \$10(a), Dec. 12, 1980, 94 Stat, 3028. Note that "computer software' is used differently than "computer program" here and elsewhere in the literature; the former includes such ancillary material as written instruction manuals, books, and supporting documentation. "See Apple Computer Inc.\}, Franklin Computer Corp.. 714 F.2d 1240 (3dCir.1983), cert. dismissed per stipulation, 104 S. Ct. 690; and Apple Computer, Inc. v. Formula International, Inc., 724 F.2d 521 (9th Cir.1984). By implication, copyright would also extend to programs in Programmable-ROMs (PROMS) and Erasable-Programmable ROMS (E; PROMS).
Any Form: The program may be "source code, i.e., the form in which a programmer writes the program in a particular language (such as BASIC or PASCAL or FORTRAN); or "object code, " which is the source code translated into a form directly processed by the computer. " Any program, whether used to govern the internal operations of a computer or used to interact with the user, may be considered copyrightable. ${ }^{83}$

Any Computer: The term "computer" is quite broad, encompassing everything from fast, specially designed Cray supercomputers, which may be constructed out of thousands of integrated circuits, to a single microprocessor chip.

Computers are commonly described in terms of hardware, which is the physical machine components, and software, the term for computer programs. In modern computer design, however, hardware and software functions are largely interchangeable. The allocation of func-

\footnotetext{
"'This "(breakdown" is usually accomplished automatically! by the computer through the use of an "interpreter," "compiler, or ' 'assembler' (which is itself a programl. Any computer program in a given language may be used as the source code for an object code in another language. "1 łighlevel" languages, such as "1.1 SP, in their machine code form, mayserve as the object code for a source code written in another language, such as FORTRAN. The FORTRAN" program can in turn function in the presence of a "PL 1 " interpreter as the source code for source code written in the language PI. 1. In this fashion, programs may be layered upon programs. Object code and source code are merely relational terms, designating which language the programmer may be working in, and which language the machine operates in, Indeed, the so-called hardware in a given machine may itself be configured in IISP' (or any other) "software language; the hardware software distinction is not absolutely distinct.

"', Microcode," also know as "firmware, is the most primitive level of programming, and embodies the sequence of paths that a given electrical signal is to follow between the arithmetic and logic units of the computer. Its function is to replace a "hardwired control system that " mediate[s] the transfer of information between the central processor, the main memory units, and the various input and output devices. David Patterson, " Microprogramming, Scientific American, vol.248, March 1983 , p. 50. The copyrightability of microcode remains unest ablished, but it seems in principle no less "a set of statements or instructions' than any other form of program, although it is not usually changed, or even seen, once it is embedded in a microprocessor. Microcode has been held patentable, in re Bradley. 600 F.2d 807 (C. C.P.A.1979), aff 'd, by an equally divided court, subnom. Diamondv. Diehr, 450 U.S. 381,19811, and a case is pending on the issue of its copy. rightability, $N E C V$. Intel,Civ. Action No. 84-20799, A motion for summary judgment in the N FC case has been denied, and is scheduled for trial in April 1986.
} 
tions between them is the result of design decisions that balance such factors as the speed, cost, and flexibility required in the final product. The symbols in any computer program, therefore, are ultimately substitutes for hard wiring. This interchangeability between software (symbols) and hardware (circuitry) make programs a paradoxical sort of "writing, since they are symbols expressed as components of machines.

Like other copyrightable works, programs symbolize information to human beings, and can be read and understood by programmers. The CONTU Report stressed that programs, like other copyrightable works, communicate to those who can read them.$^{84}$ Because computer programs are symbolic, they appear to be at least as eligible for copyright as sound recordings, which require a record player to be understood by human beings. ${ }^{85}$ But, computer programs unlike previous "literary works, are both writings in the traditional sense and tools for accomplishing particular results. All traditional forms of writings are inert and purely representational. Books, movies, musical compositions, paintings, or statuary do nothing that a user does not do with them. They simply convey information or entertain a reader, viewer, or listener. But, as one expert in artificial intelligence says:

IIII [t]here is a qualitative difference between the computer as a medium of expression and clay or paper. Like the genetic apparatus of a living cell, the computer can read, write and follow its own markings to levels of self-interpretation whose intellectual limits are still not understood. ${ }^{86}$

Computer programs also differ not only from works of art and fact, but also from traditional works of function such as cams, thermostats, instruction manuals, code books, or recipes.

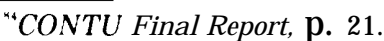

"To accommodate the way in which technology mediates information between human beings, a provision in the Copyright Act says that all original works of authorship are copyrightable so long as they can be perceived, reproduced, or communicated, "either directly or indirectly with the aid of a machine or device. " 17 U.S.C. \$102(a),

"Alan Kay, "Computer Software," Scientific American vol. 251 September 1984, p. 53.
}

These traditional works either describe a process to a person, who then intervenes to lend the words or phrases their utility, or they implement a process without describing it. Computer programs, as hybrid functional works, describe and implement processes. They cause physical changes to occur in a machine, and can interact with other programs or with an environment. A recipe encoded in a program language cannot only tell a programmer how to bake a cake, it can 'tell' the computer, too. With the appropriate robotic apparatus, the recipe can cause the cake to be baked.

The hybrid character of computer programs raises some very difficult problems for the law of copyright, and has prompted commentators to point to inconsistencies in copyright protection for programs:

No one would ever advise you that the copyright on a schematic diagram of a diode matrix would extend to the diode matrix, yet that is exactly what is being done by extending copyright on $1 \mathrm{~s}$ and 0 s to a diode matrix which it represents. Thus the same diode matrix could be covered by copyright on one form of work and not the other. This is obviously wrong. ${ }^{87}$

These inconsistencies grow out of the basic copyright distinction between unprotectable ideas and protectable expressions, and they are symptoms of a very fundamental problem with copyright protection for computer programs. The problem is whether copyright protection can be limited to the "expression" of a computer program, without also protecting the "idea, procedure, process, system, method of operation, concept, principle, or discovery. ${ }^{188}$ Although both CONTU and Congress made

\footnotetext{
${ }^{\alpha 7}$ Letter to OTA from Manny D. Pokotilow, Esq., Cesar, Rivise, Bernstein \& Cohen, Ltd., Philadel phia, PA, Aug. 5, 1985. See also: Richard Stem, "The Case of the Purloined Object Code: Can It Be Solved?" BYTE, September 1982; and Pam Samuelson, "CONTU Revisited: The Case Against Copyright Protection for Computer Programs in Machine-Readable Form, " 1984 Duke Law J ournal, 663 (1984).

${ }^{n k}$ The quoted language is from 17 U.S.C. $\$ 102(b)$. The "idea/expression dichotomy codified therein is a broader formulation than "ideas," per se. It comprehends the distinction made in Baker v. Selden between the expression and the "art expressed, rather than just the abstract manner of presentation.
} 
clear that "the expression adopted by the programmer is the copyrightable element in a computer program, and that the actual processes or methods embodied in the program are not within the scope of the copyright law, "189 the question still remains. What is the expression in a computer program?

Part of the problem is that the scope of the expression of a computer program can vary widely, depending on how the word expression is interpreted. As figure 3-4 illustrates, computer programs can be described in many ways, ranging from those descriptions that focus on the precise code used to those that generally describe the procedure or algorithm to be implemented by the program. The boundaries of copyright protection in programs will depend on what is considered an expression and what is considered an idea.\%' Opinions vary on where the protectable expression should stop and where unprotectable ideas begin, One author believes that the expression in the software does not consist of the exact written source code, but the specific logic and design of the program. ${ }^{111}$ others take an opposing view, and argue that copyright protection in a computer program, "is limited to the literal code and does not extend to the structure or other nonliteral elements of the computer program."

Regardless of how legal scholars resolve the issue of idea and expression, the Federal courts, in interpreting copyright law, will eventually face a dilemma; either: 1) the copyrightable expression in a computer program will be limited

\footnotetext{
“'\{Rep. No. 94.473, 94th Cong., 1st sess.1975.p. 54;and H R Rep No94-1476, 94th Cong..2d sess.1976, p.57(emphasis added). I n keeping with this notion, the circuit court in Applecomputer. Inc i Franklin Computer Corp., $714 \mathrm{~F} .2 \mathrm{~d} 1240$ 13d(Cir. 1983), said that "Apple does not seek to copyright the met hodwhichinstructs the computer to perform its operating functions hut onlyt he instructions themselves.

"See' ['art lof this chapter for a discussion of idea and expressionas the determinant of the boundaries of intellectual property ow nership.

I)uncan I )avidson, “ ['protecting Computer Software:A Comprehensive Analysis," Jurimetrics Journal,summer 1983. p 367

'I lefendant's.Memorandum in Support of Their Motion for Vew Trial and or to Alter Judgment. Whelan Associates, Inc. v.Jaslow Iental Laboratory, Inc. Civil Action No. 83-4583(E). I).Pa 1 985),p. \&; reported in 225 (1, S. P.Q.156(E.I) Pa. 1985).
}

to the strict line-by-line program code, in which case the unscrupulous might easily escape liability for infringement by simply varying the code in a trivial way, or 2) the copyrightable expression will be extended to the logic, design, structure, performance or even the output of the computer program, in which case one has copyrighted a "procedure, process, system, or method of operation, " The cases that have been decided thus far indicate that the courts are adopting the latter alternative, and have extended the meaning of expression in computer programs to include the processes that the programs implement. One opinion, for example, suggests that a program that achieves results similar to other programs, or even to other works of function-such as a commodities trading manual- will constitute an appropriation of a copyrighted expression. "The court in this case emphasized a similarity in "overall structure' between one work and the other. In another case, a court found that 44 out of 186,000 lines of code constituted substantial similarity of expression. ${ }^{94} Y$ et another court ruled that "the protectable expression in a computer program is the manner in which the program operates, controls, and regulates the computer in receiving, assembling, calculating, retaining, correlating, and producing useful information either on a screen, print-out, or by audio communication." ${ }^{.195}$

In theory, none of these rulings is permitted under traditional copyright principles. This is not because the courts have misinterpreted copyright law, but because copyright law cannot be successfully applied to computer programs. Unlike artistic or factual works, which

\footnotetext{
Williams v. Arndt. F. Supp. (I) Mass., 1985), No. 83-3397. In this case, the plaintiff's work was a step-by-step method for trading in various commodities. The defendant, without authorization, translated the plaintiff work into a computer program that achieved similar results, and was found guilty of infringement.

${ }^{4}$ SAS Institute v. S\&H Computer Systems. Inc.. F'. Supp. (M.D. Term. 1985), No. 82-3669. The court in this case also had before it evidence of actual copying by the defendant s-a fact which made the conclusion of infringement easier to draw.

'Whelan Associates, Inc. v. Jaslow Dental Laboratory)', Inc., 225 USPQ 156 (F.. D. Pa. 1985), hut see: Q.Co. Industries. inc. v.Hoffman, F. Supp. , No. 85 Civ.4653 RWS (S. D. N.\}. 1985)
} 
Figure 3-4.-Computer Programs - "What Is Protected?"

Each of items (a) through (g) represents a different, but equivalent expression of a procedure for computing an average. Each of these expressions could act as a program for computing an average, depending on the sophistication of the computer operating system handling the information.

If copyright protection in one of these expressions is broadened to include any or all of the equivalent expressions, then copyright protection has been extended to ideas or processes, and assumed patentlike status without stringent patent requirements (such as novelty and nonobviousness).

If copyright protection in one of these expressions is limited only to that expression, then copyright protection is almost useless, because it allows others to escape infringement by insignificant variation of the expression.

The scope of patent protection in programs is also hard to ascertain. The distinction between mathematical formulae, algorithms, and computer programs, is not clear. In theory, one cannot patent mathematical formulae or laws of nature, but how is this distinction between discoveries and inventions to be drawn in the context of computer programs?

Intellectual property protection for such fundamental procedures as computing an average is problematic. Proprietary rights in the "building blocks" of computer science may impede, rather than further, its progress. If rights are to be granted in functional works such as programs, at least one question is: what is so basic as to constitute a "staple" item in the trade?

As computers become more sophisticated in their ability to process natural language (conversational English, for example), the line between what counts as a protectable program and what constitutes user input will begin to blur. As this illustration shows, "program" and "algorithm" have no fixed meanings.

(a)

To compute an average, sum the numbers in the set to be averaged, and divide by the number of items in the set (b)

$$
x=\sum_{\substack{t=1 \\ n}}^{n} x
$$

(c)

Get a data item add item to total increment index

if no more items, continue: else go to get

divide total by index

(d)

10 data $10,12,17,22,6,-1$

20 read $X$,

30 If $\mathrm{x}=-1$ goto 70

40 let $X_{t}=X_{t}+X$,

$50 \mathrm{n}=\mathrm{n}+1$

70 average $=X_{t n}$

80 print average

(e)

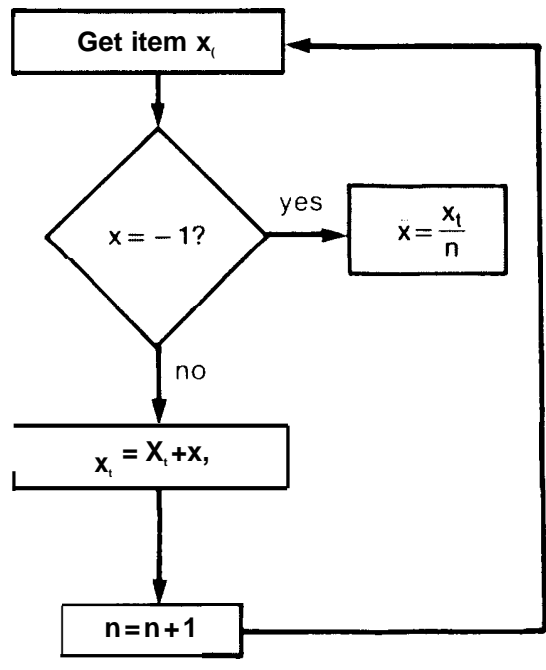

(f)

Call average

$10,12,17,22,8$

(9)

01100100110101010

10010011011001110

01110101001100100

110100110 
are subject to the "abstractions test between idea and expression, copyright in computer software is an either/or choice. Either one protects the words or variables as they are literally represented by the programmer, or one is forced to interpret those words or variables in terms of the procedure they implement in a computer system; thus protecting a procedure, process, or method of operation. 'G The "clear distinction" made in Baker v. Selden, "between the book, as such, and the art it is intended to illustrate, collapses in a computer program, because the program embodies both "the book" and "the art." one cannot arrive at a "clear distinction" between idea and expression in a computer program by using traditional copyright analyses.

Policy Implications, The practical import of appropriate protection for computer programs lies in the public policy objectives of the copyright system itself. For computer program proprietors and creators, as well as to the domestic and international economies, it is important that computer programs be adequately protected. ${ }^{97}$ If courts construe copyright protection in computer programs narrowly, creators and proprietors may well find unprotected the very thing that distinguishes their product from others-its logic and design. Equally important, if only the precise code is considered expression, copyright protection will be of limited use, since this expression can be easily changed by competitors.

\footnotetext{
"Consider the distinction logicians make between "object language and " met a 1 angu age for language about the object languagel in the context of the following statements:

Bake the cake

Execute "Bake the cake"

The former is the object language; the latter is the meta language. This distinction collapses in computer programs, since propositions can be "'recursive": i.e., they can serve as both object and meta statements. "Bake the cake, depending on the con te $\mathrm{xt}$ of use within the running of a computer program. may either be information to be displayed to the user, or a subroutine instructing the computer to bake the cake.

A major, if not the chief means of inventing today is being done in a non-engineering liberal arts mode which is alien to the historical patent-copyright paradigm, From a speech given by JohnLautsch. "Why Be Concerned About Proprietary Protection of Software'?' American Bar Association Conference. Washington. DC.July 1985.
}

If, on the other hand, courts continue to interpret the expression in computer programs as broadly as they have in recent cases, developers of computer programs may also be adversely affected, If copyright in computer programs is held to extend to the "useful knowledge' '-the method of achieving certain results-embodied in the program structure or algorithms, copyright may block software innovators by preduding the creation of programs that differ in detail, but implement and perhaps improve on copyrighted programs."' The patent system was designed to have this effect, but it is inappropriate for the copyright system, which was neither doctrinally nor administratively designed to protect functional information. Overly broad copyright protection would give the owner patent-like protection over processes for a much longer duration than patent law provides, and do so with no examination for the program's novelty or nonobviousness, as is required by patent law. Moreover, patent law requires that an invention bean advance over the 'prior art, requiring an inventor to examine previously patented claims before gaining patent protection. For this reason, the Patent and Trademark Office keeps records of all patents that have been issued. But the Copyright Office does not keep records of "prior art, ${ }^{\prime 99}$ which leaves no way of predetermining whether a program that performs similar functions or obtains similar results will infringe a previously copyrighted program.

Copyright law does not distinguish between the types of computer programs it protects, which may exacerbate some of the difficulties described above. The type of computer program that is copyrighted may significantly af-

"AS Justice Bradley commented in Bakerv.Selden: "The very object of publishing a book on science or the useful arts is to communicate to the world the useful knowledge it contains. But that object would be frustrated if the knowledge could not be used without incurring the guilt of piracy of the book. $101 \mathrm{U}$. S. 841 at 10311880 .

"Deposit of programs in the Copyright office is required if the program is published with notice. 17 U.S. C. $\$ 407$. However, only the first and last 25 pages of a program need be deposited, and these need only be sufficient to identify the program in question. $37 \mathrm{CFR} \$ 202.20$ (c)(viii(A). These pages need not disclose any of the workings of the program, 
feet the market power a copyright owner can possess. ${ }^{100}$ For example, both operating systems and applications programs are generically computer programs, but crucial distinctions exist between the two. Operating systems govern the internal operation of a computer, and allow it to communicate with a range of applications programs (e.g., spreadsheets, graphics, and word processing programs). The operating system will, therefore, determine which applications programs can run on a particular computer. Thus, copyright on an operating system may be a far more powerful right than a copyright on an applications package, and may govern the market for applications packages. Indeed, this desire to make one's applications program marketable may have been at the heart of the Apple $v$. Franklin case, since it was unlikely that the 15,000 applications programs written for Apple's operative system would be rewritten to run on the Franklin Computer's machines. "'"'

Reverse Engineering. The trend of interpreting expression broadly in copyright for computer programs may also pose problems for reverse engineering. Reverse engineering refers to the unauthorized, although not necessarily illegal, reproduction of programs in their object or source code form for the purpose of teaching, analyzing, or evaluating the concepts, techniques, or ideas embodied in the program. ${ }^{102}$ This process promotes innovation by allowing programmers to build on the works of others in the creation of new works. It also eliminates the need for redundant research and development. Reverse engineering allows abstract knowledge and techniques to be passed on, while prohibiting the wholesale appropriation and sale of another's work.

\footnotetext{
“'”'F or a thorough discussion of copyright and market power, see ch. 6.

'“' Allan Schmid, "Intellectual Property Rights in Biotechnology and Computer Technology, " to be published in Zeitschrift fur die gesamte Staatswissenschaft, 1985. One writer argues, however, that this problem has been contradicted by the facts. Duncan Davidson, "Software and the Wealth of Nations," to be published in Computer Law and Practice, 1985.

${ }^{102}$ The language used in this definition is adapted from the Semiconductor Chip Protection Act, 17 U.S.C. $\$ 906$.
}

Computer programs create unique concerns about reverse engineering because, unlike other copyrightable works, their expression is not disclosed when they are published. '03 While a journalist can learn his craft without copying, by reading the others' published works, a programmer cannot. He must copy the program from its original storage medium-probably by decompiling it into source code form-in order to read and learn from the works of his predecessors. This copying may give rise to copyright liability, even though it may in no way interfere with the market value of the copied software. ${ }^{104}$ The copy that is made in the course of reverse engineering may have relatively little financial value. It may bear little, if any, resemblance to the work that is allegedly infringed, and may even be destroyed after use. Instead of examining the work, the court looks to the "paper trail" left by the defendant in the research and development process. The infringement often occurs in the process of copying a program to create a new one. However, courts have used this initial copying as the basis for finding that the final work produced by a defendant was an infringement, even though it resembled the copied program only slightIy. ${ }^{105}$ This creates uncertainty whether any copying, even that for reverse engineering, is legal.

As it exists, copyright law offers two conceivable ways of dealing with the problem of reverse engineering. One possibility, Section 117 of the Copyright Act, permits copying of software as an "essential step" in the utilization of a computer program for "archival pur-

\footnotetext{
"For a discussion of the disclosure issues surrounding computer programs, see Pamela Samuelson, "CONTU Revisited: The Case Against Copyright Protection for Computer Programs in Machine-Readable Form, 1984 Duke Law J ournal 665.

${ }^{a 4}$ Pamela Samuelson, "The Demise of the Right To Reverse Engineer Computer Programs: Is It Appropriate?" unpublished draft, Sept. 25, 1984.

"I"I ndeed, the emphasis on the conduct of the defendant, as opposed to an assessment of the similarity in content between works can be seen in several recent cases: e.g., SAS Institute, Inc. v. S\&H Computer Systems, Inc. (1985 M.D. Term.), No. 82-3669, Whelan Associates, Inc. v. Jaslow Dental Laboratory, 225 U. S.P.Q. 156 (E. D. Pa. 1985), and Hubco Data Products Corp. v. Management Assistance, Inc., 219 U.S.P.Q. 450 (D. Idaho 1983).
} 
poses. ${ }^{1106}$ This provision does not explicitly address the issue of reverse engineering. CONTU, which wrote section 117, interpreted " 'essential step" narrowly, to include only the copying done by a computer in the process of loading a program into the machine. Likewise, the courts have followed this interpretation. ${ }^{107} \mathrm{~A}$ broader interpretation of "essential step" might permit reverse engineering. But because such a broad interpretation of section 117 may also conflict with the copyright owner's exclusive right to prepare derivative works, ${ }^{108}$ it seems to be a slim reed on which to facilitate reverse engineering.

Alternatively, the doctrine of fair use may provide for reverse engineering, because it permits copying for scholarship or research. ${ }^{109}$ Fair use, however, evolved in the context of print technology, and so several of its features make it an uncertain device, at best. Two of the criteria used in determining the fairness of a use are: ( 1 ) the purpose and character of the use, including whether the use is of a commercial nature; and 2) the amount and substantiality of the work as a whole. ${ }^{110}$ Because reverse engineering is often performed for inherently commercial reasons, the "purpose and character criterion could weigh against a finding of fair use. Furthermore, programs must often be copied in their entirety to understand their workings, or to study the relevant portions of code. The fair use factors concerning "amount and substantiality' not only deal with the number of copies of a work made, but also with the portion of a work that is copied. Hence, the fair use doctrine may not allow reverse engineering. However, because there has been no court decision on the matter of reverse engi-

"“The relevant part of section 117 reads:

it is not an Infringement for the owner of a copy of a comput er program tomake a copy or adaptation of that computer programprovided (lithat such a new copy or adaptation is created as anessentialstepin the utilizat on of the computer programin conjunction with a machine and that it lsusedin no other manner

S ee, e.g.: Midway Manufacturing Cov. Strohon, 564

F.Supp. 741 (N. I). III. 1984 )

in 17 U.S.C. 106.

"The doctrine of fair use is codified in Section 107 of the Copyright Act, and is discussed in ch. 7 of this report.

"17 U. SC. 107 , sections 1 and 3 neering, it is impossible to say definitively whether fair use will allow it.

\section{Computer Program and Patent Law}

Given the problems of applying copyright protection to computer programs, patent protection may be a more viable alternative than fair use. Among other things, patent law protects new and useful processes, ${ }^{111}$ and computer programs, as works of function, use information in a process. Many patents have been issued for computer programs.

Patent protection, however, also poses problems. Some are theoretical; not all programs that need protection will be eligible for patent protection. Some are practical, and have to do with how suitable the patent system is to the commercial environment of program engineering.

Programs and Patent Theory. Since 1966, the issue of program patentability has been juggled among the Patent Office, the Court of Customs and Patent Appeals (now the Court of Appeals for the Federal Circuit), and the Supreme Court. ${ }^{112}$ Computer programs have proven to be as problematic an "invention' for patent law as they have been a "writing" for copyright law. ${ }^{113}$ For, the same characteristics that make programs acceptable subject matter under the copyright scheme cause problems under the patent scheme. Whereas copyright has problems with the functional nature of programs, patent law has difficulties with symbolic nature of programs. They represent processes that have heretofore been mental, such

\footnotetext{
'Section 101 of Title 35 (Patents) states that whoever invents or discovers any new and useful $\mid 1$ I process, (2) machine, 13) manufacture, or (4) composition of matter, or any new or useful improvement thereof, may obtain a patent on his invention or discovery.

"See Duncan Davidson's "Protecting Computer Software: A Comprehensive Analysis, in 1983.ArizonaStatelaw J ournal $611,634-650$.

" 'One writer has suggested that "[m]uch as the distinction is breaking down in copyright because of technological changes blurring the distinction between a product and its idea, so tooespecially in the area of computer software- is the dichotomy losing its meaning in patent law. "James Beniger, Information Technologies and Commodities in the Development of Intellectual Proper.l ': Changing Rights and Practices, OTA contract report, April 1985, p. 58.
} 
as balancing a checkbook or searching for a word in a text.

Strictly speaking, computer programs are not in and of themselves patentable. At present:

... [patent protection] is available for computer programs that are intrinsically tied to a device which physically and automatically applies the results of the computer program. . . . The invention is not in the program: It is merely implemented by the program (and) is actually a new method of doing something.

Patentability is determined by whether the program implements a physical process that is itself the subject of invention, and meets the criteria for patentable processes. ${ }^{115} \mathrm{~F}$ or example, a method of typesetting, ${ }^{116}$ of timing the curing of rubber, ${ }^{117}$ of searching for oil, ${ }^{118}$ or of storing and manipulating telephone signals and records in a database ${ }^{119}$ are patented inventions that include computer programs as components of the invention. Programs that are the only novel component of an otherwise unpatentable process, ${ }^{120}$ or that merely implement an algorithm or a scientific or mathematical truth, ${ }^{121}$ are not patentable ${ }^{122}$ This is the

J ohn C. Lautsch, American Standard Handbook of Software Business Law (Reston, VA: Reston Publishing, 1985), p. 65.

"That is, useful, novel, and nonobvious (35 U.S.C. $\$ \$ 101$. 103). Similarly, machines, methods of manufacture, and compositions of matter that employ programs and that meet the statutory criteria for patentability are also patentable.

"' In re Freeman, 573F.2d 1237 (CCPA 1978).

“Diamond v. Diehr. 450 U.S. 175 (1981).

"In re Taner, 681 F.2d 787 (CCPA 1982).

1"'Patent No. 4,479,196-Hyperedge Entity-Relationship Data Base Systems (1984), for example.

Parker v.Flook, 437 U.S. 584 (1978).

Gottschalkv. Benson, 409 U.S. 63 (1972). The Supreme Court ruled that a program for the conversion of binary coded decimals into pure binary numerals could not be patented, since "the patent would wholly pre-empt the mathematical formula and in practical effect would be a patent on the algorithm itself. " 409 U.S. at 7172 (1972).

This statement is based on the caselaw that has so far developed. one observer, however, has pointed out that "[p|atents are now being granted every week with claims covering a series of steps which can be executed completely on a computer and, it appears, without any last-step output, that is, to turn a crank, light a light, eject a part, and so forth. Whether court (sic) will uphold such claims in infringement proceedings remains to be seen. "Letter to OTA from Robert Shaw, The Patent, Trademark, and Copyright Research Foundation, Franklin Pierce Law Center, Oct. 11, 1985. Many patents have been issued for "pure" programs re.g., "SWIFT-TECH" "TM is a patented computerized database search algorithm that runs on mainframe, mini, or microcomputers. U.S. Pat. No. 4,270, 182). case for a great many computerized industrial processes, and the majority of programs written for personal computers.

The courts' reluctance to uphold patent protection on programs in isolation from physical processes points to a very fundamental problem with patent protection for programs. Programs are expressions of algorithms, which are rules or procedures for achieving particular results. Algorithms, like mathematical formulae and laws of nature, are not patentable, Yet, the algorithms expressed in programs can also be configured in a computer in hard-wired form.

This equivalence between algorithms in hardware and those in software raises an issue concerning the patent 'doctrine of equivalents." The doctrine states that a patent protects equivalent configurations, even though they may neither be disclosed nor actually claimed, unless the equivalent configuration performs the function in a substantially different way. ${ }^{123}$ If, therefore, a program can be described in terms of the functioning of digital logic circuitry in the computer hardware, rather than in terms of algorithms embodied in software, patents might be issued on machines which if they were software, would be denied. ${ }^{124}$

The Practical Limitations of Patent. There are administrative and practical problems connected with seeking patent protection for computer programs. Many observers consider time and expense to be the greatest drawback. A claim may be pending for 2 to 3 years and cost an inventor upwards of $\$ 10,000$ to prosecute. ${ }^{125}$ Many innovators may find the time and expense involved in obtaining patents for computer programs prohibitive, depending on the rate at which software designs become obsolete, and the amount of financial resources available to a given software innovator. Even

\footnotetext{
Duncan Davidson, "Protecting Computer Software: A Comprehensive Analysis, " 1983 Arizona State Law J ournal 611, 643 , citing 4 D. Chism, Patents, $\$ 18.04$ (1982)

${ }_{124}$ Ibid.

"'Larry Kahaner, "Patent Reform, Pending," Across the Board, September 1984, p. 36; and conversations with Richard Stern (see note 44) and Robert Shaw (see note 122). See ch. 9 on institutional issues.
} 
after a patent is successfully obtained, it is often found invalid when challenged in court, ${ }^{126}$ making the value of a patent to investors highly uncertain. The scope of patent claims in programs, too, is uncertain, because of their symbolic nature. The actual code written by a programmer is seldom the subject of patent claims. Instead, what is claimed is the process that the code implements, and the program is incidental to this process. The scope of the patent claim may, therefore, be difficult to delineate precisely, because it does not refer to a specific embodiment or tangible item.

\section{Computer Programs and Trade Secrets}

A trade secret is a form of intellectual property that covers any confidential formula, pattern, device, or compilation of information used in a business, which gives that business an opportunity to obtain an advantage over competitors who do not know or use the secret.]" Trade secret law is a viable method of protecting computer programs, and in some cases, seems better suited to programs than either patent or copyright. Indeed, software developers rely on it heavily for protecting against the unauthorized disclosure of competitively valuable information.

Trade secret law differs substantially from both patent and copyright law. The law of each State, rather than Federal law, defines what a trade secret is, and what rights the holder of a trade secret has. Unlike copyright, trade secret protection can extend to the ideas, algorithms, and procedures embodied in a program, as well as to the expression adopted by the programmer. Unlike patent, a trade secret generally requires no compliance with formalities, no waiting time to acquire, and no proof of novelty or nonobviousness. Perhaps most important, trade secret is not encumbered with the problems of fitting computer programs into subject matter schemes of patent and copy-

\footnotetext{
"Estimates of holdings of invalidity range from 50 percent (see Davidson, op. cit. ) to 70 percent (Richard Stern, "ROM's in Search of a Remedy: Can They Find It? 1 Computer Law Reporter 4, 1982).

Restatement of Torts $\$ 757$, comment B
}

right. ${ }^{128}$ In trade secret cases, a court is freer to focus on the effects of disclosure on a plaintiff's business, and the contractual or tortious misdeeds of a defendant, rather than on strict standards of infringement. ${ }^{129}$

Trade secret protection, however, has drawbacks from both a public policy and a proprietary point of view. As a matter of public policy, an overreliance on trade secret protection may hinder technological growth in the computer industry by "locking up" information that can benefit whole sectors of the industry. Unlike the patent and copyright systems, trade secret does not further the goals of disclosure and publication. Quite the reverse: trade secret protection is lost by unrestricted or unprotected disclosure of the secret. ${ }^{130}$ Trade secrets are often enforced through contracts between employers and employees that restrict the employees' rights to enter into competitive ventures or to subsequently become employed by competitor companies. Although intended to protect employers from unscrupulous employees, abuses of these noncompetition agree-

\footnotetext{
“"'Rather than the uniqueness, novelty, or originality of the program, a court ruling upon a trade secrets case will look to the unique value of the program to a company's competitive advantage, the company's investment in the program design, or the 'unique logic and coherence' of the program. See, e.g.: Corn-Share, Inc. v. Computer Complex, Inc., 338 F, Supp. 1229 (E, D. Mich. 1971) and Computer Print Systems, Inc.v.Lewis. 422 A.2d $148(\mathrm{~Pa}$, Super. 1980), but see: Structural Dynamics Research Corp. v. Engineering Mechanics Research Corp., 318 N. W.2d 691 (Minn. 1982) ("Mere variations in general processes known in the field which embody no superior advances are not protected.")

${ }^{124}$ The same can be said of many other State law forms of intellectual property protection. Theories such as tortious interference with contract, interference with prospectiveadvantage, misappropriation, and unfair competition law all focus on the conduct of defendants, rather than on the subject matter of the item that is allegedly infringed.

"“'The factors that go into an assessment of whether certain information is one's trade secret include:

1. the extent to which the information is known outside of his business;

2. the extent to which it is known by employees and others involved in his business;

3. the extend of measures taken by him to guard the secrecy of the information;

4. the value of the information to him and to his competitors;

5. the amount of effort or money expended by him in developing the information; and

6. the ease or difficult' with which the information could be properly acquired or duplicated by others.

Restatement of Torts. §757, comment B.
} 
ments may also hinder technological advance by acting as a barrier to employee established startup companies. ${ }^{131}$

Trade secret protection is of limited usefulness to many types of software developers and vendors. Programs that are mass marketed are not suitable candidates for trade secret protection, since the trade secret status of the software is lost through disclosure, and disclosure is often the natural consequence of mass marketing. To avoid this problem, some vendors have licensed, rather than sold, their programs, and required the licensees to keep the program secret .-Depending on the number of licensees, however, these schemes may be neither legally nor practically enforceable. ${ }^{132}$ The software

",' These (noncompetition) suits hit the startups at their most vulnerable stage, when every available dollar and minute has to be poured into the nascent company. The suits have become so common as to kindle suspicions that some established companies are using the courts more to suppress competition than to right legitimate wrongs. "In High-Tech Industry, New Firms Often Get Fast Trip to Courtroom, "Wall Street J ournal, Aug. 14, 1984.

'-Davidson, "Protecting Computer Software, " op. cit. vendor also faces a number of other problems with trade secret protection, including a lack of uniformity in trade secret laws from State to State, and difficulties in attempting to obtain concurrent protection through patent or copyright law. ${ }^{133}$

\begin{abstract}
"Secrecy may be lost through copyright registration and deposit, or through a Freedom of Information Act request upon the Copyright office, The Copyright Office has promulgated "secure deposit" regulations with respect to deposit of the Multistate Bar Fxam, 37 CFR \$203.40, and see National Conference of Bar Examiners v.Multistate Legal Studies, 692 F.2d 478 (7th Cir. 1982), and the Freedom of Information Act has a trade secret exemption, 5 U.S. C. $\$ 552$ ( b)(4), but neither of these provisions has been construed with respect to computer programs. Section 301 of the Copyright Act preempts State law that provides ${ }^{4}$ 'equivalent protection. Despite the fact that the Supreme Court has found that patent law does not preempt State trade secrets law, Kewanee Oil Co. v. Bicron Corp., 416 U.S. 470 (1974), the situation is not entirely clear with respect to preemption of State trade secrets law by Federal copyright law. See e.g., Videotronics, Inc. v. Bend Electronics, 564 F. Supp. 1471 (D. Nev. 1983),
\end{abstract}

\section{PART III: IMPLICATIONS FOR POLICY}

The application of a uniform system of intellectual property principles, such as that embodied in copyright and patent law, to divergent types of information-based products may no longer be possible. Modern technologies are exaggerating dissimilarities between information products that were once protectable under a single system of law, and are, in some cases, giving rise to new products that strain the application of old legal principles.

There may be no one simple solution to the problem of accommodating intellectual property law to technological change. Being different in kind, many of the problems require different types of solutions. Determining the proper form of protection for computer programs, for example, is largely a question of which aspects of programs the law should protect; whereas determining ownership in works distributed on-line is one of finding a feasible administrative mechanism.
Problems also require different degrees of change. Copyrighting dynamic databases, for example, may call for relatively minor changes in copyright registration and deposit regulations, but the difficulties that computer and communication technologies pose for protecting works of fact may necessitate sweeping changes in the type of protection that the law currently offers.

The timeframe in which problems are likely to arise also hinders attempts to construct one comprehensive solution. Protecting computer programs is a problem that requires immediate attention, but other issues, such as interactive authorship, may not significantly affect the intellectual property system until early in the next century.

Given the complexities of formulating appropriate intellectual property law, it is convenient to organize Congress' policy options accord- 
ing to the type of action that might be taken. A choice of one option does not necessarily exclude others, and the policy maker may choose to exercise several options at once, or in sequence over time. These options, and their strengths and drawbacks, are described below.

\section{Option \#: Rely on the Marketplace}

Marketplace options accommodate technological change with little or no government intervention. Under this kind of option, private entrepreneurs, acting individually or as groups, address problems that exist in intellectual property law. Solutions to particular problems will often take the form of "technological fixes" or private contractual agreements. For example, "identifiers" electronically embedded in some works may help to solve some of the problems of integrity and identity associated with works of art that are produced and distributed on-line, and technological methods of monitoring use, although expensive, are available for some database distributors of works of fact. And, where current legal protection is inadequate for works of function, proprietors might try to supplement intellectual property protection through the use of site licensing or "shrink wrap" licensing. ${ }^{134}$

The marketplace approach to resolving intellectual property issues is favored by a majority of the public, 54 percent of whom feel that business should have the primary responsibility for solving problems associated with intellectual property. (See table 3-I.) In response to a survey conducted for OTA by Yankelovich, Skelly \& White, Inc., the public responded in the following way when asked "Thinking about this issue of intellectual or creative property, who would you say should have primary responsibility for solving any problems created by new technologies (like computers or videocassette recorders)?" Manufacturers of computer hardware and many established software developers, fearing that legislative efforts

\footnotetext{
“'Shrink wrap licenses, so called because they purport to bind the purchasers of mass market software to a license agreement rather than an outright sale, are of unproven effectiveness and legality. See ch. 6, pp. 183-184 for further discussion of shrink-wrap licenses.
}

Table 3-1.-Who Should be Responsible for Solving Intellectual Property Problems?

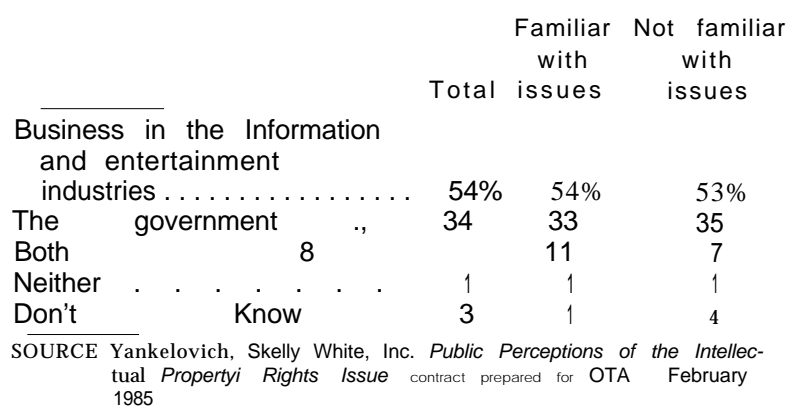

to adapt intellectual property law may create more uncertainty than it resolves, would also prefer that Congress pursue marketplace options. In some cases, private industry has already taken a marketplace initiative by seeking to establish technical standards, ${ }^{135}$ or by protecting their products through contractual agreements with their customers. However, not all representatives of the information industry believe that the marketplace alone can provide adequate protection for their products. Database vendors, in particular, are uncertain about marketing their services without adequate and appropriate legal mechanisms.

The marketplace option has several advantages over others. The marketplace is more likely to be able to respond rapidly and flexibly to rapid innovation. Contracts between computer program sellers and buyers are likely to address the specific needs of each party, and can be tailored to take unique features of the technology into account. Technological means of protecting information or monitoring use avoid costly enforcement and litigation. And, marketplace solutions can evolve as rapidly as the technology.

Marketplace solutions do not solve all of the problems that vendors of information products face, nor do they necessarily further the public interest. Unlike intellectual property law, contracts do not ordinarily bind those not

\footnotetext{
${ }^{13: 5}$ The Association of Data Processing Service Organizations (ADAPSO) has recently proposed a standard method of copy-protecting computer software, and the proposal has met with some resistance from both software vendors and users.
} 
party to the agreement. This means that, lacking adequate intellectual property protection, a creator or purveyor of information is often without legal recourse against third parties.

Technology-based protections may also be unworkable. Not only are they susceptible to the diligent 'hacker,' they may also be impracticable to market or difficult to standardize. Moreover, by protecting works that are publicly disseminated, copyright encourages dissemination. In lieu of copyright protection, information providers may be inclined to "lock up' access to information that they previously had incentive to keep open. This would not serve the public interest.

\section{Option \#2: Judicial Accommodation}

$J$ udical accommodation is an option that allows the Federal court system to treat intellectual property problems on a case-by-case basis, by fitting existing law to the particular facts before the court. By interpreting the law in specific circumstances, courts develop rules that eventually have broader application. Many judicially devel oped doctrines, such as fair use and the idea/expression dichotomy, were later codified by the legislature.

The individuals having the strongest opinions about judicial accommodation are attorneys. Those attorneys who view existing intellectual property law as adequate to deal with technological issues also feel that the judicial forum is the most appropriate method of dealing with technological advance. The great virtue of the judicial process, according to this perspective, is its ability to adapt the broad outlines and fundamental principles of statutory law to circumstances that are unforeseeable at the time law was written into statute. They also stress that many uncertainties, such as whether computer programs are copyrightable, have already been resolved by the courts, and that a foundation therefore exists for further judicial development.

A growing minority of attorneys, many of whom come from a background of engineering and patent law, strongly disagree. They argue that not only are existing methods of legal protection inadequate, but so too are judges' abilities to comprehend the subtleties of the technology and the long-range impact of their decisions. Given uncertainties in applying the law to new technologies, they often counsel their clients to proceed conservatively in order to avoid lawsuits. The clients, in turn, may forego potentially profitable avenues of research or application. Often, there is no way of knowing how the law will apply to them until they are haled into court-a prospect that many wish to avoid.

The legal profession's opinions on judicial accommodation reveal many of the strengths and weaknesses of this option. J udicial accommodation may be advantageous in some cases, where statutory law can be construed by the courts so as to avoid the need for legislative solutions. The judiciary may, for instance, be able to clarify the meaning of the fair use and idea/expression doctrines in the context of computer software. The courts' role is to adapt general law to specific circumstances and, given the idiosyncrasies of the situations that may arise, the flexibility of judicial accommodation gives it many advantages over attempting to anticipate future problems through legislation. In many cases, alternative causes of actionsuch as trade secrets, misappropriation, and unfair competition law-may also fill the gaps left in copyright or patent law because of the effects of technology.

Nevertheless, the courts, which are generalists par excellence, may be ill-equipped to deal with many of the highly technical and multifaceted problems raised by some of the technologies. Moreover, as this chapter suggests, many of the problems in intellectual property law are fundamental, and may not lend themselves to resolution through a case-by-case application of the law. In order to obtain results that seem to them just, courts have recently begun to render decisions that are, in essence, policy choices.

In light of the Supreme Court's consistent signals to Congress that the judiciary should not serve as a policymaking forum for patent and copyright law, resort to the courts to re- 
solve many of these technological issues may be tantamount to a delegation of Congress' policymaking authority. Even if the judiciary acts with restraint with respect to policymaking, the application of obsolete law to novel circumstances may end up skewing the policy objectives that the statute seeks to promote.

\section{Option \#3: Amendment}

Amendment is an option that allows Congress to modify portions of existing law in order to accommodate changes in the way the law operates brought about by technology. In 1980, for example, the copyright law was amended to include computer programs, and in 1985, it was amended to deal with the rental of sound recordings. A bill presently before Congress would amend the copyright law to include the ornamental designs of utilitarian items, such as semiconductor chip masks. ${ }^{136}$

Industries and organizations that rely on, or are affected by copyright protection, generally favor amendment, where necessary, as an option for accommodating technology. Among these groups are the recording and motion picture industries, the library and educational associations, the software and computer industries, and a variety of authors', publishers', and artists organizations. Each of these groups tends to have specific and unique concerns that are often best addressed by amendment. These organizations view amendment as the best option for a number of reasons: marketplace options may not be viable for achieving many results, such as proposed royalties on blank tapes; ${ }^{137}$ litigation may produce results that are unfavorable, as with Sony Inc. v. Universal studios, ${ }^{138}$ or not sufficiently comprehensive for the group's particular ends; and the groups' interests are seldom broad enough to favor more comprehensive legislative options, such as revision or sui generis legislation.

Amendment to patentor copyright law may bean appropriate solution to some of the problems posed by technology, especially those

"H.R. 1900, also known as "The Design Protection Act of 1985." Introduced by Represent ative Moorehead.

S. 31 and $1\{$. R. 1030

"Sony Corp.v. Lniversal (ity Studios 464 (1. S.417। 1981). amenable to relative $\}^{\prime}$ isolated legislative treatment. For example, the problems of deposit and registration for dynamic computer databases, the difficulties involved with thousands of contributors to a single database, and the issue of the scope of protection for computer programs may be soluable through amendments to appropriate sections of the Copyright Act. Accommodation by amendment offers the advantage of relative timeliness in the face of technological change. Next to judicially fashioned responses, amendment is perhaps most flexible in meeting the rapid pace of technological change. Amendment also offers the advantage of fitting specific technological accommodation within a larger precedential context, thus reducing uncertainties about whether existing legal principles would apply to new provisions.

However, insofar as problems affect the entire intellectual property system, accommodation by amendment may be but a temporary solution. If, for example, computer databases and net works become a principal means of storing and distributing information, copyright law, both in principle and in practice, may fail to protect what needs protection-algorithms and information. Amendment may fail to address the fundamental difficulties posed by technological advance, since the problems lie at the conceptual core, rather than at the periphery, of existing law. The failure of copyright law to account for the trifold nature of information-works of art, fact, and function-is an example of a fundamental problem that technology is exacerbating.

\section{Option \#4: Sui Generis Legislation}

Sui generis is a latin phrase used to describe any law that is "of its own kind or class. Sui generis intellectual property law is legislation that stands apart from existing patent, copyright, trademark, or unfair competition law. The Semiconductor Chip Protection Act is an example of sui generis law designed to protect the architecture of semiconductor chips."' The sui generis option has also been suggested for computer programs.

\footnotetext{
"The Semiconductor Chip Protection Act comprises Chapter 9 of Title $17, \mathrm{U}$. S. Code.
} 
The identity of the parties likely to favor or oppose sui generis legislation will depend on what the legislation seeks to protect, and on how it proposes to protect it. In the case of the Semiconductor Chip Protection Act, for example, the semiconductor industry generally favored protecting chips through an amendment to the existing copyright system, rather than sui generis law, because of the greater certainty that amendment offered. Other groups, such as the publishing and computer software business, favored the sui generis option because of possible adverse effects that amendment of the copyright law would have had on protection of other types of copyrightable works. In general, groups whose products sui generis law is likely to affect prefer protection under existing copyright or patent schemes because of the lag time involved in writing a whole new system of protection, and because of the uncertain way that courts will interpret the new law.

The sui generis option offers the advantage of accommodating intellectual property law to the gradual introduction of new technologies. Even with rapid technological change, many of the traditional, print-based, methods of creation and distribution will continue to form a great part of the commerce in the information industry, and traditional concepts developed for print culture may still work quite well. As new forms of expression grow up alongside of existing ones, Congress may want to consider parallel forms of intellectual property protection. Indeed, the Semiconductor Chip Protection Act is a good example of this parallel, sui generis approach. Sui generis legislation can be specifically tailored to the idiosyncrasies of the technologies and their markets, without damaging the fabric of existing law. Where doubt exists over the applicability of the intellectual property clause of the U.S. Constitution, alternative constitutional authority can be found in the commerce clause.

A sui generis law for computer programs and other works of function might be desirable for many of the above reasons, Like the Semiconductor Chip Protection Act, a sui generis law for programs and other works of function could build in a balance between proprietary and public interests, by granting appropriate proprietary rights in those aspects of the work that are valuable, by allowing for reverse engineering, and perhaps by limiting the term and scope of protection to reflect actual markets for functional works.

Works of fact might also be protected under a sui generis scheme that recognizes the importance of protecting information per se, while at the same time balancing such protections against the rights and needs of the public to that information. Compulsory license arrangements and alternative remedies, such as the imposition of "reasonable" royalties for certain types of infringement, might also be tailored to the specifics of the interests at stake.

Sui generis schemes of protection are not, however, a panacea. They are costly in terms of the political investment necessary for their creation. They may also require the creation of new administrative agencies, with appropriate expertise. Lacking a history of judicial precedent, uncertainties will also exist as to the meaning of terms and the applicability of the law to specific circumstances. Furthermore, sui generis laws may cause great difficulties for international legal, economic, and political arrangements. Computer programs, for example, have only recently been incorporated into the the body of many of the developed nations' copyright law, and only after many years of contention.

\section{Option \#5: Revision}

Revision would entail rewriting all or a substantial part of the Copyright Act of 1976 to conform to the policy goals that Congress seeks to further in a new technological context. A revision might retain the basic legal principles already developed in law, as the revision of 1976 did, or it might adopt wholly new principles.

Although many observers have commented from time to time on the obsolescence of copyright law, and although some have even envisioned the broad outlines of a future intellec- 
tual property law, ${ }^{140}$ OTA found few advocates of a general revision of copyright law. Indeed, most parties with whom OTA spoke indicated that they believed the Copyright Act of 1976 is adequate for the foreseeable future.

Nevertheless, Congress will have to give consideration to the general revision of the copyright laws in the course of the next decade. In addition to substantial and worsening enforcement problems, ${ }^{141}$ copyright law is becoming irrelevant to new technologies and more removed from the policy objectives for which it was designed. Hence, many of the same pressures exerted by technology on the Copyright Act of 1909, which required the 1976 revision, have al ready begun to undermine the Copyright Act of 1976. Congress should therefore begin now to gather the information necessary for the eventual revision of the copyright law.

This chapter suggests a framework for an eventual revision of the copyright law. The revision might be modeled on the trichotomy developed in this chapter for works of art, fact, and function; and it could specify rules for the protection of each. Under this system, works of art, whose value is closely tied to expression, might be protected in a traditional copyright fashion. Protection for works of fact, whose value lies in the accurate representation of reality, might be tailored to reflect this value, while at the same time assuring adequate public access to socially and politically important information. Works of function, which rely on algorithms as their source of value, might be protected along lines of patent law, with some threshold requirements of advance over prior art and disclosure.

The copyright proprietor could register his work under one of these three categories, com-

\footnotetext{
'See, e g MichaelPendleton. "Intellectual Property, I n formation. Based Society, and a New I nternat ional Economic ()rder-The Policy ( Iptions?" 2 Furopean intellectual Property Review:311 1985); Harlan Cleveland," King Canute and the Information Resource. "Technology Review, January 1984, pp. 12-1 5; (iary Klueck, "The Coming Jurisprudence of the Infor mation Age, "21 San Diego Law Review 1077-111 1/ 19811, R. Grant I ammond. "Quantum Physics, Econometric Models, and Property Rights to Information," 27 Mc Gill Law Journal 47 \{19X1): I thiel de Sola Pool, Technologies of Freedom (Cambridge. M A: Belknap I iniversity Press, 19X:11, especially pp 212-217. 'See ch. 4
}

ply with the relevant formalities of each, and receive a type of protection more closely suited to the value and social function of the work. Traditional limitations on rights, such as fair use, could be adapted to fit the particular nature of the type of work in question: for works of art, fair use might resemble its present form; fair use in works of fact might be limited according to the social utility of permitting nonproprietors to copy or publish the work; ${ }^{142}$ and for works of function, fair use might be shaped to meet the particular requirements of reverse engineering. Durational provisions could also be designed to reflect the economic "lifetime" of the particular type of information product,

Such a proposal, of course, has many drawbacks. The 1976 revision of the copyright law was a major political effort, requiring over 25 years of study and legislative bargaining. Like sui generis laws, a revision that departed substantially from the existing copyright framework might cause substantial domestic and international uncertainty. In addition, a revision would have to address concerns over enforcement, which would exist regardless of how care fully protection is tailored to subject matter.

\section{Option \#6: Alternatives to Copyright and Patent}

Congress may also wish to consider alternative options that dispense with traditionbound ideas of intellectual property, One scheme would be essentially distributive in nature, Under the distributive approach, the law might limit itself to prohibiting only the unauthorized duplication of works for a period of time. Issues concerning the cumbersome and increasingly obsolete definitions of intellectual property, such as what constitutes the appropriation of an idea versus an expression, what constitutes a derivative work, a performance, display, and so on, would be jettisoned in fa-

\footnotetext{
“"In Harper \& Row v.Nation Enterprises s, Supreme Court No. 83-1632 (1985), for example, the Supreme (ourt decided that the First Amendment interests asserted by NationMagazine were essentially spurious, since Time Magazine would have shortly provided the public with the Cerald Ford's memoirs anyway. In essence the court was passing on the balance that a works of fact provision would strike bet ween access and remuneration.
} 
vor of a law which looked to a desired outcome. The outcome might be specified in terms of recovery of fixed costs associated with the production and distribution of, and value added to, a particular work, plus rents limited to a certain rate of return. After rate of return objectives were met, the work would enter the public domain. The distributive scheme has the virtues of simplicity and adaptability, making it resistant to technological obsolescence.

Although it departs substantially from existing law, the distributive approach is not without precedent. The regulation of public utilities is conducted in a very similar fashion. Moreover, many aspects of current copyright law, such as royalties on cable television transmissions, are already moving in the direction of a distributive approach. Bills presently before Congress, which would impose a' 'compulsory license" on the sale of blank tapes and recording equipment, are also essentially distributive in nature. ${ }^{143}$

The distributive approach would require information about information markets that is presently unavailable (see ch. 6 on the Operation of Information Markets). Moreover, the distributive approach might be politically untenable, since it would essentially impose a ceiling on returns for a creative work. The administrative mechanism necessary to make the distributive scheme work, although presaged in some ways by the Copyright Royalty Tribunal, is nonexistent and would have to be carefully constructed by Congress.

Another alternative approach to the present system of copyright might be called the minimal scheme. The minimal approach would remove all legal protections except those absolutely necessary for the production of works. The problems of technological obsolescence could be avoided by avoiding entirely the need

\footnotetext{
"Specifically, S. 31 and 11. R. 1030. Like the distributional approach, these bills attempt to set 'fair' rates of taxation on blank tapes, and distribute the taxes to the recording and motion picture industries.
}

for legal categorization of subject matter and rights. Such an approach is described by J udge Stephen Breyer in an article, "The Uneasy Case for Copyright." ${ }^{1144}$ The minimal approach would be particularly well suited to a technological environment that is fast changing, and where the economic viability of creative ventures relies on the pace of innovation, rather than on legal protection for works that have already been created. One result of the minimal approach might be to speed up the production and marketing of works such as computer programs, since those who are first to the market with the best products are most likely to recoup rewards. The minimal approach would also ostensibly lower prices and eliminate the costs of copyright transactions.

The minimal approach, like all other solutions, suffers severe drawbacks. Notwithstanding its likely serious political impediments, the minimal scheme relies heavily on publishers' purported advantages in lead time and ability to retaliate in the marketplace-advantages that may be offset by the speed and low cost of modern communication technologies. A minimal approach would entail many risks to authorship and publishing as we know it, some of which are detailed in chapter 2.

Finally, another alternative approach would dispense with the notion of property, per se, and instead concentrate on remuneration based on access. Indeed, because of the advent of electronically disseminated works, many publishers are moving to an access-based system anyway. By removing concepts of property entirely, the conceptual and legal difficulties with respect to the boundaries of intellectual property that are caused by technology can be avoided entirely. The issues surrounding access-based systems are discussed in detail in chapter 7, and will not be dealt with here.

\footnotetext{
"'Stephen Breyer, "The Uneasy Case for Copyright: A Study of Copyright in Books, Photocopies, and Computer Programs, " 84 Harvard Law Review 281 (1970).
} 
Chapter 4

\section{Impact of Technology on Enforcement of Intellectual Property Rights}




\section{Contents}

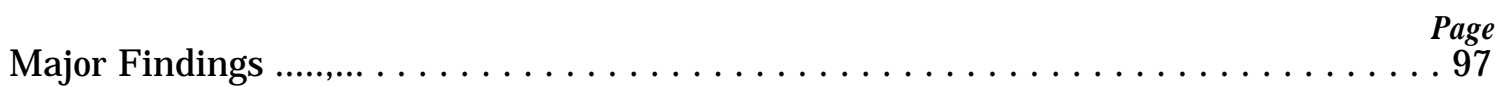

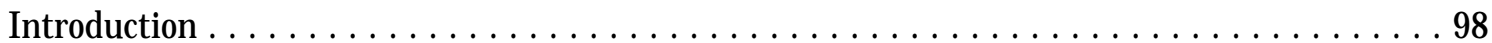

Trends in Storage Technologies: Impacts on the Right To Control

the Reproduction of Copy righted Material . . . . . . . . . . . . . . . . . . . . . . . . 99

Copyright Enforcement in the Early Print Environment $\ldots \ldots \ldots \ldots \ldots \ldots \ldots \ldots \ldots \ldots$

Impact of Reprography on Enforcement of Copyright . . . . . . . . . . . . . .99

Impact of Audio and Video Taping on the Enforcement of Copyright . . . . . . . . . 100

Impact of Computers and Digital Information on the Enforcement of Copyright. . . 102

Trends in Communication Technology: Impacts on the Right To Control

Publication and Performance . .............. . . . . . . . . . . . . . . . . . . . . . . . 104

Print, Live Performance, and Copyright . . . . . . . . . . . . . . . . . . . . . . . . 104

Impact of Radio and Television on the Enforcement of Copyright . . . . . . . . . . . 105

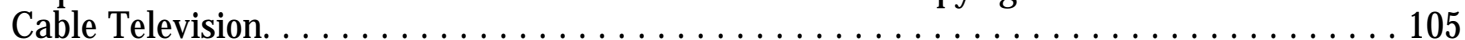

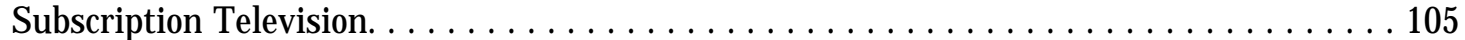

Impact of Communication Satellites on the Enforcement of Copyright . . . . . . . . . . 106

Impact of Facsimile on the Enforcement of Copyright . . . . . . . . . . . . . . . . . 107

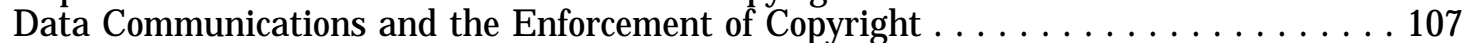

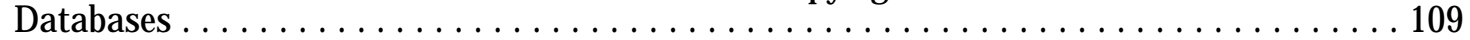

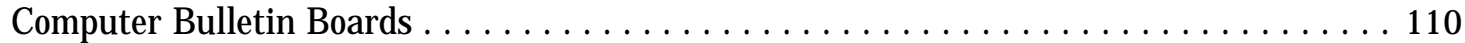

Local Area Networks . . . . . . . . . . . . . . . . . . . . . . . . . . . . . . . . . . . 110

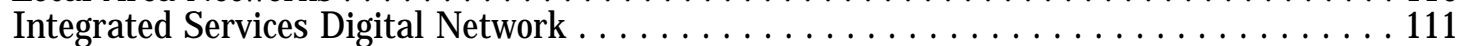

Trends in Processing Technology: Impacts on the Right To Control

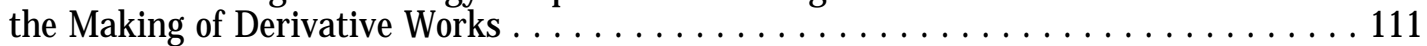

Impact of Processing Technology on the Derivation of Text . . . . . . . . . . . 112

Impact of Processing Technology on the Derivation of Music . . . . . . . . . . . 113

Impact of Processing Technology on the Derivation of Video . . . . . . . . . . . . . 113

Impact of Processing Technology on the Derivation of Computer Programs . . . . . . . 114

Adjuncts and Alternatives to Traditional Enforcement Mechanisms . . . . . . . . . . . 116

Technological Protection . . . . . . . . . . . . . . . . . . . . . . . . . . . . . . . . 116

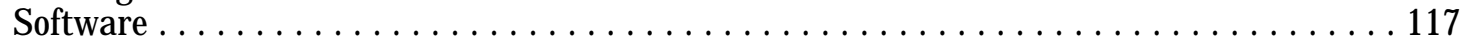

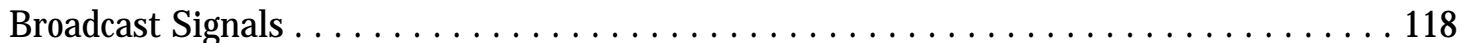

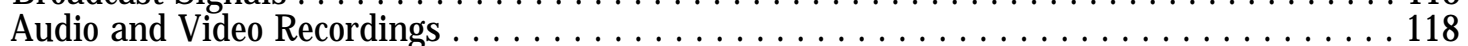

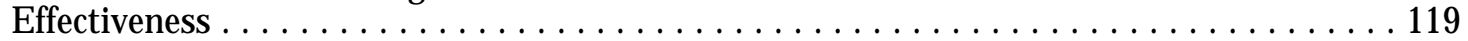

Advantages and Disadvantages of Technological Protection . . . . . . . . . . . . . . 119

Public Relations Strategies . . . . . . . . . . . . . . . . . . . . . . . . . . . . . . . . . . 120

Public Attitudes and the Legitimacy of Intellectual Property Law . . . . . . . . . . . . 121

Table

Table No. $\quad$ Page

4-1. Motion Picture Association of America Film Security Office

Recent Criminal and Civil Cases . . . . . . . . . . . . . . . . . . . . . . . . . . . . . . . . . 101

Figures

Figure No. Page

4-1. Audio Recorder Sales, 1958-80. . . . . . . . . . . . . . . . . . . . . . . . . . . . . . . . . 100

4-2. Factory Sales of Videocassette Recorders, 1977-86. . . . . . . . . . . . . . . . . . . . . 101

4-3. The Sequence of Inventions in Telecommunications, $1840-2000 \ldots \ldots \ldots \ldots \ldots \ldots \ldots$

4-4. Trends From 1960 to 1980: Volume and Costs of Communication

by Media: USA . . . . . . . . . . . . . . . . . . . . . . . . . . ...................108 
Chapter 4

\section{Impact of Technology on Enforcement of Intellectual Property Rights}

\section{MAJOR FINDINGS}

Technology is making it cheaper to copy, transfer, and manipulate information and intellectual property. For example, devices such as optical disk storage systems may allow the average person to collect entire libraries of copyrighted textual, musical, and visual works in his home. Decreasing prices and increasing capabilities of information systems will permit more people to make use of more works. Consequently, enforcement efforts will have to reckon with a much larger volume of potential infringements than exists today.

Technology is allowing the copy, transfer, and manipulation of information and intellectual property to occur more quickly. For example, fiber optic technology is currently capable, under laboratory conditions, of transferring 100 average-length novels over a distance of 100 miles in 1 second. These capabilities may soon be available in offices and homes. As a result of this and many similar developments, owners of rights may have less marketplace "cushion' in which to realize a return on their creative and financial investments. Thus, they may have less incentive to produce works.

Technology is making the copying, transfer, and manipulation of information and intellectual works more private. For example, personal computers can store, process, and communicate the contents of large commercial databases without the knowledge or consent of the compilers of such works. As a result, owners of rights face greater difficulty detecting, proving, and stopping infringements. Thus, they may have less incentive to make their works generally available.
Together, improvements in the cost, speed, and capabilities of information technologies are making traditional proprietor-initiated (civil) enforcement largely ineffective in securing reasonable control over public distribution of intellectual works. The effect might be to make investors reluctant to fund the creation of intellectual works. More likely, proprietors of intellectual property will be more hesitant to distribute their works in forms over which they have little physical control.

The technology itself is providing proprietors with ways to more tightly control the distribution of their works. Private, computerized, electronic systems can provide them with the means to enforce control by limiting and monitoring access. Policy makers may have to weigh the benefits of such control against the potential social costs of restricting public access and monitoring private citizens information use.

As technology makes the enforcement of intellectual property rights more difficult, public support for these rights becomes all the more critical. At present, however, the public has little knowledge of intellectual property rights as an issue. To the extent that citizens are aware of this issue, they draw clear distinctions between proprietors' rights to operate in the marketplace and their own rights to use information as they please in their own homes and businesses. Therefore, so long as proprietors' rights do not conflict with the public's sense of privacy and fairness, the public is likely to lend support to the intellectual property system. 


\section{INTRODUCTION}

The granting of legal rights is based on the assumption that those rights can be enforced. Intellectual property law has been based on the premise that, by and large, rightholders will enforce their own rights by monitoring the use of their works and suing infringers. To do this, they must know of specific cases of infringement, and they must be able to collect enough evidence to prove in court that a particular person or corporation violated their rights.

Information technologies are impeding traditional enforcement mechanisms. They make the copy, transfer, and transformation of works cheaper, faster, and more private, and thus more prevalent and harder to detect and prove. Without effective enforcement of their rights, intellectual property owners may have less incentive to produce and disseminate intellectual works. This, in turn, could jeopardize the benefits society gains from the open dissemination of intellectual works. And, insofar as there are widespread, unimpeded infringements, the legitimacy of intellectual property law might itself be undermined.

The enforcement problem raises fundamental questions about the nature and efficacy of the intellectual property system as a whole. Many of these issues are covered elsewhere in this report. This chapter focuses on:

1. how advances in technology are reducing the effectiveness of the traditional means of enforcement;

2. some of the private initiatives that proprietors are adopting to protect their interests; and

3. public attitudes that bear on the enforcement of intellectual property law.

To understand how technology affects the enforcement of intellectual property rights, one must begin with a central problem: As the technologies for creating, distributing, and using information change, the very concepts and definitions that have traditionally defined intel- lectual property rights and their boundaries become ambiguous. This ambiguity makes it difficult to apply the law in a consistent fashion and in a way that is consonant with the goal of promoting "science and the useful arts. In particular, controversies arise about which particular uses of new technology cause damage to creators and copyright owners, and whether such damage significantly reduces incentives to produce and disseminate works.

This chapter divides intellectual property rights into three categories, which correspond to the kinds of rights that have traditionally attached to intellectual works: the right to copy, the right to publish and perform, and the right to make derivative works. These categories are used only to describe the new technologies in terms with which policy makers are familiar. Their use should not imply that these rights should be extended or enforced. In fact, one of the challenges that policy makers face is understanding whether traditional concepts can be employed in new technological contexts.

The impact of technological change is different for different intellectual property rights. This chapter examines trends in three categories of technology, each corresponding to a particular kind of right traditionally granted by copyright law. Changes in storage technologies, for example, affect the right of proprietors to control the copying of their works. Advances in communication technologies affect their right to control publication and performance And new information processing technologies affect the proprietors' right to control the production of derivative works. Moreover, to demonstrate the effect of advancing technology on enforcement, this chapter will also look at how these technologies interact with each other in integrated computer- and telecommunications-based systems. In the long run, it is the convergence and interaction of these technologies that may prompt the most significant enforcement problems for the intellectual property system as a whole. 


\section{TRENDS IN STORAGE TECHNOLOGIES: IMPACTS ON THE RIGHT TO CONTROL THE REPRODUCTION OF COPYRIGHTED MATERIAL}

Information storage technologies are devices and systems that fix and hold information in a reusable form. Storage technologies include paper and ink, photographs, vinyl disks for musical recordings, motion-picture film, audio and videocassette tapes, semiconductor memory chips, and optical disks, among others.

Two recent trends in storage technology are likely to affect the enforcement of intellectual property rights. First, as storage technologies become cheaper and capable of holding more information, it becomes harder to enforce proprietary rights; more people can use these technologies to copy works privately. Secondly, storage technologies are becoming less specialized to specific forms of information. They are often part of computerized systems that handle many forms of information-e. g., text, graphics, music, and video. Information in computerized, digital form is much harder to control than information in traditional formats. Together, these two changes transform copying into a problem of much greater scope for proprietors than it has ever been before.

\section{Copyright Enforcement in the Early Print Environment}

When first enacted, American copyright law protected expressions of information in the form of printed text and graphics: books, maps and charts. ${ }^{1}$ Anyone seeking to fix or store these expressions for dissemination had to make a relatively large investment in capital goods: movable type, volumes of paper and ink, mechanical presses, and other equipment. They had to obtain skilled labor: typesetters, printers, draftsmen, and others. These activities were difficult to conceal. They also had to offer copies in the open marketplace. The public quality of these operations meant that copyright owners could detect and stop large-scale, economically damaging infringements, thus

\footnotetext{
'Chapter 1 15. Section 1, Statute 124, Act of 1790.
}

controlling the reproduction of their work with relative ease. Copying by hand for personal use and scholarship was not a major problem. It did not threaten proprietors because it was not a viable means of competing with copyright holders or of denying them sales revenues from their work.

Although technology changed through the 19th and early 20th centuries and provided new forms in which to fix expressions of information-photographs, lithographs, motion picture films-the capital and labor required for reproduction remained fairly high, and competitive infringing activities were still hard to conceal. Thus, these technologies posed only minor problems in copyright enforcement.

\section{Impact of Reprography on Enforcement of Copyright}

In the mid-20th century, photocopying, mimeograph, and xerography were developed, making it much cheaper and easier to reproduce printed materials. More people began to copy text and graphic images, making it harder for copyright holders to monitor such activities. As these technologies became more common, it became too costly and impractical for proprietors to try to authorize copying, collect royalties, and enforce their rights on a caseby-case basis, even if users were inclined to seek permission and pay for use.

It is difficult to estimate the economic impact of this unauthorized copying. In general, while we know that xerographic reproduction causes some lost sales for copyright holders, it does not appear to be a serious threat to the economic viability of general-interest book, magazine, or newspaper publishing. ${ }^{3}$ Publish-

\footnotetext{
"By the term "unauthorized," this chapter means those uses of copyrighted works that have not been specifically permitted by the copyright holder. It does not seek to imply that these uses are, or should be, illegal.

'The number of titles published and the profits of publishers have remained high despite the introduction and spread of (continued on next page)
} 
ers of very specialized periodicals with small circulations, such as scientific and technical journals, contend that disastrous losses of sales could result if corporations and libraries replace multiple subscriptions with photocopies. If such replacement were occurring on a large scale, one might expect a decline in subscriptions and an eventual reduction in the range of titles published. However, Copyright Office data from publishers on trends in the numbers of titles and subscriptions in this category of copyrighted works are inconclusive. They do not show that specialized scientific and technical publications are significantly more affected by photocopying than are general-interest periodicals. ${ }^{4}$

\section{Impact of Audio and Video Taping on the Enforcement of Copyright}

J ust as reprography has led to unauthorized copying of text and graphics, the recent widespread availability of audio and video taping technologies has brought about more unautho rized reproduction of recorded music and motion pictures. Here, too, copyright holders are faced with the difficult problem of controlling copying while millions of people own machines that can reproduce their works in private, at fairly low cost and with little effort.

The level of use of audio and videotape technologies is high and rising. (See figures 4-1 and 4-2.) By 1982, 52 percent of Americans over the age of 13 had used audio tape machines within the previous 2 years to record phonograph records and other materials. ${ }^{5}$ By the end of 1985, 37 percent of American homes had

(continued from previous page)

xerographic technology, which was first commercially available in 1960. See Michael Rogers Rubin and Mary Taylor Huber, The Knowledge Industry in the United Stated: 1960-1980 (Princeton, NJ : Princeton University Press, 1986 (in press)). Between 1960 and 1980, industry sales increased from $\$ 1$ to $\$ 4$ billion. Paul M. Hirsch, "U.S. Cultural Productions: The Impact of Ownership, "Journal of Communication, vol. 35, no. 3, Summer 1985, p. 117.

'Dennis D. McDonald and Colleen G. Bush, Libraries, Publishers and Photocopying: Final Report of Surveys Conducted for the United States Copyright Office, May 1982, table 4-6, p. 4-16.

${ }^{5}$ Yankelovich, Skelly \& White, Inc., Why Americans Tape: A Survey of Home Audio Taping in the United States, September 1982, p. 28.
Figure 4-1.-Audio Recorder Sales, 1958-80

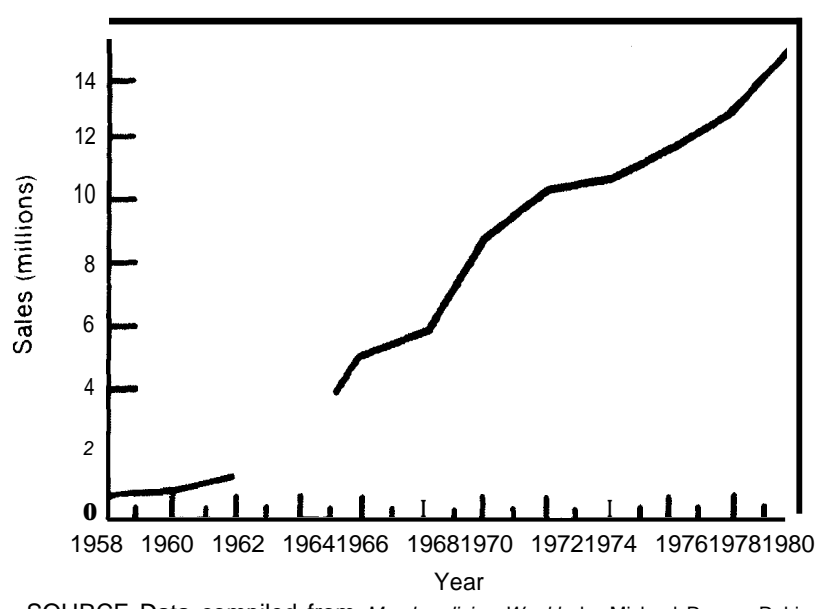

SOURCE Data compiled from Merchandising Weekly by Michael Rogers Rubin and Mary Taylor Huber, The Knowledge Industry in the United States, 1950-1980 (Princeton, NJ Princeton University Press, 1986), in press

videocassette recorders, up from 28 percent at the end of $1984 .^{6}$

Consumers use video recording machines for "time shifting" - that is, recording tel evision broadcasts to enjoy at a more convenient time.' They often use audio tape machines to record music to play in more than one location, for instance, in a car. Some tape machine owners use their machines to trade music or video programs with friends, and to build personal libraries.

These machines are also used for less casual purposes, such as the mass duplication of copyrighted works to sell in direct commercial competition with copyright holders. Many proprietors contend that commercial piracy of audio and video materials is widespread.

\footnotetext{
${ }^{6}$ Electronics, J an, 6, 1986, p. 50. Some industry analysts predict that 70 percent of U.S. households will have VCR equipment by the early 1990s. See Alex Ben Block, "Hard Dollars in Video Software, " Forbes, J une 17, 1985, pp. 128-131.

The recording of commercially broadcast television for time-shift viewing was specifically found to be fair use by the Supreme Court. See Sony Corp. $v$. Universal City Studios, 464 U.S. 417 (1984).

"The movie industry, through its trade association, the Motion Picture Association of America (MPAA), established a Film Security Office in 1975 to combat commercial piracy of films distributed by the major Hollywood studios. See table 4-1 for some of their recent enforcement statistics. The musical recording industry claims, on the basis of surveys conducted by the International Federation of Phonogram and Videogram Producers, that one out of four musical recordings sold worldwide is a pirate copy. In the United States, their data estimate 1 in 10 copies sold is illegitimate. (Reported in Variety, J uly 31,1985, pp. 1, 92.)
} 
Figure 4-2.- Factory Sales of Videocassette Recorders, 1977-86

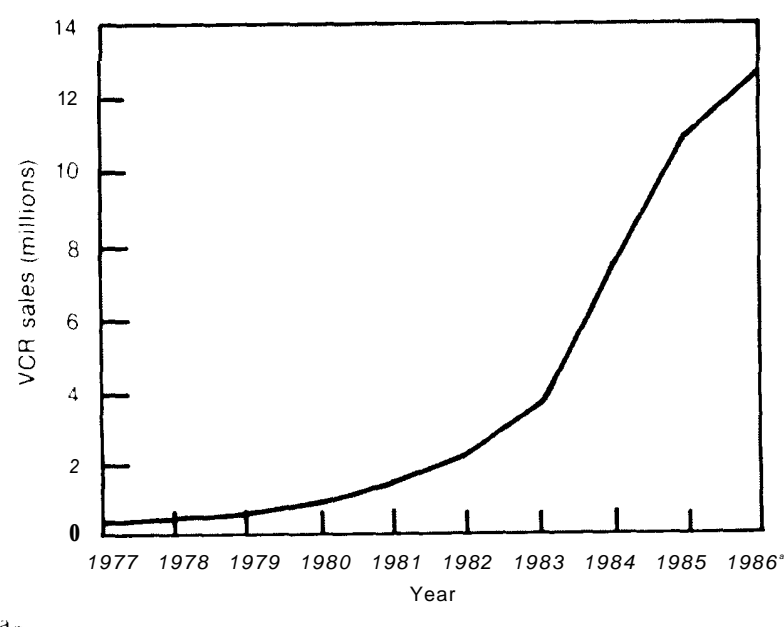

aEstimat:

SOURCES 1977.79: U S Department of Commerce Bureau of the Census Statistical Abstracts 1980. 1980-83. Statistical Abstracts 1985 1984-85. Electronic Industry Association Electronic Market Trends March 1986 1986: Electronic Industry Association estimate.

Some owners of copyright in musical recordings and motion pictures have presented figures to support their claims of substantial economic losses from consumers use of audio and video taping technologies. In testimony before the Senate J udiciary Committee on October 25, 1983, Alan Greenspan presented evidence collected for the Recording Industry Association of America suggesting that in 1982 the industry sustained sales losses of more than
$\$ 1.4$ billion that were attributable to home taping of borrowed recordings and radio broadcasts. ${ }^{9}$ Battelle Pacific N orthwest Laboratories, in a study performed for the Motion Picture Association of America, estimated that, in 1982, motion picture copyright owners had lost more than $\$ 57$ million in royalties because videocassette sales were displaced by home tape copying and off-air taping. ${ }^{10}$

These figures, however, are not definitive. As detailed in chapter 7, the question of whether a particular instance of copying actually displaced a sale of a copy is often impossible to answer definitively. Moreover, to the extent that the data are inadequate, or that the analyses are inappropriate, these studies may either grossly overestimate or underestimate the actual harm suffered by musical recording and motion picture copyright proprietors. ${ }^{11}$ Some analysts have suggested that there are better methodologies for determining the economic losses from home taping. In deciding intellectual property policy, policy makers will most

\footnotetext{
"Statement of Alan Greenspan Re. S.31 Before the Subcommittee on Patents, Copyrights and Trademarks, Senate Committee on the J udiciary, Oct. 25, 1983, p. 7.

"F.J. Cronin, R.J. Ness, A.R. Wusterbarth. and J . I,. Eisenhauer, An Analysis of the E conomic Benefits and Harm From Videocassette Recorders and Related Products, August 1983, as cited in Economic Issues Relating to New Technologies and Intellectual Property, by Stanley M. Besen (contract prepared for OTA, December 1984), p. 44,

"See Besen, op. cit., pp. 47-48.
}

Table 4-1. - Motion Picture Association of America Film Security Office Recent Criminal and Civil Cases

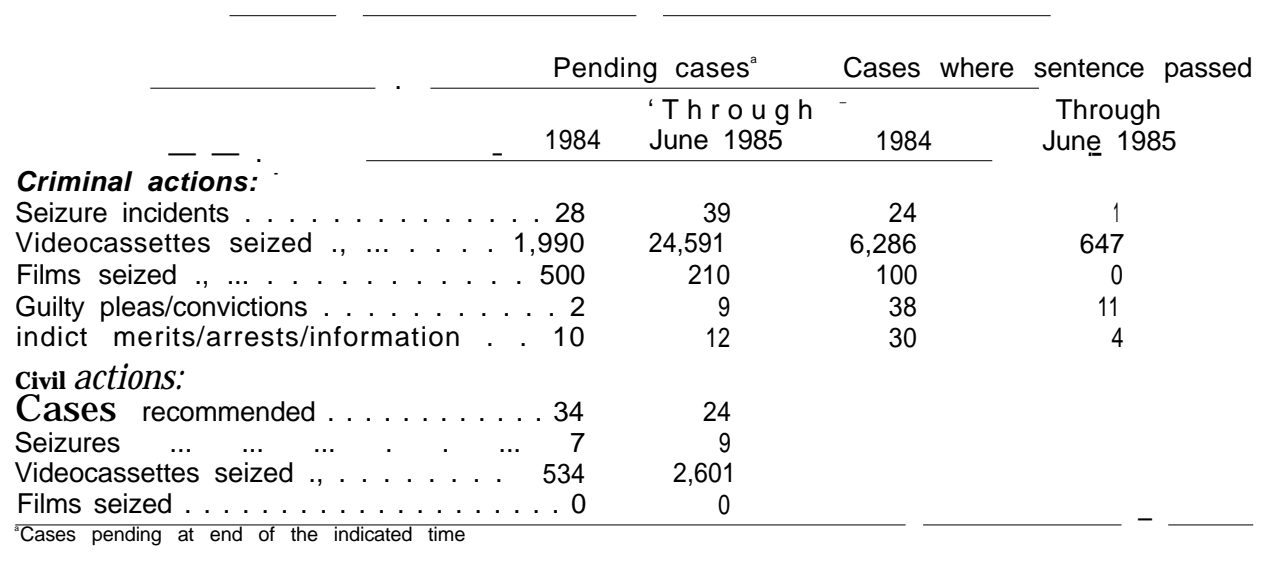

SOURCE: Motion Picture Association of America 
likely want to take these alternative analytical approaches into account. ${ }^{12}$

\section{Impact of Computers and Digital Information on the Enforcement of Copyright}

The growing use of computers to handle and store information could make it even harder for copyright holders to enforce their rights. In the case of the right to control reproduction, the computer poses three major problems for copyright proprietors that are distinct in kind as well as in degre from other technologies used to store or copy information.

First, copying digital information can be done at a fraction of the cost and in a fraction of the time that it takes with photocopying or analog audio or video taping. Second, the digit al nature of computer-mediated information means that an infinite number of perfect copies of material can be made. Possession of an original is not required to obtain subsequent copies of original quality. Thus, the information content of a work can be completely separated (or unbundled) from the medium that carries it. ${ }^{13}$ Third, in the normal course of operations, a computer makes many copies of parts of works. Some copies exist for only a few millionths of a second. Other copies may be held until the machine is turned off or the material is written over. Some copies may be held in permanent form on magnetic disk or tape. ${ }^{14}$

\footnotetext{
"See Besen, op. cit., pp. 39-40. See also Stanley M. Besen. Private Copying, Reproduction Costs, and the Supply of Intellectual Property (prepared for the National Science Foundation, December 1984); and I.E. Novos and M. Waldman, "The Effects of Increased Copyright Protection: An Analytical Approach, ' $92 \mathrm{~J}$ ournal of Political Economy 236 ( 1984).

' 'Users' ability to unbundle information may have a significant impact on the alternatives that proprietors pursue to protect their economic interests in intellectual property. See ch. 6 , for further discussion on this point.

"In the case of computer programs, "a user is at least somewhat negligent if he does not make copies of his programs. [There are] two reasons [for this]: 1) one cannot see by visual inspection if a program is intact; and 2) operator error or program "glitches" can quickly destroy a program. Thus good programming practice and copyright regulations [may be] mutually exclusive. " Personal communication from Edward Conklin, FORTH, Inc., J uly 23, 1985.
}

Because of these characteristics, computers pose novel questions for enforcement. For example, how, aside from appeals to ethics, can proprietors convince consumers to buy originals when perfect copies are probably much cheaper? How can consumers tell whether they are purchasing originals or counterfeits? At what point is the proprietor's right to control copying violated within a user's computer system? ${ }^{15}$ Similarly, how much of the material that resides in a computer can or should be recognized as part of the copyrighted work?

These problems are emerging at a time when monitoring and stopping the copying of works is becoming harder. The proprietors' right to control copying may thus be severely challenged by the growing scale and private nature of infringement made possible by increasingly powerful and widely used personal computers. Also, as discussed below, computers' processing capabilities may pose special problems with respect to proving infringement.

Currently, users receive a relatively small amount of copyrighted material in digital, computer-readable form-computer programs and a small but rapidly growing amount of material made available through on-line databases. But this is changing with other technological advances that simplify the conversion of printed text and graphics into machine-readable, digital format. Optical character readers for text input are growing in popularity in offices as prices fall and capabilities rise. Some analysts expect that these machines will be widely used by the end of the decade. And if price and capability trends continue in their current direction, the automatic conversion of printed or written text and graphics into computer-readable form may become a routine practice by the turn of the century. ${ }^{16}$

Once in a computer in digital form, text can be reproduced with a growing array of computer-driven printers. These range in price and

\footnotetext{
"section 117 of Title 17 addresses this problem, but the language has yet to be widely tested by the courts.

"Outl ook for Office Automation Technologies 1985-2000, report prepared for OTA by the Georgia Institute of Technology, J.D. Roessner, principal investigator, March 1985.
} 
capability from the cheap, fairly slow, and lowquality dot-matrix and thermal transfer devices, to very fast and high-quality laser and ink-jet devices. As these technologies mature, as manufacturing techniques improve, and as economies of scale are realized, consumers will most likely be able to get faster, better printers for lower cost. ${ }^{17}$

Record companies are beginning to offer music to consumers in digital form by way of compact disk players and laser-scan disks. In their present form, compact disks are read only, which means that users cannot record on them, although one can record analog tapes from them with cassette or reel-to-reel tape machines. But manufacturers of laser disks are developing erasable and rerecordable media similar in storage capacity and durability to compact disks. With these, consumers may be able to reproduce the full, master recording quality of compact disks on home equipment.

Copying video in digital form is now limited by the fact that current television transmitters, receivers, and video recorders supply the material in analog form. International standards-making committees are discussing the establishment of digital television and video tape standards, so this situation could change very quickly.

The digital optical disk, a technology that uses lasers to record and read information off a disk that rotates at a high rate of speed, offers great. potential for storing very large volumes of digitized information. A single read-only op-

\footnotetext{
Paper will continue to be an important temporary storage medium because people tend to prefer the higher contrast, portability, and other characteristics of print that video screens lack, But electronic and optical media are becoming more attractive for permanent storage of information in many applications be cause storage volume is vastly reduced and cost and convenience of access can be superior to paper storage. Thus the trend at least in repeated-use and interactive applications, is toward mass electronic and optical storage and on-demand printing. E.C. McIrvine at the OTA Workshop on Display, Printing, and Reprography, Mar, 13, 1985,
}

tical disk, currently on the market, can easily store several hundred thousand pages of printed text, 6 hours of master recording quality music, or 2 hours of full-motion, television quality video. In some applications, many disks are collected in an automatic playback machine much like a jukebox. This is being done for the optical disk project at the Library of Congress in which old books, photographs, and etchings are being digitized and stored on optical disks. Thus, a very large volume of information can be made available on-line (by computer terminal) at very low cost for storage and access.

In their present form, optical disks can be written on only once, and then only using a relatively expensive high-power laser device to impress digital data on the disk. But several companies, both in the United States and abroad, are working intensively to develop optical media and supporting hardware that allow a disk to be recorded, erased, and rerecorded many times. ${ }^{18}$ Their goal is to manufacture a device that the average consumer can use with his personal computer, stereo, and television equipment. This technical advance would make it even cheaper and easier to copy information, while increasing the speed at which a computer could access the large volume of information storable on optical disks.

In summary, advances in information storage technology have made the process of copying information cheaper, easier, and available to more people. These trends show every indication of continuing. The technologies are making the old definitions of "rights, "infringemerits, " and "fair use" ambiguous and largely obsolete. Because of technical advances and the blurring of definitions, the traditional copyright enforcement mechanism, whereby proprietors sue violators in civil proceedings, may no longer be effective in protecting the creative and economic interests of copyright owners,

\footnotetext{
"B. Dumaine, "Here Comes the Erasable Laser Disk, ' Fortune, Mar. 5, 1985, p. 100,
} 


\section{TRENDS IN COMMUNICATION TECHNOLOGY: IMPACTS ON THE RIGHT TO CONTROL PUBLICATION AND PERFORMANCE}

Communication technology is the term that encompasses the many devices and systems used to move information from place to place. These technologies evolved very slowly until the 1840s, when, after electronic telegraphy was developed, they rapidly grew in capability. Since then, innovations in telecommunication technology have quickly advanced the speed, distance covered, and scope of interconnection of people and places, all of which are still growing exponentially (see figure 4-3).

These technologies are now part of the basic infrastructure of society. We have come to rely, for example, on the telephone system, broadcast radio, and television to supply us with vital information about our family, friends, businesses, and government.
Increasingly, we also receive information products and services through telecommunication links that entertain, educate, and help us make decisions. Since many of these goods and services are protected by intellectual property law, advances in communication technologies will have a major impact on enforcement of intellectual property owners' right to control the publication and performance of their works over telecommunication facilities.

\section{Print, Live Performance, and Copyright}

Before the 1920s, communication technologies had very little affect on the enforcement of copyright, simply because copyrighted

Figure 4-3.-The Sequence of Inventions in Telecommunications, 1840-2000

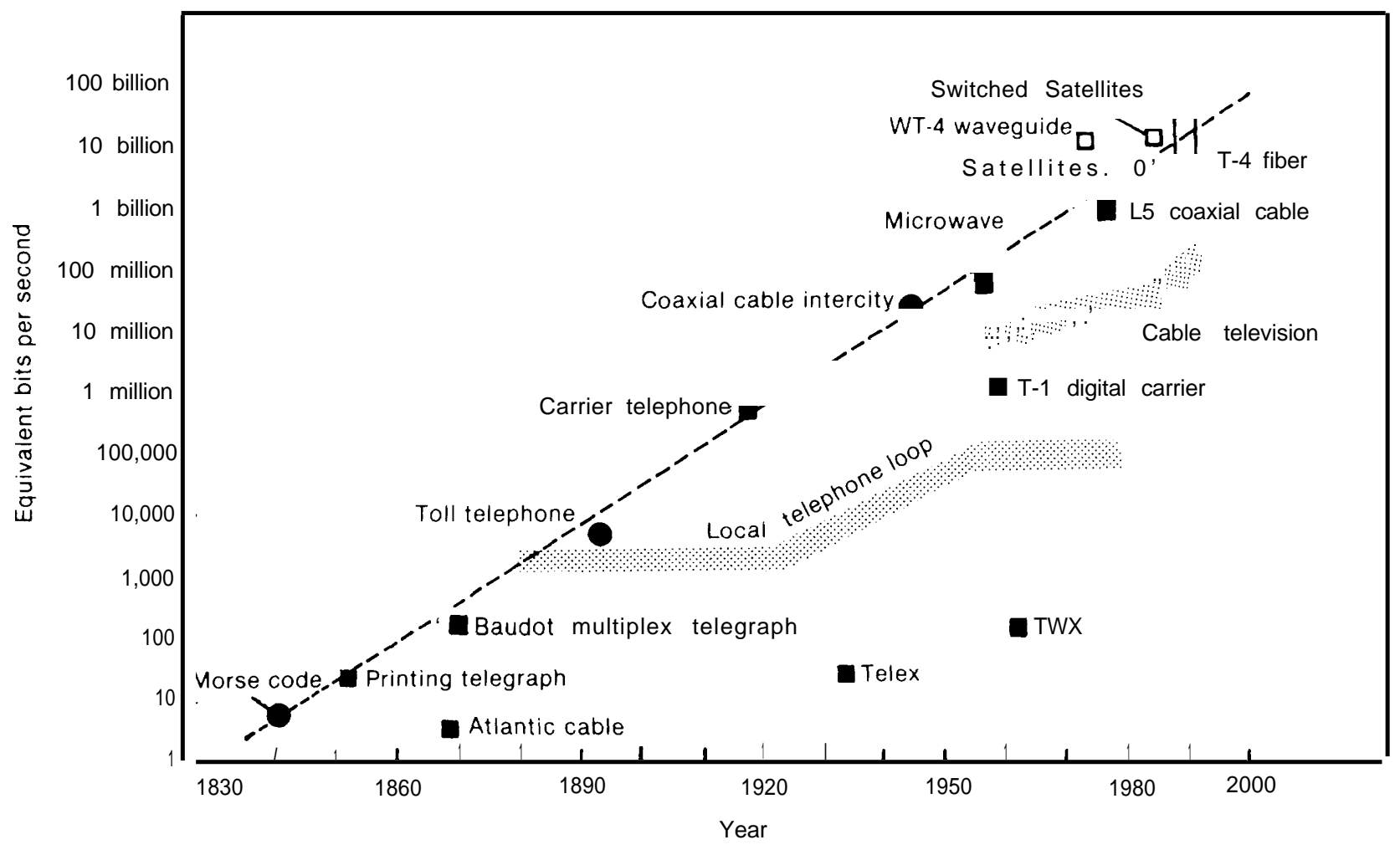

SOURCE Richard J Solomon and John Ward, Massachusetts Institute of Technology Adapted from James Martin, Future Developments In Telecommunications, 1976 1980 Annenberg School of Communications Used with permission. 
works were communicated by physically moving printed copies or by expressing the works in live stage performances. As the country expanded, there were undoubtedly many unauthorized performances of copyrighted dramatic and musical works, but the important markets for such uses were in large cities, so composers and dramatists found it possible to monitor enough of the uses of their work to protect their economic rights.

\section{Impact of Radio and Television on the Enforcement of Copyright}

Broadcasting changed this. Commercial radio broadcasting, initiated at KDKA radio in Pittsburgh in 1920, complicated copyright enforcement by dispersing a "performance" over a wide area. When the networks such as NBC were formed soon after, performances could be heard over virtually the entire nation. Thus, broadcast technology made "collecting at the door" from users of a performance of copyrighted music virtually impossible. To continue profiting from the use of their work, the owners of copyright in music and the broadcasters devel oped the system of advertiser support for the actual broadcast, and established contracts with collecting societies to monitor the use of copyrighted work and to pay composers' royalties. (See ch. 9 for details on collecting societies. )

The advent of broadcast television presented similar enforcement problems for copyright holders. To solve them, networks made similar arrangements to finance the cost of presenting "free" television to the public. This system of advertiser support and contracting with copyright proprietors for use of their work provided a viable and lucrative means of presenting and paying to broadcast musical entertainment.

\section{Cable Television}

Cable television originated as a means of providing television to remote areas by the reception of broadcasts with a tall antenna and retransmission of them by wire to subscribers.
Subsequently, because of the way the courts and Congress have intervened in the relationship between copyright holders and cable broadcasters, it has become a technology with significant implications for copyright enforcement.

Cable television itself does not present intractable problems of detecting or proving infringement because most existing cable systems are public. "But cable television systems have had to contend with two other enforcement problems. One is theft of service, which is the deliberate unauthorized connection to a cable service. The other is the high transactions costs that multiple-channel cable companies face in identifying and negotiating royalty payments with the many copyright holders in television. Congress acknowledged the magnitude of the second problem by establishing the Copyright Royalty Tribunal to set cable retransmission royalty rates and to disperse funds collected by the Copyright Office. ${ }^{20}$

\section{Subscription Television ${ }^{21}$}

Some over-the-air television stations scramble their signals to prevent access unless the consumer has rented a décoder box and paid a subscription. The direct enforcement problem with subscription television (STV) is theft of service. Some users and commercial companies build illegal decoding equipment that allows users to receive subscription television signals without paying the station. In this event, the copyright holder may be undercompensated because his royalty payments are based on the size of the paying audience for a subscription television broadcast.

Television is also relayed to paying subscribers by microwave radio. This is called $\mathrm{Mul}$ -

\footnotetext{
"+ There are a growing number of private cable television operations, generally called Satellite Master AntennaTelevision (SMATV) that may present difficult enforcement problems. These systems will be discussed below,

${ }^{24}$ U.S. House of Representatives, 94th Cong., Report 941476, p. 88

Subscription television was originally ( 1964 ) a term applied to cable television in California, Erik Barnouw, Tube of Plenty (New York: Oxford University' Press, 1982), p. 350. Now it is usually applied to transmissions over VHF and UHF channels that are scrambled.
} 
tipoint Distribution Service (MDS). In some areas, companies have set up several microwave channels for television delivery; these systems are called Multichanne Multipoint Distribution Service (MMDS). To receive these signals, consumers need a special device called a down converter and also a special antenna. Together, the converter and the antenna make the higher frequency microwave signal compatible with a standard television set. MDS companies rent these devices and charge a monthly fee for the program service. But the devices are widely available from sources other than MDS companies. Thus, like STV, the MDS enforcement problem generally involves theft of service. MDS is treated by the FCC as a common-carrier system; channel time is leased to program suppliers on a tariff basis. Copyright holders contract with MDS companies for transmission services and revenues are based on the size of the paying audience. Thus, program suppliers and transmitters are undercompensated to the extent that there are 'free riders.

\section{Impact of Communication Satellites on the Enforcement of Copyright}

Geosynchronous communication relay satellites affect the enforcement of copyright law because an increasing amount of copyrighted material is being transmitted by these systems. Currently, anyone who has a proper antenna 'dish' and a down converter can receive the material. Much of the copyrighted material transmitted by these satellites is intended for cable television "head-ends, or transmission facilities, or for broadcast stations affiliated with television networks. Many of the unauthorized users are home consumers who live far from VHF and UHF stations, have poor reception, and no cable service. For these people, satellite signals offer a wide selection of programming (more than 100 channels) with high signal quality for the one-time cost of the dish and the down converter. These systems are currently priced as low as $\$ 1,000$, depend- ing on dish size and its ability to aim the receiver at more than one satellite. ${ }^{22}$

Some hotels and other commercial establishments also use satellite-derived programming, capturing it with roof-top dish antennas and cabling it to their customers. Some apartment complexes install satellite reception gear and small, private cable distribution systems that compete directly with municipal cable operations. These are the SMATV systems mentioned earlier. Many of these uses of copyrighted programs are authorized by contract, but others may not be.

Other unauthorized users are in foreign countries that fortuitously fall within the "footprint" of one or more satellite signals. These foreign users often retransmit satellite-derived material over government or privately owned cable or over-the-air broadcast facilities without seeking the permission of, or making payment to, the copyright holders. As with other types of subscription-based television (STV, MDS, MMDS), if copyright royalty contracts are based on the size of the paying audience, these unauthorized uses deprive copyright holders of rightful compensation.

When revising the Communications Act in 1984, Congress, recognizing the already widespread use of satellite signals by home consumers, put the onus of enforcing property rights in these transmissions on the program providers and the satellite system operators. The revisions encouraged them to establish market mechanisms for payment, and to encrypt their signals. Congress struck a compromise between the interests of copyright holders and those of owners of satellite dishes, making it illegal for unauthorized users to intercept certain satellite signals. However, interception of satellite signals is not a violation if:

\footnotetext{
"'Michael Doan, "A Scramble To Break the Satellite Dish, ' U.S. News and World Report, Sept. 30, 1985, pp. 52-53. In 1985, over 1.4 million homes had satellite dishes, and some believe that this number could double in 1986. Sales are quite brisk, approaching 50,000 units per month. New York Times, July 8,1985 , pp. $1, \mathrm{C} 16$.
} 
(1) the programming involved is not encrypted: and

(2)(A) a marketing system is not established. . . ${ }^{23}$

At least one company, Home Box Office, Inc., has begun to encrypt its satellite transmissions to some cable companies. ${ }^{24}$ At present, such encryption is expensive because all receivers must be provided with decoding equipment. It is not yet clear to what extent other program providers will see an advantage in employing encryption to protect satellite television transmissions.

A new use of satellite transmission to deliver copyrighted works could further complicate enforcement. A number of companies are trying to find a way to develop a profitable market to satisfy the growing demand for distribution of television programming by satellite. One possibility, direct broadcast satellite (DBS) technology, could provide consumers with a service that offers as many channels as cable television. The service would sell or rent satellite dishes and down converters to home video consumers, and transmit television signals directly to them.

DBS could complicate enforcement of current theft-of-service and illegal signal interception laws if some DBS program providers offer free services, or if program providers cannot agree to encrypt all satellite television signals. In either case, the mere possession of a backyard dish and special microwave reception equipment would not be sufficient evidence to prove unauthorized use. "Indeed, unauthorized use could be very difficult to stop.

Todemand payment from a user, program owners must prove that the user actually snatched and watched a program. Short of staking out the farmhouse with electronic eavesdropping equipment and then storming

47 U, S.C. . Section 705, 318 (1984)

U.S. News and World Report, Sept. 30, 1985, p. 52.

- In the case of MDS receiving equipment, the courts have found that the manufacture and sale of down converters and antennas without authorization from program providers is a violation of the Communications Act and FCC regulations. See United States v. Stone, U. S. D, C., Southern District of Texas, Houston Division, Aug. 11, 1982; and Movie Systems, Inc. v. Heller, U.S. Court of Appeals, Eight Circuit, decided J une 30, 1983. it with a search warrant, how can program owners prove a farmer ripped them off?

Impact of Facsimile on the Enforcement of Copyright

Facsimile is a communication technology with potentially significant implications for copyright enforcement. Facsimile machines work by scanning a document and digitizing its image. This is distinct from optical character recognition (OCR), which scans a document and digitizes the individual characters so that the text can be manipulated in a computer system. OCR can be thought of as a further processing step beyond that employed in facsimile.

Because the present cost of facsimile is high compared to mail delivery, for which it substitutes, its current impact on copyright is probably small. But as seen in figure 4-4, the volume of information communicated by facsimile has risen sharply over the past two decades, and it is becoming more and more attractive as a means of moving documents.

Normally, a facsimile document is transmitted over telephone lines to a facsimile decoder and a xerographic copier. The document is communicated in digital form. Therefore, copyright problems could arise if the cost of transmitting information this way drops significantly for, as with data communications, the transmission of information by facsimile technology is highly covert.

\section{Data Communications and the Enforcement of Copyright}

Data communications is the term used to describe computer-to-computer transfer of digital information. The copyright enforcement problems associated with data communications result from their growing scope, scale, and speed combined with the covertness with which people can take advantage of these advances. In practical terms, this means that, as more and more copyrighted material is avail-

\footnotetext{
"Alex Ben Block, "An Eye in the Sky," Forbes, November 1984, p. 196,
} 
Figure 4-4.-Trends From 1960 to 1980: Volume and Costs of Communication by Media: USA (plotted on log by log scales)

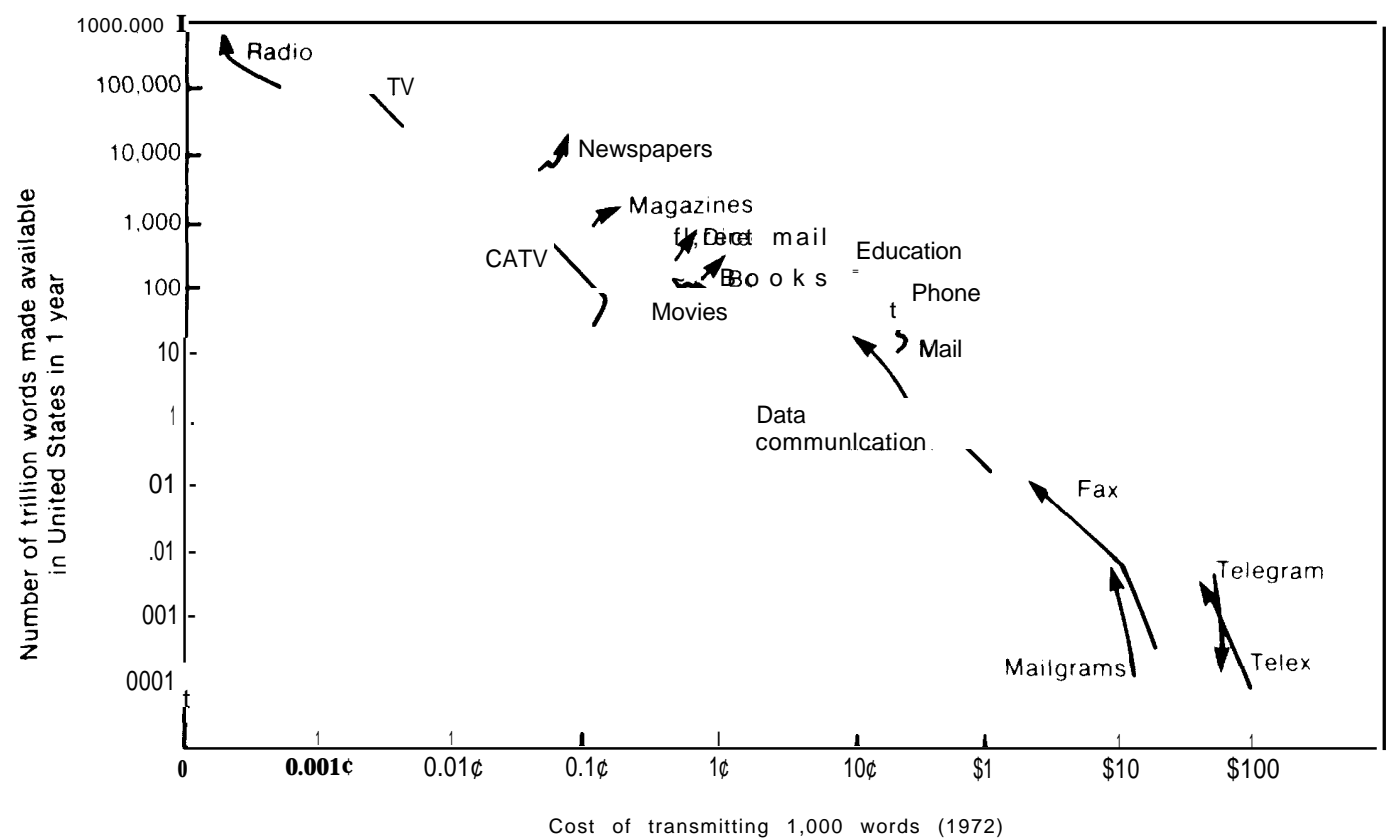

While the cost trends for print media remain steady, electronic media costs have dropped dramatically in the past two decades,

SOURCE Ithiel de Sola Pool, Hiroshi Inose, Nozomu Takasaki, and Roger Hurwitz, Communication Flows (Tokyo University of Tokyo Press or New York: Elsevier, 1984) Reprinted with permission

able in computer-mediated form, people will be able to transfer it widely and quickly without the knowledge or consent of copyright holders.

Scope, in this context, refers to the number of terminal points that are connected by communication networks. For instance, the scope of mail delivery and telephone networks are both very high. Data communication techniques use devices called modems, which convert digital computer information into analog form compatible with telephone voice transmission lines, to take advantage of the scope of the telephone network for computer-to-computer transmissions. The development of an Integrated Services Digital Network (see below) will eliminate the need for these devices and will further increase the scope of data communications.

The use of data communications is expanding rapidly for several reasons. First, scientists and engineers have made great technical advances in moving information electronically.
Satellite communications and fiber optic technology are both fruits of this progress. Second, costs of manufacturing, installing, operating, and maintaining the transmitters, receivers, switching equipment, and other components are falling as economies of scale affect microelectronics technology. Third, the use of computers is increasing people's ability to receive and handle information automatically. For instance, on-line database systems can watch for information that is of particular interest to an individual, and alert that person when new information pertaining to the subject enters the database.

The scale of communications, the second factor in enforcement problems, refers to the volume of information that is moved. There is no precise measure of information volume that can be applied across all forms of information. ${ }^{27}$

\footnotetext{
"The measure of information volume is complicated by the multiplicity of forms in which information exists (words, numbers, mathematical formulae, graphics, moving pictures, etc.), as well as by the range of media that communicate information (e.g., printed pages, -television broadcasts, motion picture film).
} 
Nevertheless, it is clear that electronic media in general, and data communications in particular, are fostering an enormous increase in the volume of information transported. This increase is due to the same factors that account for increasing scope. But the scale of data communications is also growing because information is a highly efficient means of affecting the control of processes from a distance. Thus, data communications can substitute for human observation and action.

The volume of information that passes through data communication networks is still small compared with the amount of printed material distributed through traditional channels. But, as seen in figure 4-4, data communication volume increased approximately 1,000-fold between 1960 and 1980. The personal computer and the modem will undoubtedly increase this further, and technological advances such as optical character recognition, voice recognition, and optical disks will make data communications an even more attractive way to transfer many kinds of information, some of it in copyrighted form.

The speed of electronic communications is the third factor that affects copyright enforcement, and it too is increasing at a dizzying pace. (See figure 4-3.) Not only have new inventions allowed faster communications, but $R \& D$ laboratories are continually advancing the speed of established communication devices and media. For example, the achievable speed of data communications over standard copper wire pairs, such as the wires that run to home telephones, have increased 100 -fold since 1970. The channel capacity of coaxial cable, the stand-

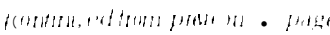

This protean quality has so far defied the development of a universally applicable unit of measurement. As more and more information is transmitted by data communications, the digital bit-electronic ones and zeros-may become a gross measure. But the relationship between the number of bits in a communication and the quantity of useful information or knowledge contained in them is very complex. "One longs, indeed, for a unit of knowledge, which perhaps might be called a "wit analogous to the "'hit' as used in information theory; but up to now no practical unit has emerged." Kenneth Boulding, "The Economics of Knowledge and the Knowledge of Economics, Economics of Information and Knowledge, D.M. L.amberton (cd. ) (Baltimore: Penguin Books, 1971 I. ard cable television medium, has increased from 12 to 54 channels since 1975, and the newer systems have potential for transmitting 72 simultaneous full-motion television channels over one coaxial cable. Geosynchronous communication satellites have increased in capacity since the 240 voice channel (or one TV channel) "Early Bird" I ntelsat I was launched in 1965. The Intel sat $V$ series, first launched in 1980, averages 12,000 voice circuits and two TV channels. The capacity of fiber optics technology has improved more than 100-fold since its commercial introduction in 1977. Recent laboratory tests of new fiber optic systems demonstrate the ability to transmit 300,000 telephone conversations, or the contents of 100 average-length novels, a distance of nearly 100 miles in 1 second. ${ }^{28}$

A characteristic of data communications with important implications for intellectual property enforcement is that digital transmission can usually be conducted with a high degree of secrecy. Thus, unless significant changes are made in the operation of public telecommunication networks, the increasing volume of data communications will make it essentially impossible for proprietors to trace the subsequent movements of their works once they are captured by users' computer and data communication systems. This raises the issue of whether proprietors should, and in practical terms can, control the transfer of their works after users first receive them,

\section{Databases}

Computer databases are collections of facts, statistics, bibliographic citations, and other information, including complete texts of some copyrighted works. Many of these collections are offered over telephone lines to users who have data communication terminals or personal computers. The user pays a fee to search through the database for the particular information that he needs. The database proprietor can obtain a copyright on the database. Thus certain uses of the information that a user obtains will be illegal.

\footnotetext{
“Telephony, Oct. 21, 1985, p. 24.
} 
One unauthorized use about which proprietors are particularly concerned is when competitors employ large storage capacity computers to download large portions of their databases." This permits unscrupulous information service entrepreneurs to avoid risking much of the investment that is required to compile a database.

Advancing technology could make the practice more common. The large-scale downloading of database information is becoming cheaper and easier with improvements in cost and capacity of computer storage media, faster telecommunication networks, and wider access to computer power. Infringers may increasingly use computer power to reprocess information and make it appear original. Thus, proprietors may find it increasingly difficult to know when a competitor is using their downloaded material.

\section{Computer Bulletin Boards}

A growing number of personal-computer enthusiasts are keeping in touch with each other and exchanging information using computer bulletin boards. ${ }^{30}$ As the name implies, a computer bulletin board is a computerized storage space offered by a computer owner that serves as a place to post messages. There are two important differences between a computer bulletin board and the more familiar variety. First, a computer can offer a very large space in which to post messages. Thus, many computer users can post copies of their favorite software programs, such as computer games. Some of these programs are in the public domain; others are copyrighted. Second, the telephone network can be employed by users of computer bulletin boards to build a community that is not confined to a physical neighborhood. Thus, some computer enthusiasts use bulletin boards to keep each other informed about the latest software releases and maintain a sense of community of interests among widely dispersed colleagues and friends. Bulletin boards are also

\footnotetext{
"Interview with Eugene Garfield, Institute for Scientific Information, Mar. 11, 1985.

${ }^{30}$ There are thousands of computer bulletin boards now in use, A. Pollack, "Free-Speech I ssues Surround Computer Bulletin Board Use, " New York Times, Nov. 12, 1984, p. 1,D4.
}

used illegally to trade credit card numbers, long-distance access codes, and the instructions to disable the copy protection of computer software packages. In this way, the unscrupulous help others steal goods and services .31

Bulletin boards are an especially thorny intellectual property enforcement problem because they can be used to very quickly spread copyrighted works throughout the community of computer hobbyists. Bulletin boards are an informal publication mechanism. Because access is generally not restricted, proprietors may monitor the contents of bulletin boards to detect unauthorized trading of their works. But, as their numbers proliferate, these informal community communications media may defy systematic surveillance and control. Moreover, it is not clear whether a bulletin board operator can be held liable for messages posted anonymously on his system. ${ }^{32}$

\section{Local Area Networks}

Local area networks (LANs) are data communication facilities that connect computers in a geographically restricted area, such as an office suite, a building, or an industrial park. These networks range in size from the very small to ones that have thousands of users. The expanding market for office automation technology, particularly personal computers and professional work stations for word processing, document management, and data analysis, is encouraging the development and deployment of network facilities that allow workers to communicate with one another. LANs allow users to transfer large files of information very quickly among personal computers, work stations, and large mainframe computers that can store and process corporate or institutional databases. LANs can also give many users access to computer software programs from a central repository.

\footnotetext{
${ }^{31}$ Ric M arming, "Policing the Boards, "Popular Computing, July 1985, pp. 37-39.

"New York Times, Nov. 12, 1984, op. cit.
} 
Copyright infringements can occur in these circumstances when computer programs, information downloaded from commercial databases, or other copyrighted materials are made available and shared in these systems. Many software license agreements and database subscription contracts specifically prohibit the use of licensed material in multiuser settings. Other contracts provide for "site licenses" to allow multiple uses of software. Enforcement of such contract provisions can be difficult because of the private nature of local area networks. Often, evidence of contract abrogation or copyright infringement must be obtained from disgruntled employees of the infringing institution or from paid infiltrators.

\section{Integrated Services Digital Network}

In its present structure, much of the national and international telecommunication network uses equipment that transmits analog signals. This is particularly true for local "final-mile" connections. Voice communication, still the largest category of telephone usage, is efficiently handled by analog transmission. But the volume of data transmitted by telephone is growing. This growth is encouraging local and long-distance companies to convert more and more of the telephone network plant to digital transmission. If efforts to set standards are successful, the end stage of this conversion process will bean Integrated Services Digital Network or ISDN - "an integrated national net work that can connect any information provider with all its potential customers and any user with all the range of information resources available." ${ }^{33}$ Planners envision that users will access such a network through a standard con-

'H.W. Mc( iraw, Jr., 'The I nformation Industry: The Prin. ciples That Findure," Computers and People, May-June 198:3, p. 10 nection resembling an electric power plug-in receptical, available in virtually every building.

As more and more of the telecommunications infrastructure is converted to digital transmission facilities, the issue of copyright enforcement will be contested on a much larger scale. On the one hand, digital transmission can be a significant threat to enforcement because scope, scale, speed, and decentralization may make it very difficult to detect transfers of copyrighted works among private users. But because of the recordkeeping and processing power of digital communications switching technology, there may be opportunity for proprietors to monitor contact between data terminals. Telephone transaction records could provide evidence that a particular terminal accessed a particular store of copyrighted material at a particular time, and so aid enforcement. Alternatively, proprietors might embed digital "signatures" in their works to aid in their monitoring efforts.

The development of an Integrated Digital Services Network raises a basic question for intellectual property: To what extent will the enforcement of intellectual property law be a factor in the design, construction, and operation of future telecommunication facilities? This raises several corollary questions: Who, in our newly deregulated telecommunication environment, will decide to what extent and in what ways intellectual property enforcement will be implemented in telecommunication systems? What criteria will be used to decide which information will be collected about users of networks and who and under what circumstances access to that information can be obtained? ${ }^{34}$

\footnotetext{
"The policy implications of new electronic surveillance technologies have been reviewed in a recent OTA publication, Electronic Surveillance and Civil Liberties, OTA-CIT-293(Washington. DC: U.S. Government Printing office, October 1985).
}

\section{TRENDS IN PROCESSING TECHNOLOGY: IMPACTS ON THE RIGHT TO CONTROL THE MAKING OF DERIVATIVE WORKS}

Information processing is the physical transformation and logical manipulation of symbols. It is an activity carried out by both people and computing machines. Information processing technology-computer hardware and softwarehas advanced rapidly since the initial devel- 
opment of electronic computers in the late 1940s and early 1950s. It has been used to automate many tasks, improving the efficiency and speed of much of the information processing work that people formerly accomplished mentally or with the aid of mechanical devices such as paper and pencil. In the last 10 years, computing resources have become increasingly available to people in private homes and offices. They use this technology to transform and manipulate many kinds of information, including some types of copyrighted works.

Increasingly, people use information processing technology to prepare derivatives of protected works-to selectively modify them or take them apart and to reassemble the pieces into new, or apparently new, works. To a large extent, the intellectual property enforcement problems stemming from the use of processing technology are nascent, but current uses offer clues to the potential impact of these problems. A discussion of the current and potential effects of this technology on several different types of intellectual property illustrates the implications of information processing technology for enforcement. Integrated with storage and communication technologies into computerized, digital information systems, processing technologies promise some truly formidable problems for the enforcement of intellectual property rights,

\section{I mpact of Processing Technology on the Derivation of Text}

Affecting the way that people prepare text, information processing technology is beginning to be used to make derivations of copyrighted textual works. Word-processing hardware and software are becoming commonplace technologies in offices. Integrated word-processing, database-management, and on-line information retrieval capabilities are also offered in personal computer software packages. These capabilities make it possible to build personal databases derived from the copyrighted works of CompuServ, The Source, and other on-line information retrieval companies. In fact, these companies design their databases with the intention of making it easy for users to make derivations. Users construct search statements that select a part of the database relevant to their needs.

Some people use these processing capabilities to extract portions of commercial databases and resell access to the information. In many cases, it is unclear whether infringements have occurred. Although containing the original information in some form, the derivation may look quite different, either because the format or other features have been changed to add value, or because of a deliberate attempt to disguise the source of the information. In other cases it is obvious that the derivative database stems from the original and may be in clear competition with it. The volume of both of these kinds of database derivation can be expected to rise as the amount of textual material available in computer-processible form increases, and as processing capability becomes better, cheaper, and more widespread. Hence, the enforcement of copyright in databases will become a larger problem, one described by some observers as insurmountable.

There are some text processing capabilities on the technological horizon that may have important, long-term impacts on the enforcement of copyright. Some of these are still experimental and others are merely speculative. Automatic indexing, abstracting, and document preparation systems that combine optical disk storage, high-speed digital communications, and perhaps novel computer architectures and intelligent text processing software may be common by the end of the decade. Such systems will be able to search a large body of machine-readable text, including many articles and books, select particular elements that are relevant to a given research question (much as current database systems do), prepare customized indexes and abstracts of relevant documents, and, most speculatively, prepare a report in proper English of specified length that summarizes the findings of the query. Should these capabilities be realized, they may require policymakers to rethink the question of what information processing activities are acceptable in relation to copyrighted materials. They 
may also demand new approaches to monitoring and enjoining infringements of copyright in textual works.

\section{Impact of Processing Technology on the Derivation of Music}

Information processing technology is affecting the way people create music, and it is beginning to affect the ways in which they can prepare derivatives of copyrighted musical works. In the last 15 years, the decreasing cost of digital electronic processing technologieslogic and memory-have brought music synthesizing, audio editing, and dubbing technology out of the academic laboratories and sophisticated professional studios where systems were often custom designed and expensive to build and maintain. Now available off the shelf, these technologies are in the hands of disk jockeys, sound engineers in small studios, and aspiring professional and even amateur musicians. At the same time, the actual capabilities of these technologies have improved significantly. According to one OTA advisor, "There has been a quantum leap in terms of the sophistication of the kinds of information that you can produce on an off-the-shelf synthesizer. ${ }^{135}$ Now, for the price of a grand piano, musicians can buy machines capable of analyzing and synthesizing sound wave forms and custom-designing sounds that have never been heard before.

Because these technologies are widely available, people are becoming accustomed to the freedom of using them to create, use, and reuse music. The groundwork is being laid for digital sound editing capability in the home. As mentioned earlier, compact disks al ready supply consumers with music in digital form. Within 3 years, digital audio tape may also be available ${ }^{36} \mathrm{~A}$ standard digital communication connection for music synthesizers and personal

\footnotetext{
Michael Kowalski at the OTA Workshop on Technologies for Information Creation, Dec. 6, 1984.

"Interview with Stan Cornyn. Apr. 4, 1985. For about $\$ 1,000$, one can now buy an adapter device that allows a videocassette recorder to be used to record music digitally. Barry Fox, "optical Memories for Home Computers, "New Scientist, Apr. 11 , 1985, pp. 17-20.
}

computers, the Musical Instrument Digital Interface (MIDI), is growing in popularity. And personal computers are now beginning to appear that have digital sound recording capability. ${ }^{37}$

Copyright enforcement problems are arising from digital music processing technologies because people can "disassemble" music when it is in digital form. This disassembly can occur vertically-that is snippets' of sound can easily be cut from a copyrighted work and incorporated in a derivation that may be nothing more than a collage of pieces of copyrighted works. Although it is more expensive, difficult to accomplish, and limited in application, disassembly can also occur horizontally. For instance, the bass line of a song maybe stripped off and used in a second work, creating what is, to some extent, a derivative work. ${ }^{38}$

Another intellectual property problem may arise from the use of sound emulators that can mimic complex sounds, including voices, with great precision. A question may arise about whether a singer can claim property rights in the sound of his voice.

These capabilities pose two questions relevant to intellectual property rights enforcement. First, how is a proprietor to recognize and prove infringement in this very dynamic musical environment? Second, what rights does or should an artist/copyright holder have to maintain the integrity of his work, and how can he enforce those rights?

\section{Impact of Processing Technology on the Derivation of Video}

Information processing technology is also affecting how people create visual works, and how they can use copyrighted visual works as raw material for other works. Digital, computer-assisted retouching of photographs has

\footnotetext{
'-Scott Mace, ' Electronic Orchestras in Your Living Room," Infoworld, Mar. 25, 1985, pp. 29-33.

"Michael Kowalski, Dec. 6, 1985. Mr. Kowalski actually played for the workshop two pieces of commercially recorded and released music that demonstrated the stripping and reuse of a bass line.
} 
reached a level of sophistication where the images of people can be added or subtracted from pictures leaving little or no trace of tampering." The pace of progress of video tape editing technology is such that a new generation of equipment appears about every 4 years. ${ }^{40}$ The television technical community is studying the establishment of a worldwide digital video tape standard. Such a standard would allow all studio-based production work, including editing, to be done in digital format. ${ }^{41}$ Thus, some early steps are being taken in the world of video toward the kind of disassembling capability now possible with music. Combined with communication technologies-UHF and VHF broadcasting, direct broadcast satellite, cable tel evision-and storage technologiesvideo tape, optical disk-video processing is revolutionizing the way visual works are made, disseminated, and reused. Thus, equally revolutionary questions may be posed regarding the enforcement of intellectual property rights in visual works.

Computer hardware and software are reaching a truly phenomenal level of sophistication in the generation of graphics. Some experts suggest that, within as few as 5 years, it will be possible to use the filmed image of J ohn Wayne, for example, and produce a full-length motion picture with a synthesized 'Duke' in the starring role. ${ }^{42}$ Lucasfilm, Ltd., of San Rafael, California, has developed and is now marketing a machine, the EditDroid, that uses optical disk storage and computer processing to automate virtually the entire process of film editing, making the actual cutting of film unnecessary, except perhaps at the very last

\footnotetext{
"Some people believe that, upon challenge, photographs may no longer be held as admissible evidence in court, S. Brand, K. Kelly, and J. Kenny, "Digital Retouching: The End of Photography as Evidence of Anything, "Whole Earth Review ${ }_{\mathrm{q}}$ July 1985 , pp. $42-49$.

"'Interview with Humberto Rivera, Apr. 18, 1985.

"Richard Green at the OTA Workshop on Display, Printing, and Reprography, Mar. 13, 1985,

"Several states, including California, have recently passed laws that would require commercial users to obtain permission from the heirs of a deceased celebrity before they can use a likeness, thus treating the person's name and likeness as the property of the heirs, D. B. Moskowitz, "Celebrities' Ghosts Are Hanging Over Advertisers," Business Week, June 3, 1985, p. 108 .
}

stage of producing a master print.$^{43}$ The marriage of optical disk storage and video processing equipment suggests the possibility of establishing 'image banks' consisting of digitized images and standard algorithms to manipulate, transform, and link together video image frames, or even parts of frames, into new visual works derived from older, perhaps copyrighted, works. ${ }^{44}$ The ownership management of such image banks could be complex.

Standards for digital television broadcasting and reception are being discussed in international standards forums. ${ }^{45}$ Digital television promises to lower the cost and improve the quality of pictures produced by home television receivers, and could also make it possible for home users to store and reprocess television programs. Again, the enforcement of the intellectual property right to control the production of derivative works would be complicated by the private and potentially widespread technical capability to make new uses of copyrighted works.

\section{Impact of Processing Technology on the Derivation of Computer Programs}

Part of the research and development effort in computer technology goes into the creation of hardware and software tools that can be used to help create other computer programs. ${ }^{46}$ These tools aid people in developing new and ever more sophisticated programs. Some tools can also be used to adapt existing software to new uses. Thus, if they are employed in the unauthorized production of derivative works, their use may violate intellectual property rights.

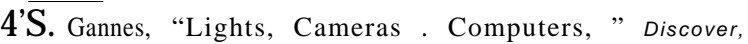
August 1984, pp. 76-79.

"Jim St. Lawrence at the OTA Workshop on Technologies for Information Creation, Dec. 6, 1984,

"Richard Green, Mar. 13, 1985.

"'Examples of such tools include workstations, program editors, code debuggers, program generators, programming environments (integrated sets of tools), and, in the future, perhaps libraries of standard information processing modules that can be assembled to perform more complex functions and tasks. For a discussion of these technologies-the potential future and the current problems of software engineering-the reader is referred to the OTA report, Information 7'echnology R\&D: Critical Trends and Issues, OTA-CIT-268 (Washington, DC: U.S. Government Printing Office, February 1985), pp. 75-87.
} 
The adaptation of computer programs to serve new or custom uses is, in many contexts, a well-accepted and widespread activity. Some computer languages and soft ware tools are designed specifically to aid in modifying programs that they help create. In particular, operating systems software is designed to help users tailor their programs and computing systems to serve special needs. " Some programmers and computer scientists believe that, because software is such a valuable resource, their creations should be in the public domain and under no circumstances restricted in their use as tools. ${ }^{48}$

The number of American homes with personal computers rose from zero in 1975 to 8 million by the end of $1983 .{ }^{49}$ This technology has spread even more rapidly into offices. As personal computers become more widespread and the demand for more specialized software rises, the opportunity and the desire to manipulate copyrighted programs to serve particular purposes may also increase.

An especially relevant example of such manipulation is the use of programs designed to disable the copy-prevention schemes of many personal-computer programs, thereby allowing users to make multiple copies of these copyrighted works. Other currently available software tools- 'interpreters '- are used to translate a program from one computer language to another. Other tools aid in the "reverse engineering' of programs. Reverse engineering refers to the practice of analyzing a program to determine how it is arranged to accomplish its functions. A major goal is understanding the underlying algorithms used by the program designers. A very fuzzy line separates legitimate reverse engineering practices and violation of the copyright owner's right to control the production of derivative works.

\footnotetext{
Interview with Edward Conklin, FORTH, Inc., Apr. 19, 1985 .

"Richard Stallman, "The GNU Manifesto," Dr. Dobb's J ournal, March 1985, pp. 30-34.

"Walter S. Baer, "Information Technologies in the Home," Information Technologies and Social Transformation (Washington: National Academy of Engineering, 1985), p. 124. In 1984, for the first time Americans spent more for machines in the "personal computer" category-i.e., those costing less than $\$ 10,000-$ than on mainframe computers or minicomputers,
}

Congress and the courts have not yet grappled with the question of what elements of computer programs copyright should protect. This issue is examined in detail in chapter 3 of this report. Here, it is important to note that much of the derivative uses of computer programs and their underlying processes and algorithms occurs in private, and as such presents proprietors with major obstacles in detecting and proving infringement of their rights, even given clear policy on what those rights include.

There is a widespread and growing research and development effort aimed at making computer software production easier. One goal of this effort is to devel op extensive libraries of standardized functional modules of computer code. Some software module libraries already exist. These standard modules comprise computer program segments that represent the most efficient known formulation of how to accomplish a particular task, such as sorting records alphabetically. Libraries of modules may soon be organized so that they can be automatically selected and combined into programs on the basis of functional specifications. The use of standardized modules would help ameliorate the problem of low productivity in the currently labor-intensive software industry.

The establishment of large libraries of reusable software modules raises questions about ownership and the management of transactions in these resources. Difficulty is likely to arise in determining whether the copyright ownership of a module constitutes a restraint on the use of a function or an idea.

The nature of the computer is at the core of many copyright enforcement problems, including those that surround the unauthorized derivation of computer programs themselves. A truly revolutionary machine, the computer was recognized as such when the ideas governing its operation were first conceived. In the 1930s, Alan Turing suggested, by way of a mathematical model, that any computer can simulate the operation of any other computer, past, present, or future."' The real limit on the use-

\footnotetext{
"'Alan Kay, "Computer Software, " Scientific American, September 1984, p. 53.
} 
fulness of this simulation capability is the speed at which a given computer operates; and the speed of computers is widely projected to continue to rise at a breathtaking pace, at least for the remainder of the century." Thus, "It is clear that in shaping software [tool] kits the limitations on design are those of the creator and the user, not those of the medium. ${ }^{152}$ The

\footnotetext{
${ }^{52}$ See OTA, Information Technology R\&D: Critical 7'rends and Issues, op. cit., pp. 324-331.

'Kay, 'Computer Software, ' p. 57
}

capabilities to manipulate and transform copyrighted computer programs into derivative works, to do so privately and without leaving a trace, are well within the limits of present computer systems. These capabilities confront legislators, courts, law enforcement agencies, and intellectual property owners with the question of what should or can be done to control the use of rapidly proliferating computer power in manipulating and transforming cop-y-righted works.

\section{ADJUNCTS AND ALTERNATIVES TO TRADITIONAL ENFORCEMENT MECHANISMS}

Faced with mounting difficulty in identifying, detecting, and prosecuting infringements of their traditional rights, intellectual property proprietors are pursuing three basic strategies to protect their economic and artistic interests, They are: implementing technological protections to prevent the unauthorized copy, publication, and use of their works; initiating public relations campaigns that appeal for citizens' moral support and respect for property rights; and lobbying for legislation that strengthens government enforcement efforts, or establishes alternative mechanisms for obtaining remuneration.

These strategies are not mutually exclusive, and do not apply uniformly across all situations. Proprietors see different enforcement problems arising from different technologies, which affect particular types of works in different contexts of use. Thus, a mix of strategies may be most appropriate to meet these differ- ent challenges. Although a given form of technological protection, for example, may effectively reduce copying of personal-computer software distributed on floppy disks, it may be totally ineffective if the software is distributed over telephone lines. Appeals to peoples sense of "fair play' may be quite useful in educational or corporate environments, but ineffective, or even offensive and counterproductive, when applied in the context of home use. The collection and distribution of royalties on the sale of blank media may be a workable solution when applied to cassette tapes for music or movies; but such a solution may be an administrative nightmare if applied to more versatile media such as magnetic or optical disks, where many more kinds of information products, and thus many more and varied interests, would have to be accommodated in distributing royalties.

\section{TECHNOLOGICAL PROTECTION}

Several varieties of technological protection are now used to prevent unauthorized use of intellectual works in the forms of computer software, broadcast video signals, and audio and video recordings. These technological approaches for securing intellectual property rights may be grouped into three categories:
1) security measures such as locks, scrambling, and encryption; 2) technological methods to monitor information flow; and 3) proprietary channels for the distribution of information. Each of these methods has advantages and disadvantages that make it appropriate for various uses. 
Every technological approach to the protection of intellectual property requires a tradeoff between the security of the property and its accessibility, marketability, cost, and quality. F urthermore, as was reiterated by every technical expert with whom OTA spoke, while any technological barrier may work in some cases by acting as a' 'stop sign warning against unauthorized use, no form of technological protection is 100 percent effective against determined opponents.

\section{Software}

Many present and proposed methods of using technology to protect intellectual property center on software, in part because it is the newest and most technologically sophisticated information-based product today. Further, software copying has three distinctive qualities that set it apart from the copying of other expressions of intellectual property, making protection a particularly critical issue, First, it is easier to copy software than other products, such as audio records or books, because the physical effort is minimal-as simple as pressing a single key. Second, a computer can copy software extremely fast compared to the length of time required to copy other materials. Finally, unlike a taped copy of an audio recording, the duplicate is typically an exact, perfect copy of the original software with no distortion of quality, Thus, the same technological qualities that make software useful also make it vulnerable to copying.

Software protection for mass-market, personal computer programs generally falls in the first category of technological approaches listed above: locks and encryption. Another alternative is the use of proprietary channels for the distribution of software.

Software embodied in disks maybe protected from copying in two basic ways. Either the protection mechanism can be built into the software, or it may be divided and coordinated between software and hardware. The essential distinction between the two methods is that the hardware-plus-software protection mechanisms are able to limit software to one com- puter or one user. In contrast, the softwareonly protection mechanisms cannot control use of the software, only the number of copies that exist. Software-only protection methods are currently in use, and implementation of more advanced and secure hardware-plus-software methods is being discussed. Some chip manufacturers are designing computer chips with machine-readable serial numbers and decryption circuits to help software makers more effectively control their products." But, in general, hardware companies have little incentive to help prevent copying because the availability of "free" software makes their products more attractive and less expensive for the individual to use.

There are numerous other mechanisms that could prevent unauthorized copying, some re quiring substantial changes in hardware, and others based on modified systems of distribution. One of the former involves providing software in read-only memory (ROM) and redesigning computers so they accept ROM modules or cartridges. ${ }^{54}$ Taking the concept of software cartridges a step further, one can imagine computers being sold with many software programs built into the machine, residing in internal ROM chips. " A developer of especially useful software, fearing lost profits due to illegal copying, could market his software only in this form-inside a computer. Such a policy has many drawbacks. It would severely limit users of computers, who would be forced to buy an entire computer to get a useful piece of software. Even if computers were inexpensive, the waste would be great and the computer's util-

\footnotetext{
"For example, "Software Protection Devices, Inc., is attempting to incorporate its Copyrighter software protection system into a microcomputer chip under joint development with The Western Design Center, " a Mesa, AR, microprocessor design firm. Edward Warner, "F ew Takers for Embedded Protection," Computerworld, Mar. 12, 1984, p. 109.

"Computers that accept software in ROM have thus far met with mixed success. For example, the Texas Instruments 99 and the IBM PCjr accept software in ROM cartridges.

${ }^{55}$ The trend toward building software into computers is, by and large, currently motivated by the desire for small, lightweight computers, not to prevent copying. For example, the Hewlett Packard Portable computer has its operating system software and two applications programs, Lotus $1-2-3^{\mathrm{TM}}$, and a text editor, provided by internal ROM to eliminate the size and weight of disk drives.
} 
ity as a "universal machine, or a device that can imitate any other device, would be lost. Such computers would be special-purpose machines only.

Another form of technological protection permits developers of programs (as distinct from suppliers of data) to keep their programs in their own computers, rather than distributing their software on the market. People who want to use the program are required to connect to the developer's computer, upload the data they want processed, and pay an on-line use fee. The disadvantages of this scheme are losses in flexibility-users are not able to link their programs to remote, protected ones easily-and communication costs for the on-line link.

One still-theoretical solution would be to link software access to a unique personal identifier. A computer terminal would be equipped with a hardware device that accepted sensory input, such as a person's appearance, fingerprints, hand geometry, voiceprint, or retinal pattern. Software could be designed to permit only the person whose appearance or prints matched to log onto the computer or to use a piece of software. ${ }^{56}$

\section{Broadcast Signals}

Because broadcast signals-television and radio transmissions-are not contained in a tangible medium or transmitted over wires, they cannot be locked like software or distributed through proprietary channels. They may be protected in only two ways: directly by scrambling or encryption, or indirectly by monitoring techniques.

Scrambling or encryption techniques alter the signals so that they are unintelligible unless the proper decoding device is used at the reception end of the transmission. Typically, the signal for a network television show has a long route to the viewer-e.g., from the network to a satellite to the affiliate station and finally to the home viewer-and so is vulner-

\footnotetext{
‘ $\triangleleft$ ohn Koehring, "Automatic I dentity Verification, " Information Age, April 1984, pp. 103-110.
}

able to unauthorized pickup at many different points, Broadcasters need to ensure that these transmissions are not accessed until the end of the process, after the local affiliate station has added local advertisements. Thus, the networks may scramble the signals so that only the affiliate station, using a decoder, has access to the satellite transmissions. ${ }^{57}$

Monitoring techniques to verify unauthorized viewing or listening have been applied in some cases, particularly by some subscription television and MDS companies. So far, the courts have upheld this form of electronic surveillance, but privacy concerns remain. In any case, monitoring individual residences for theft of service is very expensive and therefore of limited value to proprietors, except perhaps as a deterrent.

\section{Audio and Video Recordings}

In ways similar to those used for computer software, audio and video recordings may be copy protected by a mechanism built into the recording itself, or by a scheme coordinated between the recording and the playback/copying machine.

Musical recordings have traditionally included no mechanism to prevent copying. All known copy-preventer systems tend to degrade the quality of sound reproduction. Recently, there is renewed interest in protecting musical recordings because digital CD/ROM records are potentially infinitely copyable in high quality. Manufacturers of compact disk recordings are, therefore, embedding a unique "signature' in their products to serve as evidence of unauthorized copying or manipulation. ${ }^{58}$

One company now offers protection for videocassette tapes in a system that "confuses the automatic gain control of VCRs, causing them to make copies that have dim, weak pictures that are marred by video 'noise.' ${ }^{1159}$ This sys-

\footnotetext{
“'interview with David Poltrack, CBS, Inc., J une 10, 1985.

${ }^{58}$ Interview with Al McPherson, Warner Records, Inc., Apr. 19, 1985.

59" Homevid 'Club' Has Surprise for Pirates, " Variety, Apr. 24, 1985. Consumer electronics catalogs feature devices that claim to defeat these automatic-gain-control-based protection schemes.
} 
tern could also be used for broadcast signals, so that a work taped from an on-air performance and protected in this fashion would yield a very poor copy.

CBS Inc. recently announced a system to prevent copying of records, tapes, and $\mathrm{COM}$ pact disks that will be coordinated between a device in consumers' home-recording equipment and a coded signal on the purchased $r e-$ cordings."' Record distributors would likely offer two versions of recordings, one copy protected and the other not, and charge different prices for them. Industry spokesmen acknowledge that it will probably take decades for this scheme to significantly affect consumer copying, because people will be able to copy protected recordings with their existing equipment. Also, equipment manufacturers are likely to continue to offer equipment that does not include the copy-protection device, unless the law requires such devices.

\section{Effectiveness}

The ability of technological protection to prevent illegal copying or access depends on the medium and the type of protection, but a few absolutes can be stated. Any form of technological protection will prevent Some unauthorized use; no form of technological protection will stop all unauthorized use. Some systems are relatively easy to defeat, others more difficult. And it is conceivable that new forms of technology will alter the effectiveness of these devices.

Another factor is the level of technological literacy in society. Today, many children have early and frequent exposure to the new computer technologies, and so will be better equipped to use-or misuse-technology. The higher the level of society's computing skill, the more difficult the job of technological protection becomes-at least for computer-based intellectual property.

For technological protection to work on a large scale, the challenge is to find a level high

\footnotetext{
"Martha M.Hamilton. "Record Industry Unveils Deviceto Block Copying," The Washington Post, Mar. 26, 1986, p. G3.
}

enough to reduce unauthorized use to a manageable level, but low enough so that consumers would not find the protection mechanism so distasteful that they would refuse to purchase and use protected materials. ${ }^{61}$ The marketplace will tend to set an equilibrium of acceptable protection. But given the uncertainties of technological change and shifting consumer preferences, industry will have to monitor the market carefully to assess the effectiveness of protection and to gauge consumer reaction to protection mechanisms.

\section{Advantages and Disadvantages of Technological Protection}

Some analysts believe that proprietors' reliance on technological protection is a natural and reasonable process. They argue that using such protection is like building fences to protect real estate. Thus, improvements in technologies for copying and manipulating intellectual property will probably result in better technologies to prevent these activities, just as the opening of western lands was followed by the invention of barbed wire. ${ }^{62}$

However, from the point of view of public policy, technological protection may be a poor way to protect intellectual property rights because it ignores part of the constitutional compromise between the public welfare and the profit-making of intellectual creators. Technological bars may block dissemination of and access to intellectual property.

One result of this loss of access could be re dundancy in spending for research and development. Since technological protection bypasses intellectual property law, software producers, for example, might decide not to disclose the contents of their software, depriving competitors, experimenters, and researchers of the benefits of their work. Thus, some software research and development would repeat previous, but undisclosed, work. This duplication and waste of resources is precisel $_{y}$

- Christopher Weaver, OTA Workshop on Storage and Database Technologies, Jan. 11, 1985.

'Personal communication from Fred Smith, ('competitive Enterprise Institute, January 1986. 
what patent law strives to avoid. Moreover, technological protection of software does not expire after a set period of time, as other intellectual property rights do. The creator of software could, in effect, have a perpetual monopoly on his work.

Technological protection in and of itself does not necessitate changes in intellectual property law, but it could precipitate changes by weakening the distinctions between different types of intellectual property-patents, trade secrets, trademarks, and copyrights. If technological protection were effective, intellectual creators would not have to observe the formalities required for legal protection, e.g., submitting to the lengthy and expensive patent process, or disclosing works to the Copyright Office. They might still choose to do so for additional protection if technological protection fails, but there would be less reason. Technological protection, if applied indiscriminately to any or all kinds of intellectual property, could blur the legal distinctions among these forms of protection. In reflecting what might become a widely accepted public practice, the law itself could likewise cloud the differences. ${ }^{63}$

Widespread technological protection could make intellectual property law more effective in one important way: it would alert consumers who attempt to copy that they are breaking the law. This would not necessarily stop them, but by forcing them to take elaborate steps to make copies, it would at least make the act less convenient and emphasize its illegality.

Widespread use of technological protection could generate a need for new, related laws or regulations. In addition to the potential need for standards legislation, laws that proscribe the manufacture, sale, distribution, or use of devices or program software intended to defeat technological protection mechanisms may

\footnotetext{
${ }^{63}$ ohn Hersey, in the final report (1978) of the National Commission on New Technological Uses of Copyrighted Works (CONTU), worries about the "subtle dehumanizing danger" of blurring the distinction between types of intellectual property. He opposes extending copyright to computer programs at the moment at which the program ceases to communicate with human beings and is made capable of communicating with machines." CONTU, p. 33.
}

be necessary to ensure effectiveness. This type of legislation has two drawbacks. The first is that there are some legal uses of duplicated materials, which would make it necessary to outlaw devices with legitimate uses. The second drawback, closely related to the first, is that it would be necessary to define and characterize devices and methods used for defeating technological protection. Those definitions and characterizations would cover specific applications of technology, and would themselves exist in a changing technological environment. The law would require making the precise technological definitions necessary to prevent defeat of protection mechanisms, while at the same time allowing the use of related technologies.

Another kind of legislation, similar to control of copying methods, could be enacted that would outlaw the intentional defeat of, or tampering with, technological protection mechanisms, regardless of any violation of intellectual property rights. Or, perhaps, ordinary violations of intellectual property law might still be treated as they are now, but violations that involved the intentional defeat of technological protection mechanisms could carry additional penalties.

\section{Public Relations Strategies}

Even with safeguards against unauthorized use, today's information technologies provide users greater potential access to intellectual property, and the means to reproduce, store, transfer, and manipulate works. Responding to this probable increase in uses of technology, many proprietors have tried to inform the public about intellectual property rights and persuade them to respect those rights.

To influence public attitudes, business leaders have followed three basic strategies. First, they have tried to alert the public to the idea that copying is illegal and will be prosecuted. Second, they have tried to convince users that they have a stake in assuring the fair compensation of artists, publishers, and distributors. Third, they have sought to educate the public about copyright, appealing to them as citizens 
who will obey the law once they understand it. These strategies have met with varying levels of success.

When the law clearly defines infringement, it becomes easier to inform the public and build awareness about the issue. For instance, the Motion Picture Association of America (MPAA) emphasizes the protections provided by law in its posters, brochures, articles, and manuals for enforcement officers. They tell the public that video piracy is a Federal crime, and that offenders will be prosecuted. Newspapers and magazines are sent press releases about successful prosecutions to spread the word that the film industry is enforcing its rights. SimiIarly, when the recording industry uncovers large-scale piracy, the ensuing publicity alerts the public to the problem. The industry hopes that the public, aware of counterfeit tapes and records, will be less likely to buy them.

Book publishers, too, launched a major public awareness campaign after Congress passed the 1976 Copyright Act, seeking support for new provisions that defined fair use. The target audience included librarians, educators, representatives of industries that use copyrighted works, and the general public. Book publishers distributed printed materials and held sessions at professional meetings and public forums. Many publishers believe that these efforts produced only very limited results.

Book publishers point to the inherent limitations of the copyright notices on books, articles, and copying machines. ${ }^{64}$ If the industry is serious about reducing unauthorized photocopying, many believe that this intention must be made clear through well-publicized litigation. As the President of the Association of American Publishers, Townsend Hoopes, said in announcing a lawsuit against Texaco for unauthorized photocopying:

Major businesses that either make no effort to obtain clearance for their photocopy-

${ }^{64}$ The 1982 King Research report on photocopying in libraries found that 85 percent of photocopy machines in all libraries, 93 percent of the coin-operated photocopy machines in all libraries, and 100 percent of coin-operated photocopy machines in academic libraries bear a copyright warning notice. I). McDonald, Libraries, Publishers and Photocopying, pp. 2-16 ing... or like Texaco. make only token payments must under-stand that publishers will not remain silent regarding violations of their copyrights. ${ }^{65}$

Similarly, the computer software industry has undertaken an aggressive public-relations campaign. Because software copying is technically so difficult to prevent, many in the software industry argue that public relations is essential to an overall strategy of copyright enforcement. Through its trade association, ADAPSO, the software industry has brought some major legal cases $^{66}$ and has developed and widely distributed a brochure that states:

People who would never walk into a store and shoplift a software product think nothing of making several copies of the same software. The results are the same. The act is just as wrong. ${ }^{67}$

The industry has taken out advertisements in computer magazines that make the same point.

\section{Public Attitudes and the Legitimacy of Intellectual Property Law}

Neither the threat of legal action, nor the education of users about cop\}' right may be enough to change public attitudes and behavior. Only if the public perceives copyright rules as fair and reasonable will they voluntarily respect the law.

OTA commissioned a public opinion survey to identify current public attitudes on intellectual property. The major findings were as follows: ${ }^{68}$

- At the present time, "Intellectual Property Rights' is not an issue the public feels

\footnotetext{
${ }^{65}$ Press release from the Association of American Publishers, Inc., Washington, DC, May 6, 1985,

"(See, for example, "ADAPSO Suit Alleges Piracy, Com. puterworld. Jan. 21, 1985; "Micropro and ADA PS() Sue American Brands, Allege Software Piracy, Download, February 1985.

Thou Shalt Not Dupe (Washington, DC: AI) APSO, 1984) This brochure was mailed to 5,000 colleges and universities, 22,000 school districts, and 17,000 corporate counsels in the United States.

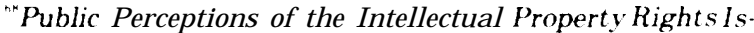
sue (prepared for OTA by The Policy Planning G roup, Yankelovich. Skelly \& White, Inc., Februrary 1985).
} 
it knows a great deal about. It is also not an issue they perceive effects them.

- The vast majority of the public finds acceptable-such that they would be willing to do it-some form[s] of unauthorized copying of copyrighted material.

- Surprisingly, willingness on the part of the public to engage in behaviors that infringe on intellectual property rights is not affected by awareness of the issue or experience, in general, with home technologies.

- Conversely, several specific attitude sets appear to be related to the acceptance of copying behaviors. Among them are: - a tolerance of "gray area' behaviors, -belief in the benefits of sharing information, and

- pragmatic responses such as the acceptance of copying copyrighted material while acknowledging that it is probably wrong,

- The public draws the line at behaviors that infringe on intellectual property rights when they involve the obvious or active circumvention of payment, when they are done for sale or profit, or on behalf of business or in a corporate setting.

- At the moment, the public perceives the intellectual property-rights-issue to be a marketplace problem whose solution should come from the industries and companies affected.

OTA also commissioned a survey of the attitudes of small business executives toward intellectual property. The major findings were as follows: ${ }^{69}$

- Small business executives appear to be more sensitive to the problem of intellectual property rights than the general public.

- They are more likely to agree with state ments that emphasize the need to preserve the proprietary nature of information. As producers, many of their products are protected by copyright, patent, or trademark

\footnotetext{
"The Intellectual Property Rights Issue: The Small Businessman's Perspective (prepared for OTA by The Policy Planning Group, Yankelovich, Skelly \& White, Inc., August 1985).
}

laws. Thus, these executives are supporters of the law.

- Because of definitions used in the sample selection, the small business executives studied are owners of, or have access to, computers. Their attitudes show that they are technology oriented-believing that more technology is better. They are strong supporters of actions that will promote and ensure the availability of future technologies.

- Small business executives appear less likely than the general public to find copying behaviors acceptable.

- While they find almost all copying behaviors unacceptable, they make an exception for the one behavior they would be most likely to engage in: the making of copies of computer programs.

-As is the case with the general public, there is consensus that any sort of copying for sale is totally unacceptable, whereas copying for personal use is more acceptable.

- Small business executives emphasize nongovernmental solutions to intellectual property rights problems. When given a choice, they prefer solutions that involve technologies that physically prevent copying. Further, they believe that the clarification of ambiguities about which copying behaviors are or are not permissible would be helpful.

-However, as is the case with the general public, the intellectual property issue is of low salience among small business executives, and there is little demand for solutions at present.

- Small business executives see themselves as potentially part of the process of finding solutions to intellectual property problems. Within their own companies, they are willing to set rules and guidelines against conduct that violates intellectual property rights. However, they will only go as far as setting standards. They feel that they cannot and will not accept re sponsibility for actual enforcement of rules or laws designed to prevent behaviors such as copying. 
From these surveys of the general public and executives of small businesses, and discussions with students and educators, OTA found that public relations strategies are likely to be most effective if they focus not on the rights of copyright holders, but on the relationship between the copyright holder and the users of the work. Messages about unauthorized copying may be more effective if they emphasize the value of an ongoing partnership between creators and users. 


\section{Chapter 5 \\ Impact of Technology on the Creative Environment}




\section{Contents}

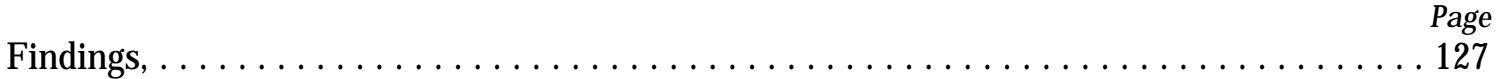

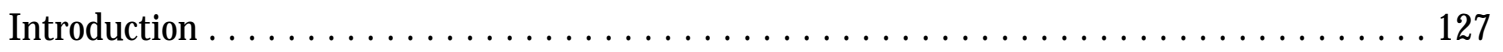

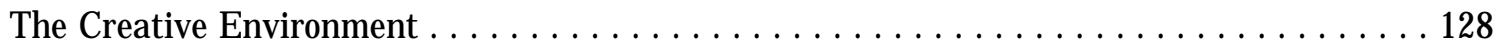

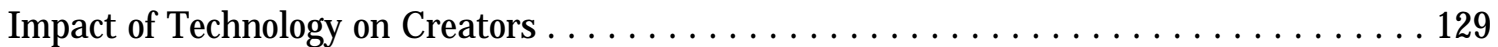

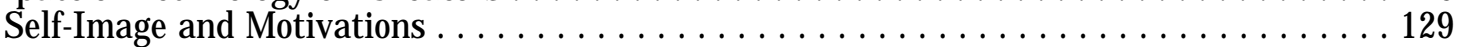

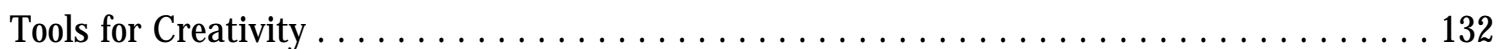

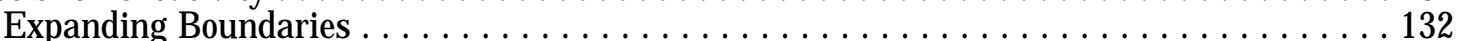

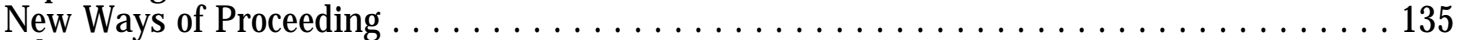

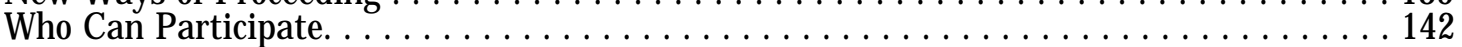

Impact of Technology on Resources and Materials . . . . . . . . . . . . . . . . . 145

Impact of Technology on Roles, Relationships, and Rewards . . . . . . . . . . . . . . . 149

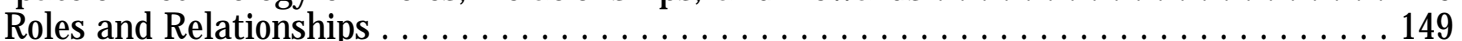

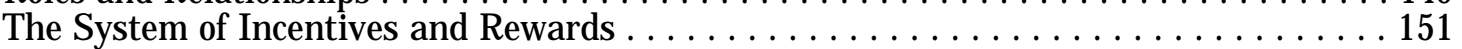

Implications for the Intellectual Property Rights System . . . . . . . . . . . . . . 153

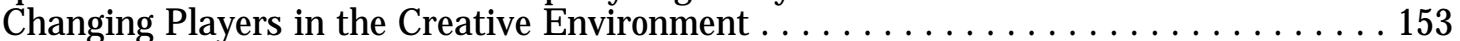

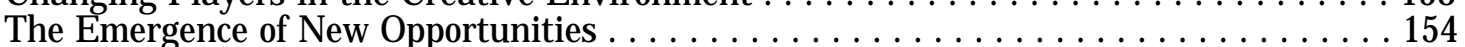

Tables

Table No.

5-1. Electronic Networking: Academic and Research Uses . . . . . . . . . . . . . . . . . . . . 141

$5-2$. Libraries in the United States . . . . . . . . . . . . . . . . . . . . . . . . . . . 146

Figures

Page

5-1. Applications of Information Technologies to the Creation and

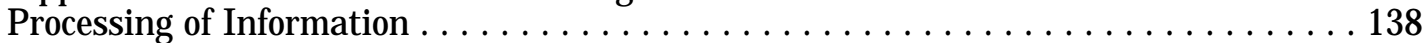

5-2. National Magnetic Fusion Energy Network . . . . . . . . . . . . . . . . . . . . . . . . 142

5-3. An Example of At-Home Publishing . . . . . . . . . . . . . . . . . . . . . . . . . . 144

5-4. Public and Private Institutions Providing Information Products and Services . . . 147

5-5. institutional Users of Computer Readable Databases . . . . . . . . . . . . . . . . . . . 148 
Chapter 5

\section{Impact of Technology}

\section{on the Creative Environment}

\section{FINDINGS}

The development and widespread use of the new information and communication technologies are changing the creative environment in a number of ways, many of which will have significant implications for the intellectual property system. These technologies, for example, are redefining who creators are and what motivates them, the kinds of tools and materials they use, and how they gain access to these tools, the skills and knowledge they need to pursue their work, and their roles and relationships to others in their environment.

In this new environment, the incentives and rewards provided by the intellectual property system may no longer achieve their intended policy goals, In many cases, they inadequately reflect the motivations, needs, and perceptions of the members of the creative environment, or the kinds of activities that they pursue. Moreover, they may miscalculate the economics of creating, producing, and distributing intellectual properties, Under these circumstances, new kinds of inducements may be required.

One of the most significant differences in today's creative environment is the growth in the number of participants and the transformation of traditional roles and relationships. New participants have entered the scene as new technological opportunities have emerged. Not parties to previous intellectual property agreements, many of the new players and even some of the older ones who now operate in new modes, have new and divergent attitudes about who should have access to works and materials, and about what kinds of activities and pursuits should be rewarded. Under these circumstances, controversies are likely to develop among players about the distribution of rewards. Furthermore, in the future, there may be less consensus about the basic aims of the intellectual property system.

The new technologies will greatly enhance the creative environment, providing new and powerful tools that can expand the boundaries of creativity, changing the ways in which creators and inventors carry out their work, and opening the way for more people to participate in the creative process and to share the products of scholarly and scientific research. At the same time, these technological capabilities also pose new problems for the intellectual property system. Allowing users to access and manipulate creative works with unprecedented ease and speed, they make it more difficult for cre ators and inventors to identify or trace incidents of copyright infringement or plagiarism.

\section{INTRODUCTION}

The American system of intellectual property rights was established to foster creativity and learning by providing economic incentives to individual creators, ${ }^{1}$ It was assumed that

Throughout this chapter the termcreators is used in agenerscsense to include all those people who are i n volved in art istic or intellectual activities. such incentives, in the form of exclusive rights, would stimulate the development and dissemination of ideas, discoveries and inventions, information, and knowledge. As a result, artists, writers, and scholars would have at their disposal the resources necessary to support their creative work. Most of what they needed was available through printed materials, 
Today, however, we have moved far beyond the print culture into an era where the new information and communication technologies are rapidly altering the environment for creativity. This raises the question of whether incentives of intellectual property rights, established in an era when the printing press dominated communication technology, remain adequate in an age of information and electronics.

This chapter analyzes the relationship between incentives and the creative environment by examining: 1) how technology relates to the creative environment, and 2) how today's new technologies are affecting that environment. Where possible it will distinguish between the environments in which artists, scholars and scientists, and information entrepreneurs operate to determine whether technology is affecting these areas in different ways in order to identify where creators might require different kinds of incentives and rewards.

\section{THE CREATIVE ENVIRONMENT}

Artists, writers, composers, and inventors do not work in a vacuum. Nor, as the social historian Elizabeth Eisenstein has pointed, "do major innovations, discoveries, and artistic works spring to life abruptly and full blown, like Minerva from J ove's brow." ${ }^{2}$ Rather, an invention, discovery, or creative act is more like a complex social process than an isolated incidents The environment in which these processes occur is the "creative environment."

The creative environment consists of several el ements:

- the creators themselves-the scholars, poets, writers, artists, inventors, and others who produce intellectual works;

- the tools and materials that creators need to perform their tasks;

- the foundation of artistic and intellectual material on which to build, which might be as fundamental as an epic poem or as sophisticated as an on-line, bibliographic database;

- a set of skills and procedures for carrying our their work;

'Elizabeth L. Eisenstein, The Printing Press as an Agent of Change: Communications and Cultural Transformations in Early Modern Europe, vol. I (Cambridge, England: CambridgeUniversity Press, 1979), p. 31. For two other discussions of the interrelated activities and processes leading to invention and creativity, see also, Arnold Pacey, The Maze of I genuity, Ideas and I dealism in the Devel opment of Technol ogy (Cambridge, MA: MIT Press, 1980); and Daniel J . Boorstin, The Discovers: A History of Man Search to Know His World and Himself (New York: Vintage Books, 1985).

${ }^{3}$ Eisenstein, op. cit., p. 31 . -a formal or informal system of education and training;

Ž a network of relationships with others, each constituting a set of roles; and

- a community of shared and supportive values and a system of incentives and rewards.

Together, these elements constitute a system in which each part affects all others. The creative environment can also be influenced by external factors, such as economic developments, politics, or social change. Technology is one external factor that is likely to have a particular significant impact because just to be able employ it generally requires the restructuring of the environment in which it is to be used. ${ }^{4}$

As the following discussion shows, the influence of technology on the creative environment is likely to take several forms. It will affect who the creators are and what motivates them, what kinds of tools and materials creators use and how they get access to them; the skills they need to carry our their work; and their roles and relationships to others in their environment.

\footnotetext{
${ }^{4}$ Langdon Winner, Autonomous Technology: Technics Out of Control as a Theme in Political Thought (Cambridge, MA: MIT Press, 1977), p. 100. See also J acques Ellul, The Technological Society (New York: Vintage Books, Alfred A. Knopf, 1964).
} 


\section{IMPACT OF TECHNOLOGY ON CREATORS}

Societies are shaped and characterized by the technology that predominates in them. one can speak, for example, of Stone Age man or of the basket weavers. Today, computer technology is becoming pervasive. While virtually everyone encounters this technology daily in one form or another, its power and scope ensure that it will have an especially pronounced effect on those involved in creative, scientific, and scholarly pursuits. In particular, it will affect how artists, inventors, and scholars see themselves-their self-image, and what motivates them.

\section{Self-Image and Motivations}

The historical case of the printing press ilIustrates how technology can affect creators' self-images and motivation. In fact, the concept of individual authorship, which definitively changed authors' self images, emerged from this new technology. ${ }^{5}$ Before the printing press manuscripts were treated more or less as sacred texts whose authorship was as irrel evant as it was difficult to ascertain. Daniel Boorstin captures how difficult it was to trace authorship before the establishment of a printed, title page: ${ }^{6}$

There were special problems of nomendature when books were commonly composed as well as transcribed by men in holy orders. In each religious house it was customary for generation after generation of monks to use the same names. When a man took his vows, he abandoned the name by which he had been known in the secular world, and he took a name of one of the monastic brothers who had recently died. As a result, every Franciscan house would always have its Bonaventura, but the identity of 'Bonaventura' at any time

${ }^{5}$ As Einsenstein has pointed out

From thefirst, authorship wascloselylinked to t he new tech nology AsFebvre and Martinsuggest, it is a ' neologism to u se' the term 'man of letters' I)' fort> the advent of printing Partly because copyists had, after all, nev er paid those whose works they copied, partly because new bookswere a smallportion of the early book trade, and part ly bec ause divisions of literarv la bor remained blurred, the author retained a quasi-ameteur st $\mathrm{a}$ tus until the eighteenth century

Eisenstein, op cit., pp 15;1- 154

'Boorstin, op. cit., p 530 could only be defined by considerable re search.

All this, as we have seen, gave a tantalizing ambiguity to the name by which a medieval manuscript book might be known. A manuscript volume of sermons identified as Sermones Bonaventurae might be so called for any one of a dozen reasons .... Was the original author the famous.Saint Bonaven tura of Fidanza? Or was there another author called Bonaventura? Or was it copies by someone of that name? Or by someone in a monastery of that name? Or preached by some Bonaventura, even though not composed by him. Or had the volume once been owned by a Friar Bonaventura, or by a monastery called Bonaventury? Or was this a collection of sermons by different preachers, of which the first was a Bonaventura? or were these simply in honor of Saint Bonaventura?

The printing press not only gave rise to the concept of the individual author, it also affected how creative people were motitated. With the enhanced economic value of printed books fostered by the new technology, creators encountered conflict concerning whether they were-or should be- 'serving the muses or mechanic printers, [or were] engaged in a 'divine art' or a 'mercenary metier.' " '] ust as the printing press affected the self-image and motivations of 17th and 18th century creators, so too are the new information technologies already changing contemporary creators' attitudes and perceptions about themselves and their work.

In many fields, the convergence of audio, video, and computer technologies now allows the creator to express his/her art in multiple modes and media, changing the way he/she defines his role. Basing her art on a variety of technologies, the entertainer, Laurie Anderson, for example, defines herself at one and the same time as a musician, a composer, a video maker, a writer, an inventor, and a pop stars The same technologies turn audio engineers into stage

Eisenstein, op. cit., p. 53

"J.Hoberman, "The New Avant-(iarde From Anderson to Byrne." Dial Magaine, July1985, pp. 5-6. 
performers, sound-mixers into composers and performers on records,' and computer scientists into film artists. Many artists are also software designers, many composers are technicians, and many biologists are information scientists. As technology becomes more integral to the arts, artists have to become technicians before they can create.

Beyond changing perceptions of their roles, the new technologies may actually affect how creators think, how they become aware of who they are and what they do, and how they define their relationship to the rest of the world. After analyzing people's experiences with the computer, Sherry Turkle observes: ${ }^{10}$

The computer becomes part of everyday life. It is a constructive as well as a projective medium. When you create in a programmed world, you work in it, you experiment in it, you live in it. The computer's chameleon like quality, the fact that when you program it, it becomes your creature, makes it an ideal medium for the construction of a wide variety of private worlds and, through them, for self-exploration. Computers are more than screens onto which personality is projected. They have already become a part of how a new generation is growing up.

By firing creators' imaginations, the new technologies are also widening the scope of creative activity itself and opening new opportunities. The interactive fiction writer, Ann Byrd-Platt, for example, was discouraged from becoming a novelist, believing she could not distinguish herself from "the hundreds and hundreds of writers just like her."'" She found that an understanding of computers and technology gave her new areas in which to exercise her creativity. In writing interactive fictionan art form impossible without computers-

\footnotetext{
'.See for example Ken Emerson, "David Byrne: Thinking Man's Rock Star," The New York Times Magazine, May 5, 1985, pp.54-57. In creating "Once in a Lifetime " teams of technical and artistic individuals create together, working out their sense of structure, relying on intuition, improvisation, and technology. Thus the creator may be both musician and engineer.

SherryTurkel, The Second Self: Computers and the $\mathrm{Hu}$ man Spirit (New York: Simon \& Schuster, 1984), p. 15.

'Ann Byrd- Platt, OTA Workshop on the Impact of Technology on the Creative Environment, Apr. 24, 1985.
}

she succeeded in finding a niche for herself and her creativity.

Technology, may also change how society perceives creators and their work. For example, while most people have always recognized that the stage director imparts a unique contribution to the performance of a play or musical, the director was unable to claim 'authorship' of his work, because his contribution could not be written down or expressed unambiguously. Today, however, video-recording technology, can 'fix' the unique way in which actors, props, motion, and scenery are arrayed in each director's interpretation of a work. By thus establishing his authorship, the stage director has greater credence in his claim to copyright. ${ }^{12}$

Technology has also affected the motivations of artists and scientists. Changes in attitude seem to be most pronounced in those areas where the new technologies have helped to enhance the market value of creative and scientific works. Again, as in the age of the printing press, many creators are wrestling with choices about whether to focus on intrinsic or monetary rewards.

Traditionally, artists have been inspired to create and scientists driven to invent and discover for reasons that can be clearly set apart from monetary rewards. The graphic artist Milton Glaser succinctly characterized these kinds of motivations when he said:

I would suspect that a good many people would say that the basic reason they do their work is that it pleases them, because they love it, because they are obsessed by it, and because they don't feel that they have any choice. ${ }^{13}$

Underlying motivations and the sense of purpose for creators remains strong. Explains Theodore Bikel:

The arts are about risk taking. More often than not [they are] about endangerment. You endanger your soul each time you put some

I ames Hammerstein OTA Workshop on the Impact of Technology on the Creative Environment, Apr. $24,1985$.

'Milton Glaser, OTA Workshop on the Impact of Technology on the Creative Environment, Apr. 24, 1985. 
pen to paper each time you try to interpret somebody else's words. We are about poetry-. We are about the gossamer fabric of hopes, of dreams. We finally in the last analysis hope that what we do create will furnish the nation laughter, the nation's tears, certainly the nation's memory of what today. was like and what yesterday was like. ${ }^{14}$

Scientists, too, have been fueled chiefly by nonmonetary concerns. One major force driving them to pursue their work has been the desire to be the first to solve a problem, to be the discoverer, or the inventor. It was, in fact, the originality of a finding that served as "testimony that one had successfully lived up to the most exacting requirements of one's role as a scientist." ${ }^{15}$ This desire to be first gave rise to numerous battles over originality in the scientific community during the 18th and 19th centuries. ${ }^{16}$

Equally important has been the scientist's desire to contribute to the advancement of knowledge in his field. Traditionally, once a scientist made an original contribution, he did not try to maintain the right of exclusive access to it. Rather, scientists' discoveries and inventions became part of the public domain available for all to use and build on.

Benjamin Franklin exemplified this ethic. Explaining why he had turned down an offer from the Governor of Pennsylvania to patent the Franklin stove. he wrote to a friend:

I declined from a Principle which has weighed with me on such occasions, vis. That as we enjoy great Advantages from the Invention of others, we should be glad of an opportunity to serve others by an invention of ours, and this we should do freely and generously.

Nor did scientists traditionally seek to market their discoveries. Louis Pasteur's attitude

\footnotetext{
'Theodore Bikel, OTA Workshop on the Impact of Technology on the Creative Environment, Apr. 24,1985.

Robert K.Merton, The Sociology of Science: Theoretical and Empirical Investigations [Chicago, IL: The University of ChicagoPress. 1973)

' Ibid,

I bid.

"As quoted i n Bruce Willis Bugbee, (ienesis of A merican Patent and (opyright $L$ a $w$ (Washington. I)C Public Affairs Press, 19761. p. 72 .
}

was typical. Although he himself estimated that the use of his method would save 100 million francs per year, he was not interested in profiting financially from his discoveries. As he explained to Napoleon III:

In France scientists would consider they lowered themselves by doing so. ${ }^{19}$

While many of these traditional motives are still in force, recent technological developments have noticeably affected how scientists and creators feel about their work, the reasons they pursue it, and the rewards they expect to gain from it. In particular, the enhanced commercial value attributed to many information products and services has brought about both conflict and change.

Changing motivations are probably the greatest in fields of science where the commercialization of research results has proved highly profitable. Industry representatives are now actively courting the traditional scholar-scientist. As one professor of biological science at Harvard University described it,

At this point, it's mind boggling. I'm courted every day. Yesterday, some guy offered me literally millions of dollars to go direct a research outfit on the west coast ... He said any price."'

Such offers have placed many scholars in conflict about their roles. While some respond favorably to these developments-even to the point of creating their own firms to exploit their discoveries for profits-others have opposed them as unsuitable for academic science. Trying to sort out what is appropriate behavior for academics and academia, a number of major universities have themselves begun working together to develop policy guidelines for university-industry relationships.

\footnotetext{
As quoted in J.D. Bernal, Science and Industry in the Nineteenth Century (I ondon: Routeledge and Kegan Paul, 1953). p. 86

"As quoted in Henry Etzkowitz, "kjntrepreneurial Scientists and Entrepreneurial Universities in American Academic Science," Minerva. vol. XXI, Nos. 23, summer/autumn 1985, p. 199

"Academe and Industry Debate Partnership," Science. vol. 219. No. 4481, January 1983, pp. 150-151, See also U.S. Congress, Office of Technology Assessment, Information Tech nology Research and Development:Critical Trends and issues, OTA-CIT-268 (Washington, DC: U.S. Govemrnent Printing Office, February 1985),
} 
Creators in the arts and entertainment face similar choices. With the development of a mass media marketplace, these fields have become big businesses where intellectual works are often treated purely as economic commodities. The development and proliferation of new channels of distribution has promoted fierce competition for entertainent products, which has greatly increased its commerical value. ${ }^{22}$ Under these circumstances, authors, artists, musicians and other creators may be faced with difficult choices about whether to develop their art in response to the market or to their own internal forces. 23 As Milton Glaser described this dilemma:

If you begin with the idea that the movie business is a business that has an artistic ele-

\footnotetext{
${ }^{22}$ Tom Whiteside, "onward and Upward With the Arts," Cable I, II, and I I I [three-part article series], The New Yorker. May 1985 .

'Just such a phenomenon occurred, as has already been noted, with the growth of the book market after the development and widespread deployment of the printing press. Such an occurrence happened again in late 19th century America, when the book market was expanded to meet the needs of an increasingly literate population. To profit from this literate, although generally less educated audience, it was common for publishers, for example, to press authors to lower their artistic standard for the sake of increasing sales, See for example, Lewis A. Coser, Charles Kadushin, and Walter Powell, Books: The Culture and Commerce of Publishing (New York: Basic Books. Inc, 1982), pp. 226-227.
}

ment to it, , .. [then you need to recognize that] the control of the movie business essentially is in the hand of the people who think of it as a business, invest the money, and are in it to make money and do. ${ }^{24}$

The choice a creator makes depends on his fundamental motives and on his relationship to others within the creative environment. For software developer David McCune, for example, there really is no choice. As he says:

I'm going to program computers no matter what. I'm concerned that I make enough money to pay the rent and buy myself a computer, basically. Other than that I don't really care much. ${ }^{25}$

Some artists are supported by government grants or endowments from private foundations. Few are successful enough to attain both the desired economic independence and artistic freedom. Most, however, choose to work within the existing system and, when they can, to finds ways to express their creativity. In effect, they work in both worlds, the world of art and the world of business.

\footnotetext{
${ }^{24}$ Milton Glaser, OTA Workshop on the Impact of Technology on the Creative Environment, Apr. 24, 1985.

${ }^{25}$ David McCune, OTA Workshop on the Impact of Technology on the Creative Environment, Apr. 24, 1985.
}

\section{TOOLS FOR CREATIVITY}

Machine tools enhanced man's ability to perform physical tasks. Similarly, the new information technology will enhance his ability to carry out intellectual pursuits. ${ }^{26}$

Because these technologies are primarily intellectual tools, they are likely to be used extensively in science, scholarship, and the creative and performing arts. In these areas, technologies may:

\footnotetext{
${ }^{26}$ For a discussion of how information and communication technology can extend man's creative process of knowing, see Marshall McLuhan, Understanding Media: The Extensions of Man (New York: Signet, 1964). For a more recent and speculative discussion about the impact of the computer on the mind, see Robert Jastrow, The Enchanted Loom: Mind in the Universe (New York: Simon \& Schuster, 1981).
}

1. expand the boundaries of the fields as we know them,

2. change the ways in which creators and inventors carry our their work, and

3. allow more people to participate in the creative process and to share the products of scholarly and scientific research.

\section{Expanding Boundaries}

History offers many instances in which new technological tools have advanced the boundaries of science and scholarship, also expanded the domains of art and entertainment. The invention of the clock and the lens, for example, greatly facilitated the development of the 
sciences of mechanics and astronomy. ${ }^{27} \mathrm{Simi}-$ larly, technologies expanded the domains of art and communication. With the substitution of oil paint for egg tempera, the course of painting was dramatically changed, giving rise to the Renaissance style of art. " The development of the camera, too, brought entirely new forms of art and entertainment. As the art critic J ohn Berger notes in his analysis of the impact of the camera on our perception of the visual arts:

The art oft he past no longer exists as it once did. Its authority is lost. In its place there is a language of images. What matters now is who uses this language and for what purposes ."'

Like their earlier counterparts, the new communication technologies are exerting a wideranging influence on the arts and sciences and on the development of other information products and services. They offer new tools. By taking advantage of computers' high-speed dataprocessing abilities, computer graphics can represent many types of information and art, from mathematical formulae to cartoons. Computers facilitate the manipulation and rearrangement of anything that can be expressed in computer-readable form-images, data files, text. The new techniques for inexpensive re production-xerography, audio and video duplication, computer copying-also allow creators and other users to gain access more easily to a much broader range of intellectual properties than ever before,

These technologies have varying effects on the actual substance of creation. For some people, new technological capabilities enhance the creative process by making it faster, cheaper, or easier to produce a work. For others, they actually change the boundaries of their art.

\footnotetext{
${ }^{27}$ John P. McKelvey, "Science and Technology: The Driven and the Driver," Technology Review, January 1985, p. 42. As McKelvey points out, the casual relationship works both ways, with pure science often given rise to new technologies.

"Milton Glaser, OTA Workshop on the Impact of Technology on the Creative Environment, Apr. 24. 1985.

"JohnBerger, British Broadcasting Corp., Ways of Seeing (London: Penguin Books, 1972). p. 21, as cited in Edward W. Plowman and L. Clark Hamilton, Copyright: Intellectual Prop erty in the Information Age (London: Routledge \& Kegan Paul, 1980).
}

A growing number of authors, for example, write on word processors because the new devices make it easier to edit, store, and transmit their documents. For these authors, word processing has not produced a new form of literary expression; it has simply facilitated the mechanics of creating literary works. Similarly, film makers use sophisticated and intelligent tools to capture or create images and sounds with greater ease and dazzling speed.

Beyond facilitating the creative process, some technological advances have actually opened new channels for the expression of creativity, thereby expanding the very nature of science and art, Using these new computerized channels to generate graphics and synthesize music, artists, film makers, and composers are creating new kinds of images. These new pictures and sounds are born of equations, algorithims, and mathematical models. Using computer programs and mathematical values to represent color, shape curvatures, shading, and even randomness, teams of engineers, artists, and film makers "produce extraordinarily complex and lifelike graphic simulations that rival and sometimes exceed those born of traditional animation. ${ }^{1130}$ Whether used to "draw" a seaside landscape (see box 5-I), to generate special effects, or make motion pictures, the power for creation lies in the software and the imagination of the team. For creators at Lucasfilms, today's tools represent only the beginning of what will later be possible: In the future, "the computer will allow Hollywood to tell stories that could not have been told any other way.'"'

Like their counterparts in the arts, scientists use increasingly powerful computers to carry out more and more complex calculations, and to represent and to simulate experiments, processes, and phenomena. The use of supercomputers and color imaging techniques for numerical computation in fields such as physics enables scientists to solve increasingly com-

\footnotetext{
"'Stuart Gannes, "Lights, Cameras Computers. " DISCOVER, August 1984, pp. 76-79,

"Ed Catmull, Head of the Computer Development Group, Lucasfilms, as quoted by Stuart Gannes, "Lights, Cameras . Computers," DISCOVER, August 1984, p. 79.
} 


\section{Box 5-1.-Using Computer Generated Imagery to "Draw" a Seaside Landscape}

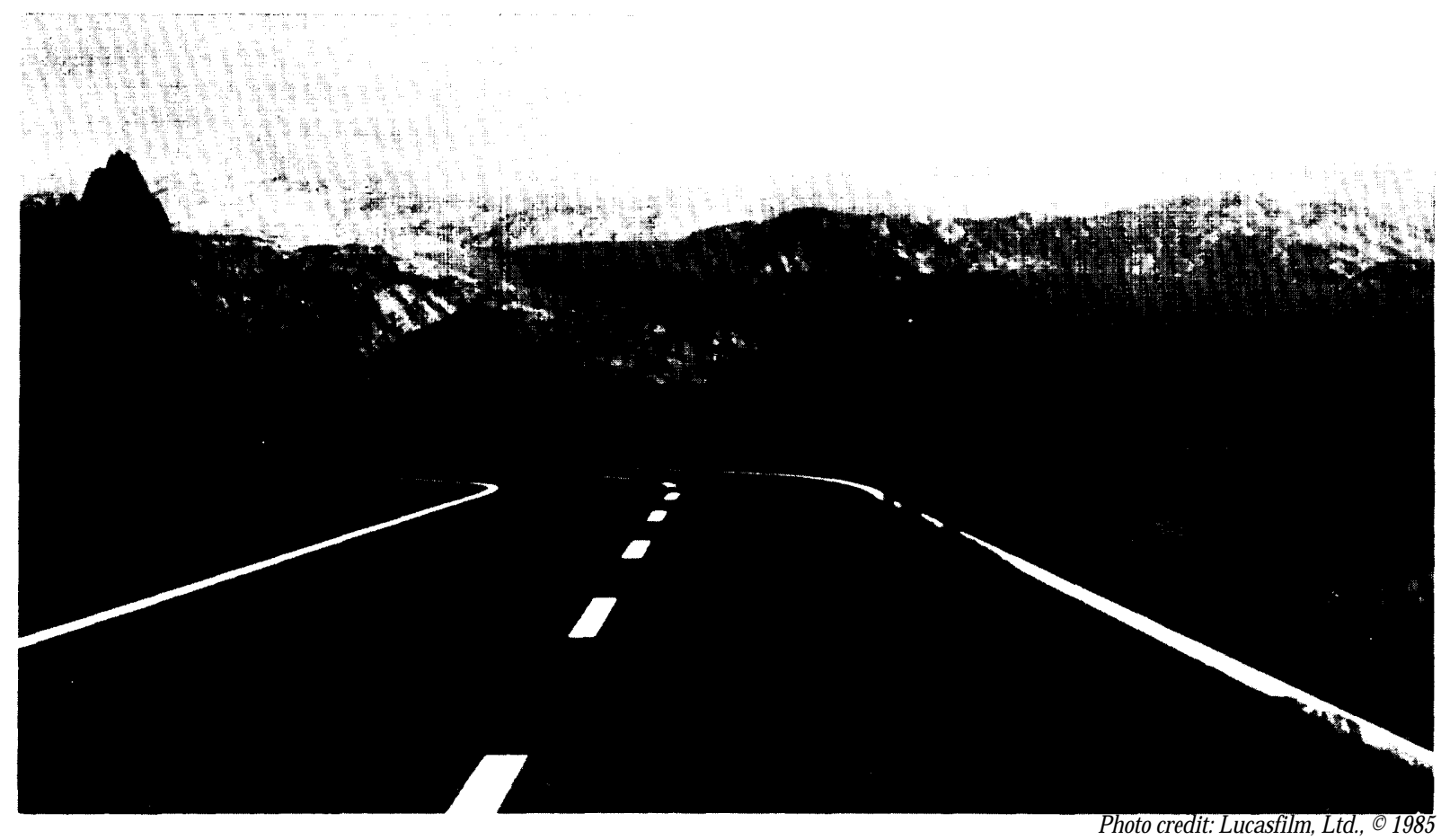

This composite image, titled "Road to Point Reyes" was produced by a team of creators working in the Computer Graphics Project at Lucasfilm. Under the direction of Robert Cook, the landscape was defined using patches, polygons, fractals, particle systems and a variety of procedural models. Each of the elements of the landscape were rendered separately and later composite. Rob Cook designed the picture and did the texturing and shading, including the road, hills, fence, rainbow, shadows, and reflections. Loren Carpenter used fractals for the mountains, rock, and lake, and a special atmosphere program for the sky and haze. Tom Porter provided the procedurally drawn texture for the hills and wrote the software by combining the elements. Bill Reeves defined the grass by means of a moving particle system he developed. He also wrote the modeling software. David Salesin put the ripples in the puddles. Alvy Ray Smith rendered the flowering forsythia plants using a procedural model. The visible surface software was written by Loren Carpenter. Robert Cook wrote the antialiasing software, a program to prevent unauthorized access.

The picture was rendered using an I konas graphics processor and frame buffers, and was scanned on FIRE 240, courtesy of MacDonald Dettwiler \& Associates Ltd. The resolution is $4 \mathrm{~K} \times 4 \mathrm{~K}, 24$ bits/pixel.

plex problems-problems with so many variables that the true visualization requires a numerical solution. For example, modeling gas flowing in black holes, where the actual manifestations of the gas dynamics around them are too small to be observed, requires numerical experiments of a new order of magnitude. Explains Larry Smarr:
A typical experiment makes use of at least 10,000 time steps. Thus, the finite-difference solution is a set of five variables on a space time lattice of 250 million points, that is, the solution of 1.25 billion numbers of nonlinear partial differential equations. ${ }^{32}$

\footnotetext{
${ }^{32}$ Larry L. Smarr, "An Approach to Complexity: Numerical Computations," Science, vol. 228, No. 4698, Apr. 26, 1985, pp. 403-405.
} 
Participants at OTA workshops convened for this study," described the multiple ways in which the new technologies are expanding the boundaries of science, music, art, dance, photography, film, and television:

In musical composition and performance, new sounds and arrangements result from computer synthesizers, digital sound analyzers, and electronic editors. Although musical notation can begin on paper, it may also be "drawn" electronically. The technology not only provides tools to generate sounds, but also the means to store and manipulate them as well. Thus composition and performance can result from revision, expansion, or recombination of unending variety of chords, melodies, rhythms, or pitch.

A dance sequence blends the performance of a live dancer with that of computer-generated images and information. Intricate and complex sequences of movement and dance are developed by the choreographer and performed by the computer. While early computer representations of dance were rudimentary representations, computer images are now essential elements of the performance itself. In some instances, the computer-generated dance sets out new steps, followed in turn by the live dancer. For some choreographers and dancers, the boundaries between technology and dance cross in the generation of new art forms. (See box 5-2.)

The new technologies not only affect performance in dance directly, as adjunct art forms; they also provide new ways to permanently record dance. In turn, once stored, these computer records not only become choreographical records, when broken down into their elements, they can also become sources for new steps and sequences.

Technological changes in cameras, film, lighting equipment, laser separators, print publishing, and computer processing of electronic images are all affecting photography.

Computing power display technologies enhance capacity that they expand science into new horizons. (See box 5-3. ) This expanded capacity allows for new ways of visualizing

"OTA Workshops: Technologies for Information (Treat) on, Dec 6, 1984; Display. Printing, and Reprography, Mat 13,1985 1 mpact of Technology on the Creative Environment. Apr 24, 1985). and analyzing physical phenomena such as the behavior of a molecule or the evolution of a galaxy.

The power of the new technologies is not limited to science and the arts, it cuts across virtually all information-related fields. New information technologies have expanded the variety, scope, and sophistication of information products and services. Described by some observers as being in the very process of "selfcreation," ${ }^{134}$ the information industry-from database businesses, software and hardware providers, publishers, cable television, information analysis centers and clearinghousescontinues to grow. In the U.S. software industry alone, there are an estimated 1,200 companies and thousands of individual free-lancers creating and producing software and providing services worth $\$ 40$ billion annually.

The new technologies can both enhance existing information products and services and generate new ones. Figure 5- I lays out the multidimensional and multifaceted technological capabilities that play a role in developing information products and services to meet a wide range of information-related functions. At the same time, the technologies enhance the value of information products and services by making them more accurate, timely, and accessible.

\section{New Ways of Proceeding}

The development and use of new tools also influences the way people perform creative activities. Historically we can see, for example, that the technology of mass printing and publishing changed the process of conducting scientific research and scholarship by imposing precision and standards for publication. Books were reviewed, examined, and marked up in ways they had never been before. For the first time, images could be printed with text. A system for organizing books was devel oped; titles were systematically arranged with bibliographies compiled, making it eas-

\footnotetext{
"Charles W. Moritz,President and Chief operating office, Dun \& Bradstreet Corp. Keynote Address, 15th Annual Convention and $F$ xhibit ion, The Informat ion Indust ry Association, Nov. 7, 1983. New York City.
} 
Box 5-2.-Dance and Computer Technology

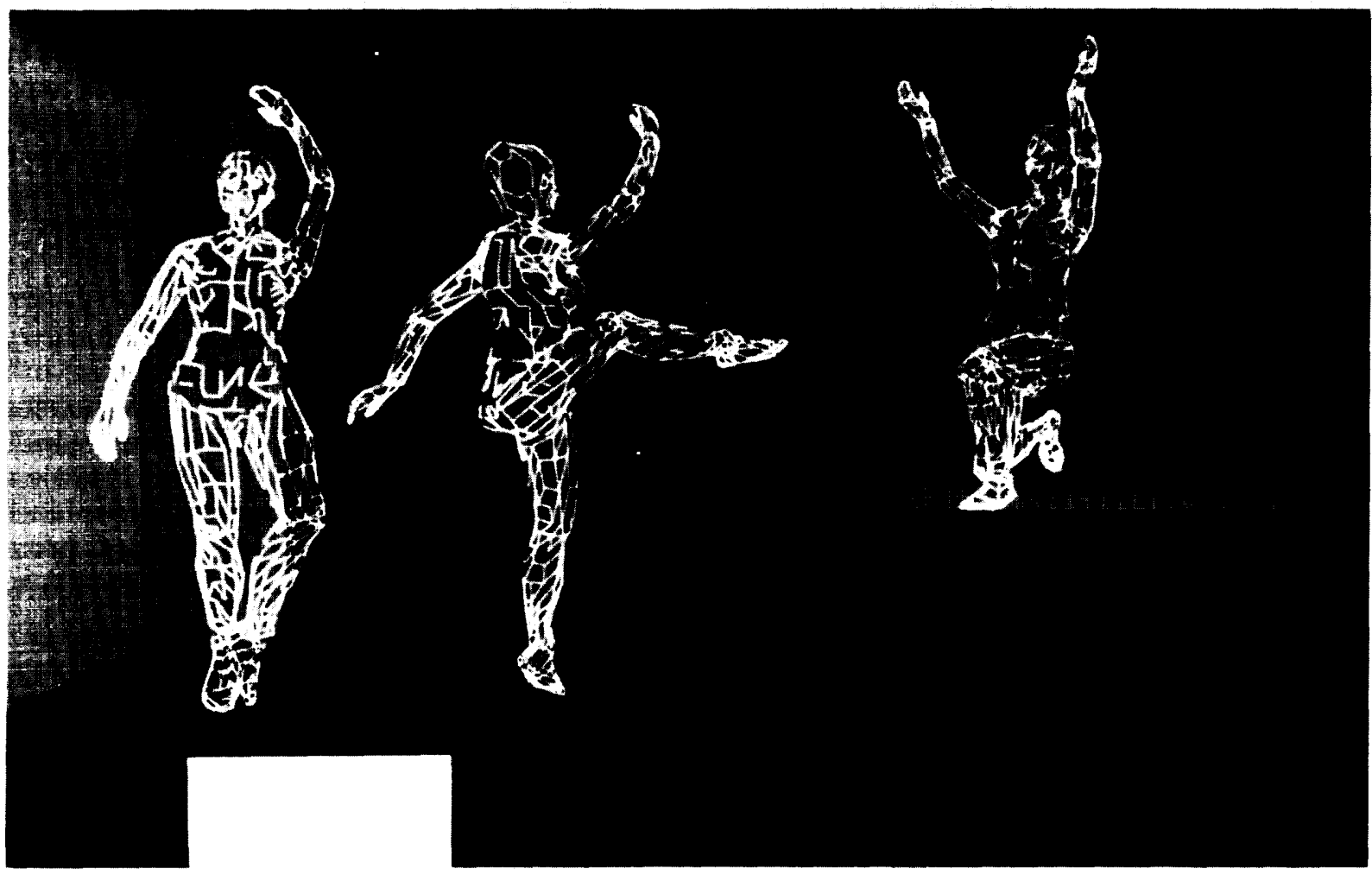

"And who can tell the dancer from the dance?"

-William Bulter Yeats

Computer graphic images depicting dancers and dance sequences were created at the New York Institute of Technology's Computer Graphics Laboratory by Robert McDermott, Rebecca Allen, Paul Heckbert, Lance Williams, and J im St. Lawrence. The computer-generated figures are "rotoscoped" to mimic the steps of a videotaped human dancer's performance. They can then be combined with live action film or video as in Twyla Tharpe's "Catherine Wheel," a co-production between Dance in America and the British Broadcasting Corp.

ier to use the growing volume of written works. These changes, in turn, facilitated the development of the scientific method. ${ }^{35}$

Printing and the widespread distribution of books also fostered new relationships among scientists, artists, intellectuals, and their geographically distant counterparts. As Eisenstein has pointed out:

The fact that identical images, maps, and diagrams could be viewed simultaneously by

\footnotetext{
${ }^{35}$ Eisenstein, op. cit., pp. 80-111.
}

scattered readers constituted a kind of communications revolution itself. ${ }^{36}$

J ust as technology affects the tools used by creators and enhances and expands the creative process, so too it will lead to new ways of operating. With computers' increased capacity to store, retrieve, and manipulate information and images, the process of creativity and research is becoming more interactive. Two phenomena illustrate this: electronic snipping and pasting and computer networking. 
Box 5-3.-Using Computer Graphics as a Tool To Explore New Surface Structures

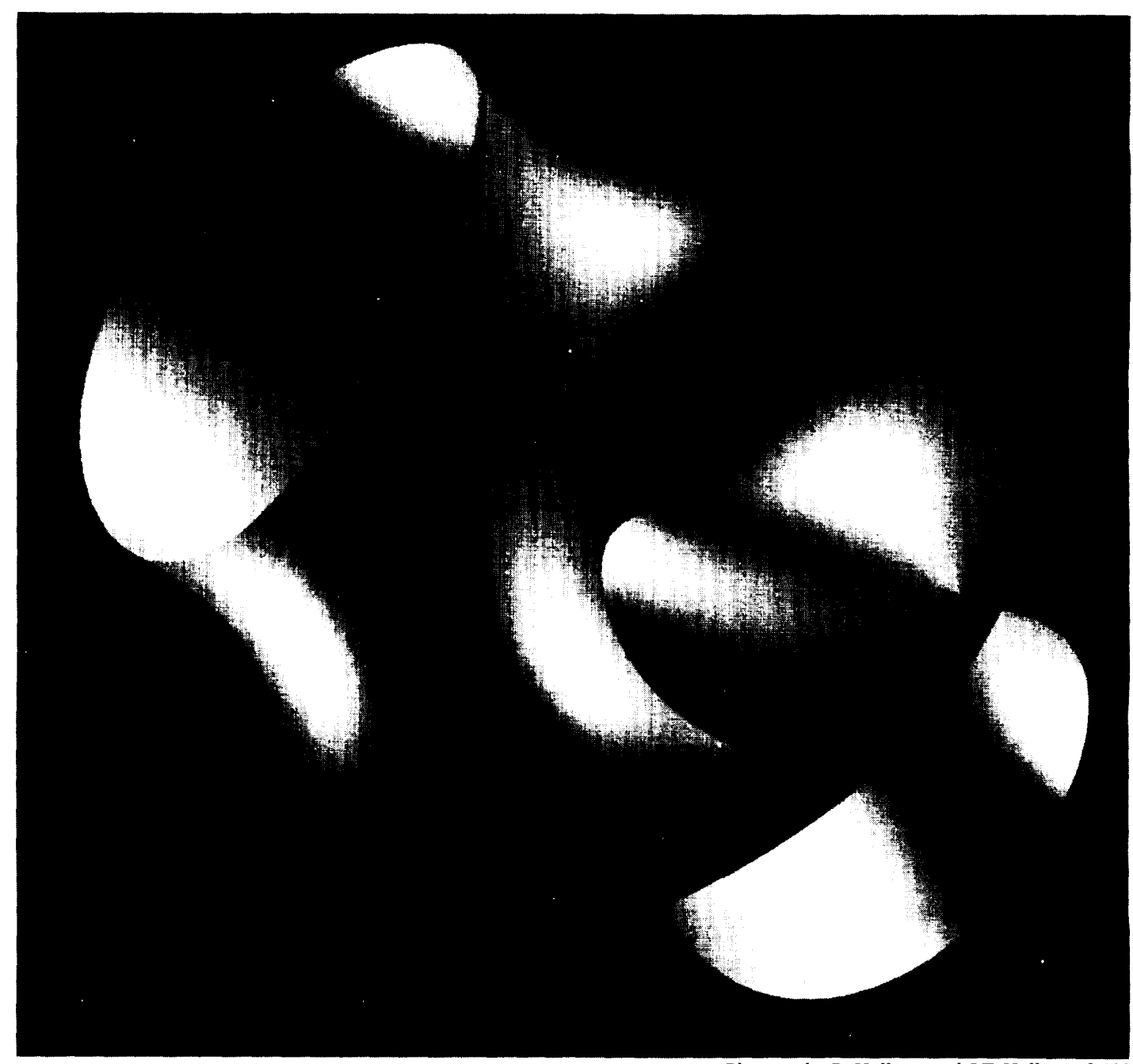

Photo credit: D. Hoffman and J .T. Hoffman. ( 1985

Minimal surfaces are mathematical idealizations of membranes which are stretched in such a way as to attempt to make their surface area as small as possible. They occur as soap films, as interfaces in liquid crystals, and have been used theoretically in physics and general relativity.

In 1984, David Hoffman, a mathematician at the University of Massachusetts at Amherst and William H. Meeks III, then at Rice University, were able to prove the existence of a new minimal surface, the first of its type to be discovered in 200 years. By using numerical methods to approximate a possible example, and then computer graphics developed by J ames T. Hoffman to view portions of it, they were able to discern that the surface was highly symmetric. According to David Hoffman, "This provided qualitative information and insight which led to a new general theory and the construction of infinitely many examples." Moreover, he notes, "The ability to process and condense large amount of information by means of computer graphics is well known in other fields, but has only recently been used in mathematics."

Pictured below, is a computer-generated view of the new minimal surface. 
Figure 5-1 .-Applications of Information Technologies to the Creation and Processing of Information

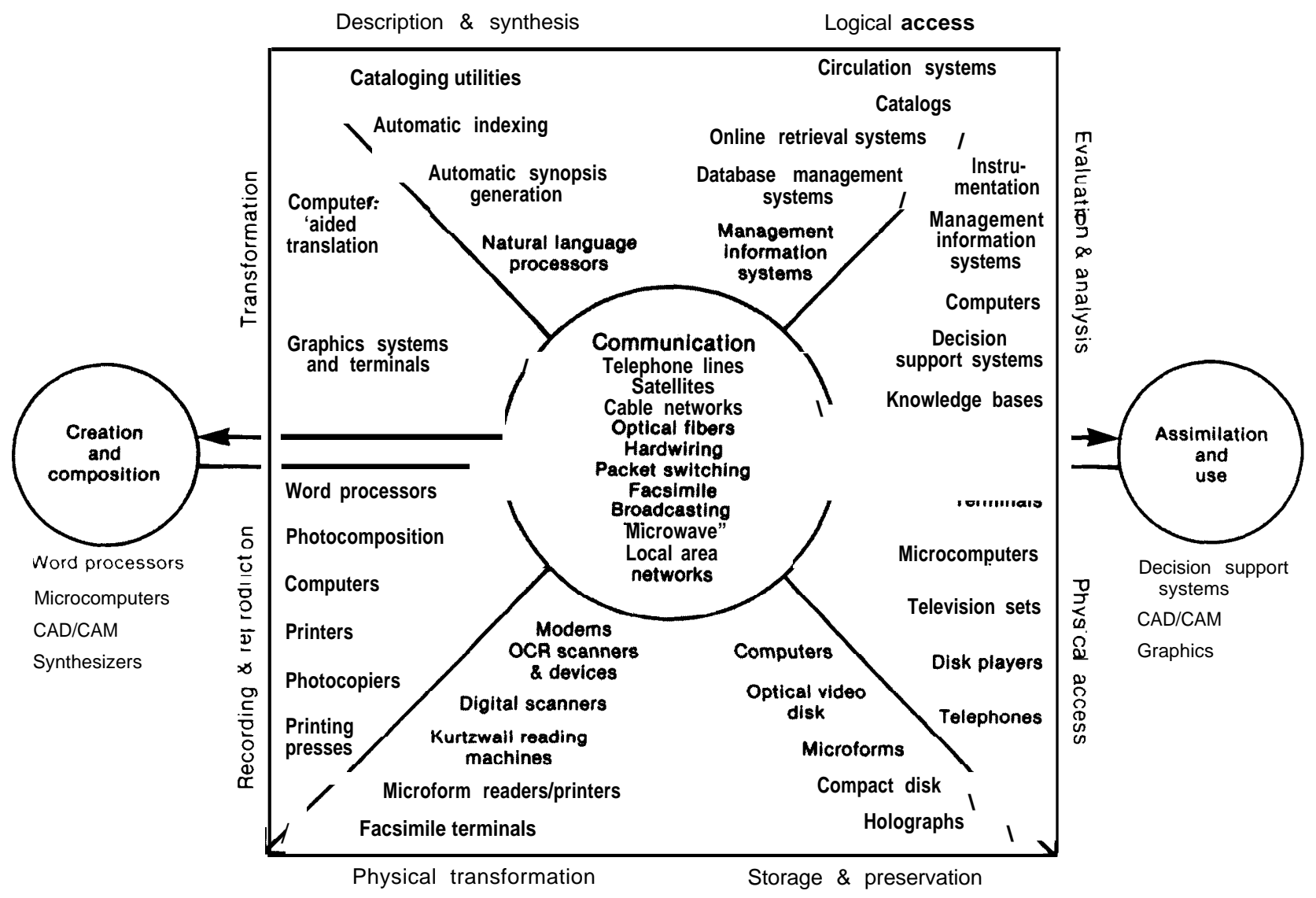

SOURCE King Research, Inc., July 1985

\section{Electronic Snipping and Pasting}

Even when done with scissors and paste, snipping and pasting consists of a process of storing, retrieving, and manipulating information. The computer, with its unique capacity to perform these tasks, is the ultimate editing tool. With this technology readily available, the creator is now as prone to re-create as to create in the first place.

Computer and video technologies are having such an effect on film editing. With tools such as EditDroid, developed by Lucasfilms, the arduous task of editing thousands of feet of film is ss simplified by electronic snipping and pasting.

"Experts point out that film editing is a major component in the making of a film. It can take as long as the shooting itself. A typical finished feature film consits of 10,000 feet of film, on six reels, the result of as many as 2,000 splices from the original footage. See Gannes, op. cit. ess, a film artist can rearrange footage in the same way a writer rearranges words on his word processor: inserting and deleting images frame by frame; taking whole sequences from one place and shifting them to another; and scrolling through sequences again and again. All this is done in a matter of seconds. ${ }^{38}$ As in creating texts or developing on-line databases and information services, films can also be edited, merged, and reformed. In the same fashion, old films, stored tape footage, and other archival material can all serve as the basis for new derivative products and creative works.

Electronic snipping and pasting has also altered the world of the still image photographer. Using laser and computer technologies to scan original photographs and convert them into 
digital data, one can manipulate the 'no-longer photographic' image in very sophisticated ways. ${ }^{39} \mathrm{Col}$ or, texture, figures, and so on can be varied slightly or totally. (See box 5-4, "Now you see them, now you don't. The same technologies can also transmit photographs electronically to printers in remote locations.

These capabilities can alter both the way a photographer works and his control over his work. Before digitized photography, for example, the photographer could control his images by controlling the film negatives. Today, however, the commerical photographer must negotiate in advance, in exact detail, how the image will be used, for what length of time, and under what circumstances. Explains Bill Weems: "The human relationships of the whole industry have changed dramatically now. . . . You have a whole new world to deal with here. I mages are not only stored and retrieved, but are digitized and re-created." ${ }^{\prime \prime 0}$ To work out these relationships, additional time must be spent dealing with administrative and transaction issues. And the photographer wonders if it is only a matter of time before it will be literally impossible to track all of the uses of one's images.

The production of music and sound is equally amenable to electronic snipping and pasting. Using the ability to store recorded sound digitally and gain increased digital control of that sound, the musician can mix and match not only sounds, but also rhythms and pitch. According to composer Michael Kowalski, these new tools allow for:

... unprecedented access to reproducing, copying and editing sound - an ability to take tiny snippets of sound, anywhere from a twentythousandth of a second of a sound to the whole piece of music, and manipulate it to your heart's content."

These technological advances have the potential to damage creators' interests as well.

\footnotetext{
'Steward Brand, Kevin Kelly, and J ay Kinney. "Digital Retouching," Whole Earth Review, No. 47, J uly 1985, pp. 42-47.

'Bill Weems, ('TA Workshop on the Impact of Technology on the Creative Environment, Apr. 24, 1985,

4. Michael Kowalski, OTA Workshop on Technologies for Information Creation, Dec. 6,1984.
}

The same images and sounds that the artist, photographer, or musician has stored to use, manipulate, revise, and reproduce can also be manipulated, revised, copied, and used in a multitude of ways by others, with or without permission. Some creators worry that a "cavalier attitude will develop toward taking whatever you want and doing whatever you want with it. "142 This attitude has al ready surfaced within the artistic community itself, as well as in the worlds of advertising and publishing." Although many of these innovative tools for cutting and pasting are still relatively expensive and unavailable, they may be more accessible in the future. With wider deployment of such techniques, artists, photographers, and musicians may find it increasingly difficult to track or trace the uses of their work. Notes J oyce Hakansson:

Now, talent, creativity, works of art are also in an intangible fashion being transmitted and we are not aware of the fact that we are stealing; that we are, in fact, impinging. We are encroaching on somebody's rights. That has to be transmitted. The new technology is now putting things in a new format and we have to be taught to look at it in a new way. ${ }^{44}$

Thus one question for the creative community is: How do you proceed?

\section{Computer Networking}

Computer networking makes it possible to use distant computing power to analyze data or generate new images; to consult with one's colleagues and jointly write papers; and to exchange ideas or reports. However, such shifts in the way information and knowledge are cre-

\footnotetext{
"I bid.

"Interview with Lauretta J ones and Bonnie Sullivan, graphic artists in New York City, March 1985, For example, J ones worried about continued reuse of her images, done easily without her permission, once her client has a copy of her disk, on which the image was fixed. Sullivan found that using a very sophisticated computer graphics system that required that she store her images on hard disk, placed her image files in a computer system in which she had no control. Finding that other users had access to her files without her knowledge or acquiescence, Sullivan chose not to work on the system until users could agree to control and respect controlled access to one another's work.

${ }^{44}$ J ovce Hakansson, OTA Workshop on Technology and the Creative Environment, Apr. 24, 1985.
} 
Box 5-4 Art of Digital Retouching

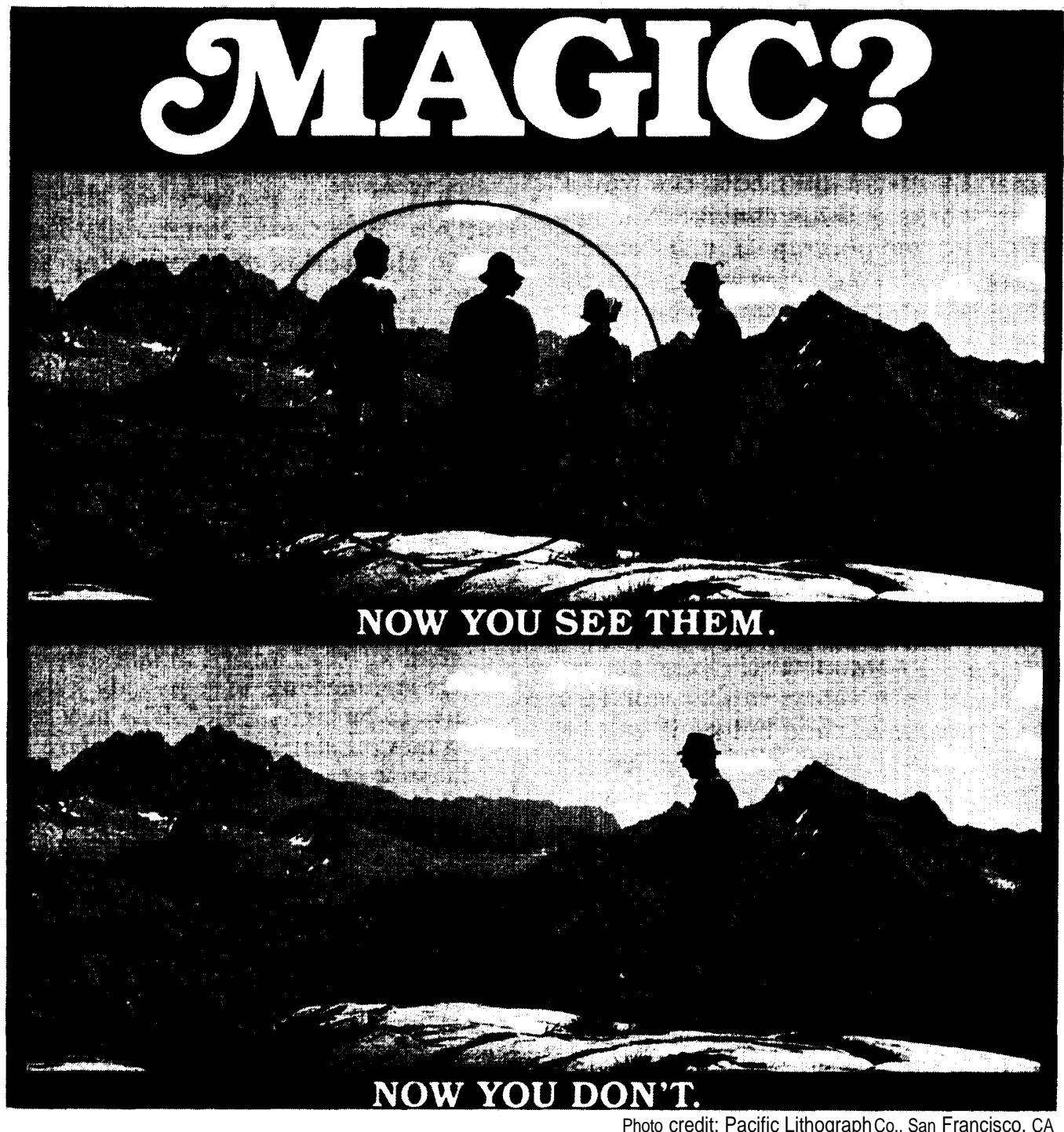

This demonstration of digital retouching was put together by Pacific Lithograph Co. What appears to be two separate photographs is actually only one. By digitizing the photograph of the four hikers, it becomes possible to capture and then manipulate information about color, patterns, and texture.With a Chromacom machine, a computer-driven device, it becomes a simple matter to copy the color texture at one point and slide it over to another. Distinctive patterns are copied exactly. Thus the three people standing in the top-me were not remooved instead they were "washed over" with sky and mountain bits, taken from the scene. Each mow of the cursors brings the seams of the changes closer and closer together. While requiring skill, the digitizing process appears to be almost a routine operation. 
ated and distributed can have a tremendous impact on the worlds of scholarship and creativity. For just as the centralization of bookmaking and publishing led to the development of authorship and standardized texts, so might electronic networking speed the decentralization of information distribution, which, in turn, may to lead changes in the processes by which research is conducted and art is created.

These changes are already becoming visible in the academic world, where scientists are using computers and telecommunication links to conduct research and communicate with one another on networks supported by the Department of Defense (ARPANET), the National Science Foundation (NSFNet), and the Department of Energy (MFENET). ${ }^{45}$ The number of networks and users are growing rapidly, not only for scientific communities, but also in other academic disciplines.

BITNET, for example, used by scientists and other scholars, provides linkages to more than 175 institutions of research and higher education in the United States and has direct links to networks in Canada and Europe. Users of BITNET and other networks send each other messages, text files, and computer programs. " Those who use computer networking describe it as an essential tool in their work. (See table 5-I.)

Some networks serve not only as mechanisms for exchange of data and information, they also provide the means to access distant computing power for conducting research. One such example is the National Magnetic Fusion Energy Network (see figure 5-2), which connects a total of 4,000 users in 100 separate loca-

\footnotetext{
"For a description of the operation and scope of those networks see, Dennis M. J ennings, Lawrence H. Landweber, I ra H. Fuchs, David J. Farber, and W. Richards Adrion, "Computer Networking for Scientists, Science, vol. 231, No. 4741, pp. 943-950.

4- Files, for example, can include any type of machine-readable document, such as memoranda, research proposals, manuscripts, and letters. J ust as networks transmit messages from one computer to another, networks also transmit information from one computer to another, in the form of data or computer programs. See I ra H. Fuchs and Daniel J. Obserst, Report on Networking, OTA contractor report, J une 1985.
}

\section{Table 5-1 .-Electronic Networking: Academic and Research Uses}

"1 have found the network to be extremely useful thus far In furthering my collaborative efforts with researchers in other cities The ability to transmit both raw and transformed data and computer printouts of analyses rapidly between locations greatly facilitated the collaborative efforts. It was possible, indeed in cases easier than if we'd been in the same city, to receive data, run an analysis, ship results, discuss the results, and plot next strategies for analysis with colleagues in Boston and New York. Further, I am actively collaborating in a research grant at -- with - -- and we both have found the ability to send copies of measures, initial data, and other forms rapidly to each other has greatly facilitated our work

., "We use BITNET for electronic mail dialogues with authors in all stages of publishing business, Including the shipment of complete book manuscripts to our editors Two encyclopedia projects are underway at remote locations. We currently carry on conversations with the authors and editors of the projects, but when they move into the copy-editing stage we plan to have a constant flow of articles, back and forth project editors to our in-house manuscript editors, and vice versa"

"Last summer,... I moved shop from - to I was able to ship the majority of files from both the CS/SOM DEC-20 and the IBM 4341 quickly and effortlessl y $\mathrm{t} \mathrm{O}$ - via BITNET “

... "I have used BITNET on several occasions to send data to and receive data from users at [several different universities]. [It] has made the scientific interactions with researchers at these institutions much easier than it would be without the network. Unfortunately several institutions with which I regularly communicate are not on the network."

Other faculty members used the network while they were on academic leave to advise graduate students who were working on their dissertations. "Using BITNET, question and answer exchange or draft approval could take place within the same day. "

SOURCE BITNET Network Information Center. EDUCOM Princeton, NJ

tions, all of whom are involved in multi-institutional research efforts. ${ }^{47}$

Electronic networks can also provide access to vast electronic libraries. Although few researchers today report using their time on electronic networks to search on-line bibliographic and content databases, more are likely to do so in the future. Eventually, researchers conceivably might acquire all they need-people, research tools, current data and information,

'Figures provided by the Office of Fusion Energy, U.S. Department of Energy, and the National Magnetic Fusion Energy Computer Center, Lawrence Livermore National Laboratory, University of California. 
Figure 5-2.- National Magnetic Fusion Energy Network

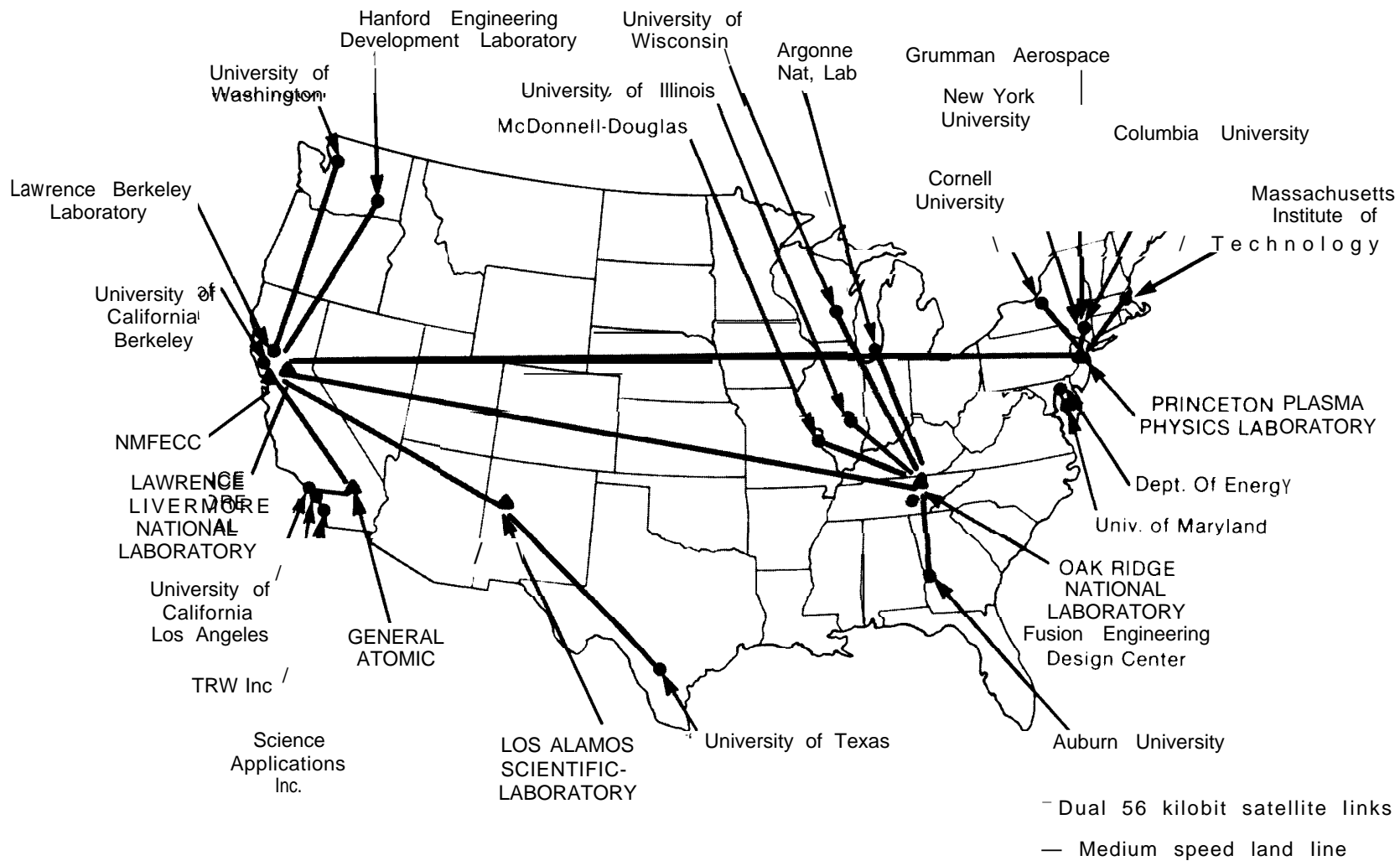

SOURCE National Magnetic Fusion Energy Computing Center, Lawrence Livermore National Laboratory

and published literature-via these electronic networks.

In such a fluid, interactive system, the possibility of discovery or invention on-line, once a vision of the future, is now a reality. As scientists and researchers work in this environment, intellectual property concerns are likely to arise on such issues as determining originality and assigning patents. International transmission of data, software, and other information may further complicate this situation.

It should be noted, however, the information distributed on networks differs in one key way from information published in technical and scientific journals. Works transmitted electronically are likely to be still in progress, with multiple authors, each at a different stage of revising the work. Eventually, scientific research may actually be published on such networks instead of on paper. This practice would have far-reaching consequences for scholar- ship. As I thiel de Sola Pool has noted, "The proliferation of texts in multiple forms, with no clear line between early drafts and final printed versions, will overwhelm any identification of what is the world's literature. " $4^{8} \mathrm{As}$ in the days prior to the printing press, originality will be hard to verify and authorship hard to establish.

\section{Who Can Participate}

The new information and communication technologies and networks may determine, in part, who can participate in the creative process. These tools, like their earlier counterparts, can increase the need for some skills and reduce the need for others. In the past, for example, the invention of letters and the development of written language increased the need

\footnotetext{
${ }^{48}$ Ithiel de Sola Pool Technologies of Freedom (Cambridge, $\mathrm{MA}$, and London, England: The Belknap Press of Harvard University, 1986), p. 212.
} 
for analytic skills and diminished the need for some of the poetic skills that facilitated memorization. Similarly, the new information technologies are bringing about changes in the skills required to participate in the creative process, helping to determine in this way who can take part in this process. The effect, however, differs depending on the product. Although these tools decentralize and democratize some kinds of activities, they might be erecting barriers to entry for others.

Until recently, computer technology was the exclusive province of a technological elite. Use of computers required a special set of skills and knowledge held by highly trained computer scientists and a select group of self-educated computer hobbyists or hackers. Today, advances in hardware design and operation, as well as improvements in software design and applications, have brought computer technology to the public as well as to artists and scholars. Now everyone can use new technologies to expand and enhance their creative powers and vision.

Before the advent of computer synthesizers or software tools such as MacPaint, innate ability and years of training were needed to play a musical instrument, compose a tune, or create an illustration for printing, While today tools substitute for neither artistic talent nor training, they do open new avenues for creative expression and communication of the uninitiated. Using a personal computer, one can generate melodies, explore harmonies, and play an instrument, bypassing the study and practice that separated the musician from the nonmusician. ${ }^{49}$ Digital synthesizers, sound systems, and recording systems can further extend the reach of both amateurs and professionals, and at increasingly lower costs. ${ }^{50} \mathrm{Now}$ a musician can create highly sophisticated sound in his basement or in a studio, using tools that were once available only in a university music research Laboratory.

\footnotetext{
"Music in the Computer Age, Compute, J anuary 1985. Scott $\mathrm{M}$ ace, "Electronic orchestras in Your Living Room," Infoworld, Mar, 25,1985, pp. 29-33.

Michael Kowalski, OTA Workshop on Technologies for Information Creation. Dec 6.1984
}

The technologies that make such things possible are now more widely available, as the case of computer graphics illustrates. A few years ago, these technologies were only available to computer scientists and engineers involved with computer-aided design, data analysis, and mathematical modeling. Now a wide range of software applications are readily available for use in diverse fields. This software does not pose problems for novices since they provide what has come to be called "a user-friendly operator-machine interface. ${ }^{1152}$ In this way, objects, ideas, and projects of study can be expressed and represented graphically for business, education, and personal use. For example, using stylized, highly professional fonts and figures that can be "called up" on a personal computer, one father, as figure 5-3 illustrates, composed a rather artistic letter to his son, off at camp.

Advances in hardware and software are also enhancing access to information itself, and to resources that can provide information. Electronic networks such as the Source or CompuServe can put people in touch with vast information resources such as on-line information services, electronic databases, and new forms of information sources, such as community bulletin boards.

Searching the literature with on-line computerized databases has, until recently, been done principally by trained information specialists, such as librarians or technical specialists employed by large companies. Such searches not only required the use of highly specialized and arcane computer commands but also highly specialized knowledge of the databases themselves. M ore accessible software designed to reach on-line databases makes it easier for users of personal computers to retrieve information. Similarly, improvements in the design interface of on-line systems themselves facilitate search and location of information. These developments enable medical professionals, market managers, or off-campus students to turn on their personal computers, connect with

\footnotetext{
Andries van Dam, "Computer Software for Graphics, Scientific American, 101.251, September 1984, pp. 146-159,
} 
Figure 5-3. - An Example of At.Home Publishing

N LETTER TO GXMP

(1)

(n)

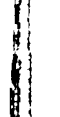

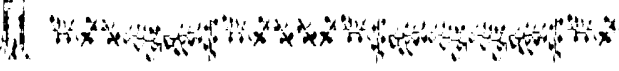

1) a

\%

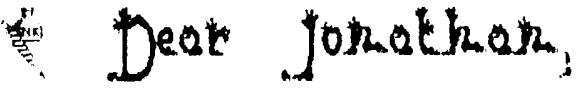

(1)

ts

We got yout Jekter kotoy. Le wes so mice tho we oll hod ko wtike you. The big mets stototho hete is

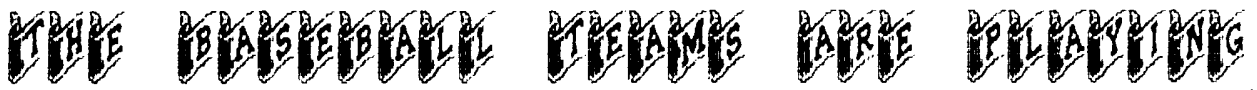

与

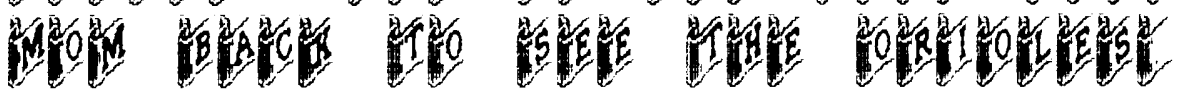

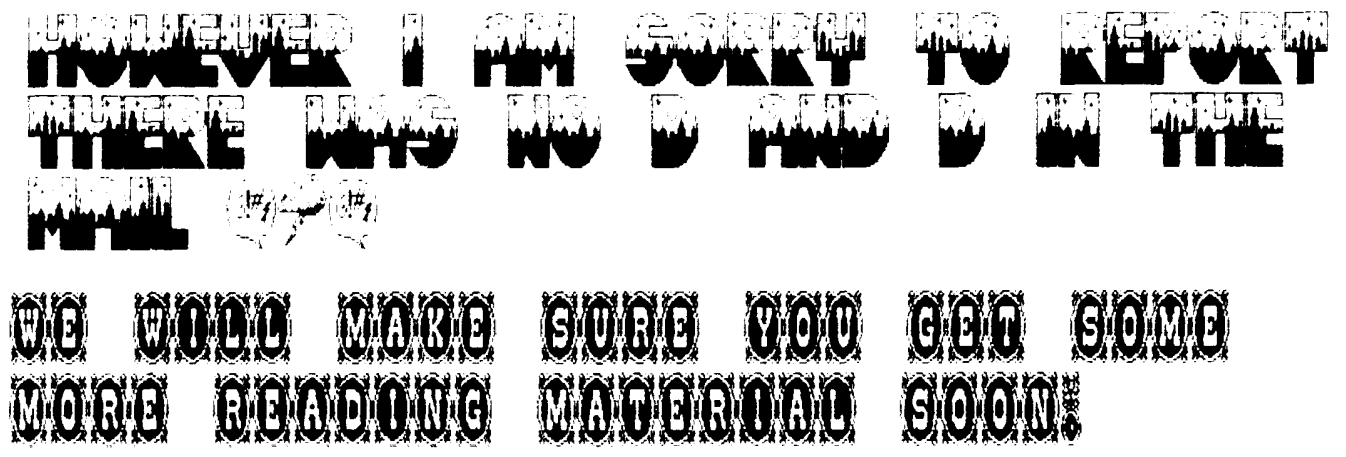

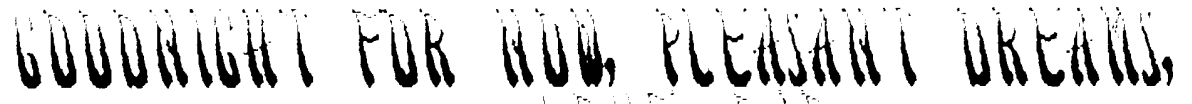

SOURCE John Willis, Frederick, MD, 1985

LOUE, UAtU 
on-line information providers, and obtain the materials they need. ${ }^{53}$

Information can be acquired el ectronically in other ways as well. Public bulletin boards allow individuals of all ages, interests, and levels of expertise to access information. Many hundreds of such bulletin boards are now operating nationwide. These facilities provide a variety of information, from answers to a user questions by other users, to digital information tidbits, opinions, articles, or even entire magazines. Many also provide access to public domain soft ware. Use of the board requires a phone line, a personal computer and disk drive, a modem, and software that makes the connection to the board. Most boards can be reached without charge by dialing a local phone number. 54 For many people, fellow bulletin board users become more than a source of information; they comprise a community."

These new opportunities for both technical and nontechnical users have not diminished

'See for example, "A New Shortcut to Electronic Libraries." Business Week, May 28, 1984, p. 106

'See Steven Levy. 'Touring the Bulleting Boards, ' Popufar Computing. February 1984.

A the O'TA Workshop on Students Perceptions of the Intellectual Property Rights I ssue, May 20, 1985, one high school student explained that he had two sets of friends: 1 ) friends from school that he might call on the phone and talk about home work or other things; and 2) friends from the computer whose real names might not be known but who are a constant source of conversation and recreation on-line. Notes this student: “ $\mathrm{My}$ computer probably doesn 't stay off more than half an hour after I get home. and before I go to bed. So it's on for essentially 6 hours “ the need for training and education in various fields. Despite potentially broad and instantly available access to information, users still must learn to use these tools to their fullest capacity. Given this need, education and training might best be used to help progress from developing routine skills to adopting more innovative processes, focusing less on the transfer of facts, and more on understanding how to find and use information. ${ }^{56}$

As Ithiel de Sola Pool notes in Technologies of Freedom:

The technologies used for self-expression, human intercourse, and recording of knowledge are in unprecedented flux. A panoply of electronic devices puts at everyone's hand capacities far beyond anything that the printing press could offer. Machines that think, that bring great libraries into anybody's study, that allow discourse among person's a half-world apart, are expanders of human culture. They allow people to do anything that could be done with communication tools of the past, and many more things too."'

\footnotetext{
“ For example, some companies provride corporate training in on-line searching to give the end user. such as the research chemist, the skills that would enable him to use highly technical on-line databases, such as Chemical Abstracts. I n learning to use such search systems, researchers find they understand more fully both the possibilities and limitations of the database, and are able to use information professionals even more effectively for more complicated searches. See "on-l ine I,iter. ature Searching Catches on Among Researchers, ('heroical \& Engineering News, May 7, 1984,pp. 29-31,

'-Pool, op. cit., p. 226
}

\section{IMPACT OF TECHNOLOGY ON RESOURCES AND MATERIALS}

In the process of creating, artists, scholars, and others build on the works of the past and draw on those of their contemporaries. In preliterate societies, the poets, storytellers, and artists drew their content from national lore. The epic poem served, in effect, as a cultural database. In more recent times, the university and other institutions of learning have housed a nation's accumulated wisdom. Individuals gained access to this knowledge either through their own education and training or through informal or self-initiated activities. Modern information technologies are greatly expanding our capacity to store, input, search, and distribute any type of information that can be represented in digital form.

Traditionally, the library has been a key repository for information resources. Today, the Nation's approximately 110,802 libraries supported by universities, education, research, and business institutions, and by local communi- 
ties (see table 5-2), remain committed to organizing knowledge, supporting continuing scholarship and learning, and offering open-ended access to the universe of knowledge. ${ }^{58}$

This universe of information has grown exponentially, doubling steadily every 15 years or so." Scientific journals now number 50,000 worldwide and 6,500 in the United States. Similarly, scientific books published in the United States now number 20,000 annually. '()

Works in other fields have grown as dramatically as those in science. For example, between 1900 and 1970, the libraries of major universities in the United States doubled their book holdings every 17 years. ${ }^{61}$ The Library of Congress, the "Nation's Library," has more than 80 million items in its collection, including over 20 million books and pamphlets, Its collections continue to grow at the rate of 7,000 items a day. ${ }^{62}$

\footnotetext{
"See, for example, Scholarship. Research and Access to Information, A Statement from the Council on Library Resources, Washington DC, J anuary 1985,

"See King Research Inc., Impact of Information Technology on information Service Providers and Their ('Iien tele. OTA contract report, J uly 1985.

“'Derek de Solla Price, Little Science, Big Science (New York: Columbia University Press, 1963).

"I sabel Cilliers, 4I mpact of the Information Society on the Information Profession, "I nformation Age, vol. 7, No.2, April 1985,

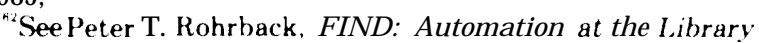
of Congress, The First Twenty'five Years and Beyond (Wash. ington, DC: The Library of Congress, 1985).
}

\section{Table 5-2.- Libraries in the United States}

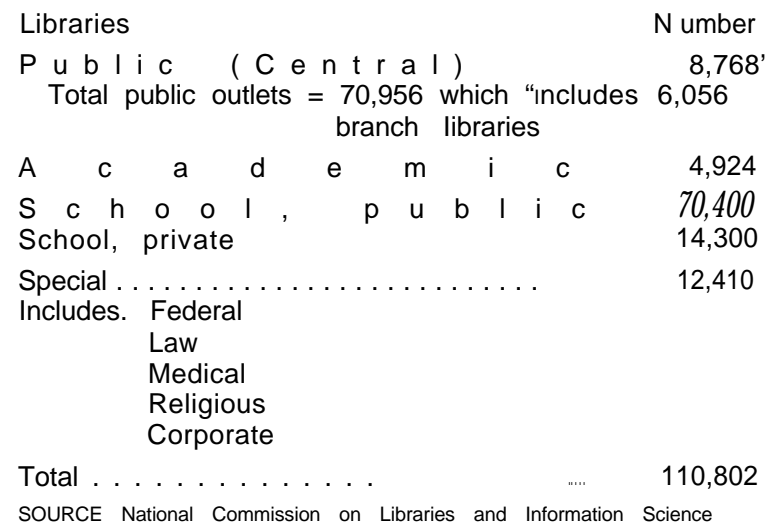

As the amount and use of information increases in all sectors of society, other public and private institutions have joined libraries to provide information and services. ${ }^{63}$ These new institutions describe and synthesize information, provide logical access to it, evaluate and analyze information, and store and preserve materials. (See figure 5-4. )

Dramatically affecting the ways information is stored, organized, accessed, reprocessed, and used, the new technologies may have a radical impact on libraries and analogous institutions, They permit libraries and information providers not only to enhance and expand the services they offer, but also to provide new services that were previously unavailable. ${ }^{64} \mathrm{U}$ sing electronic networks and databases, location or size are no longer the sole determinants of the services that such institutions can provide. ${ }^{65}$

Computer databases, themselves, now constitute a new kind of library. Members of the legal profession, for example, now rely extensively on on-line databases such as WESTLAW and LEXIS (see figure 5-5). Users can access many different kinds of information ranging from bibliographic, full text, or abstracted materials to compendiums of processes on physical and chemical properties. These data may be compiled separately or jointly by government agencies, academic institutions, libraries, information analysis centers, clearinghouses, publishers of books, journals, newspapers, newsletters, and business and industry.

Databases have also been created by individuals, small groups, and communities of users with shared interests. Developed to meet particular needs, they have often come to life spontaneously and informally. Some are acces-

\footnotetext{
"See H.R. Brinberg, "Information in the U.S.-An Industry Service Industry, "I nformation and the Transformation of Society,G.P. Sweeny (cd. ) (New York: Elsevier North- Holland Publishing Co., 1982)

"See for example, Patricia Battin. "The Electronic Library: A Vision for the Future, "EDUCOM Bulletin, summer 1984. Battin describes the application of computer and communication technologies to library processing activities over the past 15 years. In addition see, Peter T. Rohrbach, FIND: A utomation at the Library of Congress, The First Twenty-five Years and Beyond (Washington, DC: Library of Congress, 1985).

"See Battin, op. cit.
} 
Ch. 5-Impact of Technology on the Creative Environment $\bullet 147$

Figure 5-4.- Public and Private Institutions Providing Information Products and Services

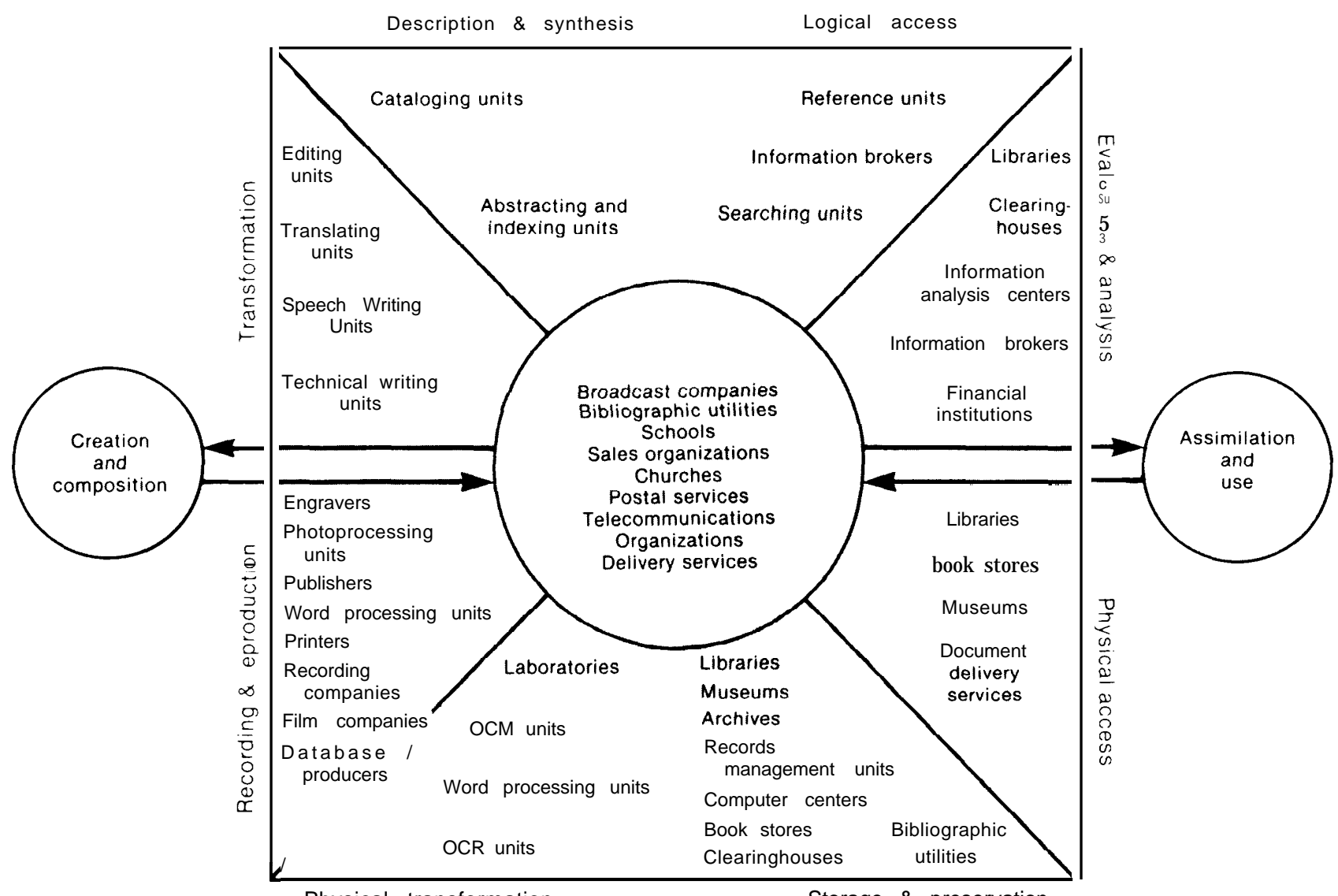

SOURCE Kinq Research Inc June 1985

sible only to authorized individuals; others are open to the public. Spurred by the desire to share ideas or obtain needed information, users create these new information resources on electronic bulletin boards or computer networks. ${ }^{66}$ Computer engineer and software designer Lee Felsenstein envisions thousands of such user communities providing information within and across communities and serving as the com-

${ }^{6 n}$ Take the example of database teaching ideas brought together by members of the math/science forum on CompuServe. The database came about when one participant in the forum asked others if they had examples of effective approaches to teaching physics. Almost immediately, several members of the forum responded. In turn, other suggestions and revisions or expansions of the original set of ideas were shared. Thus the entries in this database increase just as they do on databases which compile information about published literature or laws and legal decisions. In this instance information is upgraded and revised, not by professional editors, librarians, or researchers, but by users themselves. munity memory" owned and shared by all participants. $^{67}$

Other kinds of technology-driven resources are also emerging. Laser-read optical storage systems are being used to store and retrieve visual images, such as photographs, maps, drawings and paintings. At the Smithsonian National Air and Space Museum, for example, videodisks derived from 1 million photographs currently stored at the museum will be used to capture the entire history of aviation. ${ }^{68}$ Ten archival videodisks are planned, each containing color and black-and-white photographs of U.S. and foreign aircraft, as well as the ar-

\footnotetext{
“Interview, Apr. 15, 1985.

${ }^{n *}$ See M. Woodbridge Williams, " 100,000 Photos on a Platter," Photo District News, J uly/August 1984.
} 
Figure 5-5.- Institutional Users of Computer Readable Databases

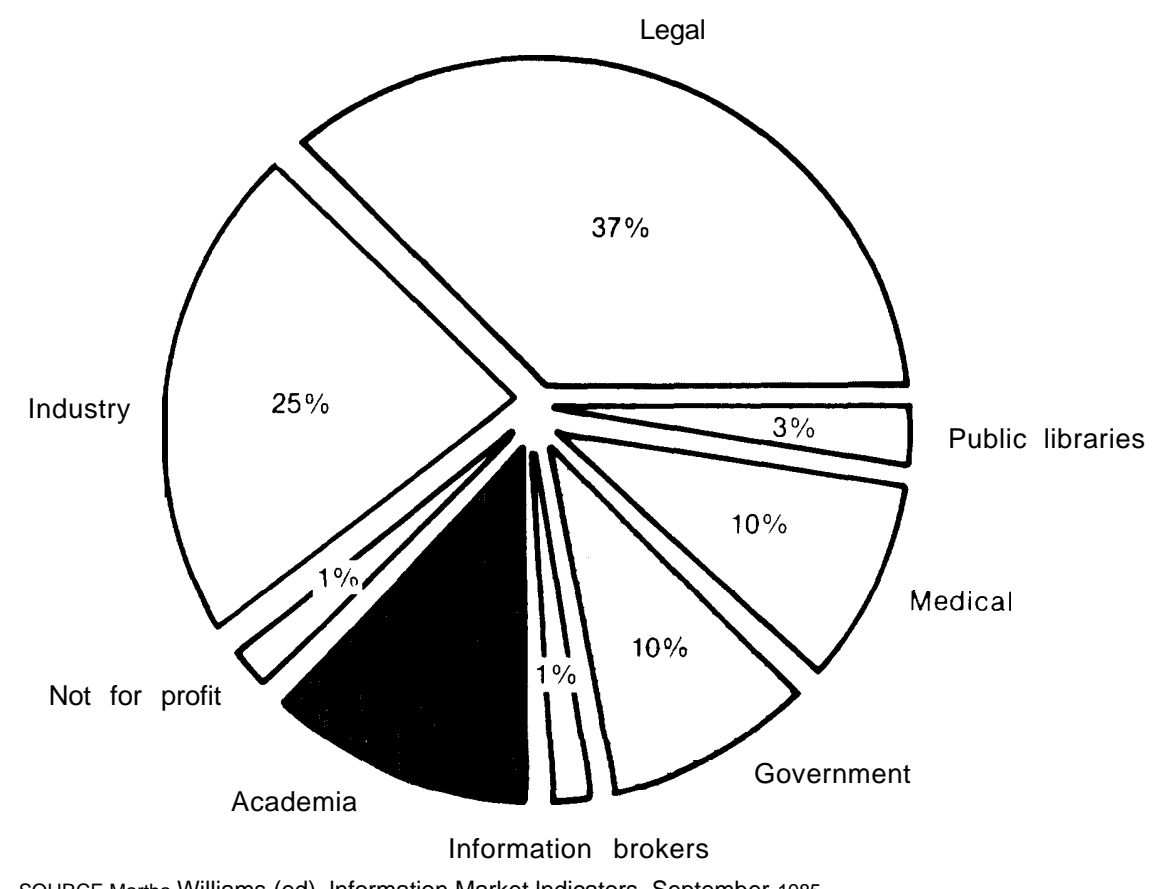

SOURCE Martha Williams (ed), Information Market Indicators, September 1985

tifacts and people associated with the development of aviation and space flight. ${ }^{69}$

The use of videodisk for this and similar projects offers significant advantages over print technology. Once they have been stored on videodisk and indexed by location on the disk, subject matter, and cross references, the photographs become database entries-interactive, and easily accessible. Searching becomes a dialog between the searcher and the database or electronic library. In this dialog the searcher is not limited by old structures of knowledge that have been built into traditional library indexes; he can put together whole new combinations of ideas. ${ }^{70}$

Electronic databases and libraries are powerful tools and important resources because they

$$
\text { - - .... . }
$$

"It is interesting to note that most of the photographs are in the public domain. Some, however, are still under copyright and will require permission for use by the photographer. As a research project, the developers hope that such permission will be given. But there are some members of the photography community who view the "precedents" of this project with alarm. (Interview with Philip Leonian, New York City, November 1984.

"'J ames Ducker, "Electronic Information-Impact of the Database, " Futures, April 1985, vol. 17, No. 2, pp. 164-169. provide greater access to more indices and source material than single libraries contain. Like computer databases, videodisks make resources such as photographs more accessible to more people. Similarly, digital libraries of software routines and tools, and optical disk libraries of motion pictures, offer these materials to larger audiences. Eventually, libraries of audio data may be compiled for musical composition.

In creating new ways to capture and handle information, the use of information technologies may conflict with traditional methods of scholarship, which require a clear record of each contribution and a published work that is fixed. A computer-readable database, for example, can archive information in permanent form. But at the same time, this information will be in constant flux if it is continuously updated, revised, and deleted. These capabilities raise concerns for many in the research community. As the Council on Library Resources recently described the problem:

Scholarship is personal, but its results are not private. To judge the validity of scholar- 
ly work, the records of past and present research must be open to scrutiny. This is the only way the intellectual audit trail that is at the heart of discovery can be maintained. Limited or conditional access to bibliographic records (or information about information in any form) is of particular concern . ${ }^{71}$

A second problem arises out of the increased capacity to manipulate information in computer databases. Accuracy, reliability, and quality are concerns for both author and publisher when they enter their works or products in a database. Although in some instances, the author may cooperate with the publisher in developing abstracts of technical works or books, in others, the author does not play a role. Instead, teams of editors and research librarians, or others who are developing or assembling the database, may abstract the works. In all cases, authors and publishers want to assure that the abstracted or summarized work maintains its integrity.

The issue of information presentation, integrity, and documentation of sources is also becoming a problem for artistic creators, such as photographers and artists whose images may become part of large electronic libraries.

'Scholarship, Research, and Access to Information, A Statement from the Council on Library Resources, Washingt'on, D.C. J anuary 1985.
Although most creators want others to learn and benefit from their works, they also want assurance that their personal contribution is recognized and kept intact.

A final concern for all creators, be they scientists, scholars, artists, or individual learners, is one relating to cost and access. As more databases and electronic libraries develop, information that was once available in journals or other paper forms may now appear only in computer-processable forms. Now providing computer database services, academic and public libraries face new and increasing costs. Some have been able to pass on costs of on-line searching to users rather than subsidizing those costs within the library budget. But, while grants and subsidies may fund the work of many scholars and scientists and, therefore, cover these additional costs, they will not fund others, who will be disadvantaged. And those who can pay, cannot only tap into electronic resources, they can also take advantage of information brokers and information on demand services now available at additional cost. ${ }^{72}$

'See for example, David Streitfeld, "Ask and They Shall Retrieve," The Washignton Post, Aug. 16, 1985, p. B5. A typical information on demand research project may cost a client about $\$ 300$. Clients include businesses, foundations, hobbyists, and ini'enters, even writers who are "reasonably successful" - and can afford to pay, for these services,

\section{IMPACT OF TECHNOLOGY ON ROLES, RELATIONSHIPS AND REWARDS}

\section{Roles and Relationships}

The use of technology in society involves individuals working in relation to one another. The characteristics of the technology they use help to define the roles people play in these relationships. Again, the case of printing illustrates how this might take place. Before publishers became established, authors depended on patrons to support their work. With the advent of publishers, this dependency ended, to be replaced by another. The author became de- pendent on the publisher who had a monopoly on the distribution of works. ${ }^{73}$

New information technologies, too, can make creators more or less dependent on others, altering the relationship between author and publisher, film maker and producer, database compiler and distributor, and inventor and manufacturer. Whether this change in the rela-

'Benjamin Kaplan, An Unhurried View of Copyright $\{\mathrm{New}$ York and London: Columbia University Press, 1967). 
tionship occurs depends on how technological advances affect the costs of new tools, the location of tools and resources, the restructuring of roles, and the control over the mechanisms for distribution. The nature and scope of creative endeavors also help to shape the relationships among creators and others. Where creators must work in expensive, large-scale, centralized operations, they will be more interdependent.

As tools based on new technology become cheaper, more powerful, more available, and easier to use, a greater number of creators can use them to explore and manipulate images, sounds, and information, The increasingly sophisticated tools also enable the artist to produce a more polished professional work. Musicians, for example, who once depended totally on recording studios, now may have equipment in their basements for performing, recording, mixing, and producing musical works. ${ }^{74}$ This technology can be used to produce tapes that, on the basis of quality, are indistinguishable from commercial studio tapes.

Such tools and technologies will also open new avenues for distribution. As musician, Richard Green, explains:

... musicians can for very small amounts of money do their recording project, print unlimited cassettes and distribute them, totally bypassing the larger aspects of the music business as we call it, Totally bypassing, among other things. ... copyright laws [and] government regulations. There are a lot of bad things about this. The good point about this is that it allows the individual to disseminate his work. ${ }^{75}$

In film making, too, highly sophisticated cameras and audio equipment are no longer the exclusive domain of major studios. Dropping in price, this equipment is more widely available to a growing number of independent film makers. These creators find they are able to work cheaply and have the creative freedom they say would not be possible in Hollywood,

'Richard Green, OTA Workshop on the Impact of Technology on the Creative Environment, Apr. 24, 1985.

"'l bid. where the average film budget is $\$ 11$ million. ${ }^{76}$ J ust as audio technologies enable musicians to create finished products, so too have the tools to create and edit images allowed the film maker to produce professional and appealing products, on modest budgets, with funds scavenged from foundations, government, individual investors, and even relatives. Moreover, with their greater sophistication and appeal, and their more extensive distribution mechanisms, these films are being extended beyond traditional audiences on college campuses and in art houses. Public and cable television, as well as local multiplex theaters, are now showing independent films alongside firstrun Hollywood features. ${ }^{77}$

The world of publishing has similarly been affected by the new technologies. Using a stateof-the-art printing system, a publisher such as Westview Press can quickly produce books in limited editions of between 100 to 2,000 copies. This kind of production run allows the publisher to rapidly accommodate the needs of the market and to produce highly specialized books for limited markets. ${ }^{78}$ The number of small, independent publishing houses has increased while the older, larger, commercial publishing industry is becoming more centralized through mergers and acquisitions. It is estimated that as many as 200 new publishers start operations every month. In the last decade, the number of publishing houses has quadrupled and now stands at about $20,000 .^{79}$

Whether creating and publishing computerreadable databases, monographs, or full manuscripts, both authors and publishers can use computer-driven tools and resources. At the same time, technology itself is changing the

"Kathleen Hulser, "Ten Cheap Movies and How They Got That Way, " American Film, May 1984, pp. 22-25, 53.

${ }^{7}$ See for example, J ulie Salamon, "It's Boomlet Time for Moviedom's Little Guys, "Wall Street J ournal, Mar. 28, 1985. Notes Salamon, the number of such film makers is growing: the Association of Independent Video and Filmmakers has grown to more than 3,000 members from 700 in 1980.

"See for example, Lisa See, "Frederick Praeger: Portrait of a Publisher, " Publishers Weekly, J une 14, 1985.

${ }^{7 y}$ See Marc Leepson, "The Book Business, Editorial Research Reports," The Congressional Quarterly, Washington, DC, J une 28, 1985. 
relationship between the author, publisher, and user of copyrighted works. Some observers see this as a dramatic change, where products and services can be tailored with increasing specificity to meet the needs and requirements of users:

The user, in turn, becomes more than just a buyer of titles. Through his selective use of the databases, he signals to the publisher his specific interests, and through user-driven publishing he can become a publisher in his own right. ... In fact, one can say that there is no true end product until the user tailors the data into his unique set of ideas, for example, his own published product. $^{80}$

With an estimated 20 million printers now available, xerography has "made everybody a printer, according to Paul A. Strassman, former Xerox Vice President. ${ }^{81}$ Each improvement in reprographic technology, such as image clarity, color reproduction, speed, and compilation, makes it more feasible for creators to publish and distribute their own work. In particular, where traditional modes of publishing and distribution are either not accessible or financially impractical, this mechanism can make it much easier to disseminate information and images. Thus, for example, one can easily publish a newsletter for a special-interest group, a community association, or a group of scholars. Moreover, the technology permits more people to share their work-be it a collection of poems, a book of recipes, or a series of drawings.

The development of electronic networks that transmit text, numerical, or graphic images to printers at remote locations can further expand authors' publishing and distribution capabilities. The result is that roles once held by several people are now all held by one person. Starting with a single copy of a letter or article composed at a computer and transmitted to readers at the other ends of the network, one person can become author, printer, publisher, and distributor of a work.

\footnotetext{
"Herbert R. Brinberg. "The Brave New World of Electronic Publishing, " Publishers Weekly, Nov 23,1984, pp. 32-35

"'See Michael Kernan, "The Deans of Duplication, "The Washington Post. Aug. 21, 1985.
}

While an increasing number of computerdriven tools are dropping in cost, some will always be prohibitively expensive for the individual artist, scientist, or inventor. Moreover, hand-held calculators or portable computeraided design systems now exist that are more powerful than the early mainframe computer systems that occupied whole rooms, certain classes of artistic work, or scientific problems demand even more power and sophistication than even these systems provide. Thus, some creators find that to do their work, they must be part of a well-equipped facility, such as a computer graphics production studio. In other instances, the writers, programmers, and artists who choose to work in a highly innovative and capital-intensive venture, such as videotex, may need to join a corporate entity to work in that field. And the scientist whose research requires access to a multimillion dollar supercomputing facility has to be affiliated with industry, government, or academic institutions. ${ }^{82}$

Other factors may also limit use of new tools and mechanisms of distribution. Taking full advantage of these technologies may require technical expertise not normally held by authors, artists, or dancers. Thus, technology can require the creator to interact with people with whom he has never dealt with before.

\section{The System of Incentives and Rewards}

The granting of rewards requires that creators and inventors be given a special status in society. Historically, this did not happen until the time of the Renaissance. Before then, creativity was considered the prerogative of God. Because the Renaissance notion of creativity deemed the work of any major poet, artist, or inventor as a product of a special creative genius, which most mortals lacked, it became something to be rewarded."

\footnotetext{
"The capital costs of buying and maintaining a supercomputer facility requires sponsorship by large institutions. Once established an individual user could simply buy time in small amounts still supporting only a fraction of the true costs of maintaining the facility.

"'Pacey, op. cit, p. 87.
} 
The technology of printing fostered this notion of the individual, as creator. With the invention of the printing press it was possible for a single author to produce a work, no longer dependent on communal efforts. Moreover, conventions such as standardized texts and a title page were devel oped, making individual attribution practical. Today, the new information technologies are affecting society's attitudes about creativity, regarding both how it treats the creative genius and how it assigns rewards.

The intellectual property system can be conceived of as a societal device to foster creativity. To be most effective, however, it requires that an author's particular contribution and work can be clearly identified. The new technologies are undermining this assumption. They foster multiple authorship and intangible works. Thus, instead of a situation in which a single author, artist or scientist creates one single product, such as a book or mechanical device, now many authors work jointly and their individual contributions are often difficult to distinguish from one another. Moreover, to the extent that they are working in and on electronic media, their materials may be constantly changing.

Examples of multiple authorship are found in the world of arts and entertainment, as well as in research and development. Whereas traditionally, a song was the work of a composer and a lyricist, whose particular contribution was easily discerned and rewarded by the intellectual property system, today the creation of a song, the production of a film, the development of computer software or an electronic database, and the design of a new hardware system, may involve many different creative inputs, connected in a myriad of ways. Creating a seaside landscape with computer-generated imagery, for example, may entail one artist creating the atmosphere, another texture, and others rocks and beaches. In the final execution, a software program will "glue" it all together.

When designers, artists, musicians, and programmers are parts of teams that receive joint remuneration as teams, individual authorship may not be an issue. To avoid problems of dividing rewards, some creative teams have formed their own companies or economic units, jointly sharing their creative expertise, the development costs, and eventually, the profits. Many computer software efforts have been built by such creative entrepreneurial teams.

In other cases, teams of creators and scientists are salaried and supported by an institution such as a software development company, an advertising agency, a hardware manufacturer, or a university or a government laboratory. In these circumstances, the creative contribution of the employed inventor or artist is often treated as a work-for-hire. The work of the individuals in the team might be recognized in the process of applying for an institutional patent or copyright. In scientific fields, technical papers are commonly authored jointly .84

Although there are many independent writers, artists, composers, and poets involved in creative activities, most information products and services are devel oped by employee working teams who rarely receive financial rewards in direct proportion to their particular contributions. ${ }^{85}$ Attribution is normally to the source of publication, not to the writer. Profits flow for the most part to the investors, not to those who found the data, organized the presentation, or created an efficient expression.

Nevertheless, there are many creative efforts that go unrewarded or unrecognized, and it is these examples that freelance creators often cite when calling for changes in the present system. Some free-lance graphic artists and photographers believe, for example, that as creators, they should maintain control over their images even when their materials have been

\footnotetext{
“'Like creators employed by businesses, scientists are paid salaries, but the relationship between this compensation and the incentives to create intellectual property is weak. Gaston studied the reward system in British and American science and affirmed what has generally been believed: that scientists are rarely motivated by salary or other compensation. Rather, they operate more under nonpecuniary incentives such as distinguished titles at universities, distinguished levels of membership professional associations, honors, prizes, and fellowships, editorships of journals, and citation in journals. See J erry Gaston, The Reward System in British and American Science (New York: J ohn Wiley \& Sons, Inc., 1978).

"See Christopher Bums and Patricia A. Martin, The Economics of Information, OTA contractor report, 1985.
} 
commissioned as works-for-hire. This attitude is becoming more pronounced as creative materials become easier to manipulate and reuse." While creators want their works to be widely seen and distributed, they also want adequate compensation for derivative uses, which bring additional profits to publishers. They are concerned, moreover, that the images attributed to them are, in fact, of their own creation.

The new information technologies can also affect how society views the work of the creator and the values it attributes to his work. The growing economic value of information in the arts and entertainment industries fuel public perceptions of superstars, superbooks, computer millionaires and the like. In focus group sessions conducted by Yankelovich, Skelly \&

"See the Graphics Artists Guild and the American Society of Magazine Photographers, Testimony Regarding Work-forHire Under the Copyright Act, before the J udiciary Committee, U.S. Senate, Oct. 1, 1982. See also additional testimony presented by Robin E3rickman, Graphic Artists Guild Member.
White for OTA, participants pointed out that rock stars, movie actors, and information industries were making a lot of money. They were skeptical of the claim that such individuals or companies would be seriously affected by personal copying. ${ }^{87}$ And yet many book, film, and computer companies are small, high-risk, lowprofit operations. Similarly, many free-lance artists and performers barely make ends meet.

It should be noted that the intellectual property system is only one means by which society supports the creative environment. In addition, there still exists public and private programs providing grants and patronage. To the extent that alternative mechanisms will affect public policy choices about intellectual property rights, they are discussed in other chapters of this report.

\footnotetext{
${ }^{87}$ Yankel ovich, Skelly \& White, Inc., Focus Group Sessions in Philadelphia, PA, and Greenwich, CT, October 1984.
}

\section{IMPLICATIONS FOR THE INTELLECTUAL PROPERTY RIGHTS SYSTEM}

As we have seen in this chapter as well as in previous ones, the intellectual property systern governs the relationships among individuals involved in the creative environment. It determines who are creators, what tools and resources are available to them, and how and under that circumstances their work will be distributed to the public.

Technology is affecting the creative environment in a number of ways that are likely to have implications for the intellectual property system. These can be summarized under two major headings: 1) changing players in the creative environment, and 2) the emergence of new opportunities.

\section{Changing Players in the Creative Environment}

Traditionally, the intellectual property system was a simple one, involving only a few players-the creator, publisher/distributor, and user. New participants have come on the scene as new technologies have emerged. Thus in addition to the writer and artist, we now have the composer, photographer, and the film maker. In addition to the publisher, we now have the record company, the television producer, and the cable operator. And added to the reader, we have the radio and record listener, the television viewer, and the computer user.

With the new information technologies, the number and variety of players have increased many fold. Moreover, now more than ever before, technology is affecting the roles that each player plays and his relationship to others in the system. Today the user, whether he is dealing with audio, visual, or computer-generated materials is not just a passive receiver. He can at the same time be a creator or a distributor of his own or others' materials. In this sense, for example, the personal computer user who make copies of software for several of his 
friends while making one for himself, is, in fact, acting as a distributor. And the university that houses educators and researchers is increasingly claiming rights as the creator of their works.

Above all, these changing roles and relationships may affect the consensus on which support for the system has traditionally rested. Many of the new players, not a party to the agreements of the past, may hold different values about who should have access to what materials and who should be provided rewards. One such newcomer on the scene is the computer hobbyist who finds the thrill of creating something useful and successful more important than either owning the copyright or being recognized as the author. ${ }^{88}$

Given the trend identified in this chapter towards joint authorship and the increasingly fluid creative process, controversies may also emerge among players about the distribution of rewards. Describing the culmination of the development of the Data General Eclipse MV/ 8000, Tracy Kidder depicts the dilemmas around the distribution of rewards:

Long before it disbanded formally, the Eclipse Group, in order to assist the company in applying for patents on the new machine, had gathered and had tried to figure out which engineers had contributed to Eagle's patentable features. Some who attended found those meetings painful. There was bickering. Harsh words were occasionally exchanged. Alsing, who during the project had set aside the shield of technical command, came in for some abuse-Why should his name go on any patents, what had he done? Someone even asked that question regarding West. I ronically, perhaps, those meetings illustrated that the building of Eagle really did constitute a collective effort, for now that they had finished, they themselves were having a hard time agreeing on what each individual had contributed. But, clearly, the team was losing its glue. 'It has no function anymore. It's like an afterbirth, ' said one old hand after the last of the patent meetings. ${ }^{89}$

\footnotetext{
${ }^{88}$ Stephen Levy, Hackers: Heroes of the Computer Revolution (Garden City, NY: Anchor Press/Doubleday, 1984), pp. 43-44.

"Tracy Kidder, The Soul of a New Machine (Boston, MA: Little, Brown \& Co.), p. 288.
}

As the economic value of information-based products and services increases, disagreements such as these may become more intense.

The technology will also affect the expectations of the user, making him more or less willing to comply with the rules of the system. As the Yankelovich study suggests, the more technology to which people have access, the more they expect of technology. Youth have particularly high expectations. Often they take the new technologies for granted. As one young user recounted at a recent OTA workshop, he was willing to pay for work only if "it was really awesome.

\section{The Emergence of $\mathrm{New}$ Opportunities}

As this chapter points out, the new technologies greatly enhance the creative environment, providing new and powerful tools and new opportunities for artistic expression, societal advancement, and financial gain. As in the past, the intellectual property system will establish the rules by which these opportunities will be taken advantage of and who will get to benefit from them. Because of the enhanced social and economic value of creative and scientific works, intellectual property law becomes an important public policy tool in an information age. It will determine, for example, whether new technologies are used to increase access to the Nation's information resources and if so, by whom, and at what cost.

By virtue of their ability to increase access, these technologies may pose problems for the intellectual property system and for the integrity of the creator's work. As noted in the chapter, they allow users to access and manipulate creative works with ease and speed previously unheard of. While this may enhance their ability to work jointly and create new products and services, it will also make it more difficult to identify or trace cases of copyright infringement or plagiarism that may occur. This is significant for the creator's motivation. For, as we have seen, the creator is as often concerned about the integrity of his works as he is about his own financial gain.

\footnotetext{
"OTA Workshop on High School Students Perceptions of Intellectual Property Issues, May 20, 1985.
} 
Chapter 6

Technology, Intellectual Property, and the Operation of Information Markets 


\section{Contents}

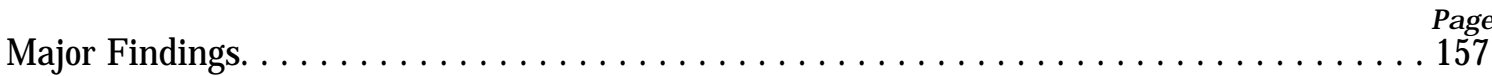

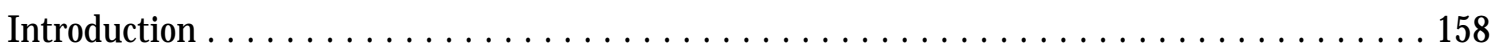

Technology and the Emerging Economic Characteristics of Information. . . . . . . . . . . 158 Information Distribution and Economies of Scale . . . . . . . . . . . . . . . . . . . . . . . 159 Information Production and Economies of Scope . . . . . . . . . . . . . . . . . . . . 162

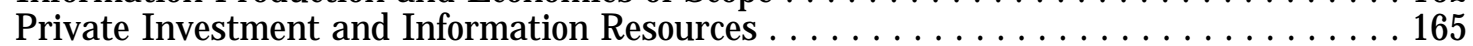

Government Policy and the Diversity of Information-Based Goods . . . . . . . . . . . . . . 170 Problems in Framing Policy To Promote Information Diversity . . . . . . . . . . . . . . . 171 Proprietor Concerns, Government Policy Tools, and the Diversity of Information . . 171

Problems in Selected Markets for Intellectual Works . . . . . . . . . . . . . . . . . . . . . 174 Print Technology and the Functioning of Copyright in Book Markets . . . . . . . . . . 174 Motion Pictures, Videocassettes, and the First Sale Doctrine . . . . . . . . . . . . . . . . . 176 Information Services, Electronic Databases, and Derivative Works . . . . . . . . . . . . . . 180 Computer Software, Market Size, and the Cost of Contract Administration . . . . . . . 182

Tables

Table No. Page

6-1. Production Costs for PBS Television Programs . .........................159

6-2. Selected Information Markets: Costs, Profits, Revenues, and Economies of Scale . . . . . . . . . . . . . . . . . . . . . . . . ...................160

6-3. Representative Charges for On-Line Database Access . . . . . . . . . . . . . . . . . . 168

6-4. Primary Activities of Information Industry Association Members . ..............180

Figures

Figure No. $\quad$ Page

6-1. Decision Tree for Communications Regulation Under Computer Inquiry III . ... .. 166

6-2. Representative Release Sequence for a Major Theatrical Feature . ..............177

6-3. Feature Motion Picture Releases. . . . . . . . . . . . . . . . . . . . . ....................179

6-4. A Shrink-Wrap License Contract . . . . . . . . . . . . . . . . . . . . . . . . . . . . . . . . . . 184 


\section{Technology, Intellectual Property, and the Operation of Information Markets}

\section{MAJOR FINDINGS}

New technologies are causing information to assume economic characteristics that make it significantly different from other commodities in the way markets develop and operate. These economic characteristics-economies of scale and scope in production and distribution, and reusability and expandability as a resourceare further complicated by information's social and political significance. Therefore, government intervention, through intellectual property laws or other government policy mechanisms, is a particularly critical factor in the operation of information markets.

Policymakers currently have little objective, quantitative data with which to make policy judgments about information markets. The data problem stems, in part, from the rapid changes in information markets attributable to technological change. As well, data collection in this area of the economy is not yet institutionalized in government. Often, the available data are fragmentary and are supplied by stakeholders in the policy debates. As a result, policymakers face a high level of uncertainty about the impact of decisions on the cost and availability y of specific varieties of information.

The effects of policies designed to govern transactions between sellers and buyers of information are becoming more complicated. It is likely that a decision made to affect one variety of information may be ineffective or inappropriate if applied more generally. Moreover, more people are making a living by creating, distributing, and using information, so these policies are becoming more important in regulating the economy as a whole. The marketplace rules that intellectual property policy establishes will need to evolve, and perhaps become more subtle and complex, as information markets change.
Intellectual property law is increasingly outdated in providing appropriate incentives for the production and distribution of many information-based goods. Because of this, markets may increasingly fail to provide economically and socially efficient varieties of information. In trying to remedy information-market failures, policymakers face trade-offs among interests with high stakes in intellectual property debates. When they enact changes in intellectual property law they may be required to make some explicit decisions about the actual nature, content, and distribution of goods based on information.

It is clear that changes in intellectual property policy alone will not remedy all the market failures to which information-based goods are subject. Communication, antitrust, public information, education, tax, and government $R \& D$ policies, and perhaps others, can be expected to interact more and more with intellectual property policy in their impact on the operation of information markets.

Although the information industry is relatively unconcentrated today, this may change in the future: economies of scale and scope, the requirements for large capital investments, and market power and high profits that may come through control of communications and content resources are potentially strong incentives to ownership concentration. Considering the social and political importance of information in a democracy, Congress may consider it important that the information industry remain less concentrated than other industries. Intellectual property rules affect the distribution of wealth and opportunities in society; therefore, they must be carefully crafted to maintain a balance between private and public interests in information. 


\section{INTRODUCTION}

Intellectual property law is based on the premise that intellectual works differ from other commodities traded in free markets. The U.S. Constitution authorizes Congress to enact intellectual property law, recognizing that "writings and inventions" require special treatment.

Intellectual works are taking on greater significance for society. Information's value as a commodity and as a source of productivity and wealth is rising; the range of available information-based products and services is expanding; the technologies through which these products and services are created and distributed are changing; and the number of people whose livelihood depends on information production, trade, and use is increasing. Because of these changes, the markets that determine the supply, variety, price, and availability of different kinds of information are in flux.

The operation of markets for intellectual works is of particular interest because all citizens require many kinds of information to make political choices and to become productive members of society. Because an informed and free citizenry is essential to democracy, the first amendment requires that the Federal Government value and defend freedom of expression: the exchange of information unencumbered by government. The government has intervened in information activities where policy makers concluded that private enterprise, acting on its own, would not provide citizens with the full range of information that they deemed necessary for society.

The Federal Government has along history of involvement in the production and dissemination of information. The government has produced information when private enterprise saw no advantage in doing so or when the information was vital to government operations. The government has also used a variety of strategies, including intellectual property law, to encourage private investment and markets in intellectual works.

The mechanisms of intellectual property law were originally designed to counteract a basic economic characteristic of information: It is much more costly to originate valuable information than to reproduce it. Thus, the law gave producers limited control over reproduction and dissemination in the form of copyrights, patents, and trademarks. The grant of such marketplace control was intended to induce producers to continue producing and disseminating works by allowing them to gain enough income to cover their costs and earn a profit. In this way, the public interest in learning was made to coincide with the economic interests of creators and publishers. In the marketplace for printed works, governed by copyright, the incentive to produce was linked to the incentive to disseminate printed copies as widely as possible; for selling copies was how producers generated income.

As technologies for creating and marketing information change, as new uses for information are developed, and as information takes a more central place in the economic and social life of the Nation, information is beginning to display a number of characteristics that alter the incentive structure for production and dissemination. This chapter examines some of these characteristics and explores how they affect the interests and the marketplace activities of producers, distributors, and users of different kinds of intellectual works.

\section{TECHNOLOGY AND THE EMERGING ECONOMIC CHARACTERISTICS OF INFORMATION}

An information-based good is a package that consists of an intangible content portion-the information itself-and a medium in which the content is embodied and through which it is communicated. Information content is changing as people find new ways to use informa- 
tion to entertain, educate, make decisions, and produce other goods and services. The media that make information available are also in the midst of rapid and profound change. In particular, technology is increasing the economies of scale and scope under which information packages are produced and disseminated; and information-based goods are emerging as basic and essential resources for the economy, the polity, and culture. These changes in the media, the content, and the uses of information are altering the operation of markets for information-based goods, and thereby stressing the intellectual property system.

\section{Information Distribution and Economies of Scale}

At the outset, intellectual property protection was a response to an economic characteristic of information-based goods in the print medium: origination costs are high in comparison to reproduction and distribution costs. Economists describe goods with this characteristic as having economies of scale. Modern media allow even greater economies of scale in information distribution, so that in some cases an information-provider marginal costs approach zero. ${ }^{1}$ For example, radio and television broadcast stations incur no additional costs when additional people tune in; a computer database company can serve additional

\footnotetext{
'Economies of scale exist when the initial investment needed to begin production of a good (fixed cost) is high relative to the cost of producing additional units of the good (marginal cost), and when marginal costs decline with increased production. In the case of electronic information-based goods, in contrast to other products, a distributor's marginal cost may involve only the cost of serving an additional customer, rather than the cost of producing an additional, tangible unit. In this way, information-based goods resemble services. With electronic distribution, one "performance" may serve all customers, as is the case in radio and television broadcasting. Thus, in contrast to other services, the marginal cost of providing information can be essentially zero. Electronic information is often mediated by a system. Part of the cost of establishing the system is paid by the provider (e. g., broadcast transmitters or database computers) and part by the customer (e.g., radio or TV receivers or personal computers). Thus, a significant portion of the cost of distributing electronic information must be "sunk" before any information is sent or received. See A. All an Schmid, A Conceptual Framework for organizing Observations About Parties Interested in Intellectual Property, contract report pre pared for OTA, February 1985,
}

users, within the limits set by their equipment, at very low incremental cost. This is so because many information-based goods that are embodied in and distributed through electronic media assume a basic characteristic of intangible information content: They are not necessarily depleted with use. ${ }^{2}$

However, with time, much information does become obsolete, or at least less interesting. Although information technology promises to improve the productivity of many aspects of information production, it is still expensive to originate movies, television programs, electronic databases, computer programs, and other valuable information because these activities are labor intensive, requiring human knowledge, creativity, and skill. Hence, the cost of originating information relative to the cost of distributing it is high and is likely to remain so. (See tables 6-1 and 6-2. )

The increase in distributional economies of scale achieved with modern information technologies affects the incentives for producing and disseminating information-based goods, and so influences the operation of information markets in three direct ways.

'How marvelous it is that, once recorded, an intellectual work can potentially be reproduced and communicated an infinite number of times. The value of a given piece of information, as for example a weather report, may change or diminish over time. But the information itself can be used simultaneously or successively by many people without being consumed in the process. The value of information is a result of the context in which it is received and used. (Gregory Bateson defines information as "the difference that makes a difference. See Mind and Nature (New York: Bantam Books, 1979).) Context is essentially the knowledge possessed by the receiver of information that shapes its meaning. Thus, information actually expands and takes on new meaning as it is received and used by more people. See Harlan Cleveland, "Information as a Resource, The Futurist, December 1982, p. 36.

Table 6-1 .-Production Costs for PBS Television Programs

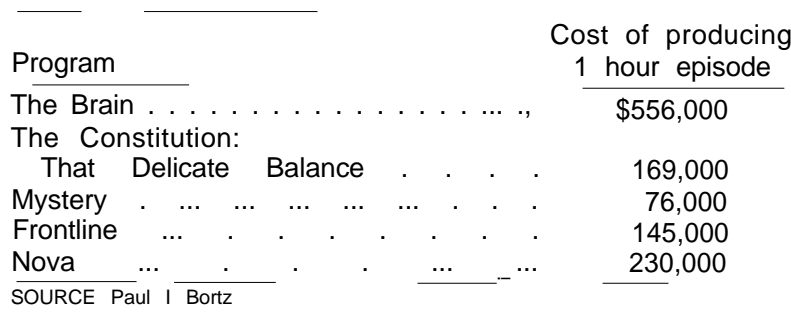


Table 6-2.-Selected Information Markets: Costs, Profits, Revenues, and Economies of Scale

\begin{tabular}{|c|c|c|c|c|c|c|c|}
\hline & $\begin{array}{l}\text { Creation } \\
\text { (percent) }\end{array}$ & $\begin{array}{l}\text { Conversion } \\
\text { (percent) }\end{array}$ & $\begin{array}{l}\text { Fixed costs } \\
\text { (percent) }\end{array}$ & $\begin{array}{l}\text { Variable costs } \\
\text { (percent) }\end{array}$ & $\begin{array}{l}\text { Economies } \\
\text { of scale } \\
\text { (percent) }\end{array}$ & $\begin{array}{l}\text { Profit and taxes } \\
\text { (percent) }\end{array}$ & $\begin{array}{c}\text { Revenues } \\
\text { (billion } \$ \text { ) }\end{array}$ \\
\hline$\overline{\text { Television }{ }^{a} \ldots \ldots}$ & 17 & 24 & 41 & 23 & 64 & 35 & 13.8 \\
\hline Recordings $^{\mathrm{b}}$ & 22 & 34 & 56 & 34 & 62 & 10 & 6.1 \\
\hline Movies ${ }^{c} \ldots \ldots$ & 26 & 18 & 44 & 31 & 62 & 25 & 4.1 \\
\hline Online service . . & 17 & 33 & 50 & 39 & 56 & 11 & 3.1 \\
\hline Radio $^{a} \ldots . . . \ldots$ & 24 & 26 & 50 & 45 & 56 & 6 & 5.1 \\
\hline Newspapers . . . . . & 16 & 16 & 32 & 52 & 38 & 16 & 29.4 \\
\hline Magazines . . . . . . & 17 & 12 & 29 & 62 & 32 & 9 & 13.5 \\
\hline Documents $^{a} \ldots$. . & 12 & 15 & 27 & 70 & 28 & 4 & 0.7 \\
\hline Books ........ & 15 & 11 & 26 & 69 & 27 & 5 & 12.0 \\
\hline
\end{tabular}

Error in total percent due to rounding

These numbers are based on revenue from the sale of both audio records and tapes.

These numbers are based on revenue from theatrical showings only

NOTE Creation: Percentage of revenue that goes to Initial production of a work, including royalties, artwork, and editing. Conversion: Percentage of revenue that goes to embodying work in reproducible form, i.e., typesetting, entering data into computer, film negative cost, master recording cost, etc.. Fixed costs: Creation costs plus conversion costs as a percentage of revenue Variable costs: Percentage of revenue that goes to reproducing individual units and getting those units to end users, including reproduction, shipping, advertising and promotion and discount for retail houses Does not include users' costs Incurred in purchase and operation of equipment necessary to use a good, such as television sets, radios, VCRs, and computer equipment Economies of scale: Fixed costs divided and operation of equipment necessary to use a good, such as television sets, radios, VCRs, and computer equipment Economies of scale: Fixed costs divided
by the sum of fixed costs and variable costs Profit and taxes: Percentage of revenue that goes to profit and taxes Revenue: Estimated 1984 Industry revenue

SOURCE Off Ice of Technology Assessment, data from C Burns and P A Martin, The Economics of Information, prepared for the Off Ice of Technology Assessment by Christopher Burns, Inc., contract *433.9520 0,1985. tables li-I. II-2, 11.3, II-4, 11-5, 11-6, 11-7, 11-8, 11-10, and 11-11

First, assuming he can charge each customer for access, and assuming that the cost of collecting payment from a customer, the transaction cost, is not higher than the price he can charge, ${ }^{3}$ a seller has an incentive to increase the number of customers for an information package. Of course, some kinds of information, such as stock-market tips, secret formulas, and entertain ment with current "snob appeal" may be more valuable if only a small number of people have access. But for a wide range of information, proprietors find that even a small marginal profit can yield large returns when many customers are served. Conversely, originators may have less incentive to create or to publish valuable information if they do not share

Transaction costs are those expenditures that a proprietor must make to negotiate and execute a transaction agreement. They include the cost of price setting and billing. In selling information-based goods proprietors may also incur marginal costs in monitoring and enforcing special transaction conditions, such as the exclusion of nonpayers and the prohibition of subsequent copy and transfer of the information. Thus, transaction costs serve as a check on providers' ability to exploit distributional economies of scale. Broadcast radio and television are two media with high economies of scale where it has been difficult to charge the consumers of information because the transaction costs would be so high. In these circumstances, advertisers have found it profitable to pay broadcasters for the opportunity to influence the purchasing behavior of the vast numbers of consumers of broadcast information. in the profits being made through large-scale distribution.'

Second, rising economies of scale give information sellers a greater incentive to deny access unless they strictly control the conditions under which they offer it. In the world in which the printing press was the only mass medium for reproducing and distributing information, proprietors of intellectual works saw uncompensated use, such as in libraries or through users trading books, as possibly troubling but generally unthreatening. But since electronic information can be reproduced and disseminated so cheaply, the modern proprietor is much more interested in maintaining physical control over works, and in selling access only if users agree not to reproduce and distribute identical or similar works. Because electronic media make it costly and possibly ineffective to exclude nonpayers and compet-

This suggests that, in general, the increase in economies of scale reinforces the rationale for intellectual property protection: The profits made from the wide distribution of information should contribute to the cost of originating it. On the other hand, because the cost of disseminating information declines with increased economies of scale, the benefits given up by society through the grant of exclusive copyrights increases. See Competitive Enterprise Institute, "I ntellectual Property and Copyright Laws, " issue brief, 1985. 
itors, proprietors may, more than ever, favor government intervention to help them enforce exclusion or collect payment. Alternatively, they may invest in more efficient " fences," or private means to exclude unwanted users. This alternative is explored in detail in chapter $4 .{ }^{5}$

A third effect of increasing economies of scale on information markets is that ownership of distribution facilities tends to concentrate in fewer hands. ${ }^{6}$ Since the per-user cost of distribution dedines as the number of users rises, a large network can price information lower than a small network and may eventually buy out or drive out the smaller business. ${ }^{7}$ This tendency is enhanced where the fixed costs of developing a network infrastructure are very high, as they are for launching communication satellites, laying cables, or securing broadcast licenses or other government regulatory approval."

The potential of economies of scale to cause media concentration in electronic distribution is currently checked by the number and variety of distribution technologies.' Newspapers compete with television in providing news and advertising; videocassettes compete wit $h$ theaters and cable television to supply feature movies; newsletters and magazines compete with on-line computer database services to provide specialized information on a wide range of subjects.

\footnotetext{
Another alternative, adopted by television and radio broadcasters and also newspaper and magazine publishers, is to bundle the entertainment or news information with advertising. The advertiser may associate his message to buy with desirable aspects of the information-based good-e.g., the integrity of the news, or the pleasures of the entertainment.

'W. Curtiss Priest, The Character of Information: Characteristics and Properties of Information Related to issues Concerning Intellectual Property, contract report prepared for OTA February 1985, p. 27.

See (ierald Brock, The Telecommunications Industry: The Dynamics of Market Structure (Cambridge, MA: Harvard University Press, 1981).

MCI spent $\$ 10$ million in regulatory and legal costs over an 8-year period to obtain approval for its first microwave long distance telephone service. Brock, The Telecommunications Industry, p. 213. The facilities of television station KTLA in Los Angeles, and its $\mathrm{F}$ ('C broadcast license, sold for $\$ 510$ million in 1985.

"See Benjamin M.Compaine, Christopher H. Sterling, Thomas Guback, and J.Kendrick Noble, Jr., Who Owns the Media? (White Plains, NY: Knowledge Industry Publications, 19821.
}

There will probably be uncertainty for some time over the most profitable ways to provide different types of information. Companies and research institutions are experimenting widely with new media forms, exploring whether one medium may have a competitive advantage over others. ${ }^{10}$ People consider a complex set of factors in choosing one medium over another for receiving a particular type of information. ${ }^{11}$ Cost is a major consideration; it may drop slowly for a new medium as people adopt it and economies of scale come into play. While uncertainties rule, the ownership of media can be expected to fluctuate.

Fiber optic systems are being rapidly added to the mix of information-distribution technologies. ${ }^{12}$ The single-mode fibers now being installed in the country's telephone plants have communication capacities significantly greater than copper wire or coaxial cable. One fiber can carry the entire Encyclopedia Britanica from Washington to Baltimore in a second or 300 simultaneous television channels within a city, Laboratory results suggest that this capacity may rise 1,000-fold or more with improvements in signal transmission and detection equipment that can be used with existing fiber lines.

The economies of scale offered by fiber optics are certain to affect communication companies' strategies as they learn to employ this technology profitably. Many other distribution technologies may prove much less economical. For a time, large businesses with great data communication needs will benefit the most from these economies. " Small businesses will

\footnotetext{
"'Although technological innovations may cause cost changes that move slowly at first, their longer term effects 'can change cost ratios by orders of magnitude rather than by the few percentage points that constitute common static barriers to entry, " Brock, The Telecommunications Industry.p. 301.

"J. Dimmick and E. Rothenbuhler. "The Theory of the Niche: Quantifying Competition Among Media Industries, " J ournal of Communication, vol. 34, No. 1, 1984, pp. 103-120.

${ }^{2}$ See the OTA report Information Technology R\&D: Critical Trends and Issues, OTA.CIT-268 (Washington. DC: U.S. Government Printing Office, F ebruary 1985). for a case study on fiber-optic technology.

" 'Many large companies that rely heavily on data communications, in particular, banks such as Citicorp, are installing their own fiber lines in buildings that house their offices and computers and between their facilities and long-distance telephone (Continued on next page)
} 
also benefit as they begin to use data communications for such things as credit-card verification and remote bookkeeping services. ${ }^{14}$

An unresolved question is whether peoples' needs to communicate to and from the home can support the high cost of running fiber-optic cable the expensive "final mile' to American residences. If this occurs, people at home will be able to receive and transmit everything from television shows to computer software to electronic mail over switched telephone lines, and be billed, and conceivably bill others, directly for use. $^{15}$

One of the major advantages society gains from public communication media, such as the post office, is the ability to connect every citizen and organization with every other. Modern communication media and their inherent economies of scale can be made available to every citizen, as the post office and public roads have been, if efficient and equitable rules can be established for the development and use of these societal resources. To establish rules for information commerce in a public electronic communication system of the capacity of digital fiber-optic technology, policy makers will need to balance many interests: public and private, individual and corporate, economic and social. In the electronic information environment supported by technologies such as fiber optics, intellectual property rules will work hand-in-glove with rules that govern, for example, the operation of the local public telephone central-office switch. ${ }^{16}$

continued from previous page

access points. (See Michael A. Laviola, "The Citibank FiberOptic Network, " Telecommunications, February 1984, pp. 8694.)

"See, for example, "Bell Companies Race To Offer Local Data Services," Data Communications, April 1985, pp. 46-50.

"'Some believe that even rural users and others on thin routes that cannot support the cost of fiber-optic lines may still be served by broadband telecommunication links with cellular radio and low-cost satellite earth-station gear. SeeI thiel de Sola Pool, "U ser I nterfaces, "The Information Society, vol. 2, Nos. 34. p. 439.

Given a broadband, public-switched telecommunication network available to all, Pool suggested that opportunities would abound for small, diverse information businesses to flourish in an electronic environment. Ibid., pp. 433 and 441.

\section{Information Production and Economies of Scope}

Economies of scope are present when a producer, because he makes one product, has a cost advantage in making other products. ${ }^{17}$ The production of information-based goods clearly involves economies of scope. ${ }^{18}$ In writing a book, for example, the an author builds skills, experience, and a reputation that afford him an advantage in producing and selling subsequent writings.

Electronic media establish an entirely new dimension for economies of scope in information production. Information content may be packaged in many forms to serve the particular preferences or requirements of different users. For example, a book may be produced with paper and ink, on audiocassette, or on optical disk; its content may be adapted into a television "mini-series' or an interactive game that can be distributed in a variety of forms. Users of information can gather content from many sources, analyze it, and rearrange it to produce new information. For example, daily stock market statistics may be processed very quickly to help investors adjust to changing conditions. I nformation may be extracted from a larger bundle and used in a new context. An artist, for example, can electronically pluck the image of an eye from a motion picture film frame and use it to create a magazine advertisement or a T-shirt logo.

Intellectual property concepts are fundamental in determining who may take advantage of the economies of scope inherent in information production. Serving as marketplace rules that govern the conditions under which information-based goods are traded, intellectual property laws specify what rights attach to a work, what rights are retained by the original proprietor, and what rights accrue to the purchaser when he buys the work. The rules that govern how purchasers may use a work in producing their own works are particularly

"For example, a steel maker may have an advantage in producing coke, pig iron, specialty steels, or perhaps knives, cookware, or other finished products.

"Priest, The Character of I nformation, p. 27. 
important. These rules strike a balance between the benefits of exclusive control as an incentive to innovate, and the cost of limiting others' ability to compete with a rights holder.

Until recently policy makers could allocate the right to exploit economies of scope fairly easily using relatively simple rules. Some rules have been passed down from antiquity in the customs of scholarship, which demand that users cite and credit originators for their contributions. The legal concept of derivative use was first formalized as a rule by the courts in giving authors exclusive rights to make and sell foreign translations. In response to technological change, this concept was later extended by the judiciary to give fiction writers a say in the making of movies based on their books. In 1976, rules based on derivative use rights were defined by Congress to govern a broad range of situations. Copyright now confers to a proprietor exclusive rights over all goods substantially based on an original work.

In parallel to the evolution of rules for derivative use, the concept of fair use has grown and evolved. Originally developed by the courts as an exception to exclusive copyright, it was designed to promote the scholarly use of intellectual works by suspending, under certain conditions, the rule that users obtain permission to use portions of protected works in building new works. Fair use was codified by Congress, also in the 1976 act, to apply to educational use of photocopying technologies.

Today, however, technology is complicating the allocation of rights in information. Modern information technologies force a fundamental confrontation between the two concepts of derivative use and fair use. With new electronic technologies, people have a host of new opportunities to create new information packages based on existing works; to serve new customers by manipulating and transforming works; to add value by placing existing information in new contexts; and, generally, to participate in intellectual work. These technologies have given scholarship-the building of human knowledge - a new set of tools and a broader field of operations. And as a result, the eco- nomic, legal, and social questions involved in determining proper and efficient rules for controlling derivative use have become much more complex.

From the legal perspective, modern information technologies make it harder to define which commercial uses are merely derivative (that is, copies) and thus unfairly competitive. These technologies make it more difficult and costly to detect infringements and enforce derivative use rights. Furthermore, detection of infringement and enforcement are potentially more intrusive of personal privacy. These subjects are covered in chapters 3 and 4.

From the economic perspective, it is unclear whether, as a general rule, the right to control derivative uses encourages or inhibits the growth of knowledge. Because derivative works may substitute for and undercut markets for originals, they might diminish incentives to create or disseminate works. On the other hand, the threat of competition from derivations might spur the originator to make his own derivations or to create new works. When proprietors seek to inhibit derivative uses, as they might, for example, by building technical or contractual 'fences' and suing infringers, they increase the transaction costs associated with distributing information. Such efforts reduce the benefits that society gains from the high economies of scale offered by electronic media, Moreover, if a user is not allowed to make his own derivations, society may be deprived of the unique contribution he alone could make. Thus, society could lose some of the benefit, in the form of economies of scope, that electronic information offers. ${ }^{19}$ Marketplace rules based on the right of derivative use clearly affect the competition that proprietors of information-based goods face and the profitmaking strategies that information providers pursue.

\footnotetext{
"There are two ways in which a person may be prevented from making derivations: 1 l enforceable rules prohibiting derivation:2) secrecy or technical protection schemes that physically prevent derivations. Both of these preventions may result in the costly and inefficient duplication of effort, which the intellectual property system seeks to minimize.
} 
Operating under conditions of economies of scope, information providers often construct a variety of packages to tap markets for different combinations of media and information content. For instance, the movie industry offers the same content in a variety of media forms, including movie houses, free broadcast television, monthly subscription television, "pay-per-view" and "premium-channel" cable television, and videocassettes and disks. This repackaging of movies is designed to implement price discrimination, the setting of prices according to assumptions about how much users value the information package and their ability to pay, rather than on the basis of the marginal cost of providing the information.

Another set of information-providers operate in markets that cater to users' needs for very specific information content. For example, financial analysts, engineering consultants, market research specialists, and a growing array of information brokers use their expertise to select relevant content from masses of available information and construct highly customized packages .20 These providers price discriminate on the basis of users' different content requirements, rather than on the basis of users' preferences for different media forms, as is the case, for instance, with movie distributors.

The effectiveness of price discrimination hinges on proprietors' ability to exclude competitors from offering similar packages. Providers must also know what information users need and what they are willing to pay for it. The feedback that information providers receive from their customers' purchasing behavior allows them to tailor both the goods they offer and the prices they charge. ${ }^{21}$

\footnotetext{
"One may consider many traditional "professions," such as law, medicine, and engineering, as being in the business of providing highly customized information.

${ }^{23}$ A crude form of price discrimination, which requires relatively little control of derivative use or detailed knowledge about customers' preferences and requirements, is employed by other information providers. Publishers of newspapers and magazines, for example, "bundle" information and take advantage of the fact that some people value one feature or article enough to pay a price that exceeds the cost of the article and thus contributes to the provision of other items in the bundle.
}

Computer database technology promises information providers new opportunities to amass comprehensive collections of information, offer data processing services, constantly updated information content on a broad range of subjects, and precisely tailored packages in a wide variety of forms. They can do all these things through a self-service system for "onestop" information shopping. ${ }^{2223}$ These computerized delivery systems also offer proprietors greater potential to collect and analyze feedback, in the form of transaction information, on customers' information-use habits so they can implement price discrimination more effectively. ${ }^{24}$

Computerized information-retrieval systems also make proprietors more vulnerable to uncontrolled derivative use of their resources.

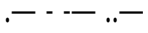

"Theoretically, any kind of information can be embodied in a computerized database. Currently, most information that is offered through publicly available databases is factual in nature--economic and financial statistics, bibliographic citations, etc. (See Martha E. Williams, "Electronic Databases, " Science, Apr. 26, 1985, pp. 445-455. ) More and more access tofunctional information is being offered, such as remote data processing for bookkeeping or statistical analysis. A number of ventures offering computer software transmitted to the user from a centralized collection have been tried, with mixed success. (See Download, J anuary 1986, pp. 1-4.) Potentially, art can also be offered on a user-selectable basis, for example, full text of novels and other books, music in a form some have termed the "celestial jukebox, and "imagebanks" that contain content and software for making and manipulating pictoral works.

"Electronic technologies also make the cruder form of price discrimination that relies on bundling less effective. Photocopy machines, videocassette recorders, and especially computers allow users to quickly and conveniently "unbundle' information, taking only those pieces that are valuable to them. Christopher Burns and Patricia Martin, The E conomics of I nformation, contract report prepared for OTA, April 1985, p. I-7. This same unbundling capability threatens advertising revenues.

${ }^{2}$ This transaction information has growing economic value as a marketing tool and a commodity in its own right. There is a potential conflict between the development of highly efficient computerized information markets and the right of citizens to privacy in their personal affairs. The Cable Communications Policy Act of 1984 places specific limits on the collection and use of personally identifiable data on subscribers of cable systems (section 631). The Videotex I ndustry Association has developed voluntary privacy guidelines for the use of transaction data collected in their operations. A spokesman for the on-line computer database industry says that, at present, it is too expensive to collect and use detailed transaction data from their operations. It may be possible to have computerized, electronic transaction systems that technically limit the collection and use of personally identifiable transaction information. See, for example, David Chaum, "Security Without Identification: Transaction Systems To Make Big Brother Obsolete, " Communications of the ACM, October 1985. 
Their competitors can employ these technologies to offer the same or similar information packages and compete for customers. Consequently, information providers may support strong intellectual property laws to protect their investments in originating, purchasing, and customizing information, and to achieve and retain market share. Although they now have legal rights over derivative uses, proprietors still have an incentive to strictly control access because legal enforcement is so difficult and expensive.

Economies of scope, like economies of scale provide incentives for ownership concentration. ${ }^{25}$ Users of information want to go to the most comprehensive source. Suppliers of content have an incentive either to deal through large distributors with popular recognition and prestige (who may require contract provisions that exclude dealing through competitors) or to become employees of a large company and "work for hire. And proprietors of information resources have greater freedom to price discriminate if ownership is concentrated and competition is checked.

Proprietors of electronic information also have an incentive to integrate vertically-to combine ownership of content resources and distribution facilities. In the current deregulatory climate they are freer than in the past to do so. Policy makers are particularly concerned about vertical integration among communication and information providers in situations where competition in distribution facilities is weak. ${ }^{26}$ In these instances, a vertically integrated information provider has an incentive to favor its content over that of competitors by cross-subsidy, "predatory" rate discrimination, or outright refusal to deal. Commoncarriage regulation, and the more recent efforts at structural separation, leased or equal access, and "Computer III" regulations are govern-

\footnotetext{
Priest, The Character of Information, p. 27.

:". A firm with monopoly power over part of the system has an incentive to restrict access to its part in order to extend control over other parts. .. With public systems, such actions can lead to a total monopoly. To have competition in a public system with some parts monopolized, it is necessary that nondiscriminatory access be maintained. Brock, The Telecommunications Industry, p. 301.
}

ment attempts to check the market power potential of vertically integrated communication entities. ${ }^{27}$ (See figure 6-I.)

\section{Private Investment and Information Resources}

For individuals and for society, information is the raw material of knowledge and learning. ${ }^{28}$ New information technologies are providing tools and techniques for capturing, creating, using, and sharing information in unprece dented forms and quantities. These technologies make possible a vast expansion of knowledge about the world, and they allow the establishment of information resources that people can draw on for many purposes As detailed in chapter 5 , by automating many of the tasks that artisans, scholars, and managers have traditionally had to master, they promise to raise productivity in creative and intellectual work. We also expect these technologies to enhance learning and amplify the social and economic benefits that come from knowledgeable people and an educated society. ${ }^{29}$ Chief among these benefits, as seen in chapter 2, are opportunities for citizens to more fully participate in society-to develop and contribute their unique talents and insights to the economy and to the community.

Information-based products and the technologies that support them are also important as factors in the production of an expanding range

\footnotetext{
For overviews of the issues being addressed by the Computer $11 \mathrm{I}$ inquiry see Andrew D. Lipman, "Taking the Competitive Plunge: The FCC Dives Into Computer II 1, Telephony, Oct. 7, 1985, pp. 48-49; and Edwin E. Mier, "Computer Inquiry III: The Emerging Monolith, " Data Communications, March 1986, pp. 51-58.

${ }^{24}$ Information has been characterized as a nondepletable re source. For example, see Karen Levitan. " Needed Research in the Economics of Information Resources, proceedings of the American Society for Information Science, vol. 17, p. 334; and "I nformation Resources as "Goods" in the Life Cycle of Information Products, "J ournal of the American Society for I nformation Science, J anuary 1982, pp. 44-54; see also, Cleveland, "Information as a Resource."

"In 1776, economist Adam Smith identified the skill, dexterity, and judgment of the labor force as primary determinants of economic and social well-being. See Adam Smith, The Wealth of Nations (New York: The Modern Library, 1937).
} 
Figure 6-1 .-Decision Tree for Communications Regulation Under Computer Inquiry III

Is it a common carrier?

Is it a dominant carrier?

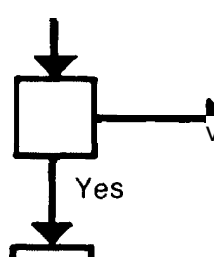

No

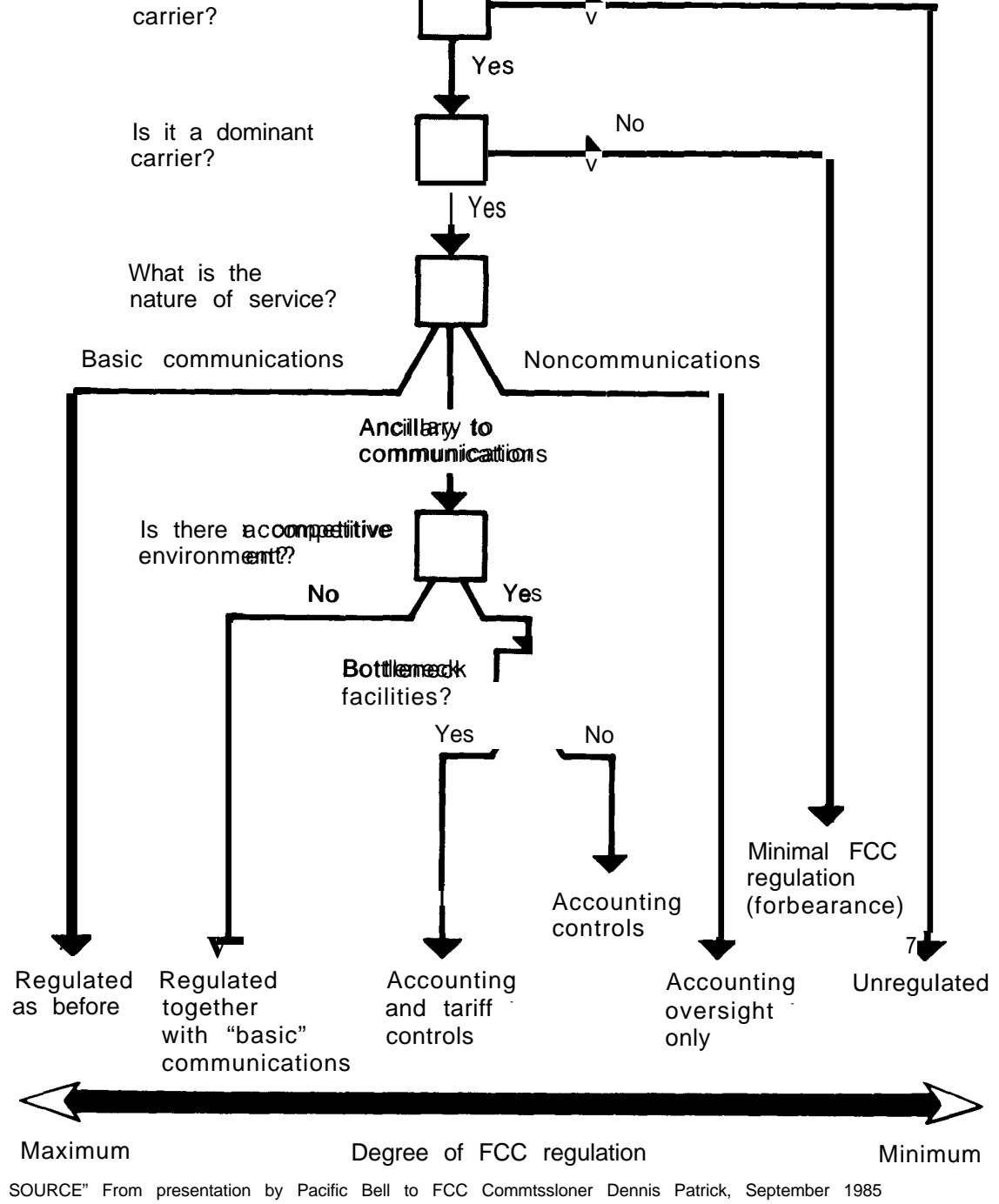

of goods and services ${ }^{30}$ Information technology increases productivity and contributes to the material wealth and well-being of society; ${ }^{31}$ and information itself imparts competitive advantages to those that possess it and can make good use of it. ${ }^{32}$

\footnotetext{
${ }^{30}$ See ch. 2 for a discussion of the importance of information to the economy.

"Charles J onscher, "Information Resources and Economic Productivity, "Information Economics and Policy 1, 1983, pp. 13-35.

"Michael E. Porter and Victor E. Millar, "How Information Gives You Competitive Advantage, " Harvard Business Review, J uly/August 1985, pp. 149-160.
}

Although information is essential to material production and social welfare, economists generally believe that private enterprise invests less in its production and distribution than is socially desirable or efficient. ${ }^{33}$ The root cause of this inadequate private investment is uncertainty. Motivated by profit, individ-

\footnotetext{
${ }^{33}$ See Yale Braunstein, "Information as a Factor of Production, "The Information Society, vol. 3, No. 3, pp. 261-273. An increased amount of valuable goods and services could be produced with a given amount of land, labor, and capital resources if more were invested in information that is applicable to productive activities.
} 
uals and corporations are uncertain whether they may benefit by investing in the development of information resources.

The producers, distributors, managers, and users of information, and the people that invest in these activities, all operate in an environment characterized by uncertainy. ${ }^{34}$ Many originators of information, whether they are artists, scientists, or computer programmers, are working at the frontier of knowledge, so the outcome of their work is inherently uncertain. They may succeed or fail in accomplishing their goals, or the goals themselves may be poorly defined, deliberately ambiguous, or self-justifying. They often do not know in advance how much time will be required to meet their objectives, what the ultimate value of their work will be, or how much money they will make from a work.

Distributors of information face uncertainty because they have only imperfect control over the public dissemination and use of their products. Information is inherently "leaky," so it is both expensive and difficult for them to exclude nonpayers and competitors from using it. Also, because users' requirements and preferences are hard to define precisely and they change unpredictably, price discrimination is a trial-and-error process.

\footnotetext{
"The distinction between information distributors and managers is informed by an analysis by Charles J onscher. ("Information Resources and Economic Productivity, pp. 18-1 9.) As J onscher states, it is difficult to precisely ascertain the relative magnitude of effort accounted for by market allocation versus centralized management of information, but:

The distinction is quite fundamental, in that the extent to which economic [and information resource] management is centralized or left to the interaction of independent trading parties lies at the heart of the distinction between market and nonmarket allocation processes, and indeed between socialist and capitalist economies.

J onscher estimates that in 1978 information management and distribution activities, which together account for more than 80 percent of total information economic activities, were carried out approximately half by distributors (39 percent of total activity) and half by managers working for firms or government bodies (42 percent of total). Intellectual property rules are fundamental to the operations of independent distributors, and thus crucial to market-driven allocation of information resources, In the absence of adequate incentives for independent distribution of information, it is reasonable to assume that private sector firms will be compelled to rely more on internal production and distribution and centralized management of information resources, and the need for government to provide publicly available information will rise.
}

The professional managers of informationemployees of companies and government who obtain, organize, and provide access to information-also face large uncertainties. They must contend with increasingly complex media and information content, while continuing to meet organizations ever-changing information needs. Moreover, within corporate and State bureaucracies, the real cost of generating and managing information resources is generally accounted for very poorly or not at all, so there is often little ability or incentive to engage in rigorous "make or buy" decisions when information is needed. ${ }^{35}$

Users, perhaps, face the greatest uncertainties of all. Economist Kenneth Arrow recognized a paradox in trying to determine the demand for information. "[The] value [of information] for the purchaser is not known until he has the information, but then he has in effect acquired it without cost. ${ }^{1136}$ Of course, through experience and exposure to advertising, users build expectations about the value of information packages that they consider for purchase. They may browse through printed information in book stores and, if facilities and resources are available, at public libraries. But the user of electronic information is generally denied access unless he agrees in advance to pay. Therefore, he may be unable to compare one package with another. Moreover, because access to electronic databases is charged for by the hour or minute, the user is under the pressure of the clock. ${ }^{37}$ (See table 6-3.) Also,

\footnotetext{
"Marc Porat, "Information Workers Within Bureaucracies, Bulletin of the American Society for Information Science, February 1984, p. 17. See also, Burns, The Economics of Information. pp. V-I-9.

"Kenneth J . Arrow, "E conomic Welfare and the Allocation of Resources to Invention, "Economics of Information and Knowledge, D.M.Lamberton (cd.) (Baltimore, MD: Penguin Books, 1971), p. 148.

${ }^{37}$ Both of these factors sharply limit peoples' opportunity to browse randomly and make the occasional serendipitous discovery. This is a complex subject that involves the design of computerized information-delivery systems and the methods used to index, access, retrieve, and charge for computerized information, Automated systems may yet be designed and offered that can promote the ability to make new connections among disparate pieces of information. But this capability is limited in present systems, and the pressure of a 'running meter' further limits their use as general tools in knowledge building. The question of how information resources are to be structured to
}

(continued on next page) 
Table 6-3.-Representative Charges for On-Line Database Access

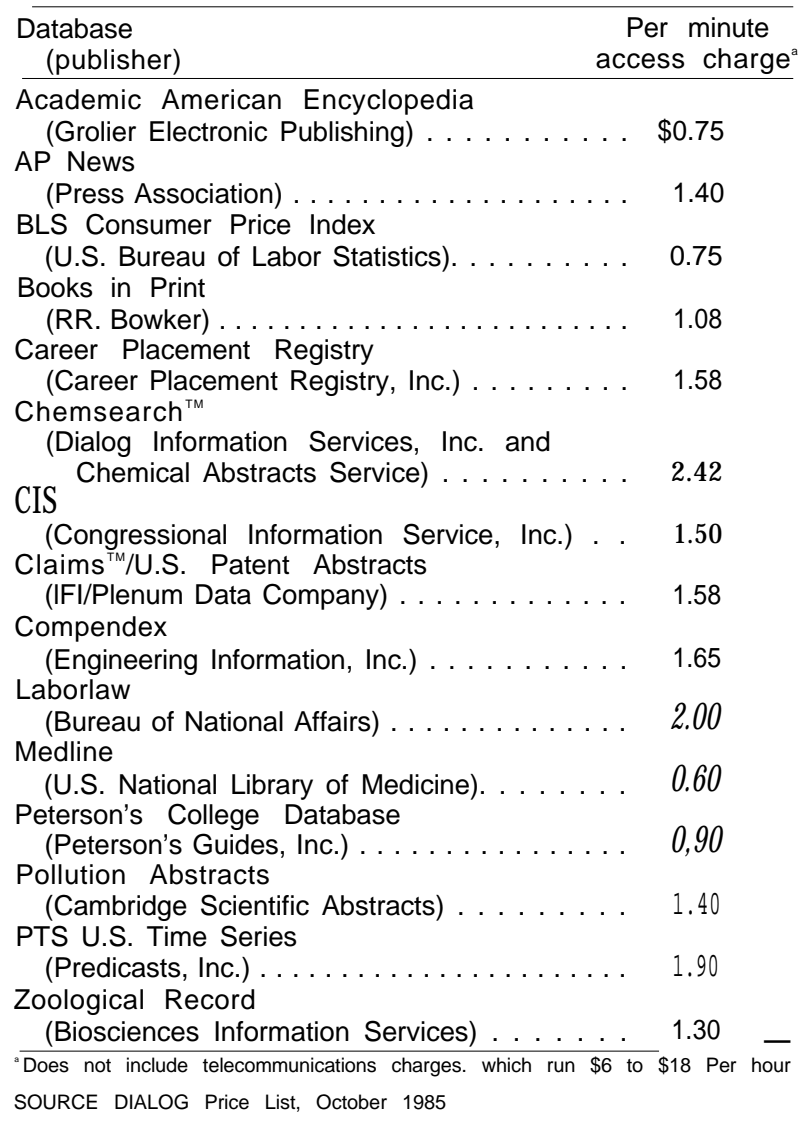

unless public or shared facilities are available, he must buy equipment before he can receive electronic information, equipment that may subsequently fall drastically in price or soon become obsolete.

Investment in information production, distribution, management, and use is risky. Only

\section{(continued from previous page)}

meet different information needs is a problem that libraries constantly face. Public libraries are increasingly compelled to make either/or choices, in a time of shrinking budgets, among investments in different kinds of information resources for their patrons. The issue of charges for information services in public libraries is sparking great controversy, and the introduction of computerized retrieval systems is at the center of that debate. See, for example, Brett Butler, "Online Public Access: The Sleeping Beast Awakens, " Bulletin of the American Society for Information Science, December 1983, pp. 6-10; and J oseMarie Griffiths and Donald W. King, Impact of Information Technology on Information Service Providers and Their Clientele, contract report prepared for OTA by King Research, Inc., J uly 1985, pp. $54-84$. a small portion of the total value that individuals and society gain from the use of information resources can be expected to be returned to producers and distributors through payments for use. This is because information is intangible and leaky, and its value expands unpredictably through new uses and the building of knowledge. ${ }^{38}$ As a result of this discrepancy, the private economy allocates less land, labor, and capital to information resource production than is socially efficient or desirable.

Economists characterize those markets in which resources are unlikely to be allocated efficiently as exhibiting market failure. There are numerous types and degrees of market failure; ${ }^{39}$ study of market failures associated with information began in the mid-1920s. ${ }^{40}$ In their analyses, economists generally have included information in a class of goods called public goods. Others in this class are parks, lighthouses, and national defense." Because the pri-

\footnotetext{
${ }^{3 *}$ Priest, The Character of Information, pp. 33-35.

"See, for example, Francis M. Bator, "The Anatomy of Market Failure, "Quarterly Journal of Economics, August 1958, pp. 351-379; and Robert H. Haveman and J ulius Margolis (eds.), Public Expenditures and Policy Analysis (Chicago, IL: Markham, 1970).

"Pigou recognized that knowledge provides benefits to society as well as to the purchaser. Arthur C. Pigou, The Economics of Welfare, 4th ed. (London: Macmillan, 1932). In 1962, Arrow wrote a seminal piece on the subject in which he recognized three forms of market failure associated with information: indivisibilities, inappropriability, and uncertainty. (Kenneth Arrow, "Economic Welfare and the Allocation of Resources to Invention.") More recent looks at information and market failure include: Yale M. Braunstein, "The Functioning of Information Markets, " in Issues in Information Policy, directed by J ane H. Yurow, edited by Helen A. Shaw (U.S. Department of Commerce, National Telecommunications and Information Administration, February 1981), pp. 57-74; Michael D. Cooper, "The Structure and F uture of the I nformation E conomy, "I nformation Processing and Management, vol. 19, No. 1, pp. 926; W. Curtiss Priest, "Characteristics of Information in Commerce and Transactions, " working paper (Cambridge, MA: MIT Center for Policy Alternatives, Oct. 25, 1984); and W. Curtiss Priest, "Development of Economic Guidelines and Alternative Options for Public Investment Decisions in Scientific and Technical [formation," working paper (Cambridge, MA: MIT Center for Policy Alternatives, Mar. 15, 1984).

"According to Samuelson, a public good has the attribute "that each individual's consumption of such a good leads to no subtraction from any other individual's consumption of that good . ." Paul Samuelson, "The Pure Theory of Public Expenditure, "Review of Economics and Statistics, vol. 36, 1954, p. 387. Actually, Samuelson uses the term "collective consumption good, " but public good is now the commonly accepted terminology. Stanley M. Besen, Economic Issues Relating to New Technol ogies and Intel lectual Property, contract report prepared for OTA, December 1984, p. 1.
} 
vate economy underinvests in them, public goods are often provided or subsidized by the government."

Given the importance of information resources and the fact that the private sector underinvests in them, the public policy question is: How might the government best encourage their growth and use? Can the government reduce the uncertainties faced by people engaging in information activities, and if so, how? May reducing the uncertainty of one group re sult in problems or expense for others? And, given that it costs more to originate information than to reproduce and distribute it, a corollary question is: How might the government best encourage the growth of the human resources that form the pool of knowledge, creativity, and skill from which valuable information originates?

Motivated only by financial profit, the private sector will produce and distribute those types and forms of information from which they can inexpensively exclude nonpayers and competitors, and for which they can collect enough revenue to cover their costs and realize a profit that is competitive with other investments. ${ }^{43}$ To compensate for insufficient private investment, government could:

1. institute policies that help proprietors to

\footnotetext{
'-Since exclusion is difficult and may be socially inefficient, the use of tax-payer money to supply thegood can often be justified. Economists and public administrators point out that government is not obligated to provide all public goods. There are situations in which the waste and distortion that government may incur in trying to counteract market failures associated with public goods may produce more inefficiency than it cures. See, for example Fritz Machlup, Knowledge: Its Creation, Distribution and Economic Significance, Volume III: The Economics of I nformation and Human Capital ( Princeton, NJ : Princeton University Press, 1 984). p. 157.

'Fortunately, there are many motivations for producing and disseminating information aside from financial gain. See ch. 5, 'The Creative Environment. ' See also, Robert M. Hurt and Robert M. Schuchman, "The E conomic Rationale of Copyright, " American Economic Review, May 1966, pp. 425-426.
}

exclude nonpayers and competitors, collect payment, or price discriminate;

z. subsidize investment in the production or distribution of information that the private sector finds unprofitable; and/or

3. undertake the task of producing and/or disseminating information.

The latter two approaches require that government identify unprofitable kinds of information for which there is a compelling social need and public interest. Some of these judgments are straightforward. Public investment has long supported most basic scientific research, a large part of the applied research in fields such as medicine, agriculture, and energy, the bulk of economic and social statistics on which government policy is based, a large share of the cost of formal education, and many other information activities.

The first approach-helping private enterprise exclude, collect payment, and price discriminate-has been the traditional role of intellectual property policy and law. It has afforded three distinct advantages over government subsidy or direct investment in production. First, it minimizes the government need to make judgments about the specific value and uses of information. Second, it permits private markets to respond quickly to changes in consumer demand where profits signal investors to shift resources and where there are no substantial barriers to competition. Third, intellectual property protection has traditionally promoted both learning and private investments in the production of ideas.

Changes in technology that alter the incentives for producing and disseminating information may in some cases weaken the advantages of intellectual property protection. If unchecked, the incentive to control access and to concentrate ownership of media and content may undermine the promotion of learning and widespread participation in the development and use of knowledge and information resources. 


\section{GOVERNMENT POLICY AND THE DIVERSITY OF INFORMATION-BASED GOODS}

A basic goal of intellectual property law is to promote a healthy diversity in the ideas, information, and knowledge available to society. In the age of print, diversity was fostered by granting individual creators the right to control the conditions under which their works were published, printed, and distributed in tangible copies. The questions of what rights attach to works embodied in tangible copies, which particular rights a proprietor retains, and which rights are transferred to a buyer of a copy of a work have been relatively easy to determine. The incentives to originate works and disseminate copies were clearly fostered by the limited controls afforded by copyright. Users' ability to employ existing works in learning and scholarship were supported by the legal limits of copyright control developed in the fair use and first sale doctrines. ${ }^{44}$ Thus, a rich diversity of information, and the growth and use of knowledge, was promoted by a balanced set of rights over information.

As information is increasingly distributed in less tangible electronic forms, these questions of rights in information become more complicated. If one assumes that, in the information age, more people will make a living producing, distributing, and using information, these questions of rights become all the more important. As detailed in chapter 3, new technologies are blurring the boundaries defined by the traditional legal rights over information. Concomitantly, as seen in chapter 4, the enforcement of those traditional rights is increasingly difficult and troublesome. Works in electronic form take on a fluid character. Form and content are transformable and dynamic; separating idea from expression is a more arbitrary judgment; and information is an integral part of automated processes, as well as a conveyor of meaning to people.

\footnotetext{
"The first sale doctrine states that ownership of a copy of a work passes to the purchaser of the copy. The purchaser may then sell or otherwise dispose of his copy (section 109). The first sale doctrine allows the development of trade and rental markets out of the control of the copyright owner and thus limits his potential market power.
}

Alongside changes in the character of information as a technical package, as an economic and social good, and as a cluster of legal concepts, the structure of incentives for originating, disseminating, and adding value to information is undergoing change. To maintain a balance in the rights over information, new definitions that correspond to the emerging technical, economic, and social characteristics of electronic information must be developed. In particular, the definition of rights should clarify the ways purchasers may use works: What are the rules for using protected works in producing and distributing information? How may one compete with his source of information or with sellers of similar works?

For some types of information, especially works of fact, proper inducements to add value may be as important in the information age as incentives to originate works were in the age of print. ${ }^{45}$ For other types of works, especially art, rules that help creators preserve the integrity of their contributions may be most appropriate. New types of art that arise from collaborative or interactive processes may require new kinds of corporate arrangements. Functional works may require new administrative mechanisms to assure that proper, policy-consistent controls are placed both on infringements and on the market power inherent in patent-like protection. ${ }^{46}$ In these ways, intellectual property law may continue to foster the creation and dissemination of emerging information-based goods, a healthy diversity of works, and the profitable trade of information in open markets.

Historically, many other government policy mechanisms-communications regulation, antitrust enforcement, R\&D management and support, the development and promulgation

\footnotetext{
"Burns, The Economics of Information, pp. 111-17-18.

${ }^{4 B}$ See Carroll Pursell, Historical Case Studies of the Influ. ence of Intellectual Property Laws on Technological Change, contract report prepared for OTA, August 1985, for a discussion of the history of market power derived from patents in a selection of information technology industries.
} 
of technical standards, special tax provisions, the funding of education, and public information production and dissemination-have also had significant effects on the development of information markets. As markets change in response to new media and the expanding role of information in economic life, policy makers may need to think about how all of these mechanisms interact in their affect on the diversity of available information.

\section{Problems in Framing Policy To Promote Information Diversity}

Designing policy to promote diversity in information is fraught with difficulty. Few efforts have been made to collect adequate data to make policy judgments about information markets based on strict, quantitative criteria. ${ }^{47}$ The data that exist reveal little about how different kinds of information are produced and used, about the factors that guide producers and users in their investment and purchase decisions, or about how to measure the influence of different kinds of information as factors in the production of subsequent information or other goods. 48 Moreover, much of the available

\footnotetext{
${ }^{47}$ Two comprehensive efforts at collecting data on the information economy have been undertaken and published. The first, Fritz Machlup's The Production and Distribution of Knowledge in the United States, published by the Princeton University Press in 1962 and since extended in three additional volumes, Knowledge and Knowledge Production, 1980, The Branches of Learning, 1982, and The Economics of Information and Human Capital 1984, presents data on aspects of the production of some varieties of information. The second, $M$ arc Porat The Information Economy, published in 1977 by the Department of Commerce, Office of Telecommunications, is a snapshot of information-related economic activities for the year 1967. A third study, which updates some of Machlup's work, is scheduled for publication in 1986: Michael Rubin and Mary Taylor Huber. The Knowledge Industry in the United States: 1960-1980 (Princeton, NJ : Princeton University Press, in press). The Copyright Office has begun to produce a series of studies on the size of the copyright industries, the first of which was presented to the Senate J udiciary Committee in December 1984. Many economists and other writers use a wider array of industry-level statistics in analyzing the operation of information markets. It is often the case that these data are incomplete or may even be inappropriate to the analytic questions under consideration.

" "A strong argument can be made that this new kind of capital [knowledge capital] is more critical to the growth of the American economy than is money capital. But knowledge capital does not show up in the numbers economists look at (or quote) when evaluating capital formation. From "Gnomons, Words and Policies, a speech given by Walter B. Wriston to the Fx ecutives' Club of Chicago on May 8, 1985, as quoted in Harper 's, September 1985, p. 22.
}

data is supplied by stakeholders in the policy debates, and thus may be biased. At present, the available data are inadequate to directly and objectively test hypotheses about investment in and supply of different kinds of information.

Another problem is that the optimal diversity of information-based goods is difficult, if not impossible, to specify. Each person's needs for information are unique; and individuals place different value on information depending on the uses to which they plan to put it. In some cases, the information package may be most valuable if it is standardized, as, for example, is information on the toxicity of chemicals. Other kinds of information are most valuable when they are simultaneously available to a wide audience, as, for example, is news coverage of a historic event. Other information is uniquely prepared for, and only valuable to, a single individual, as is the financial analysis of one's estate. Therefore, the intellectual property goal of fostering a balanced diversity of information is difficult to achieve, given the vastly different kinds of content and the wide range of media that are needed to efficiently serve audiences ranging from one to millions of users.

\section{Proprietor Concerns, Government Policy Tools, and the Diversity of Information}

The actual diversity of information-based goods available to individuals and society depends on a complex set of factors. Because of economies of scale and scope, proprietors' choices of profit-making strategies will be guided by whether, and to what degree, they can select the audience for a given information package. They select customers focusing on three major criteria: exclusion (of nonpayers and competitors), collection, and price discrimination. Government policy interacts with proprietor concerns and their strategies for selecting audiences on a technical level and a transactional level to affect the diversity of available information. 


\section{Technical Concerns}

I nformation providers must select a distribution medium with technical characteristics suitable for their particular variety of information content. For example, a broadcast television signal requires a dedicated portion of radio spectrum; a publicly available computerized database information service requires computer hardware, software programs, and a public switched telephone network.

Government support for and promulgation of technical standards will fundamentally affect the development and operation of communications media. The regulation and licensing of radio spectrum affects the operations of information providers who use broadcast or private radio channels (including terrestrial microwave and geosynchronous satellite links) to distribute goods. The development of Integrated Services Digital Network (ISDN), which will rely heavily on fiber-optic lines, is currently the subject of a worldwide, but loosely coordinated, standards-making procedure. The resulting system will have major and long-lasting effects on markets for information-based goods."

Technical standards are also of fundamental importance in regulating the content of certain kinds of information, particularly factual and functional information. The National Bureau of Standards (NBS) has been interested for some time in establishing "Data Quality Indicators" for scientific and technical information that could help universities, businesses, and government agencies by increasing the

\footnotetext{
${ }^{49}$ See, for example, Michael D. Bander, "Pacific Bell Forsees Three-Phase ISDN Revolution, "Telephony, Mar. 24, 1986, pp. 44-53. In general, technical standards perform four basic functions in markets:

1. they provide information on terminology and test and measurement methods;

2. they promote minimum levels of acceptable quality, such as safety standards do;

3. they promote compatiblity of components in systems to allow users to purchase components from multiple vendors; and

4. they promote reduction in variety to allow economies of scale to be realized.

J ohn H. Young, Effects of Standards on Information Technology R\&D: Local Area Net works and Integrated Service Digital Network, contract report prepared for OTA, November 1983.
}

reliability of factual information distributed by computer databases. "These indicators would provide the user with enough information to determine the utility and suitability for specific purposes. ${ }^{150}$ Such information, many believe, could yield substantial productivity improvements in research, development, and manufacturing in a wide range of fields, and increased safety for workers and for the public. NBS is also at work on technical standards for computer software to improve government operations. These efforts may affect the nature of computer programs used by the private sector as well.

Because of technical differences among media, the difficulty of excluding, collecting, and price discriminating will vary according to the medium. For example, many goods published in tangible copies, such as books, are available to everyone at more or less identical prices. They are paid for in individual transactions, and require a visible capital investment to be competitively reproduced for sale. Information broadcast over radio and television is, by and large, available to all and paid for by advertisers, and competing broadcasts are easy to recognize and exclude from competition. ${ }^{51}$

Information-based goods may also be leased or exhibited to consumers on a per-use basis. Movies shown in theaters, pay-per-view television, and electronic databases are paid for in this manner. Many goods are provided by subscription on a more or less continuing basis. I nformation packages offered by lease or subscription vary widely in terms of how proprietors can exclude, collect, and price discriminate. Some of these packages and transaction mechanisms are looked at in detail

\footnotetext{
"National Bureau of Standards, Workshop on Data Quality Indicators: Summary Report and Recommendations. Gathersburg, MD, Feb. 10-12, 1982, p. iii.

"Printed and broadcast information are increasingly vulnerable to advanced copying technologies, Proprietors' ability to exclude private copying is a subject of heated debate, and is discussed in other sections of this report. At this point, it is important to consider the potential for private copying as one of the factors that all information proprietors must consider in their marketing strategies.
} 
below. ${ }^{52}$ As technologies for storing, communicating, and processing information converge in computer-based systems, proprietors are increasingly concerned about the extent to which users may subsequently reuse or trade their works, and thus diminish proprietors' opportunities to collect for use and price discriminate.

Some forms of distribution and payment will encourage mass markets for goods and tend to restrict the diversity of the goods offered. ${ }^{53}$ Other forms of distribution and payment will encourage highly diverse varieties of information that are tailored to individual needs and preferences. "' E conomic theory suggests that producers will use the feedback they receive, from observing how consumers purchase and use goods, to fine-tune products and services to serve consumer preferences. Information providers may also use this transactional information to improve price discrimination and thus increase their profits.

\section{Transactional Concerns}

A second factor a proprietor must consider in selecting distribution media and offering information content is the cost of administering business transactions with his customers. Transaction costs will depend on the technical characteristics of the media, the number of customers the proprietor must deal with directly, and government-derived rules that specify the legal conditions to which transactions must adhere. The information he receives from transactions will, in turn, provide the proprietor with feedback, allowing adjustments in products, services, and prices.

\footnotetext{
"What we must do is to analyze the natural structure of the new systems of communication as they seem to be emerging to try to identify what systems of payment are enforceable and socially acceptable. " Ithiel de Sola Pool, Technologies of Freedom (Cambridge, MA: Belknap Press, 1983), p. 5.

"If the profitable provision of highly differentiated products can occur only where different prices can be charged to different customers of the same product, while undifferentiated products can be sold profitably at a single price, the differentiated products will not be offered even if efficiency would be increased by doing so." Besen, Economic Issues Relating to New Technologies and Intellectual Property, p. 4.

"Ithiel de Sola Pool, "*The Culture of Electronic Print, " Daedalus, vol. 3, No. 4, fall 1982, pp. 17-31.
}

Intellectual property law and other government mechanisms may affect diversity by encouraging one form of distribution over another. For example, the enforcement of theft of service laws might make terrestrial microwave (MDS) more attractive than free broadcast television as away of distributing movies by making transactions with individual consumers profitable. Government-sanctioned mechanisms that aggregate transactions, such as the Copyright Royalty Tribunal or private collecting societies such as ASCAP, can reduce the cost of managing the transactions between proprietors and users. This may give media that are covered by such arrangements cost advantages in obtaining content for distribution. The aggregation of transaction arrangements may also affect ownership concentration and market power in the information industry. For example, eliminating the compulsory licensing provision for cable television retransmissions may give cable program suppliers increased incentive to merge with or buy out competitors. ${ }^{55}$ Other regulations, such as those that govern common carriers and those called for in the Cable Communications Act of 1984, can require companies to offer leased access to channels on a competitive basis.

Government policy may also encourage investment in certain types of information content by affecting the risks producers face in transacting business. For example, tax credits and subsidies may discriminate among different types of information-based goods. Compul-

\footnotetext{
${ }^{55}$ Priest, The Character of Information, p. 37. The current operation of the Copyright Royalty Tribunal (CRT) encourages programs suppliers to work together to settle royalty disputes so as to avoid the Tribunal's adjudication procedure. This requires suppliers to seek representation from powerful tradeassociations, such as the National Association of Broadcasters and the Motion Picture Association of America, who can afford the cost of presenting a case for remuneration to the Tribunal. The Copyright Act grants antitrust immunity for private agreements on the distribution of royalties by the CRT. There is no public record of how the trade associations decide to disburse funds to the copyright holders they represent. See Cable Retransmission of Broadcast Television Programs Following Elimination of the "Must Carry" Rules (Washington, DC: Office of Policy Analysis and Development, National Telecommunications and Information Administration, U.S. Department of Commerce, 1985), p. 7. Some private collecting societies operate under antitrust consent decrees that serve to inhibit price fixing and anticompetitive behavior. (See footnote 70, p. 281.)
} 
sory licenses and royalty collection and distribution may affect the relative costs of rebroadcasting versus originating information content. ${ }^{56}$ Government R\&D and public information activities may make information-based goods available that can compete with goods produced or offered by the private sector. Rules limiting the transferability of intellectual property rights between creators and publishers may affect the transfer of risk. Common-carriage, cross-ownership, equal-access, and antitrust rules can set limits on industry concentration and check anticompetitive transaction arrangements.

Private sector transactions may not provide all the information society requires because the profit motive may not allow for the production or distribution of some kinds of information. Some information may be of such critical importance to citizens and to the process of governing that policy makers may decide that no one should be denied access for any reason. Therefore, free or subsidized public information sources, such as libraries and public schools, and tax-supported public information content, such as the census, weather forecasts, and information on the operations of government agencies, may be reasonable and proper alternatives to reliance on private-

\footnotetext{
"Se Cable Retransmission of Broadcast Television Programs Following Elimination of the "Must Carry" Rules.
}

sector, profit-motivated information transactions..$^{77}$

At the most basic level, intellectual property law may specify which works are public information or are of such a fundamental nature that they are neither copyrightable or patentable. In this way, the law can prevent companies from discriminating in the selection of users or from employing de facto proprietary standards to exclude competition and exercise market power. ${ }^{58}$ And, as discussed above, legal distinctions, such as those implied by the categories of art, fact, and function, may be useful in adjusting the incentive structure to the realities of electronic information production and distribution.

\begin{abstract}
OTA has studied the question of the impact of changing technology on the provision of public information. See Federal Government Information Technol ogy: Management, Security, and Congressional Oversight, ch. 7, pp. 139-158,February 1986, for an overview of policy concerns relating to government information.

${ }^{5 x}$ The fact that electronic information is often available only through a system, that is, "a set of complementary products which must be used together to provide value" (Brock, The Telecommunications I ndustry, p. 16), the potential for attaining market power is enhanced. For example, a computer manufacturer may be able to restrict competition in markets for peripheral components by developing proprietary processor-interconnection standards (Brock, p. 17). Similarly, a company may employ copyright on operating system software to restrict competition for its hardware or applications software; and a communication company may restrict competition by refusing to provide competitors with connecting lines to customers.
\end{abstract}

\section{PROBLEMS IN SELECTED MARKETS FOR INTELLECTUAL WORKS}

\section{Print Technology and the Functioning of Copyright in Book Markets}

Traditionally, copyright law has been most concerned with the relatively simple markets for distributing information-based goods in printed form. Printing production technology is efficient on a relatively small scale; for example, printers may produce a fairly small number of copies of books at a per-copy cost that is not much higher than large-scale printing. Thus, there are more than 15,000 American book publishers, and most of these com- panies are small. ${ }^{59}$ But large advertising expenditures, buyouts of publishing houses by conglomerates that may be more adverse to taking risks, ${ }^{60}$ and the concentration of book retailing ${ }^{61}$ have, some observers contend,

\footnotetext{
"9."The Book Business, " Editorial Research Reports, J une 28, 1'385, p. 479.

Twelve publishing firms, all of them divisions of conglomerate corporations, garnered 45 percent of book sales in 1983. “The Book Business, ' p. 486. See also, Lewis A. Coser, Charles Kadushin, and Walter W. Powell, Books: The Culture and Commerce of Publishing (New York: Basic Books, 1982), p. 29.

"Although approximately 80 percent of the 9,500 full-line bookstores are independently owned, the volume of orders that publishers obtain from the major chains, Waldenbooks, B. Dal-
} [continued on next page) 
erected substantial and growing barriers for authors trying to publish their first book. ${ }^{62}$ Others contend that, "the cost of printing, offsetting, or photocopying a manuscript remains low enough that virtually anyone can publish anything. "163 Thus, the problem for new authors may not be getting their books published, but getting them reviewed and widely read.

Not all publishing firms perceive of their business in the same ways. Some consider themselves to have an almost exclusive responsibility to maximize profits for owners and stockholders. Others feel they are primarily responsible to the educated public, to the general public, or to the cultural traditions of the Nation. ${ }^{64}$

Publishers are increasingly influenced by the media industries and corporate world in which they must do business. The growth and resulting complexity of many publishing houses has, in some cases, caused a loss of contact between publishers and the writers, thinkers, and literary critics who previously were central to the publishing business. The integration of book publishing into conglomerate corporations also tends to divorce publishing decisions from purely literary criteria. Publishing contracts are more often negotiated with literary agents or lawyers rather than with authors.

Independent authors use copyright in negotiating the conditions under which publishers will offer their books to the public. In most cases, the author transfers his copyright own-

(continues from previous page)

ton, Barnes \& Noble, and Crown, give them a major influence over what gets published.

[T] he chains tend to reserve shelf space for guaranteed bestsellers by name authors, books that are hot at the moment isuch as celebrity exercise books or diet books) and low-cost sale books called remainders [unsold hardcover books returned to publishers and wholesaled to chains at very low prices]. Many books that have been published in the recent past and sell in steady but low quantities, are difficult, if not impossible, to find at the discount chains.

"The Book Business, " p. 495.

"Will Books Survive?"' a discussion held at the American Booksellers Association convention in San Francisco, Lewis H. Lapham, moderator, Harper's, August 1985.

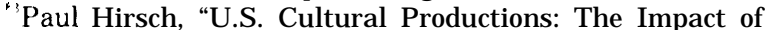
Ownership, "Journal of Communication, vol. 35, No. 3, summer 1985, p. 114

${ }^{n}$ Coser, Kadushin, and Powell, Books, p. 15.

"'l bid., pp. 31-32, ership to the publisher in exchange for editing, typesetting, printing, distribution, advertising, and promotional services. The author may receive compensation in advance of the sale of copies. He also will receive a royalty, usually about 10 percent of the sale price, for each copy sold. Often, the advance payment is deducted from the author's forthcoming royalties.

Currently, the players in the intellectual property community are debating the transferability of intellectual property rights, and the potential alterations in the bargaining positions of creators and publishers that might occur should the transferability of rights be changed. The transfer of rights is closely related to the transfer of risk between author and publisher. Some economists contend that a change in intellectual property law that limits the extent to which authors may transfer rights over their works will limit their ability to transfer risk. ${ }^{66}$ Such a view assumes that "work for hire" is the extreme case in which a creator is so averse to risk that he exchanges all rights in his work for a salary.

Existing copyright law returns control of a work to an independent author after 35 years unless he renews the transfer contract. ${ }^{67} \mathrm{Pol}-$ icymakers could shorten this term, taking into account the reasonable shelf life of different kinds of works, and so give independent authors more long-term control over their work without producing a large effect on their ability to transfer risk.

The work-for-hire situation is more complicated. Employers often supply hired creators with sophisticated and expensive equipment, and therefore claim ownership in the works produced in their shops. Another problem is that many works are produced by teams of creators, and it can be very difficult to divide rights in a work. In such cases, corporate ownership may be a more efficient way of orga-

\footnotetext{
${ }^{4 h}$ Besen, Economic Issues Relating to New Technologies and Intel lectual Property, pp. 30-33.

'Generally, publishing contracts allow publishers, but not authors, to terminate the contract. Coser, Kadushin, and Powell, Books, p. 229.
} 
nizing production, distribution, and rewards to creators. Thus, although modifying the rules about transfer of rights may foster the diversity of some kinds of information by encouraging independent authorship, other kinds of information production may be too complex for anything but corporate sponsorship and control.

Subsidiary rights to derivative works is another issue of interest in the negotiations between a creator of an intellectual work and a publisher. The law allows a copyright proprietor to exploit markets for a work other than those for the initial form in which the work is published. This raises the question of whether the creator or the publisher is to control the exploitation of markets for these works. When the subsidiary markets are known (e.g., a novel always has a potential to be produced as a play or movie), the contract between author and publisher can specifically address the control of subsidiary rights. However, given the rapid changes in information uses and distribution technologies, it is conceivable that new forms for distributing works will emerge that are not contemplated in current publication contracts. In this context, intellectual property law could specify which party owns rights in unanticipated markets if contracts are not explicit about subsidiary rights.

The questions raised by the issue of the transferability of rights between creator and publisher may be relevant to a wide range of situations. For example:

- the development of computer software, where the question involves the way in which the authors of software and firms that market and distribute their products divide the revenues from sale or lease;

- the production of motion pictures, where the questions involve the rights retained by producers and those transferred to a film's distributors;

- the production of television programs, where the questions involve the rights retained by producers and those transferred to the networks; and

- the invention of technical processes or new products, where the questions involve the rights retained by the inventor and those transferred to the exploiters of the invention.

\section{Motion Pictures, Videocassettes, and the First Sale Doctrine}

Motion picture production and distribution is a part of the information industry in which the definition of rights and the conditions under which those rights may be transferred are of growing importance. In this part of the information industry, intellectual property rules have a major influence on the diversity of products produced and made available to the public. The markets for motion picture products have expanded since the 1950s as television, followed by videocassettes, became alternative methods of distribution, augmenting traditional theater exhibitions. ${ }^{68}$

The major motion picture distributors stagger the release of feature films in these markets to maximize the per-viewer net revenue they can obtain in each, and thus maximize their profits for each film. ${ }^{69}$ (See figure 6-2.) The staggered or 'tiered' release strategy is away of implementing price discrimination. Those consumers who value early access to a movie are willing to pay a higher price than those who are content to wait for it to appear on pay television or those who can wait 2 years or more until they may expect to see the movie on free television.

\footnotetext{
${ }^{6 \times x}$ The characterization of "scope" in movie products may be a subject of disagreement. To be characterized, on a priori grounds, as distinct markets for different products, the different forms of movie distribution would have to substitute very little for each other. In practice, there apparently is substantial substitution between at least some of the forms, in particular rented cassettes and pay television. Other forms, such as theater attendance and cassette sales, substitute less and may in fact be complementary products. See David Waterman, "Pre recorded Home Video and the Distribution of Theatrical Feature Films, " ch. 7, pp. 221-243, in Video Media Competition: Regulation, Economics and Technology, Eli M. Noam (cd.) (New York Columbia University Press, 1985). The J ustice Department has specific guidelines for defining market scope in merger and antitrust actions that are based on the ability of producers to control prices. See U.S. Department of J ustice, Antitrust Division, Merger Guidelines, 1984.

"'Waterman, "Prerecorded Home Video and the Distribution of Theatrical Feature Films, " p. 231.
} 
Figure 6-2. -Representative Release Sequence for a Major Theatrical Feature

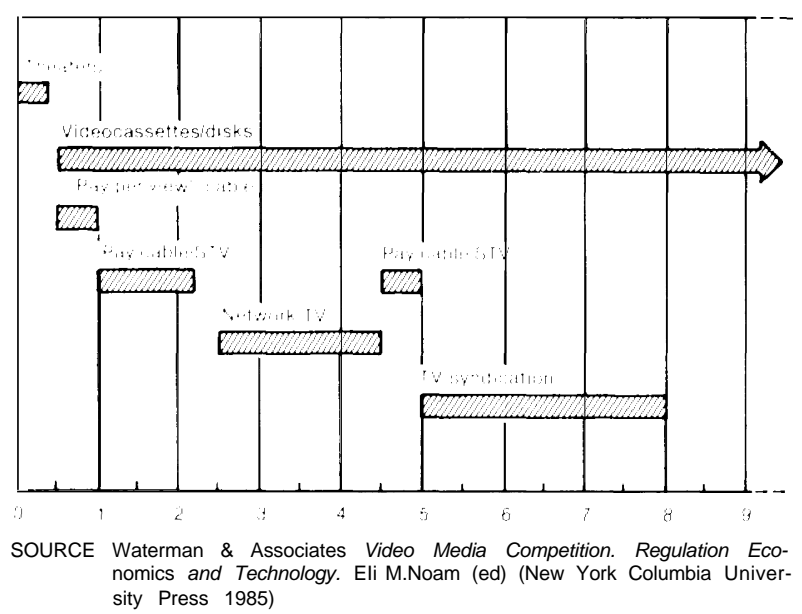

The profitability of the tiered release strategy depends on the distributor's ability to control the timing, number of exhibitions, and price of the movie in each market. Such control allows him to coordinate advertising and promotion, and segment markets according to the cost of the various distribution media and the value of the product to different consumers.

Price discrimination in the sale of information-based products may promote efficient allocation of investment since the revenue returned to a producer more closely approximates the value of the good to consumers. The profitability of markets for different forms can alert producers and distributors to trends in consumer preference. However, extensive price control combined with barriers to market entry for potential competitors may reduce market efficiency by allowing producers to restrict supply and obtain monopolistic profits. Traditionally, movie distributors have almost completely controlled access to their products and the prices charged for access." This has been

\footnotetext{
I hid,

Marketplace controls by motion picture producers, distributors, and exhibitors have been the subject of antitrust litigation for many years. See, for example,Paramount Famous Lasky Corp. v. United States, 282 U.S. 30,42 (1930), Schine Chain Theaters, Inc.v.United States, 334 U.S. 110 (1948). United States v. Paramount Pictures, Inc.. 334 U.S. 131 ( 1948), and United Statesv. Loew's Inc., 371 U.S. 3811962). These and other cases
}

possible, in part, because until recently movies were not distributed to end-users in individual, tangible copies. And lease agreements for theaters and television have strictly controlled the conditions under which movies may be exhibited.

The release of movies in videocassette form and the growth of the video rental market have loosened distributors' control over the timing, frequency, and prices charged for access to their products. The first sale doctrine is a major impediment to distributors' control over the cassette rental market. ${ }^{72}$ Because of this, the major distributors of feature movies support amendment of the first sale doctrine to allow distributors more income from videocassette rentals and to compel rental outlets to seek specific permission to rent cassettes. ${ }^{73}$ Other cassette distributors who do not also distribute movies to theaters for exhibition oppose this change. $^{74}$

Amendment of the first sale doctrine could have mixed effects on the overall efficiency of the videocassette market. On one hand, distributors would probably try to raise prices for cassette rental. This would tend to push their per-viewer revenues on cassette rentals closer to those from the highly price-efficient pay-perview cable and theater distribution modes and thus increase the major distributors' net revenues. The major distributors argue that this revenue would be used to finance the production of more movies to meet the increased demand for films fostered by the new distribu-

are analysed in Michael Conant, Antitrust in the Motion Picture Industry (Philadel phia, PA: Ayer Co., 1978).

"'The fact that distributors choose to release movies on prerecorded software [video cassettes and disks] in spite of the [first-sale] doctrine is evidence that they increase their net revenue by doing so. Waterman, p. 236.

"The Motion Picture Industry Association and its member companies, Paramount, Columbia, MGM/United Artists, 20th Century Fox, Universal, Warner Brothers, Embassy, Orion, and Buena Vista (Walt Disney), who together controlled more than 89 percent of theatrical distribution and 90 percent of videocassette distribution in 1983 (data from Waterman, tables 1 I and IV) have been the major proponents of first sale doctrine amendment for videocassettes. Two bills to amend the first sale doctrine for audio-visual works were introduced in Congress and had hearings held on them in 1983 and 1984: H.R. 1029 and S.33.

"'Statement of Austin O. Furst, J r., before the House J udiciary Subcommittee on Courts, Civil Liberties, and the Administration of J ustice, Apr. 12, 1984. 
tion technologies. ${ }^{75}$ They argue, moreover, that the prices for cassette purchases by users would decline because distributors could price discriminate between sales to rental outlets and to final consumers.

On the other hand, higher cassette rental returns to distributors may force many rental outlets out of business. The market for cassette rentals is in the process of consolidation and shake-out even with the first sale doctrine intact. ${ }^{76}$ Any increase in rental prices that caused a substantial reduction in rental volume would be likely to cause further concentration and would work to the disadvantage of smaller outlets. ${ }^{77} A$ reduction in rental outlets would tend to reduce price competition among the remaining outlets; a reduction in rental volume could force the outlets left to devote more shelf space to mass-market feature titles and less to titles appealing to smaller, more specialized consumer markets. ${ }^{78}$

Some opponents of past attempts to amend the first sale doctrine for videocassettes are also concerned that modifications could lead to the imposition of "tie-in' or "full-line" sales requirements by distributors. In such arrangements, a distributor would require a rental outlet to purchase additional titles as a condition for obtaining one or more very popular works. If this were legal, ${ }^{79}$ a distributor would have

\footnotetext{
75. The Consumer Video Sales/Rental Amendment of 1983 Briefing Materials" (Washington, DC: Motion Picture Association of America, 1983),

"'Alex Ben Block, "Hard Dollars in Video Software, " Forbes, J une 17, 1985, pp. 128-131.

"'Statement of Nina W. Cornell, President, Cornell, Pelcovits \& Brenner Economists Inc., before the Subcommittee on Courts, Civil Liberties, and the Administration of J ustice of the House J udiciary Comrnittee, Economic Impacts of Repealing the First Sale Doctrine for Audiovisual Works, Oct. 27, 1983, pp. 29-31.

${ }^{7 *}$ Statement of Stuart Karl before the House J udiciary Subcommittee on Courts, Civil Liberties and the Administration of J ustice, Apr. 12, 1984, pp. 13-15.

${ }^{79}$ The Supreme Court has ruled that tying arrangements are illegal because they, "deny competitors free access to the market for the tied product, not because the party imposing the tying requirements has a better product or lower price but be cause of this power or leverage in another market. At the same time buyers are forced to forego their free choice between competing products. " Northern Pacific Railway v. United States, 356 U.S. 1,6 (1958). The amendment of the first sale doctrine proposed in H.R. 1029 may not specifically permit such tying arrangements, but it may lead to many situations in which liti-
}

more control over a rental outlet shelf space, and could compete with other distributors on bases other than the price and quality of his goods.

The conflict over the first sale doctrine among players in the videocassette market is especially interesting in light of the motion picture industry's overall current situation. Figure 6-3 shows the number of feature movie starts by major studios and independent producers. The steep rise in feature film production beginning in 1982 was predicated on the industry's perception of increased demand, fostered by the growth of the cable television and videocassette markets and by an infusion of more than $\$ 1$ billion in capital in $1984 .{ }^{80}$ Some stock analysts consider markets for feature motion pictures to be facing an impending glut. They have cautioned investors not to expect impressive earnings from the major distributors. ${ }^{81}$ In fact, the major movie studios have recently cut production sharply .82

The important policy question is whether the proposed amendment of the first sale doctrine will, as the major distributors claim, lead to increases in the number of films produced and make the films more valuable and available to consumers. Faced with impending market glut, the producers of feature films often react by cutting production. Alternatively, they may attempt various mechanisms to exact more revenue from the films they produce. Adver-

gation would be required to nullify cases of tying, whereas their likelihood is much less under the current video cassette market structure. See Statement of J onathan Rose, Professor of Law, Arizona State University College of Law, before the Subcommittee on Courts, Civil Liberties, and the Administration of J ustice of the House J udiciary Committee, Feb. 23, 1984. Generally, unlike the legal precedent in patent infringement cases, antitrust violations have not been treated as a valid defense of copyright infringement. See Robert A. Feitel, "Copyright Misuse and Cable Television: Orth-O-Vision, Inc. v. Home Box office,"' Federal Communications Law J ournal, vol. 35, fall 1983, pp. ,347-373.

${ }^{x /}$ Harold A. Vogel, "Glitterless Glut," Entertainment Industry, Merrill Lynch, Capital Markets Securities Research Division, J an. 28, 1985.

"Vogel, "Glitterless Glut. "

"*:"A cut in production apparently improves the quality of films-and improves their chances to become hits by giving them more exposure. " Ellen Farley, "The Movie Studios Hope Less Will Be More, " Business Week, J an. 13, 1986, p. 9. 
Figure 6-3.-Feature Motion Picture Releases

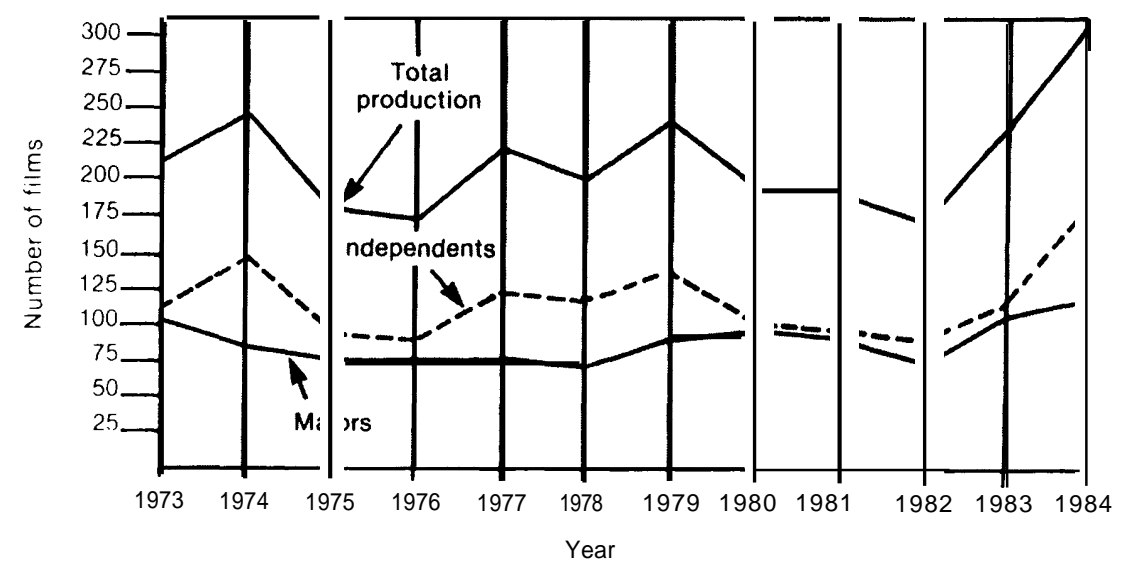

SOURCE Weekly Variety, Jan 2, 1985

tising and promotion for individual films may increase. Concomitantly, distributors may try to increase the efficiency of price discrimination.

The amendment of the first sale doctrine, as we have seen, could be expected to aid the major feature film producers, at least, in doing this. Some have suggested other ways to increase price efficiency. One proposal is to give rebates to purchasers of cassettes to, in effect, discriminate between the sale-only and rental markets. ${ }^{83}$

The industry is responding to market conditions in the absence of changes to the first sale doctrine. Distributors are beginning to use the broad retail market base that has sprung up from demand for cassette rentals to segment rental markets into more specialized and diverse video offerings. This trend is al ready evident in the growing popularity of educational titles and such specialty items as "J ane Fonda's Workout."

The videocassette market may represent an opportunity for independent film producers to market their movies without signing over con-

\footnotetext{
Rose, pp. 32-33. The important factor- in the success of this strategy would be the elasticity of demand for cassette purch ases. Some evidence suggests that sales of some very popular title+ can be increased dramatically by lowering the price tonearer the marginal cost. See Waterman, p. 235, and Cornell. pp 19-21
}

trol of all distribution rights to the major distributors, as they have generally been obliged to do with feature motion pictures. The independent distributors are also beginning to use their revenues to finance the production of films. ${ }^{84}$ The issue of first sale doctrine repeal may thus involve the question of whether the videocassette market is to be an ancillary market for feature films or a new means of offering consumers a diverse range of video products based on a new technology.

I mplicit in the above analysis of the videocassette market is a policy question that may be particularly difficult to answer definitively: What level of investment on a given intellectual work does and should intellectual property law encourage? For example, should policy encourage movies that cost $\$ 15$ million to produce? This is not the kind of question that intellectual property law has heretofore been consciously concerned with. But decisions about intellectual property rules may have a major influence on the level of investment in a given work that is profitable. Because film makers compete for consumers' time as well as money, a decision to uphold the first sale doctrine in the case of videocassettes may encourage investment in cheaper film projects at the expense of investment in costlier

\footnotetext{
“'” F'urst pp. I5-16
} 
projects. ${ }^{85}$ Thus, intellectual property policymaking may require hard, explicit decisions about the nature and content of some information markets, which may compel policy makers to make judgments about the social value of private investments in different kinds of works.

\section{Information Services, Electronic Databases, and Derivative Works}

The scope of the information services industry is illustrated by table 6-4 which lists the variety of activities carried out by member companies of the Information Industry Association. These companies find or create infor-

\footnotetext{
"'At least one film-industry analyst disagrees strongly with this conclusion. He believes that the number of projects undertaken, and not the per-project spending or quality of films, will be reduced by upholding the first sale doctrine. David Waterman, personal communication, J anuary 1986. However, another analyst cites the movie industry reaction to the introduction of television to argue that per-movie investment levels may de cline in the face of competition from new technologies. Hirsch, "U.S. Cultural Productions, " p. 116; see also Paul Hirsch. "Processing Fads and Fashions: An organization-Set Analysis of Cultural Industry Systems, American J ournal of Sociology, J anuary 1972, pp. 639-659.
}

mation and package it in forms most useful to their clients. They may obtain the information from government sources, nonprofit institutions, other private information companies, or they may originate it themselves. They add value to this information by packaging the most relevant, timely, and reliable information in its most useful form.

Within the information services industry, the impact of intellectual property law is a subject of great interest and some controversy. In particular, these markets are directly affected by the rules governing derivative uses of intellectual properties.

Many information service providers obtain information from several sources and then profit from distributing the package of information they create. Often, the information service company claims a property right on the package. In other cases, the service company administers the property rights of those who provided them with information content.

A producer's profits and leverage in attracting information from originators depend on his ability to exclude nonpaying customers from

Table 6-4. -Primary Activities of Information Industry Association Members

26 Document acquisitions and delivery (S)

26 Periodicals-publishers $(P)$

25 Publishing $(\mathrm{P})$

22 Consulting services (S)

22 Databases-design and/or management $(\mathrm{S})$

22 Databases-information $(\mathrm{P})$ (publishers of information about databases

20 Indexing publishing (P)

19 Databases-searching (S) (firms that carry out database searches)

19 Information systems-design and evaluation (S)

19 Market research services (S)

18 Business information $(P)$

18 Micropublishing

17 Current awareness services (S)

17 Databases-vendors/lessors (S) (companies that produce or sell the use of databases)

17 Government information (P)

17 Literature searches (S)

16 Corporate information $(P)$

KEY (S) Service

(P) Product

SOURCE Carlos A Cuadra, 'The Role of the Private Sector in the Development and Improvement of Lbrary and Information Services "Library Quarterly, vol. 50, No 1. January 1980 p 98
15 Directories $(\mathrm{P})$

13 Abstracting publishing $(\mathrm{P})$

13 Indexing services (S)

13 International business information (S) 6 Records management services (S)

12 Energy information (P)

11 Abstracting services (S)

11 Financial information (P)

10 Marketing services (S)

10 Software (S)

9 Scientific literature $(P)$

8 Audiovisual materials $(\mathrm{P})$

8 Cataloging services (S)

8 Engineering information (P)

8 Environmental information $(P)$

8 Legal information $(P)$

8 Television information (P)

7 Clearinghouse (D)

7 Library Automation Services (S)

7 Medical literature (P)

7 Newsletters-publishers

7 Typesetting services (S)

6 Asia $(\mathrm{P})$

6 Economics (P)

6 Electronics information

5 Management information $(P)$
6 Forecasting services (S)

6 Microform system design services (S)

6 Reprint publishers (P)

5 Accounting information $(P)$

5 Agriculture $(P)$

5 Book information $(\mathrm{P})$

5 Bookselling services (S)

5 Chemical information $(P)$

5 Computers-hardware (S)

5 Conferences-information (P)

5 Drug information $(P)$

5 Education $(P)$

5 Europe $(\mathrm{P})$

5 Financial Information (International) $(P)$

5 Information industry (P)

5 Looseleaf services $(P)$

5 Patent information $(P)$

5 Product development (S)

5 Social science literature $(P)$

5 Statistics (P) 
using his goods. Success also depends on whether he can prevent others from commercially exploiting his various packages, and whether he can prevent competitors from repackaging his products. Such exclusion will affect his competitors' available sources of supply and the ways they may use the information available. Thus, the stronger derivative use rights are, the greater the potential for control a producer will have over the prices he charges and the exclusion of competition. But if derivative use controls are too weak, the producer may be unable to receive compensation adequate to cover the cost of constructing a particular package.

The information service providers' dilemma over derivative use rights is mitigated somewhat by the nature of their business. Their products are valued because they meet the specific needs of their clients. Thus, given some latitude in the derivative use of others' products, small companies can succeed by targeting a particular market niche and serving those customers well.

Since the products are highly customized, the market for a particular product may be quite small because the demand for additional copies is quickly exhausted. Thus, a service provider may be able to succeed by focusing his efforts to exclude competitors on a small group of people; and control over his products need only limit the ability of competitors to steal his customers. With no marketplace rules, competitors could do this by unfairly undercutting prices and competing without investing in finding and purchasing or developing their own information. The regulation of unfair trade practices may serve as well or better than copyright in this situation. ${ }^{86}$

Electronic delivery of information services complicates the situation. Over the past 10 years, this segment of the information economy has grown to the point where there are now over 2,800 data files publicly available to

\footnotetext{
${ }^{n}$ The formalities of copyright, registration and deposit of copies with the Library of Congress, may be especially burdensome to the producers of highly diversified and frequently updated information products.
}

users with the proper computer and communication equipment. ${ }^{87}$ These services operate by making a very large file of information, such as scientific journal bibliographic citations or industry statistics, available with software that allows users to search the file and create a customized information product themselves. Competitors may copy the entire file or significant portions of it, construct their own search software, and exploit the original producer's market by undercutting prices. Thus, derivative uses of large electronic databases can be more attractive to competitors; and derivations may damage the original producer of a large database more than they would a company serving a small market niche. Conversely, producers of large electronic databases have economies of scale and scope not available to those who employ people directly in producing customized products. Thus, the on-line information service industry may have a greater tendency to concentrate than does its print counterpart, and large electronic database producers may have greater power to control the supply and price of information. ${ }^{88}$

Another potential problem related to concentration in the electronic publishing industry concerns the question of private control over information in a particular field. Although it may be most efficient for consumers to be able to go to one source to obtain all the available information on a particular subject, the monolithic control thus afforded the proprietor of such a source may allow him to eliminate all effective competition-to corner the market for information on a subject-and thus set conditions on access and prices so as to earn monopoly profits. $^{89}$

\footnotetext{
"'Martha E. Williams, "Policy Issues for Electronic Databases and Database Systems," The Information Society, vol. 2, Nos. 3/4, 1984, p. 445.

${ }^{* 8}$ The top four (out of 14 total) vendors of electronic databases in the U.S. information center library market accounted for 92.6 percent of the $\$ 54.08$ million in 1984 revenues in that industry. Two firms accounted for approximately 84 percent of 1984 revenues. Martha E. Williams, Information MarketIndicators, summer 1985, pp. 1-2.

${ }^{\wedge 9}$ MarthaE. Williams, "Policy Issues for Electronic Data bases and Database Systems, "The Information Societv. vol. 2, Nos. 3/4, 1984, p. 4 11; and Pool, "User Interfaces, p. 441. Pool suggests that information resource monopolies are likely to be narrow and perhaps short-lived.
} 
Computer Software, Market Size, and the Cost of Contract Administration

The dynamics of markets for computer software programs depend, to a large extent, on market size - that is, the number of users who may find a particular type of program useful to them. Many programs are so specialized that markets for them are quite small. In these cases, it is possible for distribution to proceed on the basis of contracts worked out with individual purchasers. Individualized contracts have the advantage of spelling out in detail the rights that a user purchases and the rights that a proprietor retains. For example, software for mainframe computers has largely been distributed under contract lease or license arrangements where the purchaser does not actually buy a copy, but instead buys rights to use and perhaps modify a program. The vendor often agrees to provide certain services, such as expert help in customizing a program for specific user requirements, provision of updated versions at favorable prices, or on-call response to problems that crop up in using the software. Often, the software distributed under contract is treated as a trade secret. Thus, when software is distributed under terms of individualized contracts, the government role may be confined to adjudication of contract disputes at the State level. Software proprietors may also seek Federal copyright for additional protection against programs that may compete as substitutes. ${ }^{90}$

Computer software proprietors often face particular problems in controlling or excluding the marketing of programs that are potential substitutes for their programs. There is often a range of programs available that may provide similar value to users. These programs may have been developed in the course of government-sponsored $R \& D$, and many are in the public domain. For example, the computer language called "Forth" was developed at the National Radio Astronomy Observatory. One company that deals in developing and marketing products based on Forth has to compete

\footnotetext{
'See SAS Institute, Inc. v. S\&H Computer Systems, Inc. (M.D. Term. 1985, nos. 82-3669 and 82-3670).
}

with some programs in the public domain, and some that have been developed by hobbyists who are not especially interested in profiting from the use of their work. ${ }^{91}$ In such situations, users may see a wide disparity in the prices being charged for programs that may appear to have similar capabilities. A proprietor in commercial business, in these circumstances, will have to compete with such substitutes by advertising and offering superior service. Such competition can result in a healthy diversity of software products. But users can also be confused by this diversity, and they may be bewildered by the prices that commercial software providers charge. ${ }^{92}$ Thus, the software business can be particularly risky, and is often dependent on elaborate and expensive marketing techniques.

Software developers have tried a number of innovative marketing techniques for software programs. For example, one successful effort goes under the title "F reeware." The concept of Freeware evolved of necessity, according to Andrew Flugelman, the program's creator and developer.${ }^{93}$ Flugelman was searching for a way to share a program he devel oped for communicating among computers by telephone, and make money from his efforts at the same time. To protect his investment, he considered a software protection scheme, but he discarded the idea because he figured that it would be unpopular, ineffective, and would limit the use of his software. Having been a book publisher, Flugelman was well aware of both the high value and high cost of advertising a product and of setting up mechanisms to distribute it. Putting these two concerns together, he came up with the idea of offering his software freefirst on electronic bulletin boards and later by mail. He anticipated that, once his method took

\footnotetext{
${ }^{9}$ Interview with Edward Conklin, FORTH, Inc., Apr. 19, 1985.

${ }^{92}$ Software companies, like most information providers, have significant discretion in setting prices because, once a package is developed, reproduction and distribution costs are relatively low. They often set prices high under the assumption that a package with a high price is perceived as superior to one that serves a similar function but is much cheaper. Elizabeth Ranney, "The Puzzle of Software Pricing," I nfo World, Nov. 4,1985, pp. 35-39.

Interview with Andrew Flugelman, Apr. 15, 1985.
} 
hold, users would themselves advertise and distribute his product. However, while Flugelman offered his software for free, he encouraged those who used it to pay a nominal fee to show their satisfaction with the product.

Several other software developers have used similar approaches to launch their products. Some, like Flugelman, have been successful in generating healthy revenues and in maintaining full-time businesses. ${ }^{94}$ These approaches, however, have had their problems. Since software products often require extensive documentation and user support to be fully utilized, the costs of such support can grow uncontrollably. Furthermore, as Flugelman has noted, the Freeware concept appears to have worked most successfully with the individual userthe computer hobbyist, the home user, and the very small business man. With these users, the creator can appeal on a one-to-one basis to "the morality and basic honesty of the public." ${ }^{195}$ In the environment of large corporations, personal appeals are apt to get lost.

Software designers may indeed increasingly have to resort to approaches that rely on users to advertise and distribute software, because both advertising and distribution are beginning to constitute larger and larger proportions of software companies' total costs. AshtonTate, for example, spent \$4 million on advertising during the Democratic Convention and the Los Angeles Olympics, Similarly, other companies are aggressively pursuing a variety of advertising and marketing schemes in an effort to stay at the top of what is now a highly turbulent and competitive industry. To increase the sales and name recognition of their products, some companies are even offering their buyers coupons, trial samples, and tradeins on previous models. In such a climate, a whole variety of new advertising and distribution schemes can be expected.

As personal computers have come into widespread use, the cost to software proprietors

\footnotetext{
"See Larry Thompson, "Freeware and Freeware. " Discover. November 1984, pp. 87-89.

" "Software: The New Driving Force: With Computers Becoming More Alike, the Action Shifts to Programs, Business Week, Feb. 27, 1984, p. 74.
}

of managing individualized contracts and providing customized user services has risen dramatically. Proprietors have tried a number of strategies to lower these transaction costs. For instance, many software companies offer" site licenses" that authorize a purchaser, such as a company or government agency, to make a specific number of copies for multiple use within the institution. But site licensing may not be practical unless the proprietor deals with a relatively small number of institutions. This is because the proprietor must have frequent contact with the user institution, sending representatives to the site regularly enough to assure that the terms of the agreement are not being violated." Moreover, when proprietors are dealing with very large institutions, site licenses may make the problem of enforcing compliance with the license extremely costly to monitor.

Another strategy adopted by the distributors of personal computer software is the "shrink-wrap" license. With these, vendors of mass-market programs, such as word processing packages, display a licensing contract on the cover of the container in which the software and its documentation are sold that specifies the exclusive rights that they retain. (See figure 6-4.) By opening the package, the purchaser tacitly agrees to the provisions of the contract. The legality of such 'take it or leave it contracts has been tested in only one State, Louisiana, which passed a specific statute validating shrink-wrap licenses.

Many computer program users are concerned about shrink-wrap licensing because it increases their uncertainty in making computer software purchase and use decisions. A user may decide after trying a program that it is not appropriate for his particular needs. There is also a question of what rights a purchaser might have should the software vendor go out of business. A purchaser may entrust valuable information that is critical to his business to the operation of a particular software system, and come to rely on vendor support. Industry is addressing this problem

\footnotetext{
"Edward Warner, "Site Iicensing Stirs Debate at Comdex, "Computerworld, May 13, 1985, pp. 1,11.
} 
to some extent by establishing "software es-
crow" systems in which a third party holds
a program's source code and development and
maintenance documentation for release to licensees should the vendor go out of business or terminate service on a particular program. ${ }^{97}$

${ }^{97}$ Liliane Choney, "Software Escrow and the Security Practitioner," Computer Security J ournal, summer 1984, pp. 67-76.

\section{Figure 6-4.-A Shrink-Wrap License Contract}

XYQUEST Program License Agreement

YOU SHOULD CAREFULLY READ THE TERMS AND CONDITIONS OF THIS AGREEMENT BEFORE BREAKING THE SEAL OF THIS PACKAGE OPENING THE PACKAGE INDICATES YOUR ACCEPTANCE OF THESE TERMS AND ('CONDITIONS XYQUEST PROVIDES THIS PROGRAM AND LIENSES ITS USE IN THE UNITED STATES AND PUERTO RICO. YOU ASSUME THE RESPONSIBILITY FOR THE SELECTION OF THE PROGRAM TO ACHIEVE YOUR INTENDED RESULTS, AND FOR THE INSTALLATION, USE AND RESULTS OBTAINED FROM THE PROGRAM

LICENSE

You may

a) use the program on a single machine,

b) copy the program into any machine readable or printed form for backup or modification purposes in support of your intended use of the program on a single machine.

c) modify the program and/or merge it into another program on the single machine (Any Portion of this program merged into another program will continue to be subjecl to the terms and conditions of this agreement.); and, d) transfer the program and license to another party if the other party agrees to accept the terms and conditions of this Agreement If you transfer the program, you must at the same time either transfer all copies whether in printed or machine readable form to the same party or destroy any coples not transfered, this includes all modifications and portions of the program contained or merged into other programs

You must reproduce and include the copyright notice on any copy, modification or portion merged into another program

YOU MAY NOT USE, COPY, MODIFY OR TRANSFER THE PROGRAM, OR ANY COPY, MODIFICATION OR MERGED PORTION, IN WHOLE OR IN PART, EXCEPT AS EXPRESSLY PROVIDED FOR IN THIS LICENSE

IF YOU TRANSFER POSSESSION OF ANY COPY, MODIFICATION OR MERGED PORTION OF THE PROGRAM TO ANOTHER PARTY YOUR LICENSE IS AUTOMATICALLY TERMINATED

TERM OF LICENSE

The license is effective until terminated. You may terminate the license at any other time by destroying the program together with all copies, modifications and merged portions in any form It will also terminate upon conditions set forth elsewhere in this Agreement or if you fail to comply with any term or condition of this Agreement. You agree upon such termination to destroy the program together with all copies, modifications and merged portions in any form

Limited Warranty

THE PROGRAM IS PROVIDED 'AS IS' WITHOUT WARRANTY OF ANY KIND, EITHER EXPRESSED OR IMPLIED, INCLUDING, BUT NOT LIMITED TO THE IMPLIED WARRANTIES OF MERCHANTABILITY AND FITNESS FOR A PARTICULAR PURPOSE THE ENTIRE RISK AS TO THE QUALITY AND PERFORMANCE OF THE PROGRAM IS WITH YOU. SHOULD THE PROGRAM PROVE DEFECTIVE, YOU ASSUME THE ENTIRE COST OF ALL NECESSARY SERVICING, REPAIR OR CORRECTION. SOME STATES DO NOT ALLOW THE EXCLUSION OF IMPLIED WARRANTIES, SO THE ABOVE EXCLUSION MAY NOT APPLY TO YOU THIS WARRANTY GIVES YOU SPECIFIC LEGAL RIGHTS AND YOU MAY ALSO HAVE OTHER RIGHTS THAT VARY FROM STATE TO STATE

XYQUEST does not warrant that the functions contained in the program will meet your requirements or that the operation of the program will be uninterrupted or error free.

Limitations of Remedies

XYQUEST's entire liability and your exclusive remedy shall be:

a) the replacement of any diskette not meeting XYQUEST's Limited Warranty and which is returned to XYQUEST or an authorized XYQUEST distributor along with a copy of your receipt, or

b) if XYQUEST is unable to deliver a replacement diskette which is free of defects in materials or workmanship, you may terminate this agreement by returning the program with all documentatlon and your money will be refunded. PROFITS, LOST SAVINGS OR OTHER INCIDENTAL OF CONSEQUENTIAL DAMAGES ARISING LOST OF THE USE OR INABILITY TO USE SUCH PROGRAM EVEN IF XYQUEST HAS BEEN ADVISED OF THE POSSIBILITY OF SUCH DAMAGES OR FOR ANY CLAIM BY ANY PARTY.

SOME STATES DO NOT ALLOW THE LIMITATION OR EXCLUSION OF LIABILITY FOR INCIDENTAL OR CONSEQUENTIAL DAMAGES SO THE ABOVE LIMITATION MAY NOT APPLY TO YOU.

General

You may not sublicense, assign or transfer the license or the program except as expressly provided $\mathrm{m}$ this Agreement. Any attempt otherwise to sublicense, assign or transfer any of the rights, duties or obligations hereunder is void. This Agreement will be governed by the laws of the state of Massachusetts.

Should you have any questions about this Agreement, you may contact XYQUEST, Sofeware Sales and service, P.O. Box 372, Bedford, Massachusetts 01730 .

YOU ACKNOWLEDGE THAT YOU HAVE READ THIS AGREEMENT, UNDERSTAND IT AND AGREE TO ITS TERMS AND CONDITIONS. YOU FURTHER AGREE THAT IT IS THE COMPLETE AND EXCLUSIVE STATEMENT OF THE AGREEMENT BETWEEN YOU AND XYQUEST WHICH SUPERSEDES ANY PROPOSAL OR PRIOR AGREEMENT, ORAL OR WRITTEN, AND ANY OTHER COMMUNICATIONS BETWEEN US RELATING TO THE SUBJECT MATTER OF THIS AGREEMENT . 
Chapter 7

\section{New Technologies and the Intellectual Property Bargain}




\section{Contents}

Findings $\ldots \ldots, \ldots, \ldots, \ldots \ldots \ldots \ldots \ldots \ldots \ldots \ldots \ldots \ldots \ldots$

The Intellectual Property Bargain ....

Transformation of the Constitutional Bargain $\ldots \ldots \ldots \ldots \ldots \ldots \ldots \ldots \ldots \ldots \ldots$

The Intellectual Property Bargain in a New Technological Context ............ 193

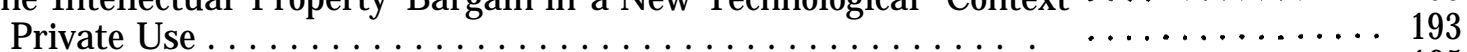

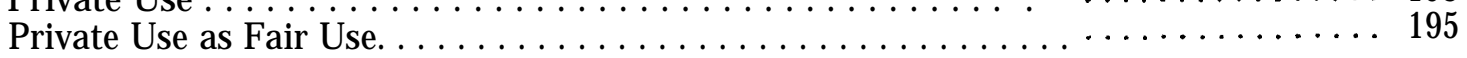




\section{Chapter 7 \\ New Technologies and the Intellectual Property Bargain}

\section{FINDINGS}

- Technology is spawning a wide range of new opportunities to use information-based products and services. A central question for intellectual property law is who shall benefit from these opportunities. In the Supreme Court's "Betamax" decision, for example, the question was whether proprietors or users would benefit, either directly or indirectly, from home videorecording capabilities. As even newer technologies affect individuals' abilities to copy, store, and modify information, such questions are likely to multiply.

- Because it evolved in a period when duplication and storage technologies were centralized and deployed in a commercial context, copyright law offers little guidance to courts in resolving conflicts over who shall benefit from new uses afforded by technology. Neither the existing framework of rights nor limitations on those rights, such as fair use, clearly apply to the private use of information-based goods.

- Some survey research has been conducted on the financial benefits that would accrue to proprietors if they were remunerated for new technological uses, and unremunerated uses are often considered harmful to copyright proprietors. Estimates of harm, however, are in and of themselves insufficient to assist Congress in resolving the issue of who is to benefit from new uses. They presuppose and cannot be the foundation for a legal right to profit from new uses of copyrighted works made available by technology. Whether Congress wishes to consider new uses as harmful will depend on the goals that it seeks to promote through copyright law, and where it believes the benefits of new technologies should be allocated.

- The need for congressional action on this issue is immediate. Public opinion, while tending to favor free private use, is not yet firmly established. However, as technologies for duplicating, storing, and manipulating information become more prevalent and sophisticated, public opinion and public behaviors may become more entrenched.

- A separate, but related issue is that of access to information goods distributed electronically. Traditionally, copyright law has provided a quid pro quo between proprietors and the public in information goods sold in copies. The sale of copies ensured public access to copyrighted works. However, because electronically disseminated works are not sold in copies, but accessed through communications media, Congress may need to rethink the intellectual property bargain to ensure adequate access to information goods. The policies pursued with respect to access and communications law will affect the resolution of the private use issue.

\section{INTRODUCTION: A NEW INTELLECTUAL PROPERTY CONTEXT}

Innovations in information technology require that policy makers address two fundamental questions about property rights in information-based products and services: 1) what rights in information products and services should be granted to a proprietor and 2) what 
rights should be retained by the public? Although copyright law has traditionally answered these questions, information and communication technologies have created a new context in which the application of copyright law is uncertain. In some cases, the technology is shifting the capabilities of printing, publishing, and distributing information from the centralized commercial entrepreneur to private individuals. In others, the technology is creating new and unprecedented uses for information products and services. The videocassette recorder, for instance, not only allows a user to watch motion pictures where and when he will, but also to store video transmissions taken off the airwaves.

The current debate before the courts and Congress centers on whether copyright proprietors or the public shall benefit from these new technological capabilities, and whether and how both can benefit. On the one hand, technology gives the public an unprecedented ability to access, store, transmit, and manipulate information, with little or no need for publishers, printers, or distributors. On the other, the same technologies simultaneously permit the copyright proprietor to exploit markets that have never before existed. In many cases, the interests of the proprietor and the public are in conflict; as, for example, with home video recording.

In resolving the question of who should benefit from new technology, one must begin by understanding that rights granted to a proprietor in a work act as prohibitions on the subsequent uses that others may make of it. To grant a right is to make certain activities illegal for all but the author of a work. Thus, the benefit conferred on an author by the grant of a right exacts a corresponding cost from the remainder of society.

The rights granted the author are not, however, meant to be gratuitous burdens on the freedoms of the public. Congress has in the past stressed that rights are granted to authors for the purpose of benefiting the public, and so,

... [i]n enacting a copyright law Congress must consider ... two questions: First how much will the legislation stimulate the producer and so benefit the public, and, second, how much will the monopoly granted be detrimental to the public? The granting of such exclusive rights, under the proper terms and conditions, confers a benefit upon the public that outweighs the evils of the temporary monopoly.

The effect of technology on this 'cost/benefit" equation underlies the discussion in this chapter. To understand how the current debate arose, the chapter looks first at the U.S. Constitution and the bargain that it established between authors and the public. It then examines how technology has changed the context in which that bargain is carried out, causing ambiguity and uncertainty over which rights should belong to the proprietor and which should be retained by the public. Finally, this chapter suggests that resolving this issue will depend on which criteria are chosen for analysis, and which goals Congress seeks to implement through intellectual property policy. Four such criteria are considered: harm, efficiency, access, and public opinion.

'H. R, Rep, No. 2222, 60th Cong., 2d sess. (1909).

\section{THE INTELLECTUAL PROPERTY BARGAIN}

We saw in chapter 2 that American intellectual property law can be thought of as a bargain between individual creators and the publie. In exchange for granting authors and inventors exclusive rights in their writings inventions, the American public is to benefit from the disclosure of inventions, the publica- tion of writings, and the eventual return of both to the public domain. ${ }^{2}$ The purpose of copyright, in particular, is to benefit the public by encouraging learning through the disseminaand

$\bar{U}$. S. Const. Art. I, sec. 8, cl. 8. At the time the constitution was written, the word "science" meant knowledge in the broadest sense of the word. 
tion of works. Although the Supreme Court has consistently interpreted the intellectual property bargain to be "primarily" for the benefit of the public, ${ }^{3}$ J ames Madision-the principal author of the intellectual property clausebelieved that "[t]he public good fully coincides ... . with the claims of individuals' in intellectual property.' In Madison's view there was no question of subordinating the interests of either the author or the public. The purpose of the intellectual property clause-the public benefit-and the mechanism for achieving that purpose - the creator's exclusive right-were merged in one simple bargain.

Although few disagree that the ends that intellectual property seeks to promote are in the public interest, many feel that the means chosen are in fact inimical to it. Because the constitution grants exclusive rights, copyrights and patents are sometimes considered "monopolies," and-at best-necessary evils. Thomas Macaulay, a British legal historian, voiced this opinion in a speech on the subject of copyright before Parliament:

Copyright is a monopoly, and produces all the effects which the general voice of mankind attributes to monopoly. The effect of monopoly generally is to make articles scarce, to make them dear, and to make them bad. It is good that authors should be remunerated; and the least exceptionable way of remunerating them is by a monopoly. Yet monopoly is an evil. For the sake of the good we must submit to the evil; but the evil ought not last a day longer than is necessary for the purpose of securing the good.'

\footnotetext{
"The Copyright law, like the patent statute, makes reward to the owner a secondary consideration."' Fox Film v. Doyal, 286 U.S. 123, 127, as quoted in Sony Corp. v. Universal City Studios, 464 U.S. 417, 429 [1984).

'From The Federalist, No. XLIII, 281 (italics added).

Leon Seltzer, author of a noted book on copyright, wrote that "to say that the benefit to the author is a 'secondary consideration' is like saying that when reliance is put on a flask to transport wine across a carpeted room, whether or not the flask leaks is, with respect to getting the wine there, a 'secondary consideration. " Leon Seltzer, Exemptions and Fair Use in Copyright (Cambridge, MA: Harvard University Press, 1978), p.14.

Thomas Macaulay, "Speeches on Copyright" (1841), quoted from Barbara Ringer, The Demonology of Copyright (New York: R.R. Bowker, 1974), p. 13. More recently, Stephen Breyer and Benjamin Kaplan have expressed similar views on copyright,
}

J ames Madison, too, was aware of the monopolistic connotations of a governmentally granted exclusive right. ${ }^{7}$ However, he distinguished American intellectual property and thus copyright from the pernicious monopolies that had preceded it:

Monopolies are sacrifices of the many to the few. Where the power is in the few it is natural for them to sacrifice the many to their own partialities and corruptions. When the power as with us is in the many not in the few the danger cannot be very great that the few will be thus favored.

To avoid the evils of monopoly, Madison intended that the exclusive rights afforded by copyright be very limited; he envisioned limited rights, owned by "many," for limited periods of time.

Madison's concerns over monopoly and his confidence in the "coincidence" of the public and private interest were reflected in the parsimonious bundle of rights granted by the first copyright act. ${ }^{9}$ To accomplish its stated goal of encouraging learning, the act granted authors rights that were far more limited than those of the most recent copyright statute. Copyright law gave authors only the rights to "print, reprint, publish and vend" their writings. The author retained the right to reproduce the copyrighted work for sale, but he held no property rights in books as such. A copyright was infringed, not by the uses to which a work was put, but by the unauthorized exercise of the author's commercial rights to sell the work and to print copies of it. "' Thus, af-

calling for limits on its scope and duration. See: Stephen Breyer "The Uneasy Case for Copyright, 84 Harvard La w Review 281 1970; and Benjamin Kaplan, An Unhurried View of Copyright (New York: Columbia University Press, 1967).

As ch. 2 discussed, many of the earliest intellectual property schemes, such as the Stationers Copyright, were true monopolies, concentrating a good deal of economic and social power in the hands of a small number of people.

'Letter from J ames Madison to Thomas J efferson, Oct. 17, 1788 , as quoted in Bruce Bugbee, Genesis of American Patent and Copyright Law (Washington. DC: Public Affairs Press, 1967), p. 130.

${ }^{9}$ Act of May 31,1790, ch. 15, 1 Stat. 124.

"At the time that the constitution was written, printing and publishing required large, costly equipment that made them essentially commercial enterprises. The constitutional bargain therefore presupposed a commercial environment for the exploitation of Writings; it could hardly have done otherwise, since the technology of the day necessitated a publisher. Thus, because of the economics and technology of publishing, the rights (continued on next page) 
ter a work had been commercially printed and sold, others could display it, read from it publidy, or even write other books based on it, without infringing the author's copyright. ${ }^{11}$ Even though the author might have profited from these subsequent uses, the drafters of the first copyright act did not believe it necessary to grant such extensive rights in order to encourage learning.

Numerous other features of the first copyright law ensured that the bargain struck between the author and the public would not constitute a monopoly. ${ }^{12}$ For example, the term of copyright protection was limited to 14 years, ${ }^{13}$ after which time the work would return to the public domain and anyone would be free to print it. The copyright term ended within the lifetime of both the author and his reading public, so that, even if copyright were a monopoly, it was one that could not last long. Moreover, copyright was initially vested in the author, although he could thereafter assign his copyright to others. By creating as many copyrights as there were authors, the law avoided the concentration of market power, as Madison said, in "hands of the few."

\footnotetext{
(continued from previous page)

conferred by the intellectual property clause on authors had operational significance as a regulation of the business of publishing. Indeed, this notion of copyright as a form of trade regulation is, as we shall see, substantiated in other developments. The precursor to the concept of copyright-the Stationer's Charter-granted publishing rights to printers, rather than authors; furthermore, the first Federal copyright statute was held to extinguish any common law rights of the author upon publication (an activity which at the time required the commercial publisher as intermediary).

"Each of these activities would be illegal today,

${ }^{12}$ It is doubtful that a copyright would qualify as a monopoly as defined by antitrust law. Monopoly, as the term is used in antitrust, is the power to set prices or exclude competition in a relevant geographic and product market. See, e.g., United States v. Grinnell Corp., 384 U.S. 563 (1966). A single copyright is at most a monopoly of a product, which seldom gives the copyright proprietor market power. Others are free to compete with the author, so long as they do not copy or produce works that are substantially similar.

${ }^{13}$ This term was renewable by living authors for another 14 years. The drafters of the act may have arrived at 14 years based on previous experience. Several of the States had, per a 1783 recommendation of the Continental Congress, passed copyright legislation with a term of 14 years. The recommendation was modeled on the Statute of Anne, which also implemented a 14year term. L. Ray Patterson, Copyright in Historical Perspective (Nashville, TN: Vanderbilt University Press, 1968), p. 183.
}

\section{Transformation of the Constitutional Bargain}

During the 19th and 20th centuries, this constitutional bargain was gradually transformed, perhaps the most significantly through the gradual expansion of rights. Like the expansion of copyrightable subject matter (see ch. 3 ), the expansion of rights granted under copyright largely tracked technological development. Those granted under the first copyright act of 1790 corresponded to the capabilities of the printing press; these were the rights to print, reprint, publish, and vend a writing. ${ }^{14}$ New rights were gradually added to the copyright scheme as social and technological change prompted Congress to include an expanding variety of subject matter. The "right to perform, " for example, was first granted in 1856 for dramatic compositions, ${ }^{15}$ and in 1897 was applied to musical compositions. ${ }^{16}$ In 1909 , Congress granted musical compositions a "mechanical recording right, ${ }^{117}$ at which time the duration of copyright was also lengthened from its initial 14 to 28 years, ${ }^{18}$ and on renewal, to 56 years. ${ }^{19} \mathrm{Finally}$, in 1976, the term of copyright was extended to the life of the author plus 50 years. $^{20}$

During this period of statutory expansion, the judiciary also sought to mark the boundaries of the exclusive right. In the beginning, the courts confined infringement to literal word-for-word plagiarism, and seldom assessed the ostensible similarities between one work and another. They did not extend copyright protection to protect what are now known as "derivative works." ${ }^{\text {"21 }}$ A playwright, for example, did not require permission from the author of a novel to base his play on the novel. Courts strictly limited infringement to printing the author's book without his consent.

- ${ }^{14}$ Act of $\bar{M}$ ay 31, 1790, ch. 15, 1 Stat. 124

"Act of Aug. 18, 1856, ch. 169, 11 Stat. 138.

“Act of J an. 6, 1897, ch. 4, 29 Stat. 481.

"Act of Mar. 4, 1909, ch. 320, 35 Stat. 1075.

"Ibid.

“Former Title 17 U.S.C. $\$ 24$.

${ }^{20}$ Current 17 U.S.C. $\$ 302$.

"For example, a German translation of the entirety of Uncle Tom Cabin was held not to infringe. Stowe $v$. Thomas, 23 Fed. Cas. 201, No. 13514 (C. C. E. D. Pa. 1853). 
Gradually, however, the courts began to adopt a broader and more qualitative approach to the question of similarity. ${ }^{22}$ They began to interpret "copying" to mean more than simple duplication and to include mimicking or extensive borrowing within its definition. They decided whether a defendant had infringed a plaintiff's right to print, reprint, publish, or vend on the basis of an often subjective estimation of what was essential and unique to a given author's writing. ${ }^{23}$ As chapter 3 details, the courts began to use the concept of "idea" versus "expression" as the accepted tool of analysis for determinations of similarity. They ruled that infringement occurred not only when an individual printed the writings of another, but also when one author adopted an expression that was similar to another's. Courts found no infringement only when the similarities between works were confined to ideasthe abstract concepts or themes employed in the work.

It was Congress however, that, unwittingly and perhaps accidentally, granted written works the most far reaching of rights in the act of 1909. To the exclusive rights of printing, reprinting, publishing, and vending, it added the right to copy. ${ }^{24}$ Before then, "copying' was a right applied only to photographs, paintings, engravings, and other graphic works: works that were not ordinarily reproduced through "printing" or "reprinting." Although section 1 of the 1909 act claimed to "retain without change" the rights granted under prior

\footnotetext{
${ }^{22}$ See, for example, the case of Daly v. Palmer, 6 Fed. Cas. 1132, No 3552 (C.C.S.D.N.Y. 1868), in which an escape from bondage to a train track constituted the sole common theme between two plays, and the basis of infringement.

"Kaplan, Unhurried View, p. 28

"The word "copy" was first used in conjunction with the infringement of etchings in an amendment of 1802, ch. $36, \$ 3$. 2 , Stat. 171. Again, in an amendment of 1831, copying was a term applied to the infringement of other than literary works. See the Revision of 1831, Ch. $16, \$ \$ 6-7,4$ Stat. 436 . In 1870 , when paintings, drawings, chromos, statuettes, and other three dimensional works were added to the growing list of subject matter, the rights afforded all copyrighted works were aggregated under one section (\$86), but the activities constituting infringing conduct were separated so that "copy" applied to works other than maps, books, and charts. Revision of 1870 , ch. $230, \$ \S 99-100,16$ Stat. 198. In the general revision of 1909, infringing conduct was not defined, and "copy" was retained as a right applying to all works.
}

law, ${ }^{25}$ it nevertheless extended the right to copy to a new subject matter. ${ }^{26}$

This seemingly trivial change in the wording of the law would have far-reaching consequences. The change meant that "copyright proprietors, without seeking it and apparently quite by accident, acquired at least the semblance of a right of an activity that was to have increasing importance in the new century. " 2 " For the ambiguity of the word "copy" subsequently endowed proprietors with rights, not only against commercial piracy, but also against noncommercial personal or private use. ${ }^{28}$ To some, this expansion of copyright law is at odds with the traditional intention of copyright. Commenting on the issue of photocopying, Francis Nevins, a copyright scholar, notes that:

... [copyright is intended to govern relations between the creator of a work and all those business people who intervene between the creator and the work's ultimate consumers. It is not intended to control non-commercial

\footnotetext{
${ }^{25}$ H.R. Rep. No. 2222, 60th Cong., 2d sess. 4 (1909).

"Thus, the redundancy of the terms "print, reprint, and copy" was noted years later in a Report of the Registrar of Copyrights on the General Revision of the U.S. Copyright Law, 87th Cong., 1st sess., 1961. Although the verbs "copy" and "print are nowhere defined in the law, Webster offers a definition of print most clearly fitting the context of authorship and publication: "to publish in print." This defintion would make sense of phrases such as "out of print. " "Copy" is described as a synonym for "imitate, mimic, ape, mock."

${ }^{27}$ L. Ray Patterson, "Copyright, Congress and Technology: The Public Record "'-Book Review, 34 Vanderbilt Law Review, 833 (1981), n.30; see also Vernon Clapp, Copyright - A Librarian View (1968)

${ }^{2 k}$ The dubious pedigree of the right to copy was later recognized in the watershed case of Williams \& Wilkins Company v. United States, 487 F.2d 1345, 1351 (Ct. Cl. 1973), aff'd, 420 U.S. 376 (1975), which stated that ' 'copy' is not to be taken in its full literal sweep, thus raising "a solid doubt whether and how far 'copy' applies to books and journals. In this case, publishers of medical journals sued the United States for the copying activities of the National Libraries of Medicine and National Institutes of Health, which, in a split decision, the Court of Claims determined to be fair use. Professor Nimmer notes the ambiguity regarding "copy," and says that the confusion is no longer present "since under the 1976 act the term 'copy' clearly includes a photocopy (citing Section 101 of the Act which defines "copies" )." Nimmer on Copyright \$13.05[E] (]984). However, the definition to which Professor Nimmer alludes is of the noun form-i.e., "the tangible object' '- while the ambiguity noted in Williams \& Wilkins revolves around the meaning and application of the verb form-i.e., whether the activity of copying is one in which the copyright owner holds a right.
} 
use of copyrighted works nor to permit lawsuits against non-commercial users. ${ }^{29}$

At a critical juncture in the emergence of new technologies such as the photocopier and the tape recorder, the vagaries of copyright law may have yielded a fundamental change in the bargain between the proprietor and the public. A literal interpretation of the right to copy transformed copyright from the right to control the use of copyright for commercial profit (vis-à-vis competing publishers) to the right to control the copyrighted work itself (vis-àvis the user of the copyrighted work) .30 Ironically, proprietors' control over the copyrighted work emerged at same time as technology was perfecting methods of denying them that control-the photocopier and the tape recorder.

This distinction between control over a copyright and control over a copyrighted work is critical. If copyright is essentially the right to commercially exploit an intellectual creation, then it is a form of regulation designed to ensure that only an author will be allowed to sell his work to the public. It also means that end users of the work are free to copy, store, manipulate, and share copies that they have purchased. If, on the other hand, copyright is a right to control how a work is used, then it is a form of property; a bundle of rights that follows each and every copy of a book, record, or computer program. Under this theory, proprietors have rights to profit from the uses to which the work is put. ${ }^{31}$

\footnotetext{
"Francis M. Nevins, J r., "University Photocopying and Fair Use: An American Perspective, " 8 European Intellectual Property Review 222 (1985) (italicx added). Support for this notion of copyright as an essentially commercial right can also be found in Supreme Court opinions:

An author who possesses an unlimited copyright may preclude others from copying his creation for commercial purposes without permission. . Congress may guarantee to authors and inventors a reward in the form of control over the sale or commer cial use of copies of their works.

Goldstein v. California, 412 U.S. 546,555 (1973) (italics added).

"'Note that this is different than the distinction made in Section 202 of the Copyright Law between the work and the copy.

"Today, rights to these uses is confined to reproducing, de riving, publically performing or displaying, and distributing the copyrighted work. 17 U.S.C. $\$ 106$. Other rights to uses of a work have been proposed, such as rights to royalties on library lending.
}

The theory of copyright as property is the source of much confusion and conflict over copyright law. It provides the basis for saying that copyright proprietors have a problem of enforcing unauthorized uses, such as home videotaping (see ch. 4). If copyright is a public policy tool, directed toward regulating competitors in the marketplace, rights to these uses do not exist. Nor do problems of enforcing them. Also, as new uses for copyrighted works are bred by technology (see later in this chapter), conflicts arise over who benefits from these new uses. Again, if copyright is construed as a right to commercialize one's creation, rather than a property right in each copy of that creation, the benefits of new technologies will go to the public.

The central question that Congress needs to address is whether copyright shall be considered property or regulation. If Congress were to resolve the question, clear guidelines on the legality of the "private use" ${ }^{\prime 32}$ of copyrighted works might be possible. So far, however, Congress has not given a clear statement of the nature and purpose of copyright. When it enacted the latest revision of the copyright law in 1976, Congress folded the exclusive rights to print, reprint, and copy into the right "to reproduce the copyrighted work in copies. ${ }^{133}$ Ambiguities remain, however, about whether this and other exclusive rights are proprietary or regulatory in nature, and therefore, whether they apply to private use activities. The House Committee Report that accompanies the act sheds little light on the question, but suggests that at least the right to reproduce copies is directed at commercial printing and publishing activities, and is therefore regulatory .34 Significantly, no court has yet held private use to be an infringement, which also suggests that

\footnotetext{
${ }^{32}$ Private use is defined and discussed in greater detail in the next section.

"17 U.S.C. \& 106(1)

"H.R. Report No. $94-1476$ says that:

A single act of infringement may violate all of these rights (under \$106) at once, as where a publisher reproduces, adapts, and sells copies of a person's copyrighted work as part of a pub lishing venture. Infringement takes place when any of the rights is violated: where, for example, a printer reproduces copies without selling them or a retailer sells copies of a person's copyrighted work as part of a publishing venture.
} 
copyright is regulatory and not meant to prohibit copying by end users of a work. ${ }^{35}$ The "Betamax" decision, in which the Supreme Court ruled that videotaping for purposes of "timeshifting' is legal, left the question of private use open. The status of rights in sound recordings are also ambiguous. Although the House Report accompanying the 1971 recording rights amendment says that 'private copying' is excluded from the act, ${ }^{36}$ advocates of the record-

\footnotetext{
The Williams \& Wilkins case seems to be the closest that courts have come to deciding the issue of private use. That case- which decided that the substantial and systematic copying and distribution of journal articles by two governmental institutions was fair use - has little resemblance to the private use concerns of the record, software, and motion picture industries. The case was heard by a total of 16 judges, and was split 8 to 8 on the issue of infringement. In dicta, SONY Corp. $v$. Universal City Studios, 464 U.S. 417 (1984), the Supreme Court has said that

., [e]ven copying for noncommercial purposes may impair the copyright holder's ab ilityt $n$ obt ain the rewards that Congress intended him to have

But. the status of such private use was further obscured in the next sentences:

But a use that has nodemonstrable effect upon the potential market for, or the value of, the copyrighted work need not be prohibited in order to protect the author's incentive to create The prohibition of such noncommercial uses would merelv in. hibit access to ideas without any countervailing benefit.

The issue of private use, as a class of uses to which copyrighted works may be put, remains unresolved.

“H.R. Rep. No. 92-487, 92d Cong.. 1st sess. $2(1971)$ reads:
}

ing and electronics industries disagree over whether these comments apply to the 1976 revision. Proposed legislation, which would provide for "royalties' on blank tape, ${ }^{37}$ and exemptions for home-taping activities" are all predicated on the resolution of this policy issue, which existed since the time the photocopier was introduced over 20 years ago.

The issue of whether copyright is regulatory and governs only commercial entrepreneurs, or whether it is proprietary and controls the ultimate users of copyrighted works is still unsettled. A definitive answer will require congressional action. Whether, in deciding the issue, Congress wants to strike a new bargain will depend on a number of criteria, four of which are considered in the next part of this chapter.
Specifically, it is not the intent ion of theC'ommittee to restrain the home recording, from broadcasts or from tapes or records, of recorded performances, where the home recording is for private use and with not purpose of reproducing or otherwise capitalizing on it This practice is common and unrestrained today, and the record producers and performers would be in no different position from that of the owners of copyright in recorded musical composition over the past 20 y ears.

S.31 and H.R. 1030 (Sen. Mathias and Rep. Don Edwards), 98th Cong., lst sess.

S. 175 and H.R. 175 (Sen. DeConcini and Rep. Foley).98th Cong., 1st sess.

\section{THE INTELLECTUAL PROPERTY BARGAIN IN A NEW TECHNOLOGICAL CONTEXT}

Technology is transferring activities such as printing, publishing, reproducing, and modifying works from the commercial entrepreneur to the end user. As a result, policy questions are emerging about whether and how the copyright proprietor is to be remunerated for end user, or private use, activities. The private use of copyrighted works raises questions of how far the rights currently granted to the copyright proprietor should extend when new technologies change the context in which these rights operate. Because copyright law does not clearly extend to private use, Congress needs to consider whether it should, and if so, under what conditions. Whether copyright should extend to private use depends, in turn, on a number of criteria, including whether it causes harm to copyright proprietors, whether it would be economically efficient to extend rights, whether political support for an extension of rights exists, and whether access to information can be ensured.

\section{Private Use}

Private use of copyrighted works differs from commercial piracy in several ways. Private use is private, meaning that it is difficult, 
if not impossible, to detect, monitor, and control the use. ${ }^{39}$ Unlike commercial piracy, private use is not a commercial activity. The person who makes a copy of a television program or a magazine article does not ordinarily attempt to sell that copy. He is typically an end user of the information, and as such, does not compete commercially with the proprietor. However, as is discussed below, the aggregate economic effect of individuals' private use may be equivalent to what might occur with commercial piracy.

For puposes of this discussion we shall define private use as the unauthorized, uncompensated, noncommercial, and noncompetitive use of a copyrighted work by an individual who is a purchaser or user of that work. ${ }^{40}$ The "time shifting" videotaping involved in Sony Corp. v. Universal City Studios, ${ }^{41}$ the home recording of a piece of music, the copying of a magazine, a newspaper article, or a computer program might all be considered instances of private use. Private use may be occasional or insubstantial-as when a cartoon is photocopied (possibly infringing reproduction rights) and posted on an office door (possibly infringing display rights) -or it can be systematic and substantial-as when music "libraries" are built on blank tape (possibly infringing reproduction rights) and shared amongst friends (possibly infringing distribution rights) .42

Technology has fostered private use, and it will continue to expand individuals' capabilities to make private use of copyrighted materials. With each new application of technology,

\footnotetext{
${ }^{39}$ The difficulties of enforcing private use activities is discussed in ch. 6 on enforcement.

"'See Anne Branscomb, The Accommodation of Intellectual Property Law to the Introduction of New Technologies, OTA contract re ort, December 1984, discussed under the term"ersonal use. "It should be noted that "unauthorized" heredoes not mean "illegal" -it means without consent. "Noncompetitive" means that the fruits of private use are not sold commercially. Private use is also referred to as " rsonal use, " "private copyng, " "noncommercial use, " anp "home use."

${ }^{4}$ SONY Corp. v. Universal City Studios, 464 U.S. 417 (1984).

"The literal application of Section 106 of Title 17 would, subject to the application of fair use or exemptions, make any reproduction, derivation, dissemination, performance or display, regardless of its context, an infringement. It may well be that the new wave of technological uses, unlike the technologies of reprography and reproduction, would implicate each of these rights.
}

new forms of private use will occur. At present, these uses principally involve the copyright proprietor's right to reproduce the copyrighted work. ${ }^{43}$ The photocopier and the audio and videocassette player, for example, each enable users to reproduce information, and perhaps infringe the proprietor's reproduction right. As more information becomes distributed electronically and downloaded over networks, the issue of private use involving reproduction may become more complex. In the age of print, for example, a person could purchase a book, and read and re-read it as often as he pleased. When accessing information over a network, however, a person may need to reproduce a work tore-use it. Thus, conflicts may arise between proprietors and users requiring a policy decision about the rights people have in information they have purchased.

Private use involving reproduction rights may be only the beginning of private use issues. As inexpensive home computers become more prevalent, and as more information is stored in computer processible media, ${ }^{44}$ the proprietor's exclusive right to make derivative works may become an equally important issue. ${ }^{45}$ The extreme manipulability of digitally mediated information will allow individuals to reconstruct, enhance, and modify information to suit their taste or needs. This is already possible with computer programs, and may soon be feasible for music, video, and text. In the future, a user might enter the digital version of a song-perhaps stored in a medium similar to today's compact disk-into the memory of his computer. Once in the computer, he could subject the song to any number of modifications: he may take the vocals out and substitute them with his own; he may vary the pitch, rhythm, and melody; or he may add instruments. The issue will then be whether the copyright proprietor has the exclusive right to provide users with modified versions of his work. J ust as today's audiotaping potentially harms proprietors by displacing a sale (see below), so too might proprietors say that user derivation of their works deprives them of potential sales.

\footnotetext{
${ }_{44}^{43} 17$ U.S.C. $\$ 106(1)$.

See ch. 4 on enforcement.

"17 U.S.C. §§ IOI, 106(2).
} 
As computer networks proliferate, private use may assume other forms, and create issues involving the proprietor's exclusive rights to distribute, perform, or display the copyrighted work. ${ }^{46}$ If, for example, a user in a computer network sends copyrighted information to another network user, has he infringed the proprietor's right to distribute the work? If policymakers or the courts liken this sharing over networks to sending a book to a friend through the mail, they will find no infringement of copyright, and hence no issue of private use. If, instead, they compare it to a person photocopying and sending a book to a friend, they may find that the proprietor's copyright has been infringed. Whether private use is considered an illegal activity will often depend on the analogies that policy makers use.

New methods of distributing information, such as Cable Television, Satellite MasterAntenna Television (SMATV), Multichannel Multipoint Distribution Service (MMDS), and Direct Broadcast Satellites (DBS), augment the technologies for private use and exacerbate existing tensions with respect to it. ${ }^{47}$ In many cases, the communication issues created by the new distribution technologies are very similar to copyright issues involving private use.

The case of DBS and "satellite viewing rights' is one example. A recently enacted law allows people to sell and own receiving equipment, such as dish antennae, but requires them to pay a "reasonable" fee to program owners if a marketing system for collecting such fees has been set up. ${ }^{48}$ Although ostensibly a communications law, this prohibition of unauthorized reception is bound up with intellectual property issues, including private use. ${ }^{49} \mathrm{As}$

\footnotetext{
“17U.S.C. § 106(3),(4), (5).

"Although these communication technologies are presently used primarily for television, their application need not be so limited. Telephone signals, videotext, teletext, and data transmissions may eventually be routed through cable and satellite systems. Trudy Bell, "The New Television: Looking Behind the Tube,"IEEE Spectrum, September 1984.

"'Section 705 of the Communications Act (Section 5 of the Communications Policy Act).

"'Unauthorized reception of signals by an individual infringes none of the rights of the copyright holder. SMATV, which ties many receivers to a master antenna, may infringe the right to perform.
}

with activities such as home taping, the proprietors of DBS programming assert that the unauthorized and unremunerated reception of signals deprives them of revenue. Cable Television operators, who are the intended recipients of many of these satellite signals, also assert that unauthorized reception undermines their subscription system. Like private use, the satellite viewing rights issue also involves the balancing of compensation to proprietors with public access to the signals. ${ }^{50}$ Like private use, unauthorized reception is difficult to monitor and prove, and detection may raise privacy problems. ${ }^{51}$ Because of these similarities, much of the following analysis of private use applies with equal force to unauthorized reception.

\section{Private Use as Fair Use}

Fair use is a judicially developed doctrine, which originated in 1841 in the case of Folsom v. Marsh ${ }^{.52}$ Its purpose, like that of the copyright itself, is to benefit the public by facilitating the access to and dissemination of works. It is a "safety valve" for cases in which copyright law does not serve the public interest. ${ }^{53}$ In other words, fair use concerns those uses of a work that would be technically infringing, but for the fact that they themselves further the promotion of science and useful arts.

Fair use is not subject to precise definition. Which uses are fair will often depend on the particular circumstances of a case. For this reason, fair use is often called an "equitable rule of reason. ${ }^{154}$ Although Congress codified the

\footnotetext{
"S.1618 (Sen. Gore), "Satellite Viewing Rights Act of 1985, " for example, seeks to ensure access by limiting broadcaster discretion over distribution, pricing, price discrimination, and decoder availability.

"'"Short of Staking Out the Farmhouse, How Can Program Owners Prove That a Farmer Ripped Them Off? Answer: They Probably Can't. " Forbes, Nov. 5, 1984. Se also ch. 4 on enforcement.

${ }^{52} 9$ Fed. Cas. 342,246, No. 4,901 (C.C.D. Mass. 1841).

${ }^{53}$ In some cases, "courts in passing upon particular claims of infringement must occasionally subordinate the copyright holder's interest in a maximum financial return to the greater public interest in the development of art, science and industry. " Berlin v. E.C.Publications, Inc., 329 F.2d 541,544 (2d Cir. 1964).

"41 7 U.S.C. \$ 107; "Indeed, since the doctrine is an equitable rule of reason, no generally applicable defintion is possible, and each case raising the question must be decided on its own facts. " H.R. Rep. No. 94-1476 (1975).
} 
doctrine in the 1976 Copyright Act, it preferred not to define the term, and instead delegated its interpretation to the courts. Even the type of 'use" that falls under the term 'fair' in the statute was left unspecified by Congress, but a House Report says that such uses would "include" reproduction. ${ }^{55}$

Fair use is not, however, a tabula rasa. It is a defense to a claim of infringement that, if successful, negates a finding of infringement. ${ }^{56}$ Section 107 of the 1976 Copyright Act lists four factors that courts may consider in deciding whether a particular use is fair:

1. the purpose and character of the use, including whether such use is of a commercial nature or is for nonprofit educational purposes;

2. the nature of the copyrighted work;

3. the amount and substantiality of the portion used in relation to the copyrighted work as a whole; and

4. the effect of the use upon the potential market for or the value of the copyrighted work. ${ }^{57}$

Although the fair use factors are neither exhaustive nor determinative of the "fairness" of a particular use, they are nevertheless used by courts to balance the competing claims of learning and economic incentive. J udicial history is replete with interpretations of the fair use factors, and the types of activities that can be labeled fair use are well charted. The fair use doctrine has proven most difficult and controversial in cases of first impression, where the court must proceed with little or no guidance from prior rulings.

Despite its usefulness as a safety valve for copyright protection, the fair use doctrine may be an inappropriate mechanism for resolving the private use issue for a variety of reasons. First, and perhaps most important, the application of the fair use doctrine presupposes infringing conduct. Although legal scholars disagree about whether fair use excuses or negates

\footnotetext{
${ }^{55}$ Id. Arguably, fair use comes into play anytime there is an allegation of infringement of any of the exclusive rights in $\S 106$ of Title 17.

See n. 58

17 U.S.C. $\$ 107$.
}

a claim of infringement, it is clear that the defense of fair use is only relevant where infringement is alleged. ${ }^{58} \mathrm{~F}$ or instance, one need not claim that sharing a book with a friend is fair use, because sharing books is not infringing conduct under copyright law. Since neither the courts nor Congress has unequivocally determined that private use constitutes an infringement, the application of the fair use doctrine to private use may be premature.

Secondly, fair use is a tool used by the judiciary to resolve competing claims over the use of copyrighted works. However, the judiciary may be an inappropriate forum for addressing the private use issue. Private use is essentially a policy issue. It involves a determination of whether whole classes of activities, such as audio or video taping, should be considered infringements. It requires, moreover, an evaluation of who shall benefit, and how, from new technological uses, and whether copyright protection should extend beyond protecting commercial activities to protecting profits in markets that did not exist before the introduction of new technologies. However, the function of courts is not to make policy, but to interpret law. In recognition of this point, the Supreme Court stated in Sony v. Universal Studios, "it is not our job to apply laws that have not been written.

\footnotetext{
“'” Professor Nimmer seems to favor the latter interpretation (despite a substantial similarity of works, "the defendant is rendered immune from liability because the particular use which he has made of the plaintiff's material is a 'fair use. ' " Nimmer on Copyright, § 13.05 (1985)); as does Professor Goldstein ("[t]he effect of the fair use defense is to excuse otherwise infringing conduct in circumstances where the public interest compels free access " Goldstein, "Copyright and the First Amendment, 70 Columbia Law Review 1011 (1970)). Messers Kaplan ("policy runs throughout our subject . . . it would, I think, be possible to dispense with it (fair use) in relation to (infringement). " Kaplan, An Unhurried View of Copyright (New York and London: Columbia University Press, 1967), pp. 69-70 and Seltzer ("[f]air use. .. has to do with whether a particular cost-free use is one both foreseen by the author and contemplated by the Constitution." Seltzer, Exemptions and Fair Use in Copyright, (Cambridge and London: Harvard University Press, 1978), p. 29 seem to favor the former. For purposes of this discussion, the matter may be academic, since the fair use defense arises only in cases where a claim of infringement is made.

"Sony Corp. v. Universal City Studios, 464 U.S. 417 (1984). For a discussion of the institutional reasons why the courts may not be best suited to deal with these issue, see ch. 9 .
} 
Moreover, because fair use evolved in a commercial context, the fair use doctrine may simply be inapplicable to private use activities. Traditionally, fair use has been limited to cases in which a copyrighted work was used in the production of yet another work.$^{60}$ The use of a work for its own sake-for intrinsic purposes-has traditionally fallen outside of the fair use doctrine. The reason for this interpretation had to do with the very purpose of copyright: the promotion of learning. ${ }^{61}$ Without some "give" in the exclusive rights of an author to his or her work, other authors might be thwarted in their ability to make contributions to the public good by way of "criticism, comment, news reporting, teaching, scholarship or research." ${ }^{162}$ Fair use, then, does not shield every ostensibly infringing use of a work, only those justified by the very purpose of copyright itself.

F air use evolved in the context of print era technologies, and was designed to resolve the tensions between an author and others making use of his work. Typically, the doctrine was invoked by an author who wanted to use portions of another's work. Thus, it was aimed primarily at the resolution of tensions between copyright interests, broadly construed to include those activities for the promotion of learning. The emergence of reprographic technology, however, created a new and uncertain context for fair use. For the first time, it was end users and not competing authors who invoked the doctrine, seeking to use material for its intrinsic purposes. ${ }^{63}$ Thus, fair use was

\footnotetext{
"Fair use "has always had to do with the use by a second author of a first author's work. Leon Seltzer, Exemptions and Fair Usein Copyright. p. 24. This principle, termed "productive use" by the Circuit Court in Universal City Studios, Inc. v. Sony Corp., 659 F.2d 963 (9th Cir. 1981 ), rev 'd, 464 U.S. 417 1 1984)104 S. Ct. 774 ( 1984), was rejected as a sole criterion by the Supreme Court majority in the Sony case, but the rejection has no support in prior case law. Indeed, in a study prepared by Alan Latman for the Senate Committee on the J udiciary, Copyright Law Revision, Subcommittee on Patents, Trade marks, and Copyrights. 86th Cong. . 2d sess., 1 (1960), not a case was found upholding the fair use defense in the instance of intrinsic, private use.

" See: Patterson, Copyright and New Technology: The I mpact on the Law of Privacy, Antitrust, and Fre Spech, OTA contract report, 1985 .

'-17 U.S. c. $\$ 107$

"Y\{illiams \&Wilkins Co, v. United States, 487 F.2d 1345 (Ct. Cl. 1973), aff'd, 420 U.S. 376 (1975).
}

called on to resolve extra-copyright claims between proprietors and end users.

To decide the issue of reprography, the courts drew an analogy between photocopying and making a handwritten copy of the work for private consumption. Photocopying was regarded as merely a more efficient way of doing the same thing as hand copying, and as such, was not considered to be an infringement. ${ }^{64} \mathrm{Al}$ though similar in principle, the analogy between hand and photocopying soon breaks down, however. For, precisely because photocopying is more efficient than hand copying, its potential to cause economic harm is much greater. ${ }^{65}$ This is the problem of harm in the aggregate, a problem that becomes more troublesome as technology continues to improve the efficiency of private copying.

In addressing the private use issue to which the new technologies give rise, the fair use doctrine, as we have seen, is of limited value. Instead, policy makers will need to decide the issues on the basis of value judgments about who should benefit from the new uses that technology creates-proprietors or private users. The four criteria discussed below may serve as the basis for such a discussion.

\section{The Criterion of Economic Harm}

Within the copyright community, many people argue that private use damages the copyright proprietor economically by displacing potential sales and thus profits. This argument, founded on an interpretation of existing law and on economic analyses of harm, presup-

\footnotetext{
"The legal status of hand-copying for personal use is not known. Nimmer reports that "[t]here is no reported case on the question of whether a single handwritten copy of all or substantially all of a book or other protected work made fort he copier's own private use is an infringement or fair use, "Nimmer on Cop>Tright $\$ 13.05[\mathrm{E}]$, but the Williams and Wilkins case states that "... it is almost unanimously accepted that a scholar can make a handwritten copy of an entire copyrighted article for his own use. .." 487 F.2d at p. 1350. "[A]nyway," says Professor Kaplan, " it was a question no one would be interested to litigate,"' op. cit. p. 68.

6i" "Few people hand copy, but millions find machine copying economical and convenient. . . . (the argument) fails to take into account the true economic effect when thousands of individual decisions are aggregated." "New Technology and the Law of Copyright, " 15 U.C.L.A. Law Review 931, 951 (1968). Whether such deleterious economic effects exist is uncertain (see ch. 4).
} 
poses the existence of a right to profit on private use. ${ }^{66}$ Such a right, however, does not clearly exist. Instead, policymaker have yet decide to what uses the proprietors' exclusive rights should extend. In doing so, they may want to take the economic consequences of private use into account. They should also note that assertions that private use causes economic damages presupposes the transgression of a legal right, and cannot, therefore, be the foundation of that right.

One of the difficulties of using economic harm as a criterion for determining the issue of private use is that the economic consequences of new technological uses vary significantly according to the type of use, the type of work, and the marketing adaptations that copyright proprietors make to accommodate that use. Moreover, technologies that permit copying can either harm or benefit both proprietors and users, depending on several empirically determined factors: the costs of production and distribution, the behavior of producers and consumers in the absence of unauthorized copying, and the effects of copying on subsequent purchasing behavior. Using harm as a criterion for determining rights in new technological uses would require, therefore, the compilation and analysis of a significant amount of information.

It is not surprising, therefore, that not all of those involved in the intellectual property debate agree that harm should be used as a basis to determine rights. David Ladd, a former Register of Copyrights, for example, argues that to require a showing of harm in order to secure protection would inevitably prejudice the interests of proprietors, since such a showing is difficult in any event, and it assumes that a neutral observer could determine what "fair" compensation is for new technological uses. ${ }^{67}$ Others, however, suggest that a heavy

\footnotetext{
'N otwithstanding those uses which are fair uses, or which are exempt or not covered by the act.

"Mr. David Ladd, from a speech, "Seven Years of the New Copyright Act, " sponsored by the American Bar Association Forum Committee on the Entertainent and Sports Industries, Section on Patent, Trademark and Copyright Law, Washington, DC, Oct. 26-27, 1984. Some have also argued that since Section 504(c) of the Copyright Act permits a court to, in its
}

burden of proof for extending rights to new areas and showing harm should lie on those seeking proprietary rights. David Lange would have the proponent of a new right prove not only that it would make him more secure economically, but that the public domain would ultimately be enhanced by the extension of existing or new rights to the new uses. ${ }^{68}$ The Supreme Court, in Sony Corp. v. Universal City Studios, proposes yet a different standard:

... [a] challenge to a non-commercial use of a copyrighted work requires proof either that the particular use is harmful, or that if it should become widespread, it would adversely affect the potential market for the copyrighted work. ${ }^{69}$

The use of harm as a criterion is made even more difficult by the fact that the concept has no clear qualitative definition. Rights define harm. Where there is no right, there may be economic consequences, but not harm. If, for example, a person wished to charge money every time his name was uttered in public, he would need a right to do so. If his claim to remuneration went uncompensated, he might be said to suffer economic consequences (he would not receive money), but in lieu of a right to receive money, one would hesitate to say he had been harmed. Harm to intellectual property owners therefore hinges on how policymakers define the proprietors' rights, but new technologies have made the application of rights to new contexts ambiguous.

Notwithstanding these difficulties, OTA found that a calculation of harm is unavoidable in instances where new technology rearranges the relationships between proprietors and the public. Because intellectual property

discretion, award statutory damages in lieu of actual damages for willful infringement, the issue of harm is irrelevant to infringement. This argument, however, is not entirely germane to the policy issue of whether a right should be granted or extended in the first place, and assumes that a fair use defense is unsuccessful.

'Statement of Professor David Lange, Duke University School of Law, Hearings Before the Subcommittee on Courts, Civil Liberties, and the Administration of J ustice of the Committee on the J udiciary, House of Representatives, 98th Cong., 1st sess., J uly 20 and 21, 1983.

“Sony Corp. v. Universal City Studios, 464 U.S. 417 (1984). 
law itself serves to compensate for market failure in the production or dissemination of a public good, ${ }^{70}$ and because the allocation and strength of rights determines who and what will be compensated, the question of harm cannot be dispensed with. ${ }^{71}$ Moreover, in the absence of clearly defined rights to new uses, ${ }^{72}$ it is still possible to distinguish between at least two different types of claims to harm in intellectual property: actual harm and potential harm.

Actual harm occurs when there is a reduction in the profits of the producer below their level prior to a new unauthorized use. ${ }^{73}$ Actual harm does not occur, however, if the unauthorized use leaves profits from all previous uses unaffected. ${ }^{74}$ The criterion of actual harm looks to whether new uses made available by technology compete with proprietors' preexisting economic interests. For example:

Ž if a commercial broadcaster's programs are taped off-air by a viewer, and the broadcaster's advertising revenues from that program do not decline, the broadcaster has suffered no actual harm; ${ }^{75}$

- if a radio broadcaster or cable company transmits a long-playing album to an audience, and the audience avoids purchas-

\footnotetext{
"'For a discussion of market failure, see ch. 6 .

"Moreover, copyright law-through the vehicle of the Copyright Royalty Tribunal-is al ready determining what constitutes a "fair return' to creators and 'fair income' to users under two of the compulsory licensing provisions of the act. 17 U.S.C. $\$ 801(\mathrm{~b})(1)(\mathrm{A})$, governing the objectives of rates under Sections 115 and 116. In addition, bills submitted in the 98th Congress (S.31 and H. R.1030), which deal indirectly with the issue of private use by imposing a' 'compulsory license' on purchasers of video and audio equipment and tape, would have an arbitration board determine "the projected impact of home video recording on copyright owners. The 'compulsory license' created by these bills differs from any previous compulsory license. Formerly, compulsory licenses were imposed on the copyright owner for the benefit of competitors; the bills would impose a compulsory license on the user for the benefit of the copyright owner. Patterson, Copyright and New Technologies.

${ }^{72}$ The analysis of harm that follows is, in other words, based on the assumption that the proprietor's exclusive rights under $\$ 106$ of Title 17 do not clearly apply to private use.

Besen, op. cit., p. 46.

it Ibid.

"Even though the copyright holder's right to reproduce the work may have been infringed.
}

ing the album by taping it off-air, the proprietor has suffered actual harm; ${ }^{76}$

- if a purchaser of a computer program runs that program simultaneously on several machines, no actual harm has occurred; ${ }^{77}$

- if the purchaser of a computer program modifies the program to run more efficiently, the copyright proprietor of the unmodified program has suffered no actual harm; ${ }^{78}$ and

- if a SMATV system is set up in a hotel to receive commercial broadcasts and distribute them to the hotel rooms, no actual harm has occurred. ${ }^{79}$

Actual harm cannot be presumed on the basis of infringement-it is a thoroughly empirical measurement. The same standard of measuring actual harm can be used regardless of the technology involved: if a new technologically based use causes a reduction in profits by substituting for previous uses, then actual harm is present. Causation, however, is not always easy to establish, even with empirical data available, since mere correlation (e.g., declining sales in the presence of a new use) is not tantamount to causation (e.g., the substitution of a new use for a previous one).

The second type of harm is potential harm, where harm occurs if the new use reduces profits below the level they would have reached had the producer been able to exploit the market served without authorization.$^{80}$ In other words, potential harm arises where a proprietor could have and would have been able to supply the product and receive compensation. Unlike actual harm, potential harm occurs even if existing markets are unaffected.

\footnotetext{
"N ote that the copyright owner of the sound recording has no performance right, and a broadcast of sound recordings is not an infringement, even though the broadcast may be taped. The end-user's taping may be an infringement, but this is uncertain.

"Technically, loading programs into several machines may be an infringement of the reproduction right, but this is uncertain under Section 117 of the Copyright Act.

${ }^{78}$ The modification of the program is probably an infringement of the proprietor's right to prepare derivative works, unless allowed by Section 117.

"This conduct may be in violation of Section 705 of the Communications Act.

"'Besen, op. cit., p. 46.
} 
Claims of potential harm are based on a right to the new opportunities provided by technology. In a potential harm situation, proprietors and users have competing claims to the value of the new use. To the copyright proprietor, these new opportunities represent new and profitable markets. To the copyright user, the opportunities provide enhanced flexibility, widespread availability and inexpensive access.

Arguments based on an analysis of harm presume-and so cannot be the basis of-a proprietary right in the new opportunities for use. ${ }^{81}$ Potential harm, therefore, cannot in and of itself justify the extension of a right. Instead, some other criterion, such as an increase in efficiency or access (see below), is needed in order to determine whether to extend a right to new uses.

Like actual harm situations, potential harm can take many different forms and appeal to many different rights:

- An unauthorized off-air videotape of a subscription television motion picture is made by a consumer. The proprietor of the motion picture has suffered potential harm if the consumer could have and would have purchased the motion picture from the proprietor-or if the consumer could have and would have paid for the right to make an authorized videotape of the motion picture. $^{82}$

- A computer program designed to run in BASIC computer language is translated, without authorization, by a user to run in FORTRAN. The author of the program has suffered potential harm if the user could have and would have purchased a translated version of the program from the author.

- A user of an on-line database downloads, without authorization, the entire text of

\footnotetext{
"To predicate a proprietary right on a potential harm analysis is circular: $X$ is harmed because $X$ has a right to the new use and $X$ has a right to the new use because $X$ is harmed.

"'Note that in this scenario, potential harm exists even though the conduct may be entirely legal.
}

an article. The user thereafter consults the article at his leisure. Database articles are normally paid for on a "pay per use" basis. The proprietor has suffered potential harm if the user could have and would have paid for each use.

- A television station broadcasts its news stories and shortly thereafter erases the videotapes on which they are fixed. A business videotapes the news programs offair, and later sells copies of the tapes to interested parties. The news program has suffered no potential harm, since interested parties could not have purchased the tapes from the television station. ${ }^{83}$

The criterion of potential harm makes intellectual property rights considerably more powerful than that of actual harm. This added strength of rights under a theory of potential harm stems from the fact that the potential uses to which a work can be put are unlimited in number and variety. Once the criterion of potential harm is accepted, its amount is limited in principle only by the activities covered by intellectual property rights. So long as a case can be made that a user could have and would have ${ }^{84}$ remunerated the proprietor for the use, all conceivable uses that infringe a right could be said to cause potential harm.

Potential harm, however, is not an easy case to make. Empirical studies of the potential harm done to proprietors all suffer from a basic methodological shortcoming: they do not clearly describe the behavior of either consumers or producers in the absence of private use. ${ }^{85}$ The assertion that consumers "would have" purchased an original in the absence of private use

\footnotetext{
${ }^{\times 3}$ See: Duncan v. Pacific and Southern, 744 F.2d 1490 (11) th Cir. 1984), cert. denied, 105 S. Ct. 1867.

"Note that even "would have and could have" suffers from definitional ambiguity. "Would have" can refer to a subjective disposition of the user to buy in the absence of an ability to copy (a most difficult item of proof), or to the collective economic behavior of the market in the absence of copying (it is the latter of these that Besen uses in his resolution of the problem of indeterminacy (see below)). "Could have" can refer to either the financial ability of the user to buy in the absence of copying (calculated either individually or in the aggregate) or to the availability of an original (problematic in the case of television broadcasts).

${ }^{*}$ See Besen, op. cit.,pp 52-54.
} 
depends on what the price of the original would have been in the absence of private use. But by the same token, the price of the original cannot be determined until the behavior of consumers in the absence of copying is known, The harm done to producers by private use is therefore indeterminate."

The situation is even more complicated when no copy (i. e., no original tangible object) is available-as is the case with television and radio broadcasts, tel etext and videotext, and on-line databases. In these instances, the allegedly infringing copy is often not a substitute for the sale of an original, since the original is seldom sold in copies (i. e., published or distributed). The copyright holder must then use other empirical criteria to demonstrate harm-i. e., the user would have and could have made further use of, or further access to, the ephemeral copyrighted work. It should be noted, moreover, that works disseminated over electronic media, instead of in copies, also raise questions of access. This issue is discussed below.

Most estimates of harm to producers of intellectual property are based on surveys of user practices, in combination with data on sales and the costs of production. However, a consideration of the beneficial effects of new technological uses to either new or existing mar-

\footnotetext{
"To know what consumer behavior "would have been, " one must determine price in the absence of private use; but price is itself partially depend ant on consumer behavior. A model for estimating harm that may account for this indeterminacy has been suggested, but has not yet been used in any empirical study of harm.

In order to estimate the effect of copying. it is necessary to de termine what would have been the situation if copying had not occurred. the determination of a counterfactual. The technique is to 'calibrate' the model. using data on the number of copies made per original, the cost of copying, the cost of producing originals, the number of originals sold, and the price being charged for originals $m$ the absence of copying. The intercept of the demand curve can be determined using data on the price of originals, the costs of producing originals and copies, and the number of copies per original. The intercept, together with the cost of originals, can then be employed to dererminetsic; in original) the price of originals that would have prevailed if there were no copying. With data on the number of originals sold, the estimated intercept of the demand curve, and the number of copies per original, the slope of the demand curve for originals can be calculated. Together wit $\mathrm{h}$ information on the cost of producing originals, the market equilibrium that would have existed in the absence of copying can he estimated.

Besen, op. cit., pp. 54-55.
}

kets for intellectual property is often absent from such estimates. Although the videocassette recorder may give rise to copying, it also permits the exploitation of markets that would otherwise not exist. Both factors must be taken into account in considering harm. The policymaker is ther efore still left with a decision over who will benefit from new technological uses, and for what reasons.

To make such decisions, Congress may itself need to gather timely and accurate data on harm. Existing surveys vary considerably, and rapid changes in technologies and use make previous surveys of harm increasingly less relevant. Conducted by parties involved in the intellectual property debate, most of the surveys that are available are, moreover, subject to bias.

The discrepancies in previous analyses are clearly illustrated in a sampling of principle findings of surveys conducted over the last 10 years, listed below. Because these surveys often focused on a unique product or geographical market, and because each employed different methods of research and presentation, no attempt has been made to list them in a comparable form.

Survey Sponsor: Recording Industry Association of America (RIAA)

Year: 1983 ffor sales year 1982)

Domain: audiocassette taping

Conducted by: Greenspan

Principal Findings;

- Overall, more than two-fifths of home taping was in lieu of the purchase of prerecorded records and tapes, representing lost sales of approximately 32 percent, or about $\$ 1$ billion out of a total of $\$ 3.2$ billion in actual sales. This sales displacement is said to have depressed all record sales by 5 percent, bringing total losses from home taping to $\$ 1.4$ billion. In particular, the study found that:

-Approximately 50 percent of taped, borrowed records or tapes "would have generated" purchases of originals, if no taping had occurred.

-F orty-two percent of taping from owned records "would have resulted' in purchases of additional records and tapes, if no taping had occurred. 
-Forty percent of all off-air taping "would have generated" record and tape purchases.

Survey Sponsor: Motion Picture Association of America (MPAA)

Year: 1983 (for sales year 1982)

Domain: videocassette taping

Conducted by: Battelle Pacific Northwest

Principal Findings:

- Tape-to-tape copying: If no blank videocassettes were sold, the market for prerecorded videocassettes would approximately double (by inference, lost sales due to tape-to-tape copying). Using this figure, lost sales for 1982 would be about 1.1 million units, or about \$11 million in royalties (based on a $\$ 10$ per unit royalty rate). Projections for 1990 , using the same assumptions, amount to approximately 11.2 million units lost sales, or \$112.4 million in lost royalties

- Off-m-r taping: The survey predicts that prerecorded videocassette sales would again approximately double, were there no off-air taping from television. Using this result, they estimate royalties lost in 1982 of approximately $\$ 26.9$ million for commercial television, and approximately $\$ 19,3$ million for pay television. Comparable estimates for 1990 are $\$ 273.7$ million and \$196.7 million, respectively, for commercial and pay television.

Survey Sponsor: International Federation of Phonogram and Videogram Producers (IFPI)

Year: 1979

Domain: video and audio cassette taping (United Kingdom)

Conducted by: G. Davies

Principal Findings:

-Audiotaping In 1979, approximately 280 million LPs had been copied. Approximately 25 percent of these copies replace retail sales, resulting in lost sales of approximately $\$ 622$ million-or the equivalent of 70 percent of the value of retail sales in 1979.

- Videotaping A' 'tentative estimate' of losses to the video industry of $\$ 24$ million at the retail level, and $\$ 9$ million to the copyright holders. (No details of methodology provided.)

Survey Sponsor: British Phonograph Industry Year: 1973, 1975, 1977

Domain: audiocassette taping (United Kingdom) Conducted by: Anna, Impey, Morrish \& Partners (AIM)
Principle Findings:

- Loss estimates based on the length of time of music taped in-home correlated with the LP equivalent-hours were used. . .

- ... in combination with a survey of whether consumers would have purchased if not for taping. This yielded a loss sales estimate of between $f 63$ and $£ 98$ million.

- .... in combination with estimates of the proportion of blank tape used for home taping and with the above survey. This produced a loss sales estimate of between $£ 90$ and f 139.5 million.

- ... a third estimate based on a comparison between actual sales and projected sales (using data from 1972 to 1974) produced an estimate of lost sales of $f 85$ million.

Survey Sponsor: National Music Publishers Association (NMPA) and Recording Industry Association of America (RIAA)

Year: 1982

Domain: audiocassette taping

Conducted by: Roper Organization

Principle Findings:

- Based on a survey of people who taped at home from any source, in which the respondents were asked how many records and tapes they saved buying as a result of taping. The survey revealed that 90 percent of everything taped from other than respondents' own collections would have been purchased if not taped at home. This translates into 268 million albums and 213 singles. Roper ultimately accepted a potential sales loss of 14 percent.

Survey Sponsor: Audio Recording Rights Coalition Year: 1982

Domain: audiocassette taping

Conducted by: Yankelovich, Skelly \& White, Inc. Principal Findings:

- This survey-unlike others-concerned primarily audiocassette taping practices and the reasons cited for those practices, rather than estimates of harm done by audio taping. Among the major findings were:

-Seventy percent of the respondents recorded primarily to construct their own program selections, rather than to avoid paying for prerecorded selections. From 1 to 3 percent cite cost as the only reason for home taping. -Seventy-five percent tape for reasons of portability; 51 percent cite quality; and 57 percent cite convenience. 
-Fifty-two percent of all audiotaping was of something other than prerecorded music. Fifty-one percent of tapes were made from respondents's own selections.

- "Heavy tapers" owned approximately three times as many prerecorded selections (which, according to the survey, indicates that taping stimulates purchases).

Survey Sponsor: Recording Industry Association of America (RIAA)

Year: 1983

Domain: audiocassette taping

Conducted by: Audits and Surveys

Principal Findings:

-Americans tape the equivalent of 564 million albums of music annually, resulting in lost sales of 325 million albums. Non-copyrighted materials accounted for 302 million album equivalents.

- Only 7 percent of retail purchases of prerecorded tapes are stimulated by taping.

- Eighty-four percent of blank tapes are used to record prerecorded music,

Survey Sponsor: Warner Communications, Inc.

Year: 1981 (1980 Survey Year)

Domain: audiocassette taping

Conducted by: M. Kapp, S. Middlestadt, and M.

Fishbein

Principal Findings:

- A "conservative estimate' the total value of home-taped music is $\$ 2858.5$ million.

- Seventy-five percent of all blank tapes purchased were ultimately used to record music. Consumers spent $\$ 609$ million for blank audio tape for the purpose of recording music or other professional entertainment

- Twenty-five percent of all home tapers taped in order to avoid buying prerecorded music.

Survey Sponsor: CBS Records

Year: 1980 (1979-80 Survey Year)

Domain: audiocassette taping

Conducted by: CBS Records Market Research

Principal Findings:

- Audiocassette taping costs the prerecorded music industry 100 million units annuallyor lost sales of $\$ 700$ to $\$ 800$ million.

- Seventy-five percent of home tapers tape in order to "customize" tape selections,

- Fifty-five percent of home tapers tape in order to save money. Twenty-five percent cite "better quality" as the reason for taping.
- Forty percent of consumers tape from their own records or tapes, and 30 percent tape from borrowed records or tapes. An additional 20 percent tape from radio broadcasts.

Survey Sponsor: The Association of Data Processing Service Organizations (ADAPSO)

Year: 1985 (Survey Year 1984)

Domain: Computer Software

Conducted by: Future Computing, Inc.

Principal Findings:

- Fifty percent of all programs (database programs, spreadsheet/accounting programs, and word processing programs) are unauthorized copies. (No distinction made between legal "backup" copies authorized by 17 U.S.C. $\S 117$ and other copies).

- Estimated loss revenues in 1985 were $\$ 800$ million.

\section{The Criterion of Efficiency}

Another criterion for determining rights in private use is that of efficiency: does private use either hinder or promote an economically efficient market for particular types of information-based products or services. ${ }^{87}$ The term "efficiency" assumes that the welfare of producers and users will both be simultaneously maximized. It is a relevant criterion, therefore, because the intellectual property bargain also assumes that the interests of the public and the author coincide. Like harm, however, efficiency is hard to determine. Depending on the particular market for the type of information that is being produced and on the costs of transactions in these markets, uncompensated use may either increase, decrease, or have no effect on efficiency. The problem of determining efficiency is made more difficult by the fact that, as the previous chapter points out, information markets are subject to market failures, and our understanding of, and knowledge about, these markets is still quite limited.

\footnotetext{
${ }^{* 7}$ A market is economically efficient when the cost of producing an additional unit of a good equals the value of that unit to consumers. An economically efficient market maximizes the welfare of both the producers and consumers of information, and allocates resources to their most valued use. These concepts, as they apply to information markets, are discussed in greater detail in ch. 6 .
} 
Using efficiency as a criterion for allocating rights, policymakers might extend proprietors rights to private use so as to allow them to recover income equal to the value of private use to consumers. Under ideal market conditions, the producer would then be able to invest this additional income in more information products, and the market would receive the signal it needs to identify and supply consumer demand. Consumers would also benefit from the resulting increase in productivity and from a market that was attuned to their preferences.

In the case of information markets that are not ideal, however, the criterion of efficiency is more difficult to apply. Because information is a public good, it does not operate efficiently in the marketplace. Hence, it is impossible to determine precisely at what point rights to private use would maximize the joint welfare of users and producers. ${ }^{88}$

The costs of transactions in information impedes efficiency, and thus greatly complicates this problem. The user's need to obtain clearance and pay for use, and the producer's need to monitor use and obtain payment may offset the actual value of the use to the user, or the income to the provider. Transactions costs may be reduced through the formation of collecting societies (for example, Copyright Clearance Center), or by compulsory licenses administered through a governmental or nongovernmental agency (such as The Copyright Royalty Tribunal). In these arenas, outcomes often have less to do with efficiency than with the extent of the resources that stakeholders can bring to bear.

\footnotetext{
${ }^{88} \mathrm{~F}$ or example, if all consumers pay the same rate to download from a database, those who value the use at less than that price will be unwilling to purchase it. This is inefficient since there are no additional costs to serving these consumers, At the same time, consumers who value the use at more than the market price contribute less to its production and distribution than its value to them. This, too, is inefficient, because the value placed on the use by the consumer is not reflected in the price that he is charged. In the absence of an ability to price discriminate between users based on value, a market based on legal rights to private use is unlikely to be efficient. In other words, it is impossible to determine whether rights to private use would simultaneously maximize the welfare of both producers and users of information.
}

Determining efficiency in the granting of intellectual property rights will become even more troublesome as new technologies allow individuals not just to copy, but to reprocess information in their homes. In effect, private use will take the form of derivative use. And, as in all cases of derivative use, policy makers will find it difficult to use efficiency as a criterion for determining rights. For they will not be able to anticipate all future uses to which a work might be put, or the values that might be attached to them.

Unable to establish an efficient level of rights, policy makers may want to leave some leeway for unremunerated private use. In the absence of clear evidence to the contrary, flexibility may be the best way to encourage the greatest variety of works and those that are best suited to individual needs. In this way, if they err, it will be on the side of creativity.

\section{Access as a Criterion}

One criterion that will have to be used in resolving issues surrounding private use is access. This criterion differs from efficiency or harm in one important respect: the right to access is part of the constitutional bargain. Moreover, unlike the other criteria, access is not hard to define or measure. Rather, the problem for policymakers in an electronic era is in establishing rules that will continue to provide access to information.

Problems of access can arise, for example, when copyright protection is extended to information that is communicated through a means other than publication- e.g., television, teletext and videotext, and computer networks. The access problem occurs because electronic dissemination-unlike printing-does not involve the publication of copies. As a consequence, copyright ownership is transformed from the right to reproduce a copyrighted work in copies for sale to the right to control access to the copyrighted work for any reason. ${ }^{89}$ Thus, when copyright is applied to works that are

\footnotetext{
"This potential was articulated by L. Ray Patterson, Copyright and New Technology: The Impact of the Law of Privacy, Antitrust and Free Speech, OTA contract report, 1984.
} 
electronically disseminated, the balance between the rights held by the proprietor and those retained by the public is changed. This problem of access can best be seen by contrasting what happens when works are disseminated by print and electronic technology.

Dissemination by Print. Copyright law, from the Statute of Anne in 1710 to the Copyright Act of 1976, has adopted the technological paradigm of printing - the distribution of a work in copies for sale-as its underlying conceptual paradigm. 90 Indeed, until the invention of radio around 1900 and television in about 1928, no other form of dissemination was possible; copyrighted works were always found in printed copies. $^{91}$

Until the Copyright Act of 1976, copyright protection was conditional on publication. That is, unless the work was available to the public in copies, it did not receive statutory copyright protection. ${ }^{92}$ Common law protection was available for unpublished works, but Federal law required that, if statutory protection was sought, the author's discretion over whether to publish was relinquished. ${ }^{93}$ The 1976 act abolished this requirement, replacing it with the principle of "automatic copyright '-that is, copyright now subsists from the moment

\footnotetext{
"ItThe Statute of Anne was concerned exclusively with books, since the printing press was the only "information technology" then in existence. The Statute is prefaced by this phrase: "An Act for the Encouragement of Learning, by Vesting the Copies of Printed Books in the Authors or Purchasers of such Copies, during the Times therein mentioned. "8 Ame C. 19(1710) (underline added). The Statute contemplated that the only method for distributing information was in books.

The 1909 Act predicated copyright protection on publication of a work in copies. Former Title 17 U.S. C. $\$ 10$ ).

Similarly, the Copyright Act of 1976 contemplates the distribution and publication of a work in copies, 17 U.S.C. $\$ \$ 106$, 101 , and the formal requirements of $\square$ otice $(\$ \$ 401-406)$ and deposit (\$407) are also based on publication.

"A copy is the material object in which a work is fixed; it is, for example, the printed and bound version of the literary work Gravity 's Rainbow, or the exposed strip of celluloid in which the work known as Citizen Kane is fixed. For sound recordings, the material object is referred to as a "phonorecord " 17 U.S.C. $\$ 101$

"'section 10 of the 1909 act required publication of the work with notice as a condition of copyright. An exception to this rule was found in Section 12, concerning works, such as motion pictures or statuary, which are not normally reproduced for sale (published), but performed or exhibited in public.
}

${ }^{y 3} 17$ U. SC. $\$ \$ 2,10$ (repealed). the work is created and fixed in a tangible medium. ${ }^{94}$

Where a work is sold in copies, a proprietor's control over these copies (but not the copyright) ceases after they are sold.${ }^{95}$ This is known as the first sale doctrine and it permits a purchaser of a copy of work to lend, sell, or freely reuse that copy without authorization from the proprietor. Once a copy enters the public arena, its presence there is permanent and uncontrolled; determining who sees the copy, for how long, and under what conditions are not the prerogatives of the proprietor. Copyright control extends to the first sale of the copy, ${ }^{96}$ after which efforts to control distribution or price are prohibited by law. In print publishing, the proprietor does not control the conduits through which the public has access to a work-or, if he does, the control was not based on copyright. Thus, a publisher's effort to maintain the retail prices of its books was rejected as counter to the first sale doctrine. ${ }^{97} E$ ven when the copyright owner does not exercise his right to vend the work, and instead licenses its use, attempts to maintain prices or control performance of work sometimes may run afoul of antitrust laws. ${ }^{98}$

Under a print system, the legal rights are also limited to control over the first sale of a copy. Property rights in the intangible "work," such as a literary work, do not extend to the tangible "thing," such as a book, in which the information is embodied. The public access to a copyrighted work - the number and variety of conduits through which copies of a work can be obtained and the ability to use and dispose of the copy freely-is thus guaranteed under a print system requiring publication as a con-

\footnotetext{
${ }^{94}$ Sections 102 and 302 of Title 17. The act also preempted commonlaw copyright.

${ }^{95}$ This principle is known as the doctrine of first sale. See: 17 U.S.C. $\$ 109$ (formerly $\$ 27$ ). Under the first sale doctrine, copyright permits no restraints on the alienation of a copy.

'F ormer Title 17 U.S.C. \$27, the first codification of the "first sale doctrine."

${ }^{97}$ Bobbs-Merrill Co. v.Straus, 210 U.S. 339 (1908); See also: Scribner v. Straus, 210 U.S. 352 (1908) and Straus v. American Publisher's Association, 231 U.S. 192 (1913),

"'E.g., Interstate Circuit, Inc. v. United States, 306 U.S. 208 (1939) and United States v. Paramount Pictures, Inc., 334 Us. 131 (1947).
} 
dition of protection. The bargain between author and public is built into the law, and assumes the dissemination of a work in copies.

Electronic Dissemination: A New Copyright Milieu. While the system of print publication may to an extent still reflect reality, it has in recent years been largely superseded by a new system of dissemination. ${ }^{99}$ For purposes of this discussion, we will refer to the new system as electronic dissemination, ${ }^{100}$ and define it as the transmission of information in the form of electronic signals. Under this system, a work is communicated, rather than distributed. In other words, the work is disseminated in an intangible, rather than tangible, medium. ${ }^{101}$ Hence, novels and newspapers, which have traditionally been distributed in print on paper, may now be stored and delivered electronically. ${ }^{102}$ The last vestiges of information as a

\footnotetext{
${ }^{99}$ As I thiel de Sola Pool observes:

The nonprint media are not just passing the print media (in terms of the amount of information as measured by the number of words), but are for the first time showing signs of displacing them in part.
}

Ithiel DeSola Pool, Technologies of Freedom, (Cambridge, MA: Belknap Press, 1983), p.20.

"'"The word "dissemination" is used in place of either "distribution" or "publication." The latter are terms of art having a unique legal denotation. Under the Copyright Act, " 'publication" is the distribution of copies or phonorecords of a work, 17 U.S.C. $\$ 101$, and "distribution" occurs by offering copies or phonorecords of the work for sale or other transfer of ownership, 17 U.S. C. $\$ 106(3)$. Both terms are predicated on the notion of a copy-the material object in which the work is fixed. 17 U.S.C. $\$ 101$.

'("Electronic dissemination can be said to be an intangible medium for a number of reasons:

1. electrons, el ectromagnetic waves or photons are transient (for our purposes these can be considered the same phenomena); they disappear when their energy stimulus is turned off. On a high speed telecommunications circuit they appear and disappear as rapidly as 10 billion times each second;

2. without a receiving devise of some kind, the transmission is for all practical purposes, non-existent; and

3. unlike physical media (disks, tapes, film), wire or other transmission does not lend itself to physical controls (such as a locked box).

From Solomon, "Intellectual Property and the New ComputerBased Media, " OTA contractor paper, p.8.

${ }^{\text {"I } T h e ~ d e m i s e ~ o f ~ t h e ~ b o o k ~ h a s ~ b e e n ~ p r o p h e s i e d ~ f o r ~ s o m e ~}$ time now (See; e.g., C. Overhage, and R. Harmon, Project Intrex (Cambridge, MA: MIT Press, 1965), speculating on the promising future of microfilm), but despite a growing infrastucture (i.e., the growing popularity of the home computer, the growing availability of online information, and the prospect of the Integrated Services Digital Network), it is likely that-for cer- tangible "thing" to be bought and sold have been removed, and it has taken on the attributes of a service. ${ }^{103}$

Not all technologies for electronic dissemination have the same potential to raise issues of access. The technologies differ widely in their format, limitations, and suitability for use with particular types of information. ${ }^{104}$ Moreover, technological limitations, consumer demand, and the economics of production will variously affect the likelihood that these technologies will replace or augment a traditional mode of distributing copyrighted works. Other factors, such as whether the dissemination system is "open' or "closed, "1105 and prohibitions on copying or downloading, may also affect the salience of the access issue. Also, many of the technologies now being developed are of unknown technological or commercial viability, ${ }^{106}$ or lack definite application. These uncertainties further obscure the possibility of conclusive statements regarding affect of access concerns on private use.

In general, the technologies of electronic dissemination can be, or are now used for communicating copyrighted or copyrightable works to the public. Each technology makes it unnecessary to distribute copies. Each also represents a way of moving information from place to place that has no clear analog in the system of print. Electronic dissemination requires a consideration of how copyright principles that apply to it-automatic copyright, ${ }^{107}$

tain uses, such as temporary storage media-printed information will always be with us. OTA Workshop on Storage Technologies, 1985.

"'Electronic dissemination is not new, only the copyright protection of electronically disseminated works. Television and radio broadcasts have been around since early in the century, but were not copyrightable until the 1976 act.

'("For present purposes, electronic dissemination technologies comprise television (including broadcast, cable, SMATV, DES, STV, and others); radio; video and teletext (included, perhaps, under the designation of television); and online services.

"Broadcast television is an example of an open system; pay television or on-line database services are examples of a closed system.

"'Pay-per-View television is a case in point. See: "Here We Go Again," Forbes, Aug. 26, 1985, pp. 108-114.

'("Automatic copyright, endows the proprietor with copyright protection from the moment a work is created, with no obligation to make the work available to the public-in copies or otherwise. 17 U.S.C. §102(a). 
uniform protection, ${ }^{108}$ and the first sale doctrine $^{109}$-affect private use issues.

Because no copies are distributed, electronic dissemination means that the proprietor must either monitor or control access in order to be remunerated. ${ }^{110111}$ In broadcasting, where access to works can be measured but not controlled, advertising has proven a successful method of paying for the copyrighted work. ${ }^{112}$ In other cases, advertising may not be viable or desirable. In these instances, the communications medium must lend itself to the measurement and control of access, whether by subscription, pay-per-use, or user-identification. The proprietor is remunerated through control over access to either the medium (e.g., cable television) ${ }^{113}$ or the work (e.g., on-line databases, and videotext and teletext). ${ }^{114}$

"All original works of authorship are copyrightable, re gardless of how they are disseminated, as long as they are perceptible either directly or with the aid of a machine or device. 17 U.S. C. $\$ 102(a)$. Thus, books disseminated in tangible copies and books that are distributed in the form of intangible electromagnetic signals receive the same protection. While the copyright holder of the printed book loses control over price, use, and distribution of the copy once the work is published, the copyright holder of the "electronic" book does not. Performances and pictures of events transmittedlive are also protected as long as a tangible copy - e. g., a videotape-is fixed simultaneously when the signal is transmitted. However, a performance, e.g. a news broadcast, does not constitute publication. (It should be noted that different rights for different kinds of subject matter are provided in Section 106, and that Section 108 through 118 set subject matter specific limitations on rights).

"The doctrine of first sale, Title 17 U.S.C. $\$ 109$, which has always abbreviated the rights of the copyright holder in the copy, is largely irrelevant to works disseminated electronically, since no tangible version of such works is ever sold. Instead, what is sold is access to the copy in limited slices of time or quantity.

"'The copyright proprietor of many television shows, for instance, is also the broadcaster, but need not be-the copyright proprietor may be the producer, or even the filmmaker. Ultimately, a copyright proprietor must be compensated for proceeds of a broadcast (whether by assignment of performance or display rights, or license, or royalty).

"The measurement or control of access may take many forms. In television, for example, it maybe based upon by viewer penetration rate, as measured by "Nielson Ratings,"' which is in turn translated into advertising revenues (as with network. broadcasts); or it may be based on a set royalty (as is the case with cable television rebroadcasts); or on a pay-per-use basis (as with many database services).

“- For a discussion of private alternatives, see ch. 6.

Where access to the medium is controlled, the copyright proprietor is often remunerated indirectly. In cable television, for example, the copyright proprietor is remunerated (often via a compulsory license) indirectly on the basis of the cable companies' ability to control access to the coaxial cable.

${ }^{114}$ The situation occurs most often in cases in which the
Copyright protection is, however, still use ful to proprietors whose works are electronically disseminated. Indeed, the value of copyright to the proprietor may be enhanced, since he may avoid the consequences of the first sale doctrine. Consequently, the proprietor can capture payment for more of the value of additional uses of the copyrighted work, and can price discriminate among buyers, thereby recovering the marginal utility of a work to a variety of users. ${ }^{115}$ The proprietor may also avoid the need for channels of distribution, including shippers, wholesalers, and retailers. The result may be an overall increase in the economic efficiency of production and distribution, but may pose problems insofar as the dissemination of copyrighted works is encumbered with the public interest.

Electronic dissemination creates some very complex issues with respect to the public interest, and involves the intellectual property system in other issues, such as communications, antitrust, and freedom of speech. The very means by which the proprietor secures remuneration is by controlling dissemination to the public. The public does not gain access to copyrighted works by buying or borrowing published copies, but through the reception of ephemeral performances or displays, such as television programs. Because works are never published, the proprietor need not give up legal control over access. As a consequence, the public is dependent on the information provider for each and every access made to a work, and the provider may be the sole source for the work. Competitive pricing between retailers, and the competition for the copyrighted work from alternative sources, such as libraries and "second hand" booksellers is removed.

Situations in which access is controlled by a proprietor heighten the potential for anti-

proprietor, assignee, or licenser and the disseminator are one and the same entity. In such cases, copyright control is direct: access to the work itself is controlled.

")"See: Besen, op. cit., p. 4; and David Waterman, Videocassettes, Videodiscs, and the Role of Theatrical Distribution, Waterman and Associates, and Annenberg School of Communications, University of Southern California, Mar. 13, 1984, from a conference on "Rivalry Among Video Transmission Media: Assessment and Implications. " (Harriman, NY: Arden House, Apr. 13-15, 1984). 
competitive behavior, especially where crossownership exists between the medium of communication and the material that is communicated. This potential becomes even more acute when the copyrighted content is accessed, but not purchased by the consumer. Since the copyright owner need not lose control over distribution, it can at once be the owner and the sole source of access to the copyrighted work. ${ }^{116}$ This combination of content and distribution is a form of vertical integration, and forms the junction between copyright policy-which has traditionally dealt with ownership of content -and communication policy-which has traditionally dealt with the ownership of carriage.

When communications becomes the necessary condition for access to a work, it is necessary to consider what interrelations exist between carriage and content. In particular, when control over content and control over carriage are located in one and the same entity, the power of copyright becomes closely related to the number of channels of access to a given work. Some cross-ownership restrictions ${ }^{117}$ address themselves primarily to cross-ownership between the media (telephone and broadcast television), but do not deal with the mediumcontent issue. The FCC's Computer I and II, and most recently, Computer III regulations are efforts to address the issue of vertical integration through restrictions on the communications industry. ${ }^{118}$

There may also be first amendment considerations involved in the issue of access. When

"There are some indications that the vertical integration of production and dissemination through cross-ownership is be ginning to occur, especially in the cable industry. The motion picture industry is presently an oligopoly of seven companies which comprising 85 percent of the market (based on box office gross]. Business Week, Feb. 21, 1983, p. 78. Each major production studio, or its parent, either owns or is involved in joint ventures in pay-television stations. See Ithiel de Sola Pool, Technologies of F reedom (Cambridge MA: Belknap Press, 1983); and Who Owns Whom (London: Dun \& Bradstreet, 1984). In general, acquisitions and mergers in the information industry hit a new record in 1984. Information Hotline, vol. 17, No. 5, May 1985, pp. 1, 12.

For example, Section 613 of the recently enacted Cable Communications Policy Act of 1984 (Title VI of the Communications Act of 1934).

${ }^{1 /}$ See ch. 6 on information markets for a more thorough discussion of the vertical integration. no copy of a copyrighted work is available to the public, the "right to receive information and ideas ${ }^{1119}$ may conflict with the right to restrict access based on proprietary discretion. ${ }^{120}$ Robust debate requires that information be available for public inspection and analysis. ${ }^{121}$ Fair use may be a way of reconciling conflicts between private rights and political rights, but there are important theoretical as well as practical differences between fair use and the first amendment. ${ }^{122}$

\section{The Criterion of Public Opinion}

Finally, the importance of public opinion in decisions about intellectual property rights cannot be overlooked. For the public's perception of what is fair and equitable is bound up with questions of legitimacy and enforceability $\mathrm{y}$ :

On few points in the longstanding debate over the "rule of law" is there greater consensus than on the close and necessary relation between societal support for a system of

\footnotetext{
${ }^{19}$ Board of Education v. Pico, 457 U.S. 853, 867 (1982); Cf. Stanley v. Georgia, 394 U.S. 557, 564 (1969).

“'II In Duncan v. Pacific\& Southern Co., Inc., 744 F.2d 1490 (11 th Cir. 1984), cert. denied, 105 S. Ct. 1867 (1985), for example, a defendant to a copyright infringement suit was enjoined from taping local television newscasts and selling them to interested parties. Despite the fact that the television station erased tapes of its news programs after they were retained a week, and the fact that the news clips were sold only to the subjects of the station's broadcasts, the court found for the plaintiff. Unlike the recent case of Harper \& Row, Inc. v. Nation Enterprises, S. Ct. No. 83-1632 (citing the Duncan case), the plaintiff in the Duncan case, per its own admission, was neither in competition with nor harmed by the defendant news service. I $\mathrm{n}$ the Duncan case, ironically, the infringed videotape was obtained through a customer of the defendant's.

${ }^{\prime 2}$ Such was the basis of the defense in the CBS v. Vanderbilt University litigation (Civ. No. 7336 (M.D. Tenn., filed Dec. 21, 1973), a case in which Vanderbilt University was engaged in copying CBS's news coverage for archival and educational purposes. The suit was later dropped when Section 108(b) of the new copyright law essentially mooted the issue.

"'''The scope and extent of fair use falls within the discretion of the Congress itself. Fair use, when properly applied, is limited to copying by others which does not materially impair the marketability of the work which is copied. The First Amendment principle, when appropriate, may be invoked despite the fact that the marketability of the copied work is thereby impaired. Nimmer, Cases and Materials on Copyright (1978), Section 1.10 A, pp. 1-64 as quoted in Rosenfeld, "The American Constitution, Free Inquiry, and The Law, " in Fair Useand Free Inquiry, Lawrence and Timberg (eds.) (Ablex Publishing Corp.: New J ersey) 1980, p. 287, 302.
} 
law and the effectiveness of such a legal system in regulating conduct. The viability of the legal order of a free society cannot rest solely on applications or threats of force by authorities. It must rest on a people's sense of the legitimacy of the rule-making institutions and of the rules these institutions make. ${ }^{123}$

A survey of the public commissioned by OTA on the issue of intellectual property rights reveals a number of findings of relevance to the public's perceptions of what rights should and should not exist in information products. ${ }^{124}$ With respect to the issue of private use, in particular, the public's attitudes seem to reflect a rough congruence to the distinction between commercial and noncommercial uses.

The survey reveals that two-thirds of the public is neither familiar with nor feels affected by intellectual property rights issues. However, neither familiarity nor self-interest appear to be related to their responses; the knowledgeable and the uninformed responded in very much the same way. Among the more significant of those responses were:

- The vast majority of the public (over 7 in 10) believes that copying personal possessions, like a record or a program from one's own TV, is acceptable behavior.

- A majority of the public believes that trading and copying information and entertainment such as computer programs and records is acceptable behavior.

- When there is an issue of access-either the information is readily available such as a library book or there is a question whether the information (broadcast signals or airwaves) should be free-the public is divided.

While each of these behaviors involved personal or private behavior which might give rise

Shat tuck. Public Attitudesand the Enforceability of Law, OTA contract report. 1985.p2. "Sometimes . the official sector may bedetached from the private sector, in the sense that there is no longer general obedience tot he rules which are valid according to the cu it cria of validity in use in the courts. The varietyof ways in which $t$ his may happen belongs to the pathology of legulsyst e In s." "H.I.A. Hart, The Concept of law ILondon: ()xford [niversiJ Press. 1961), p 114.

"Public Perceptions of the "Intellectual Property Rights" issue, prepared by The Policy Planning (iroup Yavkelovich Skelly \& W'hite, Inc., February 1985. to civil liability under copyright law, ${ }^{125}$ there appears to be little public support for such consequences.

However, when asked about conduct which generally involved commercial, for-profit activity or willful, active attempts to avoid paying for something the public responded as follows:

- More than 8 in 10 among the public find behaviors that obviously circumvent a fee or service (such as purchasing a descrambler to watch pay TV, or secretly recording a concert) to be unacceptable.

- There is almost complete unanimity among the public that behaviors which jeopardize privacy, such as entering a database without permission are unacceptable.

- If copying of copyrighted materials is done for reasons other than private use, for public display, for sale or personal gain, or on behalf of a large corporation, the majority oft he public found the behavior less acceptable.

While the public was not informed of the illegality or criminal nature of any of the behaviors on which they were questioned, it is interesting to note that many of their responses reflect the criteria for criminal infringement set forth in in the copyright law: the infringement of copyright "willfully and for purposes of commercial advantage or private financial gain."1126 In general, the public seems to be in support of laws regarding criminal infringement or access, and competitive or institutionalized copying activities, but it withholds support for prohibitions on civil infringement or private use copying behavior.

"Under 17 U.S. C $\$ \$ 106,501$, if these protrusions are interpreted to cover private use,

17 U.S.C, $\$ 506$. This is not to suggest that criminal infringement is not a problem for the motion picture and recording industries. "While reports of raids and confiscation of pirated materials are quite common, it should be emphasized that the statistics suggest that there are many more pirates operat ing than are ever apprehended, . " Statement of Mr. Donald C. Curran, Acting Registrar, Library of Congress, Hearing on Civil and Criminal Enforcement of the Copyright Laws Before the Senate Subcomriattee on Patents, Copyrights and Trademarks, Commit tee on the Judiciary, Apr. 17, 1985. According to industry sources, criminal infringement has stabilized. Wil. liam Nix, MPAA and.Joe Moscaret, \ice Prescient of Film and Video Security at Paramount P'ict ures, as cited in Curran, op. cit. 


\section{Chapter 8 Impact of New Technologies on the International Intellectual Property System}




\section{Contents}

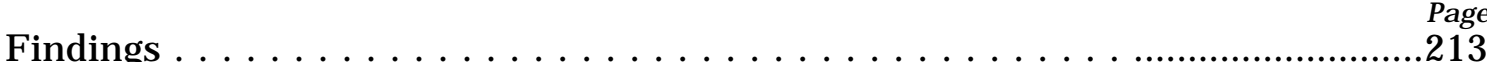

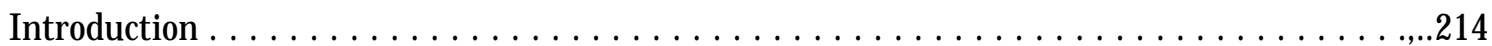

Early History . . . . . . . . . . . . . . . . . . . . . . . . . . .......................214

Present International Intellectual Property System $\quad . ., \ldots \ldots \ldots \ldots \ldots$... . . . . . 215

Harmonization of Disparate National Intellectual Property" Systems . .............215

Principle of National Treatment . . . . . . . . . . . . . . . . . . . . . . . . . . ...........219

Minimum Rights . . . . . . . . . . . . . . . . . . . . . . . . . . .......................219

Stresses on the International Intellectual Property System. . ......................220

Increasing Flows of Information and Information-Based Products and Services

Between Nations . . . . . . . . . . . . . . . . . . . . . . . . .......................2221

Policy Implications . . . . . . . . . . . . . . . . . . . . . . . . ....................,223

Growing Importance of Information and Information-Based Products and Services to National Economies and International Trade and Competitiveness ....224

Policy I mplications . . . . . . . . . . . . . . . . . . . . . . . . . . .......................225

Increasing Cultural and Political Significance of Information and

Information-Based Products and services . . . . . . . . . . . . . . . . . . . . . ......228

Policy Implications . . . . . . . . . . . . . . . . . . . . . . . . . . . . .....................230

Emergence of New Information-Based Products and Services That Do Not

Correspond to Traditional Intellectual Property Protections . . . . . . ............232

Policy Implications . . . . . . . . . . . . . . . . . . . . . . . . . . . . . . . . . .......235

Increasing Difficulty of Enforcing Intellectual Property Rights Caused by

Emerging Information and Communication Technologies . .....................237

Policy Implications . . . . . . . . . . . . . . . . . . . . . . . . . .........................246

Growing Convergence of International Intellectual Property Issues With Other

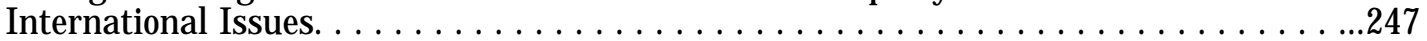

Policy Implications . . . . . . . . . . . . . . . . . . . . . . . . . ....................249

Implications for Future U.S. International I ntellectual Property Policy . ............250

Tables

Table No.

8-2. Membership in the Berne Convention, the Universal Copyright Convention, and the Paris Convention for the protection of Industrial Property ...., . .......218

8-3. Estimated Losses From Piracy in Ten Selected Countries . ......................241

8-4. Countries and Regions That Infringe Copyrights of U.S. Motion Picture and Television, Prerecorded Entertainment, Publishing, and Advertising Industries . . .242

8-5. Policy Options for Addressing International Intellectual Property Issues ........251

Figures

Figures No. $\quad$ Page

8-1. Shrinking of Our Planet by Humans' Increased Travel and Communications .. ...222

8-2. Computer Utilization: Selected Countries, 13 Sectors . .........................226

8-3. The Speed of Change: Intervals Between Discovery and Application in

Physical Science. . . . . . . . . . . . . . . . . . . . . . . . .......................233

8-4. The Level and Location of International Counterfeit Activity of U.S. Products ...239 


\section{Impact of New Technologies on the International Intellectual Property System}

\section{FINDINGS}

OTA found that recent developments in information and communication technologies are creating new stresses on the international intellectual property system. Such developments include:

- the increasing flow of information and information-based products and services among nations;

- the growing economic importance of information and related products and services, both within and between nations;

- the increasing cultural and political significance of information and related products and services;

- the emergence of new information-based products and services that do not correspond to traditional categories of protection;

- the increasing difficulty of enforcing intellectual property rights at the international level; and

- the growing convergence of international intellectual property issues with other international issues.

Given their magnitude, these technological developments pose novel difficulties that challenge the relative stability of the international system. They affect not only the international legal system, but also international economic and political relations. Consequently, they have major implications for the United States both as a participant in the international intellectual property system and also with respect to its choices for domestic intellectual property policy. These policy implications are:

-As information and communication technologies facilitate the international ex- change of intellectual property, domestic intellectual property issues will need to be resolved within an international context and according to internationally agreed upon norms.

- As technological change prompts greater need for rapid international consensus on how and what to protect, the United States will need to take greater international action to keep abreast of as well as influence the development of international policies for the protection of new technologies.

- As information and information-based products and services become major trade items and the basis for economic growth, international trade and economic considerations will increasingly be brought to bear on the resolution of international intellectual property issues.

- Given the growing cultural and political significance of information-based products and services, international political relations will need to be taken into account in resolving international intellectual property issues.

- As information and communication technologies undermine the traditional mechanisms for enforcing intellectual property rights, the international community will need to cooperate and coordinate their efforts to provide adequate and uniform enforcement mechanisms and remedies.

- Given the convergence of international intellectual property issues with other international issues, the United States might need to establish domestic institutional arrangements to develop and coordinate consistent international policies. 
The United States can choose among a variety of policy strategies to deal with technological change and its effects on the international intellectual property system. There is no clearcut, single strategy, however, that will comprehensively address all international intellectual property issues. Moreover, many policy strategies may conflict with one another and exacerbate other stresses on the international intellectual property system. Thus, the United States will need to make fundamental decisions about how it would like to frame international intellectual property issues (for example, in terms of trade, legal, or political relations) and design its international intellectual property policies accordingly. As information and communication technologies become major factors in international trade and nations' economic and social development, such policy decisions will become more significant to many aspects of U.S. foreign policy-from international issues of trade, defense, and foreign aid to issues of international information and communication policy.

\section{INTRODUCTION}

Historically, U.S. intellectual property policy developed in isolation from the rest of the world. Such isolation was possible because print materials were confined, for the most part, within national borders. Over time and as the necessity arose, the United States slowly began to extend its participation in the international intellectual property system.

Recently, however, new technological developments have led to a great expansion in the number of ways to create, store, reproduce, distribute, and transmit literary, scientific, and creative works. The progressive development of, for example, radio, television, and computers coupled with advanced telecommunication and satellite systems have greatly increased international distribution and access to works. These technological developments are creating new stresses on the international intellectual property system, which raise questions about whether the United States should play a more active role in the international intellectual property system.

To examine the effects of new communication and information technologies on the international intellectual property system and the adequacy of U.S. participation in it, this chapter will:

1. review the early history of U.S. participation in the international intellectual property system;

2. describe the present international intellectual property system;

3. describe how technological developments may affect the international intellectual property system; and

4. suggest the implications that these developments have for both the level and type of U.S. participation in the international intellectual property system and for U.S. domestic intellectual property policy.

\section{EARLY HISTORY}

Before the 19th century, intellectual property protection was largely a domestic concern. Because of the limited intercourse and communication among nations, works were distributed almost exclusively within their authors' country. Thus, the lack of international protection caused little concern.
By the early 1800s, a variety of social and technological developments began to generate interest in international intellectual property protection. Increased trade, communications, and travel were important factors, as was the growing practice of learning foreign languages. In response, the European nations began to 
consider mechanisms to ensure protection abroad for their domestic works, as well as to protect foreign works. These nations first set up a number of bilateral protection agreements; then, in 1866, many of the European nations joined together and signed the first multilateral agreement, the Berne Convention. ${ }^{1}$

While many European states relied on multilateral agreements to regulate their copyright relations, the United States did not participate in any international copyright arrangements for the first 100 years of its existence, nor did it recognize any copyright protection for foreign works or authors. In fact, in the first U.S. copyright law of 1790, Congress explicitly restricted the protection of foreign works:

'Edward W. Ploman and L. Clark Hamilton, Copyright: Intellectual Property in the Information Age (London: Routledge $\&$ Kegan Paul, 1980), p. 18.

${ }^{2}$ The position of the United States was almost unique at the time. The major Western nations early on made provisions for the international protection of authors' rights. Acting in 1828, Denmark was the first, Prussia followed in 1836 and England in 1837. France in 1852 and Belgium in 1854 also granted protection for all for foreign works. By the mid-19th century, only the Soviet Union, the Ottoman Empire, and the United States did not grant protection for foreign works. Aubert J . Clark, The Movement for International Copyright in Nineteenth Century America, (Washington DC: The Catholic University Press, 1960), p. 26.
... [N ]othing in this act shall be construed to extend to prohibit the importation or vending, reprinting or publishing within the United States, of any map, chart, book or books, written or printed, or published by any person not a citizen of the United States, in foreign parts or places without the jurisdiction of the United States. ${ }^{3}$

It was not until 1891, when Congress passed the Chace International Copyright Act, that the United States begin to recognize international copyright relations. The act, however, provided neither for multilateral agreements nor for the protection for foreign works manufactured outside the United States. ${ }^{4}$ But it did extend copyright relations to nations found and proclaimed by the President to afford adequate protection to American works. This act provided the basis for all of the U.S. bilateral copyright relations for more than the next 60 years.

'Committee on the J udiciary, Subcommittee on Patents, Copyrights, and Trademarks, hearing on "Oversight on International Copyrights, ' Sept. 24, 1984, p. 28.

The manufacturing requirement, still in existence today albeit in a much diluted form, stipulates that nondramatic literary material must be manufactured in the United States (or Canada) to enjoy full copyright protection in the United States.

This requirement is scheduled to be repealed as of J uly 1986.

Title 17 U.S.C. Sec. 601(a)

\section{PRESENT INTERNATIONAL INTELLECTUAL PROPERTY SYSTEM}

Over the last century, the international system for protecting intellectual property has been quite stable, displaying a higher level of cooperation than other international agreements. Unlike other international agreements that are periodically readapted or completely revised, the interlocking conventions that constitute the international intellectual property system have provided a permanent legal frame work, although it is subject to amendments and revisions if required. Table 8-1 summarizes the major international intellectual property conventions. Table 8- 2 shows the national membership of each of the three major intellectual property agreements.

The system is complex and structured around many different international conventions and agreements to which different groups of countries adhere. These conventions share several outstanding characteristics that govern the international intellectual property system. They are:

1. the harmonization of disparate national intellectual property systems;

2. the principle of national treatment; and

3. the establishment of minimum rights.

Harmonization of Disparate National intellectual Property Systems

Although rooted in various philosophical traditions, the intellectual property systems of different nations have been harmonized over the years under international intellectual prop- 
Table 8-1.-International Intellectual Property Agreements

\section{$\overline{\text { Agreement }}-\underset{\text { Revisions }}{-}$ \\ Copyright agreements: \\ The Berne Convention for the Protection}

Literary and Artistic Works (1886)

1896: Paris Additional Act and

Interpretative Declaration

1908 Berlin Act

1914 Berne Additional Protocol

1928: Rome Act

1967 Stockholm Act

1971 Paris Act

The Rome Convention for the Protection of Performers, Producers of Phonograms, and Broadcasting Organizations (1961)

$$
\text { None }
$$

The Universal Copyright Convention (1957) 1971: Paris

The Convention for the Protection of Producers of Phonograms Against the Unauthorized Duplicatlon of Their Phonograms (1971)
"This Convention obliges Contracting States to protect the expression of literary and artistic works [which include] every production in the literary, scientific, and artistic domain, whatever may be the mode or form of its expression, such as books, pamphlets, and other writings: lectures, addresses, sermons and other works of the same nature, dramatic or dramatlco-musical works: choreographic works and entertainments in dumb show; musical compositions with or without words, cinematographic works to which are assimilated works expressed by a process analogous to cinematography: works of drawing, painting, architecture, sculpture, engrawng, and lithography, photographic works to which are assimilated works expressed by a process analogous to photography: works of applied art, Illustrations, maps. plans, sketches, and threedimensional works relative to geography, topography, architecture, or science. " Article II

This Convention obliges Contracting States to extend protection: a) to peformers who are its nationals, as regards performances taking place, broadcast. or first fixed. on its territory,

b) to producers of phonograms who are its nationals, as regards phonograms first fixed or first published on its territory,

c) to broadcasting organizations which have their headquarters on its terrtory, as regaras Broadcasts transmitted from transmitters situated on its territory "Article II

"Each Contracting State undertakes to provide for the adequate and effective protection of the rights of authors and other copyright proprietors in literary, scientific, and artistic works, including writing musical, dramatic, and cinematographic works, and paintings, engravings, and sculpture." Article 1.

"Each Contracting State shall protect producers of phonograrns who are nationals of other Contracting States against the making of duplicates without the consent of the producer and against the Importation of such duplicates, provided that any such making or the distribution of such duplicates to the public. "Article II.

the distribution of such duplicates to the public. "Article II.
U S membership. _ Comments . -

No Basic principles established under the Berne Convent lon

1 Principle of national treatment

2. Principle of automatic protection (with no formalities)

3 Principle of Independence of protection

4 Minimum rights

The primary purpose of the UCC was to join the United States and the Latin American countties with the countries of Europe, Asia, and Africa in a single multinational agreement. Like the Berne Convent lon, the UCC is based on national treatment and minimum rights. Unllie the Berne Convention, the UCC has several formalities, such as a notice requlirement 


\section{Table 8-1.-International Intellectual Property Agreements-Continued}

Agreement Revisions Inter American Copyright Convent Ions The Montevideo Convention (1889) The None The Mexico City Convent Ion (1 902) The Rio de Janeiro Convent lon (1 906) The Buenos Aires Convention (1910) None The Havana Convention (1928) The Washington Convention (1946) None

The Convent lon Relating to Distribution of Program-Carrying Signals

Transmitted by Satellite (1974) Non

Patent and Trademark Agreements: The Paris Convent lon for the Protect Ion of Industrial Property (1 883)

$$
\begin{aligned}
& \text { 1900: Brussels } \\
& \text { 1911 Washington } \\
& 1925 \text { The Hague } \\
& 1934 \text { London } \\
& 1938 \text { Lisbon } \\
& 1967 \text { Stockholm }
\end{aligned}
$$

The Patent Cooperation Treaty (1 978) Non

SOURCE Off Ice of Technology Assessment

\author{
Protected subject matter
}

This Convent Ion obliges Contracting States to protect the expresthery and artistic works which include books, writings, pamphlets of al I Kinds, whatever may be the subject of which they treat and whatever the number of their pages, dramatic or dramaticochoreographic and musical $w$ ithout words, drawings paintings sculpture engravings photographic works astronomical and geographical globes. plans sketches or plastic works relating to geography geology or topography archiltecture or any other science and finally all productions that can be published by any means of Impress lon or reproduction Article II

The Convent Ion obliges Contracting States to take adequate and effective measures to prevent the distribution on or from its territory of any program-carrying signal by any distributor for whom the signal emitted to or passing through the satellite is not Intended.

The protection of industrial property has as Its object patents, utility models industrial designs, trademarks, service marks, trade names indications of source or appellations of origin. and the repression of unfair competition.

Industrial property shall be understood in the broadest sense and shall apply not only to industrial and commerce proper but likewise to agricultural and extractive Industries and to all manufactured or

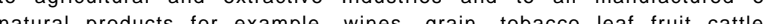
minerals mineral wers, beer, flowers, and flor Patents shall Include the various kinds of Industrial patents recognized by the laws of the countries of the Union such as patents

The Treaty facilitates the filing of the applications for patents on the same Invent lon in member countries by providing among other things for centralized filing procedures and a standardized application format

U.S. membership

Comments

No
Buenos Aires Convent Ion 1910 remains the basic Pan During the past 20 years there has been a clear trend away from these rentions conventions in Cor or worldwide agreements Consequently in many Instances American conventions as the perative agreemen 
Table 8-2.- Membership in the Berne Convention, the Universal Copyright Convention, and the Paris Convention for the Protection of Industrial Property

\begin{tabular}{|c|c|c|c|c|c|c|c|}
\hline Country & Berne & UCC & Paris & Country & Berne & UCC & Paris \\
\hline$\ldots \ldots \ldots \ldots \ldots$ & & $\mathrm{X}$ & $\mathrm{X}$ & Korea, Republic of . . . . . . . . & & & $\mathrm{X}$ \\
\hline Andorra. . . . . . . . . . & & $x$ & & 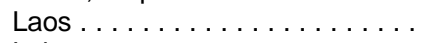 & & $\mathrm{X}$ & \\
\hline Argentina $\ldots \ldots \ldots \ldots \ldots$ & $\mathrm{X}$ & $\mathrm{x}$ & $X$ & Lebanon ................. & $\mathrm{X}$ & $\mathrm{X}$ & \\
\hline$\ldots \ldots \ldots \ldots$ & $x$ & $\mathrm{X}$ & $X$ & 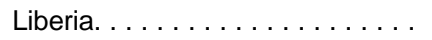 & & $x$ & $X$ \\
\hline$\ldots \ldots \ldots \ldots$ & $\mathrm{X}$ & $\mathrm{X}$ & $X$ & Libya ................ & $\mathrm{X}$ & & \\
\hline$\ldots \ldots \ldots \ldots$ & $\mathrm{X}$ & $\mathrm{X}$ & $X$ & Liechtenstein. . . . . . . . . . & $\mathrm{X}$ & $\mathrm{X}$ & $\mathrm{X}$ \\
\hline Bangladesh . . . . . . . . . . . & & $\mathrm{X}$ & & Luxembourg. ............ & $X$ & $\mathrm{X}$ & $x$ \\
\hline Barbados $\ldots \ldots \ldots \ldots \ldots$ & $\mathrm{X}$ & $\mathrm{X}$ & & Madagascar . . . . . . . . . . & $X$ & & $\mathrm{X}$ \\
\hline 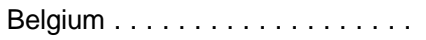 & $\mathrm{X}$ & $\mathrm{X}$ & $\mathrm{X}$ & Malawi ............... & & $\mathrm{X}$ & X \\
\hline Belize $\ldots \ldots \ldots \ldots \ldots \ldots$ & & $x$ & & Mali . . . . . . . . . . . . & $x$ & & X \\
\hline$\ldots \ldots \ldots \ldots$ & $\mathrm{x}$ & & $\mathrm{X}$ & Malta. . . . . . . . . . . . & $\mathrm{X}$ & $\mathrm{x}$ & $\mathrm{X}$ \\
\hline$\ldots \ldots \ldots$ & $\mathrm{X}$ & $\mathrm{X}$ & $\mathrm{X}$ & Mauritania . . . . . . . . & $\mathrm{X}$ & & $\mathrm{X}$ \\
\hline$\ldots \ldots \ldots \ldots$ & $\mathrm{X}$ & $\mathrm{X}$ & $\mathrm{X}$ & Mauritius . . . . . . . . . . & & $\mathrm{X}$ & $X$ \\
\hline Burkina Faso . . . . . . . . . & $\mathrm{x}$ & & & Mexico . . . . . . . . . . .., ..., & $\mathrm{X}$ & $\mathrm{X}$ & $\mathrm{X}$ \\
\hline Burundi $\ldots \ldots \ldots \ldots \ldots \ldots$ & & & $\mathrm{X}$ & Monaco . . . . . . . . . . . . . . . . & $\mathrm{X}$ & $\mathrm{X}$ & $\mathrm{X}$ \\
\hline Cameroon. . . . . . . . . . . . & $\mathrm{X}$ & $\mathrm{X}$ & $\mathrm{X}$ & Morocco $\ldots \ldots \ldots \ldots \ldots \ldots$ & $\mathrm{X}$ & $\mathrm{X}$ & $\mathrm{X}$ \\
\hline Canada $\ldots \ldots \ldots \ldots \ldots \ldots$ & $\mathrm{x}$ & $\mathrm{x}$ & $\mathrm{x}$ & Netherlands $\ldots \ldots \ldots \ldots \ldots$ & $x$ & $\mathrm{x}$ & $x$ \\
\hline Central African Republic . . . . . & $x$ & & $\mathrm{X}$ & New Zealand . . . . . . . . . . & $X$ & $\mathrm{X}$ & $\mathrm{X}$ \\
\hline Chad $\ldots \ldots \ldots \ldots \ldots \ldots \ldots$ & $x$ & & $\mathrm{X}$ & Nicaragua. . . . . . . . . . . . . . . . & & $\mathrm{x}$ & \\
\hline Chile $\ldots \ldots \ldots \ldots \ldots \ldots$ & $\mathrm{X}$ & $\mathrm{x}$ & & 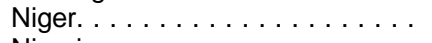 & $\mathrm{x}$ & & $\mathrm{X}$ \\
\hline Colombia . . . . . . . . . & & $\mathrm{x}$ & & Nigeria $\ldots \ldots \ldots \ldots \ldots \ldots$ & & $\mathrm{X}$ & $\mathrm{X}$ \\
\hline Congo $\ldots \ldots \ldots \ldots \ldots \ldots$ & $x$ & & $X$ & Norway ................ & $x$ & $\mathrm{X}$ & $x$ \\
\hline Costa Rica. . . . . . . . . . . . & $\mathrm{X}$ & $X$ & & Panama................. & & $X$ & \\
\hline Cuba $\ldots \ldots \ldots \ldots \ldots \ldots$ & & $\mathrm{X}$ & $X$ & Pakistan . . . . . . . . . . . . & $\mathrm{X}$ & $\mathrm{X}$ & \\
\hline Cyprus . . . . . . . . . . . & $\mathrm{X}$ & & $\mathrm{X}$ & Paraguay $\ldots \ldots \ldots \ldots \ldots$ & & $X$ & \\
\hline Czechoslovakia . . . . . . . . & $\mathrm{X}$ & $X$ & $X$ & Peru $\ldots \ldots \ldots \ldots \ldots \ldots$ & & $\mathrm{X}$ & \\
\hline Democratic Kampuchea . . . . . & & $\mathrm{X}$ & & Philippines . . . . . . . . . . & $\mathrm{X}$ & $\mathrm{X}$ & $\mathrm{X}$ \\
\hline Denmark ................ & $\mathrm{X}$ & $\mathrm{X}$ & $X$ & Poland $\ldots \ldots \ldots \ldots \ldots \ldots$ & $X$ & $\mathrm{x}$ & X \\
\hline Dominican Republic . . . . . . . . & & $x$ & $X$ & $\ldots \ldots \ldots \ldots \ldots$ & $\mathrm{X}$ & $\mathrm{X}$ & $\mathrm{X}$ \\
\hline Ecuador ............. & & $\mathrm{X}$ & & $\ldots \ldots \ldots \ldots$ & $x$ & & $\mathrm{X}$ \\
\hline Egypt . . . . . . . . . . & $x$ & & $\mathrm{X}$ & Rwanda. ................ & $\mathrm{X}$ & & $\mathrm{X}$ \\
\hline El Salvador. . . . . . . . . . . . & & $\mathrm{X}$ & & San Marine. . . . . . . . . . . . & & & X \\
\hline Fiji $\ldots \ldots \ldots \ldots \ldots \ldots \ldots$ & $X$ & $\mathrm{X}$ & & Senegal $\ldots \ldots \ldots \ldots \ldots \ldots$ & $x$ & $x$ & $\mathrm{x}$ \\
\hline Finland $\ldots \ldots \ldots \ldots \ldots \ldots$ & $\mathrm{X}$ & $\mathrm{x}$ & $\mathrm{X}$ & Singapore $\ldots \ldots \ldots \ldots \ldots$ & & & \\
\hline France .............. & $x$ & $x$ & $\mathrm{X}$ & South Africa . . . . . . . . . . & $\mathrm{X}$ & & $x$ \\
\hline Gabon ................. & $\mathrm{X}$ & & X & Soviet Union $\ldots, \ldots \ldots \ldots \ldots$ & & $\mathrm{X}$ & $\mathrm{X}$ \\
\hline Germany, Democratic & & & & Spain................. & $\mathrm{X}$ & $\mathrm{x}$ & $\mathrm{X}$ \\
\hline Republic of. . . . . . . . . & $\mathrm{X}$ & $X$ & $\mathrm{X}$ & Sri Lanka . . . . . . . . . . . . & $\mathrm{X}$ & $\mathrm{X}$ & $\mathrm{X}$ \\
\hline Germany, Federal & & & & $\ldots \ldots \ldots \ldots \ldots$ & $\mathrm{X}$ & & $\mathrm{X}$ \\
\hline Republic of . . . . & $\mathrm{X}$ & $\mathrm{X}$ & $\mathrm{x}$ & Sweden ................ & $\mathrm{X}$ & $\mathrm{X}$ & $\mathrm{X}$ \\
\hline Ghana $\ldots \ldots \ldots \ldots \ldots \ldots$ & & $\mathrm{X}$ & $\mathrm{X}$ & Switzerland . . . . . . . . . . . . & $\mathrm{X}$ & $\mathrm{x}$ & $\mathrm{X}$ \\
\hline Greece .............. & $x$ & $x$ & $X$ & Syria $\ldots, \ldots \ldots \ldots \ldots \ldots$ & & & $\mathrm{X}$ \\
\hline Guatemala . . . . . . . . . . & & $X$ & & Tanzania. . . . . . . . . . . & & & $\mathrm{x}$ \\
\hline Guinea $\ldots \ldots \ldots \ldots \ldots \ldots$ & $\mathrm{x}$ & $x$ & $X$ & Thailand . . . . . . . . . . . & $\mathrm{x}$ & & \\
\hline Haiti $\ldots \ldots \ldots \ldots \ldots$ & & $x$ & $\mathrm{X}$ & $\ldots \ldots \ldots \ldots$ & $\mathrm{X}$ & & $\mathrm{X}$ \\
\hline Holy See... . . . . . . . . . . . . & $\mathrm{x}$ & $X$ & $\mathrm{X}$ & Trinidad and Tobago . . . . . . & & & $\mathrm{X}$ \\
\hline Hungary $\ldots \ldots \ldots \ldots \ldots$ & $x$ & $x$ & $X$ & Tunisia ................. & $\mathrm{X}$ & $\mathrm{X}$ & $\mathrm{X}$ \\
\hline Iceland $\ldots \ldots \ldots \ldots \ldots \ldots$ & & $\mathrm{X}$ & $\mathrm{X}$ & Turkey ................ & $X$ & & $\mathrm{X}$ \\
\hline$\cdots \ldots \ldots \ldots \ldots$ & $\mathrm{X}$ & $\mathrm{X}$ & & Uganda . & & & X \\
\hline Indonesia . . . . . . . . . . . & & & $X$ & United Kingdom . . . & $\mathrm{X}$ & $\mathrm{X}$ & $\mathrm{X}$ \\
\hline $\operatorname{Iran} \ldots \ldots \ldots \ldots \ldots \ldots \ldots$ & & & $X$ & United States . . . . . . . . . . & & X & $\mathrm{X}$ \\
\hline Iraq $\ldots \ldots \ldots \ldots \ldots \ldots$ & & & $\mathrm{X}$ & Upper Volta . . . . . . . . . . . . & & & $\mathrm{X}$ \\
\hline 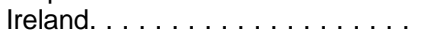 & $x$ & $x$ & $\mathrm{X}$ & Uruguay $\ldots, \ldots \ldots \ldots \ldots$ & $\mathrm{X}$ & & $\mathrm{X}$ \\
\hline Israel . . . . . . . . . . . . & $X$ & $X$ & $\mathrm{X}$ & Venezuela, . . . . . . . . . . & X & $\mathrm{X}$ & \\
\hline Italy $\ldots \ldots \ldots \ldots \ldots \ldots$ & $\mathrm{x}$ & $\mathrm{X}$ & $\mathrm{X}$ & Viet Nam . . . . . . . . . . & & & $\mathrm{X}$ \\
\hline Ivory Coast. & $\mathrm{x}$ & & $\mathrm{x}$ & Yugoslavia .............. & $x$ & $\mathrm{X}$ & $\mathrm{X}$ \\
\hline Japan . . . . & $\mathrm{x}$ & $x$ & $x$ & Zaire . . . & $X$ & & $\mathrm{X}$ \\
\hline$\ldots \ldots \ldots \ldots \ldots$ & & & $X$ & $\ldots \ldots \ldots$ & & $\mathrm{X}$ & $\mathrm{X}$ \\
\hline$\ldots \ldots \ldots \ldots \ldots$ & & $X$ & $X$ & Zimbabwe .............. & $x$ & & $X$ \\
\hline
\end{tabular}


erty agreements. This harmonization was possible because each of the national systems shared a common set of goals. In general, nations have advanced four major rationales to justify intellectual property protection. These have generally been accepted in most countries, but nations weigh them differently.

Based on these justifications, three traditions of intellectual property law have evolved. These include: the droit d'auteur system, which places the emphasis on the principles of natural justice; the Anglo-Saxon or copyright system, which is based on economic arguments; and the socialist system, which places the emphasis on socialist doctrine and the importance of the author in terms of his social role. There are, however, considerable variations among different countries that follow the same system. ${ }^{6}$ Although both the justifications for and the actual systems of protection may differ from nation to nation, overall international agreement is possible because the end result or goal is the same-to protect intellectual property.

\section{Principle of National Treatment}

The second shared characteristic of these international agreements is the principle of national treatment. In practice, this principle was adopted to achieve two goals: 1) to facilitate international judicial interpretation; and 2) to

\footnotetext{
"First, the principle of natural justice says that the author is the creator of the work, which is the expression of his personality, and therefore he should decide whether and how his work is commercialized and prevent any injury and mutilation of his intellectual offspring. The royalties he receives are the wages for his intellectual work, Second, the economic justification for protection is based on the argument that the investment in creating works, as well as in disseminating them to the public, would not be undertaken unless creators have a reasonable expectation of recouping investments and earning a reasonable profit. The third justification for protection is based on the argument that creative works are a considerable national asset, and therefore it is in the public interest to encourage and reward creativity as a contribution to the national culture. The fourth is based on a social argument that the dissemination of works to many diverse sectors of the public improves social cohesion and advances the society. Stephen Stewart, The Law of International Copyright and Neighboring Rights (London: Butterworth \& Co. (Publishers) Ltd., 1983), pp. 3-6.

'Stephen Stewart, The Law of International Copyright and Neighboring Rights (London: Butterworth \& Co. (Publishers) Ltd., 1983), pp. 6-11.
}

unify laws among countries that offer differing levels of protection. ${ }^{7}$

National treatment facilitates international judicial interpretation because it requires that judicial decisions be made within the country where the rights holder seeks protection, re gardless of his nationality. As a result, judgments are more consistent and more certain; the courts can more effectively interpret their own laws as opposed to those of other nations.

Second, many nations adhere to national treatment because they believe it leads to better political relations and unifies levels of protection among countries. Nations believe that this will occur because rights owners in countries of low-level protection, who receive higher levels of protection in other countries, will press their governments to raise their domestic levels of protection. Thus, it is believed that national treatment will give rise to a more unified and higher common level of protection among nations.

\section{Minimum Rights}

All international intellectual property agreements also establish a common set of minimum rights that may be claimed in all adhering countries, regardless of national legislation. Although convention countries are not required to grant minimum rights to their own nationals, all foreign member country nationals are entitled to these minimum rights. These minimum rights attempt to ensure that national treatment does not lead to any imbalances in levels of protection among nations. Without them, national treatment, which exclusively calls for equal treatment of foreigners and nationals within a convention country, could not prevent large discrepancies in levels of protection among countries. ${ }^{8}$ Consequently, mini-

\footnotetext{
Ibid., p. 39.

${ }^{x}$ The principle of national treatment without minimum rights might produce a serious imbalance which States would find unacceptable. For example:

If countries A and B were members of a [international] convention which provides only for national treatment and has no minimum rights and country $\mathrm{A}$ grants performance and broadcasting rights as well as a reproduction right, the effect would be that the nationals of country B would enjoy performance and broadcasting rights in country $A$, but nationals of country $A$ would
} [continued on next page) 
mum rights work in conjunction with national treatment to achieve the greatest possible uniformity of intellectual property protection among countries. ${ }^{9}$

Minimum rights also provide a flexible mechanism for unifying and increasing levels of international protection as needed. Starting with a small number of minimum rights, a convention can add others as new rights are required and as the level of international agreement rises. For example, beginning with the translation right, the Berne Convention later added the rights of public performance and broadcasting, the droit moral (moral rights), and the

\footnotetext{
(continued from previous page)

not enjoy these rights in country $B$ because the nationals of country B do not enjoy them either. This could produce a serious disequilibrium which would be unacceptable to country $A$.

Ibid., pp. 40-41.

"A history of copyright and neighboring rights bears this out ... When the Universal Copyright was negotiated 60 years after [the Berne Convention], the difference in the level of protection with rights covered by the convention became less marked, and thus less stringent measures to insure against unacceptable differences in the level of protection were required.

Ibid., p. 40.
}

cinematographic right. The Universal Copyright Convention (1952 text) originally provided only for the translation right; its revised version (1971 text) added the reproduction right, the broadcasting right, and the public performance right. "'

The harmonization of different national intellectual property systems, the principle of national treatment, and minimum rights have enabled the periodic revision of international conventions, which has given the international system the flexibility needed to adapt over time to technological change and changing attitudes about intellectual property protection. However, with the development of many new ways of creating, reproducing, and exploiting intellectual works, the international intellectual property system is currently experiencing a number of new and perhaps more serious stresses. Questions arise, therefore, as to whether U.S. domestic policy and participation in the existing international system can deal with such changes.

"'bid., p. 40.

\section{STRESSES ON THE INTERNATIONAL INTELLECTUAL PROPERTY SYSTEM}

Recent technological developments are creating pressures on the international intellectual property system. Such developments and their effects include:

1. the increasing flow of information and information-based products and services among nations;

2 , the growing economic importance of information and related products and services, both within and between nations;

3. the increasing cultural and political significance of information and related products and services;

4. the emergence of new information-based products and services that do not correspond to traditional categories of protection;
5. the increasing difficulty of enforcing intellectual property rights at the international level; and

6. the growing convergence of international intellectual property issues with other international issues.

Greater in magnitude than those of the past, today's technological developments pose novel difficulties that challenge the relative stability of the international system. Such developments affect not only the international legal system, but also international economic and political relations. Consequently, these developments may affect the U.S. role in the international intellectual property system as well as domestic intellectual property policy. A brief description of these developments and 
their potential implications for U.S. international and domestic policies are provided below.

\section{Increasing Flows of Information and Information-Based Products and Services Between Nations}

Technological advances in and the growing convergence of information and communication technologies have greatly increased the flow of information and information-based products and services across national borders. Increases in international trade, as well as the development of satellite, broadcast, fiber optics, and other telecommunication technologies, have combined with more powerful information storage, processing, and distribution technologies to bring about international exchanges of intellectual property. As illustrated in figure 8-1, these devel opments have led to greater international exchanges of information and technology and international interdependence.

Although exact measurements of computerized data flows are difficult to attain, many inquiries reveal that their rate of growth exceeds the growth rate of nonvoice communications. ${ }^{11}$ The growing number of installed terminals, telecommunication facilities, database searches, and computer services all reflect the increasing flow of information.

For example, the number of network terminating points (points of connection between user equipment and telecommunication transmission facilities) in Western Europe increased from 393,000 in 1979 to 832,000 in 1983 and is projected to reach $1,620,000$ in 1987 . The total number of bits sent per average working day grew from 1,310 billion in 1979 to 3,970 billion 1983 and is expected to reach 9,820 bilIion in 1987. In North America and Western Europe, the number of data searches increased

Cees J. Hamelink, Translational Data Flows in the Information Age (Sweden: Studentlitteratur AB, Chartwell-Bratt L.td., 1984), p. 44.

"M. Benedetti." Eurodata '79: The Growth of Data Communications in Western Europe, paper for the I B I Conference on Transborder Flow Policies, Rome, J une 1980. from 3.3 million in 1973 to 12.5 million in $1976^{13}$ and the number of users of database services increased from 10,000 in 1965 to 2 million in 1978. ${ }^{14}$ Exports by U.S. information services companies increased by 9 percent between 1982 and 1983, and are expected to continue to increase by 9 percent annually through 1987. ${ }^{15}$ The U.S. software industry also reported an increase in exports that represented 30 percent of total sales by $1982 .{ }^{16} \mathrm{In}$ addition, the use of satellite technology is greatly increasing the electronic exchange of entertainment programs internationally. Sky Channel, for example, provides by satellite many European cable systems with programs intended for the entire European market. ${ }^{17}$ Estimates place the 1985 transatlantic flow of television programs at approximately 20,000 to 30,000 hours annually. ${ }^{10}$

Other indications of international information exchanges are reflected in increases in international trade of computers and telecommunication equipment, as well as by the growing international exchange of patents, scientific information, technology, and cultural products. " For example, between 1978 and 1982, U.S. exports and imports of computers and equipment increased by 21.2 and 29.8 percent, respectively .20 U.S. exports and imports

\footnotetext{
'Paul B. Silverman, "international Telecommunications as a Tool for Technology Transfer, paper for the Technology $E$ x change '78, Atlanta, February 1978.

"P.]. van Velse. "Aspects of a European Information Industry, paper for the Commission of the European Communities, Luxembourg, September 1979.

U.S. Department of Commerce, International Trade Administration, "A Competitive Assessment of the U.S. Information Services Industry' (Washington, DC: (J . S. Government Printing Office, 1984), p. 35.

${ }^{16}$ U.S. Department of Commerce, International Trade Administration, "A Competitive Assessment of the U.S. Software Industry' (Washington DC: U.S. Government Printing office, 1984), p. 35.

"Michael Schrage, "Murdoch Reaches for Sky in European TV Battle, "The Washington Post, Mar.3,1985, p. F, 1, 6, 7.

${ }^{14}$ Kalba Bowen Associates, The Economist: Connections: World Communications Report, No. 32, May 24, 1985, p. 8 .

"F or a detailed analysis of these trends, see U.S. Congress, Office of Technology Assessment, Information Technology R\&D:Critical Trends and Issues, OTA.CIT-268 (Washington DC: U.S. Government Printing Office, February 1985).

"U.S. Department of Commerce, International Trade Administration, "High Technology Industries: Profiles and Outlooks: The Computer Industry" (Washington DC: U.S.Government Printing office, 1983), p. 24.
} 
Figure 8-1.-Shrinking of Our Planet by Humans' Increased Travel and Communications

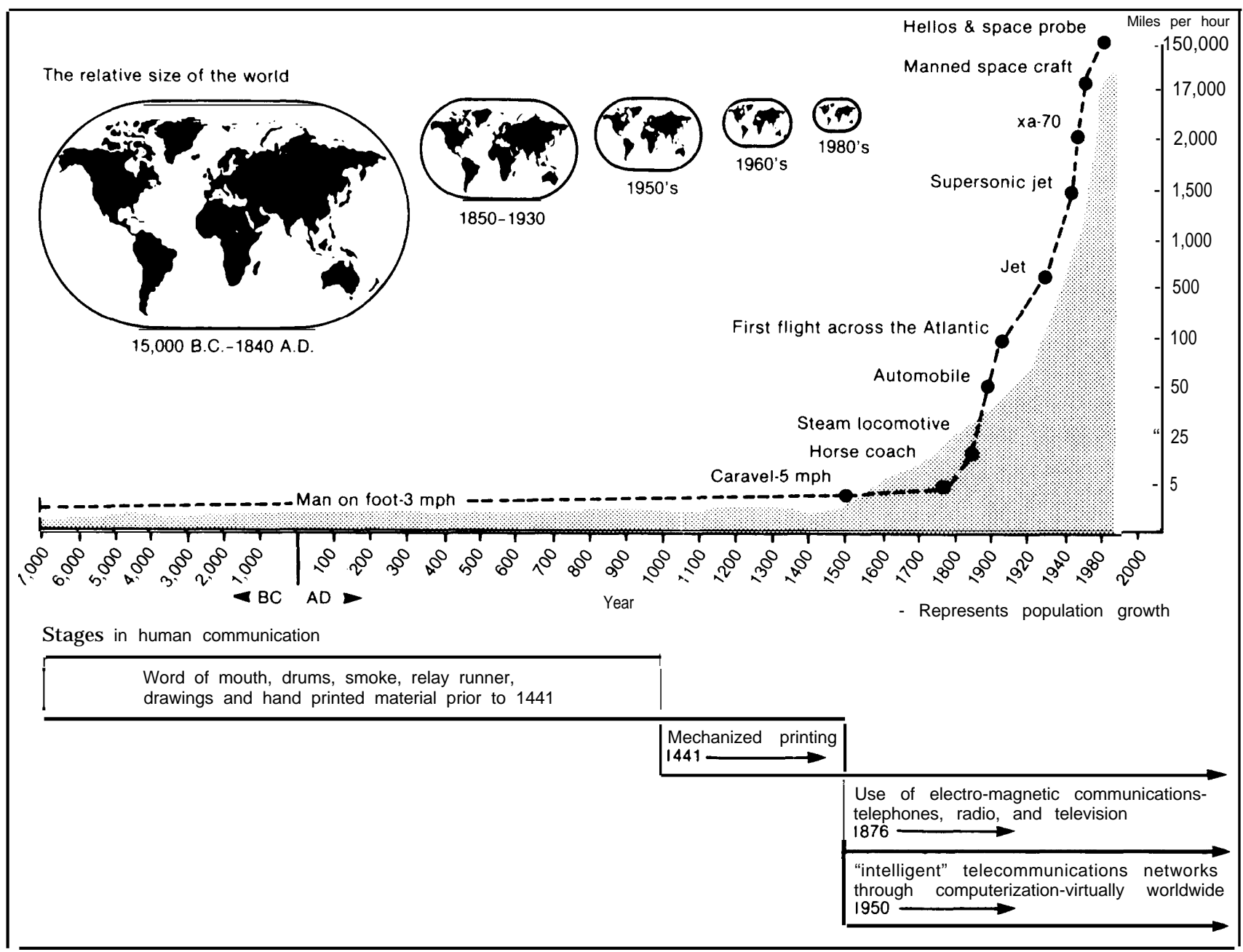

SOURCE: John McHale, World Facts and Trends (New York: Collier Books, 1972), p 3, as cited in Magda Cordell McHale, Facts and Trends: The Changing Information Environment: An Information Chartbook (Rome Intergovernmental Bureau for Informatics, 1985), p 2.

of telecommunication equipment increased from 1977 to 1983 by 22.1 and 35.3 percent, respectively . ${ }^{21}$ Between 1966 and 1981, the number of U.S. patents granted to foreign nationals increased from 13,722 to $26,546 .{ }^{22}$ The U.S. use of foreign scientific and technical liter-

${ }^{21}$ U.S. Department of Commerce, International Trade Administration, "High Technology Industries: Profiles and Outlooks: The Telecommunications industry" (Washington DC: U.S. Government Printing Office, 1983), p. 21.

"National Science Board, National Science Foundation, Science Indicators-1982 (Washington DC: U.S. Government Printing Office, 1983), p. 206; and Office of Technology Assessment and Forecast, U.S. Patent and Trademark Office, "Indicators of the Patent Output of U.S. Industry IV (1963-81)," 1982. ature increased 6 percent between 1973 and $1980 ;{ }^{23}$ the U.S. technology transfer exports (patents and management or consulting fees) equaled approximately $\$ 3,034$ million in $1973 .^{24}$ U.S. exports of cultural products (motion pictures, television programming, prerecorded entertainment, published materials) have also grown dramatically over the last few years: for example, the foreign revenues for U.S. motion

\footnotetext{
${ }^{23}$ National Science Board, National Science Foundation, Science Indicators-1982 (Washington DC: U.S. Government Printing Office, 1983), p. 12.

"Marc Uri Porat, "Global Implications of the Information Society, " Journal of Communications, winter 1978, p. 78,
} 
picture studios rose from $\$ 820$ million to $\$ 1,420$ million from 1978 to $1983 .{ }^{25}$

\section{Policy Implications}

The increasing flow of information and information-based products and services are breaking down national boundaries, thus challenging the traditional theories of international relations, which are based on the nation-state. ${ }^{26}$ With the erosion of national sovereignty, events taking place in one country will increasingly be felt in others. Consequently, intellectual property decisions, that were once considered exclusively domestic concerns, will now have to be made with international considerations in mind.

Currently, U.S. participation in international intellectual property fora is relatively limited. No longer a party to the United Nations Educational and Cultural Organization (UNESCO), the United States might not have as much political leverage in the Universal Copyright Convention (UCC), which is administered by UNESC $0 .{ }^{27}$ Although the U.S. withdrawal does not preclude the U nited States from observing UCC activities, it does prevent the United States from participating in the UNESCO General Conference, which reviews and approves the various budgets and administrative bodies of UNESCO, including the Copyright Division. As a result, the U.S. abilit $y$ to influence other nations in its favor might be weakened. Because the United States is no longer funding UNESCO activities, a reduc-

\footnotetext{
${ }^{25} \mathrm{CBS}$, inc., "Trade Barriers to U.S. Motion Picture and Television, Prérecorded Entertainment, Publishing and Advertising Industries, " September 1984, p. 10.

${ }^{26}$ The theory of the nation-state or the state-as-the-only -ac tor approach was first advanced by Arnold Wolfers. According to his theory, the most important characteristic of States is their sovereignty, which is considered indivisible and absolute. The model further implies that because States do not recognize any higher authority, they are consistently in an international state of conflict and competition. Consequently, there is almost a complete separation between politics within nations and politics between nations. Arnold Wolfers, Discord and Collabora. tion: Essays in International Politics (Baltimore: J ohns Hopkins University Press, 1962).

'-The increasing politicization that polarized UNESCO was a major impetus of the U.S. decision to withdraw from UNESCO in late 1984. Seymour Finger, "Reform or Withdrawal, " Foreign Service J ournal, vol. 61, J une 1984, pp. 18-23.
}

tion in funding for studies on emerging copyright issues which are traditionally sponsored by the UCC might also occur. Moreover, the United States might lose some of its ability to influence decisions about which substantive issues such studies will address. For example, recent U.S. efforts to convince the UCC Intergovernmental Committee to undertake studies on the copyrightability of computer software have not yet been successful.

Magnifying the problems arising out of the U.S. withdrawal from UNESCO is the fact that the United States is not a member of the only other major international copyright convention, the Berne Convention. Although, over time, the United States has amended its domestic copyright laws to be more compatible with those of the Berne Convention, several major attributes of U.S. copyright law impede U.S. ratification of the Berne Convention. These attributes include, for example, the formalities required to obtain protection under U.S. copyright law, such as registration and those enumerated in the manufacturing clause. ${ }^{28}$ As a nonmember of the Berne Convention, the United States can only observe Berne policy decisions; it cannot directly influence the development of policy concerning international protection of new technologies.

Given the increasing internationalization of intellectual property issues, the United States may want to take greater steps to influence their resolution. There are several options the United States might pursue to strengthen its presence in international intellectual property organizations. First, the United States might consider rejoining UNESCO. Because UNESCO houses not only the governing body of the Universal Copyright Convention, but also other agencies that oversee related matters of international information and communications policy, joining UNESCO might place the United States in a more advantageous position from

\footnotetext{
"Statement of Ralph Oman, Register of Copyrights, Assistant Librarian for Copyright Services, Library of Congress, Hearing on S. 1822 and S. 1938 Bills to Make Permanent the Manufacturing Clause of the Copyright Act, before the Subcommittee on Patents, Copyrights and Trademarks, Senate Committee on the J udiciary, J an. 21, 1986, p. 35.
} 
which to influence the decisionmaking process of such agencies, Rejoining UNESCO, moreover, might relieve much of the resentment harbored by many developing countries for the United States and its historical lack of international participation in the international intellectual property system.

Rejoining UNESCO, however, is not without political and economic tradeoffs. Additional funding, for example, would be required if the United States were to become a member of UNESCO. In addition, the United States would most likely need to make further political and perhaps economic concessions to address the concerns of the developing nations.

A second option to strengthen U.S. participation in the international intellectual property system would be to ratify the Berne Convention. This would benefit U.S. international copyright relations in several ways. First, the administrator of the Berne Convention, the World Intellectual Property Organization (WIPO), would provide a more favorable forum for dealing with international intellectual property issues because it specializes only in intellectual property rights and it is considered to be less politicized than UNESCO. Second, the Berne Convention provides the highest levels of international copyright protection. Third, ratification of the Berne Convention would also provide the United States with the opportunity to influence major policy development with regard to new technologies. Finally, joining the Berne Convention would show other nations, particularly developing nations, that the United States is indeed very committed to the protection of international intellectual property rights and that it is cognizant of the growing need for its system of intellectual property rights to operate within an international context. ${ }^{29} \mathrm{~F}$ or these reasons and others, there is wide agreement among those dealing with intellectual property issues, particularly at the international level, that a

\footnotetext{
${ }^{6}$ Donald Quigg, Acting Assistant Secretary and Commissioner of Patents and Trademarks, testimony on "U.S. Adherence to The Berne Convention, " before the Subcommittee on Patents, Copyrights, and Trademarks, Senate Committee on the J udiciary, May 16, 1985.
}

number of benefits would accrue to the United States if were to adhere to the Berne Convention. $^{30}$

At the same time, there are several tradeoffs associated with U.S. ratification of the Berne Convention. The major disadvantage of signing would be the legislative adjustments needed to bring the present U.S. copyright law into compliance with the Berne Convention. Although Congress has over the years sought to make U.S. law more compatible, several legal adjustments are still required. These include the need to remove copyright formalities embodied in the U.S. law-such as notice and deposit, compulsory licenses, and the manufacturing clause- and the need to add moral rights. ${ }^{31}$ The Department of State's Ad Hoc Working Group on U.S. Adherence to the Berne Convention, which is made up of representatives of the copyright community, is currently exploring how these adjustments can be made while preserving traditional U.S. laws and practices as much as possible.

\section{Growing Importance of Information and Information-Based Products and \\ Services to National Economies and International Trade and Competitiveness}

Historically, all nations have viewed the creation of intellectual works as having great cul-

'"'For example, at the Sept. 12, 1984, meeting of the Department of State's International Copyright Advisory Panel, the private sector representatives from all different parts of the intellectual property community were unanimous in their support for U.S. adherence to the Berne Convention. Moreover, all of the witnesses who testified before the Subcommittee on Patents, Copyrights, and Trademarks, Senate Committee on the J udiciary, expressed their support for U.S. adherence to the Berne Convention. Hearing on "U.S. Adherence to The Berne Convention, " before the Subcommittee on Patents, Copyrights, and Trademarks, Senate Committee on the J udiciary, May 16, 1985.

"'The importance of maintaining the attributes of U.S. copyright law, such as deposit, registration, and recordation provisions can scarcely be questioned. For these provisions have served a most important public function; they have enabled the Library of Congress to become the most important repository for U.S. cultural expression as well as for the rest of the world. " Donald Curran, Associate Librarian of Congress and Acting Register of Copyrights, Copyright Office, testimony before the Subcommittee on Patents, Copyrights, and Trademark, Senate Committee on the J udiciary, May 16, 1985. 
tural and social significance. Recently, however, intellectual products are becoming an increasingly important component of national and international economies ${ }^{32} \mathrm{~A}$ recent study on the size of the copyright industries reflects the same trend. These industries, which rely on the exploitation of the legal protections embodied in the copyright law, showed growth in sales from $\$ 6.2$ million, or 2 percent of the gross national product (GNP), in 1954 to $\$ 140.9$ billion, or approximately 5 percent of the GNP, in $1982 .{ }^{33} \mathrm{An}$ additional $\$ 11.3$ billion would be added if semiconductor chips were included. Estimates of the U.S. labor force involved in the copyright industries suggest that more that 2.2 million workers are affected by trade in intellectual property ${ }^{34}$ The U.S. Department of Commerce also estimates that in 1983, the United States enjoyed a $\$ 4.7$ billion favorable balance of payments in the licensing and assignment of patent rights, trademarks, and copyrights.

Information and information-based products and services are not only valuable economic commodities in and of themselves; their use also increasingly affects the performance of other economic sectors. The application of information technology is responsible for vast increases in productivity y in manufacturing industries, offices, financial services, and scien-

Several major studies completed over the last several years document this trend. Daniel Bell was one of the first to describe the changing role of information in society: "And if capital and labor are the major structural features of industrial society, information and knowledge are those of the postindustrial society. Daniel Bell, The Corning of Post Industrial Society (New York: Basic Books, 1976), p. xiii. A quantitative study by Marc Porat found that by 1967, the primary and secondary production, processing, and distribution of informationbased products and services constituted approximately 46 percent of the G N P and that nearly half of the labor force is engaged with informational activities. Marc Uri Porat, Office of Telecommunications, U.S. Department of Commerce, "The Information Economy: Definition and Measurement" (Washington DC: U.S. Government Printing Office, 1 977).

"Michael H. Rubin, *The Copyright Industries in the United States: An Economic Report Prepared for the American Copyright Council, " 1985, p. 1.

"U.S. Copyright Office. "The Size of the Copyright Industries in the United States, "Subcommittee on Patents, Copyrights, and Trademarks, Senate Committee on the Judiciary, December 1984.

'Eileen Hill, *'Commerce Department Seeks Greater Protection for U.S. Intellectual Property Rights, "Business America, Mar. 18, 1985, p. 3. tific research. ${ }^{36}$ Because they have become not only an important component in the U.S. economy, but also a significant productivity factor in many industrial sectors, information and information-based products and services have become an extremely crucial element in the U.S. economy and its overall international competitiveness. ${ }^{37}$

J ust as information and information-based products and services are of increased value to national economies, they are also becoming more important to the world economy. Recent evaluations have found that this complex of information industries is already the third largest in the world economy. In 1980, each of the industrialized nations spent approximately 4 or 5 percent of its GNP on information-based products and services. ${ }^{38}$ Figure 8-2 illustrates the large number of sectors in which many nations are using information technologies. Another estimate notes that the world information market equaled approximately $\$ 350$ billion or 18 percent of world trade in 1980. ${ }^{39}$

\section{Policy Implications}

Given the growing importance of information and information-based products and services to the U.S. economy, its export markets, and thus to its international competitiveness, intellectual property rights are acquiring greater significance. Policy makers are now recog-

"One economist documented these trends by showing that the introduction of information technology has made work more specialized and efficient, which in turn has led to greater productivity. Thus, the analysis showed that the quantity of real output produced by each production-sector worker in the U.S. economy was 6.4 times greater in the year 1970 than in 1900. Charles J onscher, "Information Resources and Economic Productivity," Information Economics and Public Policy, vol. 1, No. 1, 1983. p. 21.

"The President's Commission on Industrial Competitive ness, Committee on Research, Development, and Manufacturing, Appendix D, "Preserving America's Industrial Competitiveness-A Special Report on the Protection of Intellectual Property Rights, " October 1984

"Edward W.Ploman and 1.. Clark Hamilton, Copyright: Intellectual Property in the I nformation Age (London: Routledge \& Kegan Paul, 1980], p. 217.

"Cees J. Hamelink, Transnational Data Flows in an Information Age i Sweden: Studentlitt.eratur Ab Chartwell-Bratt Itd., 1984), p. 23. 
Figure 8-2.-Computer Utilization: Selected Countries, 13 Sectors

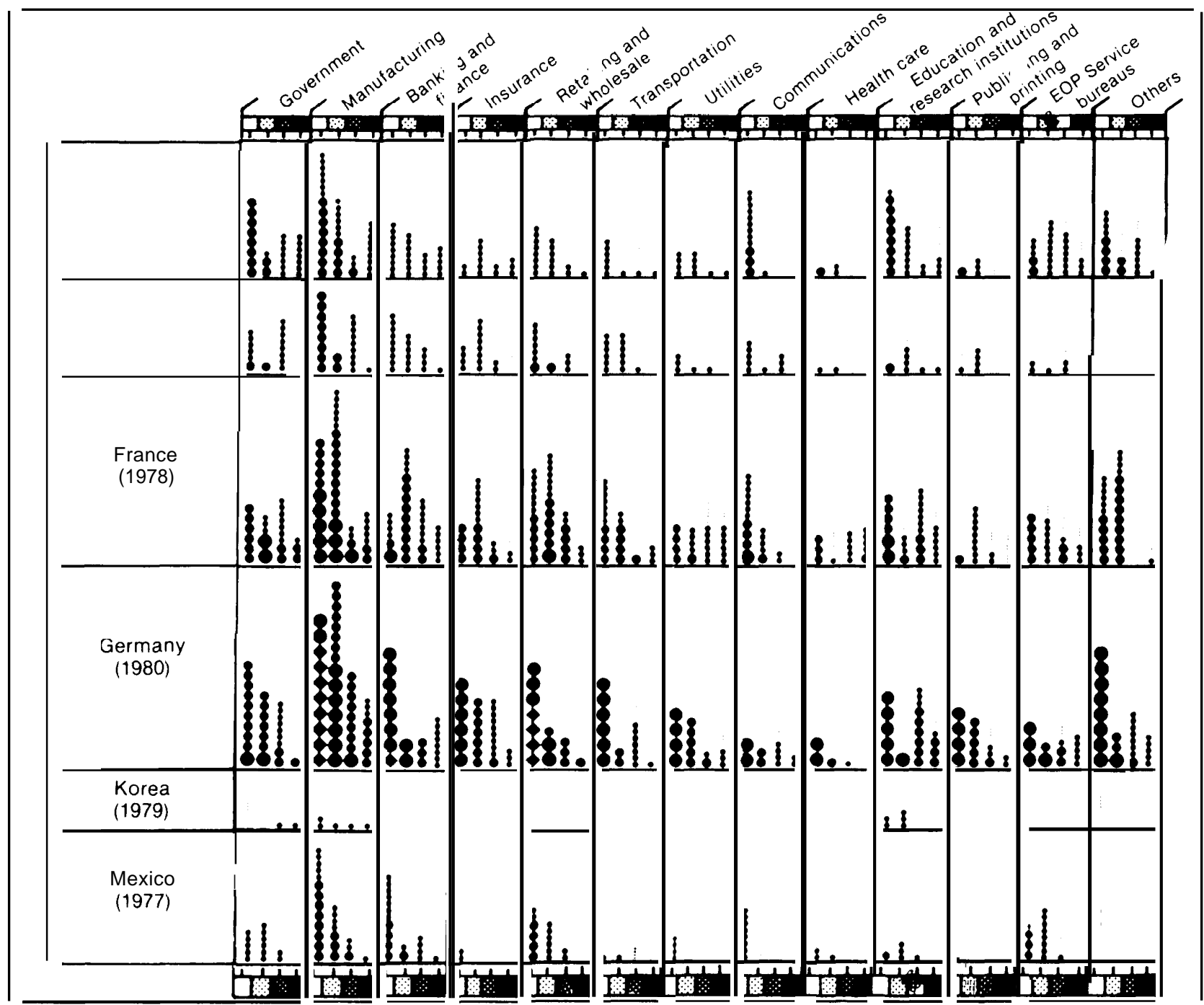

nizing the importance of factoring intellectual property protection into bilateral and multilateral trade relations. Similarly, international trade concerns are looming larger in international intellectual property relations. Such growing linkages may call for greater attention to these relationships and new ways of coordinating and addressing the issues to which they give rise. Thus, the United States might need to reassess its intellectual property policy at the national and international levels to accommodate these new linkages.
The United States has al ready taken some steps toward recognizing the protection of intellectual property rights as a major trade issue. The recent passage of the Trade and Tariff Act of 1984 (Public Law 98-573), for example, allows the President to take into account nations' laws and practices to adequately protect intellectual property rights as a condition for receiving the trade preferences granted under the Generalized System of Preferences Program (GSP). ${ }^{40}$ In addition, the Car-

${ }^{{ }^{40}}$ The Trade and Tariff Act of 1984 contains five provisions (continued on next page) 
Figure 8-2.-Computer Utilization: Selected Countries, 13 Sectors-Continued

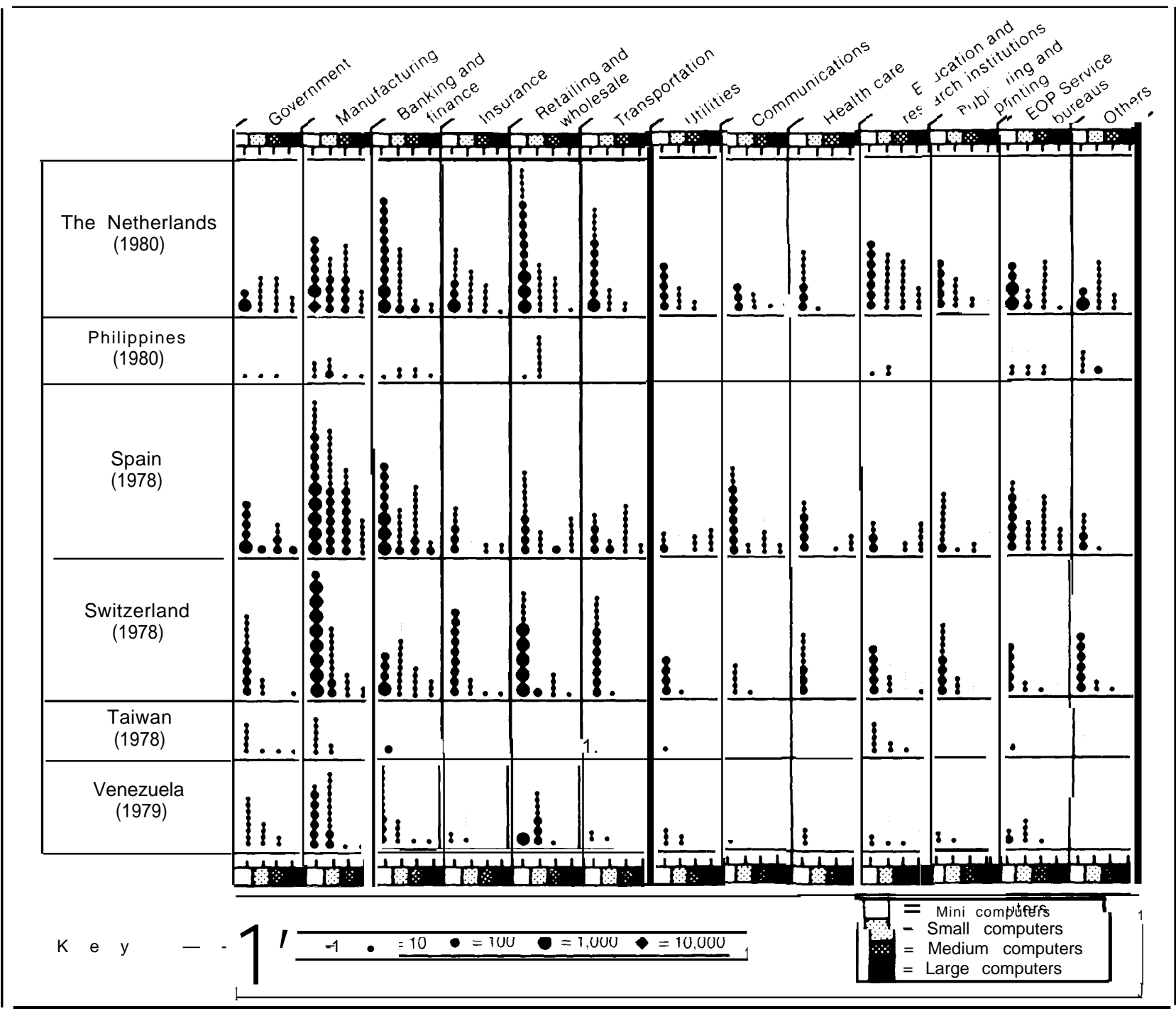

SOURCE U S Department of Commerce, International Trade Administration, Computers and Peripheral Equipment - Various Countries (Washington, DC U S Govern ment Printing Office, 1980), as cited in Magda Cordell McHale, Facts and Trends: The Changing Informatfin Environment: An informatron Char/book (Rome Intergovernmental Bureau for Informatics, 1985), p 32

ibbean Basin Economic Recovery Act (Public Law 98-67) makes the protection of U.S. copyrighted broadcast works a condition for Caribbean nations to receive U.S. aid.

(continued from previous page)

related to intellectual property protection. Many of the countries that are eligible for GSP benefits are also those countries which do not adequately protect intellectual property rights. These countries include, for example, Argentina, Bangladesh, Brazil, Chile, Colombia, Costa Rica, Egypt, Ecuador, Guatemala, India, Indonesia, Korea, Mexico, Pakistan, Peru, the Philippines, Portugal, Sr'Lanka, Taiwan, Thailand, Turkey, Uruguay, Venezuela, and Yugoslavia.
A number of other strategies are also available to strengthen trade opportunities for U.S. intellectual property products. One such option is to prevent imports of illicit copies of U.S. products or products illicitly manufactured with U.S. patented processes. The proposed Process Patent Amendment of 1985 (S. 1543 and H.R. 1069), for example, would make it a violation of patent law to use, sell, or import any product made overseas that is produced by an unlicensed patent process. 
Another recently proposed option is to include information products and services within the General Agreement on Tariffs and Trade (GATT). This option has broad support for several reasons. First, including intellectual property products in the GATT could provide international enforcement mechanisms in the form of dispute settlement mechanisms and trade sanctions as final retaliatory mechanisms for dealing with infringements-mechanisms that are not currently provided in international intellectual property agreements. Second, unlike many international intellectual property agreements, the GATT has a broad representation of the industrialized and developing nations as well as a history of consensus-building among its member states. Third, the GATT takes into account the economic development needs of the developing countries, allowing them differential treatment as a means of assisting their development.

There are, however, some negative aspects to such approaches. Linking the granting of trade preferences or foreign aid to the protection of intellectual property rights might provoke political discord between the United States and developing nations. I ncluding intellectual property products within the GATT also conflicts with many developing countries' notions of information and information-based products and services and might lead to political unrest and various forms of retaliation.

\section{Increasing Cultural and Political \\ Significance of Information and Information-Based Products and Services}

Historically, there have been political tensions between nations whose role as producers of intellectual property allowed them greater access to such products and nations that imported intellectual property products, and had only limited access to them. When the United States was still a relatively young and developing country, for example, it refused to respect international intellectual property rights on the grounds that it was freely entitled to foreign works to further its social and economic development.
Developing nations make the same argument today. Many believe they should be exempt from measures protecting intellectual property created outside their borders. They argue that access to information is vital to their development. Championing this viewpoint, developing nations were able to get revisions in the Berne Convention at Stockholm in 1967 and in the Universal Copyright Convention in 1971. Moreover, the influence of these countries has been felt at meetings of the United Nations Conference on Trade and Development (UNCTAD) and at the recent meeting to revise the Paris I ndustrial Property Convention. ${ }^{41}$

As information and information-based products and services become more important to social and economic development, questions of information access, which were formerly quite distinct from political considerations, are acquiring greater political significance. ${ }^{42} \mathrm{Be}$ cause both developed and developing nations view intellectual property protections as a major mechanism for regulating and controlling the flow of and access to information and information-based products and services, there is growing political pressure on the international intellectual property system. ${ }^{43}$

A case in point is the information gathered by remote sensing satellites. In 1972 the United States launched the Land Remote Sensing Satellite (Landsat) as part of a broader resource

\footnotetext{
"For example, the provisions for developing nations that were added to the Universal Copyright Convention in 1971 include exemptions that fall into three categories: 1 ) translation rights subject to compulsory licensing; 2 ) reprint rights subject to compulsory licensing; and 3) compulsory licensing in general. Subcommittee on Patents, Copyrights, and Trademarks, Senate Committee on the J udiciary, hearing on "Oversight on International Copyrights, " Sept. 24, 1984, pp. 61-62.

${ }^{42}$ Rita Cruise O'Brien and G. K. Helleiner, "The Political Economy of Information in a Changing International Economic Order, " International Organization, vol. 34, No. 4, Autumn 1980, p. 446.

"These access tensions, for example, have given rise to discussions of a New World Information Order in which developing nations call for freer access to technical and educational materials as well as a redress of the imbalances in the international flow of news and cultural products and a New World International E conomic Order which calls for greater controls over and access to technol ogy transfer to Third World nations. Both of these orders are intended to strengthen the self-sufficiency of devel oping nations.
} 
monitoring and assessment system . ${ }^{44}$ Uncopyrightable raw data on all countries generated by this series on the Earth Resources Satellite Program are disseminated to governments, firms, or individuals at very low prices. As Landsat is currently being transferred from government ownership to the private sector, data that have been processed and analyzed (by private sources), and thus are copyrightable, such as field-by-field analyses of croplands, blight, drought, and mineral resources, are available at a much higher price. Because less developed nations have difficulty paying these prices, or lack the computer technologies needed to process and interpret the data themselves, they often cannot gain access to such data. As a result, they believe that they are potentially at a disadvantage in world agricultural commodity markets, where private firms and wealthier governments can afford and use the data to make more well-informed, strategic decisions:

The importance of information lies in its role as a central factor in decision-making, including all matters related to development. Information is a precondition for identifying alternatives, reducing uncertainties about their implications, and facilitating their implementation. As such, information is a critical resource, not least for enhancing the negotiating capabilities of developing countries in the pursuit of clearly defined objectives, in particular in dealing with translational corporations. ${ }^{45}$

Many governments of developing countries also view information-processing and communication technologies as means to achieve major societal goals. Likening these technologies to a change in the "entire nervous system of social organization, many governments consider the establishment of information infrastructures to be crucial for development. ${ }^{46}$

"For a detailed analysis of international remote sensing satellite issues, see U.S. Congress, Office of Technology Assessment, Remote Sensing and the Private Sector: Issues for Discussion- A Technical Memorandum, OTA-TM-I SC-20 (Washington, DC: U.S. Government Printing Office, March 1984).

"United Nations Center for Transnational Corporations, Transborder Data Flows: Access to the International On-1ine Database Market (New York: United Nations, 1983).

"Simon Nora and Alain Mine, The Computerization of Society (Cambridge, MA: MIT Press, 1980).
These nations want to use information and communication technologies for such things as: national integration; administrative effectiveness; the delivery of formal and informal education; teacher training; agricultural information; medical and health care services; region-specific cultural programming; and coping with natural disasters. ${ }^{47}$ Many developing countries believe, therefore, that international intellectual property protection, which can act as a regulator of information flows, might inhibit such use and act as a barrier to development.

For these same reasons, many developing countries are wary of certain product patents. They contend that royalty payments required by patents should be relaxed for products that are necessary for development, and in some cases, human survival. ${ }^{48}$ Many industrialized nations oppose this point of view. Having incurred large costs in the research and development of products, they believe they are entitled to recoup their investments by selling in foreign markets.

One product that caused such a problem is the patented pharmaceutical product Tagamet (generic name, cimetadine, an anti-ulcer drug), developed by the U.S. company SmithKline Beckman. By the time the company was ready to market its product in Argentina, 48 percent of its market had already been undercut by a local firm selling the product at a much lower price. Due to Argentina's lack of patent protection for pharmaceuticals, the local companies could take the product and sell it at a lower price because they did not have to recoup development costs or pay royalty fees. Smith-

\footnotetext{
"Jorg Becker, Information Technology and a New International Order (Sweden: Studentlitteratur AB. Chartwell-Bratt Ltd., 1984), pp. 109-111.

"Because many developing nations believe they need to acquire technology from the advanced nations, they tend to retain patent, trademark, and copyright laws because they provide some security that helps to continue to attract foreign enterprise. However, the intellectual property protection is fre quently modified. They may offer, for example, compulsory license requirements, curbs on the manner in which the royalties are paid, exclusion of certain products or subject matter from protection, or official examination of the terms on which foreign rights owners establish their own local operations or grant licenses to local enterprises. W.R.Cornish, Intellectual Property: Patents, Copyright, Trademark, and Allied Rights (London: Sweet \& Maxwell, 1981), p. 17.
} 
Kline-Beckman claimed it lost approximately $\$ 50$ million in revenues because of the lack of patent protection in many developing nations. ${ }^{49}$

Growing political tensions between nations are also occurring with regard to intellectual property rights for plants. The United States and the other industrialized nations have no native primary crops. As a result, Western nations have traditionally used plant varieties from the Third World to genetically engineer new and better seeds for farm crops. Because many of the developing nations do not have the technology for seed development, they are generally forced to buy many of these genetically engineered seeds from the industrialized nations. Political tensions between nations arise because developing nations believe that the industrialized nations are exploiting the Third World's natural resources. They attribute the problem to the granting of intellectual property rights:

How is it that we farmers [from the Middle East] spent 10,000 years cultivating and breeding our plants, then someone else from the West works on it for 10 years, and only then is it called "intellectual property" and becomes patentable? ? $^{50}$

Although most tensions arising out of intellectual property rights have been primarily between industrialized and less developed nations, political issues related to such rights have recently begun to emerge between developed nations as well. A case in point involves the Strategic Defense Initiative (SDI) research program. Among other goals, political comity and support among nations for defense are major goals of the SDI research program. For this reason, the United States is seeking other nations' cooperation and participation in the SDI research program.

\footnotetext{
"Gerald Mossinghoff, President of the Pharmaceutical Manufacturers Association, testimony 'On the Beneficiary Country Practices," before the General System of Preferences Subcommittee of the Trade Policy Committee, June $24,1985$.

${ }^{50}$ Phillip Hilts, "Battles Sprout Over World Seed Supply: Bureaucrats and Nations Grapple With Charges of Neglect and Genetic Imperialism," The Washington Post, Nov. 4, 1985, p. A3.
}

However, one of the major impediments to gaining the support of other nations is the issue of ownership of technology. For example, the United Kingdom made it clear to the United States that it would not participate in the SDI program unless the terms for the rights to the technology were stipulated at the outset of the research. The United States, however, believes that this would be incompatible with the Defense Department's regulations, which do not allow blanket patent and technology transfer guarantees and require consideration on a case-by-case basis. Thus, intellectual property rights are the source of some political pressures among nations and may actually preclude international political cooperation and participation in the SDI program. ${ }^{51}$

\section{Policy Implications}

There are no simple solutions to the political issues raised by intellectual property rights. Although U.S. economic interests would most likely be served better by strict enforcement of intellectual property protections in other nations, political relations may also be a consideration. Many U.S. intellectual property products, for example, help promote U.S. culture abroad:

Books have unique qualities enabling them to provide foreigners substantive perceptions and insight into American society and government policies which they can get no other way. .. [T] hey smooth the path for the pursuit of our foreign policies. It has been said that next to people, books are our best ambassadors of international enlightenment and goodwill. ${ }^{52}$

\footnotetext{
${ }^{51}$ Karen DeYoung, "British, American Officials Hit Snags on SDI Cooperation: Allies at Odds Over Contract Terms, Ownership of Technology, " The Washington Post, Oct. 26, 1985, A5.

"Curtis Benjamin, U.S. Books Abroad: Neglected Ambassadors (Washington, DC: U.S. Library of Congress, 1983), p. 72. Recognizing the importance of books to increased understanding of the United States, the U.S. Government through the U.S. Information Agency distributes books worldwide in 57 languages; by 1971 it had published and disseminated 19,220 editions totaling 157,200.000 copies. Nicholas Henry, Copyright, Information Technology, Public Policy, Part 1: Copyright-Public Policies (New York: Marcel Dekker, Inc., 1967), p. 5.
} 
Similarly, copyrighted musical works, audiovisual works, sound recordings, and patented technical works also further international understanding and an appreciation of U.S. culture, and so might aid U.S. relations with both developing and industrialized nations.

Although many consider it unfair to expect producers of intellectual property to absorb large losses in international markets in order to foster international relations, the cultural and political significance of these products might require striking a new balance between producers and importers of intellectual property products. Political and cultural considerations as well as economic concerns might need to be taken into account when adjusting the international intellectual property system. These considerations might also need to be factored into U.S. domestic intellectual property policy and international trade and political relations.

Recognizing how important U.S. cultural and educational products are to its relations with other nations, the United States has established several programs within the U.S. Information Agency (USIA). These programs are designed to promote international understanding by providing developing and industrialized countries with American films, radio programs, television programs, music, books, and cultural programs at low or no cost. These programs, however, have been greatly reduced over the last few years. The USIA-sponsored book publishing program, for example, which includes translation programs and low-priced book programs, was reduced from 6,621,000 copies in 1956 to 525,000 copies in $1980 .{ }^{53} \mathrm{As}$ a result, many people have criticized the U.S. Government for failing to meet the Third World's cultural and educational needs. One former U.S. ambassador, for example, asserted that the U.S. Government's recent neglect of its overseas book, educational, and cultural programs denies our foreign policy "one of our greatest sources of strength as a nation."

\footnotetext{
"'Curtis Benjamin, U.S. Books Abroad: Neglected Ambassadors (Washington, DC: Library of Congress, 1984), p. 91.

"'"'Selling America in the Marketplace of I deas, " New York Times Magazine, Mar. 20, 1983.
}

Another U.S. diplomat pointed out that other industrialized nations, such as France, the United Kingdom, and West Germany, devote a greater proportion of their national budgets to public distribution of information products for diplomatic purposes than does the United States."

The United States has several options for addressing the political issues raised by new technologies. If the United States wishes to address the informational needs of developing countries, for example, it might increase USIA information distribution programs, and include provisions for the distribution of information in other international development programs for education, agriculture, medicine, transportation, etc. Moreover, USIA might implement new programs to help nations to develop information and communication infrastructures, so they can utilize information in electronic forms such as databases, videotapes, and software programs:

Information access is easier to transfer to the devel oping world than was agriculture or industrial know-how. While it is not possible to put the Third World on an equal footing with the First World in the next ten years, it is possible to communicate the needed expertise now. The best mathematicians in the world could create expert systems and make them available to the poorest countries through existing satellite networks and earth stations, relayed by telephones to low-cost terminals. Medical diagnosis and training or engineering design could also be redistributed throughout the world at a unit cost within national budgets.

Another option that the United States might pursue would be to earmark funds that were traditionally allocated for foreign aid for the purchase of intellectual property products. This would give developing countries access to information and information-based products and services and at the same time instill re-

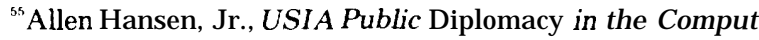
er Age (New York: Praeger Press, 1984).

"J erome Glenn, "Helping Countries Help Themselves: Keys to Third World Development, " The Futurist, December 1985, pp. 33-35.
} 
spect for the protection of intellectual property rights.

Although these options address the growing political issues relating to intellectual property rights, they might also conflict with U.S. trade and economic views of intellectual property. For if the United States contributes many of its information-based products and services to developing countries, it cannot receive the international market value of such highly sought after products and services. This, in turn, could have a negative effect on the U.S. balance of payments.

\section{Emergence of New Information-Based Products and Services That Do Not Correspond to Traditional Intellectual Property Protections}

Although rooted in different philosophical traditions, the intellectual property systems of different nations have been harmonized over the years through the international intellectual property system. This cooperation, made possible by a shared set of goals as well as by national treatment, led in the past to general agreement among nations on what constituted protectable subject matter, infringement activity, and the like. This process of reaching international agreement is generally slow, depending on years of interplay between national and international laws and policies. ${ }^{57}$

The unprecedented rapid and large-scale development of new information and informationbased technologies, which is illustrated in figure 8-3, has disrupted this formerly stable system. Such rapid and large-scale technological change has forced nations to respond faster and perhaps more dramatically in interpreting and legislating intellectual property protection. Some nations have enacted intellectual property legislation to protect emerging technologies, while other nations have not. These divergent reactions have led to great inconsistencies among nations, which, in turn,

\footnotetext{
"This slow and elastic process of unifying national intellectual property law and policies is cited as one of the most important aspects of the international intellectual property conventions.
}

have made agreement at the international level more difficult.

Intellectual property protection for computer software is one often-cited example of the differing levels of protection nations have granted a new technology:

The debate on both the possibilities and appropriate form for protection of software has now been continuing for nigh on 15 years. ... Despite the harmonization of national legislation ... we are still faced with a whole gamut of divergent solutions ranging from the full recognition of the patentability of software and its protection under copyright, through various intermediary solutions, to a radical refusal of any protection for computer software. ${ }^{58}$

Because the United States was one of the first countries where computer software became a large and important market, it was here that the debate over its protection first took place ${ }^{59}$ Like many other industrialized nations, the United States explored the possibilities of protecting software by drawing analogies between the characteristics of software and other intellectual properties that are protected by existing legal frameworks, such as copyright, patent, and trade secrets. After many heated debates and commissioned studies, the United States, in a 1980 amendment to the 1976 Copyright Act, explicitly granted copyright protection for software. ${ }^{60}$

\footnotetext{
${ }^{5 *}$ Kolle, "Computer Software Protection-Present Situation and Future Prospects, Copyright 13, 1977, p. 70.

"In 1982, the worldwide revenues from software amounted to $\$ 13$ billion and is projected to quadruple by 1987 . U.S. companies garner approximately 70 percent of the market. United States Trade Representative, "USTR Seminar on International Copyright Issues in Computer Software, " Sept. 24, 1984.

${ }^{60}$ The United States implicitly extended copyright protection to computer software in the Copyright Act of 1976, 17U.S.C. $\$ \S 101-810$. The National Commission on New Technological Uses of Copyrighted Works (CONTU), created by Congress to revise comprehensively the copyright laws of the United States, stated in its final report that "it is clear that. . . those who have administered the portions of the 1909 act concur in the position that programs are copyrightable. The Copyright Act was amended in 1980 to expressly state that computer programs were to be included as copyrightable works: Section 101 of the Act was amended by addition of the word "computer program," and a definition of that term; Section 117 was amended by the addition of certain limitations on exclusive rights pertaining specifically to computer programs. The U.S. courts have also recognized copyright protection for software.
} 
Figure 8-3.-The Speed of Change: Intervals Between Discovery and Application in Physical Science

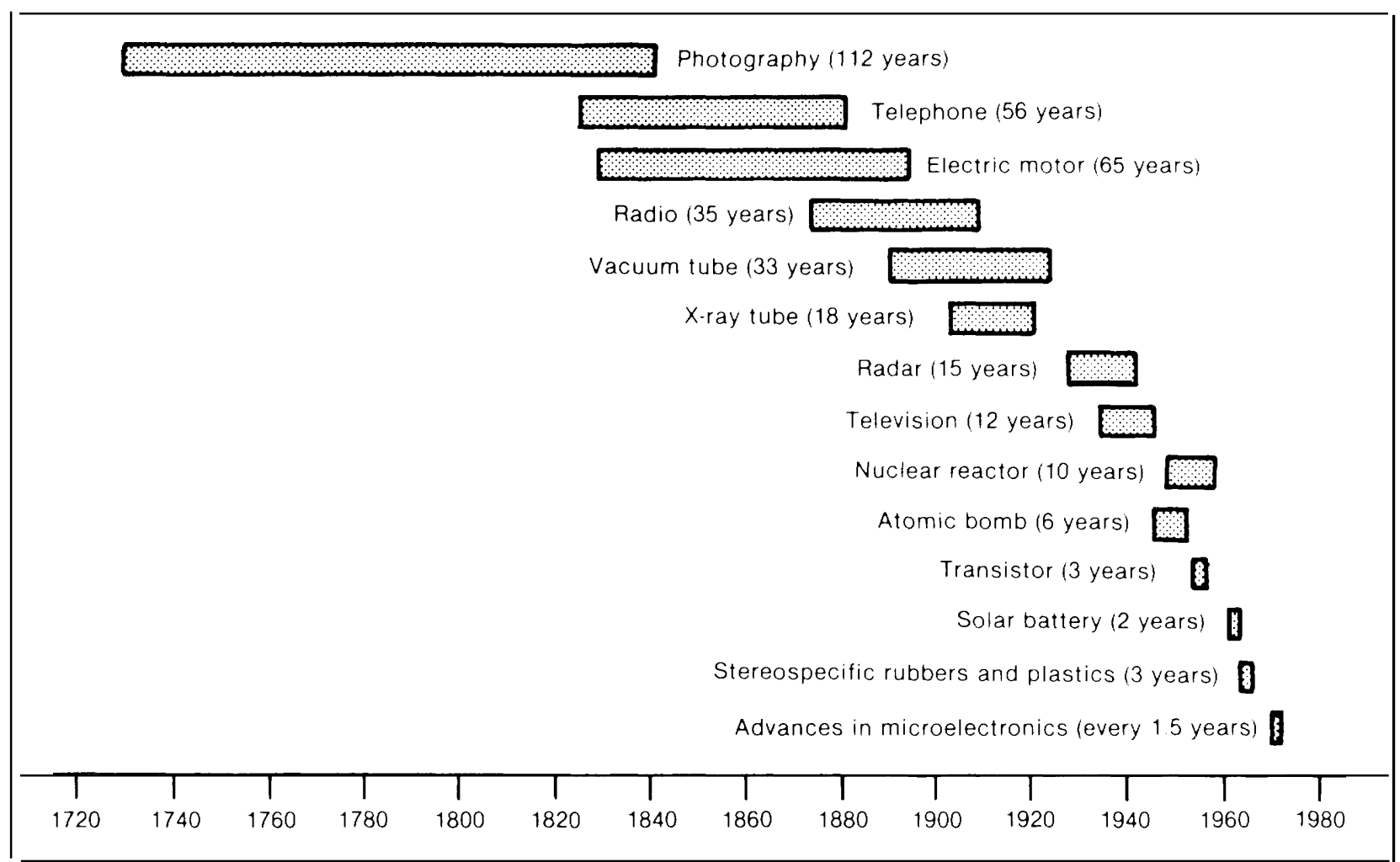

SOURCE John McHale, World Facts and Trends (New York Collier Books, 1972) p 3, as cited in Magda Cordell McHale Facts and Trends The Changing Information Environment: An Information Chartbook (Rome Intergovernmental Bureau for Informatics 1985) p 4

Although most nations have not explicitly amended their copyright laws to include software, some either consider it to be protectable under copyright law through judicial interpretation and/or are actively pursuing copyright protection. ${ }^{61}$ These countries include Austria, Canada, Colombia, France, Finland, the Federal Republic of Germany, Italy, India, J apan, Korea, Mexico, the Netherlands, South Africa, Spain, Sweden, and the United Kingdom."

\footnotetext{
' 'Currently-, Australia, Hungary, the Philippines, and Taiwan have amended their copyright laws to include computer software as protectable subject matter.

"United Nations Educational, Scientific, and Cultural Organization (UN F; SC()), World Intellectual Property Organization (WI PO), Group of Experts on the Copyright Aspects of the Protection of Computer Programs, Michael S. Keplinger, "A Survey and Analysis of National Legislation and Case Law, March 1985; and Michael S. Keplinger, "Authorship in the Information Age: Protection for Computer Programs Under the Berne and the Universal Copyright Conventions, Copyright, March 1985, pp, 119-128.
}

Among those nations that are considering protection for software, there is a wide variety of schemes envisioned. Some nations would offer such protection, but with limitations. A white paper prepared for the Canadian Government, for example, proposes to limit copyright protection for object code (machinereadable language) to 5 years. ${ }^{63}$ Other nations have declared that they will not protect software under the copyright law, although they may grant it some type of sui generis protection. Other nations may not protect software at all. Brazil, for example, is considering legislation that would establish a sui generis form of protection that would require compulsory licensing of software to Brazilian companies and compulsory registration of both source and

\footnotetext{
' Consumer and Corporate Affairs and Department of Communications, Government of Canada, "From Gutenburg to Telidon: A Guide to Canada's Copyright Revision Proposals" (Ottawa: Ministry of Supply and Services, 1984).
} 
object codes. The proposed protection, moreover, would be for a very short duration. Such varied approaches to protecting-or not protecting-software and other rapidly changing technologies might impede attempts to reach an international agreement on software protection. ${ }^{64}$

The introduction of reprographic technologies offers another example of how new technology is complicating the harmonization of national intellectual property law at the international level. The increasing use of these technologies has undermined owners' rights to collect remuneration for the reproduction of their works. To cope with these problems, many nations have legislated new rights enabling creators to collect compensation for the use of their works. The Federal Republic of Germany, for instance, has dealt with the problem by amending its copyright law to include a compulsory license that allows authors to collect equitable remuneration for the commercial reproduction of their works. In contrast, France has introduced a tax on the sale and importation of all reprographic copying machines in its 1976 Finance Act. Part of the collected revenues from the tax are paid to the copyright owners. This law applies only to French copyright holders, even though France is a member of both international copyright conventions.

Although both of these solutions aim to ensure rights owners remuneration, they are legally inconsistent with one another, and thus will cause difficulty for international agree-

\footnotetext{
“The fact that WIPO's 1978 proposed draft Treaty for the Protection of Computer Software (which includes rules for the minimum protection of software that are closely related to those of copyright and unfair competition) has not been ratified illustrates the problems of finding an adequate protection for software that can be agreed on internationally. The draft Treaty proposed that in view of the large degree of uncertainty generally related to the existence and form of protection under copyright, that a special system of protection of software similar to copyright should be set up at national and international levels. The draft Treaty, moreover, calls for the international deposit of software. Some individuals believe, however, that Article II of the Berne Convention is applicable for the international protection of software. Cynthia L. Mellema, "Copyright Protection for Computer Software: An International View, Syracuse Journal of International Law and Commerce, vol. 11, summer 1984, p. 90.
}

ment. The West German compulsory license, although under the rubric of copyright law, would be incompatible with the solution enacted by the French. The more serious difficulty, however, arises with solutions like that adopted by France. Because the right to compensation is introduced under legislation outside of the copyright law, the principle of national treatment, on which the entire international intellectual property system is built, is seriously undermined. ${ }^{65}$ The principle of national treatment is challenged because the compensation for the reproduction right does not arise from a copyright, and thus foreigners cannot collect compensation for use of their works. In general:

If that device is generally used by governments when dealing with the new uses of copyright material arising from new technology and new means of communication, the fundamental principle of national treatment and with it the [international] copyright conventions based on it, could be seriously eroded in the near future. ${ }_{66}$

Another problematic situation arises from applying patent law to activities in outer space. Domestically, the National Aeronautics and Space Administration (NASA) has adopted a

\footnotetext{
"Another example of how a right to remuneration has been taken out of the copyright sphere can be seen in the rights many countries have granted to enable creators to receive remuneration from home taping activities. In the case of home taping, a levy on recording equipment or blank tape can be treated as royalty to be divided among copyright holders as in West Germany or Austria. However, it can also be treated largely as a tax, as in Sweden, where 90 percent goes to public funds and 10 percent goes to the rights owners (authors, performers, and phonogram producers). Public lending rights (although an indirect responseto the introduction of reprographic technologies), which entitle authors of literary works to receive a royalty when their books are borrowed from a library, have also caused difficulties for international harmonization. For example, in the Federal Republic of Germany this right is granted in their copyright law, and therefore as the Federal Republic of Germany is a member of both the Berne and UCC Conventions, foreigners are entitled to remuneration if their books are borrowed. The Scandinavian countries and the United Kingdom, however, which also grant a public lending right, have chosen to do so by separate legislation outside of the copyright laws and therefore are not bound to grant the right to foreigners; although like the Federal Republic of Germany, they are also members of both conventions, Stephen Stewart, The Law of International Copyright and Neighboring Rights (London: Butterworth \& Co. (Publishers) Ltd., 1983), pp. 42-43, 282.

Ibid., p. 43.
} 
clear policy of providing maximum protection for intellectual property rights to encourage the use of and commercialization of NASAsupported and developed technology. However, as more research, particularly international cooperative research, is performed in space, it may become more difficult to determine which national legal jurisdiction of patent protection applies to it. For example, sections 102 and 104 of the U.S. Code 35 state that the factors used to determine patentability under U.S. Iaw or to establish priority in international conflicting claims to invention include where an invention was conceived, reduced to practice, or used. In addition, under the U.S. patent law patents protect use or manufacture only in the United States. As more U.S. and international research and development is performed in space, the question arises, therefore, as to how to obtain and enforce U.S. patent rights in space. ${ }^{67}$

\section{Policy I mplications}

The speed and scale of technological change, now and in the future, together with the rapid development of national and international law, are likely to heighten the pressures for the development of international intellectual property law. ${ }^{68}$ As technological change prompts more need for rapid international consensus, greater international action and coordination will become necessary. Consequently, the United States might have to participate to the

\footnotetext{
"The Applicability of U.S. Patent Laws in Outer Space, " Telecom Highlights, J une 19, 1985, p. 4; and Barbara Luxenberg (Special Assistant to the Assistant Secretary and Commissioner of Patents and Trademarks, U.S. Department of Commerce), "Protection Intellectual Property in Space: Policy Options and Implications for the United States, " presented to the Georgia Institute of Technol ogy Conference, 1985, International Space Policy: Options for the Twentieth Century and Beyond, May 16, 1985

After approximately a century without any major copyright reform, the reform of national copyright laws to adjust the law to advancing technol ogy has speeded up considerably in the last three decades. For example, new copyright acts passed in France in 1957, the United Kingdom, 1956; India, 1957; the Scandinavian countries, 1959/1960; Germany 1965; Australia, 1968; J apan, 1971; the Soviet Union, 1973; and the United States, 1976; and many Latin American countries, 1970s are evidence of this trend. Stephen Stewart, The International La w of Copyright and Neighboring Rights (London: Butterworth $\&$ Co. (Publishers) Ltd., 1983), p. 281.
}

fullest possible extent in international intellectual property fora so that it can both influence international decisions and keep abreast of national and international developments. The United States, moreover, might need to take greater account of how its domestic intellectual property legislation could affect or be affected by the international system.

As discussed above, the extent of U.S. participation in international intellectual property organizations is relatively limited because of its withdrawal from UNESCO and its abstinence from the Berne Convention. This lack of participation might seriously impede the United States from monitoring developments in international agreements. Moreover, it may also weaken the U.S. ability to influence decisions about which rights might be incorporated into the international agreements with respect to new technologies.

In addition to its lack of international participation, recently proposed and already legislated U.S. intellectual property policies might be inconsistent with international intellectual property norms. The recent passage of the Semiconductor Chip Protection Act of 1984 (Public Law 98-620), for example, created a sui generis protection for semiconductor chips. Although this new type of protection maybe well suited for the functional nature of chips, there is a trade-off with respect to its consistency with the system of international agreements. Because the Semiconductor Chip Protection Act of 1984 is a sui generis approach and does not fall under the rubric of copyright or patent law, there is no international agreement under which the protection of chips can be organized at the international level. Moreover, section 902 of the act states that foreigners may only receive protection if their nation also protects mask works. This reciprocity clause is inconsistent with the principle of national treatment which requires all nations to provide foreigners with the same protection as their citizens. Exacerbating these problems, some nations, such as the United Kingdom, disagree with the sui generis approach, considering chips to be protected under copyright 
law. ${ }^{69}$ To date, only one other nation, J apan, has legislated a sui generis protection for semiconductor chips.

The International Software Protection Act of 1985 (S. 339, 99th Congress) is another example of a proposed policy that might cause problems for the present system. This bill would amend the U.S. copyright law to protect a foreign nation's computer software only to the extent that such a nation protects software-the so-called "rule of the shorter term. "It also stipulates that, if a nation protects software for a period of less than 25 years, the U.S. will suspend all protection for that nation's software. Like the reciprocity clause of the Semiconductor Chip Protection Act, this conflicts with the principles of national treatment called for in the international intellectual property agreements.

The recently proposed renewal of the manufacturing clause also illustrates how a U.S. intellectual property policy might negatively effect U.S. international intellectual property relations. First introduced in the 1891 Copyright Act, this clause required that literary works be printed in the United States in order to enjoy U.S. copyright protection. The general purpose of the manufacturing clause was to protect those who feared that granting unrestricted copyright protection to foreign (specifically British) authors would enable foreign publishers to dominate the U.S. book market. Recognized by many as a type of "xenophobic trade barrier" the manufacturing clause has been weakened over time, and most recently was set to expire in J uly 1986 (Public Law 97215). ${ }^{70}$ However, Congress is currently considering legislation that would extend the manufacturing clause or make it permanent (S. 1938, S. 1822, H.R. 3465, H.R. 3890, 99th Congress).

The manufacturing clause has created several difficulties for U.S. international intellectual property relations. Because it imposes formalities (the requirement of U.S. publication)

\footnotetext{
${ }^{6 \cdot} \mathrm{R}$. Hart, "Legally Protecting Semiconductor Chips in the UK, " European Intellectual Property Review, vol. 9, 1985, pp. 258-263.

"'Benjamin Kaplan, An Unhurried View of Copyright (New York: Columbia University Press, 1967), p. 124.
}

on works of foreign origin, it impedes U.S. adherence to the Berne Convention. For to join the Berne Convention, member nations cannot impose formalities as a condition of copyright. The manufacturing clause has also been the subject of complaints of unfair trade practices by the European E conomic Community (EEC), and found to be an import restraint that is inconsistent with Article XI of the General Agreement on Tariffs and Trade (GATT) .7' Because it restricts the protection of foreign works and precludes the United States from ratifying the Berne Convention, this clause might also lead other nations to believe that the United States is disingenuous in its attempts to convince other nations to ratify international intellectual property conventions.

If the United States proceeds with policies that are incompatible with either international agreements or other nations' domestic laws and practices, it might jeopardize its ability to incite other nations to protect U.S. intellectual property products. For unlike many other items of international trade, the financial returns from intellectual property products are largely dependent on other nations' laws and enforcement actions. Therefore, the United States must ensure other nations' cooperation and support for the international protection of intellectual property rights. A coercive approach or the imposition of U.S. policies on other nations might not necessarily serve to elicit other nations support for the international protection of intellectual property, as one copyright analyst points out:

Of course it would be pure folly to expect all nations of the world, including the new ones, to introduce at the present stage the same copyright regime as we and other wellendowed old-timers are-or, in the case of the Soviet Union, should be-willing to accept. We should recall that in 1891 that this country, claiming to be a have-not, provided no legal protection whatever for the published works of foreigners. When our legislation of 1891 finally did grant rights to such works,

-'"Ralph Oman, Register of Copyrights, Library of Congress, testimony on "Bills To Make Permanent the Manufacturing Clause of the Copyright Act, " before the Subcommittee on Patents, Copyrights, and Trademarks, Senate Committee on J udiciary, .J an. 21,1986, p. 7 . 
it was on the condition, in the case of books among certain other productions, that manufacture be carried out in the United States .... But I have brought in the manufacturing clause to suggest by example that harmonization is bound to have its difficulties and, beyond that, to propose that we [the United States] ourselves should take another step toward international pacification. ${ }^{72}$

Ratifying the Berne Convention and rejoining UNESCO are possible to options to bring U.S. Iaw into line with international intellectual property law. As previously discussed, these options would have both positive and negative effects on the U.S. position in the international intellectual property system.

Another option to address the legal issues raised by new technologies would be to establish a critical review of how proposed legislation would affect and be affected by the international system; accordingly, legislation might be modified to that effect. However, similar to the negative outcomes associated with joining the Berne Convention, conforming U.S. laws and practices to international intellectual property norms might threaten the integrity of traditional U.S. intellectual property laws and practices.

Increasing Difficulty of Enforcing Intellectual Property Rights Caused by Emerging Information and Communication Technologies

Traditionally, nations granted intellectual property rights on the assumption that they could, in fact, be enforced. In the past, this was true; copyright holders could more easily collect for uses and detect infringements of their works. This was the case because uses of creative works were easily monitored, and infringements easily detectable, and because the geographic scope of use was generally confined within national boundaries.

\footnotetext{
"'Benjamin Kaplan, "An Unhurried View of Copyright (New York: Columbia University Press, 1967), pp. 123-124.
}

While facilitating the international exchange of intellectual property, new communication and information technologies have also undermined the traditional ways of enforcing intellectual property rights. The same technological advances contributing to economic growth, trade, and international access have also made it easy and inexpensive to reproduce and pirate intellectual property .73 Moreover, these technologies, such as satellites, cable, photocopying, recording audio and video devices, computers, and electronic storage, retrieval, and distribution systems, are more powerful than their predecessors, engendering problems of enforcement that are much larger and more international in scope.

The level of legal protection for intellectual property in many nations also contributes to international piracy of U.S. copyrighted works. The problems U.S. copyright owners face abroad with respect to these conditions can be classified into three categories:

1. nonexistent (ineligibility) copyright protection in a foreign country;

2. inadequate protection in a foreign country; and

3. ineffective copyright protection in a foreign country .

The growing problem of international enforcement is exemplified in the apparent rapid increase of international piracy of protected works. Many U.S. industries have reported large losses due to foreign private copying, commercial piracy, and counterfeiting of their intellectual property products. ${ }^{75}$ The U.S. In-

\footnotetext{
“'International Intellectual Property Alliance, "I nternational Intellectual Property Alliance: U.S. Government Trade Policy: Views of the Copyright Industries, 1985, p. 10.

"'Subcommittee on Patents, Copyrights, and Trademarks, Senate committee on the J udiciary, "Oversight on International Copyrights: How To Protect the Nation's Creativity by Protecting the Value of the Intellectual Property, " Sept. 25, 1985, p. 86.

"Although piracy and counterfeiting each constitute theft of intellectual property, there are small differences in their meaning. In addition, private copying, which is not clearly defined as a legal or an illegal practice under most nations' laws, also has a potential impact on the sales of intellectual property products. Piracy refers to unauthorized reproduction for commercial gain of literary, musical, artistic, and other copyright works. Because pirates do not pay royalties and bear no development costs, they can easily sell their products more cheaply than the
} 
ternational Trade Commission estimates U.S. domestic and foreign sales losses due to patent and copyright infringements at between $\$ 6$ billion and \$8 billion per year. ${ }^{76}$ Figure 8-4 shows the level of infringing activities and some frequently counterfeited products. The International Anti-Counterfeiting Coalition and the U.S. Customs Service place losses due to the infringement of intellectual property rights closer to $\$ 20$ billion annually.${ }^{77}$ Another survey undertaken by the International Intellectual Property Alliance of the losses due to piracy of U.S. copyrighted records and tapes, motion pictures, and books in 10 selected nations estimates annual losses at $\$ 1.3$ billion (see table 8-3). A poll of the motion picture and television, prerecorded entertainment, and publishing and advertising industries also revealed that 100 percent of the executives surveyed cited intellectual property rights infringements abroad as a major barrier to sales of their products in international markets ${ }^{78}$ (see table 8-4).

Although these estimates provide a general approximation of the extent of the piracy problem, there are relatively few data on specific industries in individual countries and on the actual amounts of revenue lost due to private copying, commercial piracy, and counterfeiting. Evidence of private copying and piracy

(continued from previous page)

rights owners. Counterfeiting refers to unauthorized duplication of a product's trademark to give a similar appearance of a specific product. In addition to directly undercutting the original rights owner's market, counterfeiters by producing lower quality imitations of products may also damage the products quality reputation and further undercut the original market. Although not illegal, private copying generally refers to home copying of intellectual property products solely for individual consumption. It has resulted from the ready availability to the consumer from 1964 onwards of magnetic tape reproduction equipment coupled with blank cassettes, videotape recorders coupled with blank cassettes, personal computers coupled with blank software, etc. See Gillian Davies Privatecopying of Sound and Audiovisual Recordings (Oxford: ESC Publishing Limited), 1984.

"U.S. International Trade Commission, "The Effects of Foreign Product Counterfeiting on U.S. Industry" (Washington, DC: U.S. International Trade Commission, J anuary 1984).

"Eileen Hill, "Intellectual Property Rights: Commerce Department Program Seeks Greater Protection for U.S. Intellectual Property Rights, " Business America, Mar. 18, 1985, p. 4.

${ }^{77} \mathrm{CBS}$, Inc., "Trade Barriers to U.S. Motion Picture and Television, Prerecorded Entertainment, Publishing and Advertising Industries," September 1984, p. iii. is generally gathered indirectly: by measuring the increase of sales and availability of hardware that permits easy and inexpensive copying; the increase of sales of blank audio and video tapes; the decreasing sales of published, audio, and video works; the decreasing number of journal subscriptions in different countries; the widespread availability of unauthorized copies of American creative works; or the level of ineffectiveness or inadequacy of protection offered in different countries. These measurements, however, do not directly indicate what percentage of the purported piracy is of U.S. products. In other instances, when overall estimates of revenues lost to piracy are presented, the methodology or definitions of harm used to extrapolate such figures are often inconsistent throughout the calculations or are not readily apparent. For example, much of the survey data on the effects of unauthorized copying on producers must be carefully interpreted in light of the way in which harm is defined:

Two possible definitions [of harm] are suggested. Under the first, harm is measured by the reduction in profits of the producer below their level prior to a new unauthorized use. Under this definition, harm does not occur if the unauthorized use leaves profits from all previous uses unaffected. . . Under a second definition, harm occurs if the new use reduces profits below the level they would have reached had the producer been able to exploit the market served without authorization. . . Clearly, these alternative definitions can give very different answers to the question of whether an unauthorized use has harmed the property owner. The distinction between them must be kept in mind when examining the various claims of harm. ${ }^{79}$

The definitions of piracy also vary greatly from nation to nation, and they are generally dependent on each country's intellectual property laws and on international norms. It would seem, therefore, that because American products garner a relatively large percentage of foreign markets, foreign piracy of U.S. intellec-

\footnotetext{
"Stanley Besen, "Economic I ssues Relating to New Technologies and Intellectual Property, " contract prepared for OTA, December 1984, pp. 45-55.
} 
Figure 8-4.-The Level and Location of International Counterfeit Activity of U.S. Products

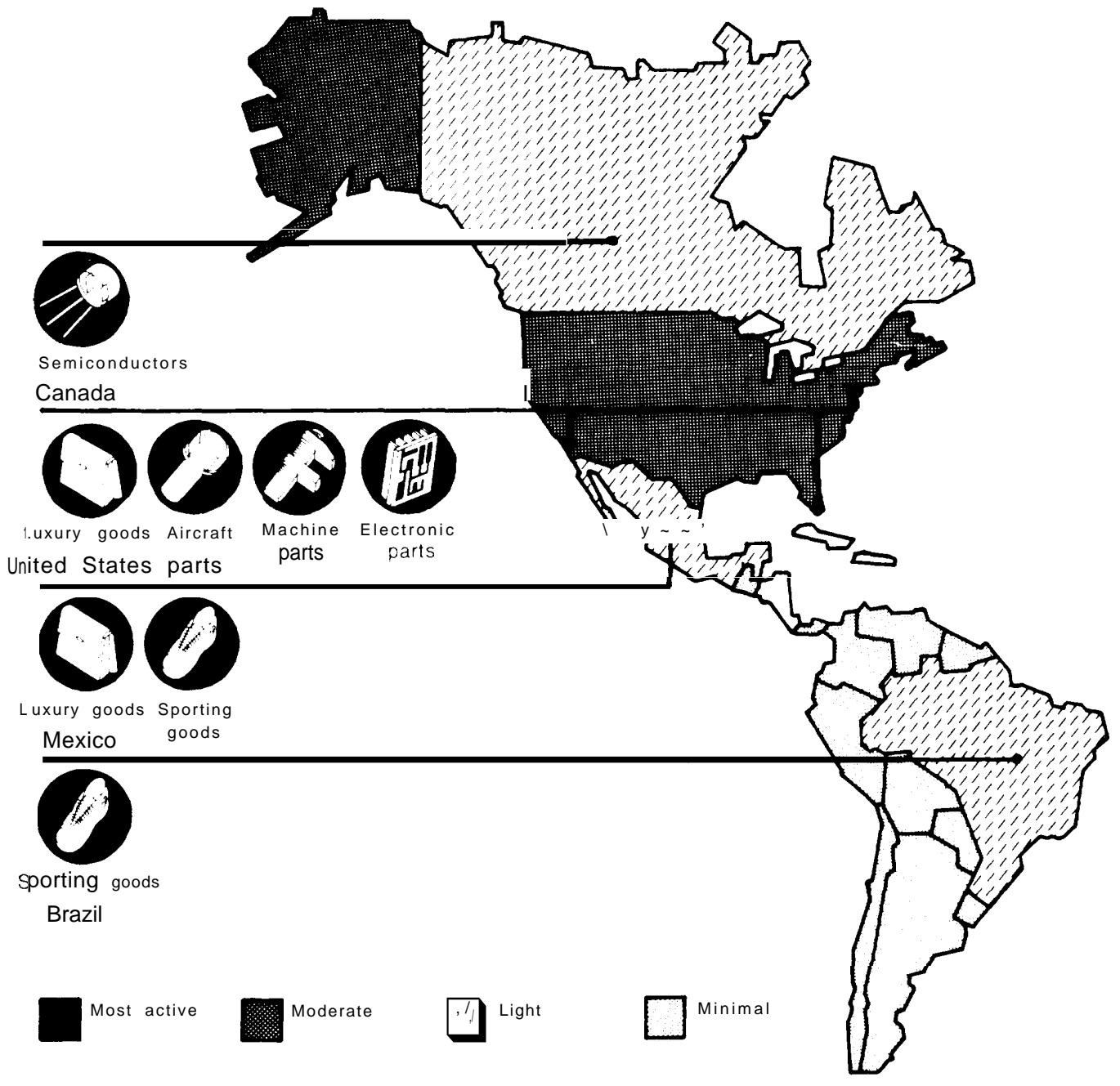

SOURCE International Trade Commission. as cited in Business Week, Dec. 16, 1985

tual property products is also sizable. These uncertainties notwithstanding, the major available statistics on piracy and counterfeiting in the publishing, recording, motion picture, and software industries are summarized below.

The Publishing Industry

According to publishing industry officials, the introduction of technologies such as photocopying, and new electronic storage and print technologies has led to vast international piracy and private copying of texts and literary works. ${ }^{80}$ Compounding this is the marriage ${ }^{80}$ Literar $\sim$ works are defined in $§ 101$ of the 1976 Copyright Act as “. . . works other than audiovisual works, expressed in of communication technologies with electronic information storage and retrieval systems, which has led to more and faster international

words, numbers, or other verbal or numerical symbols or indicia, regardless of the nature of the material objects, such as books, periodicals, manuscripts, phonorecords, film, tapes, disks, or cards, in which they are embodied. "

Internationally, literary works are protected under the UCC of which the United States is a member: "Each Contracting State undertakes to provide adequate and effective protection of the rights of authors and other copyright proprietors in literary, scientific, and artistic works, including writings, musical, dramatic, cinematographic works, and paintings, engravings, and sculpture. Article I, Universal Copyright Convention, Paris, 1971. Literary works enjoy a higher international level of minimum protection under the Berne Convention of which the United States is not a member. 


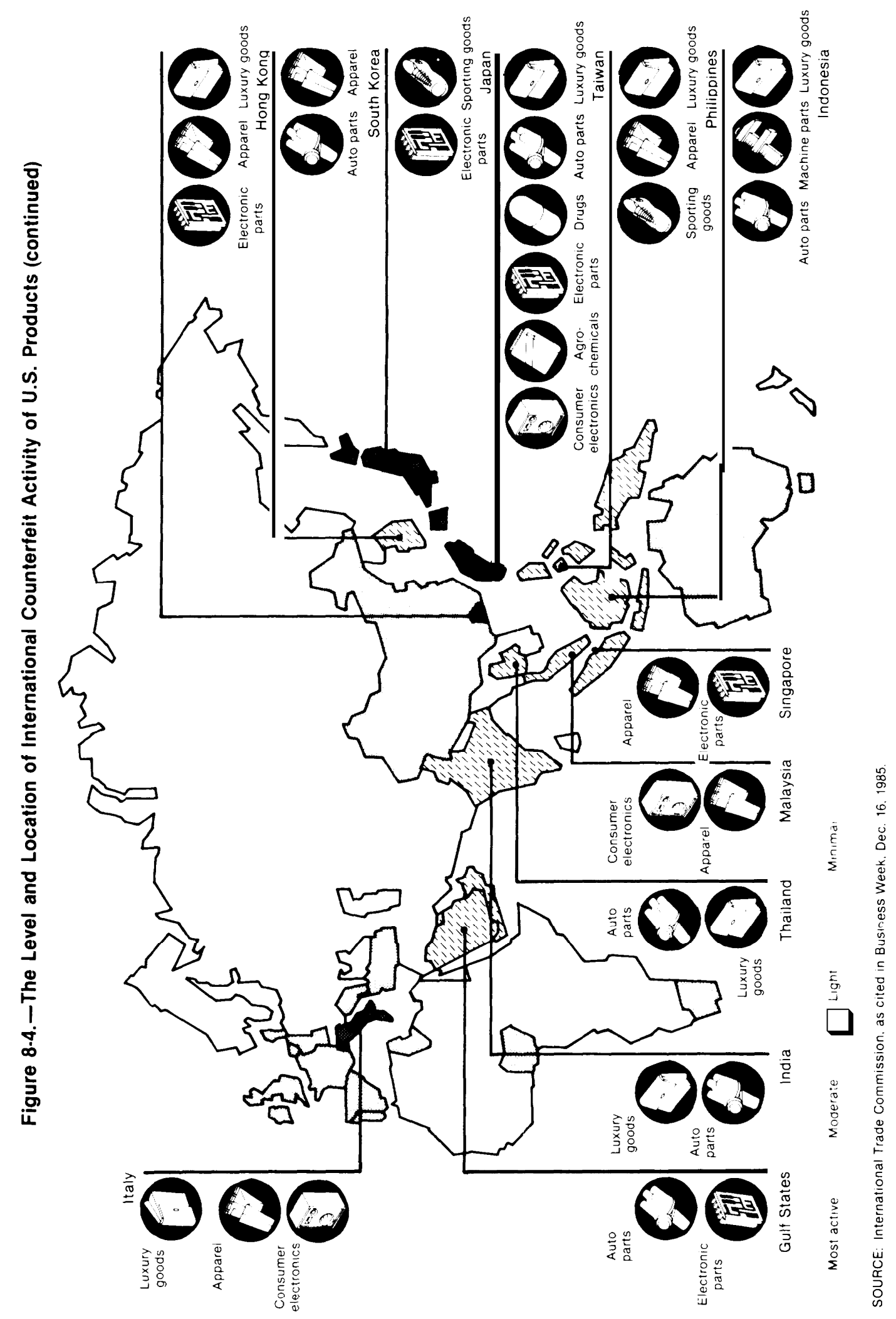


Table 8-3. - Estimated Losses From Piracy in Ten Selected Countries ${ }^{a}$ (dollars in millions)

\begin{tabular}{|c|c|c|c|c|c|}
\hline & $\begin{array}{c}\text { Records/ } \\
\text { tapes }\end{array}$ & $\begin{array}{l}\text { Motion } \\
\text { pictures }\end{array}$ & Books & Software ${ }^{b}$ & Total \\
\hline$\ldots \ldots \ldots \ldots$ & $220^{\mathrm{C}}$ & 11 & $107^{c}$ & 20 & $358^{c}$ \\
\hline 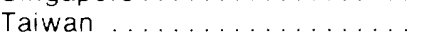 & 9 & 25 & $118^{d}$ & 34 & $186^{\mathrm{d}}$ \\
\hline Indonesia .............. & $180^{e}$ & 17 & 6 & 3 & $206^{e}$ \\
\hline Korea $\ldots \ldots \ldots \ldots \ldots$ & 40 & 16 & 70 & 20 & 146 \\
\hline Philippines . . . . . . . . . . . & 4 & 19 & 70 & 4 & 97 \\
\hline Malaysia ................ & 33 & 13 & 20 & 7 & 73 \\
\hline Thailand ............... & 13 & 12 & 7 & 2 & 34 \\
\hline Brazil . . . . . . . . . . . . . & 19 & 13 & 8 & 35 & 75 \\
\hline Egypt $\ldots \ldots \ldots \ldots \ldots$ & 5 & 5 & 10 & 3 & 23 \\
\hline Nigeria .................. & 120 & -1 & 11 & $-i$ & 131 \\
\hline Total & 643 & 131 & 427 & 128 & 1,3299 \\
\hline \multicolumn{6}{|c|}{ 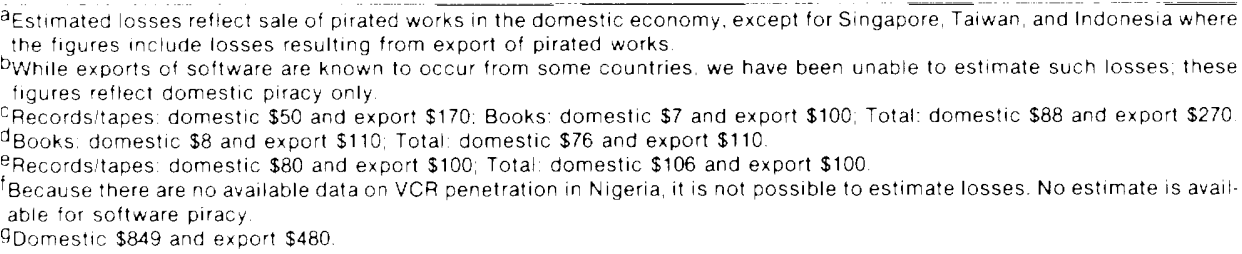 } \\
\hline $\begin{array}{c}\text { SOURCE International Intellectual Prope } \\
\text { by the International Intellectua }\end{array}$ & ce. " $\mathrm{F}$ & S. C & & Selected & Repo \\
\hline
\end{tabular}

exchanges of printed works, The third factor contributing to piracy is the lack of adequate, effective, or indeed, any legal protection for U.S. literary works in many nations.

The Association of American Publishers, Inc. (AAP) estimates that the industry loses $\$ 1$ billion each year to piracy of English-language books worldwide. Of this, AAP estimates that U.S. works account for 70 percent. The AAP also suggests that estimates of lost revenues would be greater if calculated on the basis of U.S. Iegitimate prices instead of on the basis of estimated revenues earned by pirates. The publishing industry has also completed a country-by-country analysis of the piracy of published or literary works." Although the AAP does not calculate direct evidence of actual harm to the industry, its report indicates that piracy is more common in some nations than in others. The majority of the piracy reported takes place in developing or newly industrializing nations. For example, over 27 U.S. publishers reported evidence of piracy of their materials in Taiwan:

\footnotetext{
"Association of American Publishers, Inc., "Piracy of Copy righted Material: A Report Prepared at the Request of the U.S. Department of State," 1985.
}

An estimate of at least 560 titles from reference, professional, trade, personal computer and college textbooks have been pirated in Taiwan with approximately 48,000 pirate copies in English and Chinese. . . [in addition] Taiwan is illegally exporting pirated books to Australia. The books are business and computer-related and are published by well-known American publishers."

In addition to pirating of domestic sales, Taiwan as well as other A SEAN countries pirate products to export to other nations. ${ }^{83}$ Approx-

- "“ Ibid., p. 6 .

"ASEAN (Association of Southeast Asian Nations) countries are Brunei, Indonesia, Malaysia. the Philippines, Singapore, and Thailand.

"In J anuary 1983, the Taiwanese police seized a container bound for Nigeria, purportedly carrying water filter cups and crash helmets. Hidden inside were 54,000 copies of five British titles that had not been authorized by the copyright holders for export from Taiwan. The cargo was valued at $\$ 48,000$. (Its selling price in Nigeria would have been at least $\$ 250,000$ ). After long and expensive litigation the penalty for this offense was 1 year's imprisonment, but the sentence was suspended. The infringing cargo was destroyed, but no printing plates were confiscated and only a small fine was assessed for false declaration. If 20 to 40 such shipments are smuggled out of Taiwanese ports each month, then the export value of these shipments at pirate prices would amount to a figure between $\$ 60$ million and $\$ 120$ million per year. " Association of American Publishers, Inc., "Detailed Information on Worldwide Piracy of Copyrighted Material and the Copyright Laws and Penalties, "J une 11, 1985, pp. 19-20. 
Table 8-4.-Countries and Regions That Infringe Copyrights of U.S. Motion Picture and Television, Prerecorded Entertainment, Publishing, and Advertising Industries

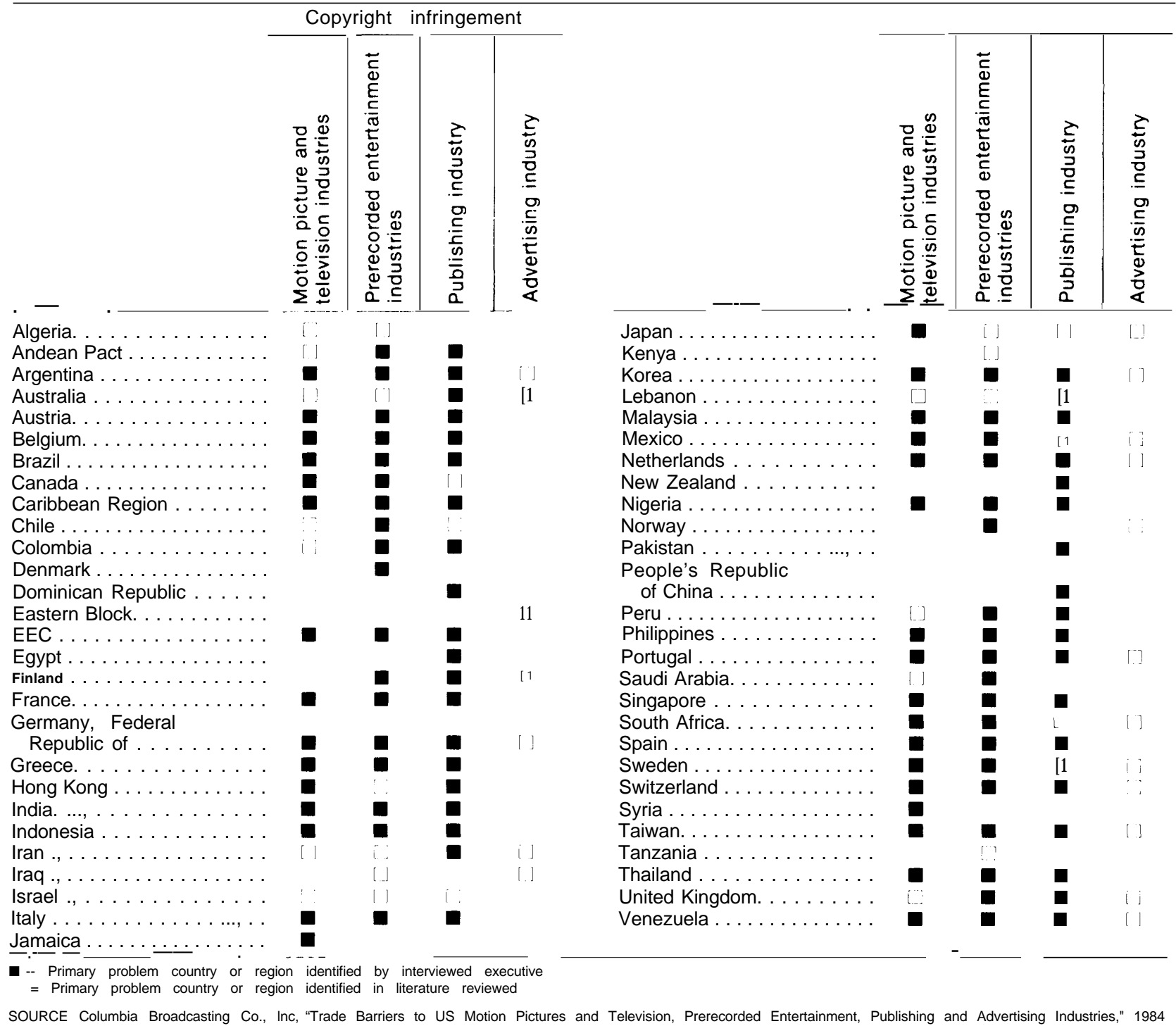

imately 16 American publishers reported infringement activity in Korea:

It is estimated that pirates sell at least $\$ 100$ million of books annually, and sales are rising each year. Importers' sales are an estimated $\$ 5$ million to $\$ 8$ million annually, but are plunging. Foreign book pirating flourishes because it is legal. This country hasn't signed any international copyright convention and local law does not protect copyrights of foreign publishers. Korean publishers can copy books without paying advertising, promotion and other costs-not to mention royaltiesthat original publishers do pay. They provide books to stores on consignment, making it easy for retailers. They also sell directly from catalogs. One such catalog distributed in Korea, entitled II Won Books Information, lists over 8,000 pirated books.

Other countries where American publishers have discovered infringements include Argen-

${ }^{\wedge *}$ Association of American Publishers, Inc., "Piracy of Copyrighted Material: A Report Prepared attheRequest of the U.S. Department of State," 1984, pp. 2-3. 
tina, Australia, Brazil, Chile, China, Colombia, Costa Rica, the Dominican Republic, Ecuador, Egypt, West Germany, Greece, Holland, Hong Kong, I ndia, Indonesia, Iran, Iraq, J amaica, J apan, Malaysia, Mexico, Nigeria, Pakistan, Panama, Peru, the Philippines, Saudi Arabia, Singapore, Thailand, Venezuela, and the Soviet Union. ${ }^{85}$

\section{The Recording Industry}

As in the publishing industry, recording companies report widespread international infringements of sound recordings. The introduction of broadcasting and of less expensive, high-quality duplicating hardware have led to increased international piracy, counterfeiting, and private copying of sound recordings. ${ }^{86}$

Another major contributing factor to this piracy is the lack of adequate or effective protection for U.S. audio works in many countries. Half of the member countries of the United Nations, for example, do not yet recognize the reproduction right in sound recordings. Many of the nations that do not provide adequate protection for U.S. literary works are also those that do not protect U.S. sound recordings. ${ }^{87}$

\footnotetext{
"'Association of American Publishers, Inc., "Piracy of Copyrighted Material: A Report Prepared at the Request of the U.S. Department of State, " 1984.

" Under U.S. Iaw sound recordings were first explicitly protected by a 1971 amendment (Public Law 92-140, 85 Stat. 391) and under $\S 101$ of the 1976 Copyright Act are thus defined: "material objects in which sounds, other than those accompanying a motion picture or other audiovisual work, are fixed by any method now known or later developed, and from which the sounds can be perceived, reproduced, or otherwise communicated, either directly or with the aid of a machine or device.

Internationally, sound recordings are protected under the 1971 Convention for the Protection of Producers of Phonograms Against Unauthorized Duplication of Their Phonograms of which the United States is a member. The 1961 International Convention for the Protection of Performers, Producers of Phonograms and Broadcasting Organizations, better known as the Rome Convention, protects sound recordings internationally, as a neighboring right. The United States, however, is not a member of this Convention.

"-These countries include Argentina, Bolivia, Brazil, Chile, Cyprus, Egypt, Greece, India, Indonesia, Italy, Korea, Kuwait, Lebanon, Malaysia, Mexico, Morocco, Nigeria, the Netherlands, Panama, Peru, Philippines, Portugal, Saudia Arabia, Singapore, Taiwan, Thailand, Tunisia, Turkey, and Venezuela. Statement of the Recording Industry of America, Inc., before the U.S. De partment of State International Copyright Panel, "The Piracy of Copyrighted Sound Recordings in Foreign Countries, ' Mar. 22, 1985, pp. 2-8.
}

Because many of the developing and newly industrializing countries do not afford adequate protection for U.S. sound recordings, these countries also are the sites of the majority of piracy and counterfeiting of these works.

Singapore is an excellent example of the magnitude of the problem, where it is estimated that 70 million counterfeit and pirate sound recordings were exported in 1984 . This incredible total, plus an additional 15 million counterfeit units produced in Singapore for internal consumption, accounted for 90 percent of sound recordings manufactured or sold in Singapore last year. A large percentage of the unlawfully duplicated products was U.S. owned. This situation exists despite energetic efforts of the IFPI (International Federation of Phonogram and Videogram Producers) to combat the problem.

Several Latin American countries are also responsible for large numbers of pirated and counterfeited U.S.-owned audio works:

In Panama, as much as 80 percent of the musical tape market is dominated by counterfeit and pirate goods. In Peru, the percentage of illicit tape recordings is approximately 70 percent. Bolivia and Chile both report that approximately 50 percent of the tape recordings manufactured and sold there are counterfeit or pirate, The huge Mexican market had a 40 percent penetration of counterfeit and pirate tapes in 1982-equaling approximately 11 million units of $\$ 30$ million in lost sales.

In addition to citing specific problems in different nations, the Recording Industry of America, Inc. (RIA) has reported overall statistics on the extent of foreign piracy and counterfeiting of U.S. sound recordings. The estimated total sales of counterfeit and pirated U.S.-owned sound recordings overseas in 1982 was, according to the RIA, well over $\$ 250$ million. Based on worldwide market shares for

\footnotetext{
'Statement of the Recording Industry of America, Inc., be fore the U.S. Department of State International Copyright Panel, "The Piracy of Copyrighted Sound Recordings in Foreign Countries, Mar. 22, 1985, p. 2.

**Statement of the Recording Industry of America, Inc., be fore the U.S. International Trade Commission, "The Impact of F oreign Product Counterfeiting on the U.S. Recording Industry," Sept. 19, 1983, p. 10.
} 
different nations' music, it is probable that approximately 50 percent of the estimated $\$ 515$ million in counterfeit and pirate sales outside of the United States in 1982 relates to recordings originally created and owned by U.S. recording companies, performers, lyricists, and composers. ${ }^{90}$

\section{The Motion Picture Industry}

Like the publishing and recording industries, the motion picture industry is also experiencing international private copying, piracy, and counterfeiting of U.S.-owned audiovisual works. ${ }^{91}$ The Motion Picture Association of America, Inc. estimates, for example, that worldwide losses due to film and video piracy are now approaching $\$ 1$ billion per year. ${ }^{92}$ In addition to the lack of adequate legal protection of audiovisual works in many nations, the major factor leading to international infringements of U.S.-owned audiovisual works is the introduction and increased use of information and communication technologies. Used individually or together, videocassette recorders (VCR), satellites, and cable technologies have been referred to by some analysts as an electronic triad, or the unholy trinity, for copyright holders of motion pictures. ${ }^{93}$

"Statement of the Recording Industry of America, Inc., before the U.S. Department of State International Copyright Panel, "The Piracy of Copyrighted Sound Recordings in Foreign Countries, " Mar. 22, 1985, p. 1, 6.

"Motion pictures and other audiovisual works are a protectable subject matter under the U.S. Copyright Law and were defined under the 1976 Act in $\S 101$ as “. . . works that consist of a series of images which are intrinsically intended to be shown by the use of machines or devices such as projectors, viewers, or el ectronic equipment, together with accompanying sounds, if any, regardless of the nature of the material objects, such as films or tapes, in which the words are embodied. "

Internationally, motion pictures and audiovisual works under Article 1 of the Universal Copyright Convention (1952 and 1971 texts) of which the United States is a member: "Each Contracting State undertakes to provide adequate and effective protection of the rights of authors and other copyright proprietors in literary, scientific and artistic works, including writings, musical, dramatic and cinematographic works, and paintings, engravings and sculpture. " Audiovisual works are also protected internationally under Article 2 of the Berne Convention for Literary and Artistic Works of which the United States is not a member.

"Motion Picture Association of America, Inc., "Film and Video Piracy: Manual for Investigators and Prosecutors, " 1984, p. 3.

‘Edward W. Ploman and L. Clark Hamilton, Copyright: 1n-
The relatively recent advent of satellite technology has had the greatest impact on international video piracy. ${ }^{94}$ Although terrestrial broadcasting has permitted some spillover into other countries of U.S. copyrighted materials, the scope of the satellite footprints is much greater and allows other nations greater unauthorized access to U.S. works. ${ }^{95}$ Although technical advances are improving the accuracy of the satellite beams, it will never be possible to shape the beams so precisely that they follow the contours of a given country." Consequently, U.S. satellite signals are poached by owners of earth station receivers or by cable systems, which retransmit them to relatively

tellectual Property in An Information Age (London: Routledge \& Kegan Paul, 1980), p. 153.

The various forms of film and video piracy can be grouped into three main categories: 1 ) film to tape transfers, 2) duplication of legitimate prerecorded videocassettes and videodisks, and 3 ) videotaping off television. Additional types of film and videc piracy include the unauthorized distribution of film prints, the unauthorized public performance of a legitimately owned film print or videocassette or disk, and the unauthorized interception of subscription TV programming. Motion Picture Association of America, Inc., "Film and Video Piracy: Manual for Investigators and Prosecutors, " 1984, p. 6,

"'Copyrighted programs carried via satellite are protected internationally by the Convention Relating to Distribution of Programme-Carrying Signals Transmitted by Satellite of 1974. On Oct. 12, 1984, the United States ratified this Convention without any amendment to domestic law. Commonly referred to as the Brussels Satellite Convention, it obligates contracting states to take adequate measures to prevent the unauthorized distribution of programming carried by satellite on or from their territories. The Convention leaves each state free to choose its own method of implementation, including designation of the specific beneficiaries of protection. The Convention, however, exempts signals that are intended for direct reception from satellite by the general public; these broadcast satellite signals are generally already regulated under the copyright or neighboring rights regimes of most nations. It also does not apply to individual reception of satellite signals for purposes of private viewing. Because there are currently only nine contracting states to this Convention, the international effectiveness of this treaty remains questionable.

"'Satellite footprints are defined as "the area of the earth's surface in which satellite transmissions can be received. . . Note that a footprint is a fluid concept and not a static one. I ts size will depend on the technical characteristics of the receiving dish and environmental conditions. Therefore, a particular satellite transmission will have one footprint when 10-foot earth-based dishes are being used and another one when 3-foot dishes are being used. " Motion Picture Export Association of America, Inc., "MPEAA Memorandum on the Uses of Satellite Technology, " 1984, p. 9

'Edward W. Ploman and L. Clark Hamilton, Copyright: Intellectual Property in An Information Age (London: Routledge \& Kegan Paul, 1980), p. 155. 
large audiences without compensation to U.S. copyright holders.

Canada, for example, takes advantage of its geographic proximity to the United States and the availability of American satellite signals:

Canadian cable systems under court decisions have no copyright liability under Canadian law for their stock in trade, their distribution to their paying subscribers of copyrighted works contained in the broadcast signals, both Canadian and American, which they capture from the air. ${ }^{97}$

Piracy of American signals is also a widespread problem in Central America. Costa Rica and the Dominican Republic, for example, pirate large amounts of U.S.-owned programming:

The most compromising form of piracy in this country [Costa Rica] is the unauthorized retransmission of cable TV signals. These signals carry a wide variety of copyrighted material. Cable Color, a pirate cable system located in the capital city of San J ose, has a subscriber count of approximately 10,000, while a similar cable TV system, Supercanal, transmits to 3,000 subscribers. Television Receive Only (TVRO) dishes as well as unauthorized public performances also present a serious problem to the American motion picture, cable, and television industries.

The theatrical and television markets for feature films and television programming continue to be severely affected by the signal theft practiced by cable TV Dominican and Telecable National. These two pirate cable TV systems cumulatively service 20,000 subscribers in the capital city of Santo Domingo, as well as the second largest Dominican city, Santiago. Television Receive Only dishes can be found in large numbers throughout the city. ${ }^{98}$

Many Caribbean nations are also responsible for pirating U.S. programming by satellite. J amaica is a prime example:

' CBS, Inc., "Statement of CBS Inc. Before the Canadian Parliamentary Standing Committee cm Communications and Culture, " April 1985, pp. 1-2.

"Motion Picture Association of America, Inc., "Brief Description of Film Piracy, for U.S. Department of State International Copyright Panel, Mar. 22, 1985, pp. 1-2.
As with nearly every other island in the Caribbean, there is wholesale video and signal piracy in J amaica. . . Many homes and commercial facilities such as hotels have Television Receive Only dishes that intercept satellite signals without authorization. One of these has been operated by the J amaica Broadcast Company, a government-owned operation that has intercepted motion picture programming and rebroadcast it to the entire island without charge. The impact of such practices is self-evident. ${ }^{99}$

In many countries, the widespread consumer use of videocassette recorders has joined inadequate or ineffective legal protection in promoting increased piracy of American audiovisual works. These pirated copies are, in turn, sometimes rebroadcast on cable or local broadcasts. Many of the countries where piracy of literary and musical works is rampant also are responsible for widespread video piracy.

Several ASEAN countries, for instance, are major centers of piracy of U.S. audiovisual works. In addition to pirating for domestic sales, many of these nations export large amounts of pirated and/or counterfeited copies. Both Korea and Indonesia are well known for these activities:

Due to the absence of adequate and effective copyright legislation in relation to foreign works, the videocassette piracy problem in Korea is serious. Pirated copies of American films are widely available and service a 550,000 VCR population in South Korea. Many of these are reputed to come from U.S. military bases in the country. Some hotels are using videocassettes for in-house entertainment without licensing agreement, and there is unauthorized use of American films by broadcast television stations. . . .

In a country with 600,000 videocassette recorders, the piracy of American motion pictures is 100 percent. This is due to the absence of adequate and effective copyright legislation which, in turn, inhibits legitimate market entry. 'no

\footnotetext{
Motion Picture Association of America, Inc., "Brief De scription of Film Piracy, for U.S. Department of State International Cop\}' right Panel, Mar. 22, 1985, p. 3.1

' "'Motion Picture Association of America, Inc., "Brief Description of Film Piracy, " for U. S. Department of State International Copyright Panel, Mar. 22, 198.5, p. 3.
} 
Other countries where video piracy occurs include Brazil, Canada, Costa Rica, Cyprus, the Dominican Republic, Egypt, France, Hong Kong, I ndonesia, I srael, Italy, J amaica, Korea, Malaysia, Mexico, the Netherlands, Nigeria, Pakistan, Panama, Peru, the Philippines, Saudi Arabia, Singapore, South Africa, Spain, Sweden, Taiwan, Thailand, Turkey, United Kingdom, Venezuela, and West Germany. ${ }^{101}$

\section{The Software Industry}

Because few major studies of the problem have been undertaken, there are few data on the extent of foreign piracy of U.S. software products. ${ }^{102}$ This is so largely because software is a relatively new industry, and also because microcomputers are much less widely used abroad than in the United States. ${ }^{103}$ Recently, however, the International Intellectual Property Alliance undertook a major study on the extent of international piracy of U.S. software products. This study found that the U.S. software industry is losing significant annual sales because of copyright violations in Brazil (\$35 million), Egypt ( $\$ 3$ million), Korea ( $\$ 20$ million), Malaysia (\$7 million), the Philippines (\$4 million), Singapore (\$20 million), Taiwan (\$34 million), and Thailand (\$2 million). ${ }^{104}$

Given the precedent of foreign piracy of other U.S. intellectual property products and the ex-

\footnotetext{
"'"'Elizabeth Greenspan, "Film and Video Piracy, " I nternational Media Law, 1983.

"Published anecdotal evidence of foreign software piracy is also rare. Some examples, however, have been cited by the AAP: "Pirated software [in Taiwan] is sold for 1 percent of the U.S. list price, or $\$ 3.50$ for a best-selling U.S. software product like VISICALC or WordStar or others that sell for approximately $\$ 350$ in the United States. Often the pirate gives away 5 or 10 pieces of software with a Pineapple (or pirated Apple) computer. Pirated computer books may also be included in this package. " Other countries where software piracy occurs include Brazil, Greece, Korea, and Singapore. Association of American Publishers, "Piracy of Copyrighted Material, " a Report Prepared at the Request of U.S. Department of State, " Mar. 22, 1985.

'("The Software Publishers Association informally estimates that for every legitimate copy of U.S. software abroad there are approximately 5 to 10 pirated copies, tel ephone conversation, J uly $8,1985$.

“'” International Intellectual Property Alliance, "Piracy of U.S. Copyrighted Works in Ten Selected Countries: A Report by the International Intellectual Property Alliance to the United States Trade Representatives, " August 1985.
}

pected growth of foreign demand for computers and computer products, the piracy of software abroad may soon become a larger concern to U.S. software manufacturers. Consequently, over the long term more in-depth analysis and documentation can be expected. With such information, U.S. software manufacturers might more effectively deter international piracy.

\section{Policy Implications}

Although these statistics can only measure the harm from private copying and piracy indirectly, they make it clear that piracy is a more serious problem at the international level than at the domestic level. Because of the increasing importance of information-based products and services to the U.S. economy and international trade, deterring foreign piracy of U.S. intellectual property products will most likely become a high priority for the United States. As new technological developments erode traditional enforcement mechanisms and permit greater international dissemination of such products, the United States will need to seek to improve enforcement of U.S. intellectual property rights abroad. Moreover, given the inadequacy of enforcement abroad, the United States might want to pursue ways of ensuring that countries strengthen their legal protection and enforcement mechanisms for both foreign and domestic works.

Currently, the United States is taking some action to ensure adequate protection. It is, as previously discussed, using the granting of trade preferences as an incentive for the establishment of legal protection and increased enforcement efforts to protect intellectual property products. Moreover, the United States has begun a series of bilateral discussions with other nations concerning international enforce ment. These include discussions with J apan on the protection of software under J apanese copyright law; discussions with Canada on the issue of protecting cable retransmissions of U.S. broadcast programming; and discussions with Caribbean nations on the unauthorized interception and retransmission of U.S. satellite-transmitted motion pictures and other programming. These meetings have proved 
successful: J apan has decided to protect software under copyright; Canada is considering the copyright status of cable retransmissions; and the J amaican broadcasting authorities are beginning negotiations. ${ }^{105}$

The United States is also initiating educational seminars on intellectual property rights for industry and government representatives, local attorneys, and educators of developing countries. In early 1985, for example, U.S. delegations from the Copyright Office, the Patent and Trademark Office, and the Department of State went to Indonesia, Malaysia, and Thailand to present lectures on crucial international intellectual property legal issues and the need to provide adequate and effective laws and enforcement mechanisms to deter infringement. These have been particularly useful because each of these nations is considering revisions to its copyright laws and is examining how to best protect new technologies, such as computer software. ${ }^{106}$ In addition, the U.S. Government has recently begun to offer training programs for patent, copyright, and trademark administrators of other nations.

There are also other options the United States might pursue to mitigate international piracy. The United States, for example, could more actively participate in international intellectual property for a, the positive and negative aspects of which have already been discussed.

To complement these efforts, the United States could also encourage U.S. industry, both producers and users of intellectual property products, to participate more actively in international associations that fight international piracy. Such associations include, for example, the International Federation for Phonogram and Videogram Producers (IFPI), the Federation Against Software Theft (FAST),

\footnotetext{
" "r'Michael Kirk, Assistant Commissioner for External Affairs, United States Patent and Trademark Office, Department of Commerce, testimony on "Copyright Enforcement, before the Subcommittee on Patents, Trademarks, and Copyright, Senate Committee on the J udiciary, Apr. 17, 1985, p. 7.

- "'F or a good case study of U.S. bilateral efforts to reduce piracy in a nation, see "Protection From Commercial Counterfeiters in Taiwan for U.S. Firms, "Law and Policy in International Business, vol. 16, No. 2, 1984.
}

and the Federation Against Copyright Theft (FACT). ${ }^{107}$

The United States might also expand current talks with developing countries on intellectual property law and piracy of U.S. products. These seminars, which might be either bilateral or sponsored through a multilateral agency, could provide developing countries with information on how to construct adequate and effective intellectual property laws and enforcement mechanisms. They might also be used to outline the importance of protecting intellectual property rights for developing nations as international trade partners, as well as for the growth of their domestic intellectual property industries.

A more coercive option would be to impose trade sanctions or other retaliatory measures on nations that do not enforce U.S. intellectual property rights. This option, however, entails trade-offs in terms of the political discordance that such sanctions might provoke between developing nations and the United States. Some trade experts, for example, warn "that with no international consensus on how to defend intellectual property rights, any attempt to impose U.S. views on others could jeopardize efforts to improve agricultural and manufacturing trade. "108

\section{Growing Convergence of International Intellectual Property Issues With Other International Issues}

Nations have come to view information and information-based products and services as components for improved productivity and

\footnotetext{
${ }^{107} \mathrm{~A}$ current example of industry efforts to reduce international piracy of U.S. products is Ashton Tate's cooperation with the International Trade Administration, the Association of Data Processing Service Organizations (ADAPSO), Lotus Devel opment Corp., MicroPro International, and other software companies to develop a series of seminars on intellectual property rights and regulations for exporting software. They are also considering the establishment of ' an industry-financed war chest to provide funds to fight piracy through legal channels as well as through public education. " "Ashton-Tate Fights at Home and Abroad, ' Download, March 1986, pp. 11-12.

${ }^{10 k}$ Bruce Stokes, "Intellectual Piracy Captures the Attention of the President and Congress, " National J ournal, Feb. 22, 1986, pp. 443-445.
} 
international competitiveness, international trade, and as a means to achieve major societal goals. As a result, international intellectual property issues are increasingly tied to international competitiveness, trade, development, and political issues. These linkages, together with the growing convergence of communication and information technologies, are creating new intersections between international intellectual property issues and other international issues, such as space and telecommunication issues.

The convergence of information and information-based products and services and communication technologies is largely due to the overall goal shared by many nations to build information infrastructures for both social and economic development. ${ }^{109}$ As information and information-based products and services are increasingly used with electronic communication systems, the communication policies that govern such systems intersect with intellectual property policies. Thus, products and services that have traditionally been regulated separately are now used in new combinations:

Current changes in technology are producing new patterns, with traditional services being combined into unexpected hybrid shapes and uses, in defiance of the established categories. . . Cable systems can be combined with terrestrial broadcasting, and either one or both of these with satellite systems. The combination of technical systems corresponds to an integration of services: television and facsimile combine in tel efacsimile; the data bases used for electronic photocomposing can also be used for information retrieval. The combination of television and telephone is at the origin of the videophone, and these, together with computerized data systems, result in teletext and videotex services. In fact, certain videotex services already represent a combination of telecommunications, computer, broadcasting, print, and information systems. ${ }^{110}$

\footnotetext{
${ }^{109}$ In an information society, such that it is envisioned, there will be a greater interdependence between information and communication technologies as nations seek to construct what the French Government calls "the entire nervous system of social organization. "Simon Nora and Alain Mine, The Computerization of Society (Cambridge, MA: MIT Press, 1980).

'“'Edward W. Ploman and L. Clark Hamilton, Copyright: Intellectual Property in an information Age (London: Routledge \& Kegan Paul), p. 151.
}

Because of these new combinations, new uses and distribution channels are developing that may have been unanticipated by the legal system. Consequently, two traditionally unrelated legal or regulatory regimes are now in contact with each other. Conflicts may arise when these regimes have mutually exclusive policy objectives.

A case in point is the unavoidable satellite spillover or footprints that cut across national frontiers. While this spillover is not materially different from spillover in terrestrial broadcasting, it is, however, much greater in scope and subject to different legal protections and regimes. Under the Radio Regulations of the International Telecommunications Union (ITU), space is considered common property, for example, which cannot be owned by individuals, corporations, or governments. ${ }^{111}$ Although such regulations recognize the privacy of transmissions, there are no enforcement mechanisms or remedies for the violation of rights. Not finding this spillover acceptable and wanting to enforce their rights, rights owners have insisted on extended protection. Their demands, however, conflict with the internationally agreed upon principle of the law of the commons, which has developed in the context of space and telecommunications law. Thus, efforts to protect the intellectual property embodied in satellite signals may need to be handled in widely differing legal and regulatory contexts. ${ }^{112}$

Also exemplifying the multifaceted nature of intellectual property issues is the increasing number of institutions that deal with such issues. At present, the World Intellectual Property Organization deals with the administration of rights; the United Nations Educational, Scientific, and Cultural Organization oversees international information flows for the benefit of education, science, and culture, and develops communications policies for the development of infrastructures; the International Telecommunications Union allocates frequency

\footnotetext{
${ }^{111}$ See Article N28/7 of the Radio Regulations, also the Final Acts of the World Administrative Radio Conference-Broadcasting Satellites, 1977.

"'Edward W. Ploman and L. Clark Hamilton, Copyright: Intellectual Property in the Information Age. (London: Routledge \& Kegan Paul, 1980), p. 155.
} 
bands and promulgates technical standards in the area of telecommunications; the United Nations Centre on Translational Corporations oversees transborder information-related services; and the United Nations Conference on Trade and Development and the General Agreement on Tariffs and Trade regulate the trade of some information-based products and services. 113

\section{Policy Implications}

Because the present set of international legal and regulatory regimes and institutions are generally linked to a particular technology, new combinations of older technologies might, like new technologies, create inconsistencies between traditionally separate policies and institutions. To deal with such cross-cutting issues, the international protection for intellectual property may need to be considered in a larger social, legal, and technical context. The United States, therefore, might want to develop an integrated approach or policy to deal with the cross-cutting nature of international issues. In addition, it may need to improve the coordination among domestic agencies that are responsible for international and intellectual property issues.

Currently, there is no agency in the U.S. Government that has centralized responsibilities for dealing with the cross-cutting international intellectual property issues. Instead, various Federal agencies perform different and separate functions with respect to international intellectual property rights. ' 1 '

The Department of State plays a lead role in coordinating other Federal agencies and representing the United States at multilateral and bilateral intellectual property negotiations. Both the Patent and Trademark Office and the Copyright Office are responsible for monitoring international legal developments, representing the United States in their respective

\footnotetext{
"'Gregorio Garzon Clariana, "Legal Framework for International Information, "Translational Data Report, vol. 8, No. 2, pp. 101-107.

"These agencies are each described in more detail in Chapter 9, "The Federal Role in the Administration of Intellectual Property Rights."
}

international conventions, and advising Congress and the Administration on developing international intellectual property policy.

The National Telecommunications and Information Agency (NTIA) plays an important role in the protection of copyrighted material transmitted outside the United States via telecommunication technologies. It also participates in negotiations of international agreements on the use of satellites for rebroadcast materials.

For trade-related international intellectual property issues, the U.S. Trade Representative plays a major role. Its responsibilities include monitoring foreign nations' efforts to protect intellectual property and then, according to such an analysis, recommending whether such nations should be eligible to receive trade preferences. The International Trade Administration also monitors international enforcement of intellectual property rights and provides this information and counseling on export opportunities and problems to the business community. The U.S. I nternational Trade Commission is an independent quasi-judicial agency that determines whether unfair trade acts related to imports, which often involve patent, trademark, or copyright infringements, are harmful to U.S. industries.

The U.S. Information Agency takes primary responsibility for culturally oriented intellectual property policy. It oversees the distribution of U.S. intellectual property products such as films, books, and music to other nations for the promotion of better understanding the United States and its citizens.

Recognizing the fragmentation of policy responsibilities for international intellectual property issues within the Federal Government, several policy coordination groups for intellectual property policy have been recently formed. These groups include the Cabinet Council on Commerce and Trade (Working Group on Intellectual Property), the Trade Policy Committee (Subcommittee on Intellectual Property), and the Senior Interagency Group on Communication and Information Policy (Working Group on Copyright and Intellectual Property). 
These efforts to coordinate area good start towards recognizing the many issues involved in international intellectual property policy. However, given the increasing legal, social, political, and economic factors affecting intellectual property rights, the current U.S. Government organization for international intellectual property issues might make it very difficult to address these multifaceted issues in a comprehensive fashion.

To deal with these cross-cutting issues, the United States might establish a governmental agency responsible for both domestic and international intellectual property rights. This agency would subsume all the administrative responsibilities of the Copyright Office, the Patent and Trademark Office, and the responsibilities of other agencies involved with intellectual property rights. Internationally, it would represent the United States on all matters that relate to intellectual property rights.
Such an agency would also have centralized in-house capabilities to analyze the effects of new technological developments on the international intellectual property system and the U.S. position in relation to the system. Using this analysis, it could advise Congress on possible domestic and international intellectual property strategies.

At the same time, the establishment of such an agency has several drawbacks. The consolidation of responsibility for intellectual property rights, for example, would take expertise on intellectual property rights from agencies that need it, such as the Department of Commerce and the Library of Congress. Similarly, consolidation might also inhibit existing access to expertise on legal, trade, and foreign policy, made possible by multi-agency involvement. Finally, such a proposal would probably meet resistance from the agencies themselves.

\section{IMPLICATIONS FOR FUTURE U.S. INTERNATIONAL INTELLECTUAL PROPERTY POLICY}

As described throughout this chapter, the United States is undertaking and considering many options to address international intellectual property issues. Table 8-5 summarizes some of the major policy strategies available to the United States for dealing with many of the international intellectual property issues brought about by new technologies. It further gives major examples, issues or stresses that would be addressed, and suggests both positive and negative outcomes of such strategies.

There is no single, clear-cut strategy that the United States could adopt to comprehensively address all of the international intellectual property issues engendered by new technologies. A policy strategy designed to deal with international trade and enforcement issues, such as those already legislated (sections of the Trade and Tariff Act of 1984 and the Caribbean Basin Economic Recovery Act), for example, fails to address any of the international political issues presented by new technologies.
Strategies designed to focus on political issues, moreover, do not readily address international intellectual property trade issues.

In fact, many policy strategies designed to address specific issues may exacerbate other stresses on the international intellectual property system. Treating intellectual property, for example, solely as international trade issues could provoke problems of international political relations, even to the point of inciting retaliation from other nations; but focus on international political relations might foreclose export opportunities for the U.S. domestic intellectual property industry. Similarly, treating international intellectual property issues as separate from other international policies might lead to conflicts with international information and communication policies and other foreign policies.

Although many of the policy strategies for addressing international intellectual property issues are not mutually exclusive, the United 
Table 8-5.-Policy Options for Addressing International Intellectual Property Issues

Policy action

Ratify the Berne Convent Ion

for the Protection of

iterary and Artistic Works

Rejoin United Nation

Educational and Cultura

Organization (UNESCO) $\overline{\text { Negotiations, education }}$ seminars, and training programs on intellectua property rights for other nations

Bilateral intellectual property agreements with nations that are not members of any international Intellectua property agreements

Legislation with specific international reciprocity

clauses
Examples

Issues or stresses
to be addressed

Internationalization

of intellectual

property

Politica

Internationalization

of intellectual

property

Political

Enforcement
Possible positive outcomes

\section{U.S. would appear more genuine in its support}

U.S. would appear more genuine in its support

U.S. might Increase its ability to Influence the

J.S. representatives involved with intellectual rolitica property could organize seminars and train - _egal

Ing programs for foreign officials responsi-

$\overline{\text { Provide other countries with an understand- }} \overline{\text { Requires additional funding }}$ broper the administration of Intellectual property rights, such as those already undertaken in Indonesia, Malaysia, and Thailand. tional Intellectual property conventions, the Enforcement United States could establish specific bilateral Intellectual property agreements, such as those already established with Romania, South Africa. and Thailand. Domestic legislation that would make specific Legal States avaibaber their nation US nationals, such as those reciprocity clauses in the Semiconductor chip Protection Act (Public Law 98-620) and the proposed International Computer Software Protect Ion Act of 1985 (S 399, 99th Congress) for international Intellectual property protection, and consequently it might be more effective in convincing other nations to enact legal and enforcement measures for Intellectual property protection and to ratify International intellectual property agreements

U.S. might have more political strength from which to Influence International Intellectual property policy development. for international Intellectual property protection, and consequently it might be more effective in convincing other nations to enact legal and enforcement measures for international intellectual property agreements

U.S. might have more political strength from which to influence International Intellectual
which property policy development number and subjects of studies on copyright and new technologies undertaken by the UCC ing of the importance of protecting intellectual property rights.

Promote international harmon

tions' domestic Intellectual property laws

Permit the establishment of Intellectual prop- Disrupts Integrity of traditiona erty relations with countries that are cur- system of international Interently not members of any international in- lectual property ageements.

Possible negative outcomes Proditional U S intel lectual property laws and practices, such as registration and deposit

S would need to make eco sions particularly to address the concerns of developing nations tellectual property agreements

Provide leverage to induce other nations to Disrupts integrity of traditional enact adequate and/or enforce international system of international

agreements intellectual property rights 


\section{Table 8-5.- Policy Options for Addressing International Intellectual Property Issues-Continued}

Policy action

Trade preferences contingent on nations' laws and effort Intellectual property rights

Trade sanctions against nations which do not respect international Intellectual property rights

rengthen U.S. Governmentsponsored information distribution programs

Foreign aid to nations for purchase of Intellectual property products

Examples_

Where countries receive trade preferences and/or foreign aid and do not have adequate laws or enforcement measures for the protection of Intellectual property, the United States could make the receiving of such benefits contingent upon the improvement of Intellectual property laws and enforcement efforts, as called for in the Trade and Tariff Act of 1984 (Public Law 98-573) and in the Caribbean Basin Economic Recovery

Information-based products and services could be included in international trade agreements that have trade sanction penalties already in place, such as in the Genera Agreement on Tariffs and Trade (GATT), Imposition of trade penalties on nations that import goods that infringe U.S. intellectual property rights, such as the penalties called or in the Process Patent Amendment (S.1543 and H R. 1069, 99th Congress).

Increased funding with focus on-developing Political

countries' specific needs for information based products and services, such as those distibution programs sponsored by the U S information Agency (US! A), the Peace Corps, and the Library of Congress.

Funding for developing countries specifically Political earmarked for the purchase of information based products and services.

\begin{tabular}{|c|c|c|}
\hline $\begin{array}{l}\text { Permanent coordinating body } \\
\text { for all government } \\
\text { agencies involved with } \\
\text { intellectual property issues }\end{array}$ & $\begin{array}{l}\text { Standing coordinating body that would con- } \\
\text { sist of representatives from all agencies in- } \\
\text { volved with Intellectual property rights Is- } \\
\text { sues, such as the working groups of the } \\
\text { Cabinet Council on Commerce and Trade, } \\
\text { the Trade Policy Committee, and the Inter- } \\
\text { agency Group on Communications and In- } \\
\text { formation Policy }\end{array}$ & Institutional \\
\hline $\begin{array}{l}\text { Establishment of government } \\
\text { agency for Intellectual } \\
\text { property }\end{array}$ & $\begin{array}{l}\text { Combining under the jurisdiction of one gov- } \\
\text { ernmental agency all of the responsibilities } \\
\text { for the administration of Intellectual prop- } \\
\text { erty rights, includlng all International intel- } \\
\text { lectual property policies, }\end{array}$ & Institutional \\
\hline
\end{tabular}

SOURCE Office of Technology Assessment

\section{Issues or stresses}

to be addressed

Trade and E

Trade and Economic

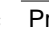

Provide a retaliatory mechanism against nations that do not have adequate legal protection and/or do not adequately entorce
ternational intellectual property rights.

rovide leverage to induce other nations to enact adequate legal protection and/or en force International Intellectual property

Possible negative outcomes Provokes new difficulties for U.S. international political re
lations rights ons and/or retaliation from other nations, particu-

$$
\text { Pro }
$$

Promote International political and cultural Requires additional funding understanding.

Provide incentives for countries to respect in

ternational Intellectual property rights.

Promote International political $\overline{\text { and cultural Requires additional funding }}$ understanding.

Provide incentives for countries to respect in-

ternational Intellectual property rights.

Promote the development of domestic intel-

lectual property industnes in other nations.

Provide a forum for better coordination among the governmental agencies responsible for property protection

Complicates decisionmaking process for International intellectual property policy by decentralizing Individual agencies' policymaking responsibilities

Provide a mechanism for presenting a more united U.S. position on international intel. lectual property issues.

Provide a mechanism to centralize expertise on foreign policy and Intellectual property within the Federal Government.

Loss of direct access to expertise or Intellectual property protection needed by individual government agencies larly from developing nations 
States must recognize the trade-offs involved in choosing one policy strategy over another, or the possibility that two policy strategies might conflict. Given such potential policy conflicts, the United States will need to make fundamental decisions about how it wishes to view intellectual property (for example, as an item of trade, an item to enhance its foreign diplomatic relations, etc.) and design its overall international intellectual property policy strat- egies accordingly. Such decisions are likely to become more important in light of the enhanced role of the new technologies in economic and social development. Decisions about international intellectual policy, moreover, will need to be made in conjunction with many other aspects of U.S. foreign policy-from international issues of defense, trade, and foreign aid to issues of international information and communication policy. 
Chapter 9

\section{Federal Role in the Administration of Intellectual Property Rights}




\section{Contents}

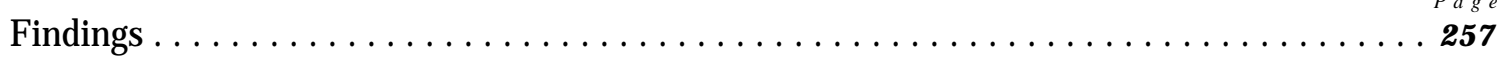

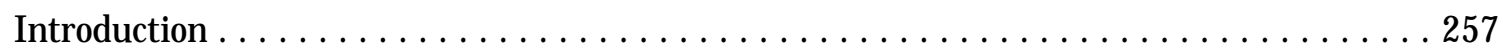

Development of U.S. Intellectual Property Policy . . . . . . . . . . . . . . . . . . . . . . . 258

Goals for Granting Intellectual Property Rights . . . . . . . . . . . . . . . . . . . . . . . . 258

Federal Role in the Administration of Intellectual Property Rights . . . . . . . . . . . . . 259

Early Development of the Governmental Institutions for the Administration of Intel lectual Property Rights . . . . . . . . . . . . . . . . . . . . . . . . . . 260

Present Institutional Arrangements for the Administration of Intellectual

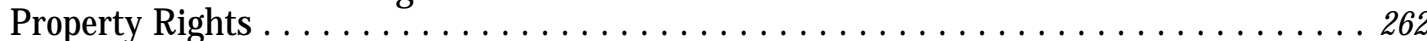

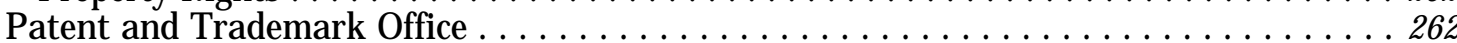

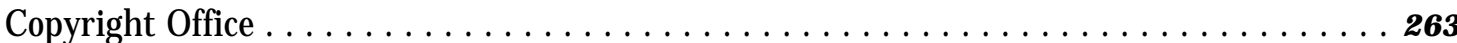

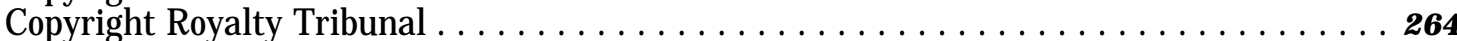

Other Supporting Agencies Within the Federal Government . . . . . . . . . . . . . 265

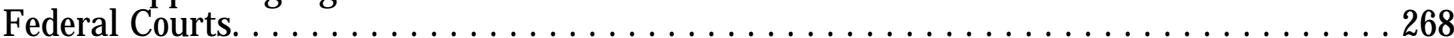

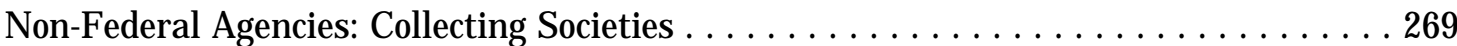

Emergence of New Technologies and Their Implications for the Present Federal Institutional Arrangements for the Administration of Intellectual

Property Rights. . . . . . . . . . . . . . . . . . . . . . . . . . . . . . . . . . . . . . . 271

Rapidity of and Uncertainty With Respect to, Changes in Information and Communication Technologies . . . . . . . . . . . . . . . . . . . . . . . . . . . . . . . 271

Growing Demand for Nontraditional Copyright Solutions Requiring a Regulatory

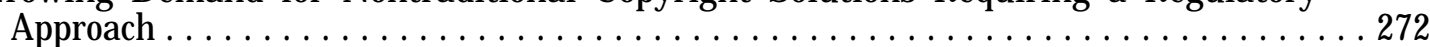

Need for Greater Understanding of and Information About the Processes By Which Intellectual Properties Are Created, Published, Distributed, and Used . . . . . . . . . . 273

Development of Technologies That Do Not Correspond to Traditional Intellectual Property Categories, and the Creation of Sui Generis Intellectual Property Legislation . . . . . . . . . . . . . . . . . . . . . . . . . . . . . . . . . . . . . . . . . . . . . . . . 274

Growing Convergence of Intellectual Property Issues With Other International Issues.. . . . . . . . . . . . . . . . . . . . . . . . . . . . . . . . . . . . . . 275

Growing Convergence of Intellectual Property Issues With Other Information

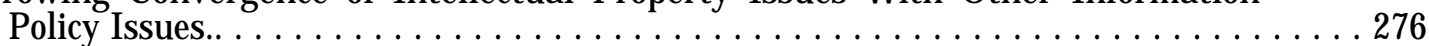

Implications for Future Institutional Arrangements for the Administration of

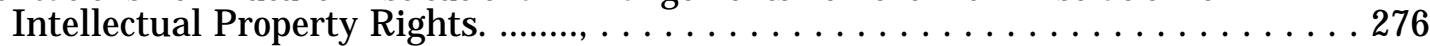

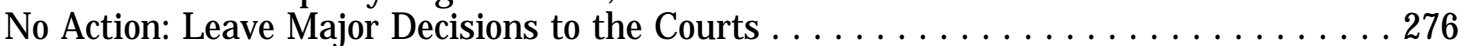

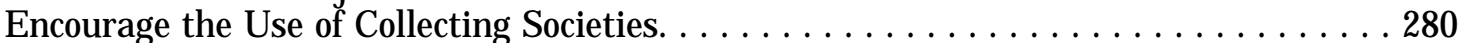

Strengthen and Increase the Responsibilities of Existing Agencies . . . . . . . . . . . . 281

Establish a Central Federal Intellectual Property Agency . . . . . . . . . . . . . . . . 282

Considerations for the Choices of Institutional Arrangements . . . . . . . . . . . . . 282 
Chapter 9

\section{Federal Role in the Administration of Intellectual Property Rights}

\section{FINDINGS}

Assuming that the granting of exclusive property rights to individuals would automatically lead to the creation and public dissemination of information, the Nation's first legislators ascribed to government a relatively inactive role in the intellectual property system. Accordingly, the Federal role and corresponding institutions have evolved to perform minimal regulatory functions. The system was designed to be self-enforcing; the government institutions granted rights, registered works, and the individual creators and users were re sponsible for protecting their rights and enforcing them through the courts.

Today, however, the emergence of new information and communication technologies is placing new demands on governmental institutions responsible for the administration of intellectual property rights. The question arises, therefore, of whether existing Federal institutional arrangements for the administering intellectual property rights, as initially designed, can adequately cope with new technological developments and the new responsibilities that may be placed on them.

To manage these stresses, Congress has several options that it could pursue. These options range from leaving the agencies as they exist to completely restructuring them. Before considering institutional arrangements for the administration of rights, however, Congress must first make overall decisions about the intellectual property system itself. Congress must determine which goals it wishes to promote, which laws and practices to establish, and how to balance competing interests in light of the effects of new technological developments. It must also determine whether the role of government in the intellectual property system should be regulatory or nonregulatory. Only after such decisions are made, can Congress begin to construct institutional arrangements for the administration of intellectual property rights.

\section{INTRODUCTION}

The granting of intellectual property rights can be viewed as a public policy tool designed to achieve policy goals. Historically, governments have granted intellectual property rights to meet different policy goals. Such goals, for example, have included economic development or industrial policy, regulation of trade, censorship, promotion of public learning, and the development of a national culture. The particular role governments play in intellectual property systems depends to some extent on the goals the policy is designed to foster.

Early in the evolution of the United States, the Founding Fathers dearly viewed intellec- tual property policy as a means to promote the progress of science and the useful arts, and to disseminate such knowledge to the public, They believed, moreover, that public dissemination of information would help to meet the other overriding societal needs of the timeto develop an industrial base, create a national literature, and maintain the level of knowledge among citizens required to sustain a democratic polity.

Assuming that the granting of exclusive property rights to individuals would automatically lead to the creation and public dissemination of information, the Nation's first legislators ascribed to government a relatively 
inactive role in the intellectual property system. This role corresponded to their preference for a free market approach, and alleviated their fears of overly centralized government. Accordingly, the Federal role and corresponding institutions have evolved to perform minimal regulatory functions. The system was designed to be self-enforcing; the government institutions granted rights, registered works, and the individual creators and users were responsible for protecting their rights and enforcing them through the courts.

Today, however, the emergence of new information and communication technologies is placing new demands on governmental institutions responsible for the administration of intellectual property rights. In reaction to the development of new technologies, for example, policymakers have passed legislation that calls for government to take on new or increased responsibilities. This raises the question, there fore, of whether existing Federal institutional arrangements for administering intellectual property rights, as initially designed, can adequately cope with new technological developments and the new responsibilities that may be placed on them.

To examine the current Federal role in the intellectual property system and how it may change in response to new technology, this chapter will:

1. describe the development of the goals and rationale for the Federal role in the intellectual property system and under what conditions it worked effectively;

2. characterize the current Federal institutional arrangements for dealing with intellectual property issues;

3. describe how technological developments may be stressing such arrangements; and

4. explore the implications for future institutional arrangements.

\section{DEVELOPMENT OF U.S. INTELLECTUAL PROPERTY POLICY}

\section{Goals for Granting Intellectual Property Rights}

In the United States a unique set of social, political, economic, and technological factors gave rise to a specific set of policy goals that intellectual property rights were designed to achieve. These factors, moreover, shaped the design of the Federal role in the administration of intellectual property rights.'

During the early history of the United States, the Founding F athers adhered to the belief in the right of the individual to own property and pursue his intellectual interests. ${ }^{2}$ The

\footnotetext{
'See ch. 2 for a discussion of how different historical circumstances influenced governments' use of intellectual property rights to achieve varying economic, political, and social goals,

IJ ohn Locke, for example, was one of the most influential philosophers on the Framers of the U.S. Constitution. Locke stated, for example, that "Every man has a property in his own person. The labor of his body and the work of his hands we may say are properly his." Garry Wills, Inventing America: Jefferson Declaration of Independence (New York: Doubleday \& Co., Inc., 1978), pp. 229-239; and Bruce Bugbee, Genesis of American Patent and Copyright Law (Washington, DC: Public Affairs Press, 1967), pp. 84-125.
}

early legislators also recognized the importance of a democratic polity, which required public dissemination of knowledge to function adequately. ${ }^{3}$ Because the United States was a developing country, its policy makers also wished to stimulate industrial growth, particularly in light of the burgeoning industrial revolution taking place in England. ${ }^{4}$

The Framers of the U.S. Constitution recognized that the granting of intellectual property rights was one way to achieve such basic social, political, and economic ideals. They believed that granting these rights would pro-

These beliefs originated from the ideas of J ohn Locke and J ean Rousseau. See, for example, J ohn Locke, Second Treatise on Civil Government, 1690, and J ean J acques Rousseau, Social Contract, 1762. Gordon Wood, The Creation of the American Republic, 1776-1787 (North Carolina: University of North Carolina Press, 1969), pp. 53-65; and Bruce Bugbee, The Genesis of American Patent and Copyright Law (Washington, DC: Public Affairs Press, 1967), pp. 84-125.

'Hunter Dupree, Science in the Federal Government: A History Policies and Activities to 1940 (Cambridge, MA: The Belknap Press of Harvard University Press, 1957); and Bruce Bugbee, Genesis of American Patent and Copyright Law (Washington, DC: Public Affairs Press, 1967), pp. 84-125. 
vide incentives for creators or industries to produce and disseminate works, which would promote public education and industrial growth. To provide an initial framework for this policy, the Framers included the clause in the U.S. Constitution:

To promote the Progress of Science and useful Arts, by securing for limited Times to Authors and Inventors the exclusive Right to their respective Writings and Discoveries. (Section 1, Article 8, clause 8.)

In The Federalist, J ames Madison clearly establishes the overall purpose of granting rights to individuals, which was the automatic promotion of the public good:

The utility of this power will scarcely be questioned. The copyright of authors has been solemnly adjudged, in Great Britain, to be a right of common law. The right to useful inventions seems with equal reasons to belong to the inventors. The public good fully coincides in both cases with the claims of individuals. The States cannot separately make effectual provision for either of the cases, and most of them have anticipated the decision of this point, by laws passed by the insistence of Congress.

A later, more definitive interpretation of this overall purpose-the stimulation of the creation and dissemination of information to the public-was stated in a legislative report on the Copyright Act of 1909:

The Constitution does not establish copyrights, but provides that Congress shall have

\footnotetext{
"The intended goals of this clause become very apparent when the original two proposals concerning intellectual property which were proposed during the Constitutional Convention are examined:

Madison's proposals envisioned a national legislature with the authority to To secure literary authors their copy rights for a limited time, To establish a University, To encourage by premiums and provisions, The advancement of useful knowledge and discoveries'; The other set of proposals was offered by Charles Pickney, and included the following contemplated powers: To grant charters of incorporation, To grant patents for useful inventions, To secure to Authors exclusive rights for a . certain time, To establish public institutions, rewards, and immunities for the promotion of agriculture, commerce, trades, and manufactures.

Bruce Bugbee, The Genesis of American Patent and Copyright Law (Washington, DC: Public Affairs Press, 1967), p. 126. 'Alexander Hamilton, James Madison, and J ohn J ay, The Federalist Papers, No. 43 (New York: The New American Library of World Literature, Inc., 1961), pp. 271-272.
}

the power to grant such rights if it thinks best. Not primarily for the benefit of author, but primarily for the benefit of the public, such rights are given. Not that any particular class of citizens, however worthy, may benefit, but because the policy is believed to be for the benefit of the great body of people, in that it will stimulate writing and invention to give some bonus to authors and inventors.'

\section{Federal Role in the Administration of Intellectual Property Rights}

The Federal role in the administration of rights evolved in a way that clearly reflected the goals of the U.S. intellectual property system. Similar to the development of the goals of intellectual property rights, political, economic, and technological factors influenced the type of role that Congress designed for the government in the administration of such rights.

First, Adam Smith's ideas of a free market, non-interventionist approach that could provide economic incentives and an efficient mechanism for markets and economic growth were increasingly accepted. ${ }^{8}$ Reacting against the English Government which used excessive regulatory controls, Americans also favored the $J$ effersonian notion of a government with as few regulatory functions as possible.' Additionally, the major technology of the time, the printing press, allowed the granting of rights to lead automatically to the dissemination of information. This was so because works had to to be published in order to enjoy protection. Moreover, in the absence of inexpensive reproduction technologies of today, publishers could more accurately estimate the returns on their investments and, thus had more direct economic incentives to publish works. Rights

\footnotetext{
${ }^{7}$ House Report No. 2222, 60th Cong., 2d sess., as cited in Alan Latman and Robert German, Copyright for The Eighties (Charlottesville, VA: Michie, Bobbs-Merrill, 1981), p. 12.

"Charles Beard, An Economic Interpretation of the Constitution of the United States (New York: Free Press, 1965); and Adam Smith, The Wealth of Nations, 1776 (New York: The Modern Library, 1937).

'Alexander Hamilton, J ames Madison, and J ohn J ay, The Federalist Papers, No. 39-46 (New York: The New American Library of World Literature, Inc., 1961), pp. 240-300; and Julian Boyd (cd.), The Papers of Thomas J efferson (Princeton, NJ : Princeton University Press, 1950).
} 
owners could also enforce their rights themselves because infringements were relatively easy to detect.

Under these circumstances, the early legislators believed that the intellectual property system could function adequately with minimal government intervention if left to its own devices:

When printing was the only information technology of any significance, eighteenth century policy makers conceived of an arrangement for knowledge-dissemination and compensation in society that was elegant in its absence of centralization and administration. Lawyers set up the machinery for granting exclusive rights to copy to those who wrote and to those who controlled the presses; Adam Smith's "invisible hand" took care of the details. As Madison noted, copyright provided an efficient means of achieving the constitutional goal of promoting science and the useful arts because it was one of the fortuitous policies in which the ends of the individual citizen and the goals of the collectivity could be made synonymous. Copyright, in short, was not a bad idea at the time. ${ }^{10}$

Consequently, the legislators of the Patent and Copyright Acts of 1790 designed a relatively inactive role for the Federal Government in the intellectual property system. These Acts clearly delineated the exclusive rights to be granted and the conditions under which they would be granted, and established the role of government as simply a register of works seeking protection. The acts also required creators who wanted to protect their works to publish them in local newspapers. The registration function, like the publication requirement, closely corresponded to the goals of intellectual property policy. For the repositories of submitted works and the publication of those works in public institutions were primarily for the public to access and learn from, thus fulfilling the original intent of the granting intellectual property rights.

The institutional arrangements for registering works were also created by the legislation

\footnotetext{
"Nicholas Henry, Copyright, Information Technology, Public Policy (New York: Marcel Dekker, 1967), pp. 56-57.
}

of $1790 .{ }^{11}$ The Patent Act established a Patent Board, which was made up of the Secretary of State, Secretary of War, and the Attorney General. Referring to themselves collectively as the "Commissioners for the Promotion of Useful Arts," the members of the board were empowered to issue a patent for any device or process "if they shall deem the invention sufficiently useful or important. The statute also established a Register of Patents, to be kept by the Secretary of State. ${ }^{12}$ The Copyright Act required the local District Courts (nearest to where the person seeking protection lived) and the Secretary of State to register and serve as depositories of creative works. ${ }^{13}$ And the courts, of course, served to interpret any problems rights owners or users might have enforcing their rights. ${ }^{14}$

\section{Early Development of the Governmental Institutions for the Administration of Intellectual Property Rights}

Since 1790, several factors have affected the evolution of the governmental institutions set up to administer intellectual property rights. These include the increasing number of crea-

\footnotetext{
"Before such institutional arrangements were established, Congress was responsible for granting both copyrights and patents on a case-by-case basis. Increases in numbers of creators seeking protection for their works was a major impetus for Congress to establish institutions to register and deposit works.

"Bruce Bugbee, Genesis of Patent and Copyright Law (Washington, DC: Public Affairs Press, 1967), p. 149.

"'The copyright law of 1790 stated that an author desiring protection thereunder was to deposit a copy of his work with the clerk of the District Court where he lived, but he was also required to send a second copy of his production to the $L^{\top}$. S. Secretary of State within six months. The clerk of the District Court was to record this work according to a detailed form prescribed in the statute, and could charge a sixty-cent fee for this service. Duplicates under seal could be issued at sixty cents each, and the grantee was required to publish, within two months, a copy thereof in at least one newspaper for a four week period-an interesting carry over of a feature which the Senate had dropped from the general patent bill prior to its passage. Bruce Bugbee, The Genesis of Patent and Copyright Law (Washington, DC: Public Affairs Press, 1967), p. 147.

The courts at the beginning construed the Act [the Copyright Act of 1790] very strictly and hence the author was obliged to proceed with the utmost caution along the tortuous copyright route lest any slip prove his undoing. "Alan Latman and Robert German, Copyright for The Eighties (Charlottesville, VA: Michie, Bobbs-Merrill, 1981), p. 5.
} 
tors seeking protection for their works and the growing number of types of works that Congress has included as protectable subject matter under intellectual property law.

In response to such changes, Congress has, over time, transformed the original institutions into larger, more distinct governmental agencies with increased responsibilities, administrative or otherwise. In spite of these modifications, these government agencies responsible for intellectual property rights have remained largely nonregulatory, their role being to register and deposit works, and to disseminate knowledge to the public.

\section{Copyrights}

Like the patent system, the copyright system of 1790 was amended soon after its creation. The major change expanded the types of subject matter to be protected under U.S. copyright law. Such expansion of the law to cover new types of works added increasing responsibilities to the Federal institutions which registered works. ${ }^{15}$

Reflecting such increases, the Federal copyright institutions grew in size and administrative functions. In 1859, the responsibility of registering works was transferred to the Department of the Interior. Then in 1870, when Congress was enacting patent legislation, it undertook a major reform of the copyright system. Congress assigned the registering of copyrights and the depositing of works to the Library of Congress, which had been established in 1800. Under this statute, the Librarian of Congress received and maintained all copyright records and deposit copies, which the District Courts had held under the old, decentralized system. In 1897, a separate Copyright Office was established within the Library of Congress, where it remains today. Much like

\footnotetext{
"Over time, legal protection, for example, has been extended to include: designs, engravings, and etchings (1802); musical compositions (183 1); dramatic compositions (1856); photographs and negatives (1865); statues and models (1870); all writings of an author (1909); motion pictures (1912); sound recordings (1972); original works of authorship (1976); computer software (1980); and mask works (sui generis protection) for semiconductor chips (1984).
}

the changes made in the patent system, the transfer of the registration and deposit function to a centralized library clearly reflected the wish to promote public dissemination of intellectual creations. ${ }^{16}$

\section{Patents}

A few years after the Patent Board was established in 1790, the large numbers of patent applications became too time-consuming for the board members whose primary responsibilities were as members in the Cabinet. ${ }^{17}$ To remedy this situation, Congress, in 1789, dropped the requirement that inventions be sufficiently useful or important to receive a patent, and replaced the examination process performed by the Cabinet members with simple registration. In 1802, Congress enacted legislation that created a Patent Office as a distinct division within the Department of State. ${ }^{18}$

Dissatisfaction with this process and the increasing number of applications for patents led to legislation in 1836 that enlarged and elevated the status of the Patent Office to a separate bureau within the Department of State. The statute also authorized the President to appoint a Commissioner of Patents, who in turn was to appoint a full-time staff of examiners and other clerks and assistants. It also reinstated the process of examining patent applications for novelty, utility, and invention. As under the laws of 1790 and 1793, applications were to be submitted with specifications, drawings, and when necessary, models. The statute further directed the Commissioner to display the models in a gallery open to the public, thus further promoting the public dissemination of knowledge.

\footnotetext{
${ }^{16}$ The Thomas J efferson Building of the Library of Congress, for example, was established by the Copyright Act of 1870 to house the growing collections that were being acquired as a result of the copyright deposit system.

"F or example, under the Patent Act of 1790, approximately 57 patents were granted: 3 in 1790,33 in 1791, 11 in 1792, and 10 in the early weeks of 1793. Bruce Bugbee, Genesis of Ameri. can Patent and Copyright Law (Washington, DC: Public Affairs Press, 1967), p. 149.

"Bruce Bugbee, Genesis of American Patent and Copyright Law (Washington, DC: Public Affairs Press, 1967), p. 150.
} 
In 1849, the Patent Office was transferred to the newly created Department of the Interior. In 1870 the Commissioner of Patents was authorized to register trademarks. ${ }^{19} \mathrm{Fi}$ -

"The Supreme Court held such legislation to be unconstitutional because trademarks did not cover a product of authorship or invention. Subsequently, the Supreme Court found that nally, in 1925, the Patent Office was placed in the Department of Commerce, where it remains today.

registration of trademarks was permissible under the power to regulate commerce. Gustavus A Weber, The Patent Office(Baltimore, MD: The J ohns Hopkins University Press, 1924).

\section{PRESENT INSTITUTIONAL ARRANGEMENTS FOR THE ADMINISTRATION OF INTELLECTUAL PROPERTY RIGHTS}

Although the U.S. intellectual property laws have been revised many times since 1790, the basic institutional arrangements have, with minor changes, remained intact-performing minimal, indirect regulatory functions. These institutions administer basic laws, register and deposit works, and provide support services. ${ }^{20}$ They have, moreover, shown a remarkable re siliency to technological change, thus far.

In adjusting to technological development, many of the institutions have undergone similar changes. First, each of the institutions has increased in size, reflecting the growing number and types of works to be protected. Second, each has begun to use information technologies to perform more efficiently. Third, to

\footnotetext{
${ }^{20}$ Donald Curran, Acting Register of Copyrights, for example, speaking before the Patent, Trademark, and Copyright Section of the American Bar Association, said that "the Federal Government does not now in any but the most tangential way "regulate' the copyright industries. . " Information Hotline, vol. 17 , No. 10, November 1985, p. 4.

Regulation can be defined as:

Federal laws or rules which impose government standards and significant economic responsibilities on individuals or organizations outside the Federal establishment. . . Regulation is carried out by Federal agencies through such means as setting or approving prices, rates or fares, profits, interest rates, and wages; awarding licenses, frachises, certificates, and permits; or estab-

lishing and enforcing standards of behavior such as worker safety

rules, air quality levels, public disclosure of financial informa-

tion, or prohibitions of price, racial, religious, or sexual discrimination.

Although almost all government activities involve a rule or a regulation, there are varying degrees of regulation. The administration of intellectual property rights, for example, relies on the law to define property rights and lets those who possess them negotiate their value either in the marketplace or in a private, decentralized fashion. A more regulatory approach would rely on public authorities to directly determine and allocate the value of intellectual property. Domestic Council Review Group on Regulatory Reform, "The Challenge of Regulatory Reform: A Report to the President" (Washington, DC, 1977), p. 47.
}

deal more effectively with the growing internationalization of intellectual property issues, all of the institutions individually and jointly, have increased their international activities. Fourth, in reaction to the increasing complexity of new technologies (particularly cable) that have given rise to new stakeholders, a new agency has been established that departs from the traditional role of government regarding intellectual property rights. ${ }^{21}$ And finally, the courts have become increasingly burdened with cases involving more complex technical issues. A brief characterization of the principal institutional actors involved with the administration of property rights and some of the current issues they face are provided below.

\section{Patent and Trademark Office}

The U.S. Patent and Trademark Office (PTO) is located within the Department of Commerce. Similar to the Copyright Office, PTO has no jurisdiction over questions relating to enforcement of patents, nor over matters that concern the promotion or the utilization of patents. PTO's major function is to administer the patent laws as they relate to the granting of patents. It examines applications for patents to

\footnotetext{
"The functions have become more regulatory in the sense that the government is actively deciding the value of royalties for intellectual works. The first time that an exception was made to the traditional copyright approach was in the Copyright Act of 1909 which required copyright proprietors of musical works to license their use in mechanical recordings for a royalty of 2 cents. Since 1909, three other exceptions have been made for cable retransrnisșions, musical recordings used in juke boxes, and noncommercial broadcasters use of music and other creative works.
} 
ascertain whether the applicants are entitled to patents under the law and grants the patents when they are so entitled. PTO also administers the trademark laws and reviews trademark applications to determine whether they meet statutory criteria for registration. ${ }^{22}$

Furthering the goal of increasing public access to knowledge, PTO also publishes issued patents and various publications about patents and patent laws. It also maintains public search rooms for the public to use to examine issued patents and records and supplies copies of records and other papers on demand.

In addition to the examining groups, PTO has a number of sections, divisions, and branches that perform various other services, such as receiving and distributing mail, receiving new applications, handling sales of printed copies of patents, copying of records, inspecting drawings, and recording assignments. ${ }^{23}$

PTO has grown tremendously since it was first established. At present, it has approximately 3,100 employees, of whom about half are examiners and technical and legal staff. over 100,000 patent applications are received annually. Because of the large number of applications, there is a 25-month backlog of 440,000 cases. To remedy this situation, PTO is in the process of automating its search files. The goal is to complete automation by the early 1990s. ${ }^{24}$

\section{Copyright Office}

The U.S. Copyright Office is located in the Library of Congress. As noted earlier, its location is important to both the Library and the Copyright Office, representing a symbiotic relationship between the two. The Copyright

\footnotetext{
"US Department of Commerce, Patent and Trademark Office, "General Information Concerning Patents: A Brief Intro. duction to Patent Matters' , Washington, DC: U.S. Government Printing Office 1984), p. 5.

"U.S. Department of Commerce, Patent and Trademark Office, "General Information Concerning Patents: A Brief Intro. duction to Patent Matters" (Washington, DC: U.S. Government Printing Office, 1984), p. 5.

"Discussion with Donald Quigg, Acting Commissioner of Patents, March 1985.
}

Office, through its deposit requirement, collects copies of all the works it receives which it then makes available to the Library of Congress' collections. This function, sometimes referred to as "America's cultural policy, " has been critical in developing the Nation's storehouse of intellectual material. ${ }^{25}$ The Library of Congress in turn supplies the Copyright Office with administrative support. This cooperative arrangement has existed for over 150 years and helps to accomplish a major goal of intellectual property protection-the dissemination of knowledge to the public. ${ }^{26}$

The divisions of the Copyright Office are organized by function. In addition to the Register's Office, there are six operational divisions:

1. the Acquisitions and Processing Division -which performs the general housekeeping and accounting work of the office and the enforcement of the mandatory deposit provisions of the copyright law;

2. the Examining Division-which determines whether the requirements of the law have been met for materials submitted for registration;

3. the Cataloging Division-which catalogs all copyright registrations and recorded documents;

4. the Information and Reference Division -which provides the public with general information on copyright, conducts searches for the public in the Copyright Office catalogs, and produces on request certified copies of office records;

5. the Records Management Divisionwhich maintains the records of the Copyright Office; and

6. the Licensing Division-which deals with payments made to the office under the compulsory licensing provisions of the law

\footnotetext{
"Discussion with Donald Curran, Acting Register of Copyrights, March 1985.

${ }^{\text {"F }} \mathrm{F}$ or an interesting discussion of the relationship between the Copyright Office and the Library of Congress, see Donald Curran, "The Copyright Office and the Library of Congress, " remarks of Donald Curran, acting Register of Copyrights to the American Bar Association, Section Patent, Trademark, and Copyright Law, Washington, DC, J uly 9, 1985.
} 
that relate to coin-operated phonorecord players (jukeboxes) and cable systems. ${ }^{27}$

The number and types of works registered have grown enormously since the Copyright Office was established. F or example, between 1790 and 1869 a total of 150,000 works were registered. Today, approximately 500,000 works are registered annually with the Copyright Office. 28 The staff of the Office has grown to 561 with an annual budget of $\$ 16.2$ million. ${ }^{29}$ In addition to expanding its organization with increased registrations, the Copyright Office has recently begun to use information technologies to automate many of its functions. This has greatly improved its efficiency, particularly in the registration process.

\section{Copyright Royalty Tribunal}

The Copyright Royalty Tribunal (CRT) is the most recently established government agency that deals with intellectual property rights. It was established by the 1976 Copyright Act as an independent agency within the legislative branch. CRT was created to administer several compulsory licenses that Congress, partly in response to new technological developments, also set forth in the 1976 act. A compulsory license permits the use of copyrighted material under certain circumstances without the permission of the copyright owner, provided a government-set payment is made to the copyright owner. Such licenses are:

- retransmissions by cable systems of distant broadcast signals by television and radio stations;

- the use of musical records in jukeboxes for profit;

- the use of music and certain other creations by noncommercial broadcasters; and

\footnotetext{
"'"86th Annual Report of The Register of Copyrights, 1983" (Washington, DC: Library of Congress. 1984), p. 1.

"'86th Annual Report of the Register of Copyrights, 1983" (Washington, DC: Library of Congress. 1984), pp. 32, 34.

"Appendix to the Budget of the United States Government for Fiscal Year 1986.
}

Ž the use of music on phonorecords. ${ }^{30}$

CRT has six responsibilities for the administration of the four compulsory licenses:

1. adjust the compulsory license rate for retransmission by cable systems of distant, non-network broadcasts by television stations;

2. determine the distribution of fees deposited with the government by cable systems;

3. determine the compulsory license paid to the Register of Copyrights for the performance of non-dramatic musical compositions by jukebox owners;

4. determine the distribution of fees deposited with the government by jukebox owners;

5. adjust the mechanical compulsory license rate on the sale of non-dramatic musical works embodied in phonorecords (these fees are paid to copyright owners without government involvement, via the Harry Fox Agency); and

6. determine reasonable terms and rates for public broadcasting entities' use of musical, pictorial, graphic, and sculptural works (these fees are paid without government involvement) ${ }^{31}$

Five appointed commissioners are responsible for holding hearings to determine rates and distribute royalties.

Because CRT performs functions that are much more regulatory in nature - that is, its rulemaking proceedings to set royalty rates and its adjudication function which entails distribution of collected royalties to claimants-it diverges sharply from the traditional role of

\footnotetext{
"Statement of Wilbur Campbell, Deputy Director, Accounting and Financial Management Division, General Accounting office before the Subcommittee on Courts, Civil Liberties, and the Administration of J ustice, Committee on the J udiciary, U.S. House of Representatives, "The Operation of the Copyright Royalty Tribunal, " J une 11, 1981, p. 3.

${ }^{31}$ Statement of Wilbur Campbell, Deputy Director, Accounting and Financial Management Division, General Accounting Office before the Subcommittee on Courts, Civil Liberties, and the Administration of J ustice, Committee on the J udiciary, U.S. House of Representatives, "The Operation of the Copyright Royalty Tribunal, " J une 11, 1981, p. 4.
} 
the Federal Government in the administration of intellectual property rights. For this reason, CRT has recently run into some sharp criticisms. ${ }^{32}$

\section{Other Supporting Agencies Within the Federal Government}

Department of Commerce

Four offices and agencies within the Department of Commerce support intellectual property activities in various ways. The growing need for support reflects the increasingly complex technical, political, and economic dimensions of intellectual property rights issues brought about by technological development. Such support draws on the industrial, technical, and scientific expertise of the following agencies.

International Trade Administration. The International Trade Administration (ITA) was established by the Secretary to strengthen the U.S. international trade and investment position. ITA provides counseling to members of the business community on export opportunities and problems. ITA offices abroad help to identify potential markets. A recent reorganization along lines proposed by the Grace Commission has brought together industrial specialists in such areas as computers and telecommunications with trade promotion staff to bring more specialized knowledge to trade negotiations. ${ }^{33}$ ITA administers the Export Administration Act to ensure that export activity is consistent with national security and foreign policy objectives. A current priority is prevention of the illegal transfer of technology. Control of technical data poses enforcement problems because such intangibles as consulting arrangements and training of foreign nationals are covered. In issuing export licenses, clearances are routinely required from the Departments of State and Defense.

\footnotetext{
"See for example, hearings held before the Subcommittee on Courts, Civil Liberties, and the Administration of J ustice, Committee on the J udiciary, U.S. House of Representatives, "The Copyright Royalty Tribunal, " J uly 11, 1985.

"President's Private Sector Survey on Cost Control, "Report on the Department of Commerce" (Washington, DC: U.S. Government Printing Office, 1983), p. 24.
}

National Telecommunications and Information Administration. NTIA is the executive branch agency principally responsible for the development of domestic and international telecommunication and information policy. The agency also manages the various government agencies' use of the electromagnetic spectrum and has research laboratories for technical support. Because of the close relationship between telecommunications and intellectual property and its role in developing information policy, NTIA participates in U.S. Government delegations to international intellectual property negotiations. NTIA also makes recommendations on legislative and regulatory issues regarding intellectual property and communication issues.

National Technical Information Service. NTIS serves as a government clearinghouse for technical information. NTIS issues notices to the public that a government agency has applied for a patent. Private organizations and individuals can then determine whether to apply for a license.

NTIS acts as an agent in support of the patent process for nine departments and agencies. These are the Departments of Commerce, Health and Human Services, Interior, Agriculture, Army, Air Force, Transportation, Veterans Administration, and the Environmental Protection Agency. NTIS makes special promotional efforts to encourage licensing and also licenses those agencies' patents.

Office for Productivity, Technology, and Innovation. OPTI, headed by an Assistant Secretary of Commerce, was created to develop measures to improve the competitive position of the United States in world markets. The passage of legislation (Public Law 96-517) in 1980 provided nonprofit organizations and small businesses with the first right of refusal to title in inventions made under government contracts and grants. Authority to implement this policy was transferred to OPTI from the Office of Federal Procurement Policy of the Office of Management and Budget by Public Law 98-620. A Presidential memorandum issued in 1983 directed agencies to permit all contractors and grantees to take title in inventions 
to the extent permitted by law. I mplementation of this directive is monitored by OPTI, which works with agencies in preparing procurement regulations. OPTI is also developing policy to cover the ownership and the use of technical data arising from federally supported research and development. This is a highly controversial area with little precedent for guidance.

\section{Department of J ustice}

The Antitrust Division of the Department of J ustice includes an intellectual property section that monitors the interface between antitrust and intellectual property matters. The section helps develop legislation with potential antitrust implications, such as the recently passed National Cooperative Research Act, which removes certain antitrust barriers to cooperative R\&D. It also provides the Administration's position on intellectual property matters to other regulatory agencies, and presents the Administration's opinion to the courts, if requested in a pending case.

The Department of J ustice also represents the Patent and Trademark Office in civil cases when, for example, it is alleged that the agency acted improperly in approving or refusing a patent application. It also represents the Copyright Office in similar circumstances.

\section{Department of State}

The Department of State's international activities in the protection of intellectual property are carried out through its Office of Business Practices. The Department of State coordinates U.S. participation in the international intellectual property treaties to which the United States is a party, such as the Convention for the Protection of Industrial Property and the Universal Copyright Convention. Within the Federal Government, the Department of State initiates or participates in the approval of papers circulated among agencies to achieve coordinated positions in multilateral and bilateral negotiations on intellectual property issues. To elicit industry viewpoints, the Department of State has created an Advisory
Committee on International Intellectual Property.

Office of the U.S. Trade Representative

The Office of the U.S. Trade Representative (USTR), created by statute in 1975 in the Executive Office of the President, is responsible for setting and administering trade policy. USTR also administers part of the Trade and Tariff Act of 1984, which refers specifically to the protection of intellectual property. Under this act, the President is authorized to determine which developing countries may export goods to this country duty free, on the basis of each country's efforts to protect U.S. intellectual property products as well as other criteria. USTR is also responsible for issuing a statutorily required annual report to Congress on trade problems, including a report on nations that are not respecting U.S. intellectual property rights.

\section{International Trade Commission}

The International Trade Commission (ITC) is an independent quasi-judicial agency that determines whether unfair acts related to imports harm U.S. industries. Investigations often involve allegations of patent, trademark, or copyright infringement. The intellectual property owner or licensee usually initiates action by making a complaint to ITC. ITC may then conduct hearings before an administrative law judge. A final decision is rendered by the Commissioners. The agency is authorized to issue orders excluding goods from entry and/or cease-and-desist orders. Exclusion orders are enforced by the Bureau of Customs. ITC works closely with the Department of Commerce's I nternational Trade Administration, which maintains information on industries that might be harmed by unfair trade practices.

\section{Policy Coordination}

Reflecting the growing number of economic, political, social, and international factors surrounding intellectual property issues, various Federal agencies have recently begun to coordinate their efforts to deal with these multifaceted questions. Responsibility for policy co- 
ordination on intellectual property is mainly vested in four interagency coremittees that are described below.

Cabinet Council on Commerce and Trade. The Cabinet Council on Commerce and Trade is chaired by the Secretary of Commerce, who has appointed the Commissioner of Patents and Trademarks as Chairman of its Working Group on Intellectual Property. The basic task of the Working Group is to coordinate the positions of Federal agencies, especially in developing U.S. positions in foreign negotiations. Seven agencies of the executive branch are represented on the working group. The Copyright Office representative also participates in the meetings.

The working group is concerned with both international and domestic issues that require a unified government position. These have included:

1. obtaining a coordinated position for the Brussels Satellite Convention, which was subsequently ratified;

2. proposing controls for imports from third parties that do not respect U.S. trademarks;

3. recommending changes in the Freedom of Information Act to protect trade secrets;

4. coordinating agencies' positions on the recently passed semiconductor chip legislation; and

5. assessing needed changes in the "first sale" doctrine.

Trade Policy Committee. The Trade Policy Committee is chaired by the U.S. Trade Representative and has a subcommittee on intellectual property chaired by USTR. In compliance with the Trade and Tariff Act of 1984, it examines international protection of intellectual property as a trade barrier. In trade matters, the committee's focus is on bilateral negotiations. Seven executive branch agencies are members of the subcommittee.

The subcommittee facilitates cooperation among agencies in carrying out responsibilities assigned to USTR under the recent legislation. These include:
1. identifying the kinds of trade barriers that result from protection of intellectual property;

2. identifying the policies and practices of individual countries that cause serious problems in the United States;

3. compiling information in support of bilateral negotiations; and

4. preparing the annual report to Congress that highlights problem areas and U.S. efforts underway to improve them.

Senior Interagency Group on Communication and Information Policy. The Senior Interagency Group on Communication and Information Policy was created in 1980 and is co-chaired by representatives from the Departments of State and Commerce. Its Working Group on Copyright and Intellectual Property, which includes representatives from nine government agencies, is chaired by a representative of the Department of Commerce's National Telecommunications and Information Administration.

The task of this working group is to coordinate and exchange information on each of the agency's efforts to improve international protection for U.S. intellectual property rights. The working group has recently been working to ensure that U.S. programmers receive remuneration for the cable retransmissions of their material by Canadians and Mexicans. A separate Working Group on Transborder Data Flow, chaired by a representative from the Department of State, coordinates U.S. positions in the Organization for Economic and Community Development (OECD) Committee on Information, Computer, and Communication Policy.

Federal Coordinating Council for Science, Engineering, and Technology. The Federal Coordinating Council for Science, Engineering, and Technology is chaired by the director of the Office of Science and Technology Policy (OSTP). Its Working Group on Intellectual Property is chaired by the Assistant Secretary of Commerce for Productivity, Technology, and I nnovation. This group addresses issues that arise in the process of carrying out legislative and administration policy on the owner- 
ship of intellectual property created during government-sponsored research and development. Nineteen agencies are represented on the working group.

This working group is used by the Assistant Secretary to help coordinate the execution of responsibilities assigned to Commerce by Public Law 98-620. Guidance is provided to agencies that are drafting Federal Acquisition Regulations that authorize vesting title to intellectual property in small businesses and nonprofit organizations performing research and development for the government. Similar efforts are underway pursuant to the Presidential directive that encourages all government contractors and grantees to take title to the extent permitted by law. The working group is drafting guidelines for the disposal of technical data arising from government-supported research and development, and is preparing model agreements that include provisions for intellectual property for use by government laboratories undertaking cooperative efforts with private companies.

\section{Federal Courts}

From the very beginning of Federal intellectual property protection, courts have played a central-albeit not highly visible-role in the implementation of intellectual property laws. Although the availability of courts for the resolution of private disputes is generally taken for granted, and not often considered part of the system, it is clear that access to the Federal judicial system has always been a crucial element of intellectual property policy. As forums for intellectual property dispute resolution, courts have: 1) developed doctrines defining the scope of protections; and 2) provided official sanctions for misallocation of rights and rewards under intellectual property law.

The role of the courts in resolving private disputes and in developing legal doctrines may become more central with the advent of new information and communication technologies. ${ }^{34}$ The volume of legislation dealing with technological intellectual property is growing rapidly and is likely to be matched by an increasing volume of litigation. ${ }^{35}$ The economic stakes involved in the allocation of technological property rights by the courts are large and will assure the availability of extensive resources for litigation. ${ }^{36}$ The resulting surge of scientific and technological disputes into the judicial arena is likely to put substantial strain on the institutional resources of the judiciary and to raise questions about judicial expertise in resolving

\footnotetext{
${ }^{34}$ udicial decisions on the allocation of proprietary rights in new information technologies and on access to new forms of communications occupy position of singular importance. What J ustice Cardozo said about the" preferred position' of the First Amendment-"that it is the matrix, the indispensable condition, of nearly every other form of freedom' '-may well be said about access to information and the means of its communication. At a time when the dimensions of advance in these technologies are seen as equal in importance to the advent of the industrial revolution and when the potential for the monopolization of control they embody surpasses anything organized societies have known so far, the power of courts to demarcate rights of ownership in and access to knowledge is the power to decide whether or not the new information and communication technologies will be used to increase the public dissemination of information. The shortcomings of intellectual property rights adjudication must be seen against that challenge. See Palko v. Connecticut, 302 U.S. 319 (1937).

${ }^{33}$ For a comprehensive list of legislation in the 98th Congress dealing with various aspects of the new information technology, see Report, 8th Annual Copyright Law Conference, Mar. 7,1985 , Washington, DC. The volume of litigation over questions of copyrightability has increased dramatically. Although the available data on copyright litigation does not distinguish between traditional copyright disputes and those involving new technologies, the number of copyright cases filed in Federal courts increased from 899 in 1976 to 2,226 in 1983. Annual Report of the Director of the Administrative Office of the United States Courts, 1984.

${ }^{46}$ In 1982, an estimated 2.8 million personal computers were sold in the United States. Another 5 million, for a total of more than $\$ 24$ billion in sales, were expected to be sold in 1983, By the end of the century 80 million personal computers will be in use. Estimates of total software revenues for 1982 run as high as $\$ 45$ billion, by 1987 packaged personal computer software sales alone are expected to reach $\$ 4.8$ billion. In 1984, gross revenues from the sale or license of computerized databases surpassed $\$ 3$ billion. Pamela Samuelson, "CONTU Revisited: The Case Against Copyright Protection for Computer Programs in Machine Readable Form," Duke Law Journal, No. 4, 1984, pp. 705-712.
} 
novel and ever more complex scientific and economic issues raised by the regulation of new intellectual property .37

\section{Non-F ederal Agencies: Collecting Societies}

Traditionally, many copyright owners have licensed use of their literary, dramatic, musical, and artistic works, as well as other forms of intellectual property, on the basis of transaction contracts worked out between individuals. The introduction of commercial broadcasting technologies, beginning in the 1920s, gave copyright owners new opportunities for presenting their works and new difficulties in collecting fees for use. Copyright owners have found it increasingly difficult to control or administer their rights on a case-by-case basis. Users also have faced difficulties in identifying and remunerating creators of works. As described below, these problems provided significant pressure for the establishment of systems of administering rights on an aggregate basis through collecting societies.

\section{Music}

The use of a collective system of administering intellectual property rights in the music industry was prompted by two events. First, the 1909 revision of the Copyright Act extended to the owners of music copyrights the exclusive right to authorize the public, forprofit performance of their works. Soon after, radio extended once-local performances to a much larger audience. Film and television followed, bringing further increases in the scale and scope of public musical performances.

\footnotetext{
"The practical value of the categorical copyright protection for computer software, for example, will be determined largely by judicial decisions on the copyrightability of particular forms and types of programs and by judicial definition of the scope of the protections that will be accorded by software copyright.
}

What copyright owners lacked in the face of these new opportunities for performance and profit was an efficient mechanism for collecting the money to which the law entitled them. To setup such a system, a group of prominent composers formed the American Society for Composers, Authors, and Publishers (ASCAP). Established to collectively license use of musical works and to monitor performances and infringements of the law, ASCAP was successful in lowering the cost and simplifying the process of licensing transactions.

A second, much smaller, collecting society was founded in 1930 by Paul Heinecke. Called the Society of European Stage Authors (SE SAC), the organization's membership was made up mostly of Europeans. Today, SE SAC has a large repertoire of American music.

In 1940, a dispute between ASCAP and a group of broadcasters produced the third music collecting society, Broadcast Music Inc. (BMI). The broadcasters charged that ASCAP's licensing fees were too high, and so split off to form their own society. BMI supplied its member broadcasters with music from sources not controlled by ASCAP. Although the broadcasters resolved their dispute with ASCAP in 1941, BMI continued to operate and is still a major competitor to ASCAP.

Print

In print publishing, the pressure for a collective approach began to build in the 1950s, when authors and publishers saw a threat to their traditional sources of income from photocopying technologies. Micrography was the first such technology, and it was followed in the 1960s by advances in photocopying techniques and mechanical paper-handling capacity.

During the process of revising the Copyright Act, Congress suggested that publishers and authors might set up a cooperative mechanism for collecting and disbursing revenues. Upon 
passage of the 1976 act, a group of publishing and other associations formed the Copyright Clearance Center (CCC). Established in 1977, CCC was designed to monitor and collect from consumers who want to photocopy copyrighted works and to distribute revenues to the copyright holders.

\section{Film}

With the introduction of cable and satellite transmission, the film industry followed the example of the music and publishing industries and set up a collecting society. Before that time, the reproduction of film prints was expensive, and profitable exhibition was generally visible, so illicit use was easily discouraged. But with satellite and cable, the film industry faced greater difficulties, particularly in foreign countries, in collecting fees for use of their works.

In response to these new technologies, an international collecting society called L'Association de Gestion International Des Oeuvres Audio-Visuelles (AGICOA) was organized in 1982. The society was founded to negotiate use of films between national collecting societies and copyright holders, to monitor the use of films, to collect royalties from those who use them, and to distribute royalties to copyright holders around the world.

\section{Collecting Societies in Practice}

Generally speaking, the main purpose of collecting societies has been to alleviate the problems of administering individual property rights by setting up a central clearinghouse mechanism. Easing the cost and complexity of licensing is also important; users can obtain a blanket license to use any of the registered works. ${ }^{38}$ Collecting societies, moreover, attempt to serve as forums for negotiations between the various interested parties and try to educate the general public about intellectual property protection.

\footnotetext{
${ }^{34}$ In some cases, however, users prefer to pay on a per-use basis. ASCAP, BMI, and the CCC each offer these types of transactional licenses. AGICOA generally operates on a pay-per-use basis.
}

To accomplish these objectives, each collecting society performs similar functions. For example, each has a department responsible for licensing users of copyrighted works. They try to identify new users and see that both new and established users are properly licensed and pay the required fees. Their responsibilities also include convincing users that they must in fact pay user fees; this is sometimes difficult. In some cases, some collecting societies have resorted to lawsuits to exact payment and enforce licensing terms. ${ }^{39}$ Although the blanket license entitles users to access to all of the society's works, the fees charged vary according to particular classes of use. ${ }^{40}$ The negotiation of fees is conducted with various industry groups, such as the American Hotel and Motel Association, the National Association of Broadcasters, the Association of American Publishers, and the Authors League of America. Each collecting society has some mechanism for adjudicating disputes in cases where users feel the fees are too high.

In addition to maintaining lists of licensees, the collecting societies have departments that are responsible for recording and updating the list of works registered with the society. Most of the collecting societies maintain these files in an electronically accessible database. The staff members in this section also respond to inquiries from the public, users, or rights holders.

Because it would be uneconomical to log and monitor every use of every registered work, collecting societies generally rely on sample

\footnotetext{
"ASCAP brings, for example, approximately 400 to 500 such infringement actions every year. Over 99 percent of these cases are settled before trial.

"The musical performance rights societies, for example, use different methods but similar criteria for deterrnininguser license fees. The criteria for broadcast users include, for example, advertising revenues and the size of their markets. For nonbroadcast users such as "general establishments, " the societies use factors such as the price of a drink, seating capacity, the frequency of music performances, and the type of rendition. Hotel and motel fees take into account total entertainment expenditures; concert rates depend on admission price and seating capacity; background music users such as Muzak pay a fee based primarily on the number and character of subscribers.
} 
surveys of use for determining the distribution of revenues to their creator and publisher members."The exact distribution of revenues to individual rights owners is calculated by formula. ${ }^{42}$

\footnotetext{
"This is usually performed in a special survey department. Although the music collecting societies and the CCC and AGICOA all use different survey methods, the overall intent of the survey is similar. Upon receipt of the survey data, the societies identify writers and publishers of the registered works. Some of the societies report that the use of information technology has greatly improved the efficiency of the survey and identification process.

"In the case of the music performance societies, these calculations are made with weighting formulas, whereby different uses of works earn different amounts of performance credits. For uses of printed works, the CCC uses rates determined by each of the copyright holders for calculating its survey data.
}

Most of the collecting societies have separate international departments that have reciprocal agreements with individual collecting societies abroad. These agreements provide for the exchange of revenues that foreign societies collect for American societies' registered works. Collecting societies also bel ong to the relevant international associations.

After calculating the credits, the music performance rights societies divide 50 percent of their revenues among writers according to the credits they earned and 50 percent to publishers according to the credits they earned. The CCC pays all of its collected revenues (less overhead) to its publisher members (who may or may not have agreements to share these revenues with authors) according to calculations made with the usage survey data. Automated information systems have also greatly streamlined the remuneration process.

\section{EMERGENCE OF NEW TECHNOLOGIES AND THEIR IMPLICATIONS FOR THE PRESENT FEDERAL INSTITUTIONAL ARRANGEMENTS FOR THE ADMINISTRATION OF INTELLECTUAL PROPERTY RIGHTS}

As illustrated above, the Federal institutions established to administer intellectual property rights have shown a resilience to technological developments over time. Today, however, new information and communication technologies are of a new order of magnitude and scope, and so are placing correspondingly greater pressure on the entire intellectual property system. The present institutional arrangements were not designed to deal with the many kinds of problems generated by these technologies. To explore how new technological developments are affecting the viability and effectiveness of the institutions now involved with intellectual property issues, a brief characterization of such developments and their potential institutional implications is provided below.

Rapidity of, and Uncertainty With Respect to, Changes in Information and Communication Technologies

Technological advances in, and the growing convergence of, computer and communication technologies, have combined with the deregu- lation of the telecommunication industry, to greatly enhance the public's access to information products and services. These same two developments significantly affect the processes of creating, producing, and using intellectual properties. As a result, they are likely to have a somewhat disruptive effect on the nature of the intellectual property system as it exists today.

The unprecedented speed and unpredictability of these changes confound efforts to design legislation that will continue to be relevant and useful. It was for this reason, for example, that technological gaps soon developed in the 1976 copyright law and its 1980 amendments were enacted, although the law itself was specifically designed to take emerging technologies into account. As illustrated in the case of Apple Computer, Inc. v. Franklin Computer Corp., for example, the law failed to address the important question of whether copyright law applied to operating code that is readable for the most part only by machine, or to information embedded in hardware. And as the case of Sony Corp. of America v. Universal City Studios 
demonstrates, the law failed to anticipate the rapid growth of the home market for videocassette recorders (VCR) and how this widespread use of VCRs might affect the intellectual property rights of the film industry. It is not surprising, therefore, the past few years have brought greater demands on the courts and many more bills related to intellectual property which seek to accommodate legislation with changing technologies.

Given the rapidity of, and uncertainty with respect to, changes in information and communication technologies and their impact on the intellectual property system, the question arises as to whether the existing institutions that were established to address intellectual property issues are either equipped with or are capable of developing an ongoing process to assess and plan for technological change.

\section{Growing Demand for Nontraditional Copyright Solutions Requiring a Regulatory Approach}

The rapid development of information and communication technologies, combined with greater public access to them, has strained many of the traditional mechanisms for protecting intellectual properties. This growth and development has also stressed the system by which creators, producers, and distributors of intellectual properties are remunerated. For example, because many of these technologies permit decentralized access and require electronic handling of information, their use can be carried out privately and is, therefore, less subject than in the past to monitoring and control. Moreover, by generating new uses and users of intellectual properties, these technologies are convoluting the process by which intellectual properties are created, published, distributed, and used. Similarly, they are altering some of the traditional roles, and relationships of actors in the intellectual property system. As a result, many of those involved are seeking new kinds of rights and forms of remuner- ation. ${ }^{43}$ Directors, for example, are looking for ways to receive property rights protection for their individual contribution to stage and film production. ${ }^{44}$ The M otion Picture Association of America, moreover, is seeking the right to be paid a fee by owners of satellite dishes who receive transmitted broadcasts. ${ }^{45}$

To overcome some enforcement problems generated by the new technologies and take into account the new kinds of claims for rights, a number of laws and bills have been enacted or introduced that depart from the traditional intellectual property scheme and require significant government involvement for their implementation. Under a compulsory licensing scheme, for example, Section 116 of the 1976 Copyright Act requires jukebox operators to pay royalties to the copyright owners of nondramatic works. To execute this requirement, the law obliges the Copyright Office to register and license operators of jukeboxes and the Copyright Royalty Tribunal (which at the time was not yet constituted) to determine which claim for fees are legitimate and allocate royalty payments equitably. Similarly, the proposed Home Recording Act of 1983, designed to circumvent the problems of enforcement by compensating copyright owners with a royalty payment, calls on the Copyright Office to initiate arbitration proceedings to determine the royalty schedule and requires the Copyright Royalty Tribunal to determine and allocate the funds collected among competing claimants.

\footnotetext{
'"I'his is not the first time that technology has given rise to new kinds of rights. Looking back at the history of intellectual proprerty laws and practices, one can see that, with the development of new technologies, pressure for the establishment of new kincls of rights emerged. Recording technology, for example, gavis rise to the demand for a "mechanical recording right. " Unlike traditional rights which were granted to an entire class of work, such as a book or a motion picture, these new kinds of rights were designed to remunerate the specific use to which a work was put.

"(ITA Workshop, "The Impact of Technology on the Creative Environment, " Apr. 24, 1985,

${ }^{45}$ Siee Public Law 94-549, Communications Act Provisions for Earth Stations.
} 
With the exception of the fledgling Copyright Royalty Tribunal, however, U.S. institutional arrangements for addressing intellectual property issues were designed, for the most part, to function within a free market, nonregulatory framework. To the extent that new legislative initiatives call for a more regulatory approach to solving intellectual property problems, the question is raised as to whether and as to how well the existing set of institutions will be able to take on new roles and adapt to a new environment.

Need for Greater Understanding of and Information About the Processes By Which

Intellectual Properties Are Created, Published, Distributed, and Used

Under the traditional copyright scheme, there is little need to know the precise economics of the process by which intellectual properties are created, published, distributed, and used. For under such a system, property rights are defined and granted to authors by law, and the economic value of those rights is determined and distributed by market forces. To the extent that intellectual property law is tending towards a more regulatory approach, however, more information and a greater understanding of this process will be needed.

The widespread deployment and use of the new information and communication technologies has complicated the traditional intellectual property process, making it difficult-but perhaps also more important-to know where economic value is added, and thus, how to determine economic incentives and rewards. These technologies, for example, have not only permitted more people to use intellectual properties in new and different ways, they have also extended the process and the opportunities throughout to enhance the value of creative and innovative works. No longer is there one "author," but rather a series of "authors" whose claims to intellectual property rights must be sorted out. No longer does one pub- lisher put out a book, or one producer release a film, but rather a variety of publishers and producers whose economic stakes need to be taken into account.

To resolve the numerous and varied competing intellectual property claims within a regulatory framework, as opposed to within a market framework, wiLI be very difficult. It will require policy makers to develop an analytic rationale for the optimum charging of fees and the economically efficient and socially equitable distribution of rewards. To do so, they will need to know about all of the parties at stake in relatively great detail, and also understand their roles in the intellectual property process, and how each might fare under alternative scenarios. The considerations specified in the Home Recording Act of 1983 for setting royalties illustrate the kinds of information that might be required to devel op such a rationale. No less than 10 factors are cited, including:

- the value to an individual of the right to reproduce copyrighted works;

- the projected effect of royalty fees on the structure and financial condition of the motion picture and audiovisual production industries and the video recording device or media importing and manufacturing industries; and

- the relative roles of copyright owners and importers and manufacturers of video recording devices or media with respect to creative and technological contribution to the development of motion pictures and other audiovisual works.

At present, reliable information of this kind is not readily available. Given the growing complexities in the intellectual property process, brought about, in part, by technological developments, it is exceedingly difficult for example, to determine such things as authorship; the point at which new value is added on to an existing intellectual property and who has added it; and what actually constitutes copying or use and, therefore, might require re- 
muneration. ${ }^{46}$ Accurate estimates of damages due to infringement of intellectual property rights are also difficult to obtain. Most of those available are not only unsystematic in their approaches; they are also somewhat suspect insofar as most have been commissioned by the very parties whose interests are at stake. ${ }^{47}$

When legislation calls for a regulatory approach instead of a market approach for addressing intellectual property issues, provisions may be needed to increase the analytic and expert support available to those organizations called on to implement and administer the law. One recent legislative proposal that moves in this direction is the proposed Free Market Copyright Act of 1983, which abolishes the offices of two of the five commissioners attached to the Copyright Royalty Tribunal and requires the Tribunal to appoint a general counsel and chief economist.

Development of Technologies That

Do Not Correspond to Traditional Intellectual Property Categories, and the Creation of Sui Generis Intellectual Property Legislation

The framers of the U.S. Constitution distinguished between writings and inventions, and set up separate rules and incentive systems for each. This distinction was relatively clear cut as long as the term writing merely described an art, rather than embodying the art itself. Today, however, this distinction is harder to maintain as new technologies emerge that do not clearly fit into either one or the other category. Because information technologies allow symbols to define a process and function as part of a machine, for example, they tend to blur the boundary between writings and inventions, between ideas and their expressions, and between functions and their repre-

\footnotetext{
${ }^{46}$ For a discussion of these problems, see Christopher Burns, Inc., "The Economics of Information, " contract report prepared for OTA, 1985.

"Stan Besen, Economic Issues Relating to New Technologies and Intellectual Property, contract report prepared for OTA, 1985, pp. 45-55.
}

sensations. This blurring of the boundaries has raised the question of what kind of intellectual property protection is most appropriate for these technologies and led to the establishment of sui generis intellectual property legislation.

Computer software was one of the first of 11 e new information technologies to raise questions of this kind. Controversy surrounded the issue of the copyrightability of computer software since the mid- 1960s, when the Copyright Office first began to register programs in their object code form under its "rule of doubt." Much of the controversy was rooted in the 1909 Supreme Court decision in White-Smith Publishing Co. v. Apollo Co., which held that a player piano roll was not copyrightable since it did not embody a system of notation that could be read and, thus, was not a copy of a musical composition but rather a part of a device for mechanically performing music. Be cause program object code was said to resemble a piano roll in its unperceptability, questions were raised as to whether it could be copyrighted. After considerable controversy and litigation, this issue was finally resolved within the traditional intellectual property scheme by including computer programs within the domain of copyright protection. ${ }^{48}$

Unlike the case of computer software, the question of how semiconductor chips might best be protected was resolved not within the framework of existing intellectual property law, but rather with sui generis legislation. Under traditional intellectual property law, the

\footnotetext{
"The 1980 Amendments to the 1976 Copyright Act, for example, specifically included computer programs, databases, and works created by the use of computers within the realm of copyright protection. Many of the remaining issues were resolved with the court case, Apple Computer Inc. v. Franklin Computer Corp., in which the Third Circuit Court of Appeals held that computer programs, whether in object or in source code, whether written or embedded in ROM, and whether an applications program or an operating systems program, are "literary works" within the meaning of the 1976 Copyright Act, and hence subject to copyright protection.

This is not to say that there are no alternative views about this decision. See, for example, Pamela Samuelson, "CONTU Revisited The Case Against Copyright Protection for Computer Programs in Machine-Readable Form, " Duke Law Journal, No. 4, 1984.
} 
semiconductor chip was unprotected. Because it was a utilitarian article, it did not fit within the traditional concept of copyright. On the other hand, the level of originality embodied in a chip mask did not meet the standards required for patent protection. To provide protection for this new technology without undermining the integrity of the law and the historical principles underlying the distinctions between copyright and patent protection, Congress created anew class of protection with the passage of the Semiconductor Chip Protection Act of 1984. Although similar in many respects to existing copyright law, it differs insofar as it provides protection for only 10 years, requires mandatory registration, permits reverse engineering, and excludes from protection designs that are commonplace, stable, or familiar. Because the registration procedures resemble those for copyright, the Copyright Office was given the responsibility for administering the new law.

The organizational structure was established to administer intellectual property law evolved in accordance with the distinctions that had been made between patent and copyright protection. To the extent that new technologies require intellectual property protection that falls outside of the traditional realms, they may require significant institutional changes.

\section{Growing Convergence of Intellectual Property Issues With Other International Issues}

Historically, intellectual property laws and practices in the United States developed with little regard for what was taking place in the rest of the world. For example, although many other countries granted copyright protection to foreign works or authors, the United States withheld such rights throughout its first 100 years. ${ }^{49}$ And while other European states un-

\footnotetext{
"It was only in 1891, with the passage of the Chace International Copyright Act that the $\mathrm{U}$ nited States extended copy right relations to any nation found and proclaimed by the President to afford adequate protection to American works--subject, as stated, to a domestic manufacturing requirement and various unfamiliar forma lit ies in this country.
}

dertook to regulate their copyright relations multilaterally through the Berne Convention of 1886, the United States continued until 1955 to act bilaterally in its intellectual property dealings with foreign governments. ${ }^{50}$

Presently, however, the new technologies have greatly increased the flow of information and information products and services across national boundaries, thus enhancing their value in international trade. Because intellectual property protection is needed to preserve this value, intellectual property policy is increasingly being brought to bear in matters involving international trade policy. The Trade and Tariff Act of 1984, for example, requires that the protection of U.S. intellectual property rights be one of the elements considered in the renewal of the benefits of the generalized system of preferences (GSP). Similarly, the Caribbean Basic Economic Recovery Act of 1983 withholds foreign aid from those countries who fail to honor intellectual property rights.

The growing importance of information products and services has also linked intellectual property policy with general matters of international politics. Viewing information technologies and information products and services as a means to social and economic development, many developing countries view U.S. intellectual property policies as a barrier to their own advancement.

To the extent that intellectual property issues continue to converge with those of international trade and international politics, questions arise as to whether the present organizational structure, designed to consider intellectual property from a domestic frame of reference, is adequate or whether some more formal coordination among agencies dealing with international issues may be necessary.

\footnotetext{
"In 1955, the United States acceded to the Universal Copy right Convention $\{-I C C)$. The UCC was created for- the express purpose of bringing the United States into the international copyright community. Negotiated and established under the auspices of U NESCO, it provided a ' 'low bridge to the' Berne ('convention by a combination of minimal substantive requirements and the super-cession of U.S. formalities by a simple "UCC notice' consisting of the familiar " $c$ ' inside a circle.
} 


\section{Growing Convergence of Intellectual Property Issues With Other Information Policy Issues}

The structure and the basic assumptions underlying American intellectual property laws and practices were designed when the United States was an agrarian society, in which communication and information use and exchange played relatively minor roles in society. In this society, decisions about intellectual property could be made relatively independently from other policy issues. For it was assumed that, through the operation of the law, social and economic goals would be jointly served, thus maximizing the benefits to society. ${ }^{51}$

Today, however, the role of information technologies and information products and services have grown dramatically. These technologies and their applications are being used not only by individuals to enrich their lives, and by businesses to enhance their productivity; they are also being used by governments as a means to achieve major societal goals. For example, the F rench Government likens the growing connection of information-processing and communication technologies throughout the world to a change in "the entire nervous system of social organization, " and plans to play a major role in their development, direct-

Leon Seltzer, Exemptions and Fair Use in Copyright: The Exclusive Rights Tensions in 1976 Copyright Act (Cambridge, MA: Harvard University Press, 1978), p. 12. ing it to be consistent and supportive of the Nation's overall societal goals. ${ }^{52}$

[n the information society, such as it has been envisioned, information and communication technologies will be more interdependent, and intellectual property issues may increasingly converge with other matters of information policy-such as telecommunication policy or privacy policy .53 Anticipating such connections, S. 786, a bill entitled the "I nformation Age Commission Act of 1985, was recently introduced into the Senate. If passed, this legislation would establish a commission to investigate comprehensively, issues relating to the information age, such as intellectual property rights, computer education, computer crime, and privacy.

To the extent that intellectual property issues converge with other information policyrelated issues, the question is raised as to whether the present set of intellectual property institutions are capable of dealing with these issues as they cut across one another.

\footnotetext{
${ }^{52}$ Simon Nora and A lain Mine, The Computerization of Society (Cambridge, MA: MIT Press, 1980).

${ }^{53}$; See U.S. Congress, Office of Technology Assessment, Cornputer-Based National Information Systems, Technology and Public Policy Issues, September 1981, and OTA staffmemoranilum, Institutional Options for Addressing Information Policy Issues: A Preliminary Framework for Analyzing the Choices, Nov'ember 1983. For other discussions and characterizations of the information society, see, for example, Susan Artandi, “M an, Information, and Society: New Patterns of Interaction," Journal of the American Society for Information Science, Januar. 1979; and Daniel Bell, The Coming of Post-Industrial Societ v (New York: Basic Books, 1973).
}

\section{IMPLICATIONS FOR FUTURE INSTITUTIONAL ARRANGEMENTS FOR THE ADMINISTRATION OF INTELLECTUAL PROPERTY RIGHTS}

As described throughout this chapter, new technologies are placing considerable burdens on the Federal agencies responsible for administering intellectual property rights. To manage these stresses, Congress has several options that it could pursue. These options range from leaving the agencies as they exist to completely restructuring them.

\author{
No Action: Leave Major Decisions \\ to the Courts
}

Congress, of course, does not have to act and might leave the agencies responsible for intellectual property rights as they currently exist. Although the intellectual property system would not experience devastating effects, the 
burdens would remain and would perhaps increase over time with new technological developments. These burdens, moreover, would most likely fall to the courts.

The ability of the courts to deal with the emerging intellectual property issues will be determined by several factors:

1. the increasing volume of intellectual property legislation and the extent to which it departs from traditional legal concepts;

2. the limited resources available to the courts and the confining attributes of adjudication; and

3. the inadequacy and bias of adjudicative information.

Volume of New Intellectual Property

Legislation and Novelty of Legal Issues

Compared to the relative stability of copyright law during the 66 years which elapsed from the enactment of the 1909 Copyright Act to the 1976 Revision of the copyright law, legislative activity on intellectual property issues has increased significantly during the last 10 years. Altogether 54 bills dealing with new intellectual property issues were introduced in the 98th Congress, $1983-85 .^{54}$ The Software Copyright Act of 1980, for example, amended Section 117 of the 1976 act to allow for the copyrightability of computer programs without specifically enumerating computer programs. ${ }^{55}$ Another 4 years later the Semiconductor Chip Protection Act of 1984 established an entirely new class of protection for an information technology that does not fit comfortably into either the patent or copyright categories of traditional intellectual property law. ${ }^{56}$ Additional legislation dealing with such diverse new technology subjects as commercial lending rights, home taping, cable copyright, aspects of the operation of the Copyright

\footnotetext{
${ }^{54}$ OTA staff memorandum, Feb. 26, 1985; and American Bar Association, 8th Annual Copyright Law Conference, Washington, DC, Mar. 7, 1985.

"J on Baumgarten, "Copyright and Computer Software, Databases, and Chip Technology, " Proceedings, 8th Annual Copyright Law Conference, Washington, DC, Mar. 7, 1985, p. 289.

'Public Law 98-620, November 1984.
}

Royalty Tribunal, the compensation of copyright owners through royalty payments, "workfor-hire, " or computer software piracy and counterfeiting has been enacted or is under consideration. This volume of new legislation is matched by the novelty of some of the major issues raised by it. For example, the protection of software under copyright law raises a number of definitional problems that call for the interpretation of statutory language and its application to new technological and scientific processes.

Because some of the legislation on new intellectual property reflects a tendency to establish regulatory policies and institutions, courts will find themselves in the familiar-but nevertheless burdensome-position of having to review a host of administrative law issues arising out of administrative rules concerning licensing or the mechanics of copyright registration. ${ }^{57}$ As the Copyright Office becomes the central institution responsible for copyright registration and administration, courts will have to resolve issues of regulatory policy. ${ }^{58}$ To the extent that registration of computer programs and computerized databases will necessitate the adoption of new procedures and policies by the Copyright Office, that agency's substantive decisions and rulemaking process are likely to be subject to extensive challenges before the courts.

Unavoidably, enforcement of copyright in computer programs will involve courts in adjudication over the enforcement process itself. Since it is likely that computer copyright protections will be less self-executing than traditional copyright, new enforcement schemes will become necessary for the application of civil

\footnotetext{
${ }^{57}$ Inclusion of object-or machine-code within the reach of copyright protection under the Act raises novel questions about the existence of a prerequisite of human interaction with copyrightable material. It poses the problem of how to reconcile the fact that computer programs can be published with the fact that they can-at the same time-be kept secret to protect their commercial value. It demands distinctions between "utilitarian" workers and those conveying information or displaying an appearance.

${ }^{5 \times}$ The Semiconductor Chip Protection Act of 1984, Public Law 98-620, though not applying copyright protections, makes the Copyright Office responsible for registration and deposit of semiconductor chip design (mask works).
} 
or possibly criminal sanctions." Investigations of suspected infringement will affect areas protected by privacy expectations and fourth amendment guarantees and are likely to come within the reach of first amendment protections. Computer crime legislation-like that enacted at the end of the last Congress-has already been criticized by the U.S. Department of J ustice as too difficult to enforce.

J udicial Resources and Capacity: Attributes of Adjudication

The capacity of the Federal courts to deal with a significant increase in their workload on a complex new subject is circumscribed by the limited resources of the courts, already short on machinery and staff, and already struggling with a growing backlog of cases.

In addition to the purely quantitative problems it poses, the increasing volume of litigation over new intellectual property rights raises substantive questions of how well the special attributes of the adjudicatory process are suited to this task. Courts will have to decide copyright questions in the context of imperfect information about the course of technological change, of doubt over the economic consequences of the allocation of new proprietary rights in information technology, of lack of public support or understanding, and in the absence of comprehensive legislative guidance.

Courts as Decisionmakers Without Control Over Their Agenda. The very fact that courts do not control their own agenda explains why the judiciary is sought after as a decisionmaking institution and why its decisions may at the same time be unsatisfactory from a large policy perspective. As long as legal questions are presented in the right form and forum and at the right time-conditions of adjudication defined with precision in advance-they will

\footnotetext{
"Imposition of criminal penalties for software piracy introduces difficult factual problems about intent and innocent infringement. Legislators themselves are concerned over the civil liberties implications of criminal laws which grant "broad Federal jurisdiction that permits Federal agents to traipse about with impunity in the data banks of individuals and corporations." In addition computer crime legislation is likely to raise Federal-State jurisdictional issues.
}

get answers. Answers are justified by reference to evidence, reasoning and legal doctrine. Once the judicial process has been set in motion, decisions must be made.

Yet from a larger policy perspective the accessibility of the judicial process may be a liability. Since judges must respond to complaints and reach decisions one case at a time, they cannot devise a coherent program or policy: they cannot await congressional action, they cannot ask for legislative darification of unclear language, they cannot anticipate the course of future action even where evidence indicates that the course of events will undermine the basis of their decision. ${ }^{60}$

Because accessibility to particular courts is random, determined by jurisdictional rules and idiosyncratic characteristics of an individual litigant residence or business operation, and because courts are generally not specialized according to subject matter, different courts in different regions of the country may deal with the same legal question at the same time without a method of coordination and consolidation. Until the Supreme Court chooses to decide between contradictory or conflicting lower court outcomes in such cases, inconsistent practices maybe pursued in different areas or by different computer industries during the not inconsiderable period of time which may elapse before a "unifying" Supreme Court decision is reached.

J udicial passivity precludes courts from influencing-much less re-directing-policy developments questionable on legal or constitutional grounds, if no litigants come forward to challenge such policy. Thus the copyrightability of machine-readable forms of computer programs became established policy despite the fact that the Copyright Office had profound questions about the statutory and constitu-

\footnotetext{
$\% 1979$, after the CONTU Final Report had been issued but before the Report recommendations had been enacted by the 1980 Software Amendments, one court applied the 1909 Act to hold that machine-readable versions of computer programs were not copyrightable subject matters. There was no way a court, equipped to see only the past, could have decided that case by reference to legislative action yet to come, no matter how certain or how soon.
} 
tional validity of the practice, when it first began to register computer programs under its "rule of doubt" in $1964 .{ }^{61}$ From a policy perspective the nonsystematic invocation of judicial controls not only allows procedures and policies of doubtful legal validity to continue, but also judicial silence may serve as a signal of approval when, in fact, courts did not have the occasion for judgment.

Inadequacy of Adjudicative Information

Among the resources at the disposal of institutions explicitly designed to make social policy is the availability of expert or specialized knowledge, of procedures for the evaluation of alternative strategies or policies and of studies projecting the consequences of alternative choices. Courts lack most of these resources.

J udicial Expertise. J udges are not experts, they are generalists par excellence. ${ }^{62}$ They are, by and large, "lawyer-generalists" before their appointment and must remain so to serve fundamental goals of equality and neutrality within the legal system. To discourage judgeshopping, cases are assigned on a random basis. Sitting alone in courts of general jurisdiction district judges must be prepared for any subject matter. While appellate courts operate as collegial bodies, the continuous reassignment to different panels provides little opportunity for a lasting division of labor or the development of expertise. Yet while the generalist judge is an essential-even necessary-part of the legal system, the lack of expert knowledge and specialization leaves judges unprepared for dealing with matters calling for expertise and skills in particular fields. In part, the difficulty stems from the scale and complexity of technical issues. In part, it results from the fact that judges have to deal with cases quite isolated from their

\footnotetext{
"CarY, "Copyright Registration and Computer Programs, " Bulletin of the Copyright Society, vol. 11. 'No. 362, 1964.

"Grossman, "Social Backgrounds and J udicial Decisionmaking, Harvard Law Review, vol. 79, No. 1551, 1966, and Carp and Wheeler, "Sink or Swim: The Socialization of a Federal District J udge, " J ournal of Public Law, vol. 29, No. 359, 1972.
}

larger context and on the basis of nonprobabilistic legal reasoning. Both factors create gaps in decisions and make them uncertain guides for the policies they inevitably build.

The tension between the conflicting needs of the judicial system for generalists able to address all subjects and specialists with particular subject expertise could, in theory, be resolved by providing judges with informational resources which would allow them to become sufficiently expert to deal with new issues as they arise. A good argument can be made, however, that the adjudicatory process does not serve that need.

The Informational Bias of the Adjudicatory Process. From a policy perspective information produced in the course of adjudication is partial in the dual sense that it is both incomplete and biased. Information is incomplete and fragmented, because the judicial focus tends to be delineated by the issues which the litigants choose to raise. ${ }^{63}$ Litigation over the copyrightability of computer programs has produced judicial decisions which holds as a matter of statutory interpretation that communication with a human audience is no longer required under copyright law ${ }^{64}$ without, however, dealing at the same time with the constitutional implications of the nondisclosure which results from registration of machine-readable programs only. ${ }^{65}$

Adjudication does not provide mechanisms for routine feedback on the consequences of decisions and it provides only limited opportunities for locating specific issues in their broader social context. The judicial process makes little or no provision for reviewing the consequences of decisions. The contrast be-

\footnotetext{
"In the controversy over the patentability of living microorganisms legal arguments focused on the intended coverage of the patent laws and the distinction between a living organism and an invention, but not on the consequences of extending the concept of proprietary rights to the creation and commercial use of new life forms.

"Apple Computer, Inc. v. Franklin Computer Corp., 714 F.2d 1240, 1247-48, 3d Circuit, 1983.

"Pamela Samuelson, "CONTU Revisited: The Case Against Copyright Protection for Computer Programs in Machine Readable Form, " reprinted from Duke Law J ournal, No. 4, 1984, pp. 705-712.
} 
tween the intensive examination of antecedent facts and the near total neglect of subsequent or consequential facts-i.e., the impact of a decision on economic, social, or scientific behavior and developments, is striking. J udges have no mechanism for assessing what the consequences of keeping source codes secret are for that free flow of information which courts have in the past always found to be essential in order to promote the Progress of Science and the Useful Arts." ${ }^{166}$

Information is biased in the sense that the adversary process subjects virtually all of the information brought before a court to the service of stakeholders. Not all interest groups with stakes in the outcome of a particular case are represented and those interests which are represented are not necessarily balanced in the resources they can bring to bear on litigation. Although conclusive data are not available, it is clear that lawsuits over software copyright are almost elusively fought between corporate interests; so far neither individualsas creators or consumers-nor other public or private entities representing nonproprietary public interests have played a role in the decisive cases. The litigation pattern thus reflects the early prominence of major corporations in the registration of computer programs. ${ }^{67}$

\section{Confining Conditions of J udicial Decisionmaking}

The rapid rate and complexity of technological change aggravate the inherent liabilities of the judicial process and may make intellectual property law issues less manageable for the courts and may, by extension, make the outcome more counterproductive from a science and social policy perspective. It is in this sense that superimposing technological infor-

\footnotetext{
${ }^{\circledR 6}$ See for example, Graham v. John Deere Co., 383 U.S. 1 at 5-6, 1965.

"Between 1964 and 1976, 1205 programs were registered with the Copyright Office; 971 or 80 percent were owned by corporations-IBM and Borroughs Corp, Hersey disent, $\mathrm{Na}$ tional Commision on Technological Uses of Copyrighted Works (CONTU), Final Report (Washington, DC: Library of Congress, 1978).
}

mation policy issues on judicial institutions primarily structured to decide individual cases in the context of traditional intellectual property law may prove detrimental to both the courts and those with large stakes in litigation over these issues. Future changes in information and communication technology are likely to leave courts perpetually a step behind the task they must perform.

\section{Encourage the Use of Collecting Societies}

Congress might also encourage the use of collecting societies to deal with some of the institutional problems presented by new technologies. A number of indicators suggest that collecting societies have been quite successful in meeting their goals. The longevity of the musical performing rights societies, and the modeling of other collecting societies after them, suggest that both users and creators have been generally satisfied with their performance over time. Collecting societies have also increased the size of their repertories, the number of users, and the amount of revenues over the years. ${ }^{68}$ Decreasing operating costs and increasing efficiency further indicate that collecting societies are accomplishing their stated objective of reducing transactional costs for both users and creators. ${ }^{69}$

\footnotetext{
${ }^{6 \mathrm{H}}$ The combined annual collections of ASCAP, BMI, and SESAC, for example, grew from $\$ 13.5$ million in 1946 to $\$ 190.5$ million in 1976. BMI reports an annual increase in their repertoire of approximately 100,000 and an increase in revenues from $\$ 53.1$ million in 1975 to $\$ 150$ million in 1984 . In the year 198485 , the number of writer members has increased from 43,000 to 45,000 and the number of publisher members increased from 25,000 to 26,000 . Although the CCC and AGI OCA are both too new to determine such overall trends, both currently report increases in the participation of users and proprietors. Leonard Feist, An Introduction to Popular Music Publishing in Amer. ica (N-ew York: National Music Publishers Association, Inc., 1980).p. 59; and discussions with BMI representatives, March 1985.

${ }^{69} \mathrm{BMI}$, for example, decreased its operating costs from 19 percent of total revenues in 1975 to 15 percent in 1985. Collecting societies have been able to lower the cost per transaction in part because an increasing number of users and creators are using their services. The major factor in lowering costs, however, has been the introduction of information technology, now used at various points in their operations.
} 
Although successful and effective in many ways, collecting societies also have problems that could limit their usefulness as a model for a broader range of information market situations. In particular, because collecting societies administer the rights for many creative works, they have been accused of monopolizing the markets and exercising unreasonable restraint on trade. These concerns have prompted antitrust suits; since 1941, both ASCAP and $B M I$ have been operating under consent decrees. ${ }^{70}$ In addition, problems of developing sufficient transactional volume to efficiently collect and disburse funds, and problems of equitable representation of members with disparate claims to compensation have plagued their otherwise smooth and effective operation. ${ }^{71}$

During the congressional hearings that led to the 1976 revision of the U.S. copyright law, many discussions focused on how new technologies undermine copyright owners rights. The enormous difficulties these technologies created for both users seeking licenses and creators seeking remuneration for their works were usually cited as the basis for establishing broader exemptions or conditions in the new legislation. As an alternative, many of the

\footnotetext{
"In 1941. the antitrust division of the Department of J ustice filed a civil complaint against ASCAP charging the organization with violations of the Sherman Act. The result was a consent decree that significantly altered three components of A SCA P's operations. First, ASC A P was prohibited from discriminating against similarly situated licenses. This order was prompted by the society's practice of withholding certain music in an attempt to extract higher fees. Second, the consent decree prohibited ASCAP from acquiring exclusive rights to license members' performance rights. Third, ASCAP was re quired to offer other licenses in addition to blanket licenses.

The consent decree was amended in 1950 following numerous problems with license terms, membership restrictions, and uneven royalty distribution, as well as new problems arising from motion pictures and television. Among other things, these amendments gave users more options, set up procedures to handle fee disputes, and established more objective criteria for distributing royalties. More amendments followed in the 1960s.

'Collecting societies have been criticized by some copyright holders who feel that the distribution of royalties is often unfairly biased in favor of a few very popular and powerful members, Because of alleged inequities in theuse-sampling or royaltycalculation methods, some believe they are inadequately represented in the bargaining process. Economies of scale enjoyed by large, powerful societies serve as effective barriersto weaker creators' formation of competing collecting organizations.
}

participants in their 1976 hearing process proposed that a collective approach might be feasible for literary works and other types of intellectual property where reprographic, performance, and recording rights were becoming more relevant in light of new technologies. ${ }^{72}$

As new information and communication technologies give rise to new creative works and new uses of traditional creative works, similar difficulties will arise for both users and cre ators. For example, amplification of distant signals and their distribution by cable to users, or the distribution of computer programs via videotex systems to users, will increase the access, distribution, and use, of creative works, thus creating enforcement problems and larger transactional costs. Given these new challenges to the administration of intellectual property rights, collecting societies may be one alternative to institutional problems posed by new technologies.

\section{Strengthen and Increase the Responsibilities of Existing Agencies}

Strengthening the capabilities of the current agencies involved with intellectual property rights is another option that Congress might consider. The Patent and Trademark Office, the Copyright Office, and the Copyright Royalty Tribunal could each be given additional resources for research and policy planning, and the authority to regulate and adjudicate. Other agencies' responsibilities for intellectual property rights could be strengthened and made more explicit. For example, creating a position of Assistant Secretary for Intellectual Property Right within the Office of the U.S. Trade Representative, could provide a higher level of attention to this aspect of international trade, within the U.S. Government and in negotiations with other nations.

\footnotetext{
“'Leonard Feist, An Introduction to Popular Music Publishing in America (New York: National Music Publishers Association, Inc., 1980), pp. 56-57.
} 


\section{Establish a Central Federal Intellectual Property Agency}

To comprehensively address the new institutional needs, Congress might consider restructuring the institutional arrangements for intellectual property rights. Congress could, for example, establish a new Federal agency that would administer all aspects of intellectual property rights. Given the new institutional needs, this central intellectual property agency could assume the following responsibilities:

- all of the current responsibilities of the Copyright Office, the Patent Office, the Copyright Royalty Tribunal, and other agencies that are involved with intellectual property rights (this would exclude, however, the deposit function of the Copyright Office which would remain with the Library of Congress);

- rule-making and determination of rates such as compulsory license fees and distribution percentages as required by legislative mandates;

- standard administrative adjudicatory functions (similar to those of other government agencies) where preliminary disputes involving patent, copyright, and sui generis protections, licensing fees, distribution percentages, etc., could be resolved;

- administration of all sui generis protection schemes that fall between copyright and patent protection;

- development of international policy positions and representation of the United States at all international intellectual property rights negotiations and conferences;

- collection and analysis of information on markets and damages, solicitation and analysis of industry viewpoints, and solicitation and analysis of the public's views and evaluation of their access to information products and services;

- policy planning and research on technological developments and their effects on the intellectual property system; and

- advice to Congress on developments in intellectual property and suggest legislation as needed.
This central agency would be particularly effective in implementing any short-term solutions that Congress might choose to address current intellectual property issues. It could, moreover, plan and oversee any longer term solutions that Congress might wish to select. In addition to relieving many of the stresses on the Federal institutions, such an agency would also alleviate many of the continual pressures due to rapid technological change currently facing both Congress and the courts.

On the other hand, centralizing responsibilities might also have negative impacts. Many government agencies, for example, currently rely on the proximity of the intellectual property rights agencies for needed information and expertise. Consolidating the responsibilities for intellectual property rights under one agency, therefore, could deprive other parts of the U.S. Government direct access to needed information to carry out their functions. The intellectual property agencies, moreover, would be deprived of direct access not only to administrative support but to other areas of expertise, such as international affairs and trade.

\section{Considerations for the Choices of Institutional Arrangements}

Before considering institutional arrangements for the administration of rights, Congress must first make overall decisions about the intellectual property system itself. For as this report has shown, institutional arrangements must reflect the goals they are designed to promote. Congress, therefore, must determine which goals it wishes to promote, which laws and practices to establish, and how to balance competing interests in light of the effects of new technological developments. It must also determine whether the role of government in the intellectual property system should be regulatory or nonregulatory. Only after such decisions are made, can Congress begin to construct institutional arrangements for the administration of intellectual property rights. 
Chapter 10

\section{Strategic Choices for Congress}




\section{Contents}

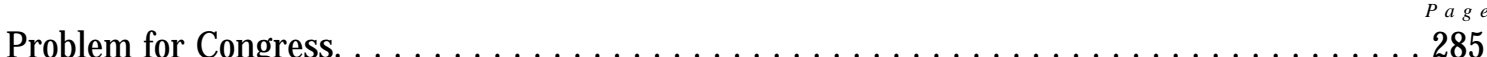

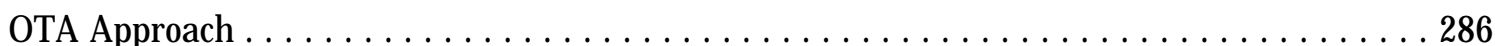

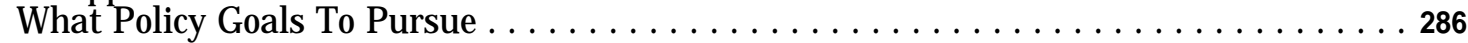

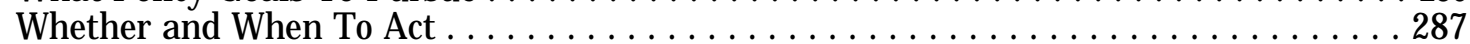

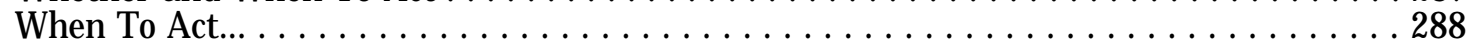

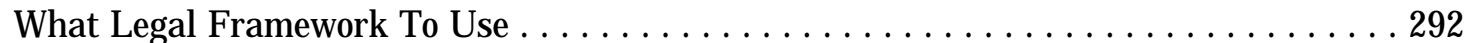

How Broadly To Define The Problem . . . . . . . . . . . . . . . . . . . . . . . . . . . . . . 294

Within What Institutional Framework Should Intellectual Property Issues

Be Resolved . . . . . . . . . . . . . . . . . . . . . . . . . . . . . . . . . . . . . . . . . . . . . 294 


\section{Strategic Choices for Congress}

\section{PROBLEM FOR CONGRESS}

The system of intellectual property rights and practices, as it has evolved in the United States, represents a balance of social, political, and economic interests that was arrived at over time and in response to changing historical circumstances. The basic framework was provided for in Section 8, Article 1 of the Constitution, which authorized Congress to grant exclusive ownership rights, for a limited period of time, for writings and inventions. The purpose of the grants of rights was twofold: 1 ) to foster the progress of science and the useful arts, and 2) to encourage the creation and dissemination of information and knowledge to the public.

Although this system of intellectual property rights was originally designed around the technologies of its time, the approach that it embodied was flexible enough to incorporate new technological developments as they appeared. Today, however, advances in technologies are so far reaching that they pose fundamental questions about the system itself. They raise issues, for example, about the appropriate goals of the system, the basic framework of the law, the mechanisms for enforcing rights, the criteria for granting incentives and rewards, as well as about the scope of the intellectual property problem itself.

Concerned about the problem that the new technologies pose, interested parties are urging Congress to initiate legislation to take these technological developments into account. Holders of existing intellectual property rights, for example, concerned lest the new technologies undermine their ability to enforce their property rights, are calling on Congress to provide new ways to assure their remuneration. Creators of new kinds of information products and services are requesting Congress to extend existing law to include their creative activities within its provisions. In addition, the creators and providers of goods and services that, prior to the information era, were of little economic value are looking to intellectual property law to justify for themselves a greater economic recompense. Meanwhile, the general public, having greater expectations of, and growing increasingly accustomed to, the information products and services afforded by the new technologies, as well as their reduced costs and increased accessibility, are looking to Congress to preserve these gains.

Faced with a growing number of requests for congressional action, in addition to a ubiquitous and rapidly changing technology, the problem for Congress is to try to take the magnitude and the scope of technological change into account, while balancing interests and responding to present day concerns. The resolution of these issues maybe more difficult than in the past when information-based products and services were peripheral to the performance of many social and economic activities, and when people had lower expectations about their use and the profits that might be derived from them. In such an environment, issues involving the granting of intellectual property rights were easily worked out among the major players without much disagreement or public involvement.

Today, on the other hand, given the variety of opportunities that the new technologies afford, the increased value of information, changing relationships among the traditional participants in the intellectual property system, and rising expectations about the benefits of these technologies, the number of stakeholders with disparate interests and competing claims on the system will be greater than ever before. Under these circumstances, the resolution of intellectual property issues will be more problematic, requiring that more viewpoints be taken into account, and that policy decisions about the distribution of incentives and rewards be made much more explicit. 


\section{OTA APPROACH}

It was to assist Congress in addressing these issues that the Office of Technology Assessment was asked to undertake this assessment, Intellectual Property Rights in an Age of Electronics and Information.

In thinking about how the new communications and information technologies might affect intellectual property rights, OTA has adopted abroad approach, looking at the kinds of stresses that technology might place on the intellectual property system, as a whole, and on each of its parts. Such an approach was required because the new technologies do not necessarily have a direct effect on intellectual property rights. Rather, more often than not, their influence on the law is felt indirectly, as a result of such things as technologically induced changes in norms, values, and expectations, as well as in the ways in which intellectual works are created, produced, marketed, and distributed.

Such an approach has also been useful because, given the political intensity of the intellectual property debate today, and the high economic stakes involved, it is extremely important to view the situation in its entirety. Those involved in the policy debate have often defined issues narrowly, in terms limited to their own interests and world views.

Examining how the new information and communication technologies might affect the intellectual property system, OTA found that these technologies are creating a wide variety of opportunities and problems that, taken together, present Congress with five major strategic choices: 1) what policy goals to pursue, 2) whether and when to act, 3) what legal frame work to use, 4) how broadly to define the problem, and 5) within what institutional framework should issues be resolved. These choices, and a description of some of the issues and options that they entail, are discussed below.

\section{What Policy Goals To Pursue}

Which policy goals a particular intellectual property system is designed to serve depends, in large measure, on history, circumstances, and the particular needs of a society at the time when such considerations are being made. Concerned primarily about building a nation, and thus about the need to establish communication links, develop a unified market, forge a common culture, and build a democratic polity, the Founding Fathers intended the granting of intellectual property rights to increase the flow of knowledge and information throughout the country. The granting of rewards was not considered to be an end in and of itself, but rather a means to achieve the goal of learning.

Given the changing role of information in society, the question is raised as to whether a goal established for an agrarian era is still appropriate in an information age. Because information-based products and services now constitute a major source of economic growth, and are essential to our balance of trade, some people, for example, are urging that the intellectual property system be restructured to give priority to economic goals. They propose a number of changes in the system that would presumably foster such a goal. One suggestion, for example, is to extend protection to information itself. Such protection, it is argued, would create a whole new source of economic wealth. Another proposal, designed to induce investment in information production, calls for the elimination of the requirement that inventions be reducible to practice, thereby allowing for the protection of ideas. Such types of protection have traditionally been denied on the grounds that they would inhibit the dissemination of knowledge and ideas.

There are others, however, who oppose changes designed to favor economic goals. Instead of 
increased protection, they prefer to see the new technologies used to enhance access and the sharing of information resources. While acknowledging that the development of information-based products and services are important to the economy, opponents of stronger protection point out that information is equally important for social, political, and cultural purposes. Librarians and educators, for example, are concerned that, if treated primarily as a commodity, information will be less available for learning.

Looking at these issues, OTA found that the potential for conflicts among cultural, economic, and political goals is indeed heightened in an information age. The ease with which the system has historically been able to mutually serve all goals is no longer possible, given that the value of information-based products and services is being enhanced simultaneously in all realms of life. And even if, as some have suggested, increased intellectual property protection significantly increases the production of information and information-based products and services, it is uncertain whether goods designed primarily with a profit motive in mind would be the most suitable for noneconomic ends. Nor would their production in and of itself lead to their widespread distribution. For, as is pointed out below, producers of works distributed electronically do not have as much incentive to make them publicly available as do producers of works distributed in hard copy.

Conflict among goals may also increase because, viewing information as a new source of wealth, many people are looking for profit where they never have before. Given these heightened expectations of economic rewards, the amount of economic growth that might result from extending property rights may indeed be insufficient to eliminate conflicts about intellectual property goals.

In an information age, therefore, Congress will most likely have to make more explicit choices among policy goals. Alternatively, other policy mechanisms, apart from the granting of intellectual property rights, might be used to foster some goals not supported by the present system. For example, other kinds of economic incentives, such as subsidies or tax exemptions, might be granted, which would have fewer negative consequences for learning and the creative environment,

\section{Whether and When To Act}

In making intellectual property policy, Congress has always had to reckon with technological change. Over time, Congress has altered copyright law to incorporate such technological developments as designs, engravings, and etchings (1802); photographs and negatives (1865); mechanical recordings (1909); motion pictures (1912); sound recordings (1972); computer software (1980); and mask works for semiconductor chips (1984). Then, in 1976, the copyright law was completely revised in an effort to deal, once and for all, with the impacts of technological change. This revision, however, failed to meet its objective. Almost as soon as it was passed, the new law was out of date.

With the new information and communication technologies, the pace of technological change is accelerating. Thus, once again, Congress is faced with choices of whether, how, and when to respond. Should Congress, for example, do nothing? Should it respond immediately to those needs deemed to be most pressing; or should it wait until it has a better understanding of the long-term impact of technology on the intellectual property system?

\section{Should Congress Take Any Action?}

Stakeholders in the system disagree about the extent and seriousness of intellectual property problems, and thus about whether Congress should take any action at all. Not particularly affected by the new technologies, many traditional copyright holders, such as book publishers, are satisfied with the system as it presently exists. Advocates of the free market approach also prefer that Congress take no action. They believe that, as markets develop, so too will natural solutions to the problems stemming from technological change. Others oppose change, fearing that major alterations in the law will be disruptive, and merely lead to greater uncertainty. 
Holding quite a different position are those who call for specific changes in the law to be made in response to particular problems as they arise. Included in this group are, for example, people from the motion picture and recording industries who, although concerned about how technology affects their ability to enforce their rights, still want to profit from the new home market that the new technologies afford. To allow them to do so, they propose a royalty on the sale of blank tapes and recording devices. By assuring them remuneration, legislation of this sort would make their enforcement problems irrelevant. Similarly, tel evision program suppliers would like to see specific changes in the law made to deal with problems they deem crucial to their interests. Believing that government rates are lower than those established in the market, they propose changes in the law that would require cable operators to bid for programming in the market place. Groups such as these, however, are generally reluctant to view intellectual property problems as being linked, and to make overall, structural changes in the system. Such an approach, they argue, will detract from those problems in need of immediate solutions.

Seeking more fundamental changes in the intellectual property system are those who are concerned lest intellectual property law be stretched to the point where it can no longer be consistently applied, or meet its intended policy goals. This view is heard most frequently among members of the legal and judicial communities. Such people are most outspoken in opposing the provision of copyright protection for computer software. Noting that reverse engineering may be precluded under copyright law, they argue that the extention of such protection may actually serve to inhibit learning and innovation.

\section{When To Act}

Decisions about when to act are clearly related to decisions about whether to act, and to decisions about whether to deal with problems separately, as they appear, or in a comprehensive fashion. Thus, those who favor a specific piece of legislation designed to deal with a particular problem also tend to press for action now; whereas those concerned about the overall system are willing to postpone action until Congress has the information and understanding required to deal with intellectual property issues as a whole.

In considering these choices, OTA found that technological developments are, indeed, affecting the intellectual property system in all of its aspects. Moreover, because we are now only just beginning to move into an electronic era, the full impact of the new technologies will not become completely apparent for some time to come. Thus, even if Congress decides to act in some areas now, it will need to be prepared to reconsider these actions at some point in the future. Acknowledging that this is the case, however, it is still useful to distinguish between short-, mid-, and long-term problems, because different kinds of problems may merit different kinds of solutions.

Short-Term Problems.-A number of problems can be considered to be pressing on the grounds that stakeholders are seeking immediate legislative action, that societal stakes are particularly high, or that technological change is occurring so rapidly that, if Congress wants to deliberately channel its impacts, it will have to act sooner rather than later. OTA has identified three such problems: the problem of enforcement, the problem of private use, and the problem of functional works.

The Problem of Enforcement. -One problem that will require attention in the short term is that of enforcement. Taken together, improvements in the cost, speed, and capabilities of information technologies are undermining the mechanisms by which intellectual property rights have traditionally been enforced. Devices such as optical disk storage systems may allow individuals to collect entire libraries of works in their homes. Under laboratory conditions, moreover, fiber optic technology is now capable of transferring 100 average-length novels over a distance of 150 miles in 1 second. Such capability can be expected soon in systems that are available to the public. Technology is also making the copying, transfer, and manipulation of information and intellectual works more private. Personal computers can store, process, and communicate the entire con- 
tents of commercial databases without the knowledge or consent of the compilers of such works. In the face of these developments, copyright holders are finding it harder to detect, prove, and stop infringements.

If this problem remains unresolved, creators, producers, and distributors of intellectual properties may become increasingly reluctant to distribute their works in forms over which they have little physical control. Moreover, if piracy becomes the norm, the legitimacy of the intellectual property system may itself be called into question, and the opportunities for policymaking in this area significantly reduced.

Information technologies provide proprietors with some technological options for dealing with enforcement. Private, computerized, electronic systems, for example, allow proprietors to maintain control by limiting and monitoring access. The government might provide support for such options were it, for example, to provide industrywide standards for these technologies. Standards such as these, however, may be very difficult to impose, since they would require a cooperative agreement between hardware and software producers, A number of proprietors, moreover, would rather maintain their freedom of action than receive such support. Nor are such kinds of solutions particularly popular among consumers, who feel that they would reduce the value of the product and perhaps constitute a threat to their personal privacy.

Recognizing that technological solutions may make their products less appealing to the consumer, a number of copyright holders are now calling on Congress to establish new ways of insuring their remuneration instead of new mechanisms for enforcing rights. The most frequently mentioned proposal of this kind is a royalty, or tax, on blank audio and video tapes.

Based on interviews with and surveys of the public, OTA found that many people would be reasonably disposed to such an option. They favor a law that would allow them the freedom to copy, without making them personally responsible for making judgments about the propriety of their actions. One of the unintended consequences of such a law, however, might be to encourage private copying.

Unlike consumers, however, hardware producers are adamantly opposed to options that would add a surcharge to their products. They argue that, before any such proposals be adopted, much better estimates of damage need to be made, and these estimates need to be weighed against the benefits that copyright holders gain from the new markets that hardware such as videocassette recorders provide.

Decisions about whether or not to seek new ways to provide incentives to creators and producers of intellectual works will also need to take into account the Federal administrative requirements and costs that such steps might entail. Given the current nonregulatory climate in the country, and recent efforts to curtail the activities of the Copyright Royalty Tribunalthe only Federal institution currently involved with distributing intellectual property royalties-it is difficult to imagine how existing institutions might effectively administer such a policy.

In light of the problem of enforcing intellectual property rights, public support for the underlying principles of the law will become increasingly critical. However, at present, the average citizen is quite unaware of the issues involved. A recent OTA survey of the public found, for example, that over two-thirds of those surveyed said that they were not at all, or were only slightly, familiar with the subject. Moreover, an equal proportion felt that intellectual property issues had very little to do with them personally. Notably, however, those who owned home technology, or who were under 40, were more aware of the issues. It would appear, therefore, that Congress has a brief window of time in which to establish policy. Under these circumstances, policymakers may want to undertake a dialog with the public in order to ascertain its viewpoint and to enhance its understanding of what is at stake for members of the public in the present debate over intellectual property issues.

The Problem of Private Use.-A second short-term problem is that of establishing pol- 
icy for the private use of information technologies. As is the case with enforcement, if Congress does not take the initiative in this area now, it maybe unable to do so later, when public attitudes and behaviors have become more entrenched.

Technology is spawning whole new opportunities in the development and use of information-based goods. A central question for intellectual property law is who shall benefit from these opportunities. In the Supreme Court's "Betamax" decision, for example, the question was whether proprietors or users would benefit, either directly or indirectly, from home videorecording capabilities.

As even newer technologies affect individuals' ability to copy, store, and modify information, such questions are likely to multiply. However, because it evolved in a period when duplication and storage technologies were centralized and deployed in a commercial context, copyright law offers little guidance to courts in resolving such conflicts. Neither the existing framework of rights, nor limitations on those rights-such as the fair use doctrineclearly apply to the private use of informationbased goods.

Stakeholders strongly disagree about who should benefit from new opportunities. Copyright holders would like to profit from the expanded home use of intellectual works. Moreover, they argue that, given the new technologies, private use, considered in the aggregate, will cause them extensive harm. Users, on the other hand, view the new technologies as a boon, reducing their costs and increasing their access to intellectual works. As the OTA survey of the public illustrates, while acknowledging that copying is wrong when done for profit, or as a part of a business, most people see private copying of copyrighted works as being acceptable. Producers of copying equipment also oppose restrictions on private use.

Some survey research has been conducted on the financial benefits that would accrue to proprietors if they were remunerated for new technological uses. OTA found, however, that estimates of harm such as these are, in and of themselves, insufficient to help Congress resolve the issue of who should benefit from new uses, since they presuppose-and cannot be the foundation for-a legal right to profit from the new uses of copyright works made available by technology. Whether Congress wishes to consider new uses as harmful will depend on the goals that it seeks to promote through copyright law, and where it believes the benefits of new technologies should be allocated.

The Problem of Functional Works.-Functional works, such as computer programs, artificial intelligence, and algorithms also present problems for the law that will need to be re solved within a short timeframe. Neither copyright nor patent law is entirely appropriate for such works. And, because they are very costly to develop, there is a strong incentive for industries to pirate them. For these reasons, it is generally agreed that rules governing their protection will be required shortly, if these works are to be developed and widely deployed. The resolution of this issue becomes increasingly important, moreover, as these works come to play a dominant role in domestic and international economies. Potential options for dealing with functional works are described be low, in the discussion of the legal framework.

Mid-Term Problems.-Other problems, although no less important, are less ripe for immediate action. Included in this category might be, for example, the problem of assigning value and distributing rewards in cases of derivative use, that of protecting the integrity of works in an electronic environment, and that of attributing and assigning authorship when works are generated by means of interactive or electronic processes.

Engendered by technologies still in their infancy, these problems are only now just emerging, and our understanding of them is severely limited. Sound government policy requires an accurate understanding of how information markets operate and of the role that these technologies might play in the creative environment. Yet, at present, such an understanding does not exist. Although there have been a few 
isolated efforts at collecting comprehensive data about information-based commodities, there is neither enough data nor sufficient quantitative analysis on which to make sound policy judgments. M ost data is fragmentary, incomparable, and available only through interested parties.

As the new technologies are developed and deployed, however, these problems, and the issues to which they give rise, will become more and more pressing. New participants will enter on the scene, as new technological opportunities appear. Not party to previous intellectual property agreements, many of them will have their own distinct attitudes about who should have access to works and materials, and about what kinds of activities and pursuits should be rewarded. These new stakeholders will lobby to have their needs and their perspectives taken into account. As a result, new controversies about the intellectual property system are likely to arise.

The Problem of Derivative Use.-The new technologies multiply the possibilities of creating new works from old ones. Using computer and video technologies to electronically snip and paste, for example, a film artist, can re arrange footage in the same way a writer re arranges words on his word processor: inserting and deleting images, frame by frame; taking whole sequences from one place and shifting them to another; scrolling through sequences again and again. All this is done in a matter of seconds. In the same fashion, all information content can serve as the basis for new derivative products and creative works.

With these capabilities to store, retrieve, and manipulate information, there come a multitude of new opportunities to expand the variety, scope, and sophistication of informationbased products and services. Taking advantage of these opportunities, the information industry-database businesses, software and hardware providers, publishers, cable television, information analysis centers, and clearinghouses-has grown rapidly in the last few years. In the domestic software industry alone, for example, there are now an estimated 1,200 companies and thousands of individual freelancers creating and producing software, and providing services worth some $\$ 40$ billion annually.

Given the growth of opportunities to create derivative works, issues will emerge with respect to who shall profit from them. Under existing intellectual property law, copyright holders have the right to benefit from all works based on their work. And, clearly, copyright holders want this right to extend to all new uses of their work. Many of those who are secondary information providers, however, oppose this point of view. In an information age, they argue, the most valuable information is that which is the most appropriate and the most timely. Custom designed, formatted, or packaged, this kind of information is by its nature derivative. To encourage its development and use, they claim, incentives and rewards must be provided not as they have in the past to the original creators, but rather to those who, making use of the new technologies, add new economic value to intellectual works.

The Problem of Artistic Integrity. - The ease with which information can be electronically snipped and pasted raises problems for creators, not only with respect to how they can assure a profit from their works, but also with respect to how they can safeguard its integrity. For the same images and sounds that the artist, photographer, or musician stores to be re used for his or her own purposes, can be accessed, manipulated, revised, copied, and used in a multitude of ways by others, with or without permission. Some creators worry that, under these circumstances, a "cavalier attitude will develop toward taking whatever you want and doing whatever you want with it. Such an attitude is already evident in the worlds of advertising and publishing as well as in the artistic community itself. Moreover, the scope of this problem is likely to increase as these technologies become cheaper and more widely available.

In the United States, intellectual property law has traditionally been unconcerned with protecting the integrity of a creator's work. 
In the new electronic environment, however, creators may become as concerned about the integrity of their works as they are about their profits. If, in the future, intellectual property protection is to be an effective incentive for creativity, it may need to secure artistic integrity as well as financial rewards.

The Problem of Assigning Authorship and of Measuring Value Added.-To effectively grant and to equitably distribute intellectual property rights requires that authorship or invention can be clearly assigned, and that new value added to intellectual works can be accurately measured. Today, however, because of the fluid, interactive, and functional nature of the new technologies, it is becoming increasingly difficult to perform either of these tasks. With intellectual works being simultaneously created, published, and communicated over electronic networks, the possibility of discovery or invention on-line, once a vision of the future, is now a reality. Such a development greatly complicates the process of determining originality and authorship, and of assigning rights. Similarly, with advances in artificial intelligence, computer-aided design, and computer-generated software, it will become more and more difficult to determine what creators have actually created. Given these trends, it is likely that, in the future, the number of controversies about the distribution of rewards is likely to increase. Moreover, as the economic value of information-based products and services increases, such disagreements may become all the more intense.

Long-Term Problems.-Even if a number of issues are effectively dealt with in the short term, another major revision of intellectual property law can still be expected in the future. Fundamental changes in technology are now taking place. And, although technology, for the moment, is multiplying the forms that works can take, and the means by which they can be transmitted, eventually all works will become available in compatible, digital, computer-processible form. Such developments will not only antiquate many of today's solutions; they may also give rise to new problems requiring new kinds of answers. For, as more and more works appear in digital form, the scope of today problems may expand so greatly so as to alter their very nature.

In the short term, for example, the enforcement problem may be amenable to a solution that requires a royalty on blank tapes. Although it might be difficult to establish an administrative structure to collect and distribute such royalties, the task is not an impossible one. However, if such an administrative apparatus had to be expanded to deal with the increasing number of works delivered on-line, the problems of effectively executing such a scheme may be so great as to, perhaps, negate the solution itself.

Another problem that will probably take on more importance in the future is that of access. For, as is described below, when works are intangible in their form, copyright holders may, under some circumstances, be able to restrict access to them. Such a problem may not warrant legislative attention now, because its extent is limited. However, if and when intangible works become the norm, the problem, being cumulative, may loom much more serious.

\section{What Legal Framework To Use}

The intellectual property system was carefully designed to balance the public and the private interest. Because the new information and communication technologies do not fit neatly within the existing framework of the law, the balance may be harder to achieve in the future. Questions arise, therefore, with re spect to how the new technologies should be dealt with according to the law, and whether or not a new conceptualization of the law may be required. Two particular problems that OTA has identified in this regard are the problem of functional works, and that of intangible works.

\section{Patents, Copyrights, and Functional Works}

Traditionally, intellectual property law provided two basic forms of protection: patent law and copyright law. These schemes reflected a basic distinction between invention and authorship. Inventions are essentially useful 
devices or processes, whereas works of authorship convey information or ideas. And, although both schemes encouraged the production and dissemination of ideas, they did so in two different ways. Patent required disclosure, and copyright required publication. Moreover, the types of protection granted reflected the differences between inventions and writings. Copyright prevented commercial copying; patent prevented commercial use.

The clear distinction between inventions and writings is beginning to break down. With the new technologies, writings act like inventions. Although considered to be writings, computer programs, for example, can run machines. They can, moreover, create new programs, and even control industrial processes. In the future, information itself will play a functional role. A piece of information entered into a database in one city, for instance, may automatically retool a factory in another. These developments raise questions about whether these new information-based products can be accommodated within the old legal framework, or whether some new categories of protection might not be required.

A subject of debate since the mid- 1960s, this question has defied conclusive resolution. Some people believe that a 1980 amendment, incorporating computer programs into copyright law, adequately settled the issue. This is the view, for example, espoused by many traditional copyright lawyers and by representatives of the computer hardware and software industries. However, a number of lawyers, many with engineering backgrounds, now challenge the wisdom of this approach. They argue that computer programs are hybrid works, sharing traits of both patentable and copyrightable works. They fear that, if the law is not revised, not only will functional works be inadequately protected, but also the sharing of ideas and knowledge, necessary for innovation, will be curtailed.

Looking at this question, OTA found that the distinction between writing and inventions is indeed breaking down with respect to functional works such as computer software and semiconductor chip masks. Because there are many kinds of these works, they may require their own framework for protection. Included within this category would be works of artificial intelligence, algorithms, firmware, and recombinant DNA. Like computer software, these works use information to affect a process.

The sui generis law for protecting chip masks might serve as one model for such works. OTA findings suggest, however, that it might be better to develop a more comprehensive approach that would treat functional works as a major, separate class of intellectual property law. Taking into account the particular characteristics of functional works, the law might be more accurately targeted to achieve specific policy outcomes, and thus serve as a more robust policy tool. Moreover, with a new category of law, both producers and users would face less uncertainty each time a new type of functional work were introduced. In addition, if the law were reconceptualized now, it might be possible to address a much older problem in copyright-that of distinguishing between artistic and factual works, a problem which is becomming more troublesome in the light of the new technologies. OTA suggests that a fruitful basis for such a revision might be found in the distinctions between works of art, works of fact, and works of function.

\section{Copyright Framework and Intangible Works}

The copyright system was based on the attributes of a print culture: works were fixed in a tangible medium; they were expensive to reproduce on a large scale; and, in order for the creator to profit from his work, he had to publish it in copies. A novel, for instance, had to be set in type, printed, and bound. Because of the expense entailed, copying was a commercial venture. A conspicuous activity, it was relatively easy to police. Moreover, because the only way of selling such a work was to sell copies, public dissemination went hand in hand with profit-making. Although the author retained the right to print and publish the novel, he relinquished control of copies of it with each sale. This promoted both the interest of the proprietor as well as that of the public. 
Works disseminated through electronic media are different from traditionally printed works. And their unique characteristics make it more difficult to balance public and private interests through copyright. Unlike a novel, a television program or a database entry need not be fixed in a copy to be sold. Thus, its creator or proprietor does not have to disseminate 'copies in order to profit from them. Under these circumstances, the proprietor retains control over access to his work, and may decide to intentionally restrict it in order to enhance his profit. Were this to occur, the public interest may suffer.

On the other hand, technology may also favor the user at the expense of the copyright holder. New reproductive technologies, such as audio and video recorders, are now widespread, allowing many individuals to cheaply and easily copy intangible works. If these privately made copies compete with sales of the original works, the proprietors' profits may be significantly diminished.

Whether, in any given situation, it is the proprietor or the public who will suffer is extremely hard to determine. Indeed, under certain circumstances, both parties may jointly benefit from advances in technology. Generally speaking, however, it is clear that, given the growing number of works being distributed electronically, it will now be harder to achieve the balance between the public and the proprietors interest under the copyright system.

\section{How Broadly To Define The Problem}

Historically intellectual property issues were somewhat isolated policy concerns. Because information did not assume the same social and economic importance that it does today, intellectual property decisions were less likely to impinge on other areas of public policy.

OTA found, however, that intellectual property policy can no longer be separated from other policy concerns. To the extent that information is, in fact, central to most activities, decisions about intellectual property may be decisions about the distribution of wealth and social status. Furthermore, given the unlimited scope of the new technologies, and the growing trade in information-based products and services, U.S. intellectual property policy is now inextricably tied to international affairs. Communications policy, too, is now linked to intellectual property policy as more and more intellectual property is being transmitted via media such as cable television, telephone lines, and communication satellites. Today, moreover, intellectual property issues give rise to concerns about privacy, as copyright holders seek technical means to monitor use. In making decisions about intellectual property policy, therefore, a whole new range of considerations will need to be taken into account, and decisionmakers in all these areas will need to strive for greater coordination.

\section{Within What Institutional Framework Should Intellectual Property Issues Be Resolved?}

Traditionally the intellectual property system required little institutional support. The system was designed to be self-enforcing: the government granted rights and registered works, while individual creators and users were responsible for protecting their rights.

As the previous findings demonstrate, however, the system is no longer so simple. Technology is creating new demands. Many more people with disparate interests are making claims on the system. Technology is advancing faster than the law and institutions can adapt. More and more, laws are being proposed that require that government play a regulatory role. In addition, given the growing complexity and diversity of information markets, more information is needed to make sound public policy decisions. The need for policy coordination is also greater as intellectual property issues converge with other issues.

This institutional question has not been widely discussed among stakeholders. In the current anti-regulatory climate, many are reluctant to recommend the creation of new institutions. For example, the proposed legisla- 
tion to impose a royalty on blank tapes and recording equipment would require that the Copyright Office collect monies and that the Copyright Royalty Tribunal distribute themthis despite the proposed dissolution of the Copyright Royalty Tribunal. Similarly, the recent passage of the Semiconductor Chip Act requires a patent-like examining procedure in the Copyright Office, even though it has no such expertise,

OTA found, however, that intellectual property issues cannot be resolved without dealing with the question of institutional capabilities and change. In the absence of institutional change, the courts will increasingly be called on to resolve highly complex technical issues and to make policy in this area. The judiciary, however, may not be the best suited for this role.
The pace of technological change will continue to put pressure on existing institutional arrangements. One way of dealing with such stress might be to establish a central governmental agency to address intellectual property issues as they emerge. Such a step would be consistent with an approach that deals with immediate issues in the short term, while preparing to address longer term issues later. Such an agency might, for example, monitor technological change, and assess the ways in which the law might deal with it. It might, moreover, provide the necessary expertise to deal with complex technologic issues and collect and analyze information about information markets and information use. It might even assume a regulatory function, distributing rewards or adjudicating disputes. Finally, such an agency might coordinate intellectual property policy with policy in other, related areas. 
Appendix 
Copies of the following contractor reports completed in support of this assessment are available from the National Technical Information Service, 5285 Port Royal Road, Springfield, VA 22161 (703) 487-4650.

1. J ames Beniger, "Information Technologies and Commodities in the Development of Intellectual Property: Changing Rights and Practices, " prepared for OTA, April 1985.

2. Clifford Berg, "Organization for Protection of intellectual Property Rights, " prepared for OTA by the National Academy of Public Administration, J une 1985.

3. Stanley M. Besen, "Economic Issues Relating to New Technologies and intellectual Property, " prepared for OTA by the Rand Corp., December 1984.

4. Anne Wells Branscomb, "The Accommodation of Intellectual Property Law to the Introduction of New Technologies, " prepared for OTA, December 1984.

5. Christopher Burns and Patricia Martin, "The Economics of Information, prepared for OTA by Christopher Burns, Inc., April 1985.

6. Herbert S. Dordick, "Intellectual Property: Protecting Rights and Privileges in an Electronic Age, "August 1984.

7. J ose-Marie Griffiths and Donald W. King, “Impact of information Technology on Information Service Providers and Their Clientele, " prepared for OTA by King Research, Inc., J uly 1985.

8 Roland S. Hornet, "New Technologies and Intellectual Property Rights: The international Dimension," prepared for OTA, August 1984.

9. Kenneth L. Kraemer, J ohn Leslie King, and David G. Shetter, "Innovative Use of Information Technology in Facilitating Public Access to Agency Decisionmaking: An Assessment of the Experience in State and Local Govern- merits, " prepared for OTA by the Irvine Research Corp., March 1985.

10. L. Ray Patterson, "Copyright and New Technology: The Impact on the Law of Privacy, Antitrust and Free Speech, " prepared for OTA, August 1985.

11. W. Curtiss Priest, "The Character of Information: Characteristics and Properties of Information Related to Issues Concerning Intellectual Property, " prepared for OTA, February 1985.

12. Carroll Pursell, "Historical Case Studies of the Influence of Intellectual Property Laws on Technological Change, " prepared for OTA, August 1985.

13. A. Allan Schmid, "A Conceptual Framework for Organizing Observations on Intellectual Property Stakeholders, " prepared for OTA, February 1985.

14 Petra T. Shattuck, "The J udicial I mpact of Legislation Extending Copyright Protection to Computer Software, " prepared for OTA, April 1985.

15. Petra T. Shattuck, "Public Attitudes and the Enforceability of Law, " prepared for OTA, J une 1985.

16. Richard J ay Solomon, "Intellectual Property and the New Computer-Based Media, 'prepared for OTA, August 1984.

17. Richard J ay Solomon and J ane Yurow, "International Intellectual Property Issues Engendered by New Technologies, " prepared for OTA, May 1985.

18. "Public Perceptions of the Intellectual Property Rights I ssue, " prepared for OTA by The Policy Planning Group, Yankelovich, Skelly \& White, Inc., February 1985.

19. "The Intellectual Property Rights I ssue: The Small Businessman's Perspective, " prepared for OTA by The Policy Planning Group, Yankelovich, Skelly \& White, Inc., May 1985. 